
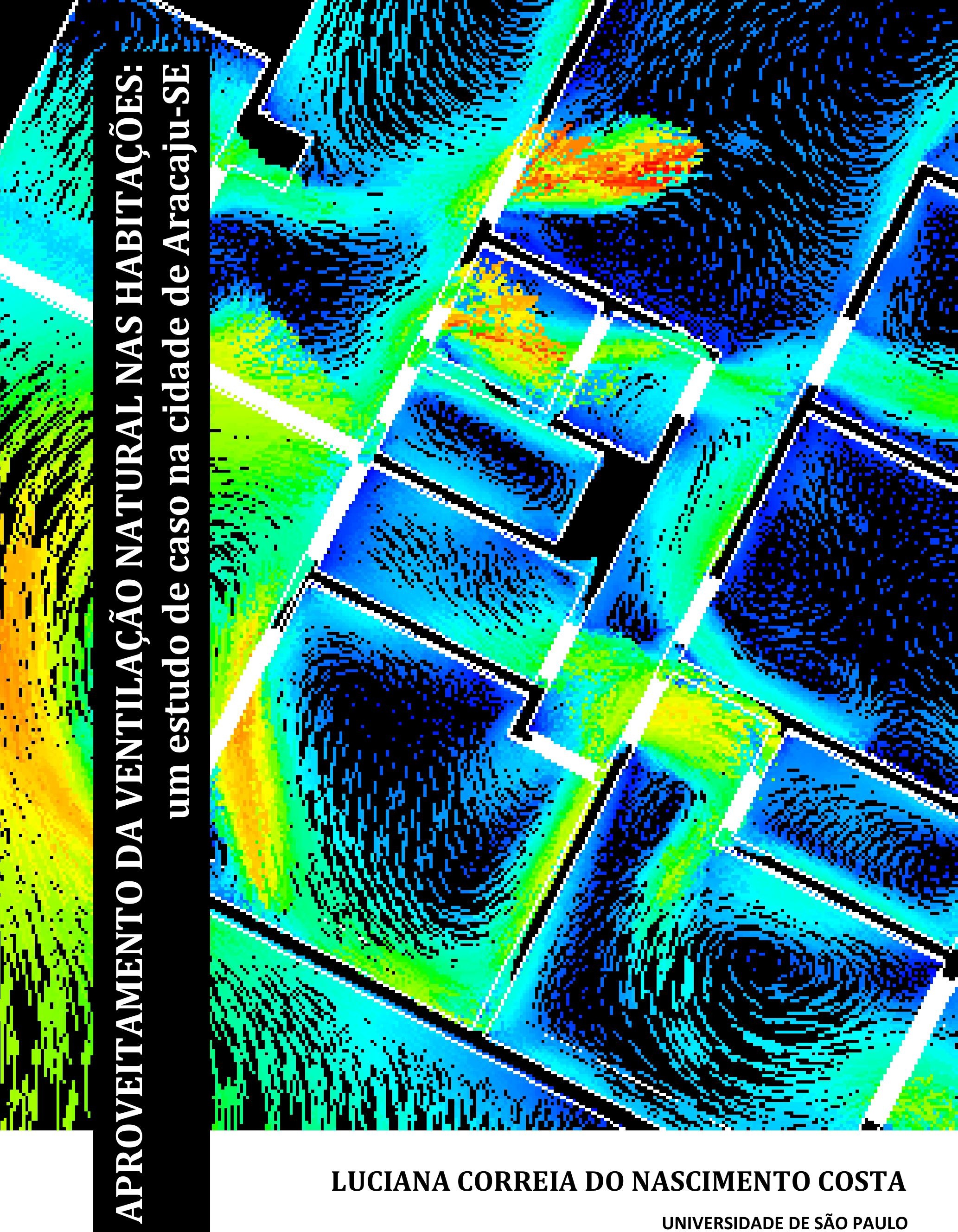

UNIVERSIDADE DE SÃO PAULO

Faculdade de Arquitetura e Urbanismo Orientadora: ANÉSIA BARROS FROTA 



\title{
APROVEITAMENTO DA VENTILAÇÃO NATURAL NAS HABITAÇÕES: \\ UM ESTUDO DE CASO NA CIDADE DE ARACAJU - SE
}

\author{
Dissertação apresentada à Comissão de Pós- \\ Graduação da Faculdade de Arquitetura e \\ Urbanismo da Universidade de São Paulo, \\ como parte dos requisitos para obtenção do \\ título de Mestre em Arquitetura e Urbanismo. \\ Área de concentração: Tecnologia da \\ Arquitetura
}

ORIENTADORA: ANÉSIA BARROS FROTA 
AUTORIZO A REPRODUÇÃO E/OU DIVULGAÇÃO TOTAL OU PARCIAL DESTE TRABALHO, POR QUALQUER MEIO CONVENCIONAL OU ELETRÔNICO, PARA FINS DE ESTUDO E PESQUISA, DESDE QUE CITADA A FONTE.

Nome do autor: Luciana Correia do Nascimento Costa

Instituição: Universidade de São Paulo

e-mail: arq.correia@uol.com.br

Costa, Luciana Correia do Nascimento

C837a Aproveitamento da ventilação natural nas habitações:

um estudo de caso na cidade de Aracaju-SE / Luciana

Correia do Nascimento Costa. --São Paulo, 2009.

272 p. : il.

Dissertação (Mestrado - Área de Concentração: Tecnologia da Arquitetura) - FAUUSP.

Orientadora: Anésia Barros Frota

1. Conforto térmico das construções 2.Ventilação

3. Softwares (Simulação computacional) I.Título

CDU 697 


\section{FOLHA DE APROVAÇÃo}

COSTA, Luciana Correia do Nascimento. Aproveitamento da ventilação natural nas habitações: um estudo de caso na cidade de AracajuSE. Dissertação apresentada à comissão de Pós-Graduação da Faculdade de Arquitetura e Urbanismo da Universidade de São Paulo, para obtenção do título de Mestre.

Área de concentração: Tecnologia da Arquitetura

Aprovado em

Banca Examinadora

1. Prof $\left({ }^{\mathrm{a}} \cdot\right)$. Dr. $\left({ }^{\mathrm{a}} \cdot{ }\right)$ : Anésia Barros Frota Titulação: Professora Doutora - Orientadora Instituição: FAUUSP

Assinatura:

2. $\operatorname{Prof}\left({ }^{\mathrm{a}}\right) \cdot \operatorname{Dr}\left({ }^{\mathrm{a}}\right)$. :

Titulação:

Instituição: Assinatura:

3. $\operatorname{Prof}\left({ }^{\mathrm{a}}\right) \cdot \operatorname{Dr}\left({ }^{\mathrm{a}}\right)$.:

Titulação:

Instituição: Assinatura: 
... 
"Admiro os poetas. O que eles dizem com duas palavras a gente tem que exprimir com milhares de tijolos." (VILANOVAS ARTIGAS) 

À minha pequena grande guerreira, Gabriela, por ter me ensinado a amar da forma mais pura e intensa que existe. 



\section{AGRADECIMENTOS}

À professora Anésia Barros Frota, pela orientação nesta dissertação de mestrado, pela confiança depositada em mim e pelo apoio carinhoso em todos os momentos mais complicados.

Ao Conselho Nacional de Desenvolvimento Científico e Tecnológico $\mathrm{CNPq}$ - pelo financiamento desta pesquisa.

Aos professores da UFRN Virgínia Araújo, que me apresentou brilhantemente o estudo do Conforto Ambiental, como professora na graduação e orientadora na iniciação científica, e Fernando Costa por despertar meu interesse na simulação computacional, me transmitindo seus primeiros conhecimentos na área.

Aos professores Joana Gonçalves e Dácio Ottoni, pela participação na banca de qualificação e interesse demonstrado nesta pesquisa.

$\grave{A}$ todos os professores e colegas do LABAUT, em especial Rafael Brandão, que com muita paciência me ajudou nas simulações, Alessandra Prata, pelas valiosas dicas e revisão final, e Daniel Cóstola pelas muitas discussões, sugestões e incentivo no desenvolvimento deste trabalho.

Ao Laboratório Master do IAG/USP e ao INMET por fornecer dados climáticos da cidade de Aracaju-SE, fundamentais para a caracterização do clima local. 
À minha mãe, que mesmo longe sempre esteve presente me apoiando com muito amor e crença no meu sucesso, e ao meu pai, que me ensinou a sempre lutar pelo meu objetivo dando o melhor de mim.

Ao meu grande amor, Rodolpho, por cuidar de mim com tanto carinho, reabastecendo minhas forças e doando parte de seu tempo para me ajudar no desenvolvimento deste trabalho.

Enfim, agradeço à todos que direta ou indiretamente contribuíram para a realização desta pesquisa. Obrigada! 


\section{RESUMO}

COSTA, Luciana Correia do Nascimento. Aproveitamento da ventilação natural nas habitações: um estudo de caso na cidade de AracajuSE. 2009. 272p. Dissertação de Mestrado, Faculdade de Arquitetura e Urbanismo, Universidade de São Paulo, 2009.

O estudo da ventilação natural como forma de amenização climática tem sido tema de diversos trabalhos científicos apresentados em congressos e encontros da área de conforto ambiental tanto no país como no exterior. E segundo o Método de Givoni, em $74 \%$ das horas do ano, a ventilação natural é a principal estratégia de projeto para se obter o conforto térmico dos usuários na cidade de Aracaju - SE. Assim sendo, tem-se como objeto desta pesquisa a ventilação natural nas habitações, e como objetivo geral um estudo do aproveitamento do vento para promover a ventilação natural em edificações residenciais na cidade de Aracaju, a fim de proporcionar melhores condições térmicas ambientais para os usuários sem a necessidade do condicionamento artificial do ar. O produto final consiste em recomendações de projeto baseadas nas pesquisas teóricas e simulações computacionais com o ANSYS CFX Computacional Fluid Dynamics Software - que serviram de base para verificar a influência da ventilação natural na edificação por meio de propostas de alterações no projeto original.

Palavras-chave: ventilação natural, conforto térmico, simulação computacional, software CFX, cidade de Aracaju. 



\begin{abstract}
COSTA, Luciana Correia do Nascimento. Use of housing natural ventilation: a case study in Aracaju city. 2009. 272p. Master's Thesis, Faculdade de Arquitetura e Urbanismo, Universidade de São Paulo, 2009.
\end{abstract}

Studies of natural ventilation as a way to minimize climate influences has been theme of several scientific papers presented in congresses and meetings concerning environmental comfort, in Brazil as well as in other countries. According to Givoni's method, in $74 \%$ of the year hours, natural ventilation is the main strategy to obtain thermal comfort for the inhabitants of Aracaju (Sergipe capital city). Based on that information, the object of this research is the housing natural ventilation, and its general objective is a study of wind use to promote housing natural ventilation and provide better thermal comfort conditions of its users without the need of artificial air conditioning. The final product of this research consists in design recommendations based on theoretical research and computer simulations with ANSYS CFX - Computacional Fluid Dynamics Software - which became the base to verify the influence of natural ventilation in a building by proposing alterations in the original project.

Key-words: natural ventilation, thermal comfort, computer simulation, CFX software, city of Aracaju. 



\section{LISTA DE FIGURAS}

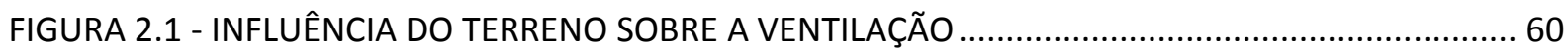

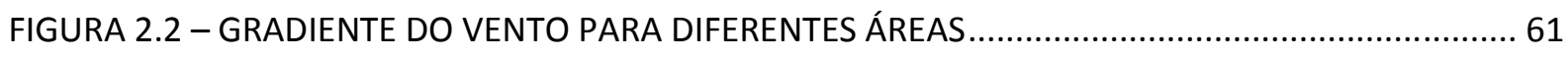

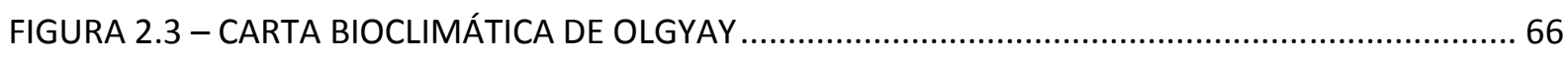

FIGURA 2.4 - CARTA BIOCLIMÁTICA ADOTADA PARA O BRASIL ....................................................... 70

FIGURA 2.5 - ESTRATÉGIAS DE ORGANIZAÇÃO PARA VENTILAÇÃO CRUZADA DE EDIFICAÇÕES COM

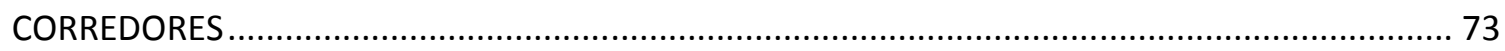

FIGURA 2.6 - ESTRATÉGIAS DE ORGANIZAÇÃO DOS ESPAÇOS QUE FAVORECEM TANTO A VENTILAÇÃO CRUZADA QUANTO A VENTILAÇÃO POR EFEITO CHAMINÉ …................................ 77

FIGURA 2.7 - INCLINAÇÃO DO TELHADO E ALTURA DA EDIFICAÇÃO EM CORTE ............................... 79

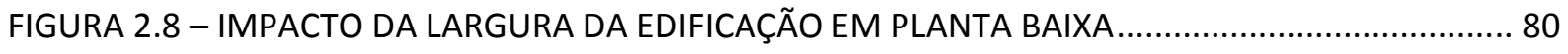

FIGURA 2.9 - CONFIGURAÇÃO E ORIENTAÇÃO DA PLANTA BAIXA …............................................ 81

FIGURA 2.10 - DIMENSIONAMENTO DE PATIOS INTERNOS, PARA UMA BOA VENTILAÇÃO VELOCIDADE MEDIA DOS VENTOS COMO UM PERCENTUAL DO VENTO INCIDENTE E SEM

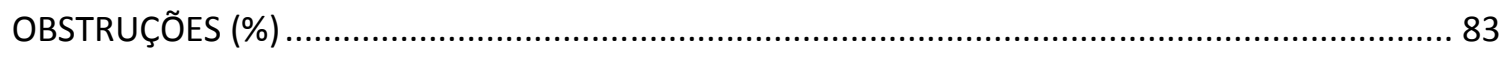

FIGURA 2.11- VELOCIDADE INTERNA MEDIA EM FUNÇÃO DA RELAÇÃO ENTRE AS ABERTURAS DE ENTRADA E SAÍDA DO AR, PARA INCIDÊNCIA DO VENTO A 45 E 90…................................... 85

FIGURA 2.12 - DISTRIBUIÇÃO DAS ABERTURAS DE VENTILAÇÃO …............................................... 88

FIGURA 2.13 - INFLUÊNCIA DA LOCALIZAÇÃO E DIMENSÃO DAS ABERTURAS LOCALIZADAS EM

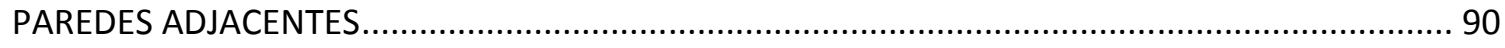

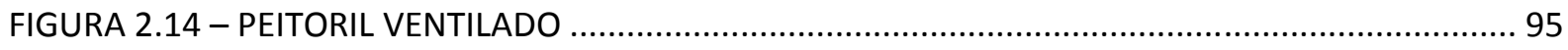

FIGURA 2.15 - CROQUI DE JANELA DE CORRER EM VISTA E EM PLANTA BAIXA ................................ 96

FIGURA 2.16 - CROQUI DE JANELA GUILHOTINA EM VISTA E EM CORTE.......................................97

FIGURA 2.17 - CROQUI DE JANELA DE ABRIR DE EIXO VERTICAL EM VISTA E EM CORTE.................... 97

FIGURA 2.18 - CROQUI DE JANELA PROJETANTE OU DE TOMBAR EM VISTA E EM CORTE ................ 98 
FIGURA 2.19 - CROQUI DE JANELA PIVOTANTE EM VISTA E EM PLANTA BAIXA..... 99

FIGURA 2.20 - CROQUI DE JANELA BASCULANTE OU GELOSIA EM VISTA E EM CORTE 99

FIGURA 2.21 - CROQUI DE JANELA SANFONADA OU CAMARÃO EM VISTA E EM PLANTA BAIXA ..... 100 FIGURA 2.22 - AS DIVISÕES DO ESPAÇO INTERNO AFETAM A CONFIGURAÇÃO DO FLUXO DE AR. .. 101 2.23 - COMPONENTES VERTICAIS AFETAM O CONJUNTO DE PRESSÕES DESENVOLVIDAS NAS ENTRADAS DO AR, ALTERANDO O PADRÃO DE DISTRIBUIÇÃO DO FLUXO DO AR. 103 FIGURA 2.24 - PROJEÇÕES VERTICAIS PODEM INTERFERIR NO FLUXO DE AR 103 FIGURA 2.25 - ESTRATÉGIAS DE DESIGN DE WING WALLS. 104 FIGURA 2.26 - EFEITOS DAS PROJEÇÕES HORIZONTAIS NO FLUXO DE AR NO INTERIOR DOS AMBIENTES 105

FIGURA 2.27- EFEITO DE ELEMENTOS HORIZONTAIS NO FLUXO DE AR EM EDIFÍCIOS. 105 FIGURA 3.1 - MAPAS DE LOCALIZAÇÃO DO UNIVERSO DE ANÁLISE 107 FIGURA 3.2 - FOTO AÉREA DA CIDADE DE ARACAJU-SE 108 FIGURA 3.3 - ZONAS BIOCLIMÁTICAS DEFINIDAS PELA NORMA DESEMPENHO TÉRMICO DE 111 FIGURA 3.4 - TABELA DOS DADOS CLIMÁTICOS DE ARACAJU/SE. 116 FIGURA 3.5 - CARTA BIOCLIMÁTICA PARA ARACAJU-SE. 118 FIGURA 3.6 - DIAGNÓSTICO CLIMÁTICO PELO MÉTODO DE GIVONI 119 FIGURA 4.1 - PLANTA DA SALA COM ABERTURA DE ENTRADA= 1/5 DO PISO, NA FAIXA MÉDIA, E SAÍDA NA FAIXA ALTA COM VENTO A 90으․ 145

FIGURA 4.2 - CORTE NO CENTRO DA SALA COM ABERTURA DE ENTRADA=1/5 DO PISO, NA FAIXA MÉDIA, E SAÍDA NA FAIXA ALTA COM VENTO A 90…... 145 FIGURA 4.3 - ETAPAS DA SIMULAÇÃO NO CFX. 150

FIGURA 4.4 - MODELO 1: ÁREA DO ENTORNO 154

FIGURA 4.5 - ELABORAÇÃO DO DOMÍNIO 156

FIGURA 4.6 - CRIAÇÃO DAS PARTES NO ICEM CFD. 157 FIGURA 4.7 - MALHA NO DOMÍNIO EM PLANTA DO MODELO EXPERIMENTAL 159 
FIGURA 4.8 - AMPLIAÇÃO DA MALHA NO DOMÍNIO EM PLANTA DO MODELO EXPERIMENTAL...... 160 FIGURA 4.9 - MALHA NOS EDIFÍCIOS EM PERSPECTIVA DO MODELO EXPERIMENTAL ..................... 160 FIGURA 4.10 - DETALHE EM CORTE DA MALHA EM UM EDIFÍCIO DO MODELO EXPERIMENTAL ..... 160 FIGURA 4.11 - DOMÍNIO COM DEFINIÇÃO DA CONDIÇÃO DE CONTORNO - MODELO EXPERIMENTAL 165 FIGURA 4.12- CONTORNO DA VEL. DO VENTO NO H1P5 (ORTOGONAL) ...................................... 168 FIGURA 4.13 - CONTORNO DA VEL. DO VENTO NO H1P5 (PERSPECTIVA) ......................................... 168

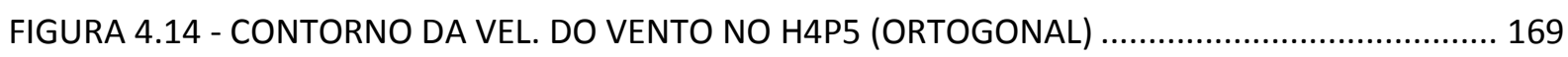

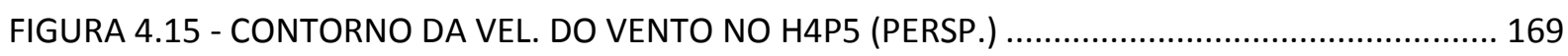
FIGURA 4.16 - CONTORNO DA VEL. DO VENTO NO H37P5 (ORTOGONAL) ..................................... 170 FIGURA 4.17 - CONTORNO DA VEL. DO VENTO NO H37P5 (PERSP.) …........................................ 170 FIGURA 4.18 - CONTORNO DA VEL. DO VENTO NO PVL1 (ORTOGONAL) .......................................... 171

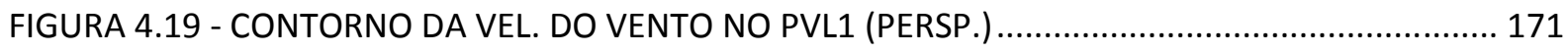
FIGURA 4.20 - CONTORNO DA VEL. DO VENTO NO PVL2 (ORTOGONAL) ...................................... 172

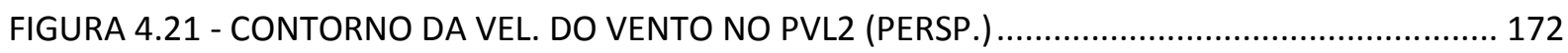
FIGURA 4.22 - CONTORNO DA VEL. DO VENTO NO PVT1 (ORTOGONAL)....................................... 173 FIGURA 4.23 - CONTORNO DA VEL. DO VENTO NO PVT1 (PERSP.) .............................................. 173 FIGURA 4.24 - CONTORNO DA VEL. DO VENTO NO PVT2 (ORTOGONAL) ...................................... 174 FIGURA 4.25 - CONTORNO DA VEL. DO VENTO NO PVT2 (PERSP.)................................................. 174 FIGURA 4.26 - VETORES DE VEL. DO VENTO NO PLANO HORIZONTAL A 1,50M (ORTOGONAL) ....... 175 FIGURA 4.27 - VETORES DE VEL. DO VENTO NO PLANO HORIZONTAL A 4,5M (ORTOGONAL) ......... 175 FIGURA 4.28 - VETORES DE VEL. DO VENTO NO PLANOS HORIZONTAL A 37,5M (ORTOGONAL) ..... 175 FIGURA 4.29 - VETORES DE VEL. DO VENTO NO PLANO HORIZONTAL A 1,5M (PERSP.) .................. 176 FIGURA 4.30 - VETORES DA VEL. DO VENTO NO PLANO HORIZONTAL A 4,5M (PERSP.).................. 176 FIGURA 4.31 - VETORES DA VEL. DO VENTO NO PLANO HORIZONTAL A 37,5M (PERSP.)................. 176 
FIGURA 4.32 - VETORES DE VELOCIDADE DO VENTO NO PLANO VERTICAL LONGITUDINAL 01 (ORTOGONAL).

FIGURA 4.33 - VETORES DE VELOCIDADE DO VENTO NO PLANO VERTICAL LONGITUDINAL 01 (PERSPECTIVA) 177

FIGURA 4.34 - VETORES DE VELOCIDADE DO VENTO NO PLANO VERTICAL LONGITUDINAL 02 (ORTOGONAL) 177

FIGURA 4.35 - VETORES DE VELOCIDADE DO VENTO NO PLANO VERTICAL LONGITUDINAL 02 (PERSPECTIVA) 178

FIGURA 4.36 - VETORES DE VELOCIDADE DO VENTO NO PLANO VERTICAL TRANSVERSAL 01 (ORTOGONAL) 178

FIGURA 4.37 - VETORES DE VELOCIDADE DO VENTO NO PLANO VERTICAL TRANSVERSAL 01 (PERSPECTIVA) 178

FIGURA 4.38 - VETORES DE VELOCIDADE DO VENTO NO PLANO VERTICAL TRANSVERSAL 02 (ORTOGONAL)...... 179 FIGURA 4.39 - VETORES DE VELOCIDADE DO VENTO NO PLANO VERTICAL TRANSVERSAL 02 (PERSPECTIVA) 179 FIGURA 4.40 - PRESSÃO DO VENTO NO EDIFÍCIO MONTPARNASSE - FACHADAS LESTE E NORTE.... 180 FIGURA 5.1 - EDIFÍCIO COM DESTAQUE PARA O ESPAÇO DO APARTAMENTO 1102 DEFINIDO......... 183

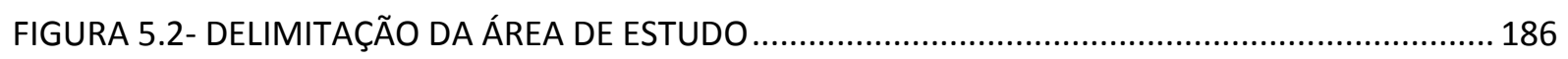

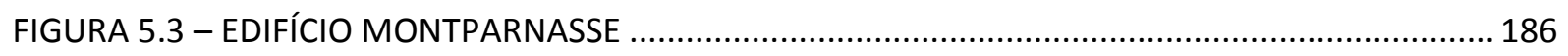

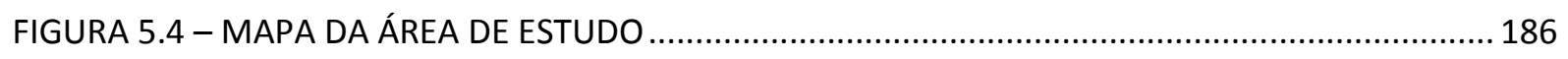
FIGURA 5.5 - PLANTA BAIXA DO PAVTO TIPO E DOS APTOS DA TORRE DE FINAL 2 - SEM ESCALA. . 187 FIGURA 5.6 - PLANTA BAIXA DO MODELO 01 COM ABERTURAS SEM PRESENÇA DE ESQUADRIAS .. 189 FIGURA 5.7 - PERSPECTIVA MODELO 01 189 FIGURA 5.8 - APARTAMENTO INSERIDO NO EDIFÍCIO - MODELO 01 189 FIGURA 5.9 - PLANTA BAIXA DO MODELO 02 191 
FIGURA 5.10 - PERSPECTIVA MODELO 02

FIGURA 5.11 - APARTAMENTO INSERIDO NO EDIFÍCIO - MODELO 02 191

FIGURA 5.12 - PLANTA BAIXA DO MODELO 03 COM DESTAQUE DAS ÁREAS OBSTRUÍDAS PELAS ESQUADRIAS.

FIGURA 5.13 - PERSPECTIVA DO MODELO 03 193

FIGURA 5.14 - APARTAMENTO INSERIDO NO EDIFÍCIO - MODELO 03. 193

FIGURA 5.15 - PLANTA BAIXA DO MODELO 04 COM DESTAQUE PARA AS PORTAS DOS QUARTOS FECHADAS 195

FIGURA 5.16 - PERSPECTIVA DO MODELO 04 195

FIGURA 5.17 - APARTAMENTO INSERIDO NO EDIFÍCIO - MODELO 04 195

FIGURA 5.18 - PLANTA BAIXA DO MODELO 05 COM DESTAQUE PARA AS PORTAS DOS QUARTOS FECHADAS COM BANDEIRAS ACIMA DAS MESMAS COM VÃOS LIVRES DE DIMENSÃO .7OM X $.30 \mathrm{M}$ 197

FIGURA 5.19 - PERSPECTIVA DO MODELO 05 197

FIGURA 5.20 - APARTAMENTO INSERIDO NO EDIFÍCIO - MODELO 05 197

FIGURA 5.21 - PLANTA BAIXA DO MODELO 06 COM DESTAQUE PARA A ALTERAÇÃO DA PLANTA ORIGINAL 199

FIGURA 5.22 - PERSPECTIVA DO MODELO 06 199

FIGURA 5.23 - APARTAMENTO INSERIDO NO EDIFÍCIO - MODELO 06 199 FIGURA 5.24 - PLANTA BAIXA DO MODELO 07 COM DESTAQUE PARA A DIMENSÃO DAS ABERTURAS DOS QUARTOS 201

FIGURA 5.25 - PERSPECTIVA DO MODELO 07 201

FIGURA 5.26 - APARTAMENTO INSERIDO NO EDIFÍCIO - MODELO 07 201 FIGURA 5.27 - PLANTA BAIXA DO MODELO 08 COM DESTAQUE NA ALTERAÇÃO DA PORTA DO QUARTO DO MEIO. 203 FIGURA 5.28 - PERSPECTIVA DO MODELO 08 203 
FIGURA 5.29 - APARTAMENTO INSERIDO NO EDIFÍCIO - MODELO 08

FIGURA 6.1 - CONTORNO DA VELOCIDADE DO VENTO NO ENTORNO DO EDIFÍCIO NO MODELO EXPERIMENTAL

FIGURA 6.2 - CONTORNO DA VELOCIDADE DO VENTO NO ENTORNO DO EDIFÍCIO NO MODELO BASE

FIGURA 6.3 - CONTORNO DA VELOCIDADE DO VENTO NO INTERIOR DO APARTAMENTO NO MODELO $01-$ PLANO HORIZONTAL H= $1.20 \mathrm{M}$

FIGURA 6.4 - VETORES DE DIREÇÃO E VELOCIDADE DO VENTO NO INTERIOR DO APARTAMENTO NO MODELO $01-$ PLANO HORIZONTAL H= 1.20M.

FIGURA 6.5 - CONTORNO DA VELOCIDADE DO VENTO NO INTERIOR DO APARTAMENTO NO MODELO $01-$ PLANO HORIZONTAL H= 2.00M 212

FIGURA 6.6 - VETORES DE DIREÇÃO E VELOCIDADE DO VENTO NO INTERIOR DO APARTAMENTO NO MODELO $01-$ PLANO HORIZONTAL H= 2.00M........

FIGURA 6.7 - CONTORNO DA VELOCIDADE DO VENTO NO INTERIOR DO APARTAMENTO NO MODELO $01-\mathrm{H}=1.20 \mathrm{M}$ 215

FIGURA 6.8 - VETORES DA DIREÇÃO E VELOCIDADE DO VENTO NO INTERIOR DO APARTAMENTO NO MODELO $01-\mathrm{H}=1.20 \mathrm{M}$ 215

FIGURA 6.9 - CONTORNO DA VELOCIDADE DO VENTO NO INTERIOR DO APARTAMENTO NO MODELO $02-\mathrm{H}=1.20 \mathrm{M}$. 215

FIGURA 6.10 - VETORES DA DIREÇÃO E VELOCIDADE DO VENTO NO INTERIOR DO APARTAMENTO NO MODELO $02-\mathrm{H}=1.20 \mathrm{M}$ 215

FIGURA 6.11 - CONTORNO DA VELOCIDADE DO VENTO NO INTERIOR DO APARTAMENTO NO MODELO $02-\mathrm{H}=2.00 \mathrm{M}$ 215

FIGURA 6.12 - VETORES DA DIREÇÃO E VELOCIDADE DO VENTO NO INTERIOR DO APARTAMENTO NO MODELO $02-\mathrm{H}=1.20 \mathrm{M}$ 215 
FIGURA 6.13 - CONTORNO DA VELOCIDADE DO VENTO NO INTERIOR DO APARTAMENTO NO MODELO $01-\mathrm{H}=1.20 \mathrm{M}$

FIGURA 6.14 - VETORES DA DIREÇÃO E VELOCIDADE DO VENTO NO INTERIOR DO APARTAMENTO NO MODELO $01-\mathrm{H}=1.20 \mathrm{M}$.

FIGURA 6.15 - CONTORNO DA VELOCIDADE DO VENTO NO INTERIOR DO APARTAMENTO NO MODELO $03-\mathrm{H}=1.20 \mathrm{M}$

FIGURA 6.16 - VETORES DA DIREÇÃO E VELOCIDADE DO VENTO NO INTERIOR DO APARTAMENTO NO MODELO $03-\mathrm{H}=1.20 \mathrm{M}$.

FIGURA 6.17 - CONTORNO DA VELOCIDADE DO VENTO NO INTERIOR DO APARTAMENTO NO MODELO $03-\mathrm{H}=2.00 \mathrm{M}$. 217

FIGURA 6.18 - VETORES DA DIREÇÃO E VELOCIDADE DO VENTO NO INTERIOR DO APARTAMENTO NO MODELO $03-\mathrm{H}=2.00 \mathrm{M}$. 217

FIGURA 6.19 - CONTORNO DA VELOCIDADE DO VENTO NO INTERIOR DO APARTAMENTO NO MODELO $03-\mathrm{H}=1.20 \mathrm{M}$ 219

FIGURA 6.20 - VETORES DA DIREÇÃO E VELOCIDADE DO VENTO NO INTERIOR DO APARTAMENTO NO MODELO 03 219

FIGURA 6.21 - CONTORNO DA VELOCIDADE DO VENTO NO INTERIOR DO APARTAMENTO NO MODELO $04-\mathrm{H}=1.20 \mathrm{M}$. 219

FIGURA 6.22 - VETORES DA DIREÇÃO E VELOCIDADE DO VENTO NO INTERIOR DO APARTAMENTO NO MODELO $04-\mathrm{H}=1.20 \mathrm{M}$. 219

FIGURA 6.23 - CONTORNO DA VELOCIDADE DO VENTO NO INTERIOR DO APARTAMENTO NO MODELO $04-\mathrm{H}=2.00 \mathrm{M}$. 219

FIGURA 6.24 - VETORES DA DIREÇÃO E VELOCIDADE DO VENTO NO INTERIOR DO APARTAMENTO NO MODELO $04-\mathrm{H}=2.00 \mathrm{M}$. 219

FIGURA 6.25 - CONTORNO DA VELOCIDADE DO VENTO NO INTERIOR DO APARTAMENTO NO MODELO $04-\mathrm{H}=1.20 \mathrm{M}$. 
FIGURA 6.26 - VETORES DA DIREÇÃO E VELOCIDADE DO VENTO NO INTERIOR DO APARTAMENTO NO MODELO $04-\mathrm{H}=1.20 \mathrm{M}$

FIGURA 6.27 - CONTORNO DA VELOCIDADE DO VENTO NO INTERIOR DO APARTAMENTO NO MODELO $05-\mathrm{H}=1.20 \mathrm{M}$.

FIGURA 6.28 - VETORES DA DIREÇÃO E VELOCIDADE DO VENTO NO INTERIOR DO APARTAMENTO NO MODELO $05-\mathrm{H}=1.20 \mathrm{M}$ 221

FIGURA 6.29 - CONTORNO DA VELOCIDADE DO VENTO NO INTERIOR DO APARTAMENTO NO MODELO $05-\mathrm{H}=2.00 \mathrm{M}$ 221

FIGURA 6.30 - VETORES DA DIREÇÃO E VELOCIDADE DO VENTO NO INTERIOR DO APARTAMENTO NO MODELO $05-\mathrm{H}=2.00 \mathrm{M}$ 221

FIGURA 6.31 - CONTORNO DA VELOCIDADE DO VENTO NO INTERIOR DO APARTAMENTO NO MODELO $03-\mathrm{H}=1.20 \mathrm{M}$ 223

FIGURA 6.32 - VETORES DA DIREÇÃO E VELOCIDADE DO VENTO NO INTERIOR DO APARTAMENTO NO MODELO $03-\mathrm{H}=1.20 \mathrm{M}$ 223

FIGURA 6.33 - CONTORNO DA VELOCIDADE DO VENTO NO INTERIOR DO APARTAMENTO NO MODELO $06-\mathrm{H}=1.20 \mathrm{M}$ 223

FIGURA 6.34 - VETORES DA DIREÇÃO E VELOCIDADE DO VENTO NO INTERIOR DO APARTAMENTO NO MODELO $06-\mathrm{H}=1.20 \mathrm{M}$ 223

FIGURA 6.35 - CONTORNO DA VELOCIDADE DO VENTO NO INTERIOR DO APARTAMENTO NO MODELO $06-\mathrm{H}=2.00 \mathrm{M}$ 223

FIGURA 6.36 - VETORES DA DIREÇÃO E VELOCIDADE DO VENTO NO INTERIOR DO APARTAMENTO NO MODELO $06-\mathrm{H}=2.00 \mathrm{M}$ 223

FIGURA 6.37 - CONTORNO DA VELOCIDADE DO VENTO NO INTERIOR DO APARTAMENTO NO MODELO $01-\mathrm{H}=1.20 \mathrm{M}$ 227

FIGURA 6.38 - VETORES DA DIREÇÃO E VELOCIDADE DO VENTO NO INTERIOR DO APARTAMENTO NO MODELO $01-\mathrm{H}=1.20 \mathrm{M}$ 227 
FIGURA 6.39 - CONTORNO DA VELOCIDADE DO VENTO NO INTERIOR DO APARTAMENTO NO MODELO $07-\mathrm{H}=1.20 \mathrm{M}$

FIGURA 6.40 - VETORES DA DIREÇÃO E VELOCIDADE DO VENTO NO INTERIOR DO APARTAMENTO NO MODELO $07-\mathrm{H}=1.20 \mathrm{M}$.

FIGURA 6.41 - CONTORNO DA VELOCIDADE DO VENTO NO INTERIOR DO APARTAMENTO NO MODELO $07-\mathrm{H}=2.00 \mathrm{M}$

FIGURA 6.42 - VETORES DA DIREÇÃO E VELOCIDADE DO VENTO NO INTERIOR DO APARTAMENTO NO MODELO $07-\mathrm{H}=2.00 \mathrm{M}$.

FIGURA 6.43 - CONTORNO DA VELOCIDADE DO VENTO NO INTERIOR DO APARTAMENTO NO MODELO $01-\mathrm{H}=1.20 \mathrm{M}$. 230

FIGURA 6.44 - VETORES DA DIREÇÃO E VELOCIDADE DO VENTO NO INTERIOR DO APARTAMENTO NO MODELO $01-\mathrm{H}=1.20 \mathrm{M}$. 230

FIGURA 6.45 - CONTORNO DA VELOCIDADE DO VENTO NO INTERIOR DO APARTAMENTO NO MODELO $08-\mathrm{H}=1.20 \mathrm{M}$. 230

FIGURA 6.46 - VETORES DA DIREÇÃO E VELOCIDADE DO VENTO NO INTERIOR DO APARTAMENTO NO MODELO $08-\mathrm{H}=1.20 \mathrm{M}$. 230

FIGURA 6.47 - CONTORNO DA VELOCIDADE DO VENTO NO INTERIOR DO APARTAMENTO NO MODELO $08-\mathrm{H}=2.00 \mathrm{M}$ 230

FIGURA 6.48 - VETORES DA DIREÇÃO E VELOCIDADE DO VENTO NO INTERIOR DO APARTAMENTO NO MODELO $08-\mathrm{H}=2.00 \mathrm{M}$. 230

FIGURA A.1 - LOCALIZAÇÃO DOS PLANOS VERTICAIS LONGITUDINAIS E TRANSVERSAIS 257 FIGURA A.2 - MODELO 01 - CONTORNO DA VELOCIDADE DO VENTO NO PLANO HORIZONTAL $\mathrm{H}=2.00 \mathrm{M}$ 257

FIGURA A.3 - MODELO 01 - VETORES DA VELOCIDADE E DIREÇÃO DO VENTO NO PLANO HORIZONTAL $\mathrm{H}=2.00 \mathrm{M}$ 257 
FIGURA A.4 - MODELO 01 - CONTORNO DA VELOCIDADE DO VENTO NO PLANO VERTICAL LONGITUDINAL 1 (PVL1)

FIGURA A.5 - MODELO 01 - VETORES DA VELOCIDADE E DIREÇÃO DO VENTO NO PLANO VERTICAL LONGITUDINAL 1 (PVL1)

FIGURA A.6 - MODELO 01 - CONTORNO DA VELOCIDADE DO VENTO NO PLANO VERTICAL LONGITUDINAL 2 (PVL2) 258

FIGURA A.7 - MODELO 01 - VETORES DA VELOCIDADE E DIREÇÃO DO VENTO NO PLANO VERTICAL LONGITUDINAL 2 (PVL2) 258

FIGURA A.8 - MODELO 01 - CONTORNO DA VELOCIDADE DO VENTO NO PLANO VERTICAL TRANSVERSAL 1 (PVT1) 258

FIGURA A.9 - MODELO 01 - VETORES DA VELOCIDADE E DIREÇÃO DO VENTO NO PLANO VERTICAL TRANSVERSAL 1 (PVT1) 258

FIGURA A.10 - MODELO 01 - CONTORNO DA VELOCIDADE DO VENTO NO PLANO VERTICAL TRANSVERSAL 2 (PVT2) 258

FIGURA A.11 - MODELO 01 - VETORES DA VELOCIDADE E DIREÇÃO DO VENTO NO PLANO VERTICAL TRANSVERSAL 2 (PVT2) 258

FIGURA A.12 - MODELO 02 - CONTORNO DA VELOCIDADE DO VENTO NO PLANO HORIZONTAL $H=1.20 M$ 259

FIGURA A.13 - MODELO 02 - VETORES DA VELOCIDADE E DIREÇÃO DO VENTO NO PLANO HORIZONTAL H=1.20M 259

FIGURA A.14 - MODELO 02 - CONTORNO DA VELOCIDADE DO VENTO NO PLANO HORIZONTAL $\mathrm{H}=2.00 \mathrm{M}$ 259

FIGURA A.15 - MODELO 02 - VETORES DA VELOCIDADE E DIREÇÃO DO VENTO NO PLANO HORIZONTAL H=2.00M 259 FIGURA A.16 - MODELO 02 - CONTORNO DA VELOCIDADE DO VENTO NO PVL1. 259 FIGURA A.17 - MODELO 02 - VETORES DA VELOCIDADE E DIREÇÃO DO VENTO NO PVL1 259 
FIGURA A.18 - MODELO 02 - CONTORNO DA VELOCIDADE DO VENTO NO PVL2 260

FIGURA A.19 - MODELO 02 - VETORES DA VELOCIDADE E DIREÇÃO DO VENTO NO PVL2 ….............. 260 FIGURA A.20 - MODELO 02 - CONTORNO DA VELOCIDADE DO VENTO NO PVT1 …........................ 260 FIGURA A.21 - MODELO 02 - VETORES DA VELOCIDADE E DIREÇÃO DO VENTO NO PVT1.................. 260 FIGURA A.22 - MODELO 02 - CONTORNO DA VELOCIDADE DO VENTO NO PVT2 …........................... 260 FIGURA A.23 - MODELO 02 - VETORES DA VELOCIDADE E DIREÇÃO DO VENTO NO PVT2 ................ 260 FIGURA A.24 - MODELO 03 - CONTORNO DA VELOCIDADE DO VENTO NO PLANO HORIZONTAL $\mathrm{H}=1.20 \mathrm{M}$ 261

FIGURA A.25 - MODELO 03 - VETORES DA VELOCIDADE E DIREÇÃO DO VENTO NO PLANO HORIZONTAL H=1.20M. 261

FIGURA A.26 - MODELO 03 - CONTORNO DA VELOCIDADE DO VENTO NO PLANO HORIZONTAL $\mathrm{H}=2.00 \mathrm{M}$ 261

FIGURA A.27 - MODELO 03 - VETORES DA VELOCIDADE E DIREÇÃO DO VENTO NO PLANO HORIZONTAL H=2.00M. 261

FIGURA A.28 - MODELO 03 - CONTORNO DA VELOCIDADE DO VENTO NO PVL1. 261 FIGURA A.29 - MODELO 03 - VETORES DA VELOCIDADE E DIREÇÃO DO VENTO NO PVL1 261 FIGURA A.30 - MODELO 03 - CONTORNO DA VELOCIDADE DO VENTO NO PVL2 262 FIGURA A.31 - MODELO 03 - VETORES DA VELOCIDADE E DIREÇÃO DO VENTO NO PVL2 ................. 262 FIGURA A.32 - MODELO 03 - CONTORNO DA VELOCIDADE DO VENTO NO PVT1 ............................. 262 FIGURA A.33 - MODELO 03 - VETORES DA VELOCIDADE E DIREÇÃO DO VENTO NO PVT1 ................. 262 FIGURA A.34 - MODELO 03 - CONTORNO DA VELOCIDADE DO VENTO NO PVT2 …............................ 262 FIGURA A.35 - MODELO 03 - VETORES DA VELOCIDADE E DIREÇÃO DO VENTO NO PVT2 262 FIGURA A.36 - MODELO 04 - CONTORNO DA VELOCIDADE DO VENTO NO PLANO HORIZONTAL $H=1.20 \mathrm{M}$ 263

FIGURA A.37 - MODELO 04 - VETORES DA VELOCIDADE E DIREÇÃO DO VENTO NO PLANO HORIZONTAL H=1.20M. 263 
FIGURA A.38 - MODELO 04 - CONTORNO DA VELOCIDADE DO VENTO NO PLANO HORIZONTAL $\mathrm{H}=2.00 \mathrm{M}$ 263

FIGURA A.39 - MODELO 04 - VETORES DA VELOCIDADE E DIREÇÃO DO VENTO NO PLANO HORIZONTAL H=2.00M 263

FIGURA A.40 - MODELO 04 - CONTORNO DA VELOCIDADE DO VENTO NO PVL1. 263

FIGURA A.41 - MODELO 04 - VETORES DA VELOCIDADE E DIREÇÃO DO VENTO NO PVL1. 263

FIGURA A.42 - MODELO 04 - CONTORNO DA VELOCIDADE DO VENTO NO PVL2. 264

FIGURA A.43 - MODELO 04 - VETORES DA VELOCIDADE E DIREÇÃO DO VENTO NO PVL2. 264

FIGURA A.44 - MODELO 04 - CONTORNO DA VELOCIDADE DO VENTO NO PVT1 264

FIGURA A.45 - MODELO 04 - VETORES DA VELOCIDADE E DIREÇÃO DO VENTO NO PVT1. 264

FIGURA A.46 - MODELO 04 - CONTORNO DA VELOCIDADE DO VENTO NO PVT2 264

FIGURA A.47 - MODELO 04 - VETORES DA VELOCIDADE E DIREÇÃO DO VENTO NO PVT2. 264 FIGURA A.48 - MODELO 05 - CONTORNO DA VELOCIDADE DO VENTO NO PLANO HORIZONTAL $H=1.20 \mathrm{M}$ 265

FIGURA A.49 - MODELO 05 - VETORES DA VELOCIDADE E DIREÇÃO DO VENTO NO PLANO HORIZONTAL H=1.20M 265

FIGURA A.50 - MODELO 05 - CONTORNO DA VELOCIDADE DO VENTO NO PLANO HORIZONTAL H=2M 265

FIGURA A.51 - MODELO 05 - VETORES DA VELOCIDAdE E DIREÇÃO DO VENTO NO PLANO HORIZONTAL H=2M 265

FIGURA A.52 - MODELO 05 - CONTORNO DA VELOCIDADE DO VENTO NO PVL1. 265

FIGURA A.53 - MODELO 05 - VETORES DA VELOCIDADE E DIREÇÃO DO VENTO NO PVL1. 265

FIGURA A.54 - MODELO 05 - CONTORNO DA VELOCIDADE DO VENTO NO PVL2. 266

FIGURA A.55 - MODELO 05 - VETORES DA VELOCIDADE E DIREÇÃO DO VENTO NO PVL2 ................. 266

FIGURA A.56 - MODELO 05 - CONTORNO DA VELOCIDADE DO VENTO NO PVT1 266 FIGURA A.57 - MODELO 05 - VETORES DA VELOCIDADE E DIREÇÃO DO VENTO NO PVT1. 266 
FIGURA A.58 - MODELO 05 - CONTORNO DA VELOCIDADE DO VENTO NO PVT2.

FIGURA A.59 - MODELO 05 - VETORES DA VELOCIDADE E DIREÇÃO DO VENTO NO PVT2 266

FIGURA A.60 - MODELO 06 - CONTORNO DA VELOCIDADE DO VENTO NO PLANO HORIZONTAL $\mathrm{H}=1.20 \mathrm{M}$ 267

FIGURA A.61 - MODELO 06 - VETORES DA VELOCIDADE E DIREÇÃO DO VENTO NO PLANO HORIZONTAL H=1.20M 267

FIGURA A.62 - MODELO 06 - CONTORNO DA VELOCIDADE DO VENTO NO PLANO HORIZONTAL $\mathrm{H}=2.00 \mathrm{M}$ 267

FIGURA A.63 - MODELO 06 - VETORES DA VELOCIDADE E DIREÇÃO DO VENTO NO PLANO HORIZONTAL H=2.00M 267

FIGURA A.64 - MODELO 06 - CONTORNO DA VELOCIDADE DO VENTO NO PVL1 267

FIGURA A.65 - MODELO 06 - VETORES DA VELOCIDADE E DIREÇÃO DO VENTO NO PVL1. 267 FIGURA A.66 - MODELO 06 - CONTORNO DA VELOCIDADE DO VENTO NO PVL2 268 FIGURA A.67 - MODELO 06 - VETORES DA VELOCIDADE E DIREÇÃO DO VENTO NO PVL2. 268 FIGURA A.68 - MODELO 06 - CONTORNO DA VELOCIDADE DO VENTO NO PVT1 268 FIGURA A.69 - MODELO 06 - VETORES DA VELOCIDADE E DIREÇÃO DO VENTO NO PVT1 268 FIGURA A.70 - MODELO 06 - CONTORNO DA VELOCIDADE DO VENTO NO PVT2 268 FIGURA A.71 - MODELO 06 - VETORES DA VELOCIDADE E DIREÇÃO DO VENTO NO PVT2 268 FIGURA A.72 - MODELO 07 - CONTORNO DA VELOCIDADE DO VENTO NO PLANO HORIZONTAL $H=1.20 \mathrm{M}$ 269

FIGURA A.73 - MODELO 07 - VETORES DA VELOCIDADE E DIREÇÃO DO VENTO NO PLANO HORIZONTAL H=1.20M. 269

FIGURA A.74 - MODELO 07 - CONTORNO DA VELOCIDADE DO VENTO NO PLANO HORIZONTAL $H=2.00 \mathrm{M}$ 269

FIGURA A.75 - MODELO 07 - VETORES DA VELOCIDADE E DIREÇÃO DO VENTO NO PLANO HORIZONTAL H=2.00M 269 
FIGURA A.76 - MODELO 07 - CONTORNO DA VELOCIDADE DO VENTO NO PVL1.

FIGURA A.77 - MODELO 07 - VETORES DA VELOCIDADE E DIREÇÃO DO VENTO NO PVL1 ................. 269

FIGURA A.78 - MODELO 07 - CONTORNO DA VELOCIDADE DO VENTO NO PVL2 ….......................... 270

FIGURA A.79 - MODELO 07 - VETORES DA VELOCIDADE E DIREÇÃO DO VENTO NO PVL2 …............... 270

FIGURA A.80 - MODELO 07 - CONTORNO DA VELOCIDADE DO VENTO NO PVT1 ............................... 270

FIGURA A.81 - MODELO 07 - VETORES DA VELOCIDADE E DIREÇÃO DO VENTO NO PVT1.................. 270

FIGURA A.82 - MODELO 07 - CONTORNO DA VELOCIDADE DO VENTO NO PVT2 …..........................2 270

FIGURA A.83 - MODELO 07 - VETORES DA VELOCIDADE E DIREÇÃO DO VENTO NO PVT2 ................. 270

FIGURA A.84 - MODELO 08 - CONTORNO DA VELOCIDADE DO VENTO NO PLANO HORIZONTAL

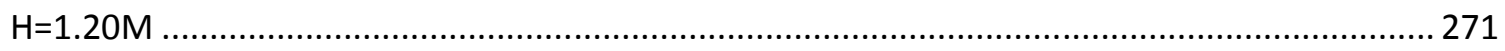

FIGURA A.85 - MODELO 08 - VETORES DA VELOCIDADE E DIREÇÃO DO VENTO NO PLANO HORIZONTAL H=1.20M 271

FIGURA A.86 - MODELO 08 - CONTORNO DA VELOCIDADE DO VENTO NO PLANO HORIZONTAL $\mathrm{H}=2.00 \mathrm{M}$ 271

FIGURA A.87 - MODELO 08 - VETORES DA VELOCIDADE E DIREÇÃO DO VENTO NO PLANO HORIZONTAL H=2.00M 271

FIGURA A.88 - MODELO 08 - CONTORNO DA VELOCIDADE DO VENTO NO PVL1. 271

FIGURA A.89 - MODELO 08 - VETORES DA VELOCIDADE E DIREÇÃO DO VENTO NO PVL1 .................. 271

FIGURA A.90 - MODELO 08 - CONTORNO DA VELOCIDADE DO VENTO NO PVL2 _................................ 272

FIGURA A.91 - MODELO 08 - VETORES DA VELOCIDADE E DIREÇÃO DO VENTO NO PVL2 .................. 272

FIGURA A.92 - MODELO 08 - CONTORNO DA VELOCIDADE DO VENTO NO PVT1 ….......................... 272

FIGURA A.93 - MODELO 08 - VETORES DA VELOCIDADE E DIREÇÃO DO VENTO NO PVT1.................. 272

FIGURA A.94 - MODELO 08 - CONTORNO DA VELOCIDADE DO VENTO NO PVT2 …......................... 272

FIGURA A.95 - MODELO 08 - CONTORNO DA VELOCIDADE DO VENTO NO PVT2 ….......................... 272 


\section{LISTA DE GRÁFICOS}

GRÁFICO 2.1 - DIMENSIONAMENTO DA VENTILAÇÃO POR EFEITO CHAMINÉ E DIMENSIONAMENTO DE ENTRADA E SAÍDA DE AR. 75

GRÁFICO 2.2 - DIMENSIONAMENTO DAS ABERTURAS PARA VENTILAÇÃO CRUZADA... 86

GRÁFICO 2.3 - EFEITO DA FORMA DA ABERTURA EM FUNÇÃO DA DIREÇÃO DO VENTO E DA EXISTÊNCIA DE PROTETORES SOLARES VERTICAIS

GRÁFICO 2.4 - EFICIÊNCIA DE COLETA DOS DIFERENTES TIPOS DE COLETORES DE VENTO ...

GRÁFICO 3.1 - VARIAÇÃO DA TEMPERATURA ANUAL E HORÁRIA. 117

GRÁFICO 3.2 - PRECIPITAÇÃO MÁXIMA EM 24H. 117

GRÁFICO 3.3 - PRECIPITAÇÃO MENSAL 117

GRÁFICO 3.4 - VARIAÇÃO DA UMIDADE RELATIVA. 118

GRÁFICO 3.5 - MÉDIA MENSAL DA TEMPERATURA DO AR DE BULBO SECO. 123 GRÁFICO 3.6 - MÉDIA MENSAL DA UMIDADE RELATIVA DO AR. 125 GRÁFICO 3.7- DIREÇÃO PREDOMINANTE DOS VENTOS. 126 GRÁFICO 3.8 - VELOCIDADE MÉDIA MENSAL DO VENTO 128 GRÁFICO 3.9 - TEMPERATURA DO AR AO LONGO DO ANO DE REFERÊNCIA $\left({ }^{\circ} \mathrm{C}\right) \ldots \ldots \ldots \ldots \ldots \ldots \ldots \ldots . . . . . . . . . . . . . . . .129$ GRÁFICO 3.10 - MÉDIAS DA TEMPERATURA DO AR (2003 A 2006) ............................................... 130 GRÁFICO 3.11 - TEMPERATURA HORÁRIA ABSOLUTA - MÁXIMAS E MÍNIMAS................................ 131 GRÁFICO 3.12 - FREQÜÊNCIA DA TEMPERATURA DO AR ENTRE 2003 E 2006 ................................. 131 GRÁFICO 3.13 - UMIDADE RELATIVA DO AR AO LONGO DO ANO DE REFERÊNCIA ........................... 132 GRÁFICO 3.14 - MÉDIA DA UMIDADE RELATIVA DO AR ( 2003 A 2006) ............................................. 133 GRÁFICO 3.15 - MÊS CRÍTICO DE VERÃO - MARÇO DE 2006 ….................................................. 138 GRÁFICO 3.16 - TEMPERATURA DO AR - 12 DE MARÇO DE 2006 ................................................. 139 GRÁFICO 3.17 - UMIDADE RELATIVA DO AR - 12 DE MARÇO DE 2006 .......................................... 139

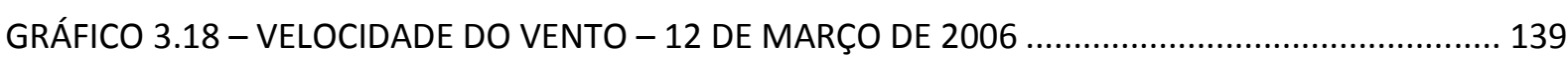


GRÁFICO 3.19 - DIREÇÃO DOS VENTOS - 12 DE MARÇO DE 2006. 140

GRÁFICO A.1 - MÉDIA DIÁRIA DA TEMPERATURA DO AR (ํㅡ) - MÊS DE JANEIRO ............................ 249

GRÁFICO A.2 - MÉDIA DIÁRIA DA TEMPERATURA DO AR (ำ) - MÊS DE FEVEREIRO …...................... 249

GRÁFICO A.3 - MÉDIA DIÁRIA DA TEMPERATURA DO AR (으) - MÊS DE MARÇO …............................ 249

GRÁFICO A.4 - MÉDIA DIÁRIA DA TEMPERATURA DO AR (으) - MÊS DE ABRIL.................................. 249

GRÁFICO A.5 - MÉDIA DIÁRIA DA TEMPERATURA DO AR (ํ) - MÊS DE MAIO................................. 249

GRÁFICO A.6 - MÉDIA DIÁRIA DA TEMPERATURA DO AR (ำ) - MÊS DE JUNHO................................. 249

GRÁFICO A.7 - MÉDIA DIÁRIA DA TEMPERATURA DO AR (으) - MÊS DE JULHO …............................ 250

GRÁFICO A.8 - MÉDIA DIÁRIA DA TEMPERATURA DO AR (ำ) - MÊS DE AGOSTO …........................ 250

GRÁFICO A.9 - MÉDIA DIÁRIA DA TEMPERATURA DO AR (ำ) - MÊS DE SETEMBRO …....................... 250

GRÁFICO A.10 - MÉDIA DIÁRIA DA TEMPERATURA DO AR (으) - MÊS DE OUTUBRO …................... 250

GRÁFICO A.11 - MÉDIA DIÁRIA DA TEMPERATURA DO AR (으) - MÊS DE NOVEMBRO ….................. 250

GRÁFICO A.12 - MÉDIA DIÁRIA DA TEMPERATURA DO AR (으) - MÊS DE DEZEMBRO …………......250

GRÁFICO A.13 - MÉDIA DIÁRIA DA UMIDADE RELATIVA DO AR (\%) - JANEIRO ……........................ 251

GRÁFICO A.14 - MÉDIA DIÁRIA DA UMIDADE RELATIVA DO AR (\%) - FEVEREIRO ….......................... 251

GRÁFICO A.15 - MÉDIA DIÁRIA DA UMIDADE RELATIVA DO AR (\%) - MARÇO ...................................... 251

GRÁFICO A.16 - MÉDIA DIÁRIA DA UMIDADE RELATIVA DO AR (\%) - ABRIL........................................ 251

GRÁFICO A.17 - MÉDIA DIÁRIA DA UMIDADE RELATIVA DO AR (\%) - MAIO ...................................... 251

GRÁFICO A.18 - MÉDIA DIÁRIA DA UMIDADE RELATIVA DO AR (\%) - JUNHO..................................... 251

GRÁFICO A.19 - MÉDIA DIÁRIA DA UMIDADE RELATIVA DO AR (\%) - JULHO................................... 252

GRÁFICO A.20 - MÉDIA DIÁRIA DA UMIDADE RELATIVA DO AR (\%) - AGOSTO................................. 252

GRÁFICO A.21 - MÉDIA DIÁRIA DA UMIDADE RELATIVA DO AR (\%) - SETEMBRO ….......................... 252

GRÁFICO A.22 - MÉDIA DIÁRIA DA UMIDADE RELATIVA DO AR (\%) - OUTUBRO ............................... 252

GRÁFICO A.23 - MÉDIA DIÁRIA DA UMIDADE RELATIVA DO AR (\%) - NOVEMBRO ……….................2252

GRÁFICO A.24 - MÉDIA DIÁRIA DA UMIDADE RELATIVA DO AR (\%) - DEZEMBRO.............................. 252

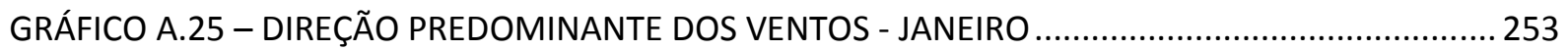


GRÁFICO A.26 - DIREÇÃO PREDOMINANTE DOS VENTOS - FEVEREIRO

GRÁFICO A.27 - DIREÇÃO PREDOMINANTE DOS VENTOS - MARÇO.

GRÁFICO A.28 - DIREÇÃO PREDOMINANTE DOS VENTOS - ABRIL

GRÁFICO A.29 - DIREÇÃO PREDOMINANTE DOS VENTOS - MAIO

GRÁFICO A.30 - DIREÇÃO PREDOMINANTE DOS VENTOS - JUNHO

GRÁFICO A.31 - DIREÇÃO PREDOMINANTE DOS VENTOS - JULHO 254

GRÁFICO A.32 - DIREÇÃO PREDOMINANTE DOS VENTOS - AGOSTO 254

GRÁFICO A.33 - DIREÇÃO PREDOMINANTE DOS VENTOS - SETEMBRO. 254

GRÁFICO A.34 - DIREÇÃO PREDOMINANTE DOS VENTOS - OUTUBRO 254

GRÁFICO A.35 - DIREÇÃO PREDOMINANTE DOS VENTOS - NOVEMBRO. 254

GRÁFICO A.36 - DIREÇÃO PREDOMINANTE DOS VENTOS - DEZEMBRO 254

GRÁFICO A.37 - VELOCIDADE MÉDIA DO VENTO (M/S) - JANEIRO 255

GRÁFICO A.38 - VELOCIDADE MÉDIA DO VENTO (M/S) - FEVEREIRO 255

GRÁFICO A.39 - VELOCIDADE MÉDIA DO VENTO (M/S) - MARÇO 255

GRÁFICO A.40 - VELOCIDADE MÉDIA DO VENTO (M/S) - ABRIL 255

GRÁFICO A.41 - VELOCIDADE MÉDIA DO VENTO (M/S) - MAIO 255

GRÁFICO A.42 - VELOCIDADE MÉDIA DO VENTO (M/S) - JUNHO 255

GRÁFICO A.43 - VELOCIDADE MÉDIA DO VENTO (M/S) - JULHO 256

GRÁFICO A.44 - VELOCIDADE MÉDIA DO VENTO (M/S) - AGOSTO 256

GRÁFICO A.45 - VELOCIDADE MÉDIA DO VENTO (M/S) - SETEMBRO 256

GRÁFICO A.46 - VELOCIDADE MÉDIA DO VENTO (M/S) - OUTUBRO 256

GRÁFICO A.47 - VELOCIDADE MÉDIA DO VENTO (M/S) - NOVEMBRO 256

GRÁFICO A.48 - VELOCIDADE MÉDIA DO VENTO (M/S) - DEZEMBRO 256 


\section{LISTA DE TABELAS}

TABELA 2.1 - VEL. MEDIA DO AR NO INTERIOR DE UMA EDIFICAÇÃO COMO PERCENTUAL DA VELOCIDADE DO AR NO EXTERIOR - ÂNGULO DE INCIDÊNCIA VARIANDO ENTRE 45 E PERPENDICULAR À ABERTURA. 91

TABELA 3.1 - CRITÉRIO DE AVALIAÇÃO DE DESEMPENHO TÉRMICO PARA CONDIÇÕES DE VERÃO (ABNT, 2004) 113

TABELA 3.2 - MÉDIAS DA TEMPERATURA DO AR (2003 A 2006)... 130

TABELA 3.3 - MÉDIAS DA UMIDADE RELATIVA DO AR (2003 A 2006). 133

TABELA 3.4 - DADOS DOS VENTOS NA CIDADE DE ARACAJU (2003 A 2006)..... 135

TABELA 3.5 - DADOS CLIMÁTICOS DE ARACAJU DE 2003 A 2006. 136

TABELA 4.1 - MÓDULO DO CFX COM AS RESPECTIVAS ATIVIDADES. 151

TABELA 4.2 - PARÂMETROS DA SIMULAÇÃO INSERIDOS NO CFX-PRE. 161

TABELA 6.1 - QUADRO RESUMO DAS SIMULAÇÕES DOS MODELOS 1 A 8. 208 


\section{SUMÁRIO}

1. INTRODUCCÃO

41

1.1 COLOCAÇÃO DO PROBLEMA E JUSTIFICATIVA DA PESQUISA

41

1.2 Objeto e objetivos

49

1.2.1 OBJEto

49

1.2.2 Objetivo geral

50

1.2.3 OBJETIVOS ESPECÍFICOS

50

1.3 Metodologia da Pesquisa

51

1.4 EStRUtURA DO TRABALHO

1.5 RECURSOS E RESTRIÇÕES

2.1 Ventilação natural

2.1.1 PRINCÍPIOS DO MOVIMENTO DO AR

2.1.2 FINALIDADES DA VENTILAÇÃO

2.1.3 HIGIENE

2.1.4 CONFORTO TÉRMICO

2.1.5 VENTILAÇÃo E AS VARIÁVEIS AMBIENTAIS DE CONFORTO TÉRMICO

2.1.6 ÍNDICES DE CONFORTO TÉRMICO

2.2 FUNDAMENTOS DA VENTILAÇÃo NATURAL

2.2.1 VENTILAÇÃO POR AÇÃO DOS VENTOS (VENTILAÇÃO CRUZADA)

2.2.2 VENTILAÇÃO POR EFEITO CHAMINÉ

2.2.3 SIMULTANEIDADE DOS PROCESSOS 
2.3.1 LOCALIZAÇÃO, FORMA E ORIENTAÇÃO DO EDIFÍCIO

2.3.2 VENTILAÇÃO NO INTERIOR DAS EDIFICAÇÕES

2.3.3 TAMANHOS E FORMAS DAS ABERTURAS

2.3.4 LOCALIZAÇÃO DAS ABERTURAS $\quad 88$

$\begin{array}{lll}\text { 2.3.5 TIPOLOGIA DAS ABERTURAS } & 93\end{array}$

$\begin{array}{ll}\text { 2.3.6 } & \text { EFEITOS DAS DIVISÕES INTERNAS } \\ & 100\end{array}$

2.3.7 ElemENTOS HORIZONTAIS E VERTICAIS 102

3. O CLIMA DA CIDADE DE ARACAJU - SE $\quad 107$

$\begin{array}{llr}3.1 & \text { CARACTERIZAÇÃo da ÁREA } & 107\end{array}$

$\begin{array}{llr}3.2 & \text { Dados Climáticos } & 113\end{array}$

$\begin{array}{llr}3.2 .1 & \text { CLASSIFICAÇÃO CLIMÁtICA } & 114\end{array}$

$\begin{array}{llr}\text { 3.2.2 COLETA DE DADOS CLIMÁTICOS } & 120\end{array}$

$\begin{array}{lll}\text { 3.2.3 ANO CLIMÁTICO DE REFERÊNCIA } & 128\end{array}$

$\begin{array}{llr}\text { 3.2.4 DIA TÍPICO DE PROJETO } & 136\end{array}$

4. SIMULACÃO COMPUTACIONAL $\quad 141$

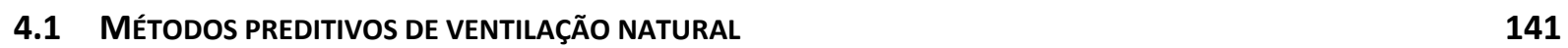

4.1.1 TÚNEIS DE VENTO E SIMULAÇÃO COMPUTACIONAL 142

4.1.2 A PRÁTICA DA SIMULAÇÃO COMPUTACIONAL 143

$\begin{array}{llr}\text { 4.2 A ESCOLHA dO SOFTWARE DE SIMULAÇÃo } & 148\end{array}$

\begin{tabular}{lr}
4.3 & Módulos Do CFX \\
\hline
\end{tabular}

4.4 PRE-PROCESSOR - ELABORAÇÃO DA GEOMETRIA E CRIAÇÃO DA MALHA 151

$\begin{array}{llr}\text { 4.4.1 GEOMETRY } & 151\end{array}$

4.4.2 DEFINIÇÃO DO DOMÍNIO E CONCEPÇÃO DO MODELO 
$\begin{array}{lll}\text { 4.4.3 } & \text { MESHING } & 156\end{array}$

$\begin{array}{lll}\text { 4.4.4 CFX-PRE } & 161\end{array}$

4.5 SOLVER - DEFINIÇÃO DAS CONDIÇÕES INICIAIS E DE CONTORNO 165

4.6 POST-PROCESSOR - CONVERGÊNCIA E ANÁLISE DOS RESULTADOS 166

4.6.1 Contorno da Velocidade do Vento no Plano Horizontal H1P5 - Nível PEDEStRe (H=1,5M) 168

4.6.2 CONTORNO DA VELOCIDADE DO VENTO do PLANO HORIZONTAL H4P5 - ACIMA DAS EDIFICAÇõES TÉRREAS

$\begin{array}{ll}(H=4,5 M) & 169\end{array}$

4.6.3 CONTORNO DA VELOCIDADE DO VENTO No PLANO HORIZONTAL H37P5 - NÍVEL DO MEIO DO APARTAMENTO

DO 11을 ANDAR (H=37,5M) 170

4.6.4 CONTORNo DA Velocidade do Vento no Plano Vertical LONGITUdinAL 1 - PVL1 - NO CENTRO do

APARTAMENTO

4.6.5 CONTORNO DA VELOCIDADE DO VENTO NO PLANO VERTICAL LONGITUDINAL 2 - PVL2 - CENTRO DO EDIFí́cIO 172

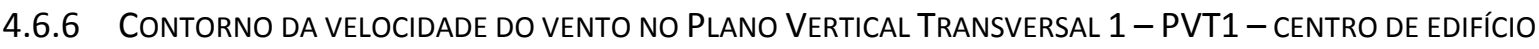
173

4.6.7 Contorno da Velocidade do Vento no Plano Vertical TRANSVERSAL 2 - PVT2 - CENTRO do APARTAMENTO

4.6.8 VETORES DA VELOCIDADE E DIREÇÃO DOS VENTOS 175

4.6.9 CONTORNO DA PRESSÃO DO VENTO NA FACHADA 179 
$\begin{array}{llr}5.7 & \text { MOdelo } 06 & 198\end{array}$

$\begin{array}{llr}5.8 \text { MOdeLO } 07 & 200\end{array}$

$\begin{array}{llr}5.9 \text { MOdelo } 08 & 202\end{array}$

6. DISCUSSÃO DOS RESULTADOS DAS SIMULACCÕES

6.1 Entorno do APARTAMento - Modelo eXPERIMENTAL X MOdelo baSe 209

$\begin{array}{lr}6.2 \text { MOdELO } 01 & 211\end{array}$

$\begin{array}{rrr}6.3 & \text { MOdelO } 01 \text { x MODELO } 02 & 213\end{array}$

$\begin{array}{rrr}6.4 & \text { MOdELO } 01 \text { x MODELO } 03 & 216\end{array}$

$\begin{array}{llr}6.5 & \text { MOdELO } 03 \text { x MOdELO } 04 & 218\end{array}$

$\begin{array}{llr}6.6 & 220\end{array}$

$\begin{array}{lrr}\text { 6.7 MOdELO } 03 \text { X MOdelO } 06 & 222\end{array}$

$\begin{array}{llr}6.8 & \text { MOdELO } 01 \text { X MOdelo } 07 & 225\end{array}$

$\begin{array}{lrr}6.9 & \text { MOdELO } 01 \text { X MOdelo } 08 & 229\end{array}$

7. CONCLUSÃO $\quad 233$

\begin{tabular}{lr} 
REFERÊNCIAS & 243 \\
\hline
\end{tabular}

\begin{tabular}{lr} 
ANEXOS & 249 \\
\hline
\end{tabular}

A. ANEXO 1 - GRÁFICOS DA MÉdIA DA TEMPERATURA dO AR MÊS A MÊS ENTRE 2003 E 2006 COM BASE NO TRATAMENTO DOS DADOS FORNECIDOS PELO INMET.

B. ANEXO 2 - GRÁFICOS DA MÉDIA DA UMIDADE RELATIVA DO AR MÊS A MÊS ENTRE 2003 E 2006 COM BASE NO TRATAMENTO DOS DADOS FORNECIDOS PELO INMET. 
C. ANEXO 3 - GRÁFICOS DA DIREÇÃo PREDOMINANTE dos VENTOS MÊS A MÊS ENTRE 2003 E 2006 COM BASE NO TRATAMENTO DOS DADOS FORNECIDOS PELO INMET.

D. ANEXO 4 - GRÁFICOS DA VELOCIDADE MÉDIA dOS VENTOS MÊS A MÊS ENTRE 2003 E 2006 COM BASE NO TRATAMENTO DOS DADOS FORNECIDOS PELO INMET.

E. ANEXO 5 - IMAGENS COMPLEMENTARES DA SIMULAÇÃO DO MODELO 01

F. ANEXO 6 - IMAGENS COMPLEMENTARES DA SIMULAÇÃO DO MODELO 02

G. ANEXO 7 - IMAGENS COMPLEMENTARES DA SIMULAÇÃO DO MODELO 03

H. ANEXO 8 - IMAGENS COMPLEMENTARES DA SIMULAÇÃO DO MODELO 04

I. ANEXO 9 - IMAGENS COMPLEMENTARES DA SIMULAÇÃO DO MODELO 05

J. ANEXO 10 - IMAGENS COMPLEMENTARES DA SIMULAÇÃO DO MODELO 06

K. ANEXO 11 - IMAGENS COMPLEMENTARES DA SIMULAÇÃO DO MODELO 07

L. ANEXO 12 - IMAGENS COMPLEMENTARES DA SIMULAÇÃO DO MODELO 08 
... 


\section{INTRODUÇÃO}

\subsection{ColocaÇão do PROBlEMA E JUSTIFICATIVA DA PESQUISA}

O homem sempre buscou, desde os primórdios da história da civilização humana, um abrigo para se proteger das intempéries, utilizando os meios que encontrava em sua região. Buscava em suas construções reduzir o calor, o frio, a umidade, etc., aproveitando as características desejáveis do clima local enquanto se evitava as indesejáveis. A esse tipo de arquitetura dá-se o nome de Arquitetura Vernacular, que nada mais é do que o resultado de uma vivência do homem com o ambiente que o cerca, por meio de muita observação e tentativas através dos tempos. É a manifestação de um saber adquirido graças a uma experiência secular, transmitida e aperfeiçoada de geração a geração. É conveniente refletir e aprender com ela, assim como perpetuá-la, mas também é necessário enriquecê-la e melhorá-la.

A grande expansão de técnicas construtivas após a II Guerra Mundial proporcionou uma mudança radical na arquitetura mundial até o ponto onde os estilos começaram a ser "importados" de outras regiões com características climáticas distintas simplesmente por representar status, ostentar progresso ou simbolizar o poder. Criou-se assim uma arquitetura globalizada permitindo, por exemplo, que edificações com fachadas totalmente envidraçadas fossem construídas em locais de clima tropical, criando verdadeiras estufas urbanas. Ou seja, o homem por um 
tempo se entusiasmou com as descobertas tecnológicas e a possibilidade de executar praticamente qualquer criação e se esqueceu dos recursos que a natureza coloca a disposição para o conforto ambiental.

Assim, a forma encontrada pelos profissionais da área de projeto para solucionar os problemas de conforto ambiental causados pelo emprego de uma arquitetura não adequada ao clima local, foi criar sistemas de iluminação e de climatização artificiais cada vez mais potentes e isso, consequentemente, gerou um aumento cada vez maior do consumo de energia para suprir essa necessidade, numa época em que não existia uma consciência sobre os impactos no meio ambiente causado pelo consumo exagerado de energia.

Na década de 70, com o surgimento da primeira crise mundial de energia, ressurgiu uma arquitetura integrada ao clima local, objetivando a melhoria da qualidade de vida das pessoas no ambiente construído e seu entorno e ao mesmo tempo fornecendo conforto ambiental com menor consumo de energia e menor impacto ambiental. Em outras palavras, voltou-se a perceber que conceitos simples como: proteção contra insolação no verão, amortecimento das variações da temperatura através do emprego de materiais de grande inércia térmica, aproveitamento da ventilação natural, aproveitamento da insolação no inverno, entre muitos outros recursos, além de tornar a arquitetura regional mais criativa e personalizada, estaria contribuindo para a preservação da natureza através da redução no consumo de energia. 
No Brasil a questão energética começou a repercutir com mais força a partir da crise no abastecimento de energia elétrica ocorrida em 2001, causando o conhecido "apagão" seguido de um racionamento e mostrando quais as prováveis consequências do consumo desenfreado de energia elétrica no mundo. A partir de então o tema eficiência energética tornouse assunto conhecido em todos os segmentos da população.

Com a necessidade imediata de se economizar energia, surge também uma renovação na consciência da população e também dos profissionais que podem e querem contribuir para a mudança do quadro mundial, ou pelo menos na estagnação do processo crescente de degradação do meio ambiente.

$\mathrm{Na}$ área do conforto ambiental, principalmente no que se refere à térmica e iluminação, surgem cada vez mais ferramentas que auxiliam o arquiteto a criar espaços com o uso de tecnologias passivas na busca do conforto do usuário e o primeiro passo é o estudo do clima local, assim como acontecia nos primórdios dos tempos. É evidente que nos tempos atuais não se pretende adotar exclusivamente técnicas passivas para solucionar problemas ambientais em locais com climas extremos, porém ao balancear todos os aspectos naturais e tecnológicos, será possível obter ambientes confortáveis e energeticamente eficientes.

O estudo da ventilação natural, como forma de amenização climática, tem sido tema de diversos trabalhos científicos apresentados em congressos e encontros da área de conforto ambiental tanto no país 
como no exterior. A ventilação natural tem como principal vantagem o baixo custo necessário a sua efetivação. No entanto, conhecimentos bastante sofisticados podem ser necessários para uma eficaz implantação dessa estratégia, pelo fato do fluxo de ar ser de difícil previsão e por envolver certa complexidade de análise e cálculo. De um modo geral é possível racionalizar o uso de energia elétrica em um edifício por meio da ventilação natural. Em países em desenvolvimento como o Brasil, o uso passivo da energia na edificação tem papel fundamental e é meta da arquitetura bioclimática que tem como objetivo:

"[...] prover um ambiente construído com conforto físico, sadio e agradável, adaptado ao clima local, que minimize o consumo de energia convencional e precise da instalação da menor potência elétrica possível, o que também leva a mínima produção de poluição" (CORBELLA \& YANNAS, 2003).

O objeto desta pesquisa é a ventilação natural nas edificações na cidade de Aracaju. E desde o início desta pesquisa procura-se destacar a forte necessidade de se analisar cuidadosamente as características climáticas apresentadas na região objeto de estudo por ser, como citado em várias referências bibliográficas, altamente importante para se adotar partidos arquitetônicos adequados ao local.

[...] além dos elementos referentes aos processos de ventilação, é indispensável que o projetista disponha de dados meteorológicos relativos ao local onde vai ser construído o edifício, pois analisando cuidadosamente os dados climáticos, concluirá se e quando a ventilação deverá ser utilizada para melhoria do conforto térmico no interior do prédio. (TOLEDO, E. 1999). ${ }^{1}$

${ }^{1}$ Publicação brasileira do Relatório "Ventilação Natural das Habitações" publicado pelo Laboratório Nacional de Engenharia Civil (LNEC), Lisboa-Portugal, em 1967. 
Para a análise dos dados climáticos da cidade de Aracaju, foi realizada uma pesquisa extensa em busca de arquivos climáticos disponíveis para uma caracterização climática atual. Os dados da temperatura do ar, umidade relativa do ar, velocidade e direção dos ventos foram minuciosamente analisados. A disponibilidade e o tratamento dos dados climáticos da região são importantes para o conhecimento das condições climáticas da cidade e, por meio de sua correta interpretação é mais fácil a adoção de partidos arquitetônicos adequados ao clima. Além disso, esses dados podem ser utilizados em uma série de simulações computacionais de desempenho térmico da edificação e de mecânica dos fluidos para análise da ventilação natural. Porém é sempre importante lembrar que não é apenas um arquivo climático que garante resultados confiantes em uma simulação computacional, mas a maneira a qual ele é utilizado e como os resultados são interpretados.

Segundo o software Climaticus $4.2^{2}$, o método de Givoni indica que em $74 \%$ das horas do ano a ventilação é a principal estratégia de projeto para obter o conforto térmico dos usuários na cidade de Aracaju - SE, cidade localizada no litoral nordestino do Brasil, que se destaca por apresentar uma temperatura na sombra que poucas vezes ultrapassa os $30^{\circ} \mathrm{C}$, mas com umidade relativa com média em torno de $75 \%$, o que provoca um desconforto acentuado que pode ser amenizado por meio da

2 Software elaborado pelo Laboratório de Conforto Ambiental e Eficiência Energética sob supervisão da Profa. Dra. Márcia P. Alucci da FAUUSP 
constante presença da ventilação natural. Além disso, o clima dessa região caracteriza-se também por uma radiação solar intensa e uma amplitude térmica pequena, tanto diária quanto sazonal, e suas características são semelhantes à maioria das cidades litorâneas do nordeste brasileiro, onde os ventos sopram constantemente.

"Por causa do alto nível de umidade nas regiões tropicais, é difícil o corpo humano perder calor por transpiração. O movimento do ar, seja ele fresco ou não, produzirá conforto por incrementar a perda de calor pelo corpo. O resultado desse efeito da ventilação acarretará uma redução aparente de até aproximadamente $4^{\circ} \mathrm{C}$, embora normalmente varie $2^{\circ} \mathrm{C}$ a $3^{\circ} \mathrm{C}$. Essa redução torna-se significativa ao se examinar a pequena diferença entre a variação das temperaturas diurnas nas regiões tropicais a qual não é muito maior que esse efeito produzido pela ventilação." (HERTZ, 1998)

A ventilação natural no interior de um edifício ainda é um campo relativamente pouco explorado no meio acadêmico se comparado à importância deste tema para o conforto térmico nas habitações localizadas em climas quentes e úmidos, principalmente, e também para a questão da eficiência energética na arquitetura.

Esse fato se deve a dificuldade de se prever o comportamento dos ventos no meio urbano e no interior das edificações, uma vez que fatores naturais, urbanos e arquitetônicos interferem ao mesmo tempo nesta resposta.

Estudos sobre a ventilação natural nos edifício podem ser feitos com base na bibliografia existente, com ensaios em túneis de vento e com o auxílio de softwares de simulação computacional de dinâmica dos fluidos. O uso de referências teóricas é de suma importância uma vez que é 
necessário entender a dinâmica do vento e seus assuntos correlatos, para que se tenha embasamento suficiente para escolher a ferramenta adequada e para saber interpretar as respostas obtidas.

A simulação computacional é uma ferramenta bastante eficiente para a análise da interação entre ventos locais, elementos naturais e os elementos construídos no entorno do sítio onde se pretende intervir na fase dos estudos preliminares de um projeto. Porém é necessário um conhecimento especializado para que essas simulações sejam feitas e, mais do que isso, sejam interpretadas corretamente.

No estudo da ventilação natural, os softwares são de grande complexidade e em geral utilizados por grupos de pesquisadores ou profissionais especializados nas áreas de conforto ambiental que buscam nas simulações a visualização das respostas aos problemas impostos. Felizmente, vários programas vem sendo desenvolvidos em várias partes do mundo e se tornam cada vez mais ferramentas bastante úteis na área da arquitetura e urbanismo.

O software escolhido para a realização da pesquisa experimental desta dissertação foi o CFX 5.7, um software de dinâmica dos fluídos adequado ao estudo da ventilação natural ou mecânica, tanto no edifício quanto no meio urbano. Segundo Prata (2005), "[...] os modelos CFD são muito poderosos e requerem cálculos intensos, mas fornecem resultados detalhados que podem mostrar claramente os defeitos em projetos sugeridos". 
A escolha deste programa de simulação computacional se baseou nos seguintes princípios:

- Disponibilidade de licença educacional para o LABAUT - Laboratório de Conforto Ambiental e Eficiência Energética - da Faculdade de Arquitetura e Urbanismo da Universidade de São Paulo;

- A experiência no uso deste aplicativo em dissertações de mestrado e teses de doutorados anteriores, permitindo que os alunos mais experientes pudessem compartilhar o conhecimento acumulado para a realização desta pesquisa;

- Estuda a mecânica dos fluidos em ambientes ou superfícies e possibilita a interação entre fluxos internos e externos;

- Apresenta os resultados das simulações em imagens 3D, facilitando a análise e visualização destes resultados;

- Permite a simulação de modelos em qualquer escala e em qualquer condição de contorno.

O universo de análise deste mestrado é a cidade de Aracaju e buscou-se escolher um tipo de edificação que representasse um dos modelos padrão de construção que vem sendo explorado nesta cidade nos últimos anos com a finalidade de aproximar os resultados alcançados nas simulações da realidade atual. Além disso, a escolha da edificação foi principalmente baseada nas características dos ventos locais e do entorno da edificação, pois como a proposta desta pesquisa é realizar um estudo da ventilação natural no interior da habitação, foi importante escolher 
uma edificação que estivesse inserida numa área ainda pouco verticalizada da cidade e com boa permeabilidade para os ventos locais para que as simulações apresentassem respostas claras e com mais objetividade. Desta forma o modelo utilizado em todas as simulações foi o apto 1102 do edifício Montparnasse, localizado na Rua Duque de Caxias, no 167, Bairro São José. E o entorno considerado foi definido para analisar a influência que as edificações vizinhas exercem no edifício escolhido, de forma que a quadra onde o edifício Montparnasse está situado ficou bem no centro do modelo.

Assim, através dos problemas expostos e das ferramentas e objetos utilizados nesta pesquisa, pode-se perceber o grande potencial ainda a ser explorado na elaboração do projeto da edificação, buscando mecanismos de condicionamento natural, por meio de uma série de critérios que definem o conforto térmico do usuário. Desse modo, enfatiza-se novamente, que antes de propor uma solução arquitetônica, o arquiteto precisa estudar o clima local a fim de verificar a melhor estratégia a ser empregada na busca do conforto térmico natural, ou seja, quais os recursos de projeto podem ser utilizados para se obter o melhor aproveitamento da ventilação natural, produzindo assim, um ambiente compatível com as exigências humanas e econômicas dos usuários e do país.

\subsection{OBJETO E OBJETIVOS}

\subsubsection{Objeto}


O objeto de estudo desta pesquisa é a ventilação natural nas habitações da cidade de Aracaju - SE.

\subsubsection{Objetivo geral}

O objetivo geral é realizar um estudo do aproveitamento do vento para promover a ventilação natural em edificações residenciais na cidade de Aracaju a fim de proporcionar melhores condições térmicas ambientais dos usuários sem a necessidade do condicionamento artificial do ar.

\subsubsection{Objetivos específicos}

São os objetivos específicos desta pesquisa:

- Identificar referências sobre ventilação natural no edifício e sua relação com o conforto térmico em climas quentes e úmidos.

- Identificar o perfil climático da cidade de Aracaju - SE.

- Caracterizar o clima da região quanto aos aspectos dos ventos predominantes.

- Escolher uma habitação padrão local para verificação do efeito da ventilação natural nos ambientes internos.

- Definir a ferramenta mais apropriada para as simulações computacionais.

- Verificar, por meio da simulação computacional a influência da ventilação natural na edificação.

- Elaborar algumas propostas para intervenção no projeto e estudar as conseqüências dessas alterações.

- Analisar qualitativamente e comparar os resultados obtidos. 


\subsection{MeTOdOLOGIA DA PESQUISA}

A metodologia empregada nesta pesquisa foi dividida nas seguintes etapas metodológicas:

A pesquisa referencial consistiu no levantamento dos dados secundários por meio de pesquisa bibliográfica sobre ventilação natural nas edificações e assuntos correlatos e também consultas à especialistas na área para reunir informações que contribuíssem para o embasamento teórico e contextual, além de levantamento de mapas, plantas, documentos e legislação urbanística do município de Aracaju-SE.

A pesquisa de campo consistiu no levantamento de dados primários com a caracterização climática da cidade de Aracaju - SE, principalmente no que se refere à velocidade e direção dos ventos predominantes e também de levantamento fotográfico.

A pesquisa experimental foi a etapa da série de simulações realizada no programa ANSYS CFX - Computacional Fluid Dynamics Software, desde a simulação do modelo escolhido com suas características arquitetônicas preservadas até a simulação de cada um do modelos referentes as alterações propostas para o estudo da ventilação natural no edifício.

A análise dos dados simulados consistiu na observação e comparação dos resultados fornecidos pelo programa CFX com o efeito do vento no entorno e no interior da edificação em sua configuração atual e com as alterações arquitetônicas propostas. 
Por fim, as conclusões finais encerraram o processo metodológico desta pesquisa, apresentando todas as conclusões obtidas juntamente com a contribuição que esses resultados proporcionam para o estudo da ventilação natural no edifício e do conforto térmico dos usuários em locais de climas semelhantes ao da área de estudo.

\subsection{ESTRUTURA DO TRABALHO}

Este trabalho está estruturado da seguinte forma:

- Capítulo 1 - Introdução: Neste capítulo é feita a colocação do problema destacando a importância do aproveitamento da ventilação natural no interior das edificações para promover o conforto térmico em locais de clima quente e úmido. A pesquisa se justifica considerando que por meio da escolha de um partido arquitetônico adequado às características climáticas locais e do estudo prévio dos ventos locais é possível criar ambientes internos bem ventilados. Além disso, são relacionados o objeto de estudo e os objetivos geral e específicos da pesquisa, esclarecendo os limites deste estudo e recorte feito sobre o tema da ventilação natural. E por fim, a metodologia do trabalho é apresentada, juntamente com os recursos e restrições da pesquisa como um todo.

- Capítulo 2 - Fundamentação teórica: A fundamentação teórica busca, através de uma revisão bibliográfica, expor os fundamentos, princípios e finalidades da ventilação natural, além de mostrar a interferência direta da arquitetura no comportamento da ventilação 
natural nos espaços internos das edificações. Mostra também o papel fundamental do arquiteto na busca de espaços bem ventilados e a importância de se conhecer e utilizar os princípios dos ventos, os dados climáticos e os métodos de simulação na fase de concepção de projeto.

- Capítulo 3 - 0 clima da cidade de Aracaju-SE: Neste capítulo se refere à cidade de Aracaju, buscando, inicialmente, situar o leitor no ambiente estudado através da apresentação geral de seus aspectos físico-espaciais. Em seguida, finalizando o capítulo, são abordados todos os dados climáticos que foram coletados e tratados com a finalidade de caracterizar o clima local com registros atuais.

- Capítulo 4 - Simulação Computacional: Neste capítulo é descrito todo o processo de simulação com CFD realizado na pesquisa. São explicadas todas as etapas, desde a elaboração do modelo e seus possíveis ajustes e a definição dos parâmetros, bem como as etapas PRE, SOLVER e POST do software CFX. Em seguida todos os resultados obtidos na simulação de um modelo experimental são apresentados, comparados e analisados.

- Capítulo 5 - Definição dos modelos para simulação: Com o objetivo de apresentar todos os modelos criados para o processo de simulação desta dissertação, o capítulo relaciona todas as características físicas destes modelos e explica as razões e os critérios adotados em cada proposta de alteração.

- Capítulo 6 - Discussão dos Resultados das Simulações: Neste capítulo, apresentam-se e discutem-se os resultados encontrados em 
todas as simulações, buscando a possibilidade de definir certos parâmetros de projeto que possam ser aplicados por arquitetos na fase de concepção de anteprojeto quando a finalidade for o aproveitamento da ventilação natural em climas quentes e úmidos.

- Capítulo 07 - Conclusões: Nas conclusões finais, é retomada a importância da realização de todas as etapas desta pesquisa, destacando a contribuição dos resultados encontrados para estudos futuros e para a prática da arquitetura consciente e adequada a região.

\subsection{RECURSOS E RESTRIÇõES}

A pesquisa foi apoiada pelo CNPq - Conselho Nacional de Desenvolvimento Científico e Tecnológico - por meio de uma bolsa de estudo para auxiliar as principais despesas vinculadas à pesquisa no período de 01/08/2006 a 30/09/2008.

As principais referências bibliográficas - dissertações, teses, artigos e livros - foram consultados nas bibliotecas da Faculdade de Arquitetura e Urbanismo, em biblioteca da autora, da orientadora e dos pesquisadores do LABAUT, em coletâneas de eventos científicos e em sistemas de busca informatizadas de outras universidades. Além disso, com o auxílio de sites científicos, foi possível ter acesso a inúmeros textos, artigos, teses, dissertações e documentos que ajudaram nesta pesquisa.

Para ter acesso aos principais dados secundários como: mapas, base de dados climáticos, e demais documentos necessários, foi importante consultar o Instituto de Pesquisa Espacial - INPE, O Aeroporto 
Internacional Santa Maria, da cidade de Aracaju, as bibliotecas das universidades locais, órgãos municipais, além de sites que dispunham de informações complementares para o desenvolvimento da pesquisa.

Ao escolher o objeto-concreto, foi considerada também a facilidade ao acesso para que fosse possível fotografar, analisar, e se houvesse necessidade, entrevistar os usuários.

O Labaut da FAU-USP dispõe de recursos computacionais para a realização de simulações, inclusive com licença educacional para o uso de softwares utilizados para estudos na área da ventilação natural e conforto térmico, como por exemplo, o CFX e o TAS (além do Energy Plus que não precisa de licença), devidamente explorados pelos pesquisadores locais. No caso desta pesquisa foi utilizado o ANSYS CFX - Computacional Fluid Dynamics Software e foi possível contar com a orientação de pesquisadores familiarizados há mais tempo com esta ferramenta. 


\section{FUNDAMENTAÇÃO TEÓRICA}

\subsection{VentilaÇão NatURAL}

\subsubsection{Princípios do movimento do ar}

A ventilação é a principal estratégia de projetos para se obter o conforto térmico dos usuários em construções situadas em locais de clima quente e úmido, visto que uma boa ventilação natural remove o excesso de calor nas ruas e promove a ventilação cruzada no interior das edificações, além do que, a ventilação também é de grande importância para a higiene geral, promovendo a renovação do ar e a dissipação de fumaças, odores, poluentes e etc.

Apesar de ser uma ferramenta da extrema importância para a produção de uma arquitetura adaptada ao clima e às necessidades humanas, ainda é muito comum que os profissionais estimem o comportamento do vento sem o real conhecimento sobre o assunto, ou mesmo ignorem essa ferramenta, produzindo ambientes desconfortáveis que necessitam de soluções ativas para resfriamento e consequentemente o consumo desnecessário de energia elétrica para resolver os problemas de temperaturas elevadas no interior das edificações.

Em geral os dados de ventos a que se tem acesso são fornecidos em aeroportos e obtidos em torres a uma altura em torno de $10 \mathrm{~m}$ em campo aberto, ou seja, sem nenhum tipo de obstrução. No entanto, sabemos que esses dados não correspondem à realidade em qualquer outro ponto de 
uma determinada cidade, onde o relevo, as construções e até mesmo a vegetação interferem na velocidade e direção dos ventos medidos. Na maioria dos casos a velocidade dos ventos na cidade é inferior àquelas onde são geralmente mensuradas.

O arquiteto que pretende iniciar corretamente um projeto de qualquer edificação deve ter em mãos dados climáticos da região, o que inclui, por exemplo, dados sobre os ventos locais, sobretudo se a utilização de técnicas construtivas e a adoção de um partido arquitetônico que aproveitem a ventilação natural forem importantes para atingir 0 conforto térmico dos usuários.

Os túneis aerodinâmicos são uma ferramenta eficiente para que o projetista se familiarize com a interação existente entre os ventos locais, os elementos naturais e os elementos construídos no entorno do sítio onde se pretende intervir. Contudo, raramente esse recurso pode ser empregado nos estudos preliminares de um projeto impedindo que grande parte dos profissionais tenha conhecimento do real comportamento deste recurso natural.

A simulação computacional é outra ferramenta que vem sendo utilizada cada vez mais com o mesmo objetivo. Porém é necessário um conhecimento especializado para que as simulações sejam feitas e, mais do que isso, sejam interpretadas corretamente. Além, evidentemente, do alto custo dos softwares. 
Assim sendo, Brown e Dekay (2004, p.40) indicam a aplicação de três "princípios do movimento do ar para adaptar os dados de ventilação coletados em aeroportos ao nível aproximado de ventilação em determinado sítio" e destaca que o fluxo de ar tem comportamento semelhante a um fluido, como a água, e que é possível visualizar o fluxo do vento usando os seguintes princípios:

a) A velocidade do vento diminui à medida que se aproxima da superfície da terra em função do atrito causado pela irregularidade do terreno;

b) O ar continua movendo-se na mesma direção quando encontra um obstáculo, da mesma forma que a água flui ao redor de uma rocha;

c) O ar flui de áreas de alta pressão para áreas de baixa pressão.

O diagrama de Influência do terreno sobre a ventilação (figura 2.1), resultado de testes em túneis aerodinâmicos, (MCCLENON \& ROBINETTE, 1975, apud BROWN; DEKAY, 2004, p.40) ${ }^{3}$ mostra os padrões de fluxo de ventos para uma variedade de relevos topográficos.

\footnotetext{
${ }^{3}$ MCCLENNON, Charles; ROBINETTE, Gary O. Site Planning for solar energy utilization. McLean, VA: American Society of Landscape Architects Foundation. 1975.
} 


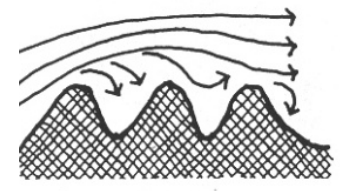

Terreno acidentado
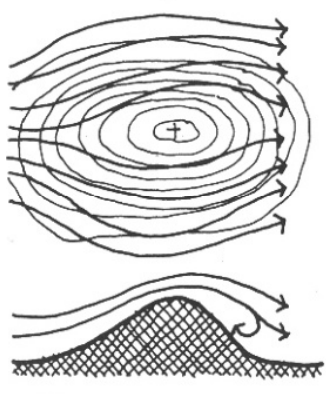

Colina
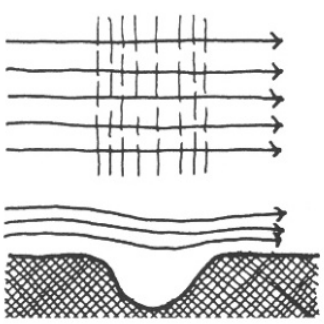

Cruzando um vale estreito
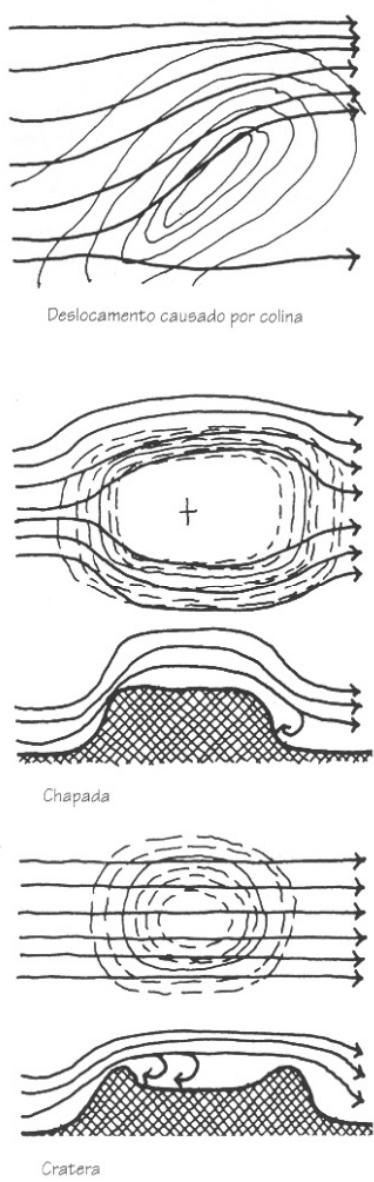

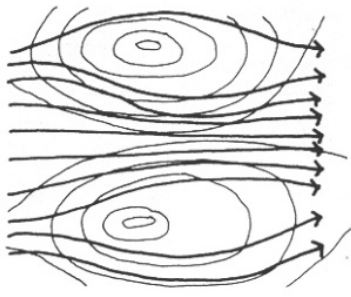

Efeito Venturi entre dunas
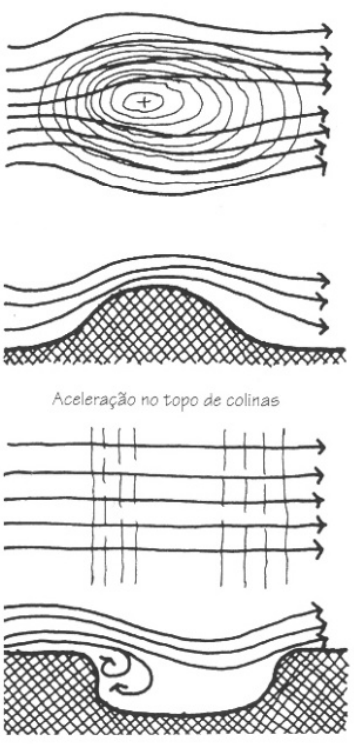

Cruzando um vale mais largo

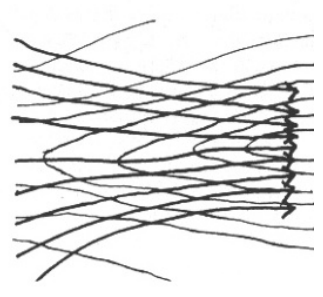

Vento encanado em um vale
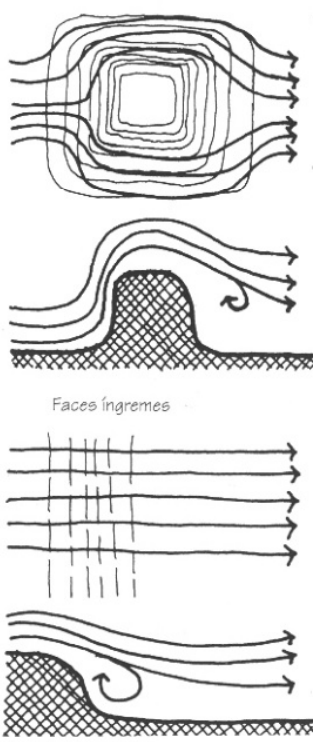

Zona de sucção à sotavento

Figura 2.1 - Influência do terreno sobre a ventilação

(MCCLENON \& ROBINETTE, 1975 adaptado por BROWN E DEKAY, 2004, p.41)

A velocidade do vento pode ser corrigida em função do gradiente do vento para diferentes tipos de rugosidade de terreno.

"O incremento da velocidade ao longo de um eixo vertical varia de zero, na superfície terrestre, até uma velocidade igual à do fluxo livre de obstruções, gerando o que chamamos de gradiente da velocidade do vento." (BITTENCOURT e CÂNDIDO, 2005, p. 34).

Assim, entende-se que a velocidade do vento que incide nas aberturas e nos espaços construídos dependerá diretamente da configuração do entorno.

A figura 2.2 mostra um gráfico de gradiente de vento que determina um fator (expoente) para diferentes tipos de áreas que servirá no cálculo 
de correção da velocidade do vento em função do tipo de rugosidade de cada terreno a ser estudado. Quanto maior a rugosidade, maior será este fator de correção e menor será a velocidade do vento no meio urbano.

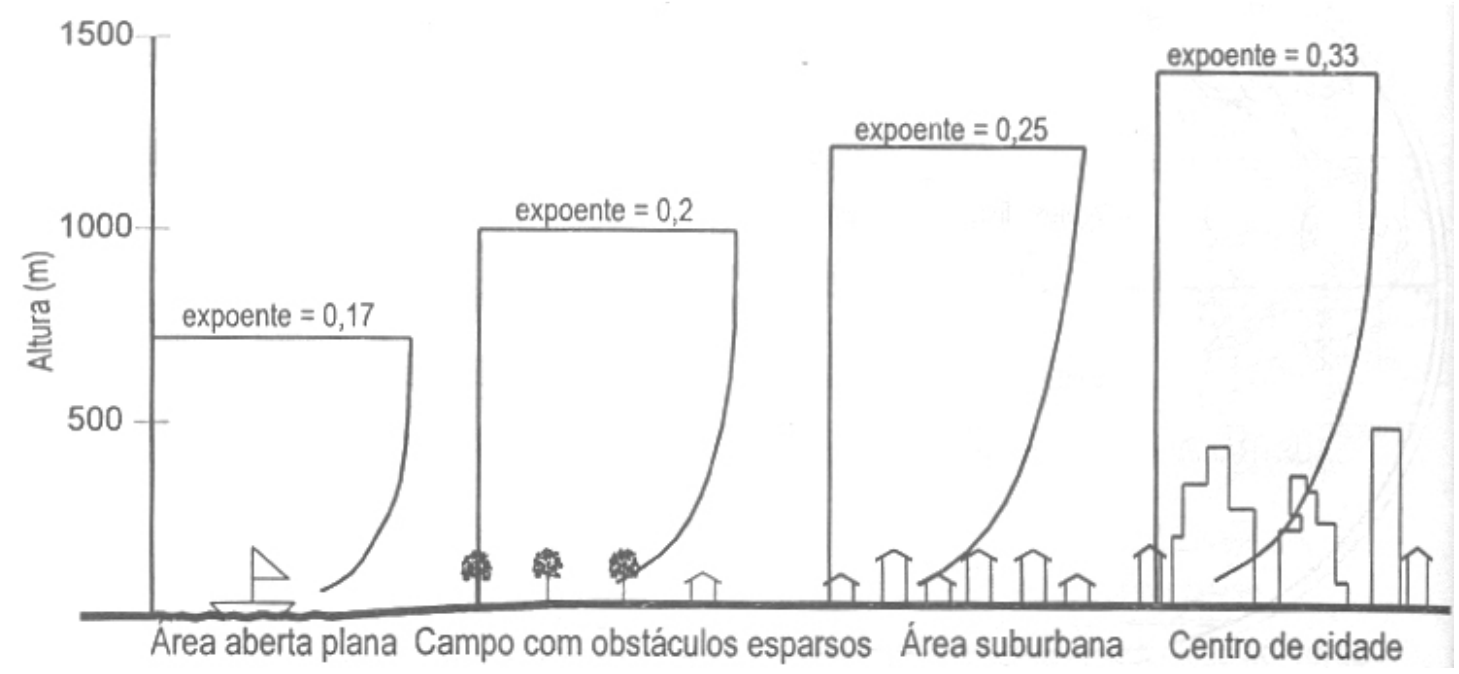

Figura 2.2 - Gradiente do Vento para diferentes áreas (JACKMAN, 1980 adaptado por BITTENCOURT E CÂNDICO, 2005, P.34)

\subsubsection{Finalidades da ventilação}

A ventilação natural a princípio apresenta dois objetivos claros: atender as questões de conforto térmico removendo a carga térmica do ambiente e ajudando na dissipação do calor do corpo humano, por convecção e por evaporação, principalmente em climas quentes e úmidos; e prover a higiene dos ambientes ao renovar o ar viciado e poluído e ao evitar o incremento da umidade do ar nos espaços. Ou seja, a ventilação natural é importante também em locais de clima frio, pois para que se tenha ambientes saudáveis, um mínimo de taxa de ventilação é necessário para contínua renovação do ar viciado por igual volume de ar fresco proveniente do exterior, partindo-se do princípio de que o ar externo é suficientemente puro. Além disso, com a ventilação natural é 
possível diminuir os gastos de energia com sistemas de aclimatação artificial.

\subsubsection{Higiene}

Sendo a higiene o objetivo da ventilação natural, deve-se levar em consideração o tipo de ambiente e seu volume, a intensidade de produção de odores e poluentes, a população prevista para a edificação, os hábitos locais e o clima. Em locais de clima frio, é importante adotar uma estratégia que proporcione apenas o mínimo de renovação do ar necessário para higiene local, pois o vento externo pode causar desconforto térmico aos usuários.

\subsubsection{Conforto térmico}

A ASHARAE (1993) define conforto térmico como um estado de espírito que reflete a satisfação com o ambiente térmico que envolve a pessoa. Em outras palavras, Lamberts et al (2004, p. 41) afirma que "se o balanço de todas as trocas de calor a que está submetido o corpo for nulo e a temperatura da pele e suor estiverem dentro de certos limites, podese dizer que o homem sente conforto térmico".

Se a temperatura do ar for maior que a temperatura da pele, a evaporação do suor produzido pelo homem é a única forma de manter o conforto térmico, uma vez que a forma que o homem tem de se defender do ganho de calor é enviando água para a superfície da pele e com a presença de movimento do ar, esse suor é evaporado, retirando o calor da pele e baixando sua temperatura e então dando sensação de conforto. De 
acordo com Corbella \& Yannas (2003, p.193), "se o ar não estiver em movimento, a água não evapora, a pele fica molhada, pingando suor, e a pessoa não conseguirá a sensação de conforto", daí a importância da ventilação para o conforto térmico do homem e é por isso que o ventilador sempre produz uma sensação de alívio mesmo quando o ar apresenta-se numa condição desagradável.

\subsubsection{Ventilação e as variáveis ambientais de conforto térmico}

"É sabido que a sensação de conforto ou desconforto térmico experimentado pelo homem no interior de um recinto depende, de um lado, da atividade que está desenvolvendo e do tipo de roupa que está usando e, de outro lado, da temperatura, umidade e velocidade do ar em contato com o corpo e das temperaturas e emissividades das superfícies das paredes, piso, teto e objetos existentes no interior do recinto." (TOLEDO, E. 1999, p. 41).

As variáveis do ambiente que influenciam no conforto térmico do homem são: temperatura, umidade relativa, velocidade e direção do ar, radiação solar incidente e as características físicas da envoltória do ambiente, como temperaturas e emissividade das paredes, piso, teto e objetos existentes no local.

Sabe-se que a temperatura, a umidade e a velocidade do ar são características climáticas da região e que penetram no ambiente, onde só podem sofrer algum tipo de modificação por meio de utilização de força mecânica, como os equipamentos de ar condicionado ou de umidificadores de ar, dependendo do clima em questão. 
Muitas vezes é possível obter temperaturas mais baixas ou mais altas no interior das edificações com estratégias passivas de projeto como a adequada orientação da edificação, sombreamento das fachadas, uso de materiais adequados ao clima nas envoltórias e coberturas além de um estudo dos ventos locais, aproveitando ou barrando os mesmos em função do objetivo final. Ou seja, utilizar as características climáticas locais em conjunto com materiais e técnicas construtivas apropriadas pode, em muitos casos, proporcionar conforto térmico dos usuários sem maiores gastos de energia elétrica. De acordo com Frota e Schiffer (2003, p.18),

"[...] o conhecimento das exigências humanas de conforto térmico e do clima, associado ao das características térmicas dos materiais e das premissas genéricas para o partido arquitetônico adequado a climas particulares, proporciona condições de projetar edifícios e espaços urbanos cuja resposta térmica atenda às exigências de conforto térmico."

Uma variável de ambiente importante para o conforto térmico é a velocidade de circulação do ar no interior da edificação, independente das características climáticas locais. Essa movimentação do ar pode ser fornecida por processos mecânicos ou naturais, ou até mesmo com a conjugação dos dois. É importante ressaltar que a velocidade do ar e a temperatura das superfícies internas, principalmente em épocas e/ou locais de calor, são variáveis de ambiente com as quais o arquiteto pode "brincar" dentro de certos limites, sem precisar utilizar equipamentos mecânicos para promover o conforto térmico. Ou seja, o grande segredo é trabalhar em conjunto com a natureza em busca do melhor resultado dentro de uma edificação. 
Além das variáveis de ambiente já citadas, devem ser consideradas também variáveis como a atividade desenvolvida pelos indivíduos e sua vestimenta assim como sexo, idade, biótipo, hábitos alimentares, entre outros.

"O tipo de vestimenta é um dado importante no fenômeno da dissipação do calor, em regiões quentes. A transferência, para regiões tropicais, de hábitos de vestir que se desenvolveram em países de clima temperado ou frio, é prejudicial ao conforto e à eficiência dos indivíduos." (TOLEDO, E. 1999, p.63)

\subsection{6 Índices de conforto térmico}

Todas as variáveis, citadas anteriormente, em conjunto geraram os índices de conforto térmico que, segundo Frota e Schiffer (2003, p. 25), sob a forma de cartas ou nomogramas relacionam todas as variáveis ambientais e reúnem as diversas condições ambientais que proporcionam respostas iguais por parte dos indivíduos.

Os índices de conforto térmico englobam diferentes aspectos e são classificados como biofísicos, fisiológicos ou subjetivos. A escolha do tipo de índice deve estar relacionada com o tipo de atividade desenvolvida pelo indivíduo, com as condições ambientais e com as relações entre as variáveis consideradas na obtenção do índice, entre outros aspectos do conforto.

Dentre dezenas de índices existentes, Frota e Schiffer (2003) apresentam apenas três por serem os mais apropriados ao clima brasileiro e às condições ambientais no interior dos edifícios: 
- Carta Bioclimática, de Olgay (figura 2.3), que utiliza como variáveis a temperatura de bulbo seco e a umidade relativa do ar aplicada para condições externas. Em 1969 Givoni corrigiu essa carta baseando-se em temperaturas internas do edifício e propondo estratégias de projeto para adequação da arquitetura ao clima local.

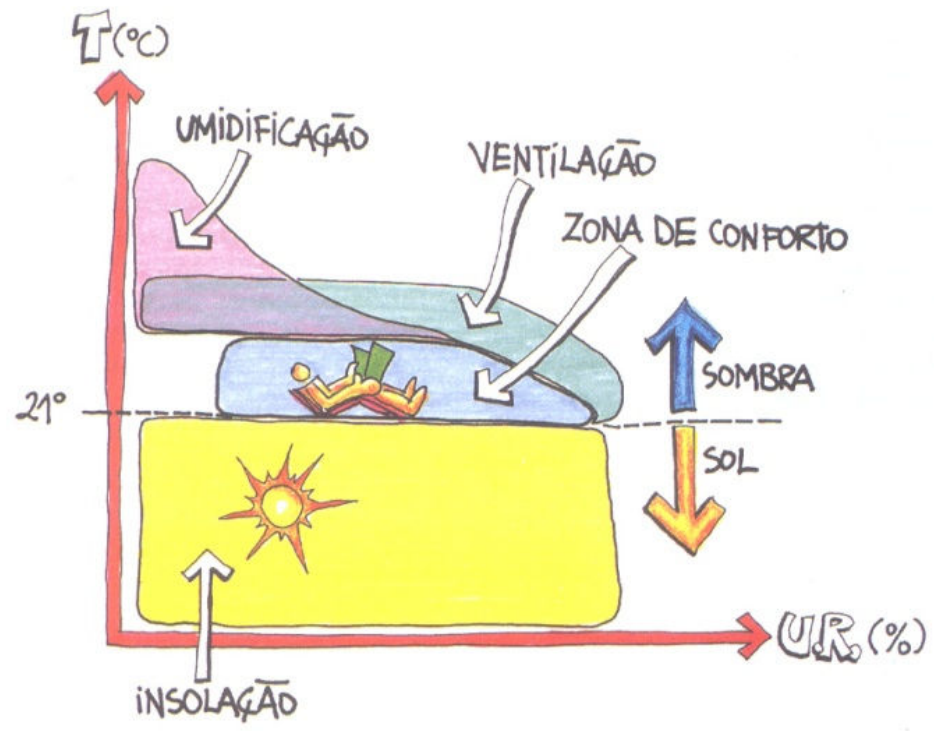

Figura 2.3 - Carta bioclimática de Olgyay

(Lamberts et al, 2004, p.104)

- Temperatura Efetiva, de Yaglou e Houghthen; ou Temperatura Efetiva Corrigida, de Vernon e Warner, que são apresentadas sob a forma de nomogramas e podem ser utilizadas quando se tem os dados da temperatura de bulbo seco ou do termômetro de globo, umidade e velocidade do ar. Esses dados normalmente utilizados em conjunto com a Carta Psicrométrica que fará a correspondência entre a temperatura de bulbo seco e a de bulbo úmido a partir da umidade relativa do ar;

- Índice de Conforto Equatorial ou Índice de Cingapura, de Webb, desenvolvido para indivíduos de climas tropicais (quente e úmido) "com base em dados obtidos a partir da psicologia experimental e análise 
de testes aplicados a indivíduos completamente aclimatados na região". (FROTA e SCHIFFER, 2003, p. 28).

É importante ressaltar que utilizar índices que foram elaborados para regiões de climas diferentes e/ou grupos populacionais ambientados a regiões climáticas diferentes, pode resultar em um diagnóstico equivocado, visto que a sensação de conforto não é a mesma para todos. Pode-se afirmar que os habitantes de uma determinada região já estão aclimatados e, portanto sofrem menos com os efeitos causados pelo clima local e conseqüentemente suas respostas em relação à sensação de conforto será diferente aos habitantes de regiões com climas diferentes.

Goulart et al. (1994) desenvolveram um estudo onde analisaram a metodologia proposta por vários autores com o objetivo de selecionar uma metodologia bioclimática a ser adotada para o Brasil. Concluiu-se então que o trabalho desenvolvido por Givoni em 1992, onde ele apresenta uma carta bioclimática adequada aos países em desenvolvimento, com os limites máximos de conforto expandido em relação ao seu trabalho apresentado anteriormente, é o mais adequado às condições climática brasileiras. Os autores explicam que adotaram a carta de Givoni porque:

"• Givoni desenvolveu um trabalho voltado para países quentes e em desenvolvimento;

- Seu trabalho foi baseado na aclimatação das pessoas a climas quentes e úmidos, e este estudo confirmado por experimentos realizados na Tailândia;

- A metodologia de Givoni adota limites maiores de velocidade do ar para temperaturas mais elevadas, coerentes com a realidade dos países de clima quente e úmido; 
- O espaço interno pode ser resfriado, quando necessário, com menor consumo de energia, já que a temperatura máxima de conforto estabelecida está mais próxima da temperatura externa do local". (GOULART, et al. 1994, p.78).

A Carta bioclimática de Givoni (figura 2.4) foi construída sobre o diagrama psicométrico e fornece os dados que permitem definir a melhor estratégia de projeto a ser empregada na busca pelo conforto térmico. Ao plotar sobre a carta os dados de temperatura e umidade relativa do ar de certa região serão identificadas as zonas que determinam a estratégia a ser empregada, conforme a seqüência a seguir:

- Zona de conforto: com os dados localizados nesta zona, indica que provavelmente as pessoas estão em conforto térmico no ambiente interior.

- Ventilação: neste caso, devem-se utilizar estratégias de projeto que promovam o maior movimento do ar no interior nas edificações para proporcionar conforto térmico, como a ventilação cruzada, o sombreamento, o uso de captadores de ventos, entre outras. É a principal estratégia para climas quentes e úmidos.

- Resfriamento evaporativo: significa que o clima é quente e seco e com a evaporação da água e consequentemente o aumento da umidade relativa, é possível obter conforto térmico nesta região.

- Massa térmica para resfriamento: com o clima que apresenta condições de temperatura e umidade relativa delimitadas por esta zona, o uso de massa para aumentar a inércia térmica irá evitar que a amplitude térmica que ocorre no exterior da edificação entre o dia e a 
noite seja transferida para o interior da edificação e dessa forma a sensação térmica no ambiente será mais confortável para os usuários.

- Ar condicionado: já para as condições climáticas delimitadas por esta zona, fica claro que apenas com uso de condicionamento artificial do ar será possível atingir níveis de conforto térmico. Este dado é importante para que o projeto seja adaptado a esta condição, evitando ganhos excessivos de calor e assim promover o menor consumo possível de energia elétrica para resfriar o ambiente interno.

- Umidificação: em climas de temperaturas mais amenas, mas umidade relativa do ar muito baixa, estimular a umidificação do ar melhora a sensação de conforto térmico.

- Massa térmica e aquecimento solar: a proposta aqui é utilizar a massa térmica para acumular o calor gerado pelo aquecimento solar durante o dia e liberá-lo para o interior da edificação durante a noite quando as temperaturas são mais baixas.

- Aquecimento solar passivo: quando as temperaturas médias variam entre $10,5^{\circ} \mathrm{C}$ e $14^{\circ} \mathrm{C}$, o uso de aquecimento solar passivo é a melhor estratégia para manter a temperatura interna mais agradável, sem esquecer que o isolamento eficiente evitará que a perda de calor seja grande.

- Aquecimento artificial: quando as temperaturas são muito baixas o aquecimento solar passivo pode não ser suficiente para o conforto, mas para melhor eficiência do sistema de aquecimento artificial, essas duas estratégias devem trabalhar em conjunto sempre que possível. 


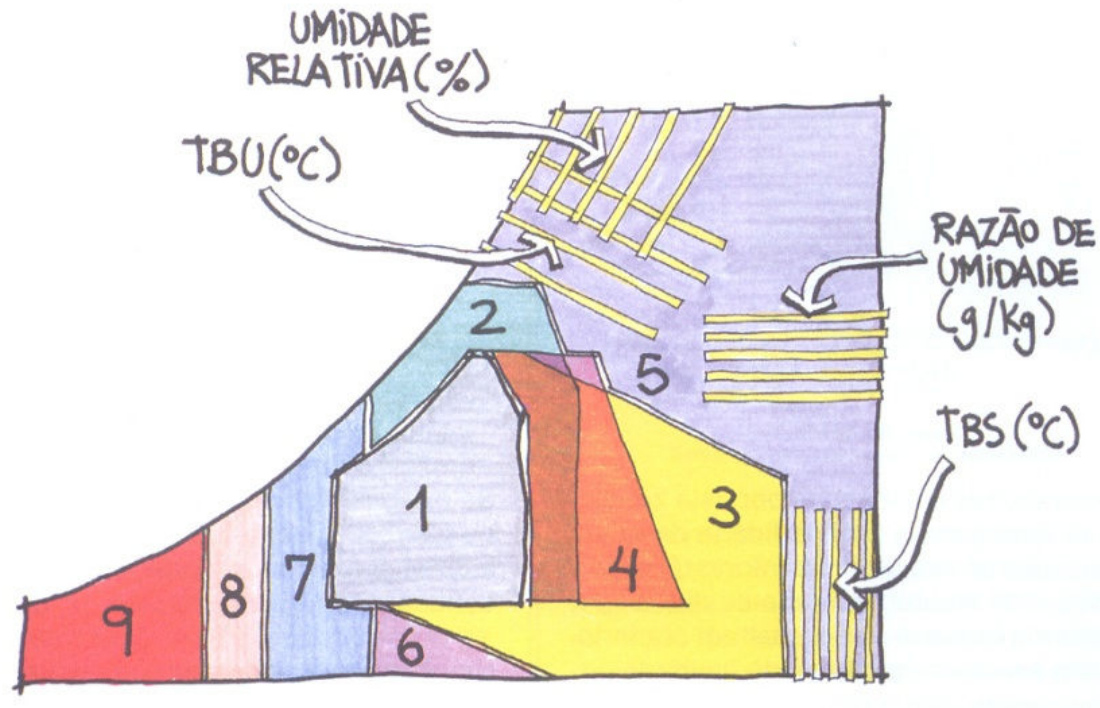

Figura 2.4 - Carta bioclimática adotada para o Brasil

(Lamberts et al, 2004, p. 105)
1- Zona de conforto

2- Zona de ventilação natural

3- Zona de resfriamento evaporativo

4- Zona de massa térmica para resfriamento

5- Zona de ar

condicionado

6- Zona de umidificação

7- Zona de massa térmica

e aquecimento solar

8- Zona de aquecimento solar passivo

9- Zona de aquecimento artificial.

É sempre importante destacar que as variações climáticas durante o ano ou até mesmo durante o dia, como ocorre em várias regiões do país, podem exigir o uso de mais de uma estratégia para se obter o conforto térmico. Muitas vezes é possível utilizar estratégias diferentes simultaneamente para se atingir melhores resultados. Caberá ao arquiteto definir prioridades, utilizar o bom senso e a criatividade para conseguir os melhores resultados para cada edificação.

Existe ainda o Método de Fanger, que consiste em um índice de conforto térmico fisiológico por ser baseado nas reações fisiológicas originadas de condições ambientais conhecidas (temperatura, umidade e velocidade do ar). É considerado como o estudo mais completo até hoje disponível sobre índice de conforto térmico.

Fanger (1972) desenvolveu um critério com a combinação de doze variáveis relacionadas ao ambiente, ao indivíduo e à roupa, que resultam 
em conforto térmico. Em seu estudo, para conhecer o grau de desconforto de um grupo de pessoas, ele definiu uma escala de sensação - Voto Médio Estimado (VME) - baseada nas teorias de trocas térmicas e balanço de calor, e comparou as respostas de 1300 estudantes no interior de uma sala climatizada, usando roupas padrão e em atividades sedentárias. Os votos das pessoas foram anotados em uma escala de sete pontos de sensações térmicas:

+3 Muito Quente

+2 Quente

+1 Levemente quente

0 Neutro

-1 Levemente Frio

-2 Frio

-3 Muito Frio.

Apesar de seu estudo ter sido realizado com estudantes dinamarqueses e americanos, pode ser aplicado a diferentes grupos e regiões, e por ser considerado consistente do ponto de vista conceitual apresenta grande aceitação e recomendação no país.

\subsection{FUNDAMENTOS DA VENTILAÇÃO NATURAL}

\subsubsection{Ventilação por ação dos ventos (ventilação cruzada)}

A ventilação cruzada é muito importante como estratégia de resfriamento em regiões de clima quente e úmido porque além de 
remover o calor do ambiente, é capaz de aumentar o nível de evaporação das pessoas, contribuindo para uma melhora na sensação térmica.

A ventilação cruzada será mais eficiente quando as aberturas de entrada do ar estiverem localizadas em zonas de alta pressão e as de saída em zonas de baixa pressão, ou área de sucção, uma vez que a taxa de fluxo de ar depende da diferença de pressão entres as aberturas. Essas zonas de pressão são criadas pelos ventos que circulam em torno da edificação, sofrendo ou não influência de seu entorno. A taxa de ar em um ambiente é função das áreas de entrada e saída do ar, da velocidade do vento e da direção dos ventos em relação às aberturas.

Brown e Dekay (2004, p.172) afirmam que:

"[...] sempre que o fluxo de ar é barrado por um recinto ou corredor, há três soluções básicas: 1) o uso de janelas com bandeiras móveis ou de respiradores elevados; 2) o rebaixamento do teto na área menor, criando um pleno; ou 3) o uso da estrutura do piso ou do teto como hipocausto 4 ."

Esses autores apresentam ainda uma matriz com estratégias de organização de edificações com corredores simples, duplos ou com pavimentos com desníveis para melhor aproveitamento da ventilação cruzada. (figura 2.5)

${ }^{4}$ Segundo dicionário Michaelis, hipocausto significa "câmara de fogo subterrânea, da qual o calor era distribuído aos aposentos por condutos de cerâmica". Disponível em: http://michaelis.uol.com.br/ Acesso em 12 de junho de 2009. 


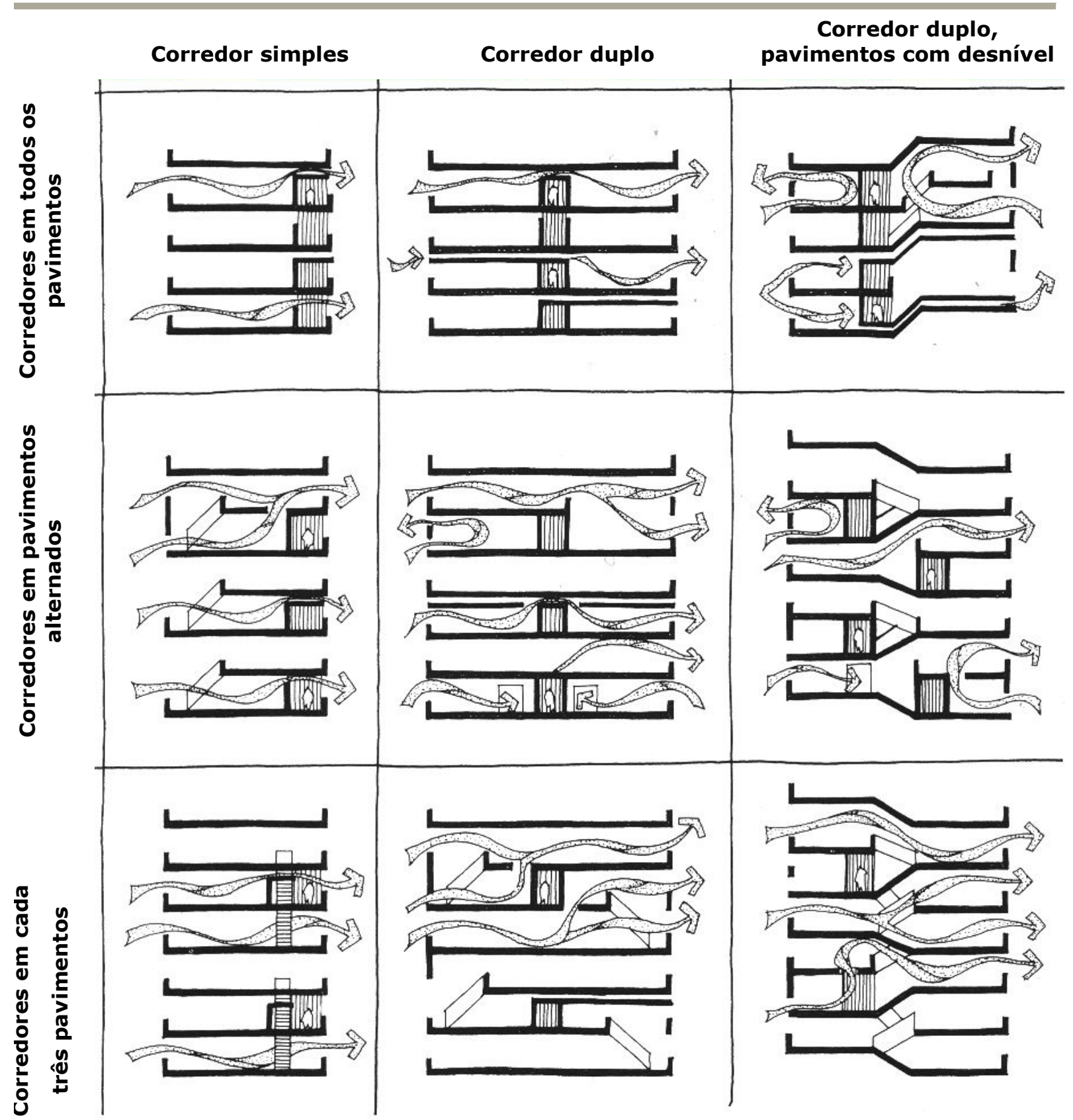

Figura 2.5 - Estratégias de organização para ventilação cruzada de edificações com corredores

(BROWN E DEKAY, 2004, P.172)

\subsubsection{Ventilação por efeito chaminé}

Quando não há disponibilidade dos ventos em alguns horários do dia ou quando existem obstáculos que impeçam o acesso do vento às edificações em função da condição urbana, climática ou arquitetônica, a ventilação por efeito chaminé pode garantir o mínimo de movimento de ar 
necessário para resfriar um ambiente interno, removendo a carga térmica ali acumulada sem precisar dos ventos externos pra isso. Toledo, E. (1999, p.70) reforça lembrando que "em tempo calmo, sem vento, é o efeito de chaminé o único responsável pela renovação do ar os edifícios não dotados de sistemas mecânicos de ventilação."

O estudo da ventilação por efeito chaminé é baseado na diferença de pressão devido à variação entre a temperatura interna e externa ao edifício. O princípio básico é que o ar quente torna-se menos denso, sobe e sai pelas aberturas localizadas na parte superior do ambiente e é substituído pelo ar mais frio que entra através das aberturas localizadas na parte inferior deste ambiente. Mas esse fenômeno e sua intensidade dependem da dimensão e distância entre as aberturas de entrada e saída do ar e da diferença de temperatura externa e interna. Quanto maior a distância entre as aberturas de entrada e saída do ar e quanto maior a diferença de temperaturas internas e externas maior será a taxa de renovação do ar no recinto e consequentemente mais eficiente a ventilação por efeito chaminé.

Para se obter a máxima taxa de ventilação por efeito chaminé a abertura de entrada de ar deve ter a mesma dimensão da abertura para saída do ar. Porém, em função do partido arquitetônico adotado, essa estratégia nem sempre é possível. Contudo, Brown e Dekay (2004) lembram que "o aumento da área de entradas-de-ar sobre a área de saídas-de-ar (ou vice-versa) aumenta o fluxo de ar, mas não 
proporcionalmente à área acrescida." Os autores sugerem ainda o uso do gráfico 2.1 para dimensionar a distância entre as aberturas de entrada e saída do ar e a área em corte necessária à ventilação por efeito chaminé em função da carga térmica a ser removida do espaço interno ou da taxa de fluxo do ar necessária para resfriar o ambiente.

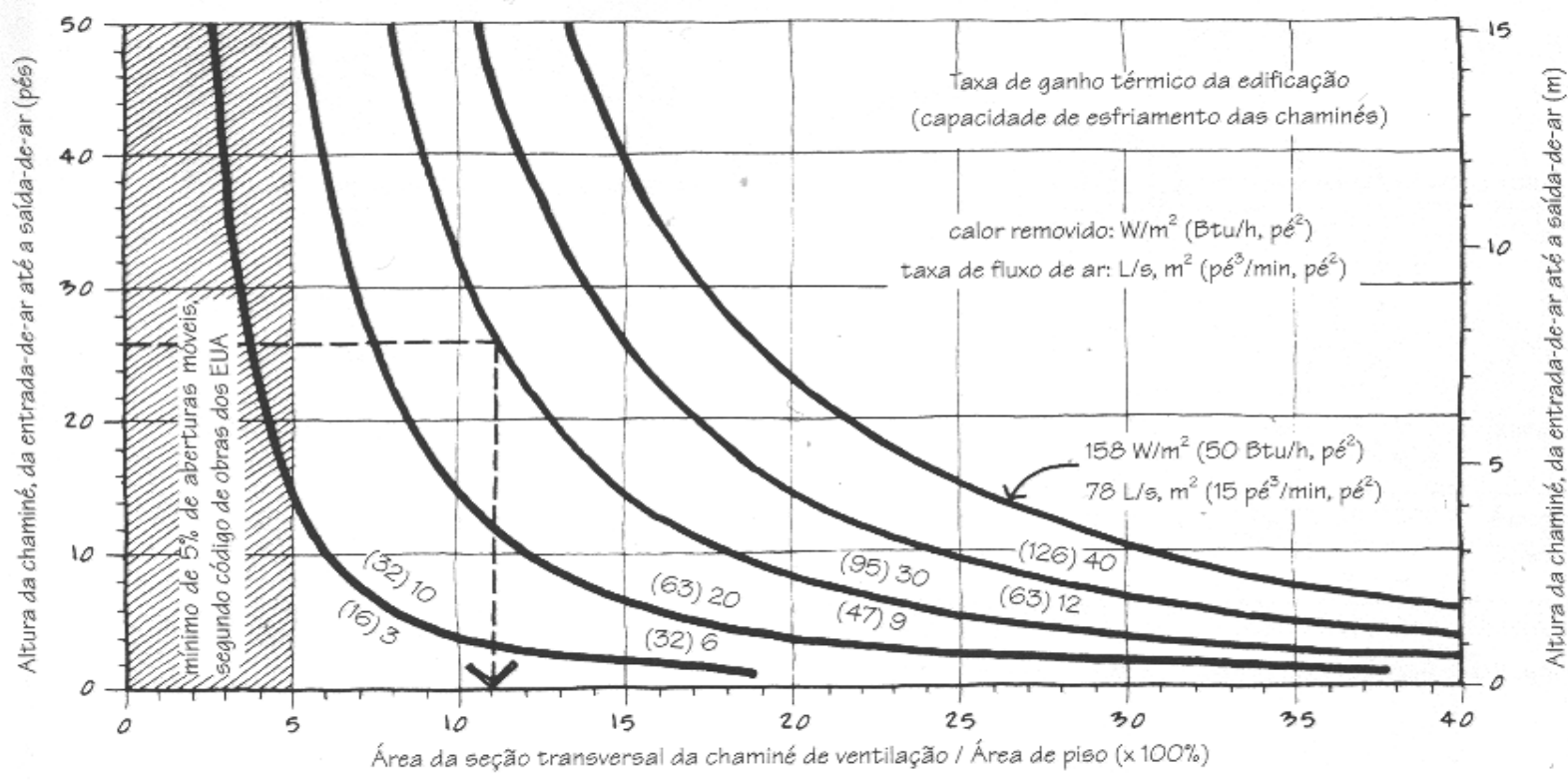

Gráfico 2.1 - Dimensionamento da ventilação por efeito chaminé e dimensionamento de entrada e saída de ar

(ASHRAE, 1997, adaptado por BROWN e DEKAY, 2004, p.210)

\subsubsection{Simultaneidade dos processos}

Em climas quentes onde geralmente o movimento do ar à noite é mais fraco que durante o dia, a ventilação por efeito chaminé pode complementar a ventilação cruzada em uma edificação. Também é possível que a simultaneidade dos processos ocorra em ambientes diferentes de uma mesma edificação em função de suas respectivas localizações em relação ao fluxo de ar. Dessa forma, os ambientes localizados em zonas de pressão positiva e em pavimentos mais elevados 
podem se beneficiar pela ventilação cruzada enquanto que os recintos localizados em zonas de pressão negativa ou nos espaços inferiores, da ventilação por efeito chaminé, independente da hora do dia.

Frota e Schiffer (2003, p.125) reforçam que:

"quando a ventilação natural de um edifício é
criteriosamente estudada verifica-se a conjugação dos dois
processos. No entanto, a simultaneidade dos processos pode
resultar na soma das forças, ou pode agir em contraposição e
prejudicar a ventilação dos ambientes."

Brown e Dekay (2004, p.170) elaboraram um diagrama com estratégias de organização dos espaços que favorecem tanto a ventilação cruzada quanto à ventilação por efeito chaminé (figura 2.6).

No eixo horizontal estão alguns esquemas de plantas baixas que visam favorecer todos os ambientes com a ventilação cruzada, enquanto que no eixo vertical eles colocaram cortes esquemáticos com várias estratégias que permitem a ventilação por efeito chaminé. E por fim, ao mesclar algumas dessas estratégias, eles apresentam combinações diagramáticas possíveis que favorecem tanto a ventilação cruzada quanto a ventilação por efeito chaminé, resfriando todos os ambientes de uma edificação 


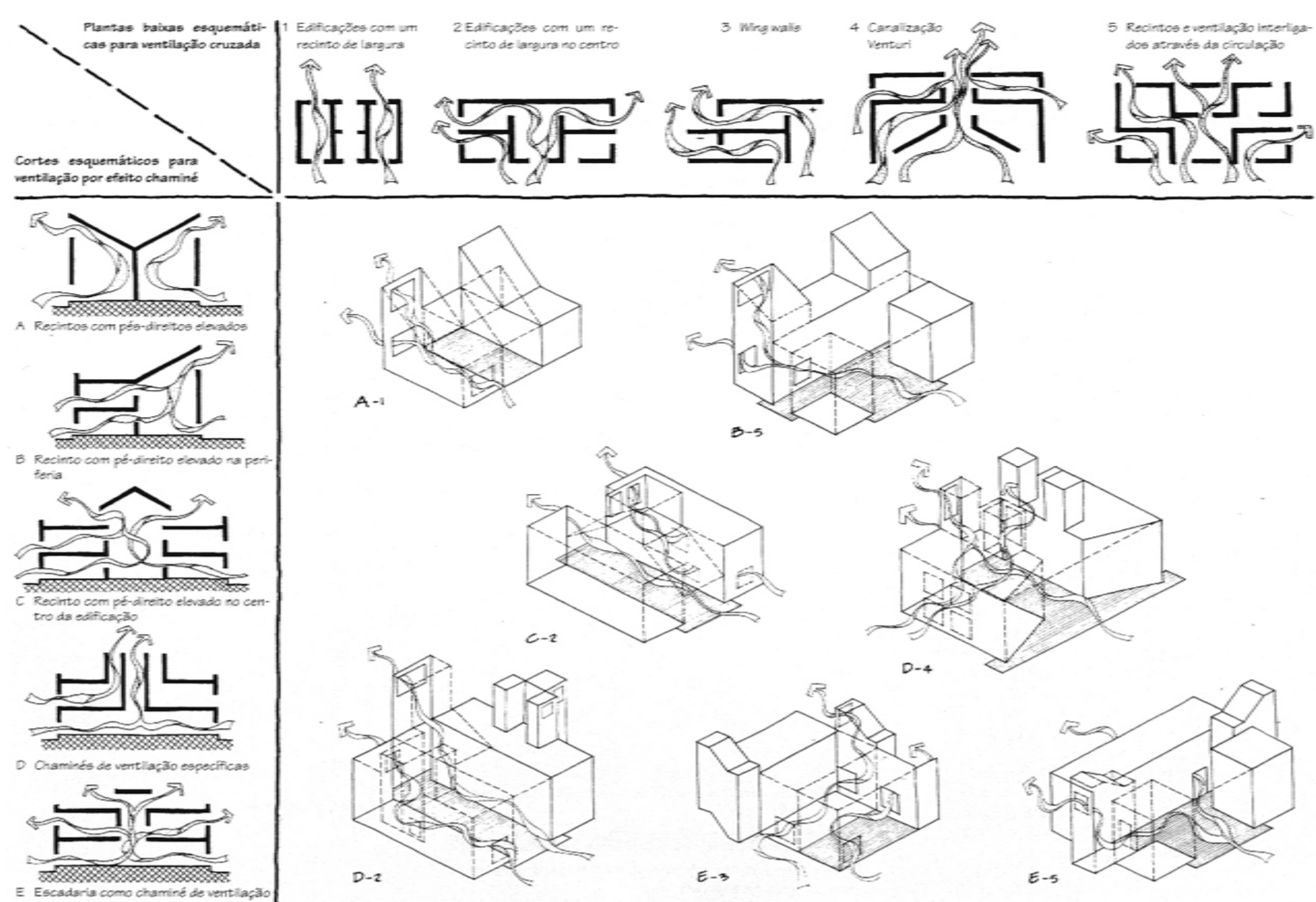

Figura 2.6 - Estratégias de organização dos espaços que favorecem tanto a ventilação cruzada quanto a ventilação por efeito chaminé (BROWN e DEKAY, 2004, p.170) 


\subsection{VENTILAÇÃO E ARQUITETURA}

\subsubsection{Localização, forma e orientação do edifício}

A configuração das ruas e edificações em uma cidade em relação à direção dos ventos predominantes pode garantir espaços urbanos mais agradáveis e ventilação natural na maioria das edificações.

As ruas paralelas aos ventos predominantes permitem a maior velocidade dos ventos, porém as ruas perpendiculares promovem 0 deslocamento do fluxo de ar sobre as edificações. Segundo Brown e Dekay (2004, p.137), "uma orientação de ruas oblíquas aos ventos predominantes resultará em dois lados de edificações com pressão positiva e dois lados com pressão negativa, otimizando o potencial de ventilação cruzada das edificações."

Evans (1957) estudou o fluxo de ventos ao redor das edificações em túneis aerodinâmicos, e mostrou por meio de gráficos como as formas construídas podem alterar os padrões eólicos. Ele representou o fluxo dos ventos com setas, e os redemoinhos, (zona de baixa pressão ou zona de sucção), com setas circulares.

Analisando os diagramas que mostram a inclinação do telhado (figura 2.7), percebe-se que quanto maior a inclinação do telhado, mais para o alto o vento é direcionado e maior é a altura e comprimento da zona de baixa pressão. Nota-se também, no diagrama em corte da edificação, que o aumento da zona de baixa pressão é proporcional ao 
aumento da altura da edificação. Dessa maneira, a presença de muros pode reduzir significativamente o movimento do ar nas edificações, principalmente se forem altos e fechados.
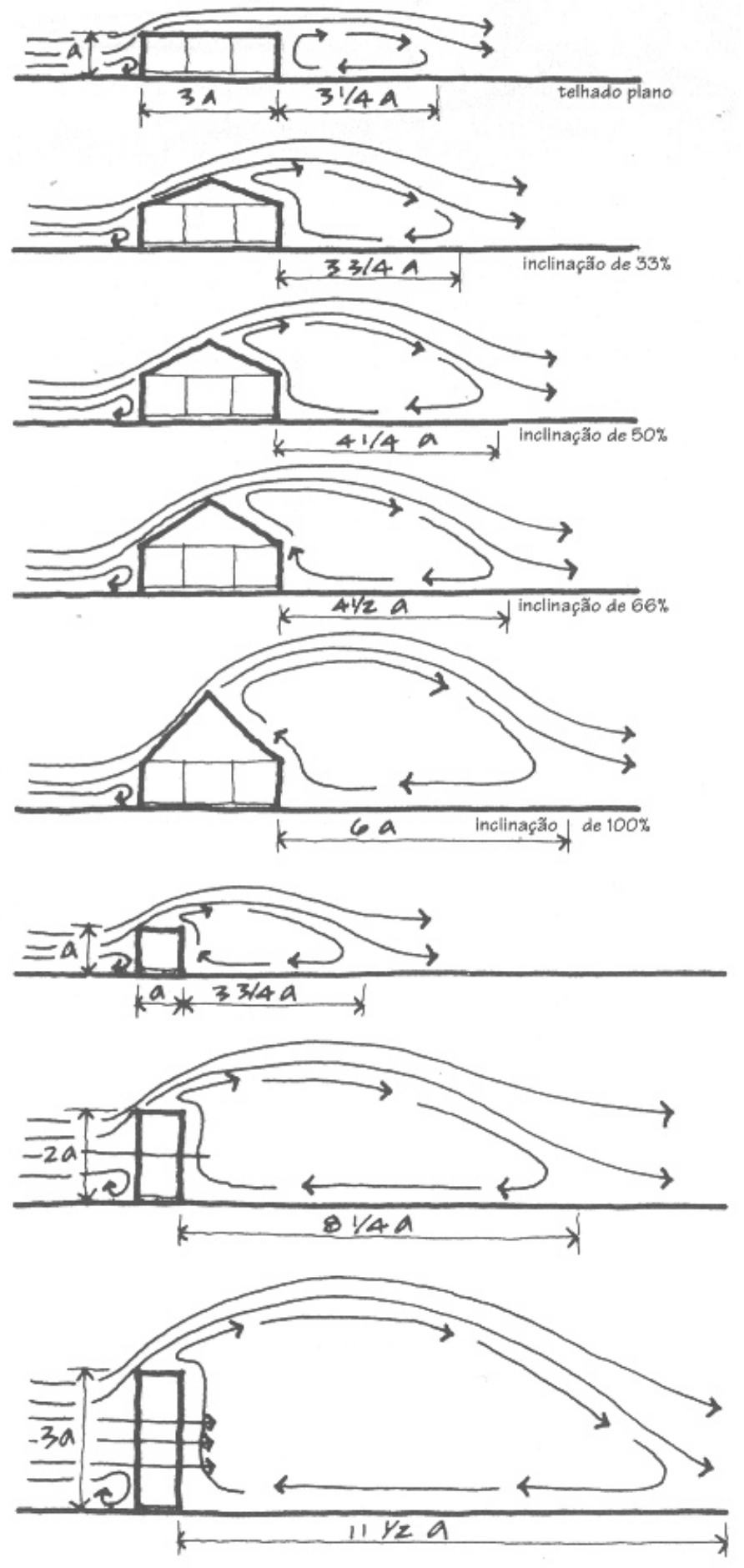

Figura 2.7 - Inclinação do telhado e altura da edificação em corte

(EVANS, 1957 adaptado por BROWN E DEKAY, 2004, p.43) 
Porém, no caso do aumento da largura em edificações da mesma altura, o padrão de fluxo eólico nas laterais das edificações é semelhante independente da largura, havendo alteração no comprimento da zona de sucção, mas não na mesma proporção como ocorre no caso de edificações de alturas diferentes. (figura 2.8)
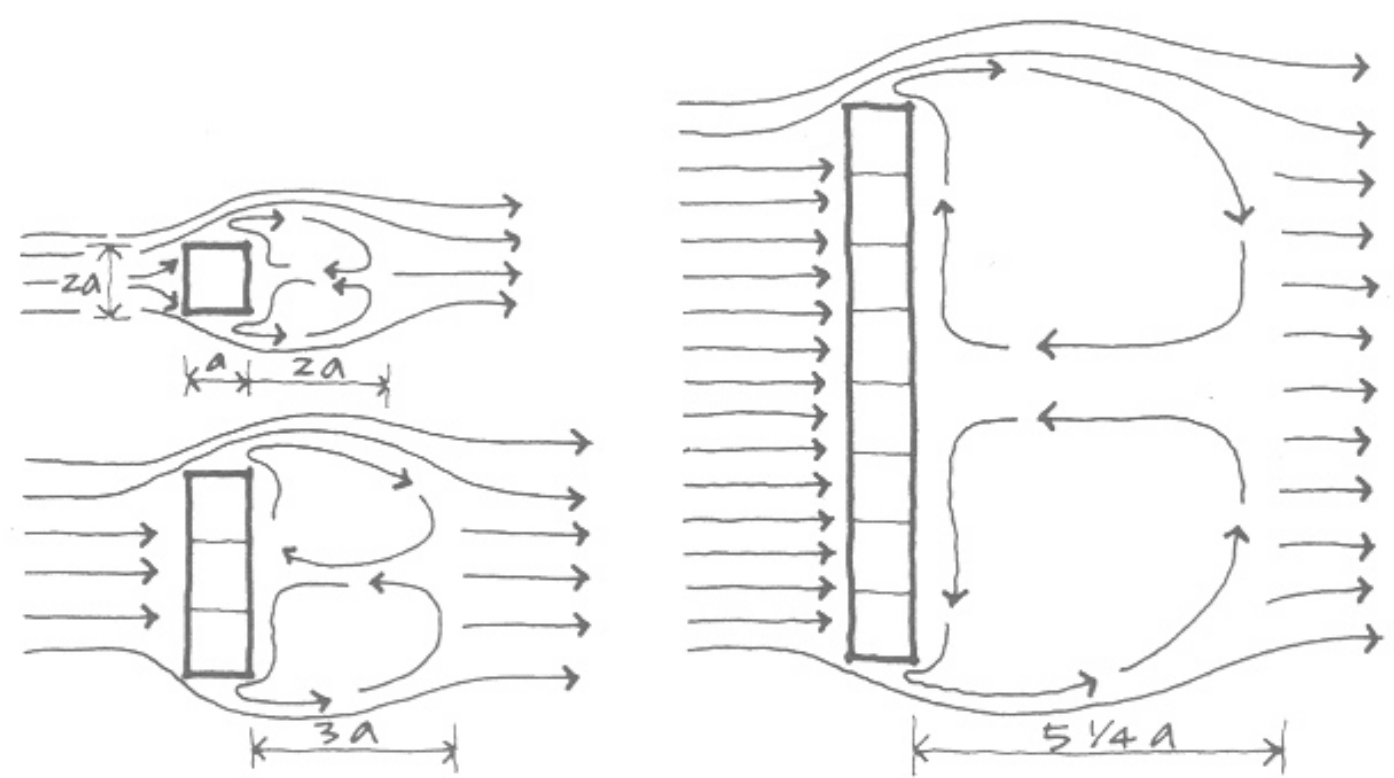

Figura 2.8 - Impacto da largura da edificação em planta baixa (EVANS, 1957 adaptado por BROWN E DEKAY, 2004, p.43)

O fluxo dos ventos também pode ser alterado pela forma e orientação das edificações de acordo com os estudos de Evans (1957). Por meio do diagrama (figura 2.9) é possível fazer uma análise criteriosa e adequar o projeto às características dos ventos locais, protegendo ou expondo os ambientes externos e internos das edificações. 

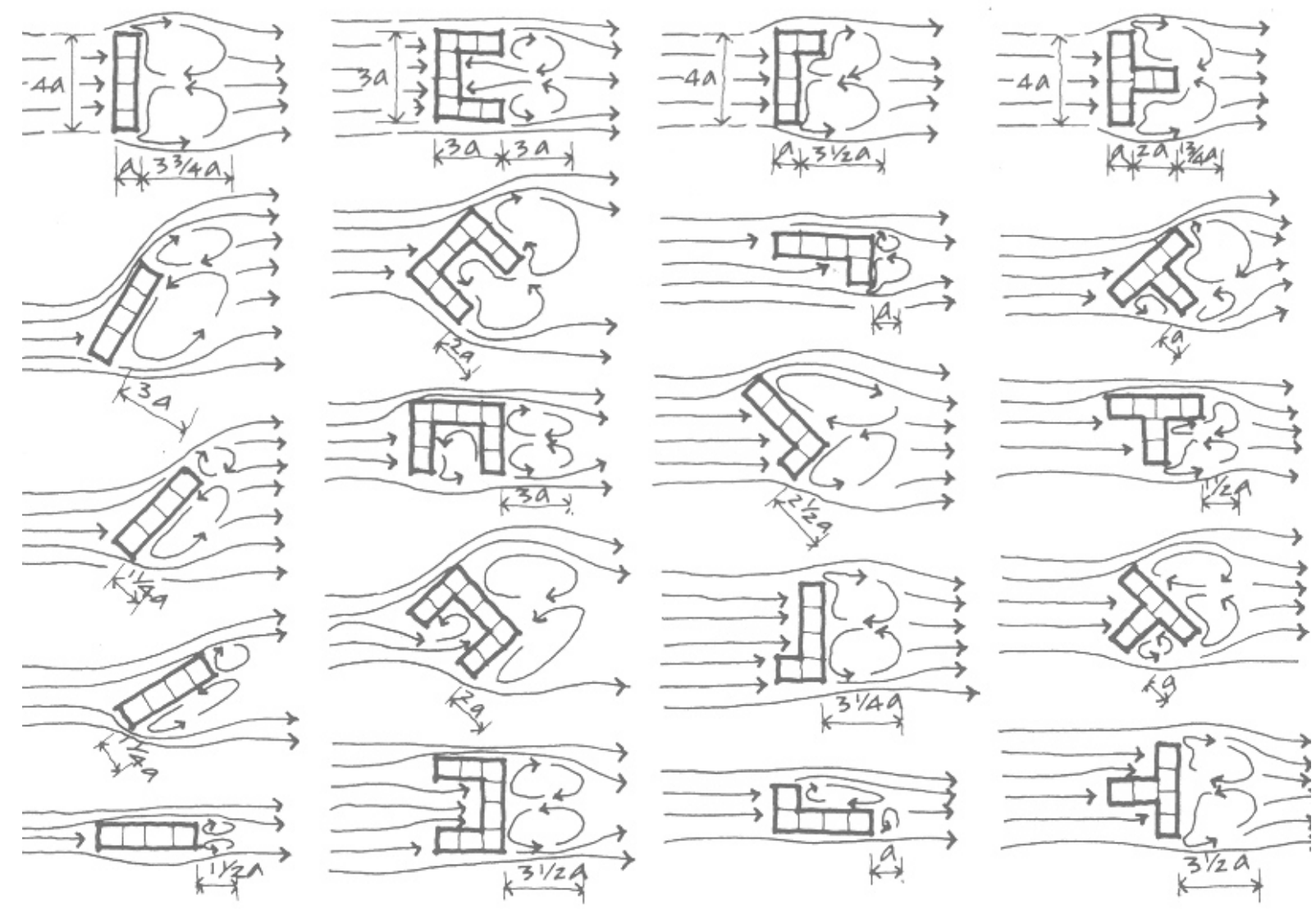

Figura 2.9 - Configuração e orientação da planta baixa

(EVANS, 1957 adaptado por BROWN E DEKAY, 2004, p.43)

Ao avaliar o fluxo de ar no interior de uma edificação não se pode ignorar o efeito das construções vizinhas no movimento do ar. Além da altura, largura, forma, tipologia e orientação da edificação, o arranjo das construções vizinhas e os obstáculos também podem modificar o perfil dos ventos no interior das edificações. Além disso, a distância entre as edificações também pode interferir na corrente de ar, portanto algumas pesquisas já demonstraram que para que isso não ocorra, as edificações devem manter uma distância de cinco a sete vezes a altura do edifício.

Alguns autores pesquisaram as formas que o fluxo de ar ao redor das edificações pode apresentar nos principais arranjos, o escalonado 
(tabuleiro de xadrez) e o arranjo normal (em grelha), tanto para ventos que sopram paralelamente a grelha, quanto para os ventos que incidem obliquamente. Assim como a relação entre as distâncias entre cada bloco e suas alturas. De acordo com Bittencourt e Cândido (2005), as pesquisas demonstraram:

"[...] que para o vento que sopra paralelo a grelha, o arranjo escalonado reduz a área de sombra de vento quando comparada com o arranjo normal. Para incidência do vento oblíqua à malha, a situação se inverte."

O uso de um pátio interno numa edificação também pode ser uma boa estratégia de resfriamento, porém a ventilação nesse espaço vai depender da proporção entre a altura da construção e a largura do pátio. Essa forma em conjunto com a direção dos ventos define a velocidade do vento no pátio interno.

Segundo Brown e Dekay (2004, p.231),

"[...] em climas quentes onde a ventilação é desejável, uma orientação do pátio interno de $45^{\circ}$ em relação aos ventos predominantes otimiza tanto os ventos no pátio quanto a ventilação cruzada nas edificações".

Esses mesmos autores sugerem num diagrama como dimensionar os pátios internos para um bom aproveitamento da ventilação natural, mensurando a velocidade média dos ventos como um percentual do vento incidente em três ângulos diferentes para pátios de formas e proporções diversas (figura 2.10). 
Proporçzes do pátio interno, orientação normal ao vento predominante (razão $\left.W_{1} / H_{1}\right)$

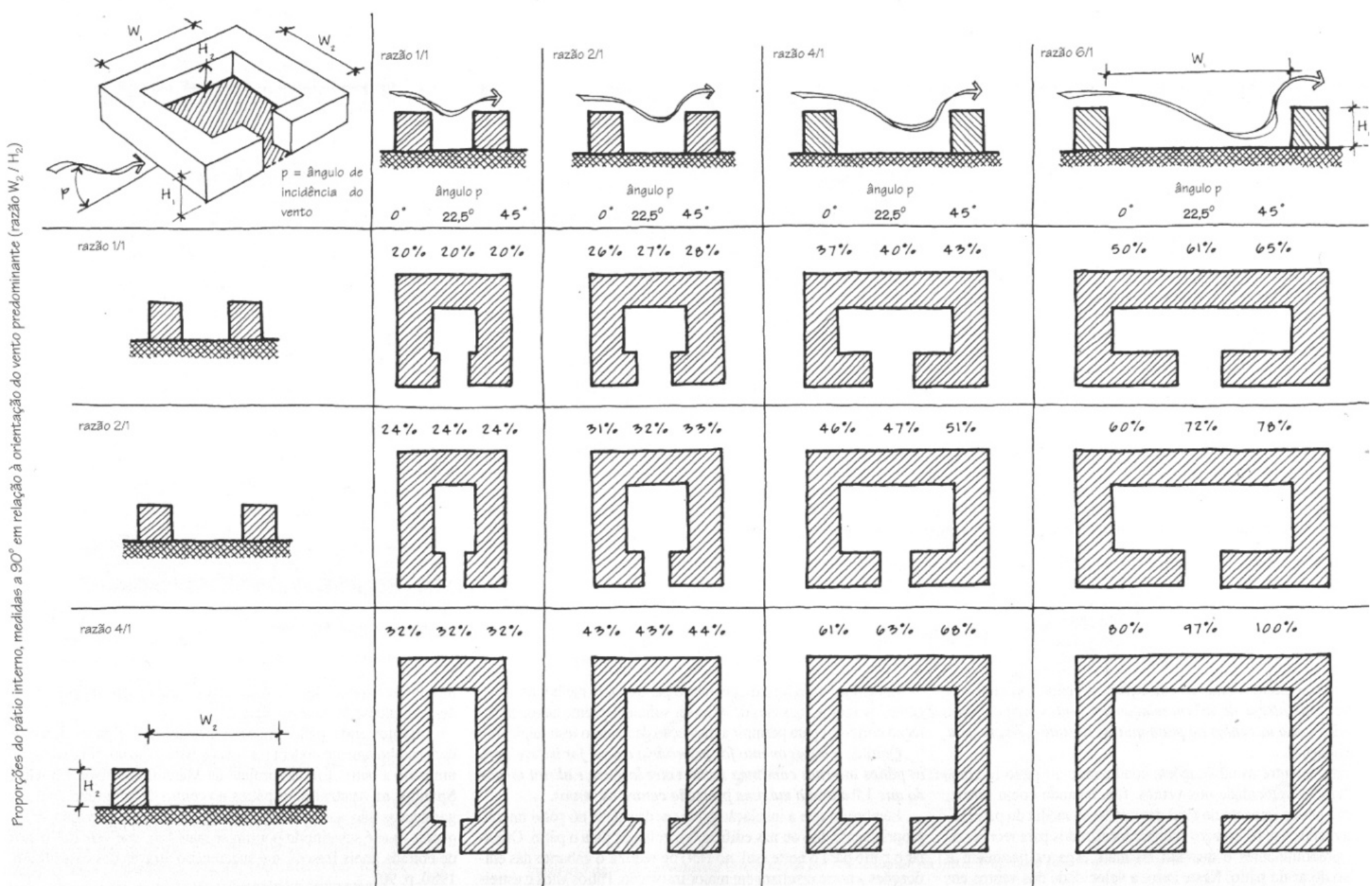

Figura 2.10 - Dimensionamento de patios internos, para uma boa ventilação - Velocidade media dos ventos como um percentual do vento incidente e sem obstruções (\%)

(BROWN E DEKAY, 2004, p.232) 


\subsubsection{Ventilação no interior das edificações}

O comportamento do fluxo de ar no interior de uma construção depende de outros fatores além da forma, orientação e localização do edifício, como já citado anteriormente. Os principais fatores estão relacionados com as aberturas de entrada e saída de ar dentro de cada ambiente, bem como a configuração interna e externa dessa construção. Portanto, para estudar o fluxo de ar no interior das edificações, deve-se levar em consideração:

- O tamanho e a localização das aberturas de entrada e saída do ar;

- A tipologia e a configuração dessas aberturas;

- A existência e a localização de alguns elementos arquitetônicos que possam interferir nesse fluxo pela proximidade das aberturas, tais como divisões internas, elementos horizontais e verticais, entre outros.

Vale salientar que estimar o fluxo de ar no interior das edificações é uma tarefa bastante complexa e é necessário um amplo conhecimento sobre o assunto e muita pesquisa na área, visto que o vento é um elemento que varia constantemente e de difícil análise e previsão. Em geral, as fontes bibliográficas de maior confiabilidade se basearam em amplas pesquisas por meio de testes em túneis de vento com modelos simulando situações reais, como por exemplo, as pesquisas realizadas pelo Centre Scientifique et Tecnique Du Bâtiment - CSTB, da França.

Em termos gerais, o importante é ter a informação de velocidade e direção dos ventos externos para que se possa quantificar a velocidade 
média do vento no interior da edificação ainda na fase de projeto. Assim, todas as possibilidades podem ser analisadas até que a escolha mais apropriada do partido arquitetônico seja feita.

\subsubsection{Tamanhos e formas das aberturas}

O tamanho, a forma e a localização das entradas e saídas de ar em um ambiente determinam a configuração do fluxo de ar no interior da edificação, interferindo na distribuição do fluxo e na velocidade média interna do ar.

Givoni (1976) apresentou um estudo que determinou a taxa de velocidade média do ar no interior das ambientes em função da relação entre as aberturas de entrada e saída do ar, para ventos com incidência de $45^{\circ}$ e $90^{\circ}$ (ver figura 2.11 ).

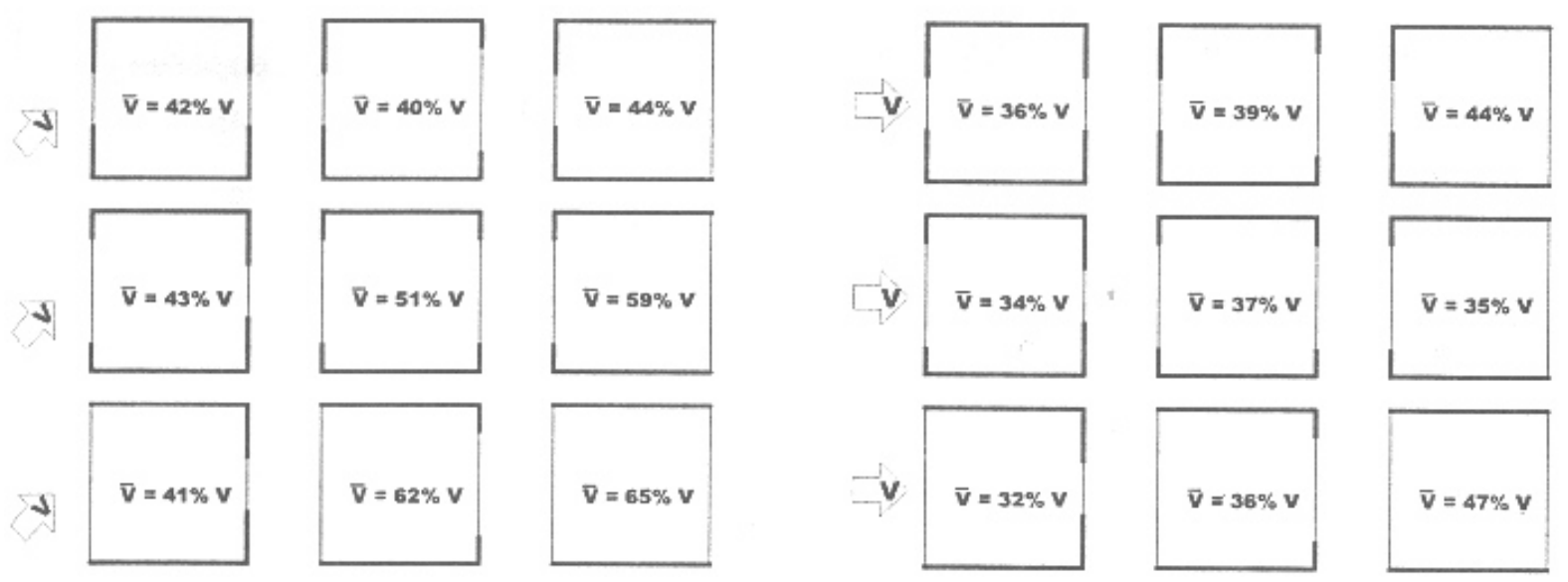

Figura 2.11- Velocidade interna media em função da relação entre as aberturas de entrada e saída do ar, para incidência do vento a $45^{\circ}$ e $90^{\circ}$

(GINONI, 1976 adaptado por BITTENCOURT E CÂNDIDO, 2005, p.61)

Concluiu-se então que com aberturas de entrada do ar do mesmo tamanho, as taxas de ventilação internas são maiores quando as aberturas de saída do vento são maiores. Outra conclusão é que com as 
entradas de ar maiores que as saídas o fluxo de ar no interior da edificação é reduzido, porém proporciona uma melhor distribuição.

Brown e Dekay (2004, p.205) apresentam um gráfico que determina "as dimensões da abertura necessária à remoção de calor de uma edificação, como um percentual da área de piso, considerando-se uma diferença de temperatura de $1,7^{\circ} \mathrm{C}\left(3^{\circ} \mathrm{F}\right)$ entre o interior e o exterior". Para isso é necessário definir a velocidade do vento considerada para o projeto e sua taxa de ganho térmico para estipular o tamanho mínimo ideal das tomadas ou saídas de ar por área de piso (\%), conforme gráfico 2.2.

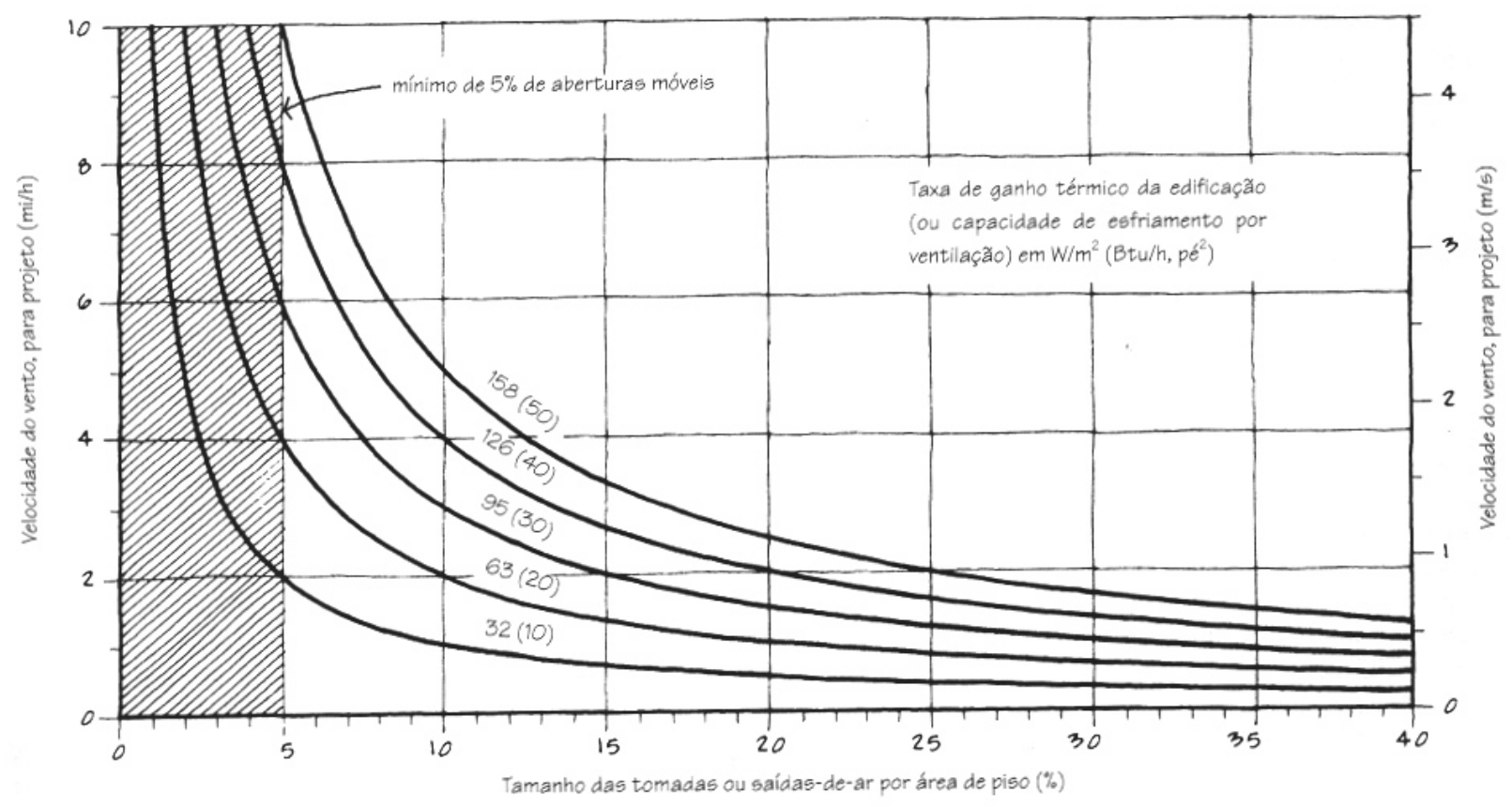

Gráfico 2.2 - Dimensionamento das aberturas para ventilação cruzada (BROWN E DEKAY, 2004, p.205)

O gráfico 2.3 adiante mostra como diferentes formas de aberturas podem interferir no movimento do ar no interior dos ambientes em função da direção dos ventos e da existência ou não de elementos verticais. De 
uma maneira geral, considerando a mesma área de abertura, os gráficos mostram que as entradas de forma horizontal apresentam uma eficiência maior em relação à velocidade média do vento, principalmente quando o vento incide obliquamente à fachada. Por isso, é possível afirmar que

"[...] a forma horizontal das aberturas produz uma ampla circulação do ar, mais apropriada à sensação de conforto térmico no interior das construções em climas quentes." (BITTENCOURT e CÂNDIDO, 2005).

Porém no caso da existência de elementos verticais, o rendimento da abertura horizontal irá variar de acordo com a relação entre o ângulo de inclinação do elemento e o ângulo de incidência do vento.
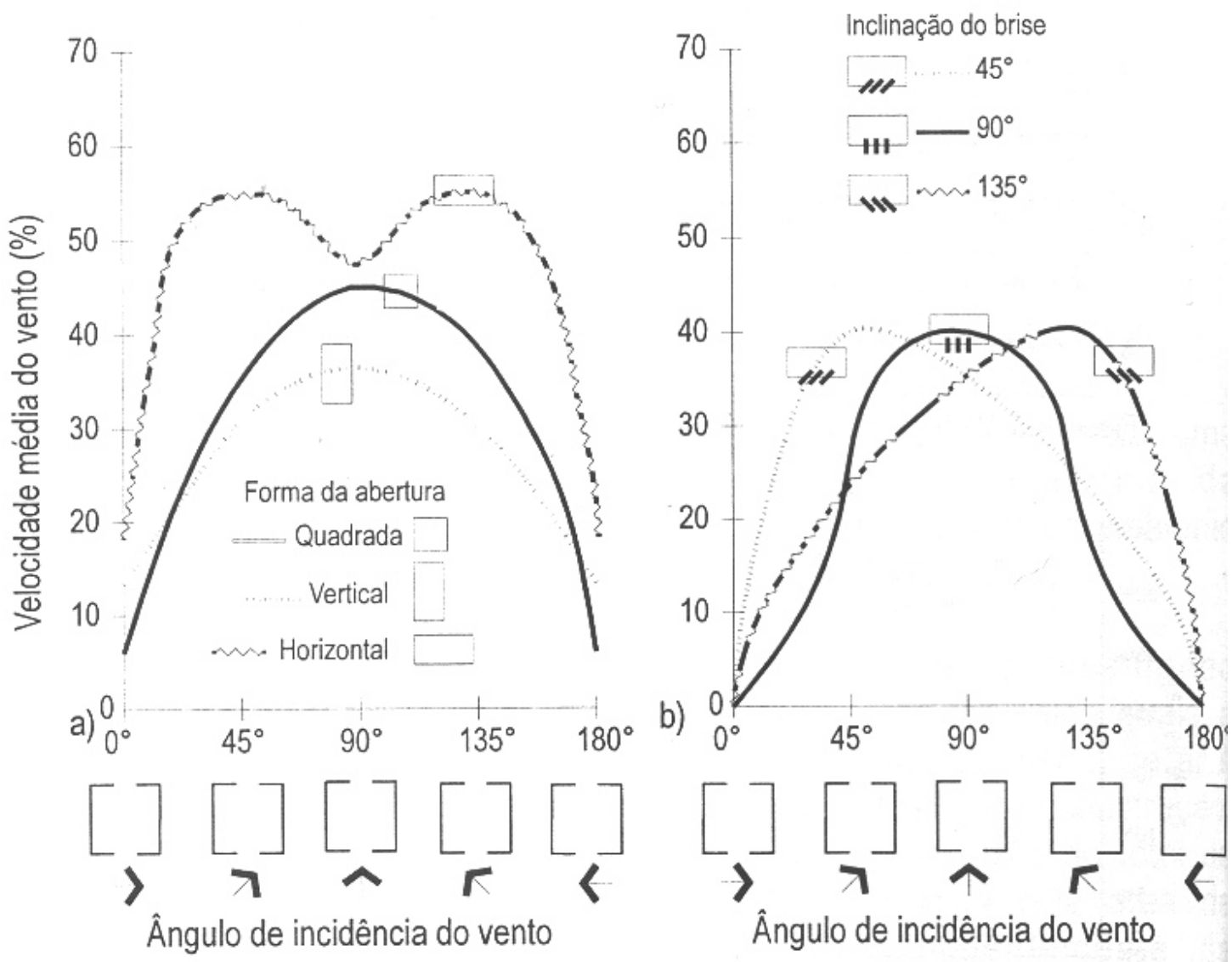

Gráfico 2.3 - Efeito da forma da abertura em função da direção do vento e da existência de protetores solares verticais

(SOBIN, 1981 adaptado por BITTENCOURT e CÂNDIDO, 2005, p.62) 


\subsubsection{Localização das aberturas}

O comportamento do ar dentro da edificação depende de diversos fatores externos à construção, como vem sendo explanado aqui, porém saber onde localizar a abertura de entrada do ar na edificação é a principal estratégia para definir a direção do fluxo do ar ao ingressar no ambiente. E para que esse fluxo circule dentro do ambiente, é necessária também uma abertura de saída do ar proporcionando assim uma ventilação cruzada. Porém, diversos estudos demonstram que a influência da localização da abertura de saída do ar na distribuição interna desse ar é menor que a de entrada. Por meio da figura 2.12 , nota-se também que a localização da abertura de saída exerce maior influência na distribuição interna do ar, contra a influência da localização de entrada do ar.

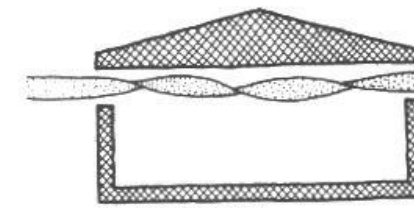

Aberturas altas

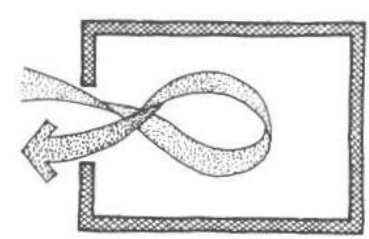

Abertura única

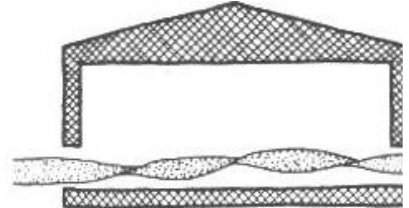

Aberturas baixas

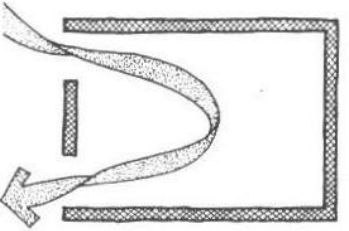

Duas aberturas na mesma parede

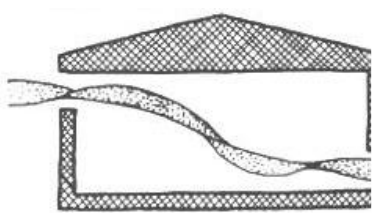

Aberturas altas e baixas

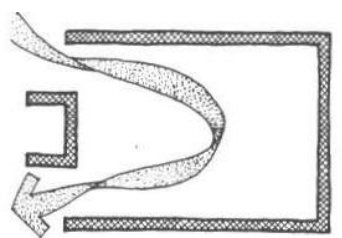

Duas aberturas com wing walls

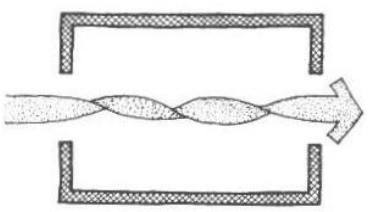

Duas aberturas em paredes opostas

Duas aberturas em paredes adjacentes

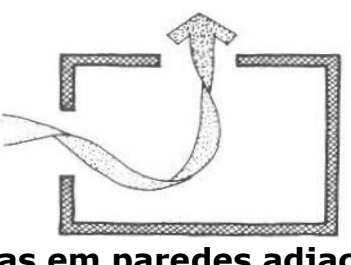

Figura 2.12 - Distribuição das aberturas de ventilação

(GIVONI, 1976 e MELARAGNO, 1982 adaptado por BROWN E DEKAY, 2004, p. 265) 
Para um resultado satisfatório, a abertura de entrada de ar deve estar localizada nas fachadas de pressão positiva e a de saída na parede de pressão negativa. Segundo Bittencourt e Cândido (2005, p.64),

"[...] em uma construção térrea, a diferença máxima de pressão é obtida se as entradas de ar forem localizadas na região de maior pressão positiva das fachadas a barlavento, e as saídas na região de pressão negativa mais intensa nas paredes a sotavento".

Desta maneira é interessante analisar as diversas condições de uma fachada em relação ao vento, para se determinar o coeficiente de pressão que o vento exerce sobre esta fachada e assim planejar a melhor localização das aberturas "[...] baseado no princípio de que a diferença de pressão entre as fachadas a barlavento e a sotavento se constitui na força motriz para o movimento do ar." (BITTENCOURT e CÂNDIDO, 2005, p.64).

Quando o objetivo é aumentar a velocidade do fluxo de ar dentro de um ambiente, as aberturas em paredes opostas são mais eficazes e dependendo da localização de cada uma delas o fluxo interno do ar pode ser diferente, o que deve ser analisado em função da atividade que será realizada no local. Porém, nem sempre é possível localizar as aberturas de entrada e saída em paredes opostas e nesse caso a localização e a dimensão das aberturas influenciam no resultado da velocidade média do ar interno, como sugere Givoni (1976). Já aberturas localizadas em paredes adjacentes promovem certa turbulência dentro do ambiente proporcionando uma melhor distribuição do ar e conseqüentemente 
melhor sensação de resfriamento entre os usuários. Por este motivo também é importante prever a altura dessas aberturas de acordo com a função desempenhada no local, pois aberturas localizadas próximas ao teto ou ao chão podem privar a pessoas de receberem os benefícios da ventilação natural no ambiente. As aberturas localizadas em uma altura média na parede irão promover maiores velocidades do ar nas zonas ocupadas.
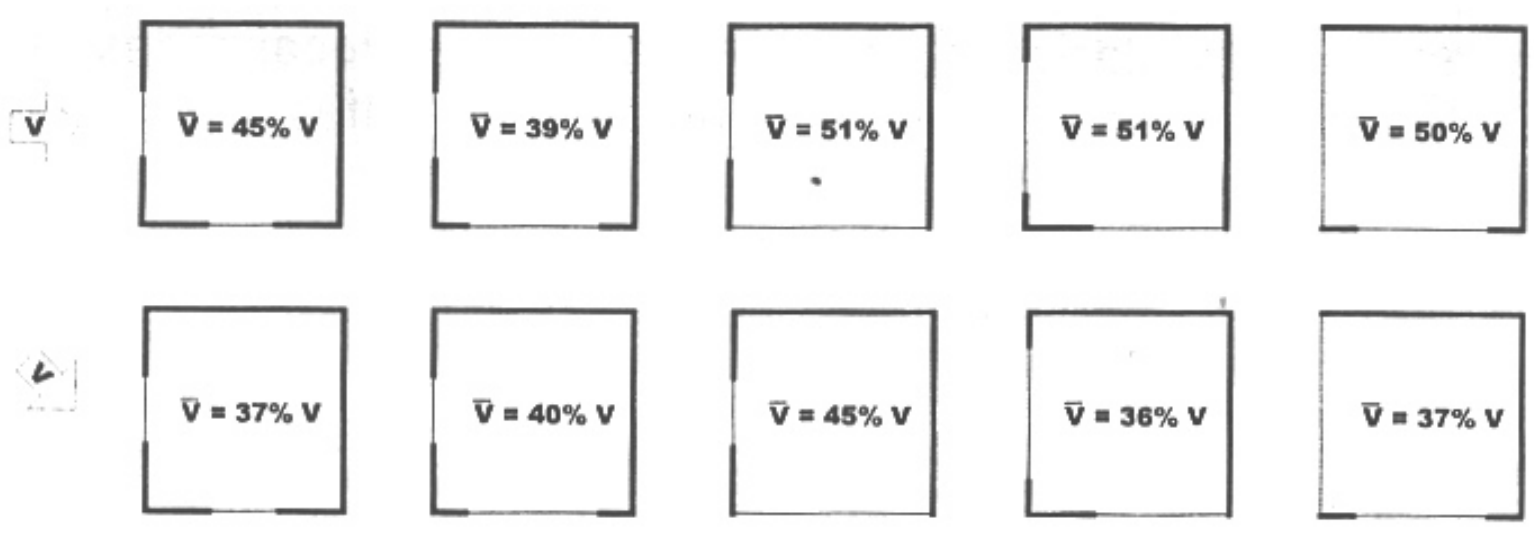

Figura 2.13 - Influência da localização e dimensão das aberturas localizadas em paredes adjacentes

(GIVONI, 1976 adaptado por BITTENCOURT e CÂNDIDO, 2005, p.66)

Brown e Dekay (2004, p.265) reuniram alguns estudos realizados por outros pesquisadores e elaboraram uma tabela que mostra a velocidade média do ar no interior de uma edificação como percentual da velocidade do ar no exterior quando o vento incide numa variação angular entre 45 e $90^{\circ}$ em relação à abertura e sem obstrução. Por esses resultados pode-se afirmar que a velocidade do ar no interior de uma edificação depende da velocidade do vento externo sem obstrução, do ângulo de incidência deste vento sobre a abertura de entrada do ar, da localização desta abertura e sua dimensão. É notável também que a 
velocidade média do ar no interior do recinto é maior quando existem duas aberturas em paredes diferentes, que é provocada pela diferença de pressão em cada uma dessas aberturas e quanto maior as aberturas, nesse caso, maior também será a velocidade do ar interno. Diferentemente do ambiente que apresenta apenas uma abertura para ventilação, onde a variação da dimensão da janela pouco influencia no resultado da velocidade do ar interno, como pode ser observado na tabela 2.1 .

Tabela 2.1 - Vel. media do ar no interior de uma edificação como percentual da velocidade do ar no exterior - ângulo de incidência variando entre $45^{\circ}$ e perpendicular à abertura

(adaptada de BROWN e DEKAY, 2004, p.265 - Tabela baseada nos trabalhos de GIVONI, 1976 e MELARAGNO, 1982)

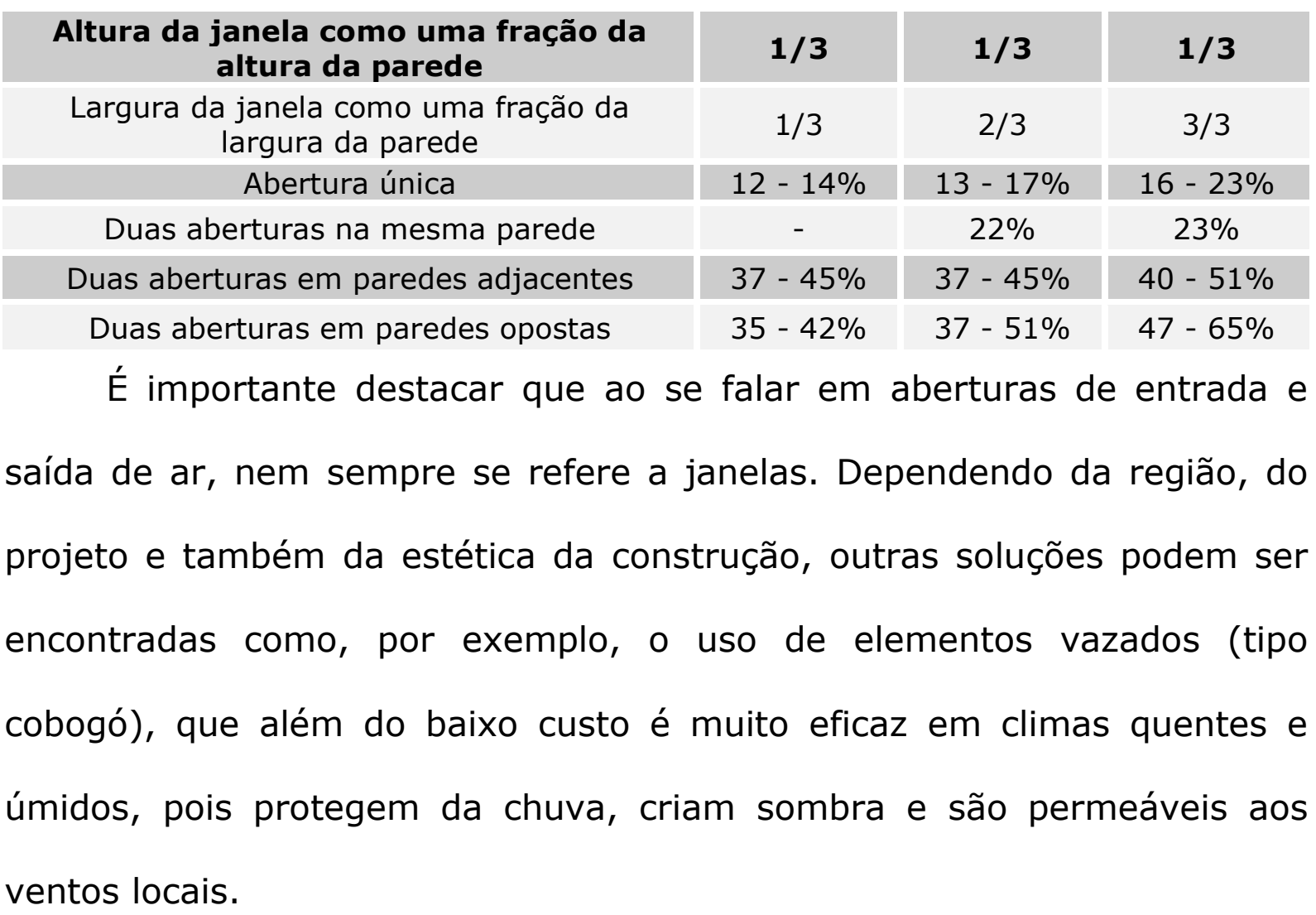

Outra solução pode ser o uso de aberturas tipo shed, que se localizam nos telhados e funcionam como captadores de ventos ou 
exautores (criando o efeito chaminé) em função da direção dos ventos externos e importantes quando as janelas baixas tem pouco acesso à ventilação.

Como a velocidade do vento aumenta com a altura, os captadores podem receber ventos mais fortes e consequentemente podem ter aberturas menores do que as janelas localizadas ao nível térreo com a mesma função, além disso, com menos obstáculos esses captadores de ventos podem, dependendo de sua configuração, receber ventos de qualquer direção.

Quando essas aberturas funcionam como captadores de vento, seu projeto deve considerar a direção dos ventos locais, e sua eficiência é definida como a razão entre a taxa de fluxo dentro da torre e a seção transversal da torre. Brown e Dekay (2004, p.213) afirmam que "para estarem acima da camada de turbulência e resistência, se possível, as entradas de ar devem estar pelo menos a 2,4m acima da altura das edificações do entorno e das obstruções". Os autores também mostram através do gráfico 2.4, quais os tipos e de captadores de ventos mais utilizados e sua eficiência em função da direção dos ventos predominantes.

É importante salientar que no caso de captadores com aberturas em mais de uma direção, cada abertura deve ser dimensionada de forma a atender a retirada de carga térmica total da edificação individualmente. 
"Cada entrada de ar voltada para uma direção não deverá ser maior do que a área da seção transversal da torre, enquanto as janelas reguláveis usadas como saídas de ar deverão ter aproximadamente o dobro do tamanho das saídas de ar" (BROWN e DEKAY, 2004, p.213).
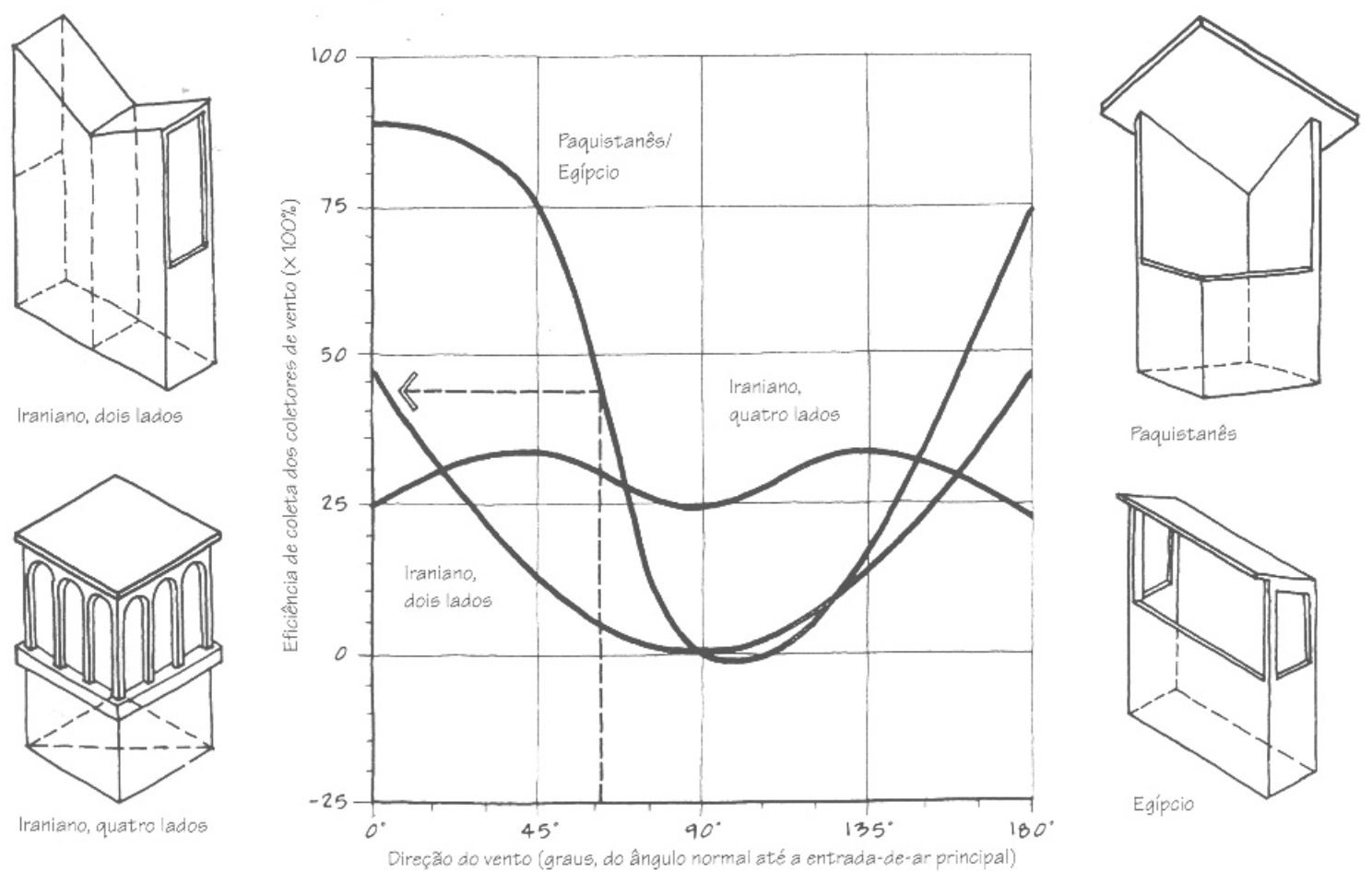

Paquistanês

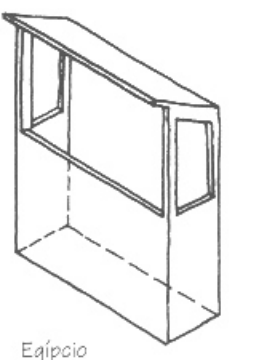

Gráfico 2.4 - Eficiência de coleta dos diferentes tipos de coletores de vento

(AL-MEGREN, 1987 adaptado por BROWN e DEKAY, 2004, p.212)

\subsubsection{Tipologia das aberturas}

"As janelas são o principal elemento para se efetuar a troca entre o exterior e o interior de um edifício. Sua influência maior é no ambiente interno, onde funciona como fonte de luz e de ar, além de representar um importante papel no aspecto visual. Em algumas regiões tropicais úmidas a janela é uma abertura sem vidros. Já nos climas temperados, ela é totalmente coberta por vidros e parcialmente manipulável, enquanto nos climas quenteúmidos é parcialmente coberta por vidros e totalmente operável". (HERTZ, 1998, p.71)

As esquadrias se destacam e ocupam amplas áreas nas fachadas das edificações, mas ao contrário da alvenaria, são por definição, móveis. Componentes da fachada, com funcionalidade para iluminação e 
ventilação, os caixilhos devem receber atenção especial por parte dos arquitetos.

Vários fatores devem ser observados antes de se escolher o tipo de esquadria a ser utilizada em uma edificação, pois tal escolha pode interferir no conforto térmico, luminoso e acústico dos usuários, além de influenciar nos aspectos estéticos, na privacidade e na segurança do ambiente, assim como possibilitam o contato visual com o exterior. Ou seja, é uma tarefa complexa e de grande importância e depende também da função de cada espaço.

Componentes das edificações, as janelas incorporam um sistema de partes fixas e móveis, incluindo acessórios que se encaixam e/ou se ajustam para permitir o funcionamento. Assim, as janelas são classificadas de acordo com a movimentação de suas folhas. Para atender as exigências de circulação do ar e conforto, o especificador dispõe de meios para combinar diferentes tipologias de janelas, adicionando funções para iluminação ou ventilação.

Quando a idéia é o aproveitamento da ventilação natural para obter o conforto térmico, a proposta é planejar esquadrias que permitam que o vento penetre no ambiente, mas que também seja possível controlar sua entrada e a direção de seu fluxo. Além disso, é interessante que ao se fechar uma abertura para o vento, não impeça a entrada de luz natural no ambiente e vice-versa. 
Nesses casos o mais apropriado seria o uso de esquadria de folhas duplas, uma com vidro que impeça a passagem do vento, mas não da luz e outra com venezianas móveis, principalmente em climas quentes, pois permite o controle da privacidade, vento, chuvas, raios solares e iluminação natural.

De qualquer maneira, quando o assunto é ventilação natural dos ambientes, a palavra chave ao se tratar de aberturas para passagem do vento, é a porosidade, seja através de janelas comuns ou com venezianas, sejam aberturas com elementos vazados, ou qualquer outra solução apropriada ao clima e a edificação.

Bittencourt e Cândido (2005, p.70) apresentam o peitoril ventilado proposto pelo arquiteto Glauco Campelo, que obtêm resultados satisfatórios principalmente quando utilizados em quartos de dormir. 0 peitoril ventilado localiza-se abaixo das janelas complementando o movimento do ar proporcionado pelas esquadrias e produzindo uma corrente de ar na altura das camas (figura 2.14). Como oferece proteção contra roubo, invasão e chuvas de vento, pode ser deixado aberto a noite toda sem impedir o fluxo de ar dentro do ambiente.

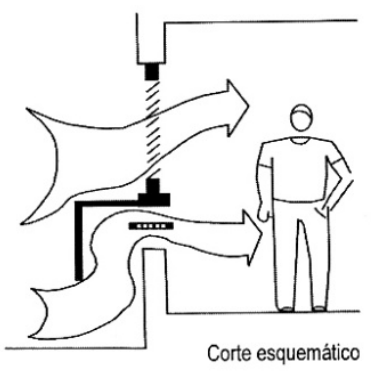

Figura 2.14 - Peitoril ventilado

(BITTENCOURT e CÂNDIDO, 2005, p.70) 
Quando existe o risco de penetração das chuvas no ambiente, é importante se prever um tipo de esquadrias que permita o controle de entrada do vento, evitando a entrada da chuva, mas sem prejudicar o aproveitamento da ventilação natural no espaço.

O mercado oferece alguns tipos principais de janela, mas que também podem ser encontrados resultantes de combinação de funções. A seguir, são indicadas as tipologias de janelas mais comuns, com suas características funcionais positivas e negativas.

\section{- Janela de correr}

É a mais utilizada nas edificações em geral. Pode ter uma ou mais folhas que são movimentas por deslizamento horizontal sem ultrapassar o limite da janela. É uma esquadria de fácil operação, baixa manutenção e suas folhas podem ter grandes dimensões. Porém, na abertura libera apenas $50 \%$ do vão, o que pode ser prejudicial para a ventilação natural e também dificulta a limpeza do lado externo.
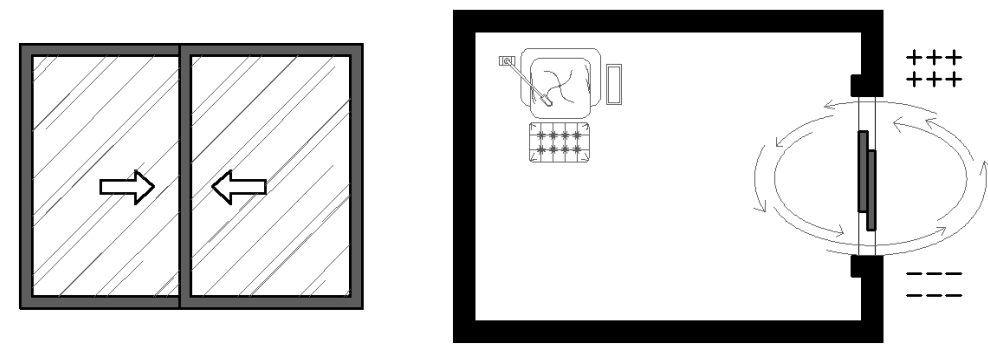

Figura 2.15 - Croqui de janela de correr em vista e em planta baixa.

\section{- Janela guilhotina}

É formada por uma ou mais folhas semelhante à janela de correr, só que movimentadas no eixo vertical. Por não ultrapassar o limite da janela 
permite a utilização de grades, telas ou persianas. Libera apenas $50 \%$ do vão em sua abertura e necessita de mais manutenção que a anterior devido à tensão gerada nos cabos que sustentam as folhas.
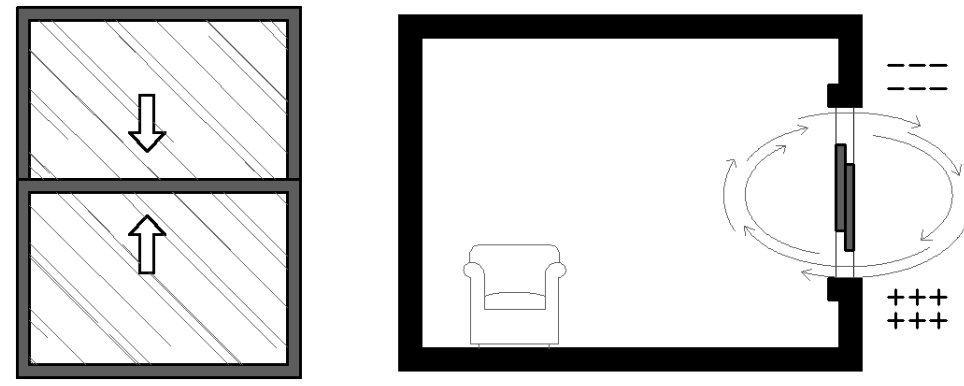

Figura 2.16 - Croqui de janela guilhotina em vista e em corte.

\section{- Janela de abrir de eixo vertical}

É formada por uma ou mais folhas e seu movimento se dá por rotação em torno de um eixo vertical localizado em uma de suas laterais. Tem como característica positiva a abertura total do vão, o que facilita a limpeza externa, porém não possibilita o controle da ventilação e em caso de chuva oblíqua é necessário o fechamento total.
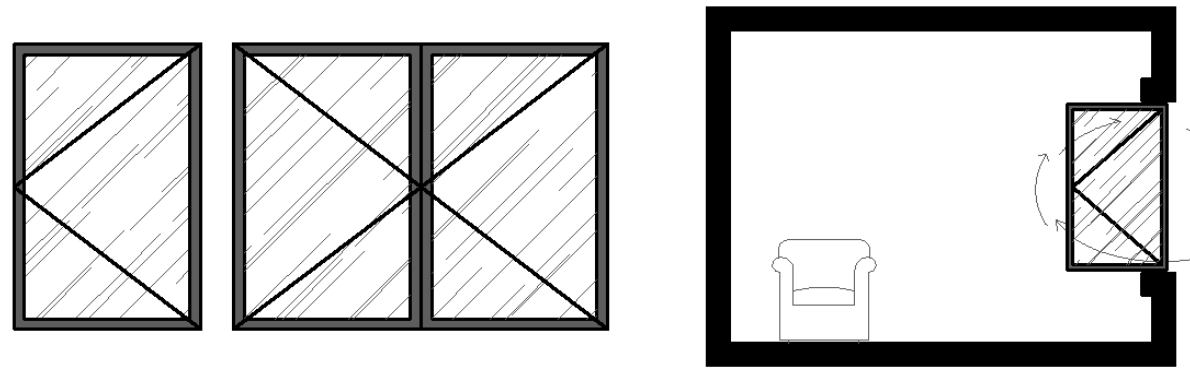

Figura 2.17 - Croqui de janela de abrir de eixo vertical em vista e em corte

\section{- Janela projetante ou de tombar}

Podem apresentar uma ou mais folhas. A semelhança entre esses dois modelos está no movimento de rotação em torno de um eixo horizontal fixo. No caso da janela projetante, o eixo se localiza na 
extremidade superior e a janela de tombar apresenta o eixo na extremidade inferior da folha. Ambas permitem uma boa ventilação mesmo em dias de chuva e apresentam boa estanqueidade ao ar e a água. Contudo, a limpeza externa é difícil e não permite o uso de grades ou persianas, além de necessitar de material de custo mais elevado para proporcionar um bom funcionamento com maior durabilidade.
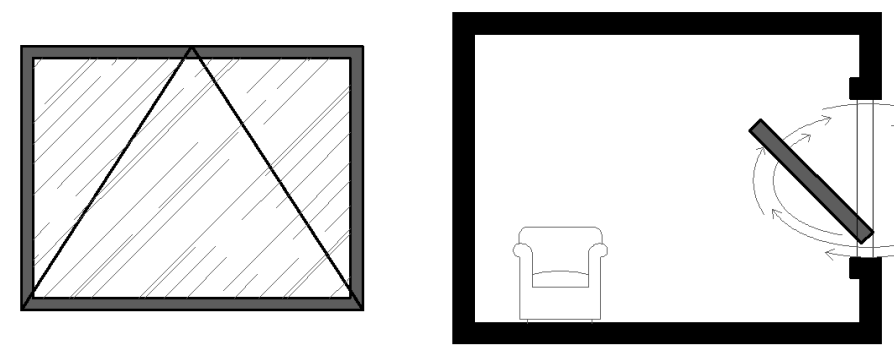

Figura 2.18 - Croqui de janela projetante ou de tombar em vista e em corte

\section{- Janela pivotante}

A janela pivotante também apresenta o movimento em torno de um eixo vertical, porém este não coincide com as extremidades das folhas. Permite a abertura de grandes vãos mesmo com uma única folha, fácil limpeza, permite controle da ventilação e permanece aberta com a utilização de dispositivos de freio da folha. O único aspecto negativo seria a projeção da folha para dentro do ambiente que dependendo da dimensão pode atrapalhar a circulação ou aproveitamento do espaço, além de não permitir o uso de grades ou persianas externas ou internas. 

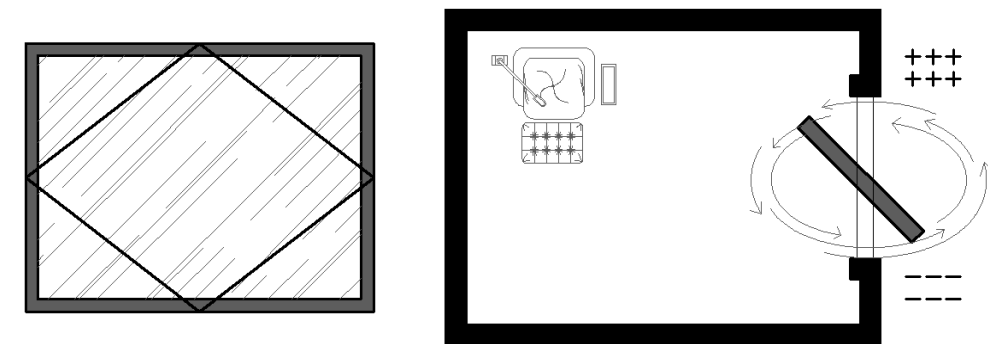

Figura 2.19 - Croqui de janela pivotante em vista e em planta baixa

\section{- Janela basculante ou gelosia}

Possui várias folhas e um eixo de rotação horizontal que não coincide com as extremidades das folhas. É muito utilizada em paredes internas porque apresenta pequena projeção para ambos os lados, sem prejudicar os espaços próximos. Normalmente são mais empregadas em cozinhas, áreas de serviço, banheiros e outros espaços que também precisem de ventilação constante como armazéns e escolas. Por apresentarem folhas de pequena dimensão, oferecem mais segurança ao ambiente, já que não liberam o vão, podendo permanecer abertas todo o tempo. Permite regulagem da ventilação e proteção contra chuvas.
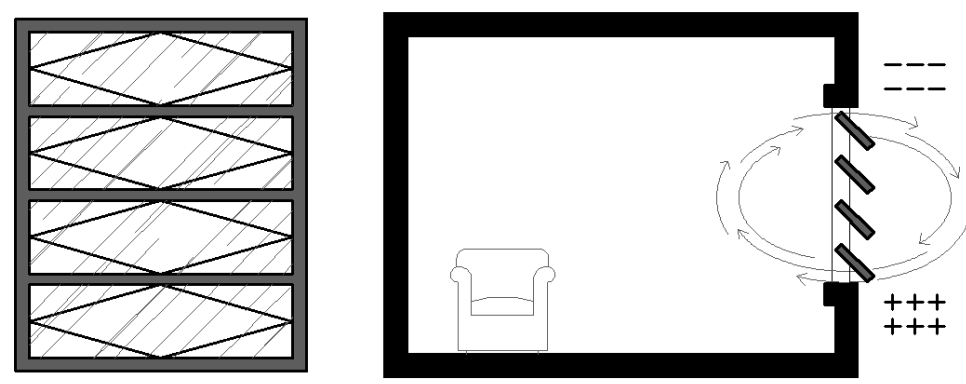

Figura 2.20 - Croqui de janela basculante ou gelosia em vista e em corte

\section{- Janela sanfonada ou camarão}

Formada por duas ou mais folhas articuladas entre si que, ao se abrir, dobra-se uma sobre as outras, por deslizamento horizontal ou 
vertical de seus eixos de rotação. Esses eixos podem coincidir com as bordas da folha ou se situar em posições intermediárias. No caso de janela sanfonada de eixo vertical, as vantagens podem ser aproximadas às da janela de abrir. Já aquela de eixo horizontal pode apresentar vantagens semelhantes às da projetante.
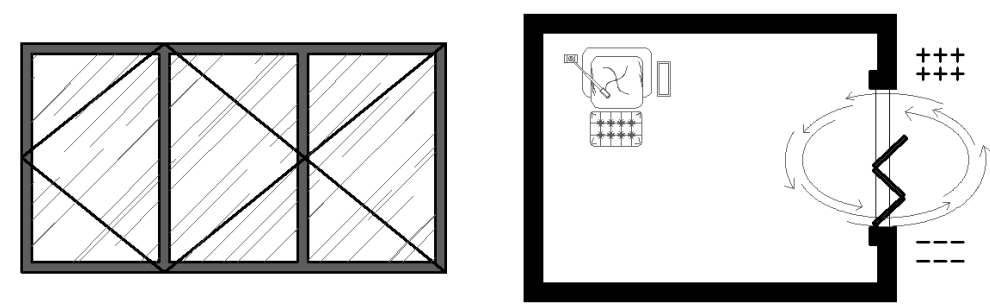

Figura 2.21 - Croqui de janela sanfonada ou camarão em vista e em planta baixa

\section{- Janelas especiais}

Constituídas de dois ou mais tipos de janelas citadas. São especiais aquelas que, por características de forma, uso e funcionamento, não se enquadram nas tipologias anteriores.

\subsubsection{Efeitos das divisões internas}

A configuração arquitetônica dos ambientes internos também é responsável pela alteração da configuração do fluxo de ar dentro dos ambientes, portanto dependendo da localização das aberturas, divisões internas podem prejudicar o fluxo e a velocidade da ventilação e até mesmo bloquear o fluxo de ar nos ambientes.

Em edificações com vários ambientes, em geral, existem ambientes mais favorecidos e outros menos em função da localização de suas aberturas, ou até mesmo da existência delas. Dessa forma, a adoção de 
divisórias com alguma permeabilidade ao ar ajuda a circulação mínima do ar por todos os ambientes.

O uso de bandeiras com venezianas nas portas internas, por exemplo, podem garantir o mínimo de fluxo de ar entres os ambientes mesmo com as portas fechadas, mantendo assim a privacidade dos usuários.

Givoni (1976) mostra como o fluxo de ar é afetado pelas divisões dos espaços internos em função da velocidade do vento e da direção do fluxo de ar (figura 2.22). Quanto mais próximo o obstáculo da abertura para entrada de ar, menor a velocidade do vento em relação ao vento externo. Além disso, as divisórias internas acabam criando espaços onde não existe a circulação do ar e dependendo da função que este espaço terá, o conforto térmico pode ser bastante prejudicado, além do que esses obstáculos também podem interferir na iluminação natural do ambiente.

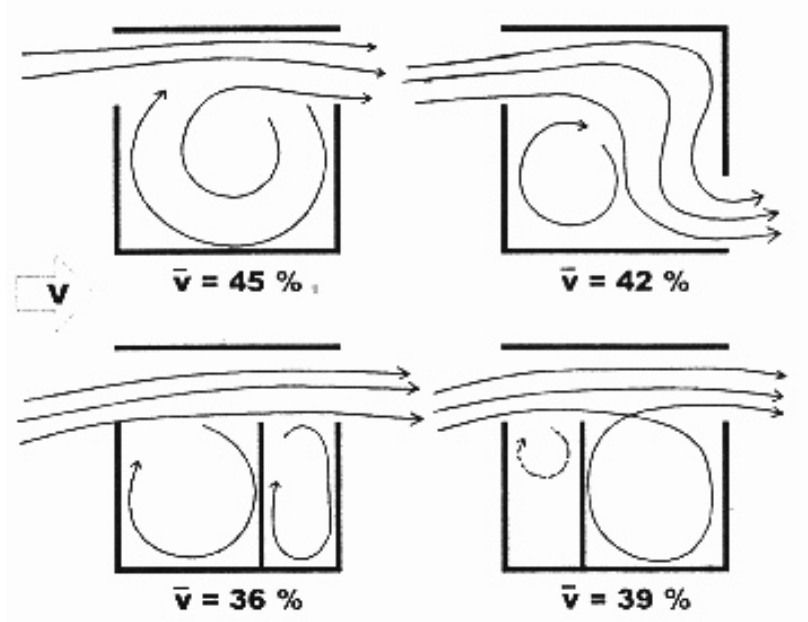

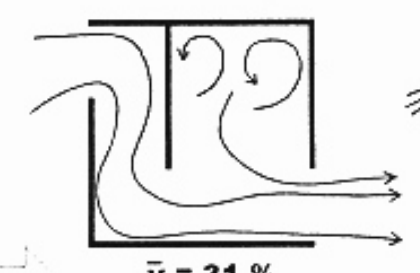

$\overline{\mathbf{v}}=\mathbf{3 1} \%$
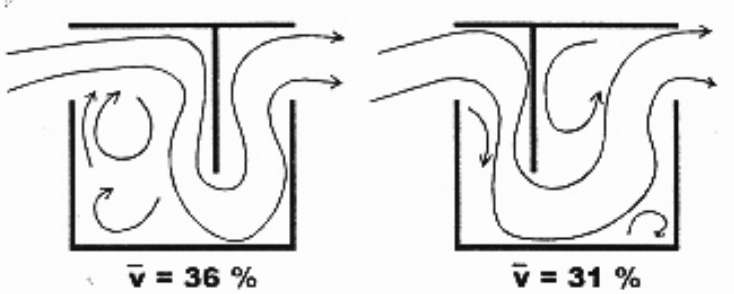

Figura 2.22 - As divisões do espaço interno afetam a configuração do fluxo de ar. (GIVONI, 1976 adaptado por BITTENCOURT e CÂNDIDO, 2005, P.77) 


\subsubsection{Elementos horizontais e verticais}

São elementos verticais os prolongamentos ou extensões das paredes internas para o exterior da construção, os protetores solares verticais ou algum elemento estrutural próximo a abertura de entrada de ar. Já os elementos horizontais podem ser protetores solares horizontais, marquises, beirais e varandas. Cada um desses elementos horizontais pode ser utilizado individualmente ou em conjunto com algum elemento vertical.

A influência de cada um desses elementos no fluxo de vento interno vai depender da posição e dimensão do elemento e também da direção dos ventos. A ventilação poder ser aumentada como também pode ser obstruída por elementos mal posicionados ou mal dimensionados. Quando bem empregados podem alterar a pressão desenvolvidas ao redor das janelas e mudar a configuração do fluxo interno dos ventos. Bittencourt e Cândido (2005, p.70) afirmam que "com a incidência oblíqua à abertura, o painel vertical pode funcionar como um captador de vento, aumentando a circulação do ar em ambientes de ventilação cruzada." Mas elementos vazados empregados nesses elementos verticais podem diminuir esse efeito, ao reduzir a diferença de pressão gerada por esses elementos. 

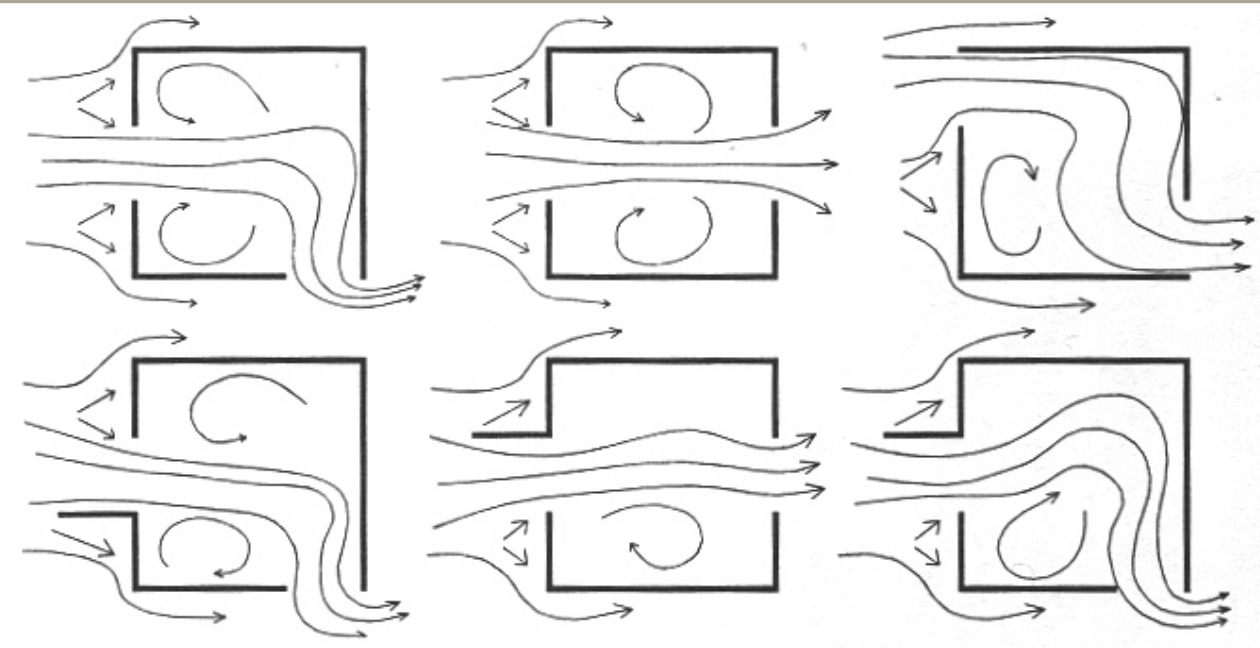

2.23 - Componentes verticais afetam o conjunto de pressões desenvolvidas nas entradas do ar, alterando o padrão de distribuição do fluxo do ar.

(KOENIGSBERGER et al, 1976 adaptado por BITTENCOURT e CÂNDIDO, 2005,
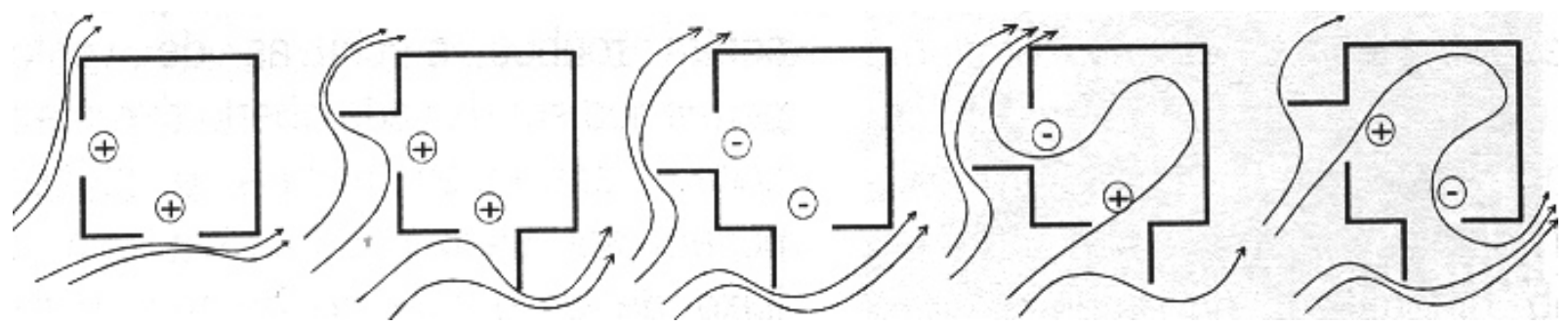

Figura 2.24 - Projeções verticais podem interferir no fluxo de ar

(FLEURY, 1990 adaptado por BITTENCOURT e CÂNDIDO, 2005, P.72)

Brown e Dekay (2004, p.206) recomendam o uso de wing walls em janelas que não estiverem orientadas para os ventos predominantes, com o objetivo de alterar as zonas de pressão no entorno da edificação e induzir o fluxo de vento para o interior dos ambientes (figura 2.25). Porém advertem que este artifício só funciona em janelas localizadas no lado de pressão positiva da construção e "a profundidade das saliências das wing walls deve ser, no mínimo, 0,5-1 vez a largura da janela e o espaçamento entre as wing walls deve ser, no mínimo, 2 vezes a largura da janela" para que funcionem positivamente, potencializando a ventilação natural no interior da edificação. 


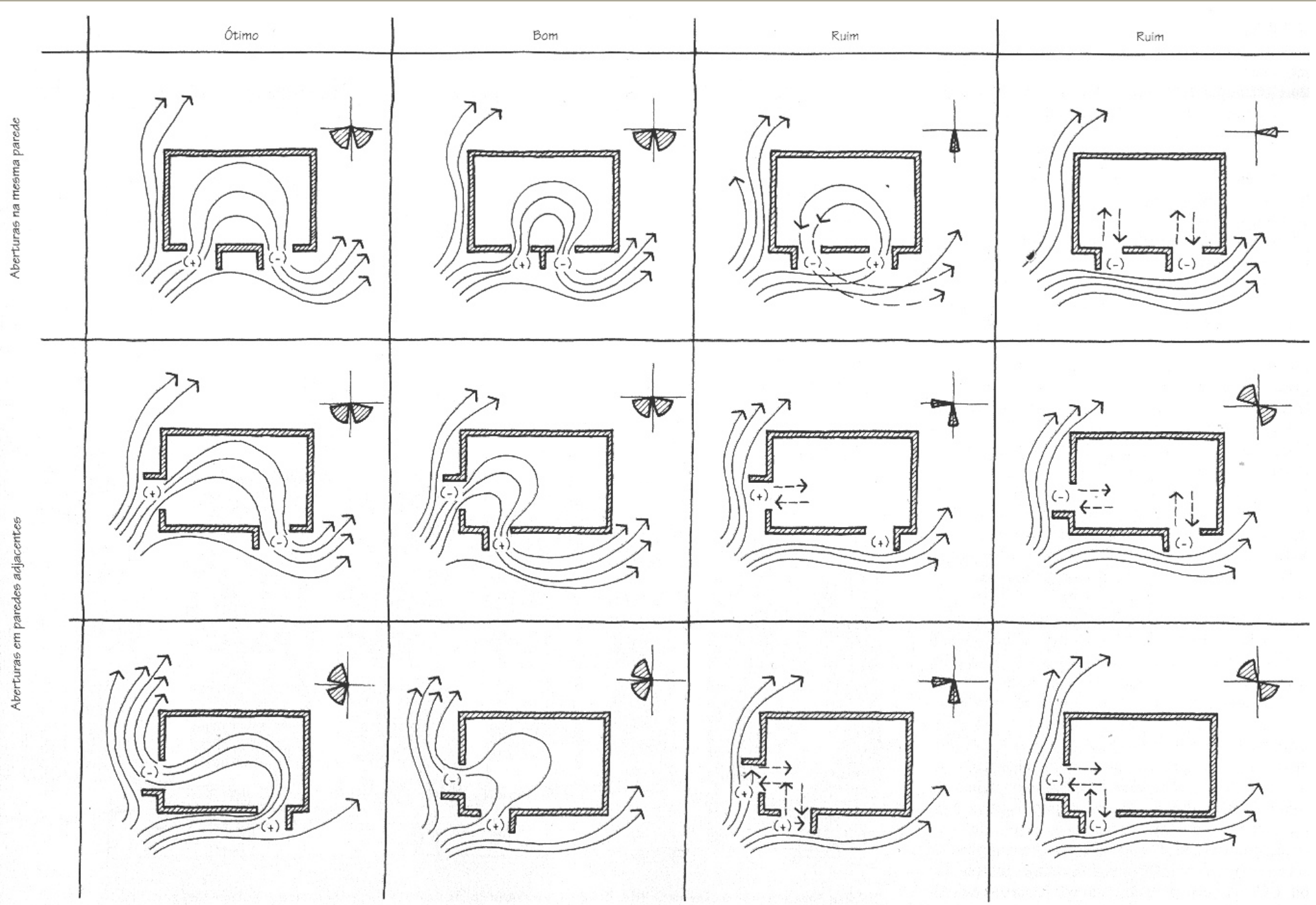

Figura 2.25 - Estratégias de design de wing walls

(BROWN e DEKAY, 2004, P.207) 
Grandes beirais e varandas também ajudam a direcionar o vento que seria desviado acima do edifício para dentro do ambiente, além de que a sombra proporcionada por esses elementos ajuda a resfriar o ar e melhorar a sensação de conforto térmico dos usuários. (figuras 2.26 e
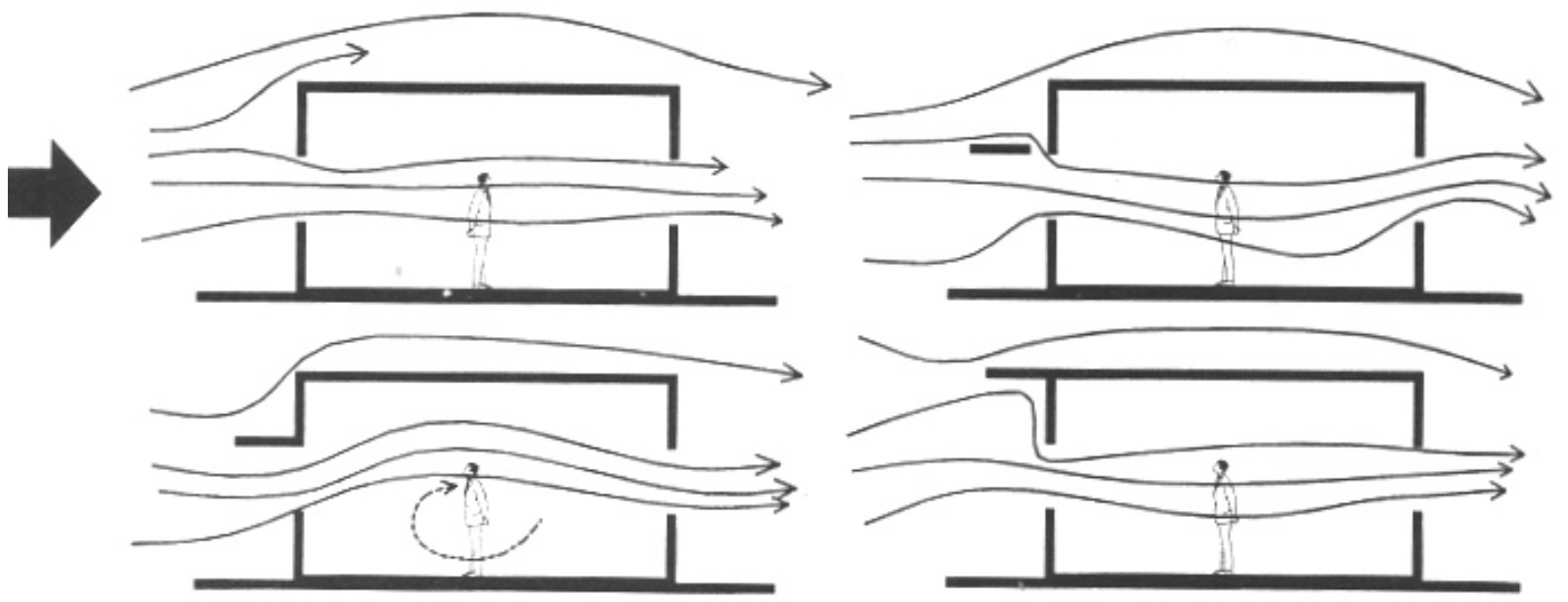

Figura 2.26 - Efeitos das projeções horizontais no fluxo de ar no interior dos ambientes (OLGYAY, 1963 e BOWEN, 1981, adaptado por BITTENCOURT e CÂNDIDO, 2005, p.74)
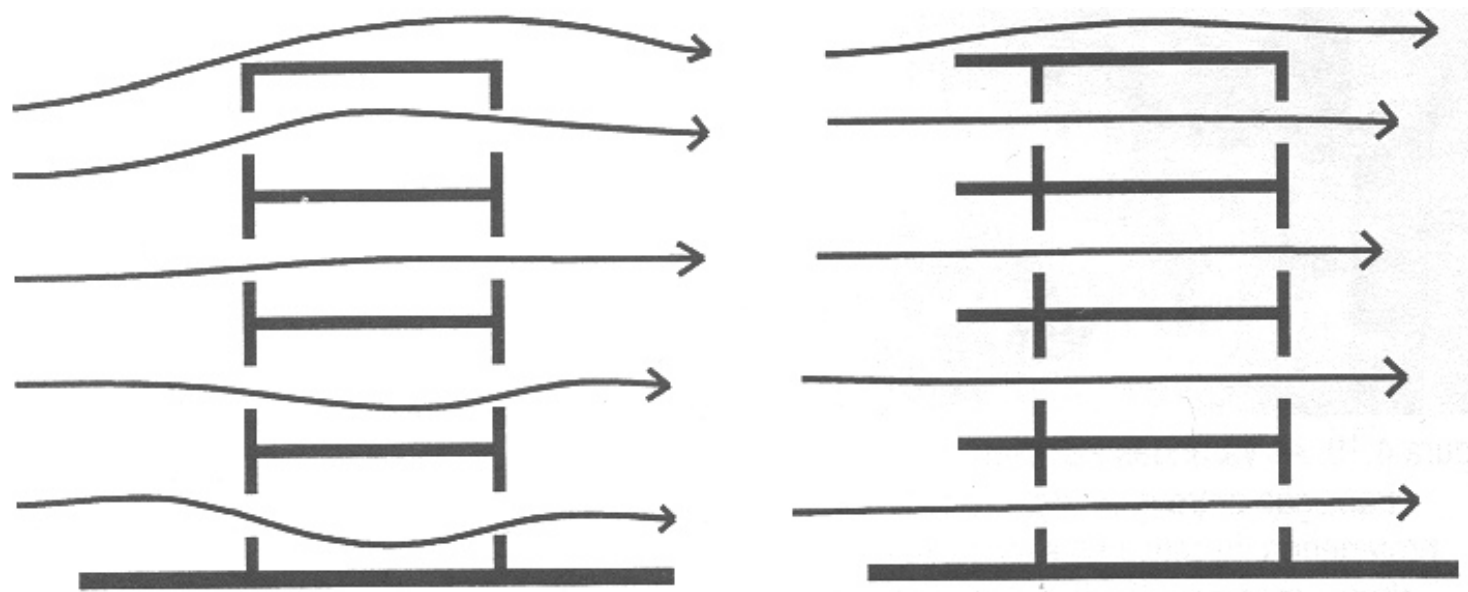

Figura 2.27- Efeito de elementos horizontais no fluxo de ar em edifícios (BITTENCOURT e CÂNDIDO, 2005, p.74) 


\section{0 CLIMA DA CIDADE DE ARACAJU - SE}

\subsection{CARACTERIZAÇÃo DA ÁREA}

Fronteira com os estados da Bahia, ao sul e Alagoas, ao norte, e com uma área de $21.910,3 \mathrm{~km}^{2}$, o estado de Sergipe, o menor estado brasileiro, corresponde a $0,26 \%$ do território nacional e 1,4\% da região nordeste. A capital, Aracaju, situa-se no litoral e apresenta uma área de $181,8 \mathrm{~km}^{2}$. Aracaju é localizada através das seguintes coordenadas: latitude $10^{\circ} 54^{\prime} 15^{\prime \prime} \mathrm{S}$, longitude $37^{\circ} 02^{\prime} 40^{\prime \prime}$ W e apresenta uma altitude de $3 \mathrm{~m}$ acima do nível do mar.

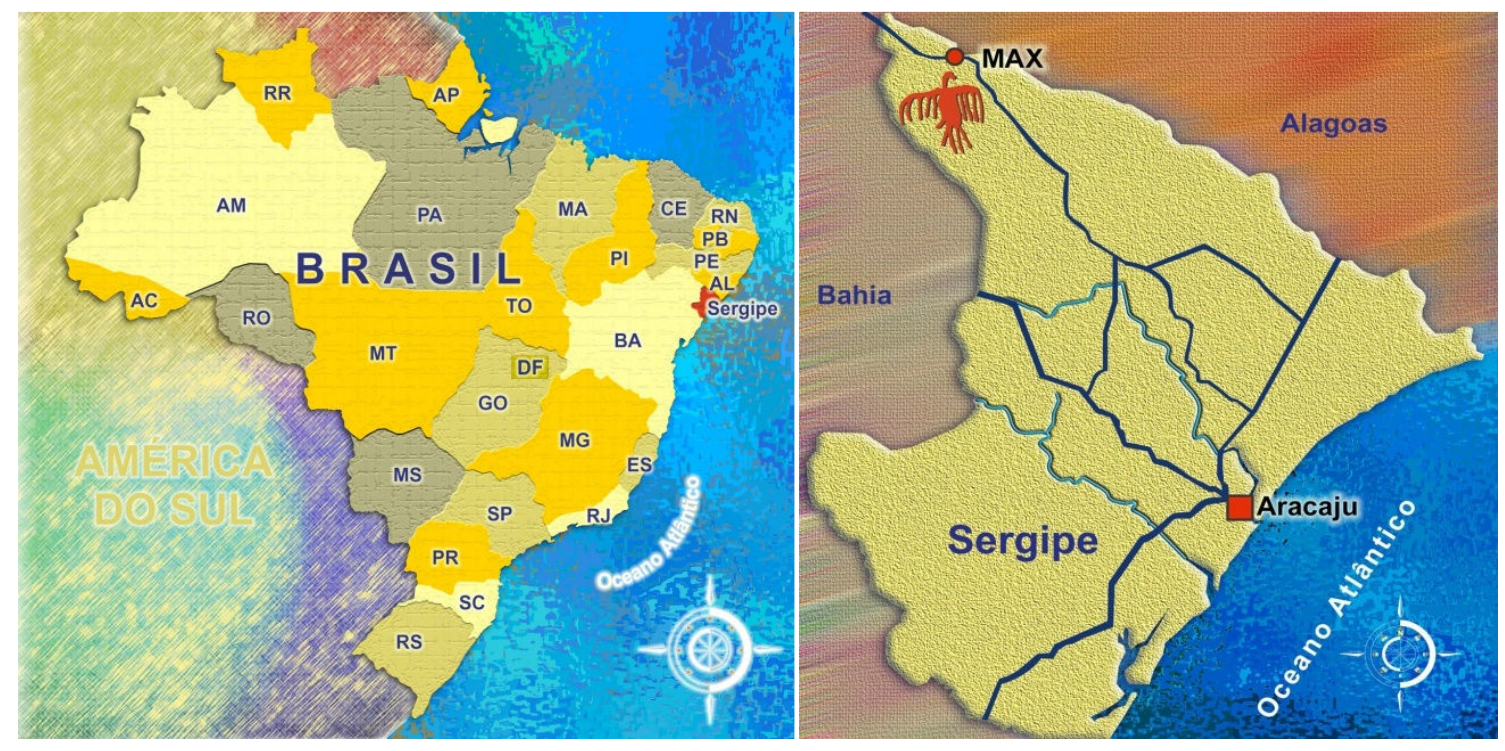

Figura 3.1 - Mapas de localização do universo de análise

Disponível em: http://www.max.org.br/imgs/mapas/

Acesso em 26 de novembro de 2007

Aracaju, a primeira cidade planejada do Brasil, foi fundada em 1855 para ser a nova capital do Estado. A cidade foi construída numa área cheia de mangues, lagoas e dunas. 
"Seu arruamento em xadrez, com vias largas e retas, e o destaque dado às praças centrais, onde foram construídos os prédios públicos, já mostravam uma nova concepção urbana. Aracaju foi símbolo de novos tempos e da busca de modernização e progresso que a economia açucareira impunha ao estado de Sergipe."(FRANÇA E CRUZ, 2007)

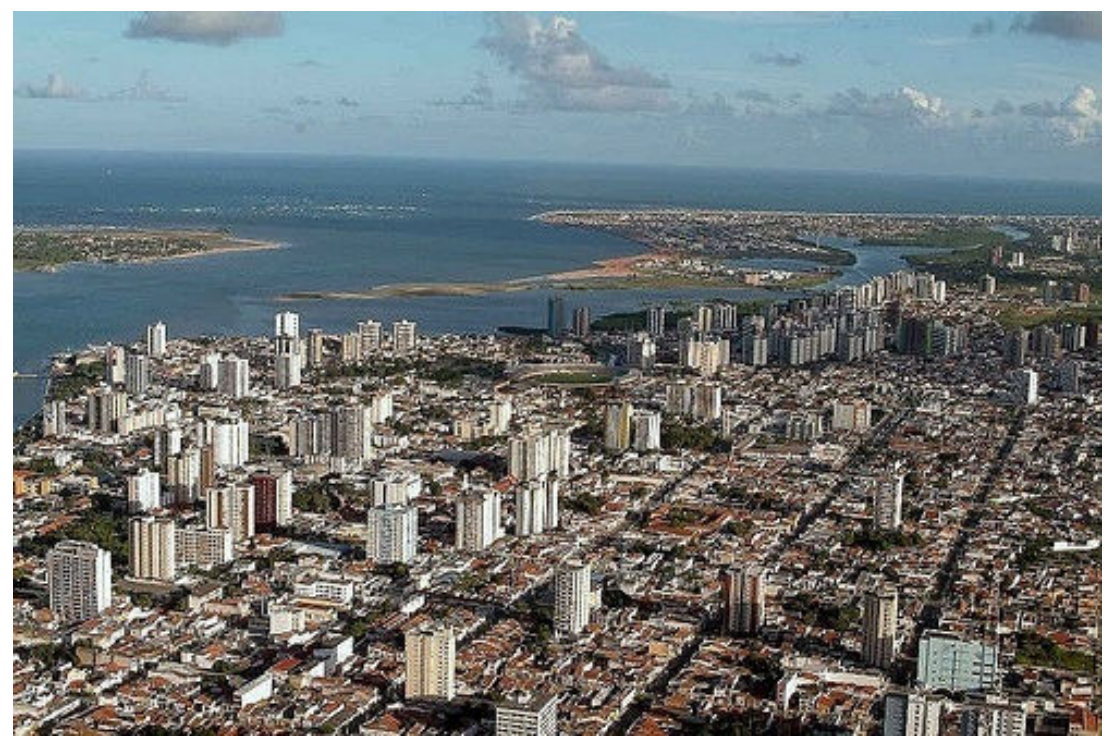

Figura 3.2 - Foto aérea da cidade de Aracaju-SE

Disponível em: http://www.flickr.com/photos/gilneyfontes/412659361/

\section{Acesso em 26 de novembro de 2007}

O Código de Obras e Edificações de Aracaju faz parte do Plano Diretor da cidade e foi instituído pelo Projeto de Lei Complementar $n^{\circ}$ 03/2000 tendo como objetivo básico "garantir níveis mínimos de qualidade nas edificações, através de exigência de padrões de segurança, conforto ambiental, adequação ao uso e durabilidade".

Tendo em vista a intenção de se estudar a importância na definição do partido arquitetônico de se considerar o aproveitamento da ventilação natural para se atingir o conforto térmico dos usuários, a leitura deste código ajudou a entender o nível de exigência desta questão, por parte das autoridades responsáveis pela aprovação dos projetos nesta cidade. 
O Capítulo VI, Seção 1 do código de obras, trata da iluminação e ventilação no projeto e transcrevendo os principais itens deste capítulo para esta pesquisa, pode-se dizer que as recomendações para se aproveitar a ventilação natural nas edificações são:

Art. 95 - Salvo os casos expressos, todo compartimento deve ter vãos de iluminação e ventilação para o exterior, satisfazendo as prescrições deste código.

§ $1^{\circ}$ - Os sanitários das edificações poderão ter ventilação por duto de tiragem e iluminação artificial, dispensando-se abertura para o exterior

$\boldsymbol{\S} 2^{\circ}$ - As áreas das aberturas destinadas à iluminação e ventilação em qualquer compartimento não poderão ser inferiores a $0,40 \mathrm{~m}^{2}$ (zero vírgula quarenta metros quadrados), excetuandose os sanitários dotados exclusivamente de vasos sanitários e lavatórios, caso em que a área poderá ser reduzida para até $0,20 m^{2}$ (zero vírgula vinte metros quadrados).

Art. 96 - Os vãos de iluminação dos compartimentos deverão atender as seguintes áreas mínimas:

I - Um sexto (1/6) da área do piso para compartimento de permanência prolongada, atendido um vão mínimo com $1,00 m^{2}$ (um metro quadrado);

II - Um décimo (1/10) da área do piso para compartimento de utilização transitória;

III - A iluminação e ventilação dos compartimentos de permanência especial ou controlada atenderão às suas especificidades funcionais.

Parágrafo único - Os compartimentos de utilização transitória especificados no Inciso II do Artigo 110 e depósitos condominiais, poderão ser iluminados e ventilados indiretamente através de outro compartimento.

Art. 97 - Quando o compartimento dispuser de uma só abertura de iluminação para o exterior, sua profundidade medida a partir desta abertura, não poderá exceder de 04 (quatro) vezes seu pé direito, para que seja considerada como dispositivo de iluminação e ventilação. 
Parágrafo único - Em caso de abertura voltada para varanda, alpendre ou compartimento similar, a profundidade referida no caput deste Artigo será medida a partir do bordo externo da varanda ou alpendre.

Art. 98 - Quando o vão se localizar sob qualquer tipo de cobertura, a porção de área externa ao mesmo será somada à área do compartimento que por ele ventila, para fins de seu dimensionamento, quando a distância ao exterior da edificação for superior a 3,00m (três metros)

Percebe-se por meio destes itens, que a ventilação natural é tratada de forma muito superficial, sem considerar questões mais específicas como, por exemplo, taxa de renovação do ar, conforto térmico, resfriamento do edifício, ação dos ventos, diferença de temperaturas, processo conjugado, localização das aberturas, direção e velocidade dos ventos predominantes, tipos de ambientes, tempo de permanência, tipologia das aberturas, coeficiente de pressão, entorno da edificação, dentre tantos outros requisitos que devem ser analisados em cada projeto em especial.

Fazendo uma comparação de exigências ou diretrizes para conforto térmico de projetos residenciais, a parte 3 do Projeto de Norma 02-135: Desempenho Térmico de Edificações da ABNT, intitulada de Zoneamento bioclimático brasileiro e diretrizes construtivas para habitações unifamiliares de interesse social, propôs uma subdivisão do território brasileiro em oito zonas com características climáticas semelhantes, definida como Zoneamento Bioclimático Brasileiro e representada pela figura a seguir: 


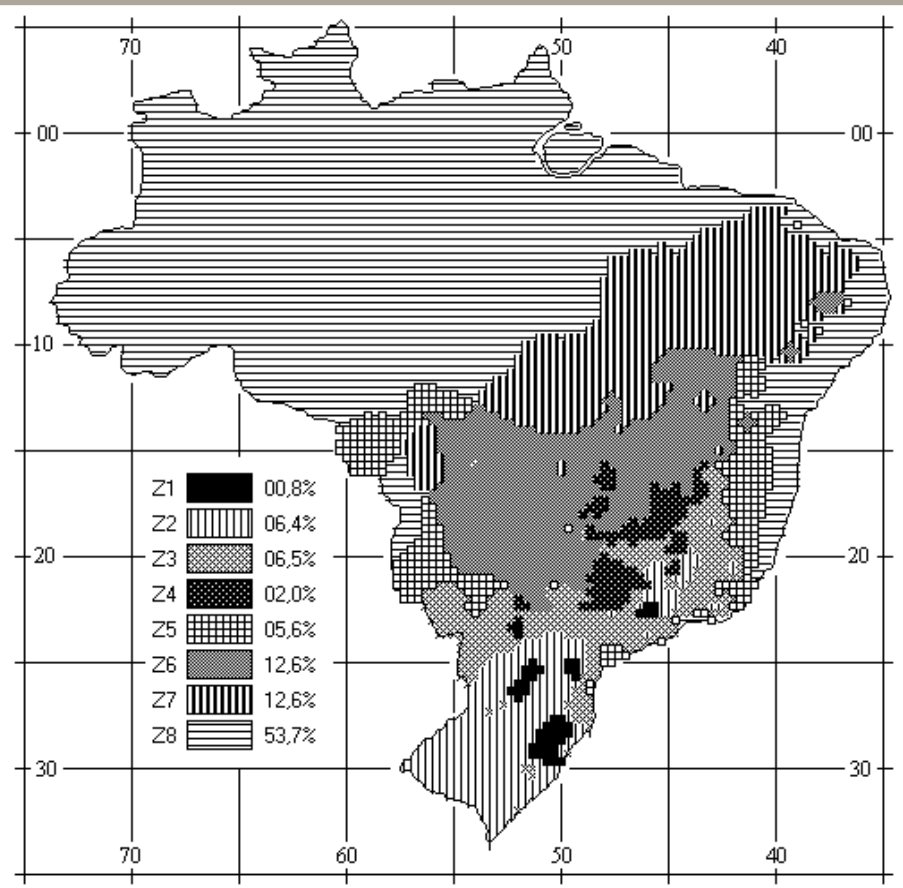

Figura 3.3 - Zonas bioclimáticas definidas pela Norma Desempenho Térmico de Edificações

(ABNT, 2003).

Para cada uma dessas zonas, foram elaboradas algumas diretrizes construtivas com o objetivo de aperfeiçoar o desempenho térmico das edificações unifamiliares de interesse social, por meio do estabelecimento das estratégias de condicionamento térmico passivo e consequente adequação climática da edificação.

Assim, foram considerados os seguintes parâmetros e condições de contorno pelo Projeto de Norma 02-135: Desempenho Térmico das Edificações (ABNT, 2003):

- Tamanho das aberturas para ventilação;

- Proteção das aberturas;

- Vedações externas (tipo de parede externa e tipo de cobertura);

- Estratégias de condicionamento térmico passivo. 
Como se pode observar pela figura 3.3, Aracaju encontra-se na Zona 8, dessa maneira, é possível resumir as recomendações de projeto para essa área por meio dos seguintes tópicos:

- Garantir grandes áreas para ventilação;

- Sombreamento das aberturas;

- Vedações externas (paredes e coberturas) devem ser leves e refletoras;

- Ventilação cruzada permanente com estratégia de condicionamento térmico passivo.

Segundo a mesma norma:

"A ventilação cruzada é obtida através da circulação de ar pelos ambientes da edificação. Isto significa que se o ambiente tem janelas em apenas uma fachada, a porta deveria ser mantida aberta para permitir a ventilação cruzada. Também se deve atentar para os ventos predominantes da região e para o entorno, pois este pode alterar significativamente a direção dos ventos." (ABNT, 2007)

De acordo com a Norma da ABNT (2004) - Desempenho de edifícios habitacionais de até cinco pavimentos - no dia típico de verão as condições térmicas dentro de uma edificação devem ser iguais ou melhores as condições encontradas no ambiente externo, à sombra. As temperaturas máximas diárias encontradas em ambientes de longa duração (sem a presença de fontes de calor) devem seguir os critérios estabelecidos na tabela 3.1: 
Tabela 3.1 - Critério de avaliação de desempenho térmico para condições de verão (ABNT, 2004)

\begin{tabular}{|c|c|}
\hline $\begin{array}{l}\text { NÍVEL DE } \\
\text { DESEMPENHO }\end{array}$ & $\begin{array}{l}\text { LIMITES DE TEMPERATURA DO AR NO } \\
\text { VERÃO }\end{array}$ \\
\hline MÍNIMO & $\begin{array}{l}\text { - Valor máximo diário da temperatura do ar } \\
\text { interior } \leq \text { valor máximo diário da temperatura do ar } \\
\text { exterior (zonas } 1 \text { a } 8 \text { ) }\end{array}$ \\
\hline $\begin{array}{l}\text { INTERMEDI } \\
\text { ÁRIO }\end{array}$ & $\begin{array}{l}\text { - Valor máximo diário da temperatura do ar } \\
\text { interior } \leq 29^{\circ} \mathrm{C} \text { (zonas } 1 \text { a } 7 \text { ) } \\
\text { - Valor máximo diário da temperatura do ar } \\
\text { interior } \leq 28^{\circ} \mathrm{C} \text { (zona } 8 \text { ) }\end{array}$ \\
\hline SUPERIOR & $\begin{array}{l}\text { - Valor máximo diário da temperatura do ar } \\
\text { interior } \leq 27^{\circ} \mathrm{C} \text { (zonas } 1 \text { a } 7 \text { ) } \\
\text { - Valor máximo diário da temperatura do ar } \\
\text { interior } \leq 26^{\circ} \mathrm{C} \text { (zona } 8 \text { ) }\end{array}$ \\
\hline
\end{tabular}

Ainda de acordo com a mesma norma, o método de avaliação deve ser a simulação computacional ou medição "in loco". E para cidades localizadas na zona 8, caso de Aracaju, o critério de avaliação de desempenho térmico para as condições de invernos não precisa ser verificado.

\subsection{Dados Climáticos}

"O Território sergipano é regulado pelas principais zonas de pressão do globo: Zona de Convergência Intertropical (ZCIT), que se constitui na linha de convergência de ventos; zona de altas pressões subtropicais do Atlântico e do Pacífico, bem individualizada em duas amplas células semifixas e permanentes sobre os oceanos, e zonas de baixas pressões subpolares."(FRANÇA E CRUZ, 2007)

O clima de Aracaju é influenciado pelos aspectos físicos, como baixa latitude, correntes marinhas ao longo do litoral, topografia e a continentalidade, todos relacionados aos sistemas de circulação atmosférica. A pequena amplitude térmica média ao longo do ano inferior a $5^{\circ} \mathrm{C}$ - é o dado mais significativo encontrado na região. 
A queda de temperatura está geralmente associada à nebulosidade, às chuvas e à intensidade dos ventos. Sendo o verão a estação seca e o inverno a chuvosa, os meses de julho e agosto apresentam as menores temperaturas.

Aracaju, por estar localizada no litoral, sofre influência dos ventos alísios e das brisas, que não são fortes, mas são constantes e bem sequenciadas, raramente mudando de direção. De acordo com França e Cruz (2007), "as brisas são mais intensas no início da tarde e quando a insolação aumenta. Desenvolvem-se melhor durante a estação seca. (...) A brisa litorânea raramente traz chuva, mas traz alívio ao intenso calor do verão."

O clima urbano de Aracaju também tem sofrido as consequências do aumento populacional e da densidade das edificações, tais como poluição, diminuição de áreas verdes, aquecimento e alagamentos em épocas de chuvas devido à pavimentação de ruas, bem como a crescente verticalização na Av. Beira Mar que interfere diretamente na circulação dos ventos, reduzindo o fluxo no sentido leste-oeste e criando turbulências próximas aos edifícios.

\subsubsection{Classificação Climática}

A classificação do clima de Köppen é uma divisão do clima, feita por Wilhelm Köppen em 1900. Ele classificou os climas em cinco tipos distintos baseado fundamentalmente na distribuição de valores de temperatura e precipitação durante as estações do ano, expondo um 
sistema matemático de classificação climática que durante décadas orientou as técnicas meteorológicas.

Segundo a classificação climática de Köppen, que é baseada em letras, a cidade de Aracaju apresenta a classificação AS. A primeira letra representa a característica geral do clima de uma região e a segunda representa as particularidades do regime de chuva. Assim temos:

- A: climas megatérmicos (temperatura média do mês mais frio superior a $\left.18^{\circ} \mathrm{C}\right)$;

- S: chuvas de inverno (mês menos chuvoso com precipitação inferior a $60 \mathrm{~mm})$.

Isso significa que, segundo a classificação de Köppen, Aracaju apresenta clima Tropical que é caracterizado por clima quente com chuvas de inverno.

Outro tipo de classificação climática bastante respeitada é a de Strahler que se baseia nas áreas da superfície terrestre, controladas ou dominadas pelas massas de ar. De acordo com essa classificação, Aracaju apresenta Clima Litorâneo Úmido, que abrange parte do território brasileiro próximo ao litoral. A massa de ar que exerce maior influência nesse clima é a tropical atlântica, fazendo com que as médias térmicas e índices pluviométricos sejam elevados e caracterizando a região como um clima quente e úmido.

O Climaticus 4.2 é um software elaborado pelo Laboratório de Conforto Ambiental e Eficiência Energética, sob orientação da Profa. Dra. 
Márcia P. Alucci da FAUUSP e conta com um banco de dados climáticos de 58 cidades brasileiras.

Neste software são tratadas as seguintes variáveis climáticas: temperatura, umidade relativa, radiação solar, precipitação, nebulosidade, insolação e iluminância (céu).

Algumas estratégias de projeto, como o diagnóstico climático (método de Givoni), a geometria ótima e eficiência energética complementam esses dados e colaboram para uma análise completa do clima de determinada cidade.

De uma forma geral, inicialmente são apresentados no software Climaticus 4.2, os dados climáticos de Aracaju em uma tabela, contendo as médias dos dados climáticos de 1961 a 1990.

\begin{tabular}{|c|c|c|c|c|c|c|c|c|c|c|c|c|c|}
\hline \multirow{2}{*}{$\begin{array}{l}\text { cidade } \\
\text { Aracajú }\end{array}$} & \multicolumn{2}{|l|}{ Lat (s) } & \multicolumn{3}{|c|}{ Long. (W.Grw.) } & \multicolumn{8}{|c|}{ Alt. (m) } \\
\hline & 10,6 & & 37 & & & 4,55 & & & & & & & \\
\hline & JAN & FEV & MAR & ABR & MAI & JUN & JUL & AGO & SET & OUT & NOV & DEZ & ANO \\
\hline Pressão Atmos (hPA) & 1012 & 1012 & 1012 & 1012 & 1013 & 1015 & 1016 & 1016 & 1016 & 1014 & 1012 & 1012 & 1013,4 \\
\hline Temperatura Média ("C) & 27 & 27,1 & 27,2 & 26,8 & 26 & 25,1 & 24,6 & 24,5 & 25,1 & 25,9 & 26,1 & 26,4 & 26 \\
\hline Temperatura Máxima $\left({ }^{\circ} \mathrm{C}\right)$ & 29,6 & 29 & 29,8 & 29,4 & 28,5 & 27,6 & 27 & 26,9 & 27,4 & 28,2 & 28,6 & 29,1 & 28,4 \\
\hline Temperatura Minima ( ${ }^{\circ} \mathrm{C}$ ) & 24,3 & 24,2 & 24,2 & 23,6 & 23,1 & 22,3 & 21,5 & 21,6 & 22,5 & 23,3 & 23,5 & 23,8 & 23,2 \\
\hline Temp Máx Absoluta ( ${ }^{\circ} \mathrm{C}$ ) & 34,2 & 33,5 & 35,2 & 32,1 & 32,3 & 32 & 30,4 & 29,3 & 29,4 & 32,5 & 34 & 33,8 & 35,2 \\
\hline Temp Min Absoluta $\left({ }^{\circ} \mathrm{C}\right)$ & 21,9 & 21,8 & 21,7 & 21,3 & 20,6 & 19,7 & 19,2 & 18,5 & 25,6 & 20,5 & 21,1 & 21,2 & 18,5 \\
\hline Precipitação Total (mm) & 58,4 & 77,7 & 149 & 242 & 273 & 216 & 207 & 101 & 95 & 72 & 46,9 & 57,3 & 1594,8 \\
\hline Precip-Máx em 24h (mm) & 155 & 147 & 135 & 157 & 172 & 154 & 377 & 50,4 & 91,2 & 112 & 97,4 & 129 & 376,5 \\
\hline Evaporação Total (mm) & 138 & 124 & 126 & 105 & 105 & 97,9 & 105 & 116 & 119 & 127 & 126 & 123 & 1411,8 \\
\hline Umidade Relativa (\%) & 78,1 & 76,6 & 78 & 79,6 & 77,6 & 77,3 & 78,2 & 78,2 & 78,1 & 78,7 & 78,8 & 79 & 78,2 \\
\hline Insolaçäo Total (horas) & 264 & 224 & 234 & 211 & 205 & 177 & 201 & 222 & 219 & 251 & 263 & 252 & 2721 \\
\hline Nebulosidade $(0-10)$ & 5,1 & 5,4 & 5,8 & 6,2 & 6,3 & 6,3 & 6,3 & 5,8 & 5,8 & 5,1 & 4,9 & 5,3 & 5,7 \\
\hline $\begin{array}{l}\text { Ministério da Agricultura e } \\
\text { Secretaria Nacional de Irri } \\
\text { Departamento Nacional de }\end{array}$ & Reform: & Agrá & 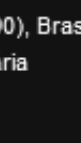 & & & & & & & & & & \\
\hline
\end{tabular}

Figura 3.4 - Tabela dos dados climáticos de Aracaju/SE

Fonte: Climaticus 4.2

A partir da figura 3.4, pode-se fazer algumas observações importantes sobre o clima local. O mês que apresenta a maior 
temperatura, tanto média quanto absoluta é Março, enquanto que Julho é o mês mais frio. A amplitude térmica anual é considerada baixa, não apresentando uma diferença muito significativa ao longo dos meses. (Gráfico 3.1)

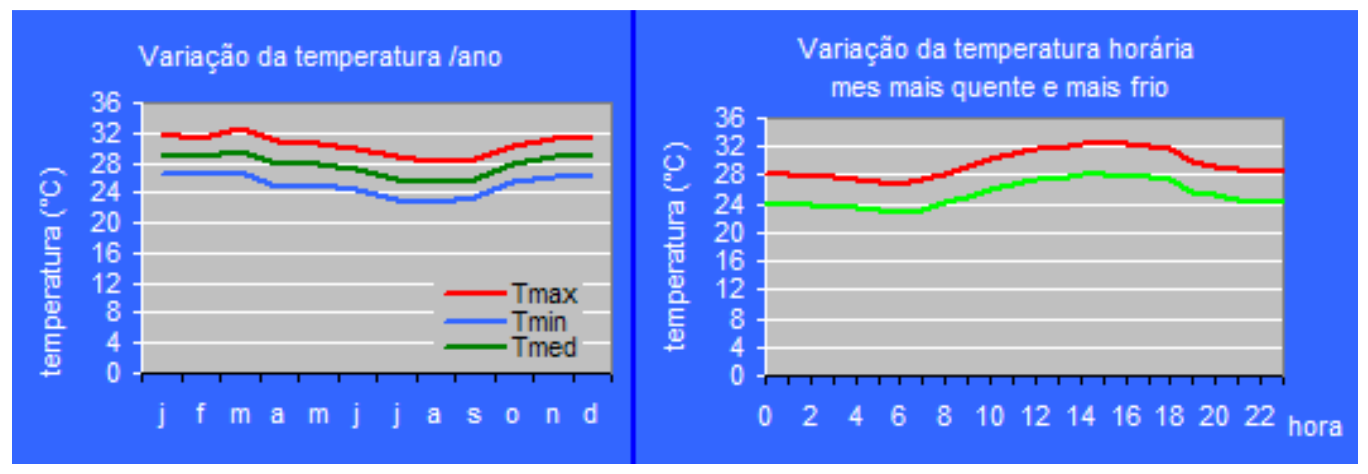

Gráfico 3.1 - Variação da temperatura anual e horária

Fonte: Climaticus 4.2

O período de chuva está associado aos meses de menor temperatura, assim define-se que o verão é mais seco e o inverno chuvoso, apresentando um índice de precipitação total maior nos meses de abril a julho, como pode ser notado também nos gráficos 3.2 e 3.3.

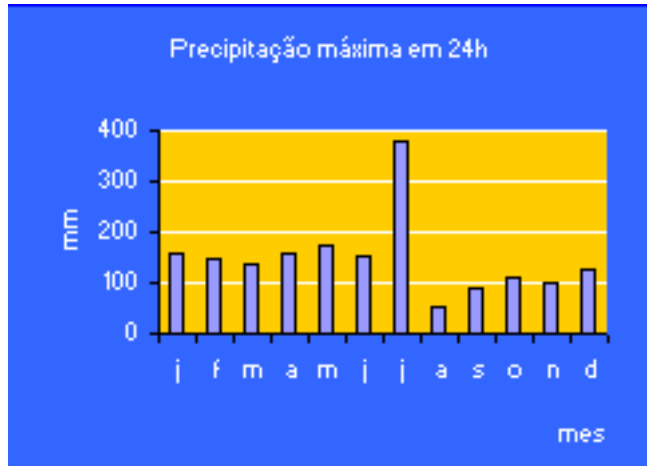

Gráfico 3.2 - Precipitação máxima em 24h

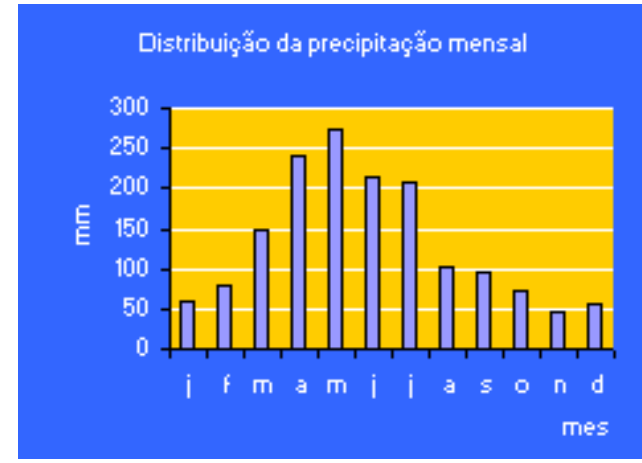

Gráfico 3.3 - Precipitação mensal Fonte: Climaticus 4.2

Fonte: Climaticus 4.2

Em relação à umidade relativa do ar, por meio dos dados apresentados pelo Climaticus 4.2, percebe-se que a variação da média anual é mínima, assim como não há uma diferença representativa na 
variação horária da umidade relativa entre os meses mais frios e os mais quentes do ano, como pode ser visto no gráfico 3.4.

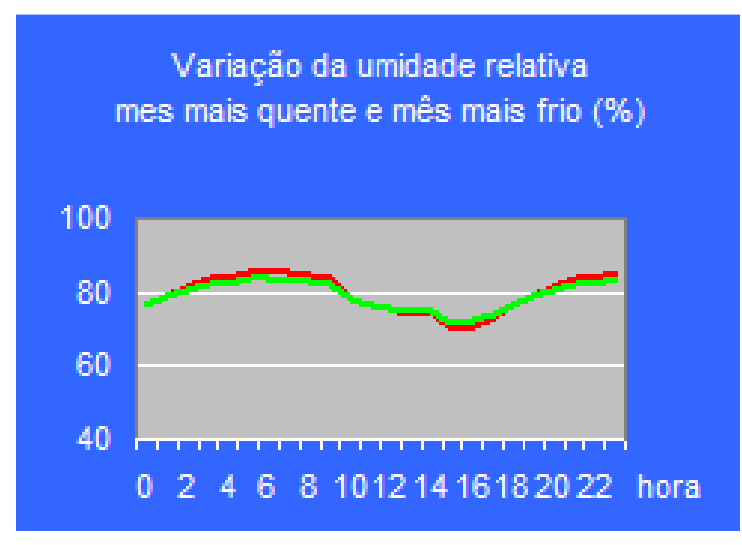

Gráfico 3.4 - Variação da umidade relativa

Fonte: Climaticus 4.2

Em seguida, o software apresenta a carta bioclimática e o diagnóstico climático feito através do Método de Givoni. (Figura 3.5).

"[...] foi em 1969 que Givoni concebeu uma carta bioclimática para edifícios que corrigia algumas limitações do diagrama idealizado por Olgyay. A carta de Givoni se baseia em temperaturas internas do edifício, propondo estratégias construtivas para adequação da arquitetura ao clima, enquanto que Olgyay aplicava seu diagrama estritamente para as condições externas."(LAMBERTS E PEREIRA, 2004)

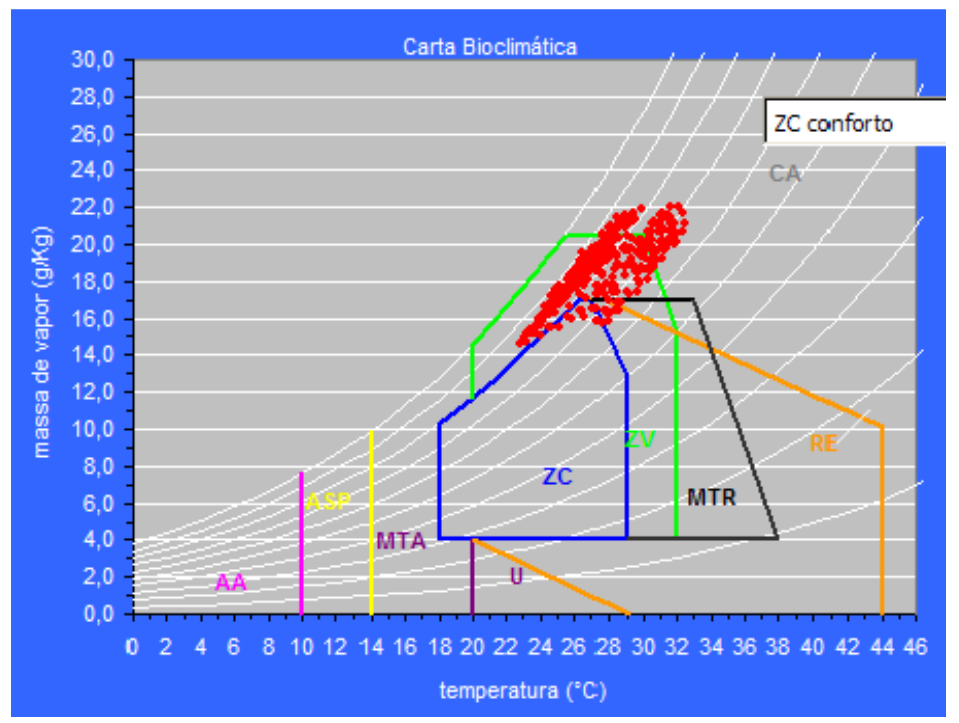

Figura 3.5 - Carta bioclimática para Aracaju-SE

Fonte: Climaticus 4.2 
O diagnóstico climático define, então, que em 5,2\% do tempo o clima da cidade de Aracaju está em Conforto; em 74\% a ventilação natural pode melhorar a sensação térmica; e em $21,2 \%$ das horas do ano, nenhum sistema passivo poderá proporcionar conforto térmico, sendo necessário o condicionamento artificial do ar.

Para que se possa analisar esse comportamento climático ao longo das horas do ano, a figura 3.6, extraída do software Climaticus 4.2, mostra-se mais eficiente:

\begin{tabular}{|c|c|c|c|c|c|c|c|c|c|c|c|c|}
\hline \multicolumn{5}{|c|}{ Diagnóstico Climático } & \multicolumn{8}{|c|}{ Método Givoni } \\
\hline \multicolumn{8}{|c|}{ Balanço Térmico } & \multicolumn{5}{|c|}{ Aracajú } \\
\hline hora & jan & fev & mar & $a b r$ & mai & jun & jul & ago & set & out & nov & dez \\
\hline 0 & $\mathrm{zV}$ & $\mathrm{zV}$ & $\mathrm{CA}$ & $2 \mathrm{~V}$ & $2 \mathrm{~V}$ & $\mathrm{zV}$ & $\mathrm{zV}$ & $\mathrm{zV}$ & $\mathrm{zV}$ & $\mathrm{zV}$ & $2 \mathrm{~V}$ & $\mathrm{zv}$ \\
\hline 2 & $2 \mathrm{~V}$ & $2 \mathrm{~V}$ & $2 \mathrm{~V}$ & $2 \mathrm{~V}$ & $2 \mathrm{~V}$ & $2 \mathrm{~V}$ & $2 \mathrm{~V}$ & $2 \mathrm{~V}$ & $2 \mathrm{~V}$ & $2 \mathrm{~V}$ & $2 \mathrm{~V}$ & $2 \mathrm{~V}$ \\
\hline 4 & $2 v$ & $2 v$ & $2 \mathrm{v}$ & $2 \mathrm{v}$ & $2 v$ & $2 v$ & $2 v$ & $2 v$ & $2 v$ & $2 \mathrm{~V}$ & $2 v$ & $2 \mathrm{v}$ \\
\hline 6 & $2 \mathrm{v}$ & $2 v$ & $2 \mathrm{v}$ & $2 v$ & $2 v$ & $z v$ & $2 \mathrm{v}$ & $2 \mathrm{v}$ & $2 \mathrm{v}$ & $2 v$ & $2 v$ & $2 v$ \\
\hline 8 & $2 \mathrm{v}$ & zv & zv & zv & $2 \mathrm{v}$ & $2 v$ & $2 c$ & $2 \mathrm{c}$ & $2 c$ & $2 \mathrm{~V}$ & $2 \mathrm{v}$ & $z \mathrm{v}$ \\
\hline 10 & $2 \mathrm{v}$ & zv & $\mathrm{CA}$ & zv & $\mathrm{zv}$ & $z v$ & $\mathrm{zc}$ & $2 \mathrm{c}$ & $2 \mathrm{c}$ & $2 \mathrm{v}$ & zv & $z v$ \\
\hline 12 & $\mathrm{CA}$ & $\mathrm{CA}$ & $\mathrm{CA}$ & $2 \mathrm{~V}$ & $2 \mathrm{~V}$ & $z v$ & ZVIMTRIRE & $2 \mathrm{C}=$ & ZVIMTRIRE & $2 v$ & $\mathrm{CA}$ & $\mathrm{CA}$ \\
\hline 14 & $\mathrm{CA}$ & $\mathrm{CA}$ & $\mathrm{CA}$ & $2 v$ & $2 \mathrm{v}$ & $z v$ & ZVIMTRIRE & ZVIMTRIREZ? & ZVIMTRIRE & $2 \mathrm{v}$ & $\mathrm{CA}$ & $\mathrm{CA}$ \\
\hline 16 & $\mathrm{CA}$ & $\mathrm{CA}$ & $\mathrm{CA}$ & $\mathrm{CA}$ & $2 \mathrm{v}$ & $\mathrm{zv}$ & $\mathrm{zV}$ & ZVIMTRIRE & zv & $2 \mathrm{v}$ & $\mathrm{CA}$ & $\mathrm{CA}$ \\
\hline 18 & $\mathrm{CA}$ & $\mathrm{CA}$ & $\mathrm{CA}$ & $\mathrm{CA}$ & $2 \mathrm{~V}$ & $2 \mathrm{v}$ & $2 \mathrm{~V}$ & ZVIMTRIRE & $2 \mathrm{~V}$ & $2 \mathrm{~V}$ & $\mathrm{CA}$ & $\mathrm{CA}$ \\
\hline 20 & $\mathrm{CA}$ & $2 v$ & $\mathrm{CA}$ & $2 v$ & $z \mathrm{v}$ & $2 v$ & $z v$ & zv & $2 v$ & $2 \mathrm{~V}$ & $\mathrm{CA}$ & $\mathrm{CA}$ \\
\hline 22 & $\mathrm{CA}$ & $2 \mathrm{~V}$ & $\mathrm{CA}$ & $z V$ & $2 \mathrm{~V}$ & $2 \mathrm{v}$ & $z V$ & $z v$ & $\mathrm{zV}$ & $2 \mathrm{v}$ & $2 \mathrm{~V}$ & $\mathrm{CA}$ \\
\hline
\end{tabular}

Figura 3.6 - Diagnóstico climático pelo método de Givoni Fonte: Climaticus 4.2

Assim é possível perceber que, com a estratégia do aproveitamento da ventilação natural, é possível se obter conforto térmico durante todo o ano em Aracaju. Apenas o período da tarde nos meses de verão, quando o clima fica mais severo, seria necessário o condicionamento artificial do ar. Porém vale salientar que esse método não leva em consideração os fatores de aclimatação da população local nem os aspectos culturais, o que pode interferir nesse diagnóstico. Além disso, os dados obtidos são do 
período de 1961 a 1990, que pode ter sofrido alguma alteração significativa ao longo dos últimos anos.

Por este motivo, sentiu-se a necessidade de uma análise climática mais atual e que inserisse também um estudo da velocidade e direção dos ventos locais, já que não existe nenhum dado de vento para a cidade de Aracaju nas análises do Climaticus, por exemplo. Dessa maneira, foi necessária um busca de arquivos climáticos para a realização de uma nova análise que complementasse todas as já expostas até aqui e sendo a ventilação natural a principal estratégia de projeto para se obter o conforto térmico nesta cidade, essa variável não poderia deixar de ser verificada e analisada cautelosamente.

\subsubsection{Coleta de dados climáticos}

Para análise dos dados climáticos da cidade de Aracaju, foi realizada uma pesquisa extensa em busca de arquivos climáticos disponíveis para uma caracterização climática atual.

Devido à dificuldade de se encontrar esses arquivos e devido à análise que se pretendia fazer, foi necessário buscar dados horários de parâmetros climáticos essenciais por meio de instituições responsáveis pelas medições climáticas na cidade de Aracaju para em seguida organizálos e analisá-los com o objetivo de alimentar todos os estudos e simulações de desempenho térmico passivo das edificações. Para isso, seria importante que os dados apresentados estivessem os mais próximos possíveis da realidade local atual. 
Alguns critérios foram estabelecidos para a escolha da base de dados, entre eles: a localização da estação meteorológica, a periodicidade dos registros, proporção de falhas, a confiabilidade do órgão responsável pela estação e o período medido.

Assim, os dados fornecidos pela Estação Meteorológica de Observação de Superfície Automática A-409 do Instituto Nacional de Meteorologia - INMET, e localizada em Aracaju-SE (Lat. $10^{\circ} 57^{\prime} \mathrm{S}$, Long. $37^{\circ} 03^{\prime} \mathrm{W}$ e Alt. $4.72 \mathrm{~m}$ ) foram os adotados nesta pesquisa por melhor atender aos critérios estabelecidos.

Segundo informações fornecidas pelo site do INMET,

"uma estação meteorológica de superfície automática é composta de uma unidade de memória central, ligada a vários sensores dos parâmetros meteorológicos (pressão atmosférica, temperatura e umidade relativa do ar, precipitação, radiação solar, direção e velocidade do vento, etc), que integra os valores observados minuto a minuto e os registra automaticamente a cada hora". ${ }^{5}$

Foram fornecidos, pelo INMET, os dados horários de fevereiro de 2003 à dezembro de 2006 da:

- Precipitação (mm)

- Pressão atmosférica ao nível da estação (mb)

- Temperatura do ar - bulbo seco $\left({ }^{\circ} \mathrm{C}\right)$

- Umidade relativa do ar (\%)

- Velocidade do vento $(\mathrm{m} / \mathrm{s})$

- Direção do vento (graus) 
Além desses dados, também foram fornecidos os dados da Estação Convencional de janeiro de 1997 à dezembro de 2006, porém tais dados foram descartados nesse estudo por apresentar registros de apenas 03 medições diárias (0:00, 12:00 e 18:00hs).

Toda a base escolhida foi analisada ano a ano para a verificação de dados atípicos que pudessem interferir no resultado final. Porém, por apresentar uma regularidade em todas as medições, nenhum dado foi descartado, mas como havia algumas falhas, foi necessário fazer a interpolação dos dados para a construção do ano de referência para projeto com as 8760 horas para cada parâmetro.

O tratamento dos dados climáticos fornece, entre outras variáveis, os valores da temperatura média, mínima e máxima de cada período do ano e assim, proporciona ao arquiteto os dados necessários para o diagnóstico dos períodos de prováveis desconfortos térmicos, com a finalidade de uma intervenção por meio de projetos arquitetônicos adequados ao clima local. Porém, é importante atentar ao fato de que a sensação de conforto térmico não depende apenas da temperatura do ar, mas está relacionado a um conjunto de variáveis climáticas, como o vento e a umidade relativa do ar.

Nota-se por meio do gráfico 3.5 que, para a cidade de Aracaju, em relação à média mensal da temperatura do ar, houve uma regularidade ao longo dos anos de 2003 a 2006, o que permite se obter uma análise média mais segura dos dados disponíveis. 


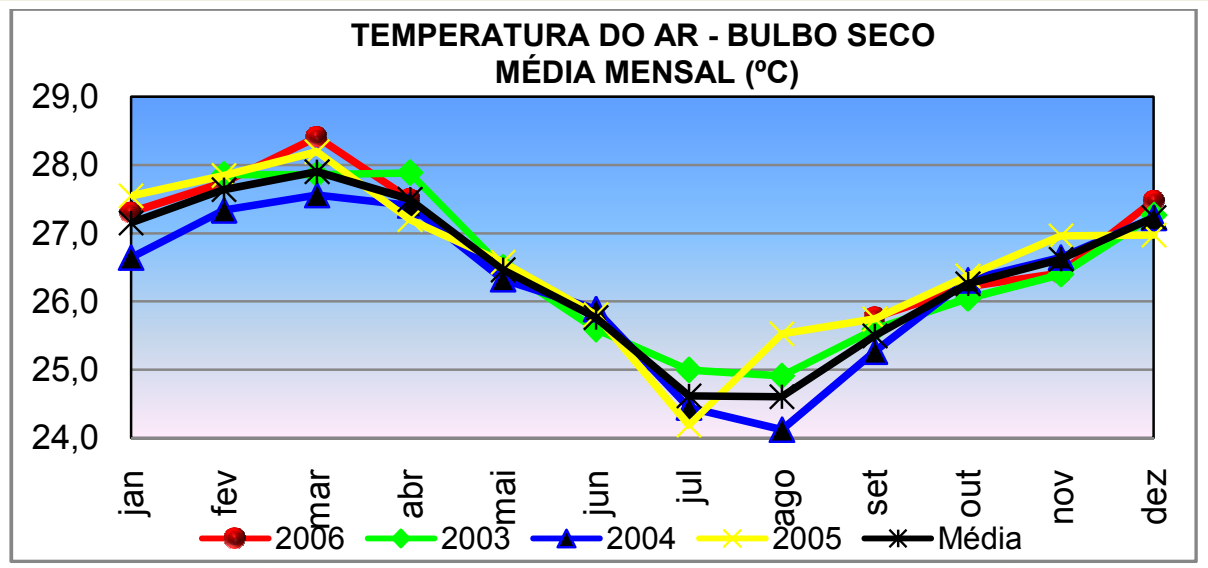

Gráfico 3.5 - Média mensal da Temperatura do ar de bulbo seco.

Mas antes de chegar ao resultado apresentado no gráfico anterior, foram calculadas as médias horárias dos registros obtidos e em seguida as médias diárias para cada um dos meses do ano até se chegar a uma média mensal. Dessa maneira, pode-se comparar melhor o comportamento das médias da temperatura mensal em cada um dos anos e sua relação com a média geral.

Segundo a classificação climática de Köppen e de Strahler, Aracaju apresenta clima quente e úmido. Em locais com alta umidade a transmissão da radiação solar é reduzida porque o vapor de água e as nuvens absorvem parte dessa radiação e a redistribuem na atmosfera refletindo uma parte de volta ao espaço.

Lamberts, et al (2004) afirma que é necessário entender que em locais com alta umidade relativa existe uma maior dificuldade em evaporar o suor, o que aumenta a sensação de desconforto térmico da população. Por este motivo é importante que o arquiteto observe a relação conjunta entre a temperatura e a umidade local ao longo do ano 
para tentar amenizar o efeito desagradável que esse conjunto pode proporcionar aliado a uma arquitetura não apropriada ao clima.

Em relação às medições aqui analisadas, entre os meses de abril e setembro de 2006, por algum motivo não esclarecido pelo INMET, infelizmente não houve registro dos dados climáticos na cidade de Aracaju.

Para se obter os resultados relativos a umidade relativa que aqui serão apresentados, os cálculos foram feitos com o valor da umidade absoluta inicialmente. As primeiras médias foram feitas com os valores diários de cada ano. Sendo assim foram encontradas as 8760 médias diárias da umidade do ar. Em seguida realizou-se as médias mensais, com valores das máximas absolutas, mínimas absolutas, médias das máximas e mínimas e médias gerais. Assim, pode-se analisar separadamente cada resultado encontrado para se entender melhor o comportamento geral como o apresentado no gráfico 3.6. Depois de achado todos esses resultados, os valores da umidade absoluta foram transformados em umidade relativa, como é mais facilmente interpretado.

Apesar da diferença apresentada no ano de 2006, a média da umidade relativa do ar ao longo do ano apresenta-se com uma variação pouco significativa, confirmando os dados fornecidos pelo software Climaticus 4.2. Levando-se em conta as médias dos quatro anos apresentadas no gráfico 3.6, a média da umidade relativa do ar variou entre 70 e $80 \%$, nos mostrando que em uma cidade onde o potencial do 
vento é bastante significativo, é possível neutralizar o efeito negativo da umidade relativa do ar aproveitando-se a ventilação natural para atingir índices de conforto térmico tanto nos espaços urbanos, quanto nas edificações, desde que haja o mínimo de preocupação no momento de projetar os espaços.

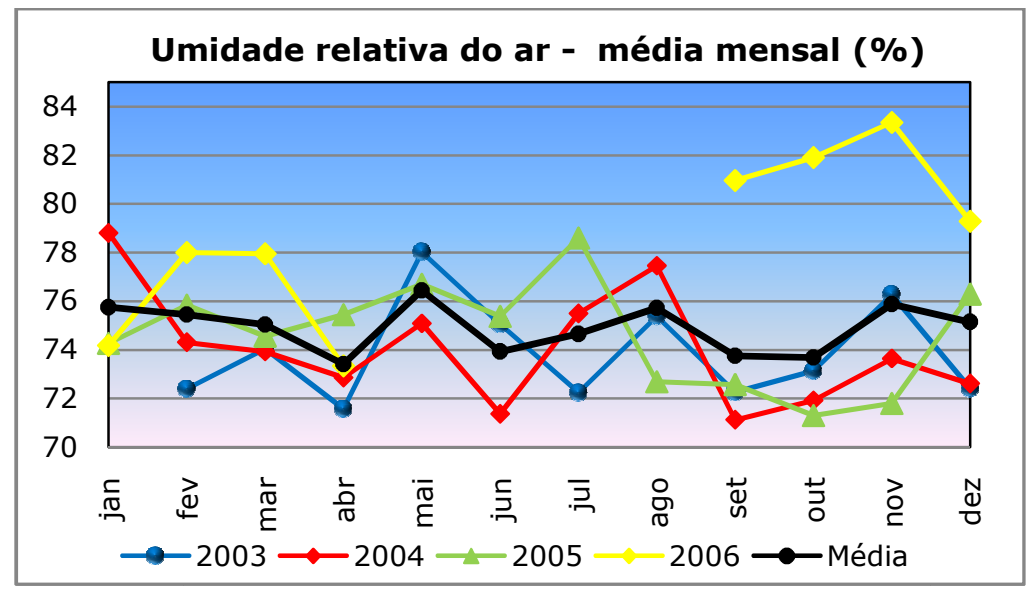

Gráfico 3.6 - Média mensal da umidade relativa do ar

Ter conhecimento da direção dos ventos de uma determinada região é de extrema importância no momento de decidir a correta forma e orientação de um projeto arquitetônico que tem como principal estratégia o aproveitamento da ventilação natural como forma de amenização climática. Dessa maneira, é mais fácil prever o comportamento do fluxo de ar dentro da edificação e é possível simular diferentes soluções em busca da mais apropriada para cada caso. Assim, o projetista ainda tem a possibilidade de projetar espaços mais fluidos, promover ventilação vertical, além de criar elementos que direcionam o fluxo de ar para o interior da edificação.

No caso do estudo da direção dos ventos para a cidade de Aracaju, tomaram-se como base as medições realizadas nos anos de 2003 a 2006, 
onde foi conseguido um total de 28.754 medidas. A partir desses dados, foi feito um cálculo para determinar a freqüência de cada uma dessas direções e dessa maneira, poder determinar qual a direção predominante da direção dos ventos em cada um dos horários de cada ano.

Analisando o gráfico 3.7, é fácil perceber que a direção do vento mais freqüente para esta cidade é o vento Leste, representado pelo ângulo de $90^{\circ}$, em todos os quatro anos de medição.

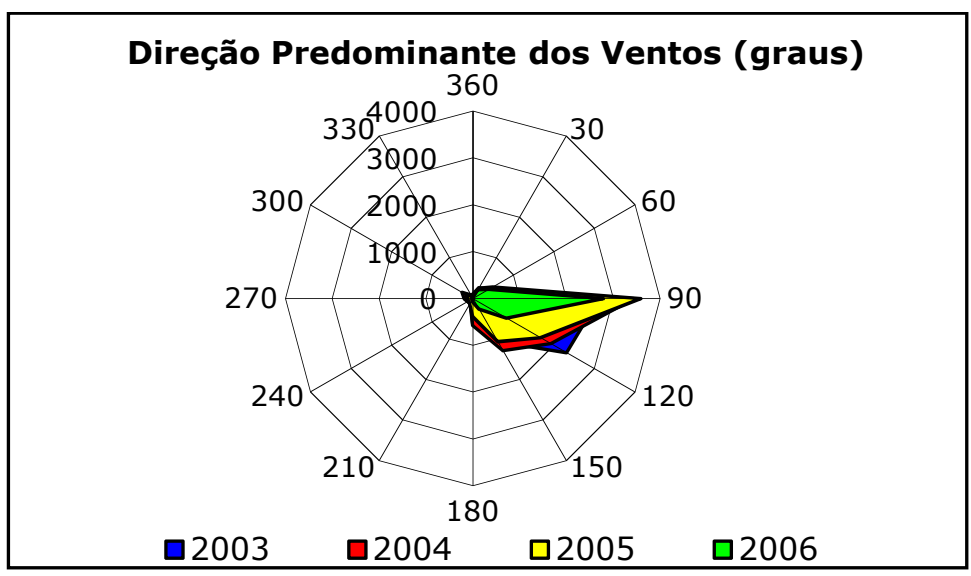

Gráfico 3.7- Direção Predominante dos ventos

Outro fator climático de grande importância para o diagnóstico climático de uma região é a velocidade dos ventos. Apesar de ser relativamente fácil obter o registro horário em determinada região, isso não significa que em qualquer local esse registro será válido, visto que inúmeros fatores podem interferir na velocidade dos ventos num determinado local, como a rugosidade, topografia, construções no entorno, a geometria do edifício, etc.

Apesar disso, sempre é possível se analisar a direção e velocidade dos ventos no local onde se pretende construir para um diagnóstico mais preciso, evitando dessa maneira equívocos que possam prejudicar o 
conforto térmico da edificação, devido a alguma característica particular de determinado espaço.

No caso desta dissertação, saber o comportamento geral do vento em uma determinada região, já é extremamente importante e permite que sejam realizados estudos e/ou simulações que contribuirão de maneira significativa na busca de uma arquitetura adaptada ao clima local, que consuma menos energia e proporcione o conforto ambiental aos usuários.

Como já descrito anteriormente, foram obtidos registros horários dos dados climáticos, incluindo também a velocidade do vento. Primeiro os dados foram organizados de forma a identificar qual a velocidade referente à primeira e à segunda predominância dos ventos. Feito isso, a média horária para os anos de 2003 a 2006 foi calculada para em seguida ser possível obter a velocidade média diária e assim serem elaborados os gráficos mensais e posteriores análises. Por último, a média mensal da velocidade dos ventos também foi calculada e o gráfico 3.8 pôde ser elaborado facilitando assim uma análise geral anual da velocidade dos ventos na cidade de Aracaju.

Percebe-se pelo gráfico 3.8 que os meses de setembro a março apresentam as maiores médias de velocidade dos ventos e que os meses de maio a agosto as menores velocidades. Numa primeira análise, juntando dados obtidos até aqui, já se pode concluir que os meses mais 
frios e chuvosos do ano apresentam menores velocidades do vento enquanto que os mais quentes apresentam as maiores.

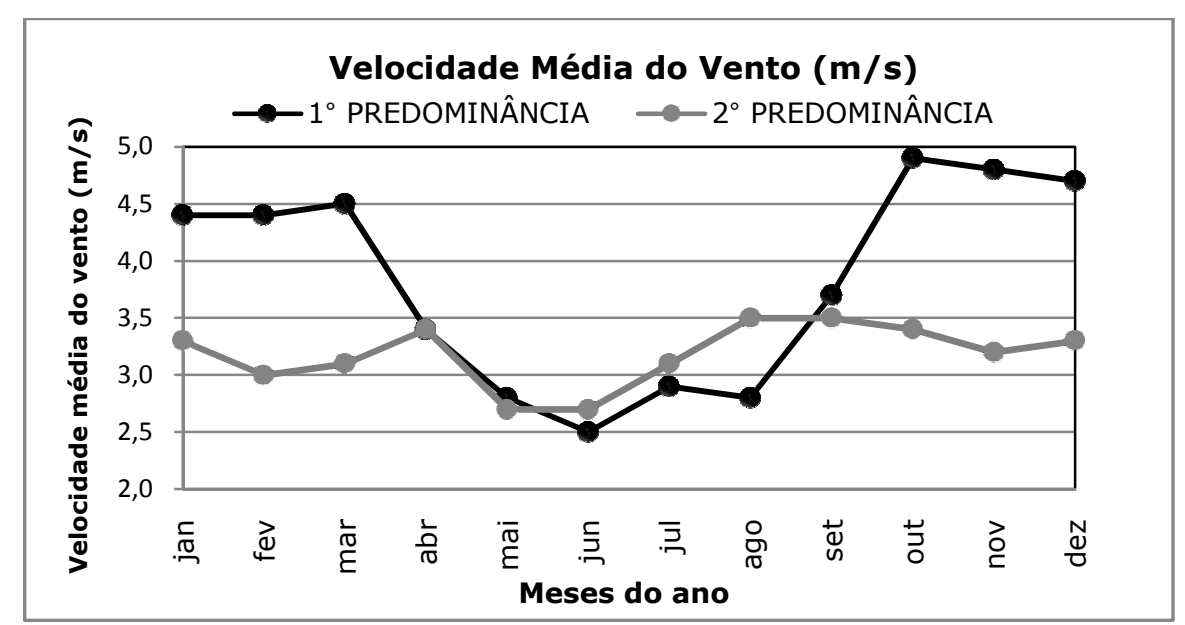

Gráfico 3.8 - Velocidade média mensal do vento

Esses dados são bastante favoráveis uma vez que na medida em que a temperatura do ar é mais elevada, precisamos de uma velocidade do vento maior para remoção da carga térmica no ambiente e amenização do desconforto causado pela alta umidade do ar e elevada temperatura. E, ao mesmo tempo, a velocidade do vento elevada em épocas chuvosas é prejudicial por não permitir a abertura de janelas nas edificações, o que poderia contribuir para o desconforto dos usuários.

\subsubsection{Ano climático de referência}

Com a finalidade de alimentar simulações com dados climáticos atuais da cidade de Aracaju, foi montado um ano climático de referência com as médias horárias da temperatura do ar, umidade relativa, direção e velocidade dos ventos para cada uma das 8760 horas dos anos de 2003 a 2006. 


\section{- Temperatura do ar}

Analisando o gráfico 3.9 é possível afirmar que a base de dados dos registros horários de temperaturas do ar ao longo dos últimos quatro anos (2003 a 2006), apresentou-se harmonicamente, significando que nesse período não houve nenhum ano atípico e validando as informações obtidas com as médias apresentadas aqui.

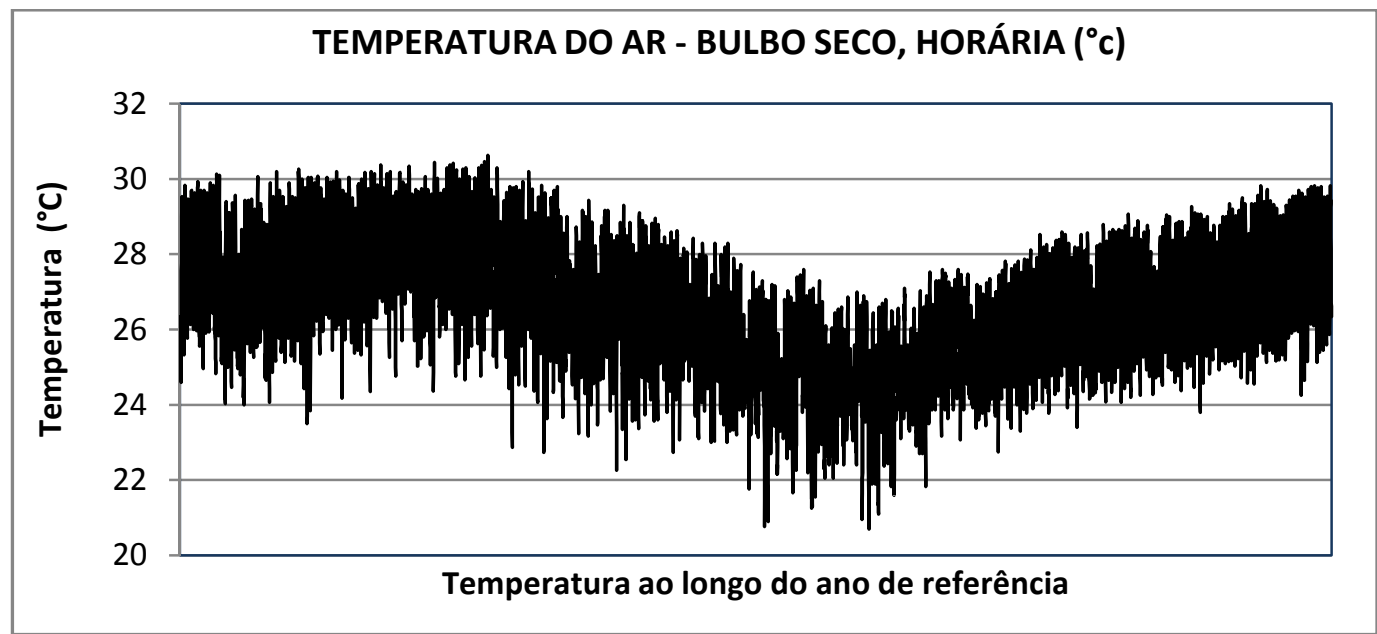

Gráfico 3.9 - Temperatura do ar ao longo do ano de referência $\left({ }^{\circ} \mathrm{C}\right)$

Após uma análise minuciosa dos dados de temperatura do ar durante todas as horas do dia, por quatro anos seguidos, chegamos a uma média anual de temperatura do ar de $26,5^{\circ} \mathrm{C}$. Porém, como se trata de uma média esse número poderia não ser muito representativo, então na tabela 3.2 se mostra um resumo de todas as médias calculadas referentes à temperatura do ar para cada mês do ano e suas variações para uma análise mais completa.

As informações inseridas na tabela 3.2 foram transportadas para 0 gráfico 3.10, possibilitando outra forma de visualizar e comparar todas as médias calculadas. 
Tabela 3.2 - Médias da temperatura do ar (2003 a 2006)

\begin{tabular}{c|c|c|c|c|c}
\hline & $\begin{array}{c}\text { TEMP. MÁX. } \\
\left.\text { ABSOLUTA ( }{ }^{\circ} \mathbf{C}\right)\end{array}$ & $\begin{array}{c}\text { TEMP. MÍN. } \\
\left.\text { ABSOLUTA ( }{ }^{\circ} \mathbf{C}\right)\end{array}$ & $\begin{array}{c}\text { MÉDIA DAS TEMP. } \\
\left.\text { MÁXIMAS ( }{ }^{\circ} \mathbf{C}\right)\end{array}$ & $\begin{array}{c}\text { MÉDIA DAS TEMP. } \\
\left.\text { MÍNIMAS ( }{ }^{\circ} \mathbf{C}\right)\end{array}$ & $\begin{array}{c}\text { TEMP. MÉDIA } \\
\text { GERAL }\left({ }^{\circ} \mathbf{C}\right)\end{array}$ \\
\hline JAN & 31,7 & 21,9 & 30,4 & 23,9 & 27,2 \\
\hline FEV & 31,1 & 22,2 & 30,5 & 24,0 & 27,6 \\
\hline MAR & 31,7 & 22,8 & 31,0 & 24,2 & 27,9 \\
\hline ABR & 31,8 & 21,7 & 30,7 & 23,5 & 27,5 \\
\hline MAI & 30,7 & 20,7 & 29,5 & 22,5 & 26,5 \\
\hline JUN & 29,4 & 20,6 & 28,6 & 22,2 & 25,8 \\
\hline JUL & 28,1 & 19,0 & 27,5 & 21,3 & 24,6 \\
\hline AGO & 28,0 & 18,8 & 27,3 & 21,5 & 24,6 \\
\hline SET & 29,2 & 20,0 & 28,0 & 22,1 & 25,5 \\
\hline OUT & 29,7 & 21,7 & 29,1 & 22,9 & 26,3 \\
\hline NOV & 30,5 & 22,1 & 29,6 & 23,6 & 26,6 \\
\hline DEZ & 34,4 & 22,5 & 30,3 & 24,2 & 27,2 \\
\hline
\end{tabular}

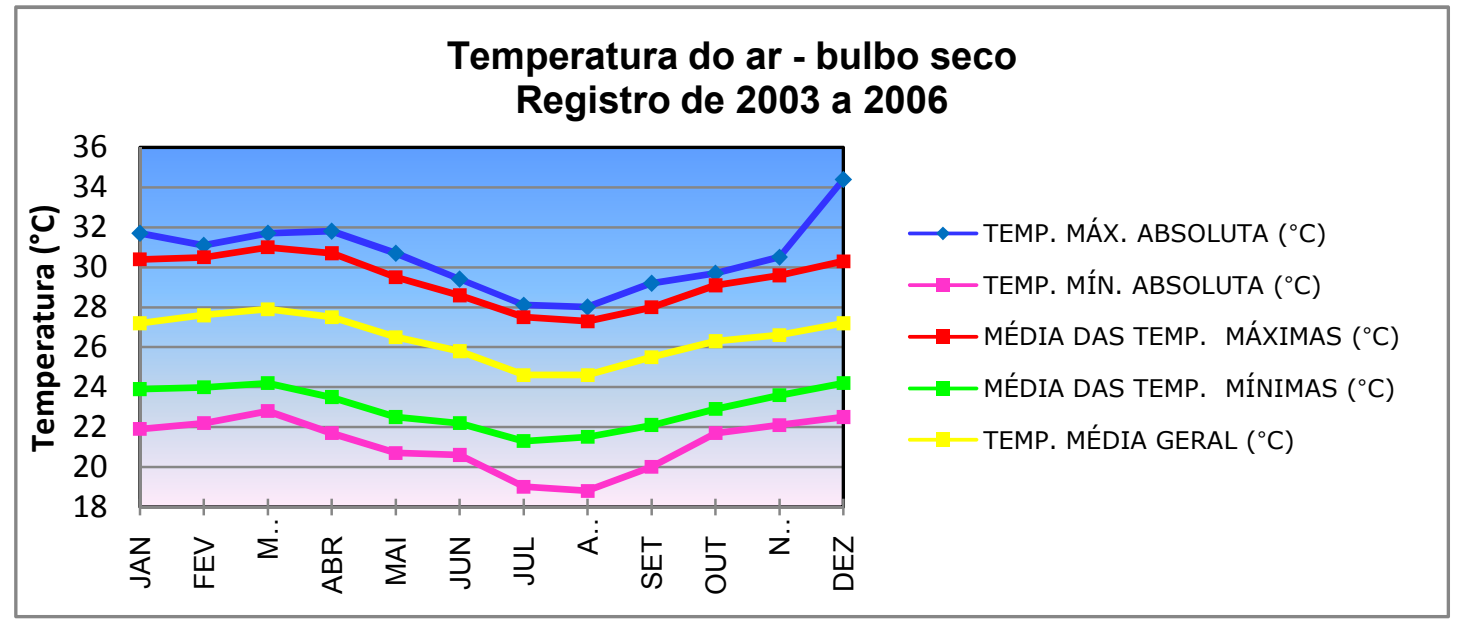

Gráfico 3.10 - Médias da temperatura do ar (2003 a 2006)

A seguir estão representadas as temperaturas máximas absolutas e as temperaturas mínimas absolutas encontradas ao longo dos quatro anos de registro, para cada hora do dia. Vale salientar que os valores do gráfico são os extremos encontrados em quatro anos de registros, e são relacionadas apenas às horas do dia, ignorando o ano e o mês referente. Dessa maneira, as informações contidas no gráfico 3.11 são meramente para informar quais as temperaturas máximas e mínimas registradas em determinado horário no período estudado e serve para complementar as 
informações fornecidas por meio dos cálculos das médias da temperatura do ar.

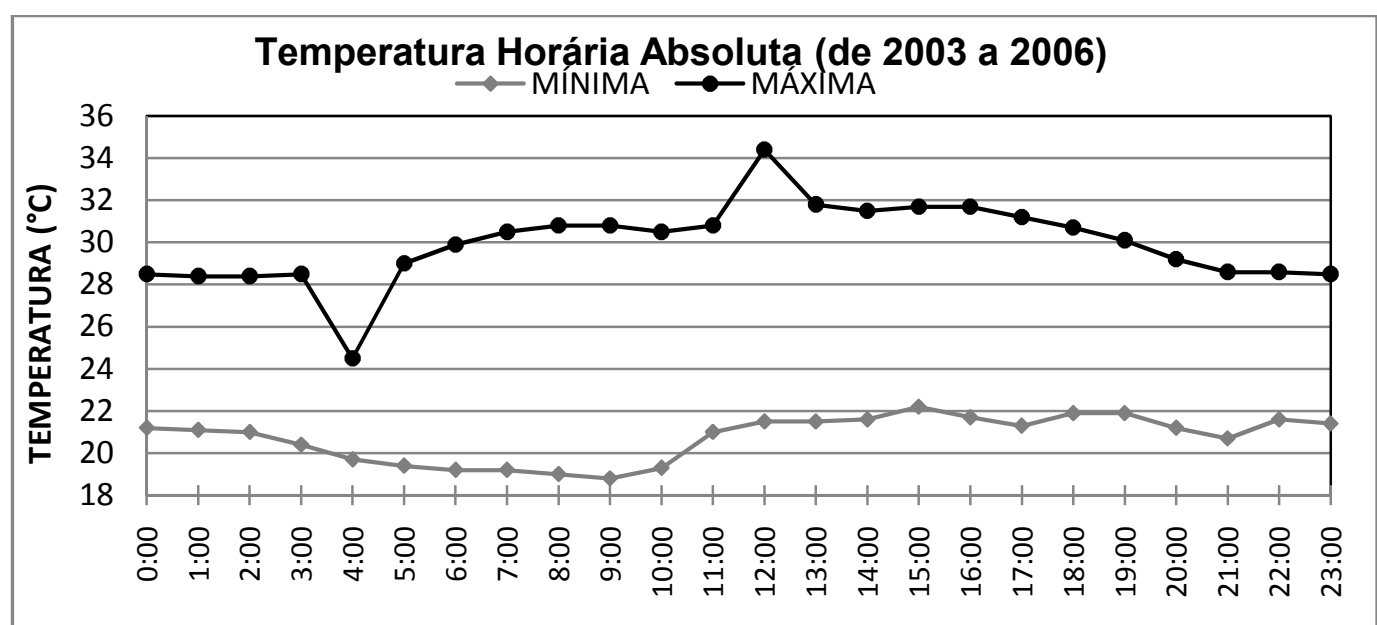

Gráfico 3.11 - Temperatura Horária Absoluta - Máximas e mínimas

Além das médias e do registro das máximas e mínimas absolutas, saber com que freqüência cada uma dessas temperaturas ocorre também colabora para uma análise climática mais completa.

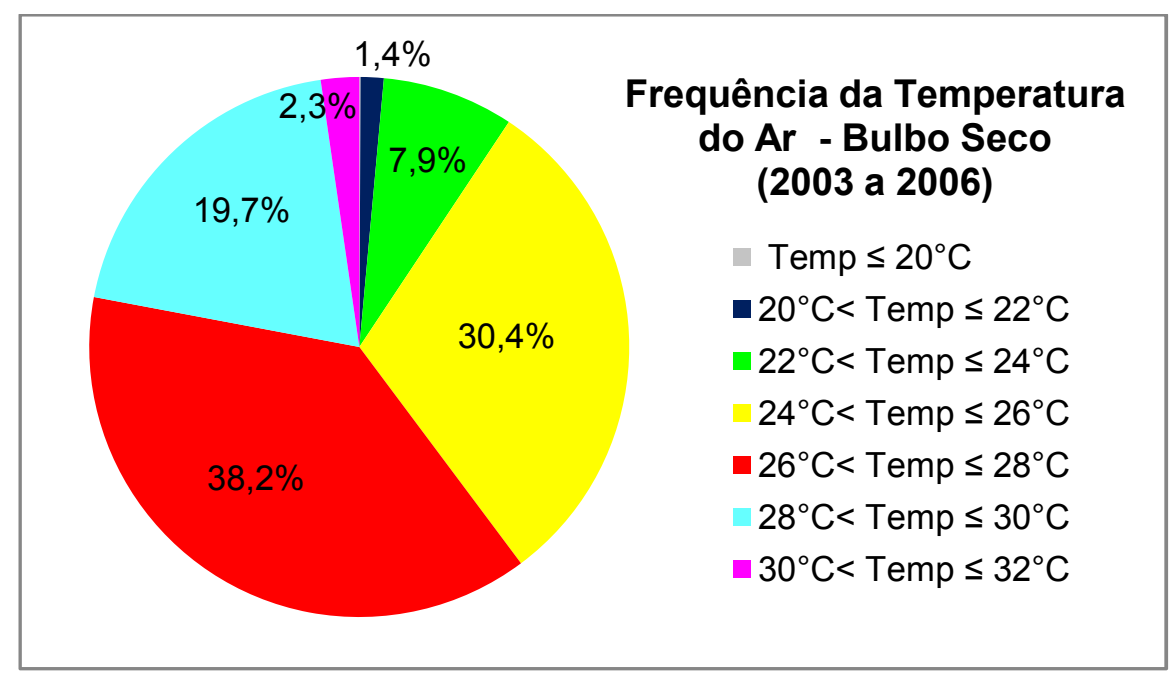

Gráfico 3.12 - Freqüência da Temperatura do ar entre 2003 e 2006

O gráfico 3.12 mostra, por exemplo, que em $68,7 \%$ dos dados registrados nos quatro anos analisados a temperatura do ar em Aracaju esteve entre 24 e $28^{\circ} \mathrm{C}$. E em apenas $2,3 \%$ dos registros a temperatura ultrapassou os $30^{\circ} \mathrm{C}$, nesta cidade. 


\section{- Umidade Relativa}

Assim como os dados da temperatura do ar, a umidade relativa registrada nos anos de 2003 a 2006 mostrou valores compatíveis o que indica que também em relação à umidade do ar esses anos foram típicos e, portanto válidos para uma análise realista do clima deste universo de estudo.

No gráfico 3.13 nota-se que a maior parte dos registros horários da umidade do ar está compreendida no intervalo de $65 \%$ a $85 \%$, o que acaba nos fornecendo uma média geral de $75 \%$.

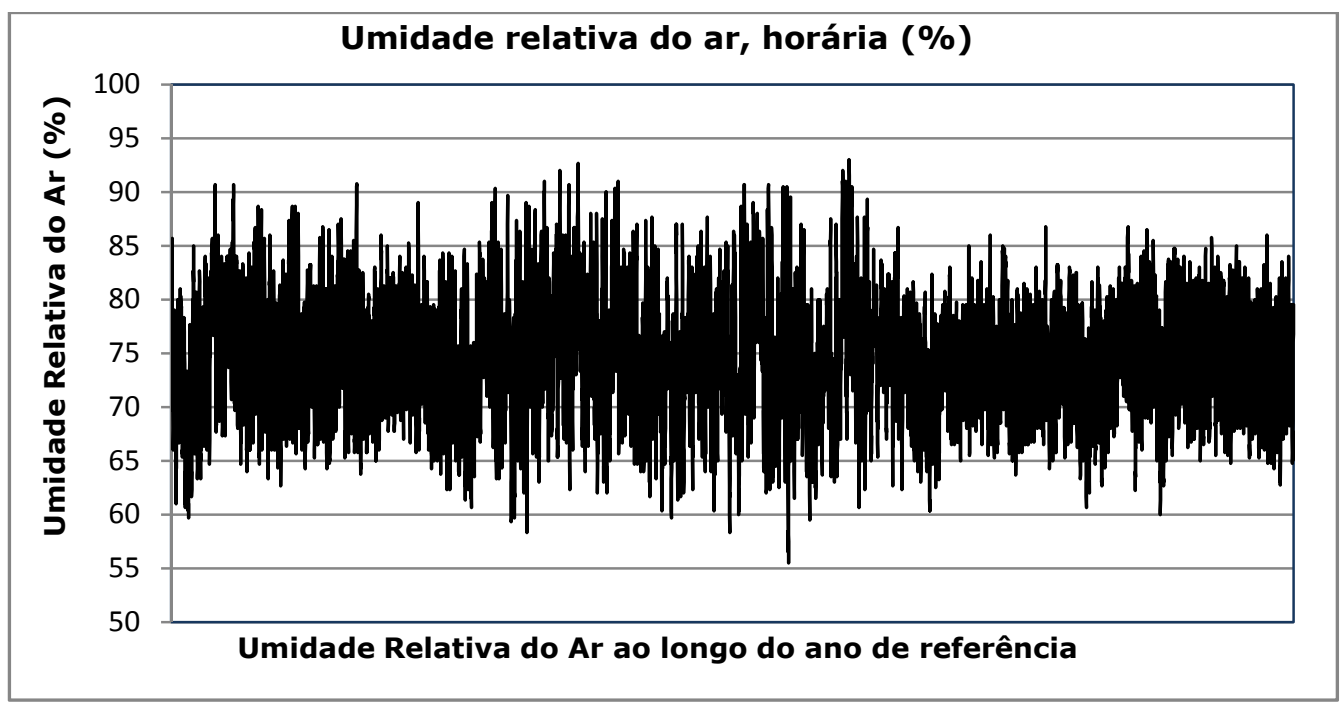

Gráfico 3.13 - Umidade Relativa do ar ao longo do ano de referência

É claro que ter uma média nos ajuda a ter uma visão geral do problema, mas é imprescindível detalhar mais os dados para ter real noção da variação que está por trás de um simples número. Por este motivo a tabela 3.3 pode esclarecer as variações encontradas na análise dos registros dos anos de 2003 a 2006. 
Tabela 3.3 - Médias da umidade relativa do ar (2003 a 2006)

\begin{tabular}{|c|c|c|c|c|c|}
\hline & $\begin{array}{l}\text { UMID. REL. } \\
\text { DO AR MÁX. } \\
\text { ABS. (\%) }\end{array}$ & $\begin{array}{l}\text { UMID. REL. DO } \\
\text { AR MÍN. ABS. } \\
(\%)\end{array}$ & $\begin{array}{l}\text { UMID. REL. } \\
\text { DO AR MÉDIA } \\
\text { DAS MÁX.(\%) }\end{array}$ & $\begin{array}{l}\text { UMID. REL. DO } \\
\text { AR MÉDIA DAS } \\
\text { MÍN. }(\%)\end{array}$ & $\begin{array}{l}\text { UMID. REL. DO } \\
\text { AR MÉDIA } \\
\text { GERAL (\%) }\end{array}$ \\
\hline JAN & 90 & 64 & 80 & 72 & 76 \\
\hline FEV & 84 & 67 & 80 & 71 & 75 \\
\hline MAR & 85 & 66 & 79 & 71 & 75 \\
\hline ABR & 89 & 62 & 78 & 69 & 73 \\
\hline MAI & 89 & 64 & 81 & 72 & 76 \\
\hline JUN & 90 & 61 & 79 & 68 & 74 \\
\hline JUL & 91 & 55 & 80 & 69 & 75 \\
\hline AGO & 88 & 63 & 81 & 70 & 76 \\
\hline SET & 91 & 64 & 80 & 69 & 74 \\
\hline OUT & 90 & 64 & 80 & 69 & 74 \\
\hline NOV & 89 & 64 & 83 & 70 & 76 \\
\hline DEZ & 88 & 66 & 80 & 70 & 75 \\
\hline
\end{tabular}

Porém, no caso de Aracaju, inicialmente citado através dos dados do

Climaticus 4.2 e em seguida pela análise detalhadas dos últimos quatro anos, a variação da umidade relativa do ar é muito baixa ao longo do ano, tanto que a variação ao longo do dia pode ser considerada maior (mesmo que ainda pequena), uma vez que a presença do sol diminui a umidade do ar, tornando as noites um pouco mais úmidas que os dias.

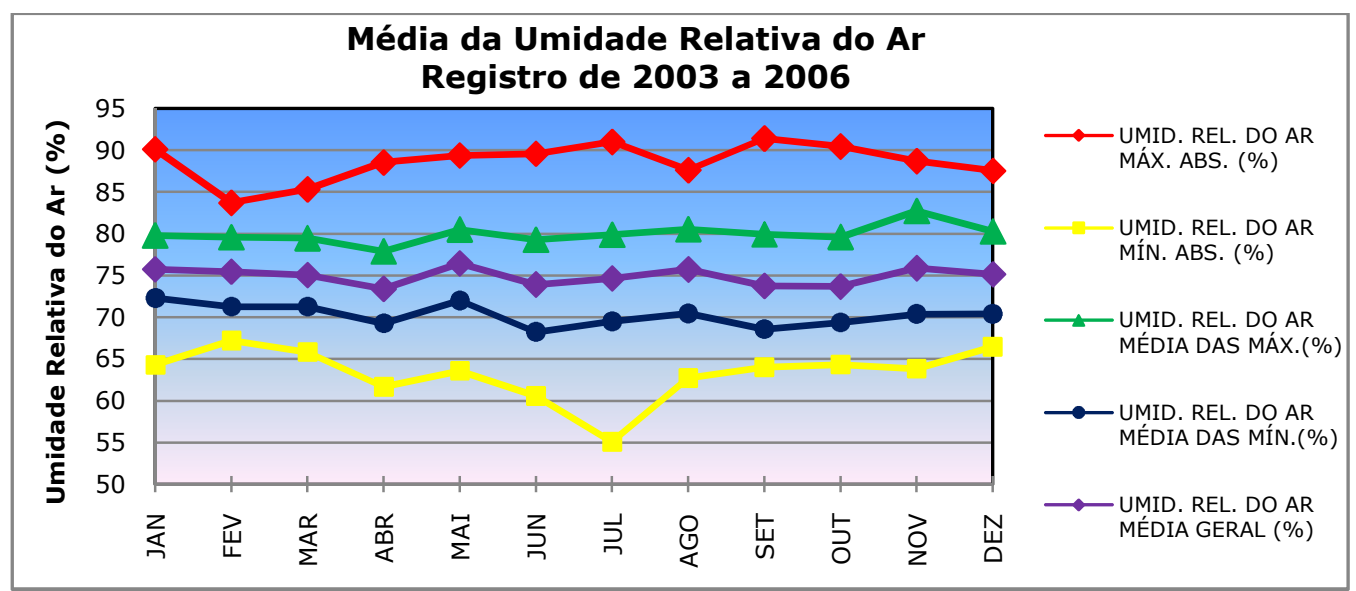

Gráfico 3.14 - Média da umidade relativa do ar ( 2003 a 2006) 
Repassando os dados da tabela 3.3 para o gráfico 3.14 é possível ter outra forma visual de análise dos resultados, sendo inclusive mais claro perceber a pouquíssima variação das médias de umidade do ar ao longo do ano.

Levando-se em consideração que a temperatura do ar em Aracaju apresenta uma média de $26,5^{\circ}$ e pouquíssimas vezes $(2,3 \%$ dos registros entre 2003 e 2006) ultrapassa os $30^{\circ} \mathrm{C}$ e que a média da umidade relativa do ar é de 75\%, é possível afirmar que com o uso de dispositivos de sombreamento e com o devido aproveitamento da ventilação natural, é facilmente possível estar em conforto térmico nesta cidade.

\section{- Direção e velocidade dos ventos}

Para a análise dos dados de vento, a verificação é feita de hora em hora e como não se estabelece médias para os dados de direção dos ventos, os valores registrados foram agrupados em quadrantes com o objetivo de identificar o quadrante predominante e então se estabelecer a velocidade do vento média para os quadrantes predominantes, definindo dessa forma, a primeira e segunda predominância dos ventos locais.

Resumindo todas as análises realizadas, a tabela 3.4 apresenta os resultados encontrados após estudo completo dos registros realizados em Aracaju no período de janeiro de 2003 a dezembro de 2006, dispostos mês a mês. 
Por meio desta tabela pode-se ter uma visão geral do comportamento dos ventos predominantes na região com sua variação ao longo do ano de referência.

Tabela 3.4 - Dados dos ventos na cidade de Aracaju (2003 a 2006)

\begin{tabular}{c|c|c|c|c}
\hline \multirow{2}{*}{} & \multicolumn{2}{|c|}{ PRIMEIRA PREDOMINÂNCIA } & \multicolumn{2}{c}{ SEGUNDA PREDOMINÂNCIA } \\
\cline { 2 - 5 } & DIREÇÃO $\left({ }^{\circ}\right)$ & VELOCIDADE $(\mathbf{m} / \mathbf{s})$ & DIREÇÃO $\left({ }^{\circ}\right)$ & VELOCIDADE $(\mathbf{m} / \mathbf{s})$ \\
\hline JANEIRO & 90 & 4,4 & 120 & 3,3 \\
FEVEREIRO & 90 & 4,4 & 120 & 3,0 \\
MARÇO & 90 & 4,5 & 120 & 3,1 \\
ABRIL & 120 & 3,4 & 90 & 3,4 \\
MAIO & 120 & 2,8 & 150 & 2,7 \\
JUNHO & 150 & 2,5 & 120 & 2,7 \\
JULHO & 150 & 2,9 & 180 & 3,1 \\
AGOSTO & 120 & 2,8 & 180 & 3,5 \\
SETEMBRO & 90 & 3,7 & 120 & 3,5 \\
OUTUBRO & 90 & 4,9 & 120 & 3,4 \\
NOVEMBRO & 90 & 4,8 & 120 & 3,2 \\
DEZEMBRO & 90 & 4,7 & 120 & 3,3 \\
\hline MÉDIA ANUAL & $\mathbf{9 0}$ & $\mathbf{3 , 8}$ & $\mathbf{1 2 0}$ & $\mathbf{3 , 2}$ \\
\hline
\end{tabular}

Aqui é fácil perceber que os meses mais quentes do ano apresentam médias da velocidade do vento mais altas que nos meses mais frios/chuvosos, o que é altamente favorável ao conforto térmico. Além disso, assim como os ventos predominantes, os valores referentes à segunda predominância apresentam uma média de 3,2m/s e uma direção muito próxima da primeira predominância tornando mais fácil a adoção de estratégias de projeto que visem o aproveitamento desses ventos.

\section{- Dados Climáticos de Aracaju}

Resumindo todas as principais informações apresentadas até aqui sobre os dados climáticos coletados da cidade de Aracaju, podemos finalizar com a seguinte tabela 3.5: 


\begin{tabular}{|c|c|c|c|c|c|c|c|c|c|c|c|c|}
\hline $\begin{array}{l}\text { ARACAJU - SE } \\
\text { Altitude: } 4 \mathrm{~m} \\
\text { Pressão: } \\
\text { 101277 PA } \\
\text { Latitude: } 10,9 \mathrm{~S} \\
\text { Longitude: } \\
\text { 37,1 W }\end{array}$ & 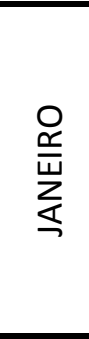 & 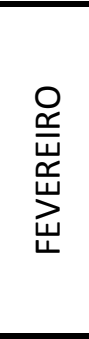 & 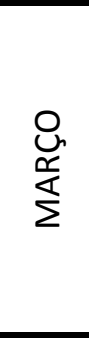 & $\begin{array}{l}\overrightarrow{\bar{\alpha}} \\
\stackrel{\underline{\alpha}}{<}\end{array}$ & $\frac{O}{\frac{0}{2}}$ & $\begin{array}{l}\text { 오 } \\
\text { 늘 }\end{array}$ & $\begin{array}{l}\stackrel{ }{1} \\
\stackrel{2}{\supseteq}\end{array}$ & 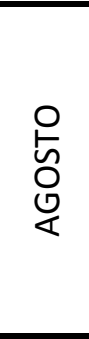 & 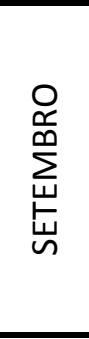 & $\begin{array}{l}\stackrel{0}{\circ} \\
\stackrel{0}{9} \\
\stackrel{2}{5} \\
\text { ○ }\end{array}$ & 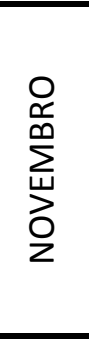 & 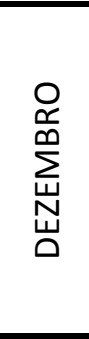 \\
\hline Temp. Méd.(으) & 27,2 & 27,6 & 27,9 & 27,5 & 26,5 & 25,8 & 24,6 & 24,6 & 25,5 & 26,3 & 26,6 & 27,2 \\
\hline Temp. Máx (으) & 30,4 & 30,5 & 31,0 & 30,7 & 29,5 & 28,6 & 27,5 & 27,3 & 28,0 & 29,1 & 29,6 & 30,3 \\
\hline Temp. Mín. (oc) & 23,9 & 24,0 & 24,2 & 23,5 & 22,5 & 22,2 & 21,3 & 21,5 & 22,1 & 22,9 & 23,6 & 24,2 \\
\hline T. Max. Abs. $\left({ }^{\circ} \mathrm{c}\right)$ & 31,7 & 31,1 & 31,7 & 31,8 & 30,7 & 29,4 & 28,1 & 28,0 & 29,2 & 29,7 & 30,5 & 34,4 \\
\hline T. Mín. Abs. $\left({ }^{\circ} \mathrm{c}\right)$ & 21,9 & 22,2 & 22,8 & 21,7 & 20,7 & 20,6 & 19 & 18,8 & 20,0 & 21,7 & 22,1 & 22,5 \\
\hline Umid. Rel. (\%) & 76 & 75 & 75 & 73 & 76 & 74 & 75 & 76 & 74 & 74 & 76 & 75 \\
\hline Vel. Vento $(\mathrm{m} / \mathrm{s})$ & 4,4 & 4,4 & 4,5 & 3,4 & 2,8 & 2,5 & 2,9 & 2,8 & 3,7 & 4,9 & 4,8 & 4,7 \\
\hline
\end{tabular}

Se compararmos os dados da tabela 3.5 com os dados fornecidos pelo programa Climaticus 4.2 (de 1961 a 1990) inserido anteriormente, podemos notar que houve um pequeno aumento nas médias da temperatura (em torno de $1^{\circ} \mathrm{C}$ ) e uma leve queda na umidade relativa do ar. Esse fato era esperado, uma vez que vivemos num crescente aumento de temperatura do ar no planeta, e, justamente com a finalidade de se avaliar e atualizar esses dados que se fez necessário e se julgou importante o tratamento dos dados climáticos mais atuais.

\subsubsection{Dia típico de projeto}

Os dados climáticos devem apresentar um significado estatístico de um determinado período de tempo para atender os níveis de exigência na avaliação do projeto arquitetônico. Para isso devem-se estabelecer os chamados dias típicos de projeto de verão e de inverno.

Seguindo a recomendação da Norma da ABNT (2004) - Desempenho de edifícios habitacionais de até cinco pavimentos - para Aracaju apenas é 
necessário analisar o desempenho térmico para as condições de verão, devido às características climáticas locais.

Existem algumas metodologias para determinar os dias típicos de projeto. Goulart e Lamberts (1993) descrevem e comparam a metodologia desenvolvida pelo Instituto de Pesquisas Tecnológicas do Estado de São Paulo (IPT) e a desenvolvida por Miguel Sattler do CIENTEC de Porto Alegre. Eles definem a metodologia do IPT como mais rigorosa, pois a definição dos dias típicos está baseada num período de tempo menor que a metodologia de Sattler. Porém chegam à conclusão que a escolha entre essas duas metodologias deve se basear na amplitude térmica diária da região.

"Em locais onde os valores de amplitude diária são próximos ao valor da amplitude média do período em questão (média das Tmáx. - média das Tmin.), recomenda-se aplicar a metodologia desenvolvida por SATTLER. Caro contrário, se os valores de amplitude diária estão, na maioria das vezes, acima do valor de amplitude média, recomenda-se, então, a metodologia desenvolvida pelo IPT." (GOULART e LAMBERTS, 1993).

No caso desta pesquisa, onde os dados analisados correspondem apenas a um período de quatro anos e, além disso, apresentam dados muito equilibrados, será utilizada a metodologia aplicada pelo Laboratório de Conforto Ambiental e Eficiência Energética da USP (LABAUT), ao desenvolverem um banco de clima para uma consultoria para o novo Centro de Pesquisa Tecnológica da Petrobrás (CENPES II), localizado na Baía de Guanabara. 
Assim, para a determinação do mês crítico de verão, identificou-se na série de dados medidos o mês real mais quente dos últimos quatro anos, para a realização de simulações das cargas térmicas dos edifícios. Dentro desse mês, analisaram-se os períodos de maior estabilidade atmosférica para se extrair o dia de referência de verão, com o objetivo de fornecer dados para simulações que avaliam o desempenho dos recintos com diferentes materiais e componentes constritivos.

Então, o mês crítico de verão considerado nesta série histórica foi março de 2006, que apresentou a maior média da temperatura do ar.

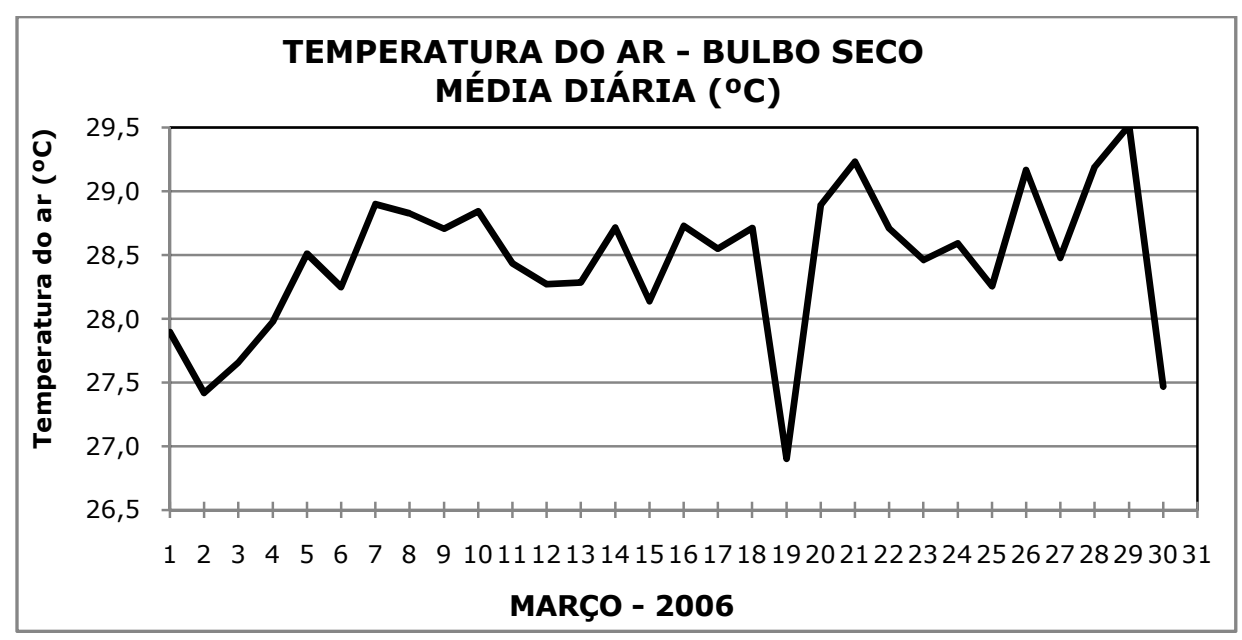

Gráfico 3.15 - Mês crítico de verão - Março de 2006

Já o dia de referência de verão adotado foi 12 de março de 2006, pelas características estáveis apresentadas nos gráficos a seguir: 


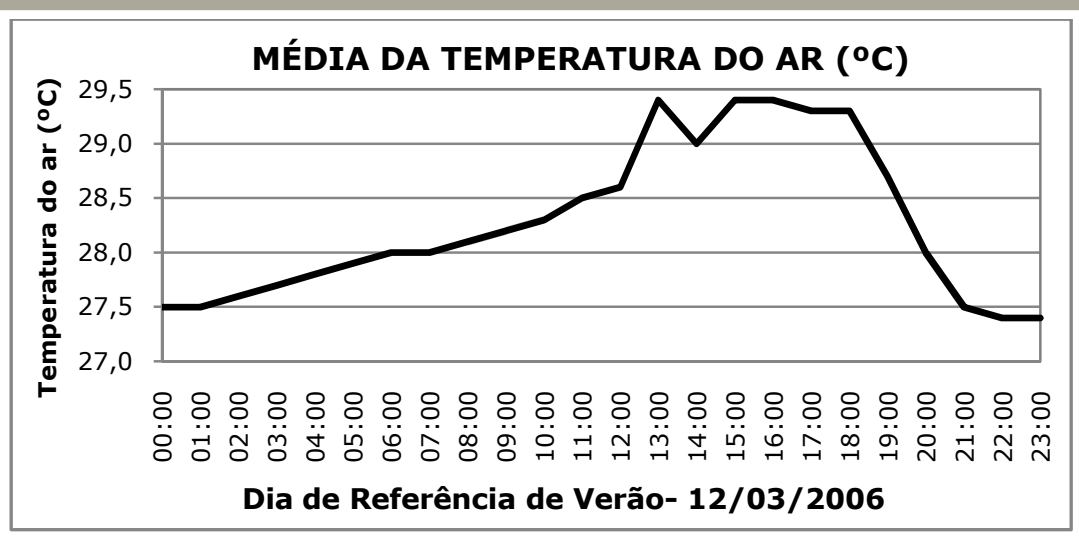

Gráfico 3.16 - Temperatura do ar - 12 de março de 2006

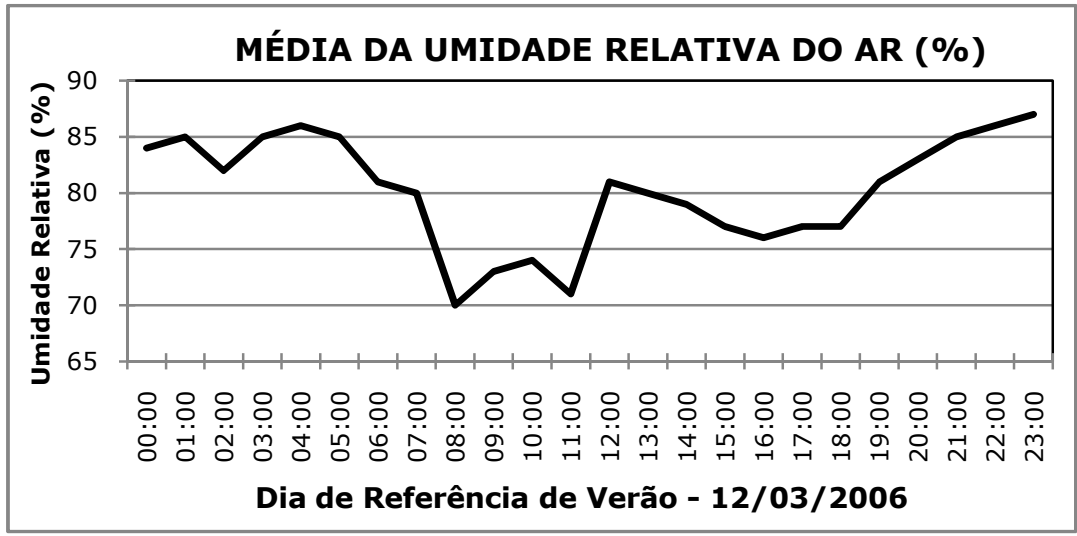

Gráfico 3.17 - Umidade relativa do ar - 12 de março de 2006

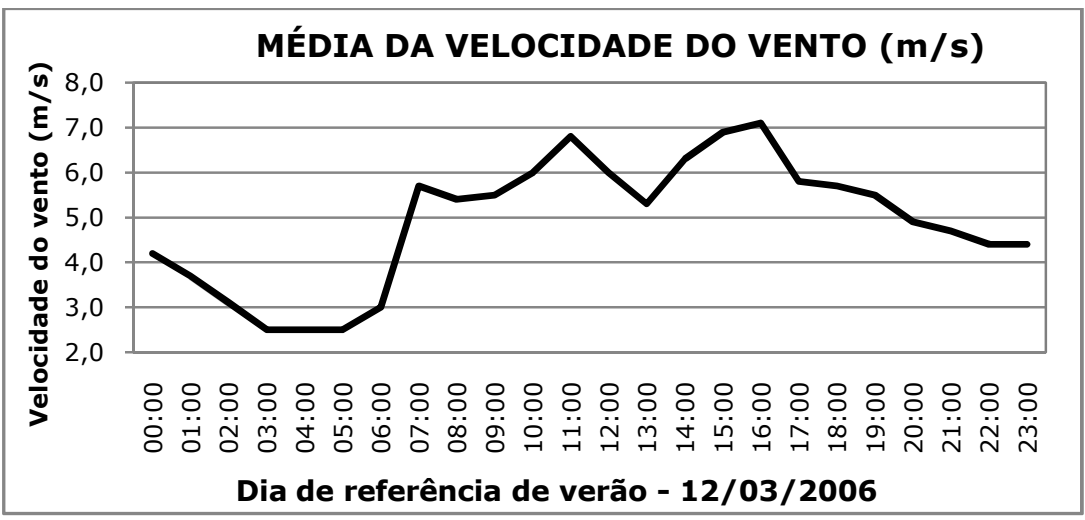

Gráfico 3.18 - Velocidade do vento - 12 de março de 2006

Considerando que em relação à direção dos ventos foi estabelecido que a direção de $90^{\circ}$ (leste) compreendia os registros inseridos no quadrante entre $67,5^{\circ}$ e $112,5^{\circ}$, percebemos que no dia 12 de março de 2006 os registros de todos os horários mostraram que a direção dos 
ventos estava totalmente inserida nesse intervalo, representando bem a tendência da direção dos ventos para a cidade de Aracaju.

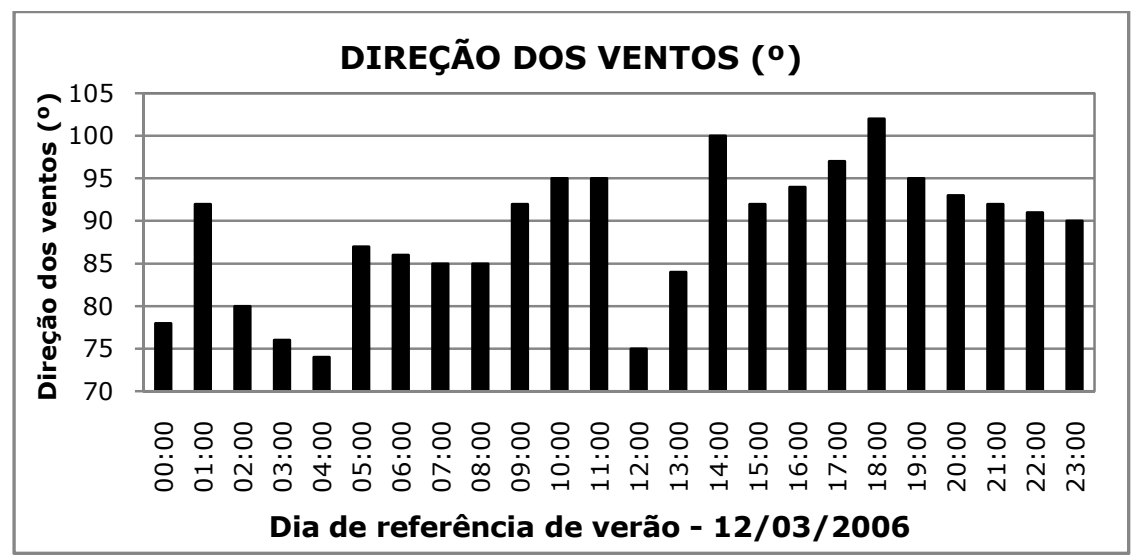

Gráfico 3.19 - Direção dos ventos - 12 de março de 2006

Ao finalizar a análise climática desta cidade, é importante destacar que o correto seria uma análise dos dados climáticos dos últimos 30 anos, porém não foi possível conseguir tais dados, sendo disponibilizados apenas os registros de 2003 a 2006. Entretanto, pôde-se perceber com a análise detalhada de todas as médias que felizmente esses quatro anos apresentaram comportamentos compatíveis entre si o que demonstra se tratar de anos típicos em relação ao comportamento climático, tornando o resultado encontrado mais próximo da realidade atual do clima desta cidade. 


\section{SIMULAÇÃO COMPUTACIONAL}

Neste capítulo serão expostas, de maneira resumida, todas as etapas e parâmetros utilizados no processo de simulação computacional no software escolhido, desde a elaboração do modelo até o tratamento da imagem com o resultado final.

Tomou-se como base para explicar todas as etapas o modelo experimental que representa o entorno delimitado para esta pesquisa, com as edificações inseridas neste espaço, inclusive o edifício objeto de estudo. Porém, neste modelo experimental ainda não está inserido o apartamento escolhido.

Nesta simulação é possível avaliar a resposta gerada pelo software escolhido, estudar a melhor definição dos parâmetros a serem utilizados nas simulações em função dos resultados obtidos aqui e adequar os modelos futuros em função das condições iniciais.

\subsection{MÉTOdos PREDITIVOS DE VENTILAÇÃO NATURAL}

"Como deve agir um projetista ante o caso real de um edifício a ser construído em um determinado local, quando deseja o efeito do vento nos problemas de ventilação natural? Em primeiro lugar, é necessário verificar se a ventilação natural constitui uma questão de vital importância para o edifício e que, por isto, carece de um estudo rigoroso. Em seguida, cabe decidir se o vulto da obra justifica as despesas dos ensaios de um modelo do edifício, em túnel aerodinâmico, ou, em caso contrário, cabe apenas aplicar no estudo da ventilação os conhecimentos gerais já existentes e colhidos em ensaios de tipos padrões de edifícios." (TOLEDO, E. 1999, p. 97) 
Existem diversos métodos de predição da ventilação natural por ação dos ventos nas edificações e sua escolha deve se basear na importância da ventilação natural para o projeto, sua localização e tipologia, além, evidentemente da disponibilidade de recursos humanos e materiais.

\subsubsection{Túneis de vento e simulação computacional}

Os ensaios em túneis de vento são utilizados com diversas finalidades, entre as quais: verificação do efeito do vento entre as edificações no meio urbano; análise da ventilação no interior das edificações e determinação do coeficiente de pressão sofrida em cada fachada; análise da dispersão de poluentes; análise estrutural de edifícios; análise da propagação de emissões veiculares, entre outros. Para isso é necessária a construção de um modelo em escala reduzida que reproduza fielmente os objetos a serem pesquisados. Essa escala deve ser a maior possível para facilitar a reprodução dos detalhes das aberturas.

Segundo Toledo, E. (1999, p.98) "praticamente todo o conhecimento científico sobre a ação do vento nos edifícios foi proveniente de ensaios de modelos em túneis aerodinâmicos". Porém, infelizmente, ensaios em túneis de vento ainda não estão ao alcance da maior parte dos projetistas que buscam uma análise detalhada dos efeitos da ventilação natural na edificação. Apesar da tecnologia envolvida na construção de um túnel de vento ter permanecido a mesma nos últimos cinquenta anos, a 
complexidade e os custos que envolvem uma simulação impedem sua popularidade.

Para Cóstola (2006) as duas principais aplicações do túnel de vento no estudo da ventilação no edifício são para validação de modelos teóricos (como os CFD's) e para avaliação da ventilação de um edifício específico. Porém, quando o uso objetiva a avaliação do desempenho de um projeto é a determinação do coeficiente de pressão a principal abordagem encontrada nos estudos realizados em túneis de vento.

O ensaio em modelo reduzido em túneis de vento é mais utilizado para estudos na área do urbanismo. No caso da arquitetura, principalmente do interior dos edifícios, cada vez mais a simulação computacional vem sendo empregada nos estudos acadêmicos e na prática profissional, inclusive em caráter obrigatório em alguns países europeus e da América do Norte, na busca da eficiência energética das edificações.

\subsubsection{A prática da simulação computacional}

O uso de ferramentas computacionais para a análise do desempenho de edificações e espaços urbanos é uma prática relativamente nova no Brasil, apesar de já estar sendo explorada há mais de 30 anos na Europa.

Na arquitetura, o uso de tais ferramentas pode auxiliar na avaliação da relação entre as questões ambientais (clima) e arquitetônicas (formas, materiais, etc.) e ajudar na conscientização da importância do emprego de técnicas passivas de condicionamento do ar e da iluminação natural em 
busca de uma maior eficiência energética nas edificações e consequente ganho ambiental.

No estudo da ventilação natural, os softwares são de grande complexidade e em geral utilizados por grupos de pesquisadores ou profissionais especializados nas áreas de conforto ambiental que buscam nas simulações a visualização das respostas aos problemas impostos. Mas é importante destacar que os softwares desenvolvidos para simulações de conforto ambiental e eficiência energética, apesar de elaborados de acordo com modelos de cálculos reconhecidos pela comunidade científica internacional, devem ser validados por medições e experimentos físicos.

Felizmente, vários programas vem sendo desenvolvidos em várias partes do mundo e se tornam cada vez mais ferramentas bastante úteis na área da arquitetura e urbanismo. Porém, a escolha do software deve ser baseada principalmente no objetivo do estudo, nos dados existentes e nas respostas solicitadas, além de que, evidentemente, na disponibilidade dos equipamentos e licenças necessários.

Em um dos estudos que exemplifica o emprego de um software, Toledo, A. (1999) questiona o critério de dimensionamento das aberturas sugerido pelo Modelo IBAM/PROCEL 1997, que se baseia na área de piso, sem considerar os fatores externos e do edifício. Assim, por meio da simulação com o software VENTIL.FOR-85, ele simula 5 modelos de dormitórios, considerando a velocidade do vento, os coeficientes de pressão e as resistências nas aberturas descartando a variação da 
temperatura para simplificação dos cálculos. Os resultados mostram que os critérios geométricos adotados, que consideram a ventilação natural com caráter genérico, não são adequados para o caso de Maceió. Por fim ele aponta para a necessidade de consideração de outros fatores, presentes em outros métodos.

Já Bittencourt e Lôbo (1999) apresentaram um trabalho sobre a influência da localização das aberturas na ventilação natural de edificações escolares com o objetivo de investigar a influência conjugada dos parâmetros arquitetônicos relativos à localização e dimensão das aberturas de salas de aulas típicas, na ventilação natural no interior destes espaços, aumentando o conforto ambiental e o rendimento discente nessas edificações. Foram realizadas simulações utilizando o programa PHOENICS 2.2.2 e por meio dos resultados, observou-se que, quando as aberturas de entrada do fluxo de ar se encontram na faixa média e as aberturas de saída na faixa alta, associadas a uma maior dimensão das aberturas, obtém-se um melhor padrão de circulação do ar no interior do ambiente.

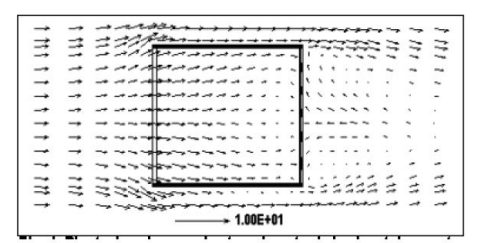

Figura 4.1 - Planta da sala com abertura de entrada $=1 / 5$ do piso, na faixa média, e saída na faixa alta com vento a $90^{\circ}$

FONTE: Bittencourt e Lôbo (1999)

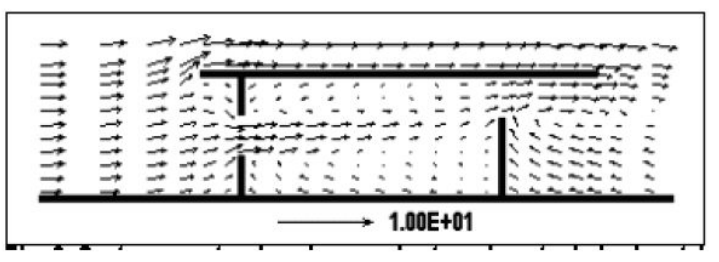

Figura 4.2 - Corte no centro da sala com abertura de entrada $=1 / 5$ do piso, na faixa média, e saída na faixa alta com vento a 900

FONTE: Bittencourt e Lôbo (1999) 
Dessa forma, os autores concluem que os resultados apresentados nas figuras 4.1 e 4.2 mostram que a localização das aberturas exerce maior influência sobre o padrão de distribuição do ar das salas de aula do que a variação da dimensão das mesmas.

Em outro estudo, ainda em salas de aula, Bittencourt e Peixoto (2003) realizaram simulações computacionais com o auxílio do software PHOENICS 3.3 com a finalidade de verificar o desempenho da ventilação natural em dois prédios distintos e em seguida propor soluções para melhorar seu aproveitamento. No final provaram por meio das simulações realizadas que simples medidas de adequação dos edifícios ao clima local podem promover edificações energeticamente mais eficientes, destacando a responsabilidade do arquiteto ao definir os partidos arquitetônicos.

Com o objetivo de investigar o potencial do uso de captadores de ventos em habitações populares em locais de clima quente e úmido visando o conforto térmico no interior das edificações, Bittencourt e Lôbo (2003) realizaram simulações computacionais utilizando o software PHOENICS 3.2 e verificaram que o uso de captadores de ventos pode gerar um aumento significativo da velocidade do fluxo de ventilação natural em alguns ambientes da edificação sem custos adicionais importantes.

Costa (2001) também utilizou os recursos do programa PHOENICS 3.2 para simular a aplicação das prescrições urbanísticas na cidade de Natal-RN, analisando os efeitos sobre a ventilação natural e concluiu que a 
redução sucessiva nos índices que definem o afastamento mínimo entre as edificações reduz a velocidade dos ventos nas áreas mais adensadas e pode provocar a formação de ilhas de calor.

Por outro lado, AKUTSU et.al. (1998) utilizaram o programa ESP-r (Energy Simulation Program - research) para a análise das condições de ventilação natural de uma edificação para condições típicas de verão da cidade de São Paulo e mostrou o quanto a ventilação de uma habitação pode ser prejudicada no caso de um mau posicionamento em relação à incidência dos ventos e que a distribuição das janelas nas fachadas é um parâmetro fundamental na qualidade de ar no interior dos recintos.

Também Figueiredo (2007), em sua dissertação de mestrado, cujo objetivo foi avaliar o potencial de utilização da ventilação natural em edifícios de escritórios sob o ponto de vista do conforto térmico, utilizou o software Energy Plus para avaliar as temperaturas operativas internas no modelo elaborado e em seguida, em caráter exploratório, a autora desenvolveu simulações no software CFX 5.7 com o objetivo de estimar se a temperatura e a velocidade do ar no interior do recinto poderiam gerar desconforto térmico no mesmo.

Prata (2005) ao estudar a ventilação natural urbana relacionada ao conforto urbano dos usuários das cidades realizou ensaios em túnel de vento que comprovaram que o padrão de vento no meio urbano é alterado pelas mudanças na altura e posicionamento dos edifícios. Em complemento e para verificar possíveis diferenças nos resultados obtidos, 
também foram elaboradas simulações com o software CFX 5.7 que se mostrou eficiente na quantificação dos valores de velocidade do ar.

Leite (2008) investigou a relação entre o processo de verticalização na cidade de São Luís e a ventilação natural de seu entorno por meio da construção de seis diferentes cenários que foram simulados no software CFX 5.7 com o objetivo de, comparado a ocupação atual, avaliar a velocidade e direção do vento no nível do pedestre, destacando como a metodologia empregada viabiliza pré-determinar o impacto que a ventilação natural urbana poderá sofrer com as futuras edificações.

Cóstola (2006) em sua dissertação de mestrado formulou um procedimento para a quantificação da vazão do ar promovida pela ação do vento no interior do edifício, em climas quentes. Diversas ferramentas foram apresentadas detalhadamente, como o uso do túnel de vento e simulação com software de dinâmica dos fluidos, juntamente com o uso e os parâmetros de entrada necessários. Ao concluir a dissertação, o autor ressalta a disponibilidade de um conjunto de ferramentas para predição da ventilação natural no interior das edificações, mas lembra que cabe ao projetista o uso criterioso destes recursos no projeto arquitetônico.

\subsection{A ESCOLHA DO SOFTWARE DE SIMULAÇÃo}

Prata (2005) afirma que "os modelos CFD são muito poderosos e requerem cálculos intensos, mas fornecem resultados detalhados que podem mostrar claramente os defeitos em projetos sugeridos." Assim, 
com o auxílio dessa ferramenta novas propostas podem ser analisadas e sugeridas até que se obtenha um resultado satisfatório.

O programa CFX utiliza as equações fundamentais de fluxo, além de permitir que o usuário insira outras equações específicas para as diversas variáveis. Segundo Harries (2005), apud Leite $(2008)^{6}$, para solucionar as propriedades do escoamento de um fluído, calculando determinados pontos em um volume de controle, conhecidos como malha, o CFX se vale das seguintes equações fundamentais de fluxo:

- Equação da Conservação de Massa (Equação da Continuidade);

- Equação da Conservação de Momento (Equações de Navier-Stokes);

- Equação da Conservação de Energia (no caso das simulações térmicas);

- Equação de Conservação Escalar - Dispersão de Fumaça e Poluentes;

- Equações para Turbulência.

Para as simulações deste trabalho foi escolhido o software CFX 5.7 pelos seguintes motivos:

- Disponibilidade de licença educacional para o Labaut - Laboratório de Conforto Ambiental e Eficiência Energética;

- A experiência no uso deste aplicativo em dissertações de mestrado e teses de doutorado anteriores, permitindo que os alunos mais experientes pudessem compartilhar o conhecimento acumulado para a realização desta pesquisa;

${ }^{6}$ HARRIES, Alan. Notas de Aula. In: Workshop: CFX - FAUUSP. São Paulo, 2005 
- Estuda a mecânica dos fluidos em ambientes ou superfícies e possibilita a interação entre fluxos internos e externos;

- Apresenta os resultados das simulações em imagens 3D, facilitando a análise e visualização destes resultados;

- Permite a simulação de modelo em qualquer escala e em qualquer condição de contorno.

O CFX é uma ferramenta de suma importância na fase de elaboração do projeto, como também na avaliação de edifícios existentes. Por ser um software de dinâmica dos fluidos, é adequado ao estudo da ventilação, natural ou mecânica, tanto do edifício quanto do meio urbano.

\subsection{Módulos Do CFX}

O processo completo de simulação no software CFX é dividido basicamente em três etapas, a Pre-Processor, a Solver e a Post-Processor, que vão desde a confecção do modelo até o tratamento dos resultados finais.

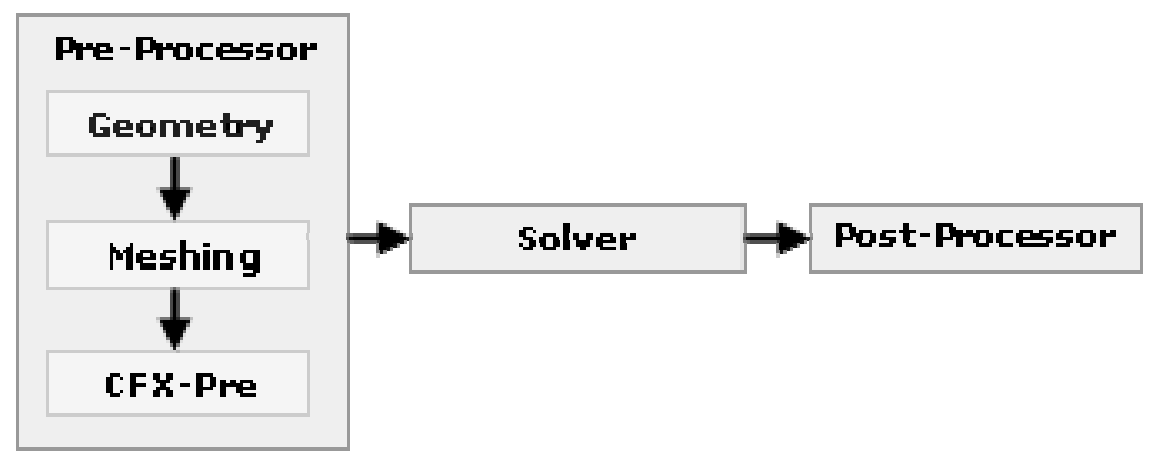

Figura 4.3 - Etapas da simulação no CFX

Disponível em: http://www.ansys.com/products/cfx.asp Acesso em 13 de outubro de 2008. 
As atividades de cada etapa do processo de simulação estão resumidas na tabela 4.1 e o detalhamento completo de cada uma das etapas da simulação será descrito nos próximos itens deste trabalho.

\section{Tabela 4.1 - Módulo do CFX com as respectivas atividades}

(Adaptada de BRANDÃO, 2008, p. 95)

\begin{tabular}{|c|c|}
\hline MÓDULO & ATIVIDADES \\
\hline ICEM & $\begin{array}{l}\text { - Correções simples na geometria; } \\
\text { - Verificação da qualidade e estanqueidade do modelo; } \\
\text { - Definição das condições de contorno, através da separação das "Parts"; } \\
\text { - Parametrização e elaboração da malha (mesh). }\end{array}$ \\
\hline CFX-Pre & $\begin{array}{l}\text { - Definição do regime de simulação (permanente ou transiente); } \\
\text { - Definição das condições de contorno (entradas, saídas, aberturas e paredes); } \\
\text { - Definição das equações a serem utilizadas para o cálculo, inclusive as de } \\
\text { parametrização as turbulência; } \\
\text { - Definição dos critérios de convergências e intervalos de iteração; } \\
\text { - Localização dos pontos de monitoramento. }\end{array}$ \\
\hline CFX-Solver & $\begin{array}{l}\text { - Apresentação dos parâmetros de simulação em arquivo de texto; } \\
\text { - Programação do tipo de simulação (serial ou paralelo); } \\
\text { - Monitoramento da convergência das equações de momento e de massa; } \\
\text { - Geração de resultados. }\end{array}$ \\
\hline CFX-Post & $\begin{array}{l}\text { - Visualização dos resultados (campos de pressão, velocidade, temperatura, etc.); } \\
\text { - Cálculo de parâmetros (vazão, Yplus, etc.). }\end{array}$ \\
\hline
\end{tabular}

\subsection{PRE-PROCESSOR - ElABORAÇÃO DA GEOMETRIA E CRIAÇÃo DA MALHA}

Essa etapa inicial reúne duas fases importantes, a elaboração da geometria do modelo em programa $C A D$ e a confecção da malha no ANSYS ICEM CFD.

\subsubsection{Geometry}

A construção da geometria do modelo foi realizada no programa AutoCAD, da Autodesk. A construção do modelo experimental (com a área do entorno) foi realizada com base no mapa do sistema viário da cidade 
de Aracaju - anexo VI do Plano Diretor de Desenvolvimento Urbano de Aracaju, fornecido pela SEPLAN (Secretaria Municipal de Planejamento) com auxílio do Google Earth e realização de levantamento do gabarito da área.

Com o objetivo de evitar erros na simulação e simplificar a elaboração do modelo, todas as construções térreas do entorno tiveram sua altura padronizada em $3 \mathrm{~m}$ e todos os recuos e distâncias entre as edificações não foram representados formando um bloco unificado na dimensão das quadras onde estavam inseridas. As edificações com dois ou mais pavimentos foram representadas com suas respectivas alturas, considerando $3 \mathrm{~m}$ para cada andar. As praças com vegetação de médio porte e mais densas foram consideradas como um bloco com mesma dimensão do terreno e altura de $3 \mathrm{~m}$. Além disso, como a área apresenta poucos espaços vazios e os mesmos pouco ou nada influenciarão no resultado final desta simulação, eles não foram considerados, uma vez que, ao eliminarmos pequenas dimensões desnecessárias no modelo, estamos evitando possíveis erros e simplificando o processo de simulação e consequentemente diminuindo o tempo total do processo.

Evidentemente que todas as simplificações realizadas foram possíveis em virtude do produto final se tratar de uma simulação no interior de um apartamento localizado no $11^{\circ}$ andar de uma edificação, e pequenos detalhes como altura de calçadas, espessura de muros, pequenos recuos, etc. não possuem relevância para os resultados que a 
pesquisa espera obter. Além disso, "o nível de detalhe do modelo a ser utilizado é proporcional à sua proximidade da área de interesse" (BRANDÃO, 2008).

Para a simulação no interior do apartamento escolhido, sua planta interna original foi inserida no bloco referente ao edifício escolhido, representando todos os ambientes internos e todas as aberturas voltadas para o exterior do edifício por onde o vento entra e sai do apartamento. Em seguida, novos modelos foram confeccionados, com algumas alterações arquitetônicas propostas com o objetivo de analisar e comparar os resultados encontrados em relação à distribuição da ventilação natural no interior da edificação, que serão apresentados, juntamente com seus detalhes, análises e comparações no próximo capítulo.

É evidente que na realidade, no edifício existem 48 apartamentos distribuídos nos 12 andares de apartamentos, mais os espaços vazios nos outros dois pavimentos, porém a confecção de um modelo nesse nível de detalhamento seria incompatível com a capacidade computacional disponível para esta pesquisa. Por este motivo optou-se por simplificar o modelo, inserido apenas o apartamento objeto de estudo e então apostar numa maior diversidade de propostas e resultados.

Por fim, o resultado gráfico da elaboração do modelo experimental pode ser visto na figura 4.4 . 


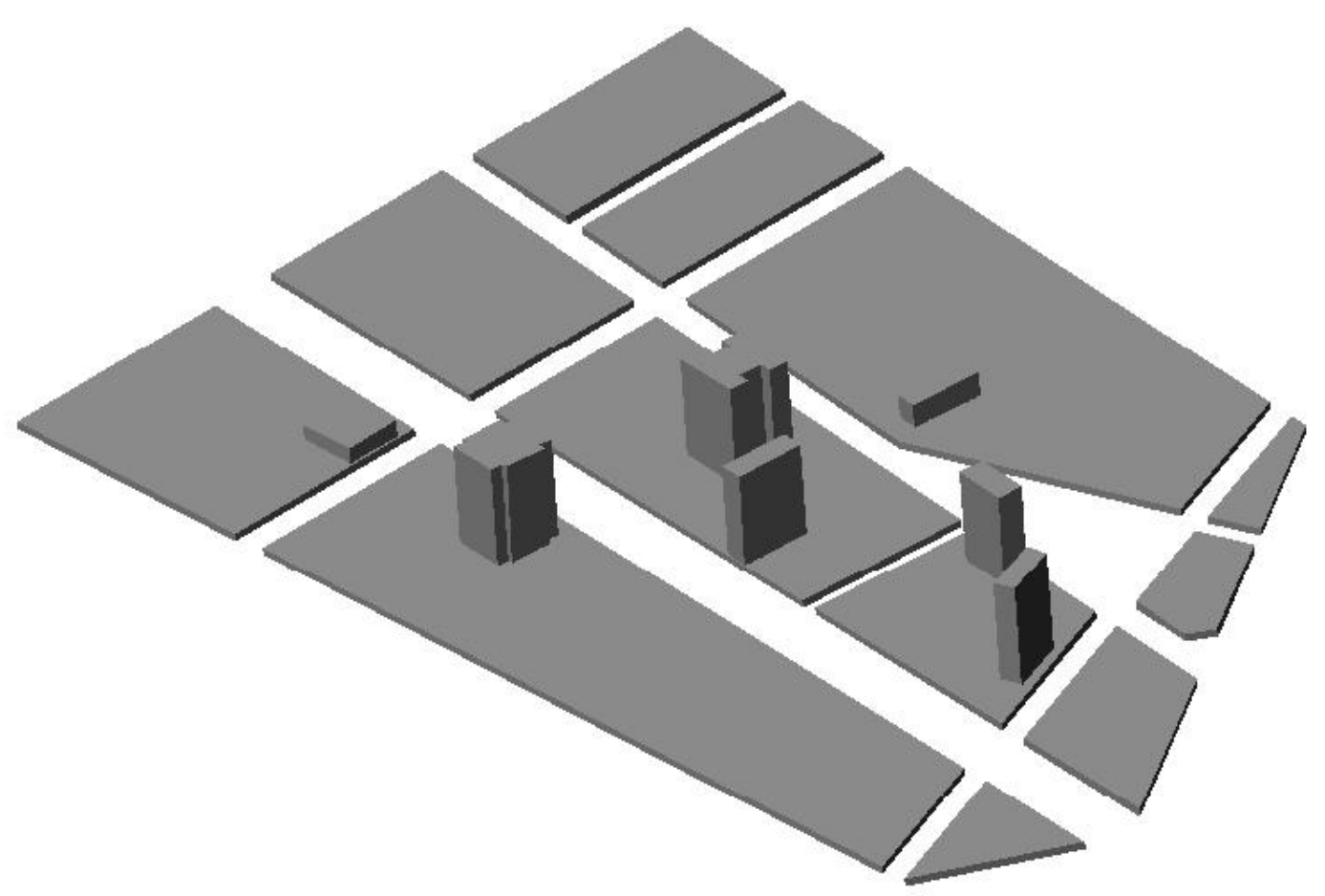

Figura 4.4 - Modelo 1: Área do entorno

Finalizadas a geometria do modelo, a próxima etapa foi definir a forma e dimensão do domínio e preparar o modelo final que foi exportado como bloco único para o ICEM.

\subsubsection{Definição do domínio e concepção do modelo}

"O modelo deve conter todos os objetos de interesse juntamente com o entorno, além de um volume para representar o domínio fluido" (BRANDÃO, 2008). O domínio nada mais é do que um volume negativo da área de estudo que representa o espaço disponível para o fluido escoar. Definir adequadamente a dimensão desse domínio é imprescindível para se manter a configuração correta do escoamento do fluido no entorno do edifício. Cost (2004) apud Brandão (2008) recomenda que a distância da entrada, laterais e topo do domínio seja 5 vezes a altura do maior 
elemento, enquanto que a distância da saída seja 15 vezes, para que o fluxo possa assumir novamente o perfil original.

Em relação ao formato do domínio, este pode ser retangular ou circular, de acordo com a área modelada e o interesse da pesquisa. No caso da forma circular é permitido simular o vento em todas as direções com uma mesma malha, alterando-se apenas a direção do vento. Porém a área do domínio deve ser maior, adotando a distancia de 15 vezes a altura para todos os lados, o que aumenta consideravelmente o número de elementos da malha e o tempo de simulação. Já a forma retangular admite uma área menor de domínio e viabiliza uma simulação mais rápida. No caso desta pesquisa, a predominância da direção do vento na área de estudo é muito significativa e, portanto justifica a adoção da forma retangular para o modelo.

Para dimensionar o domínio então, se adotou uma altura $\mathrm{H}$ correspondente a altura do maior edifício que possui 12 pavimentos-tipo + térreo + playground, totalizando 14 pavimentos. Como foi estipulado que a altura de cada pavimento seria de $3 \mathrm{~m}$, o maior edifício então tem a altura total de $\mathrm{H}=42 \mathrm{~m}$. Dessa maneira as dimensões do domínio adotadas foram de $5 \mathrm{H}=210 \mathrm{~m}$ (a barlavento, topo e nas laterais) e de $15 \mathrm{H}=630 \mathrm{~m}$ (a sotavento) a partir das extremidades da geometria. 


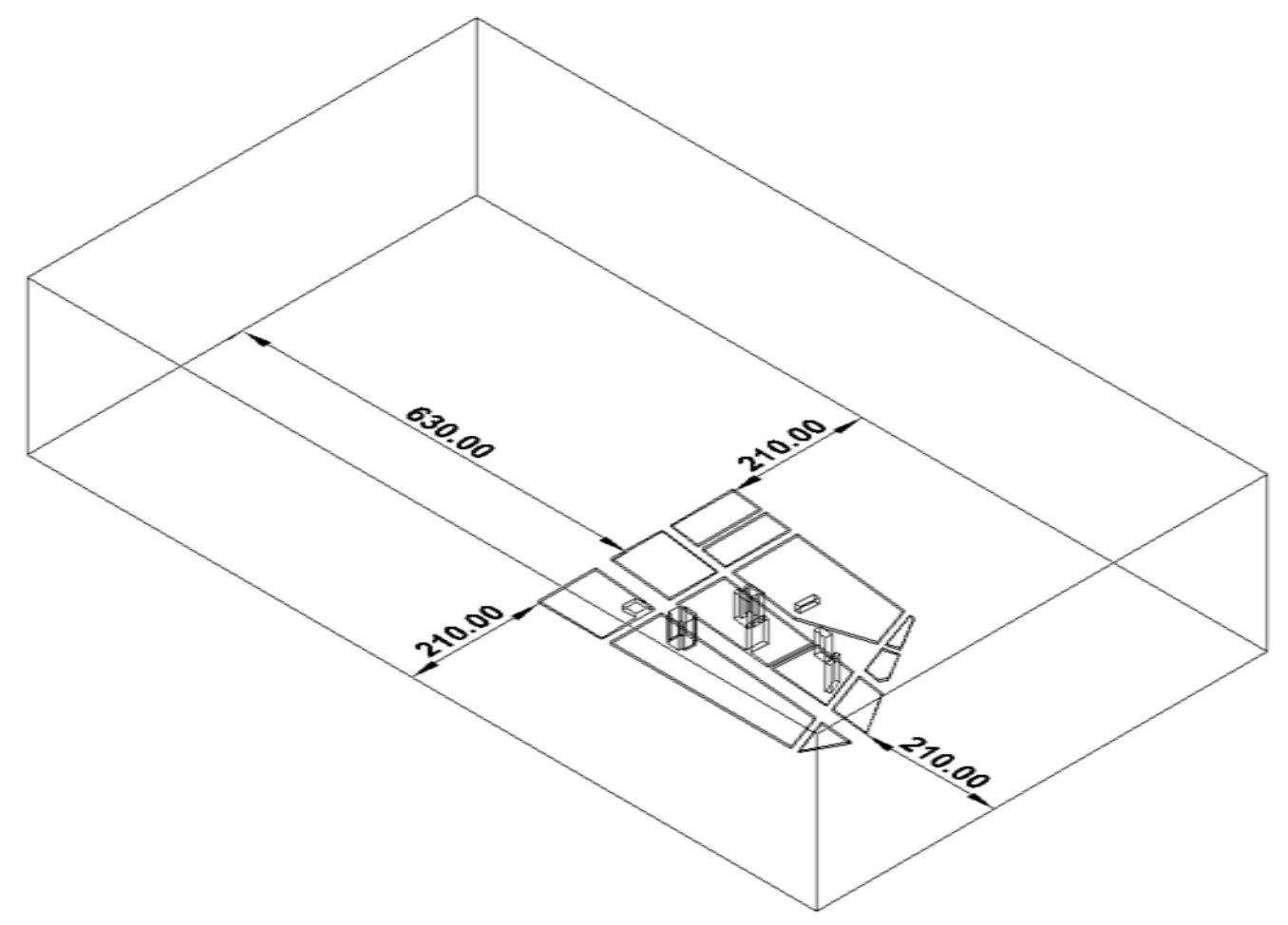

Figura 4.5 - Elaboração do domínio

Após a definição da dimensão e forma do domínio, os edifícios foram subtraídos do domínio, gerando um negativo volumétrico como dito anteriormente. Todo e qualquer elemento que não tivesse influência na simulação foi eliminado e o modelo, como um bloco único exportado no formato Acis, extensão *.sat, compatível para ser aberto no Icem CFD.

\subsubsection{Meshing}

Ao importar a geometria elaborada no AutoCAD, o Icem CFD faz o reconhecimento desta geometria e em seguida gera a malha (mesh).

A primeira etapa para realizar a adaptação do modelo é transformar cada um de seus elementos em PARTS. Cada face do modelo será transformada em uma determinada PART. 
DOM_ENTRADA e DOM_SAIDA são as PARTS correspondentes a área de entrada e saída do fluxo de ar no domínio. A área de entrada está da direção de $90^{\circ}$ e a saída na direção oposta, de acordo com a direção dos ventos predominantes da região. DOM_PISO é a PART correspondente ao piso do modelo e DOM_PAREDES corresponde às paredes laterais e superior do domínio. EDIFICIOS é a PART referente a todas as edificações presentes no modelo, com exceção ao edifício objeto desta pesquisa que teve cada uma de suas faces representadas em PARTS diferentes (EDIF_01, ..., EDIF_TETO), com o

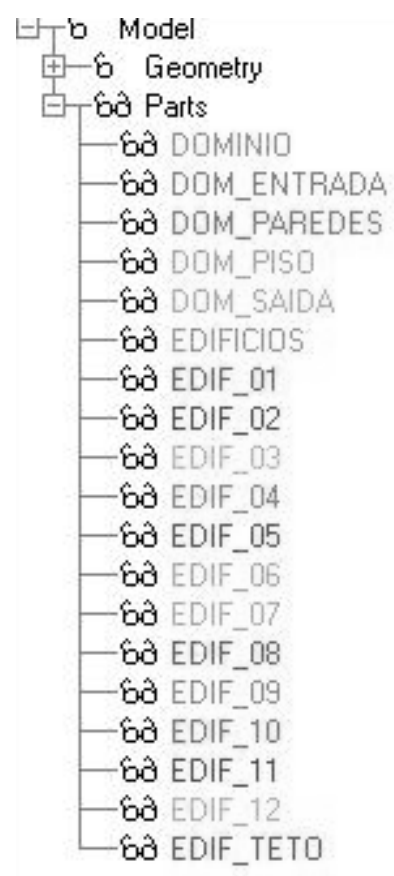

Figura 4.6 - Criação das partes no Icem CFD.

Fonte: CFX objetivo de proporcionar, se for necessário, a leitura de dados separadamente em cada face da edificação, sem a necessidade de se reiniciar todas as etapas da simulação desde o início.

Por fim, todo o espaço por onde o ar escoa dentro deste modelo está representado pela PART DOMINIO, terminando a etapa de definição das PARTS para em seguida começar a confecção da malha - mesh creation.

Segundo Brandão (2008), "a malha (ou mesh) é a discretização do espaço fluido dentro do domínio, definindo os pontos e volumes para os quais a equações fundamentais serão resolvidas". A malha é criada automaticamente pelo programa após a determinação dos parâmetros 
máximos e mínimos dos elementos. Esses elementos são formados por tetraedros, pirâmides, prismas e hexaedros, distribuídos de forma regular. São os parâmetros utilizados:

- MAXIMUM ELeMeNT SIZE: É o tamanho do maior elemento permitido nas regiões do domínio onde não há determinação por parte da geometria, determinante no número final de elementos da malha.

- NATURAL Size: É o tamanho do menor elemento permitido. Recomenda-se que seu valor seja pelo menos a metade da dimensão do menor elemento geométrico do domínio. Quanto menor o seu valor, mais refinada será a malha próximo a elementos de pequena dimensão.

- CELLS IN GAP: é o número de células distribuídas entre dois elementos do domínio, seja superfície ou espaço de ar entre os elementos.

Para estas simulações os parâmetros utilizados foram:

- Maximum element size: 64

- Natural size: 0.25

- Cells in gap: 3

Em seguida, se aplicou os métodos de geração de malha (mesh tet), definindo o número de interações, ou seja, o número de tentativas para geração de malha, e a qualidade mínima que esta malha deve apresentar. Determinou-se 5 interações com qualidade mínima de 0,4. 
Com a finalidade de descrever melhor as trocas nas superfícies, são criadas bordas com prismas (mesh with prism). Então, próximo aos elementos correspondentes aos edifícios e solo do domínio, as células da malha são dividas em prismas, refinando ainda mais esta malha. Definidos todos os parâmetros, deve-se realizar a organização de todos os elementos que compõe a malha (smooth mesh globally), para garantir que eles não se sobreponham uns aos outros e garantir a qualidade da malha.

A combinação desses parâmetros determina o número total de elementos na malha gerada no domínio. No caso da primeira simulação (modelo experimental) foram criados 1.484 .098 elementos sendo 1.137.325 tetraedros, 346.461 prismas e 312 pirâmides, além de 395.855 nós e 118.057 faces.

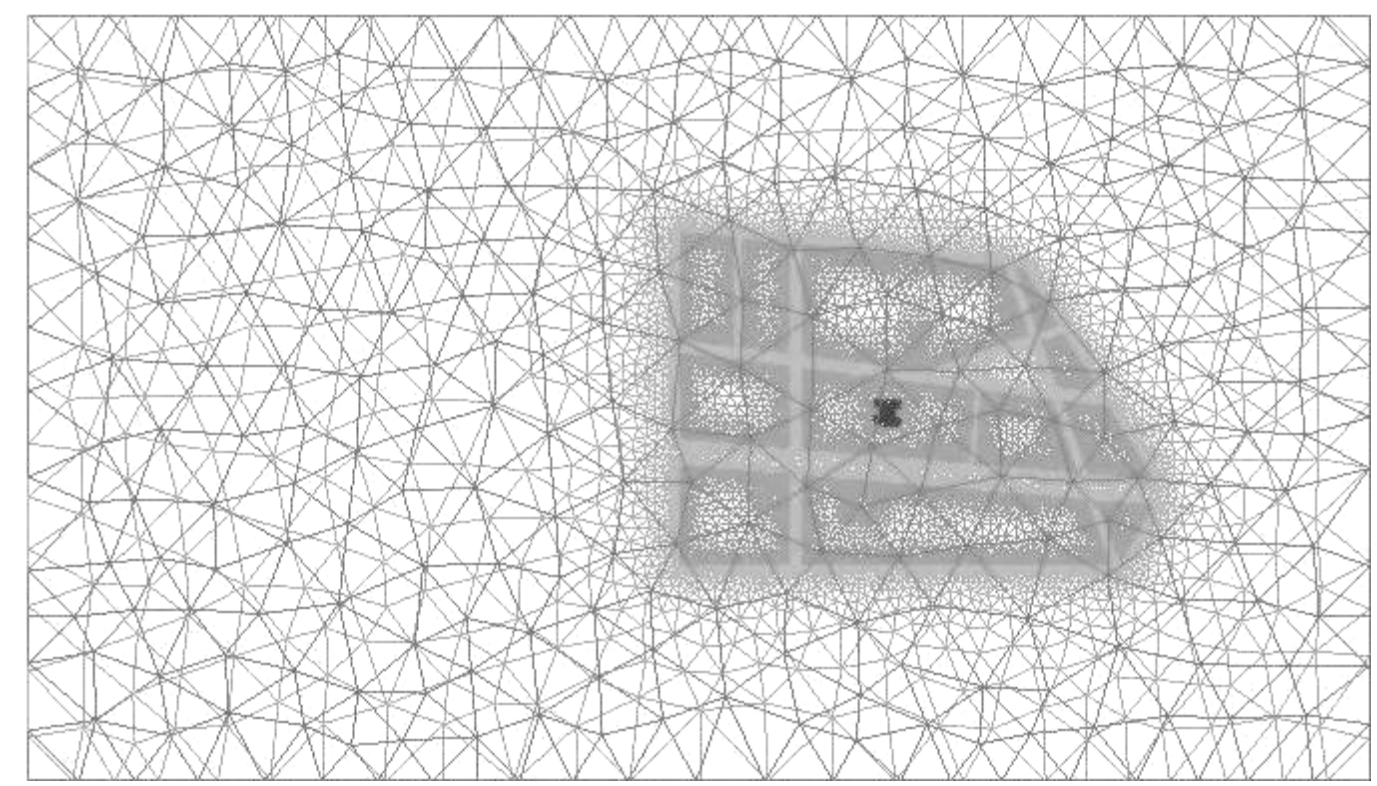

Figura 4.7 - Malha no domínio em planta do modelo experimental Fonte: Software CFX 


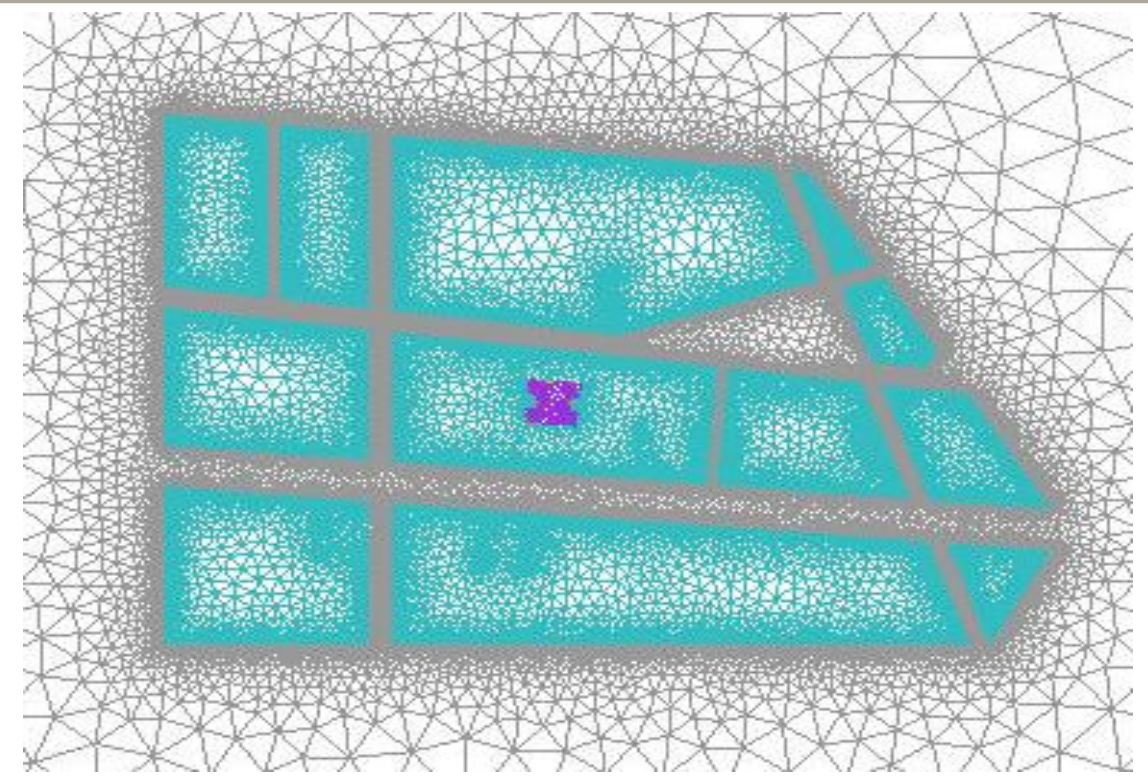

Figura 4.8 - Ampliação da malha no domínio em planta do modelo experimental Fonte: Software CFX

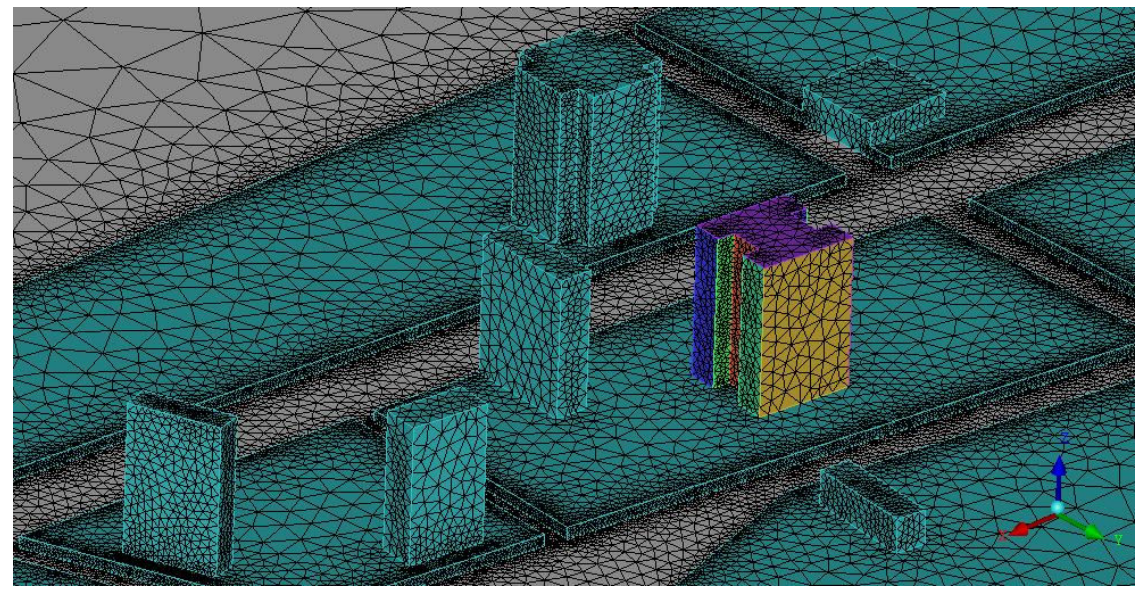

Figura 4.9 - Malha nos edifícios em perspectiva do modelo experimental Fonte: Software CFX

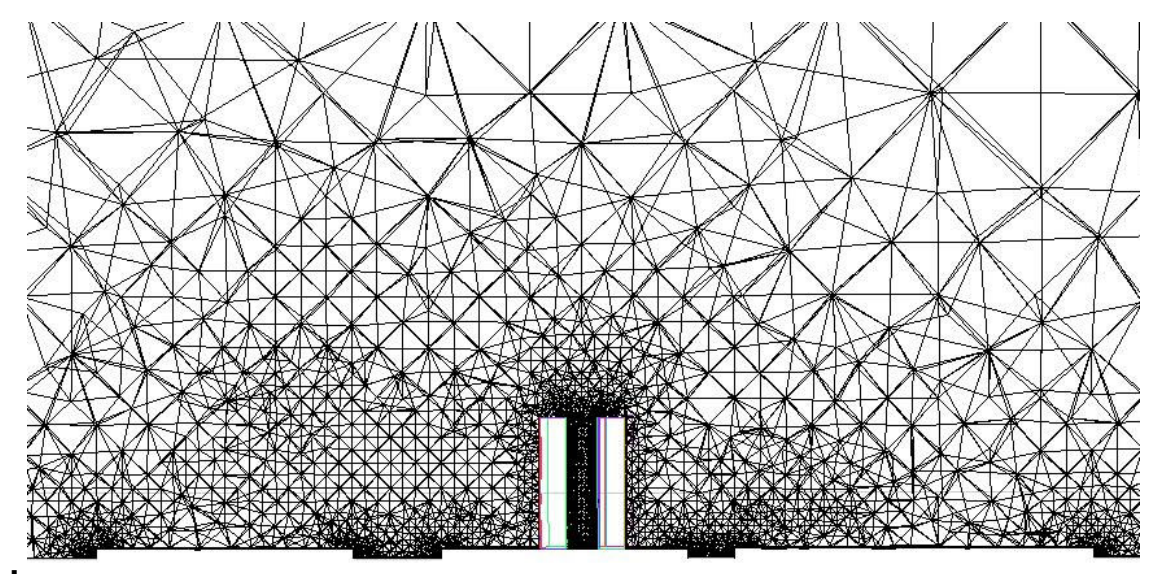

Figura 4.10 - Detalhe em corte da malha em um edifício do modelo experimental Fonte: Software CFX 
O refinamento da malha é uma etapa que merece maior atenção, principalmente próximo a fronteiras sólidas e em modelos com dimensões muito variadas, pois depende da qualidade da malha o sucesso do resultado final da simulação.

Uma vez gerada a malha, um arquivo de extensão *.msh é exportado para o CFX-Pre, próxima etapa da simulação.

\subsubsection{CFX-pre}

No CFX-Pre ocorre a preparação do processamento da simulação, por meio da definição das questões físicas envolvidas na simulação. São determinadas as condições iniciais e as condições de contorno.

As condições iniciais são todas as características referentes ao fluido, às expressões, às variáveis, às unidades de grandeza, à forma de apresentação dos resultados e ao regime adotado na simulação. Todos os parâmetros adotados para as condições iniciais estão inseridos na tabela a seguir, assim como as condições de contorno (que serão retomadas em seguida).

Tabela 4.2 - Parâmetros da simulação inseridos no CFX-Pre

SIMULATION TYPE (Regime adotado na simulação)

\begin{tabular}{l|l}
\hline \hline Option: & Steady State (Regime Permanente) \\
\hline \hline DoMAIN (Características do domínio) & \\
\hline \hline Location & Dominio \\
\hline Domain type & Fluid Domain \\
\hline Fluids List & Air at $25^{\circ} \mathrm{C}$ \\
\hline Coord Frame & Coord 0 \\
\hline Reference Pressure & 1 [atm] \\
\hline Buoyancy - Option & Non Buoyant \\
\hline Domain motion - Option & Stationary \\
\hline \hline
\end{tabular}




\begin{tabular}{l|l}
\hline Heat Transfer Model - Option & None \\
\hline Turbulence Model - Option & k-Epsilon \\
\hline \hline \multicolumn{2}{l|}{ Boundary: DoMíNIO default (características e condições de contorno da PART DOM_PISO) } \\
\hline \hline Boundary Type & WALL (parede=superfície sólida) \\
\hline Location & DOM PISO \\
\hline Wall influence on flow - Option & No Slip (com atrito) \\
\hline Wall roughness - Option & Smooth Wall (baixa rugosidade - parede lisa) \\
\hline \hline Boundary: DoMPAR (características e condições de contorno da PART DOM_PAREDES) \\
\hline \hline Boundary Type & WALL (parede=superfície sólida) \\
\hline Location & DOM PAREDES \\
\hline Wall influence on flow - Option & Free Slip (sem atrito) \\
\hline \hline
\end{tabular}

Boundary: EDIFICIOP (características e condições de contorno da PART EDIFICIOP)

\begin{tabular}{l|l}
\hline Boundary Type & WALL (parede=superfície sólida) \\
\hline Location & EDIF 01,EDIF 02,EDIF 03,EDIF 04,EDIF \\
& 05,EDIF 06,EDIF 07,EDIF 08,EDIF 09,EDIF \\
& 10,EDIF 11,EDIF 12,EDIF TETO \\
\hline WALL INFLUENCE ON FLOW - Option & No Slip (com atrito) \\
\hline WALL ROUGHNESS - Option & Smooth Wall (baixa rugosidade - parede lisa) \\
\hline
\end{tabular}

Boundary: EDIFICIOS (características e condições de contorno da PART EDIFICIOS)

\begin{tabular}{l|l}
\hline \hline Boundary Type & WALL (parede=superfície sólida) \\
\hline Location & EDIFICIOS \\
\hline WALL INFLUENCE ON FLOW - Option & No Slip (com atrito) \\
\hline WALL ROUGHNESS - Option & Smooth Wall (baixa rugosidade - parede lisa) \\
\hline
\end{tabular}

Boundary: ENTRADA (características e condições de contorno da PART DOM_ENTRADA)

\begin{tabular}{l|l}
\hline \hline Boundary Type & INLET (entrada) \\
\hline Location & DOM ENTRADA \\
\hline Flow regime - Option & Subsonic \\
\hline Mass and momentum - Option & $\begin{array}{l}\text { Cartesian Velocity Components } \\
U=u 1\end{array}$ \\
& $\begin{array}{l}\mathrm{W}=\mathrm{v} 1 \\
\end{array}$ \\
\hline Turbulence - Option & [m s^-1] \\
\hline Profile Vector Components & Medium Intensity and Eddy Viscosity Ratio \\
\hline \hline Boundary: SAIDA (características e condições de contorno da PART DOM_SAIDA) \\
\hline \hline Boundary Type & Cartesian Velocity Components \\
\hline Interface Boundary & OPENING (abertura) \\
\hline Location & Off \\
\hline Flow regime - Option & DOM SAIDA \\
\hline Mass and momentum - Option & Subsonic \\
\hline Relative Pressure & Entrainment Condition \\
\hline Turbulence - Option & 0 [Pa] \\
\hline \hline
\end{tabular}


OUTPUT CONTROL (Forma de apresentação e armazenamento dos resultados)

\begin{tabular}{|c|c|}
\hline Result - Option & Full \\
\hline File compression level & Default \\
\hline \multicolumn{2}{|c|}{$\begin{array}{l}\text { SOLVER CONTROL (Determina os parâmetros para a solução matemática do modelo pel } \\
\text { módulo de cálculo) }\end{array}$} \\
\hline Advection Scheme - option & High Resolution \\
\hline Convergence Control - timescale control & Auto timescale \\
\hline Max. No Iterations & $300^{7}$ \\
\hline Lengh sclate option & Conservative \\
\hline Convergence Criteria - Residual Type & RMS \\
\hline Residual Target & 1.E-4 (meta principal) \\
\hline
\end{tabular}

SOLUTION UNITS (Definição das grandezas utilizadas nos cálculos)

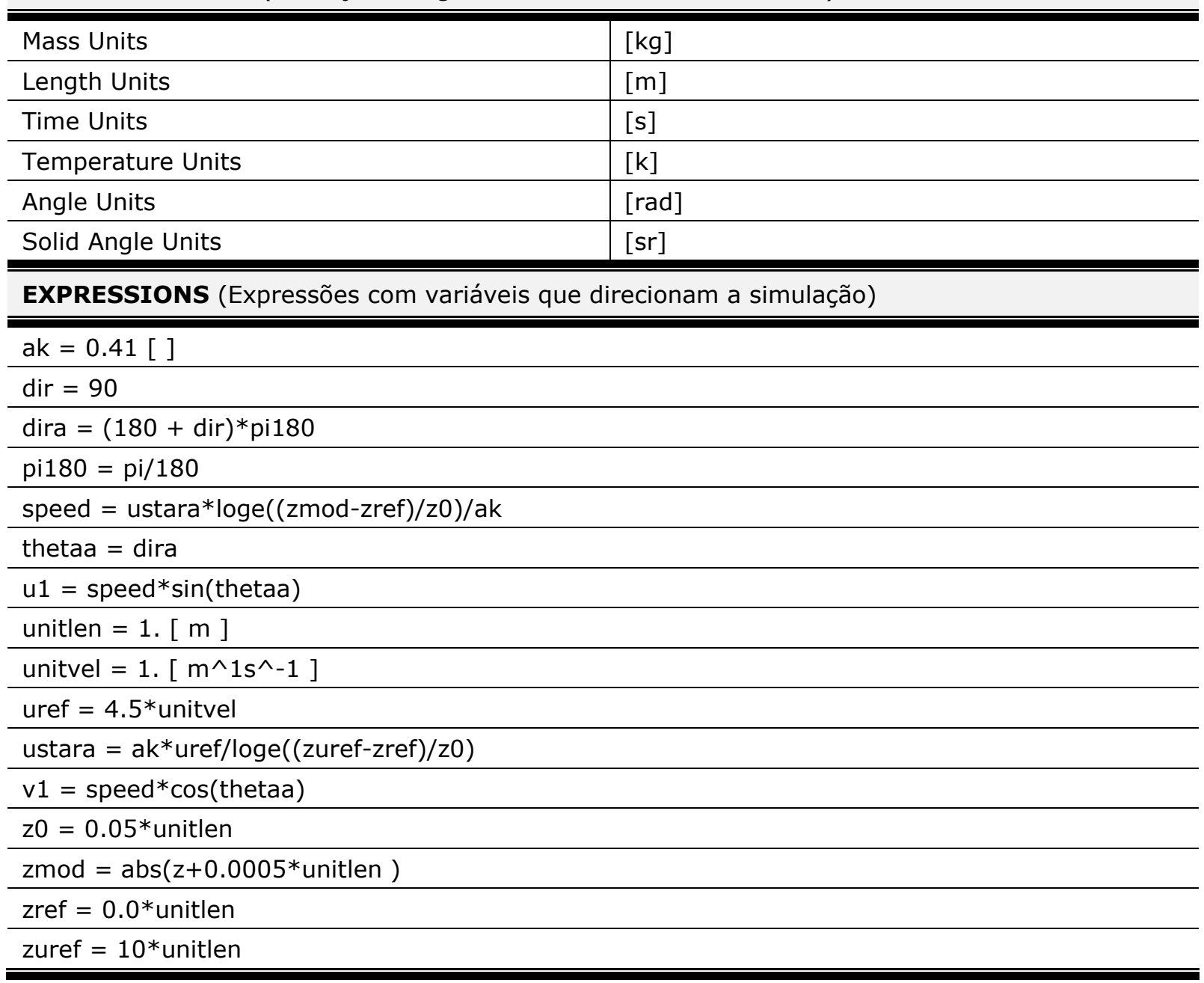

7 As 300 interações foram propostas inicialmente esperando que as simulações convergissem antes deste ponto, como não aconteceu a convergência esperada, alguns testes foram feitos com 500 ou mais interações, mas notou-se que a resposta final encontrada não apresentava diferença aumentando-se o numero total de convergências. Assim, adotaram-se as 300 interações propostas inicialmente em todas as simulações para diminuir o tempo total do processo de simulação no CFX-Solver. 
Todas estas informações da tabela anterior podem ser salvas em um único arquivo com extensão *.ccl, gerado no CFX-Pre. Este arquivo pode ser importado de uma simulação anterior e seus dados adaptados a nova simulação, se necessário. No caso desta pesquisa, este arquivo gerado nesta primeira simulação será empregado nas próximas simulações por se tratar do mesmo padrão de modelo, mesmas condições de contorno, e mesmo objetivo final.

As condições de contorno, ou boundary conditions, são os parâmetros aplicados a cada uma das PARTS do domínio, determinando as características de cada uma das faces que influenciarão no escoamento do ar. As PARTS podem ser definidas como parede (wall), entrada (inlet), saída (outlet) ou abertura (opening). Definem-se como parede as fronteiras sólidas que não permitem a entrada nem a saída do fluido. Neste caso as PARTS DOM_PISO e DOM_PAREDES e EDIFICIOS foram definidas como parede.

Entrada, saída e abertura, são as PARTS por onde o fluido entra ou sai do domínio. Nessa simulação a PART DOM_ENTRADA foi definida como entrada e então foi determinada inicialmente a direção e velocidade do vento. Já a PART DOM_SAIDA foi definida como abertura, por onde o fluido pode entrar ou sair do domínio e para isso define-se a pressão estática de 0 Pa com a finalidade de não interferir no fluxo do fluido ao longo do domínio. 
Na figura 4.11 pode-se perceber por meio das setas (vetores) onde estão localizadas a entrada e a abertura do domínio, definidas no CFX-Pre.

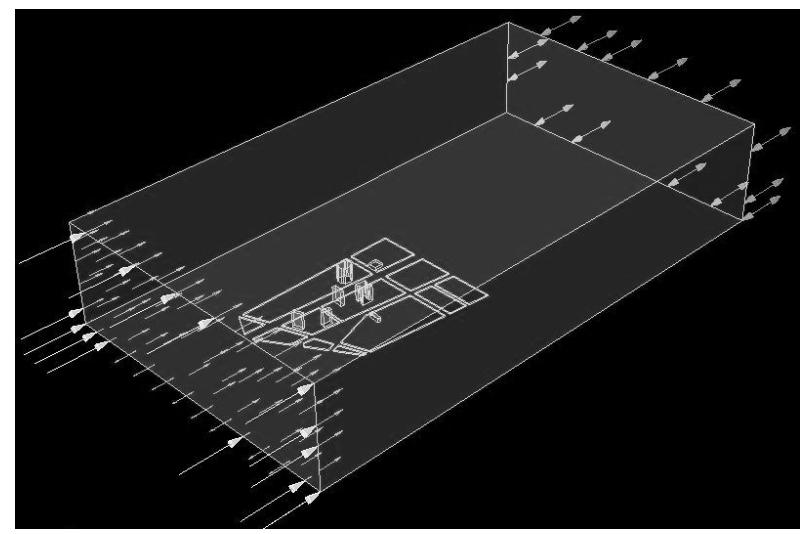

Figura 4.11 - Domínio com definição da condição de contorno - modelo experimental Fonte: CFX-Pre

Finalizando mais uma etapa, o programa gera um arquivo com extensão *.cfx e exporta para o CFX-Solver.

\subsection{SOLVER - DEFINIÇÃO DAS CONDIÇÕES INICIAIS E DE CONTORNO}

Após todas as etapas de elaboração do modelo, criação da malha, definição de todos os parâmetros descritos até aqui, é a hora iniciar o processamento no CFX-Solver, ou a simulação propriamente dita.

O tempo necessário para a finalização desta etapa vai depender do tamanho do domínio, da geometria do modelo, do refinamento da malha, da capacidade do computador, e todos os parâmetros estimados.

No caso desta simulação, o processo de simulação no Solver demorou 11 horas para realizar todas as interações pedidas no CFX-Pre. É importante destacar que inicialmente foram determinada 300 interações totais para finalizar o processo de simulações, caso o resultado esperado 
não atingisse antes o valor mínimo do critério de convergência de $1 \times 10^{-4}$, ou seja, a simulação deve parar quando atinge um desses dois parâmetros primeiro. De acordo com o manual do CFX (2003), "convergências de $1 \times 10^{-4}$ são boas convergências e deve ser a meta da maioria das simulações". Mas infelizmente nessa simulação esse número não foi alcançado mesmo após 539 interações $^{8}$, o que não elimina os resultados alcançados, já que segundo o CFX (2003), "convergências entre $5 \times 10^{-4}$ e $1 \times 10^{-4}$ são regulares e podem ser aplicadas" e o objetivo principal dessa primeira simulação (modelo experimental) foi avaliar e se familiarizar com a ferramenta CFX, para em seguida definir as próximas simulações para a pesquisa.

No fim do processamento de simulação o CFX gera um arquivo de resultados de extensão *.res. Esse é o arquivo que contem o resultado de todas as etapas realizadas e para visualizá-lo em forma de imagens bi ou tridimensionais, este arquivo é importado para o CFX-Post, última etapa do processo do CFX.

\subsection{PoST-PROCESSOR - CONVERGÊNCIA E ANÁLISE DOS RESULTADOS}

O CFX-Post é onde se podem visualizar os resultados das simulações de acordo com o interesse do estudo. É possível obter diferentes informações do escoamento do fluido dentro do domínio, como direção e

${ }^{8}$ Quando é necessário dar uma pausa nesta etapa da simulação, ao reiniciar o programa recomeça a contagem das interações previstas inicialmente, somando as interações já concluídas a, neste caso, todas as 300 previstas na definição dos parâmetros. Esta pausa no meio da simulação também pode ser útil em casos de modelos muito complexos, uma vez que um arquivo de resultado é gerado e se evita a perda de algum resultado já alcançado se algum problema ocorrer. 
velocidade do vento, coeficiente de pressão nas superfícies, diferenças de temperatura, entre outras.

Inicialmente se define os planos no domínio onde serão visualizados os resultados. Na simulação do modelo experimental foram gerados três planos horizontais. O primeiro (H1p5) localizado a uma altura de $1,50 \mathrm{~m}$ do solo, altura do pedestre. O segundo ( $\mathrm{H} 4 \mathrm{p} 5)$ foi gerado a $4,5 \mathrm{~m}$ do solo, com o objetivo de analisar os resultados num plano acima das edificações mais baixas, estimadas com 3,0m de altura. E o terceiro (H37p5) e último plano horizontal foi gerado a $37,5 \mathrm{~m}$ do solo, correspondendo à altura média onde está localizado o apartamento do $11^{\circ}$ andar, onde ocorrerão as simulações seguintes.

Também foram definidos quatro planos verticais, sendo dois transversais (PVT1 e PVT2) e dois longitudinais (PVL1 e PVL2). Nos dois sentidos os pontos centrais dos planos foram o centro do apartamento objeto de estudo e o centro do edifício. Embora nesta primeira simulação a diferença possa não ser muito significativa, mas em seguida, ao inserir as aberturas do apartamento e propor algumas alterações no projeto do apartamento, a comparação entre estes planos pode gerar respostas interessantes para o estudo.

Em cada um dos planos foram analisadas inicialmente a direção e a velocidade dos ventos. Através de vetores além de podermos avaliar a velocidade por meio da graduação das cores, a direção do escoamento pode ser visualizada claramente. Já a velocidade dos ventos é melhor 
visualizada por contornos. Portanto foram geradas as imagens com vetores e com contornos em todos os planos, além de imagens ortogonais e em perspectiva também.

Assim, para a análise da velocidade do vento em todos os planos, foram geradas imagens de contorno, inseridas a seguir.

\subsubsection{Contorno da velocidade do vento no Plano Horizontal} H1p5 - nível pedestre $(h=1,5 m)$

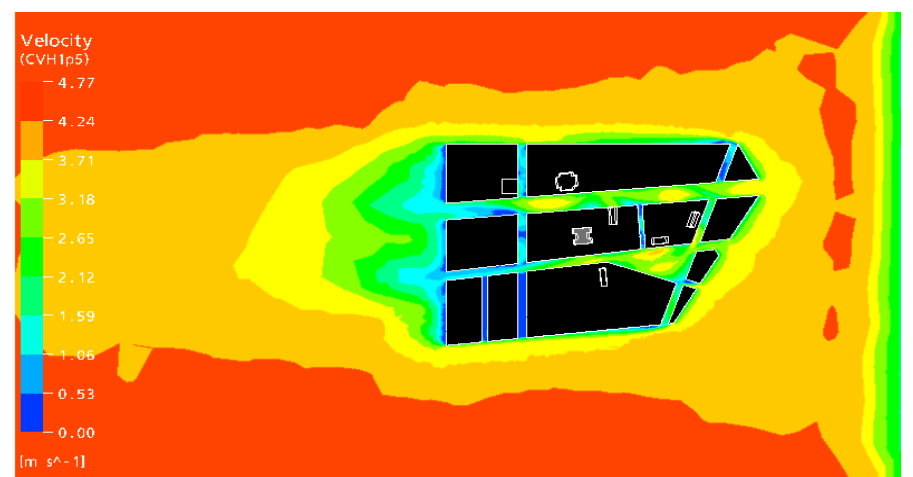

Figura 4.12- Contorno da vel. do vento no H1p5 (ortogonal)

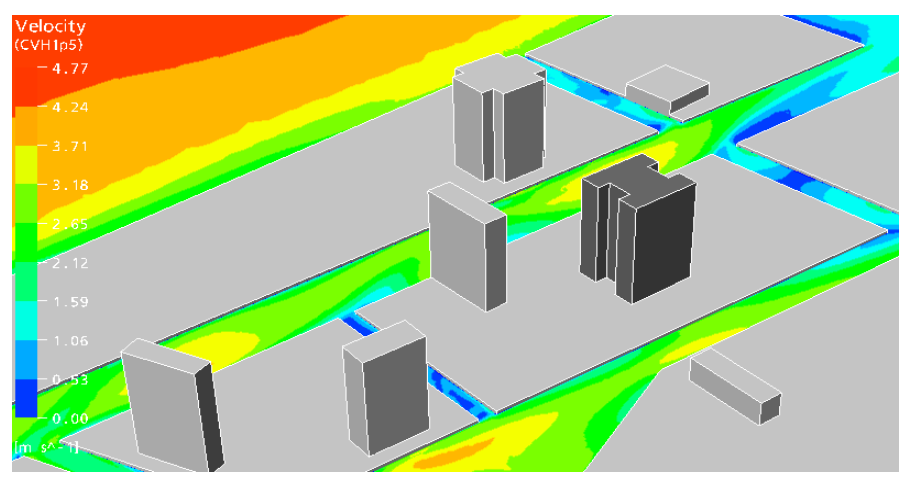

Figura 4.13 - Contorno da vel. do vento no H1p5 (perspectiva)

Na figura 4.12 tem-se uma visão geral de toda a área e notam-se claramente como as edificações alteram a velocidade dos ventos. De modo geral, eliminando as áreas onde não existem edificações, neste plano a velocidade máxima é de $3,7 \mathrm{~m} / \mathrm{s}$ nas ruas no sentido do vento. $\mathrm{Na}$ maior parte a velocidade encontra-se entre 1,6 e 3,2m/s, com exceção 
nas ruas perpendiculares a direção dos ventos, que apresenta velocidade máxima de $1,6 \mathrm{~m} / \mathrm{s}$, com pequenos pontos próximos a zero.

Na figura 4.13, pode-se analisar a imagem com as edificações em perspectiva, em destaque para a quadra central da área de estudo onde está localizado o edifício Montparnasse (em cinza escuro).

\subsubsection{Contorno da velocidade do vento do Plano Horizontal} H4p5 - acima das edificações térreas $(h=4,5 m)$

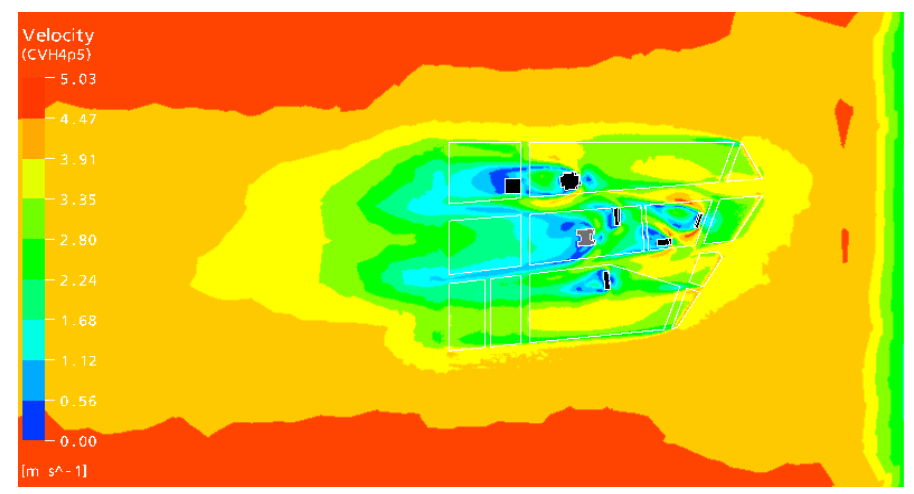

Figura 4.14 - Contorno da vel. do vento no H4p5 (ortogonal)

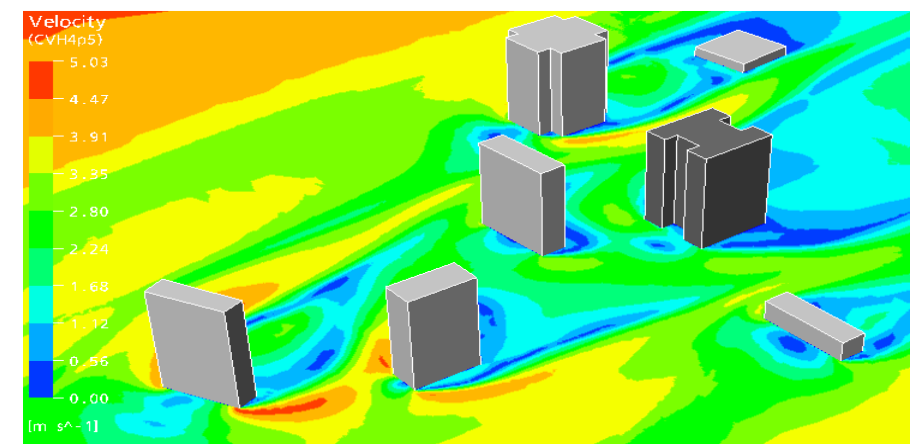

Figura 4.15 - Contorno da vel. do vento no H4p5 (persp.)

Nas figuras 4.14 e 4.15, com o plano numa altura acima das edificações térreas, é mais fácil notar como as edificações altas são uma barreira para vento, ao notarmos o contorno da velocidade do vento na parte posterior aos edifícios. Também nota-se que, dependendo da forma e orientação do edifício em relação à direção do vento, essa "sombra de 
vento" a sotavento é maior ou menor, causando impactos diferentes nas edificações vizinhas. Na altura deste plano a velocidade máxima atingida foi de $5,0 \mathrm{~m} / \mathrm{s}$, mas numa área muito pequena, melhor considerar $3,9 \mathrm{~m} / \mathrm{s}$, por apresentar maior destaque nas imagens.

\subsubsection{Contorno da velocidade do vento no Plano Horizontal H37p5 - nível do meio do apartamento do $11^{\circ}$ andar $(h=37,5 m)$}

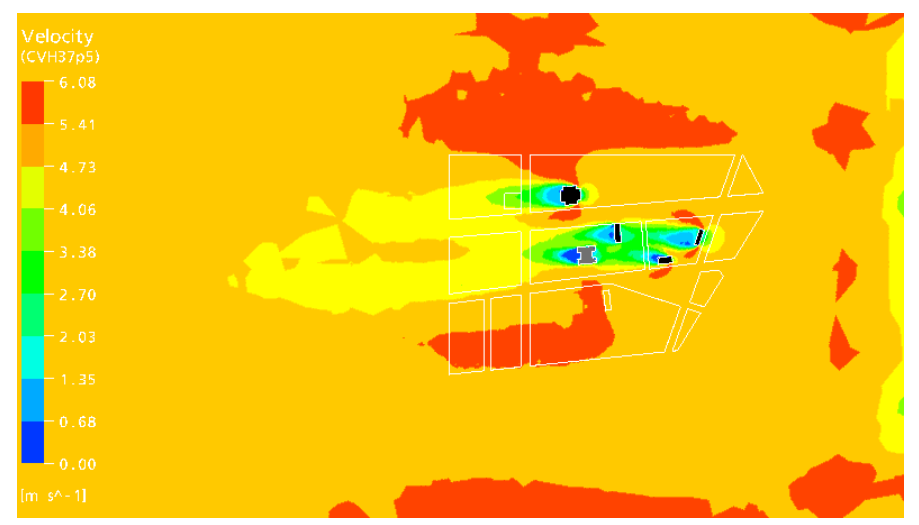

Figura 4.16 - Contorno da vel. do vento no H37p5 (ortogonal)

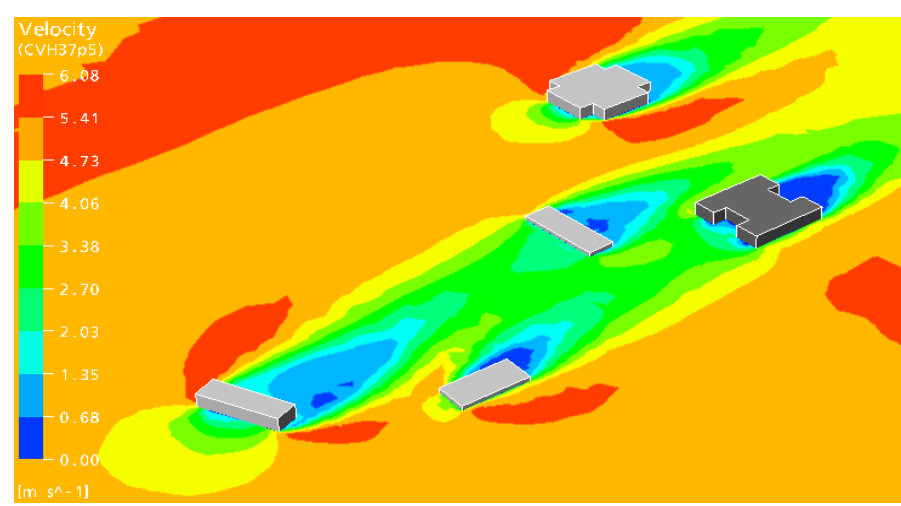

Figura 4.17 - Contorno da vel. do vento no H37p5 (persp.)

A velocidade do vento a $37,5 \mathrm{~m}$ de altura apresenta uma máxima de $6,0 \mathrm{~m} / \mathrm{s}$, com poucas áreas de pouca velocidade apenas nas regiões a sotavento dos edifícios mais altos. Porém, como a verticalização nessa área ainda não está muito presente, a distância entre os edifícios permite 
uma permeabilidade do vento de forma que nenhuma fachada voltada para a direção leste receba um vento com velocidade abaixo de $4,0 \mathrm{~m} / \mathrm{s}$.

É importante destacar que os valores apresentados são referentes apenas ao plano em que está destacado. Por isso que em cada plano a velocidade máxima encontrada e inserida na legenda é diferente uma das outras.

4.6.4 Contorno da velocidade do vento no Plano Vertical longitudinal 1 - PVL1 - no centro do apartamento

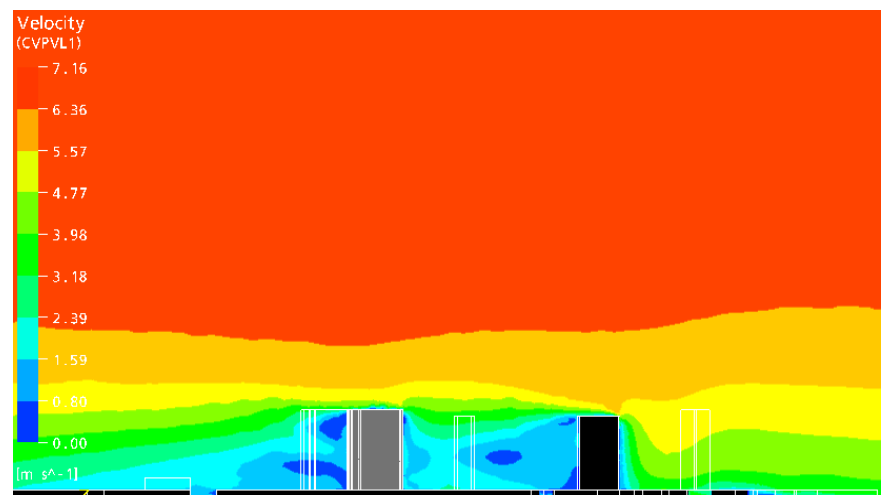

Figura 4.18 - Contorno da vel. do vento no PVL1 (ortogonal)

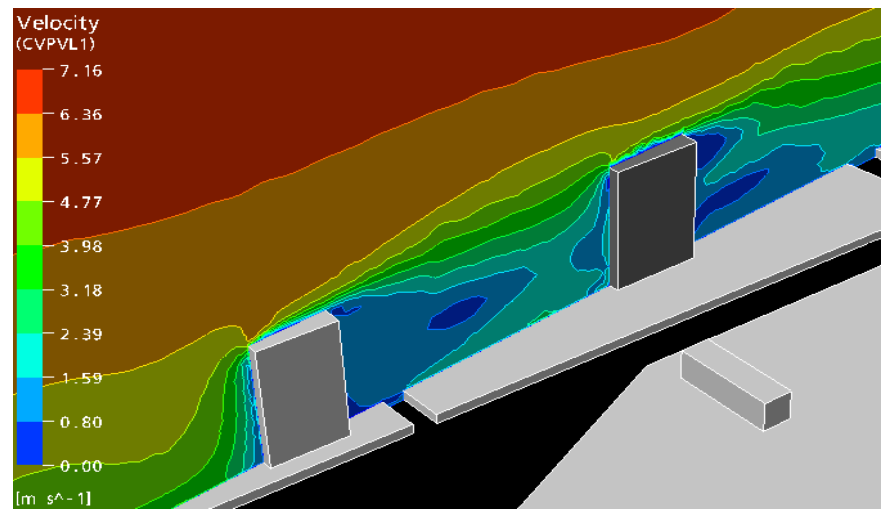

Figura 4.19 - Contorno da vel. do vento no PVL1 (persp.)

Nas imagens apresentadas nas figuras 4.18 e 4.19 , é possível notar que o programa trabalha com o gradiente de vento como também se pode perceber como as edificações vizinhas podem ser uma barreira significativa do vento dependendo da distância entre elas. 
É interessante notar também, que, mesmo que não exista uma barreira física na frente da edificação, o próprio "caminho" que o vento percorre ao encontrar uma edificação alta, faz com que sua velocidade seja diminuída. Porém, não se pode esquecer que neste modelo as edificações não são permeáveis e à medida que aberturas são inseridas nos prédios, esse fluxo próximo aos edifícios pode ser alterado. Porém, nesta primeira simulação procura-se analisar apenas o comportamento da direção e velocidade do vento na área urbana.

\subsubsection{Contorno da velocidade do vento no Plano Vertical Longitudinal 2 - PVL2 - centro do edifício}

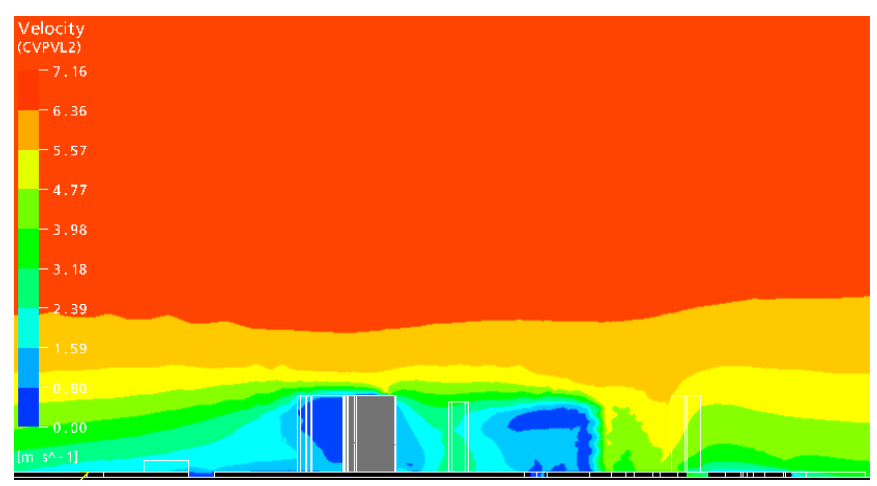

Figura 4.20 - Contorno da vel. do vento no PVL2 (ortogonal)

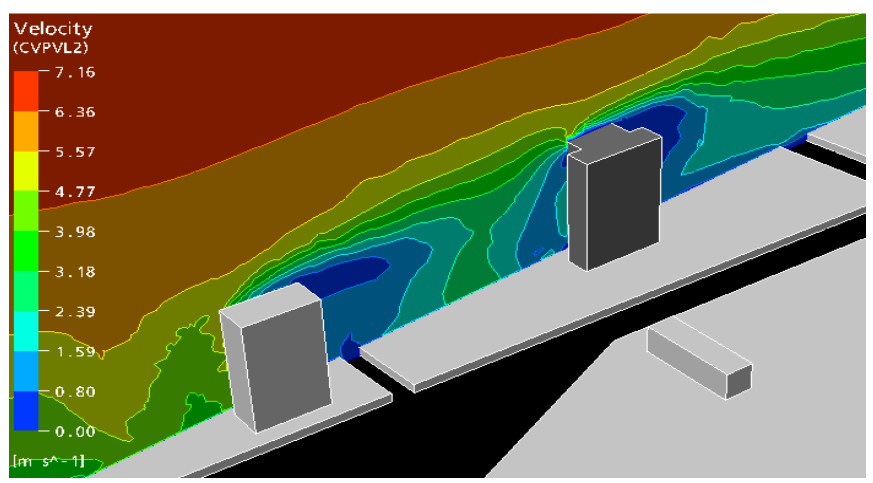

Figura 4.21 - Contorno da vel. do vento no PVL2 (persp.)

As figuras 4.20 e 4.21 representam o contorno da velocidade do vento no plano com mesmo sentindo do anterior, porém cruzando no centro do edifício Montparnasse. Interessante notar como apesar da pouca 
distância entre os planos, as respostas apresentam diferenças entre elas, o que pode ser causada pela forma da edificação, uma vez que esta forma pode estar causando certa turbulência nessa região.

Isso poderá ser melhor visualizado nas imagens geradas com vetores que representam a direção dos ventos.

\subsubsection{Contorno da velocidade do vento no Plano Vertical}

Transversal 1 - PVT1 - centro de edifício

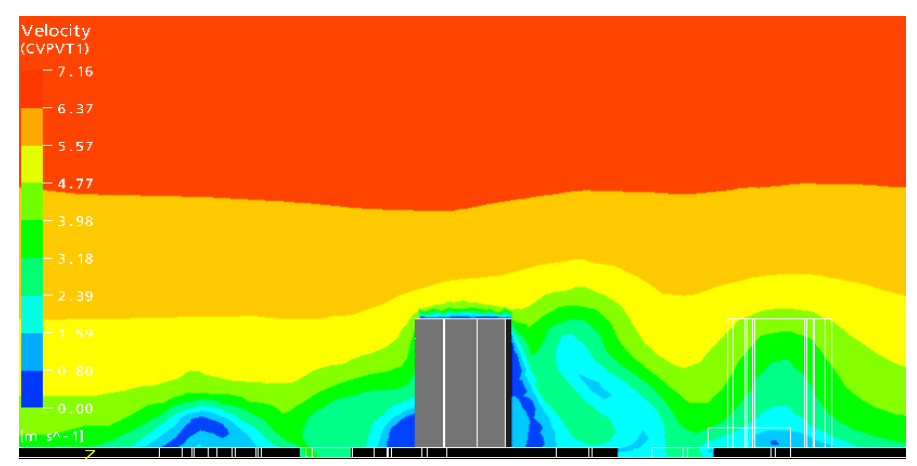

Figura 4.22 - Contorno da vel. do vento no PVT1 (ortogonal)

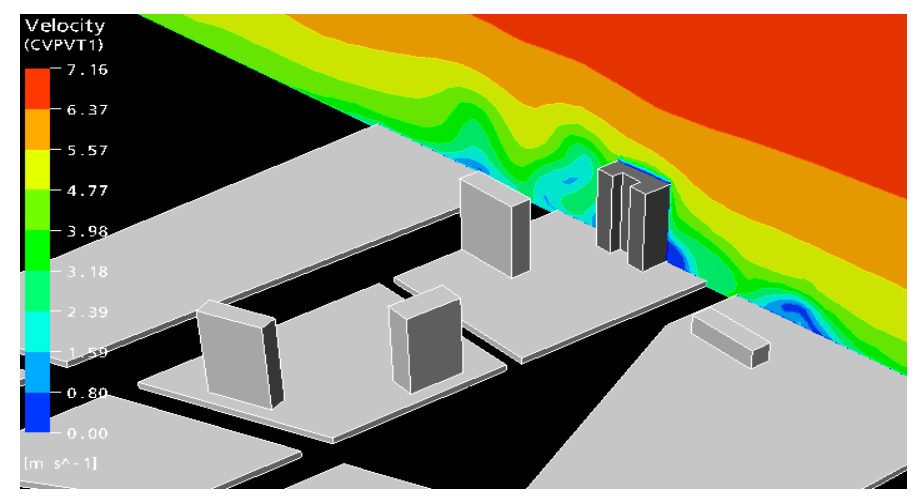

Figura 4.23 - Contorno da vel. do vento no PVT1 (persp.)

As figuras 4.22 e 4.23 mostram o plano no sentido transversal passando pelo centro do edifício e sem barreiras físicas em nenhum lado. Neste sentido o vento que atinge o edifício em velocidades maiores e a influência da edificação neste fluxo é um pouco menor uma vez que a direção do vento está perpendicular ao plano apresentado. 
Por meio dessas imagens e da comparação com as anteriores, vê-se a importância do estudo do efeito do vento em todas as direções e todas as fachadas do edifício, uma vez que o vento pode tomar direções diferentes e ter a velocidade alterada em função da forma e orientação do edifício. Esse fato é de difícil predição, uma vez que não apresenta uma regularidade por toda a extensão da edificação e seu entorno.

\subsubsection{Contorno da velocidade do vento no Plano Vertical}

\section{Transversal 2 - PVT2 - centro do apartamento}

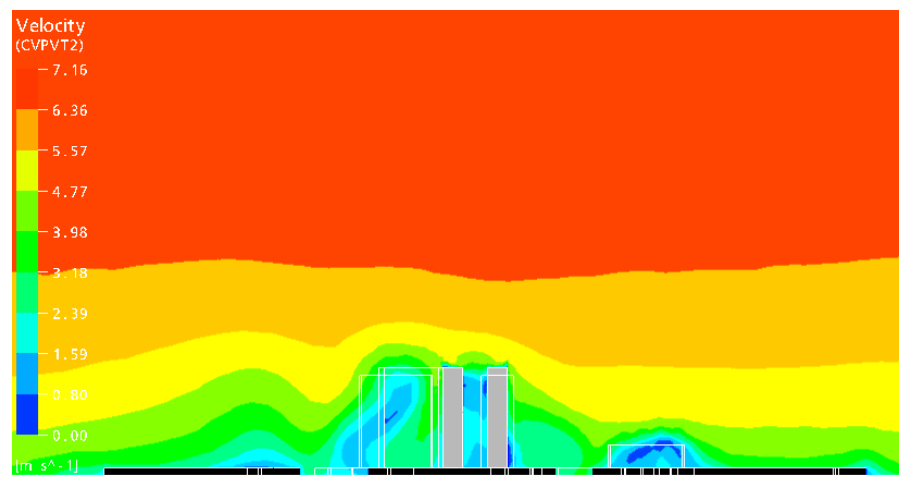

Figura 4.24 - Contorno da vel. do vento no PVT2 (ortogonal)

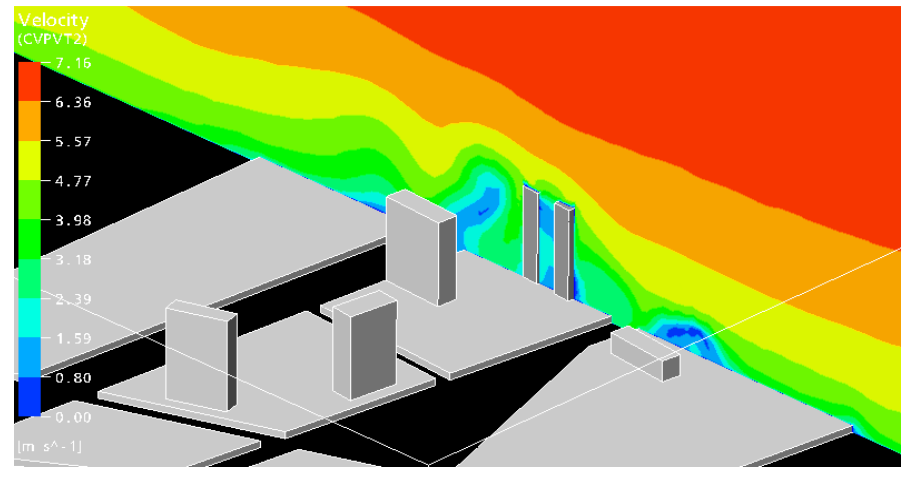

Figura 4.25 - Contorno da vel. do vento no PVT2 (persp.)

A diferença das figuras 4.24 e 4.25 para as duas anteriores a elas é a localização do plano. Neste caso ele está passando mais próximo da extremidade do edifício, onde a forma fica diferenciada, causando um padrão de vento diferenciado no centro do edifício. 


\subsubsection{Vetores da velocidade e direção dos ventos}

A seguir estão inseridas as imagens de vetores que mostram a direção dos ventos nos mesmos planos em que foram vistas as imagens com contornos. É uma forma de complementar as análises e comparar as diferentes formas de visualização dos resultados oferecidas pelo CFX.

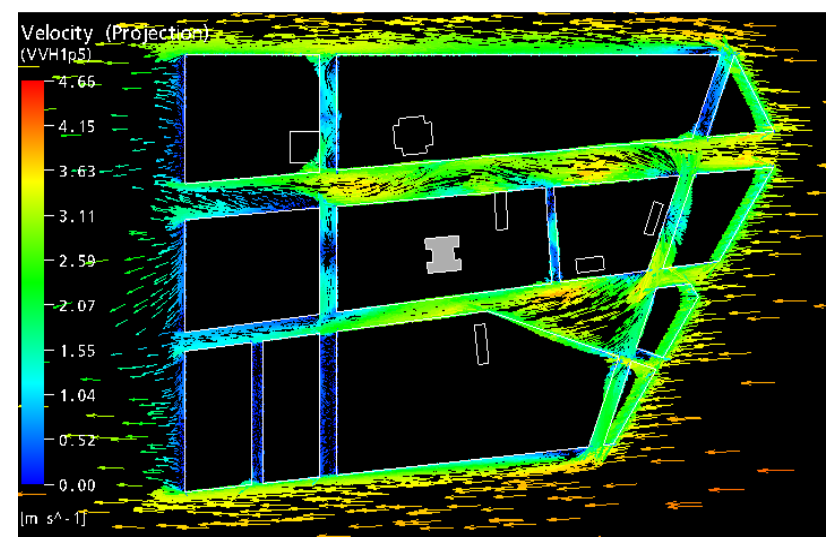

Figura 4.26 - Vetores de vel. do vento no plano horizontal a 1,50m (ortogonal)

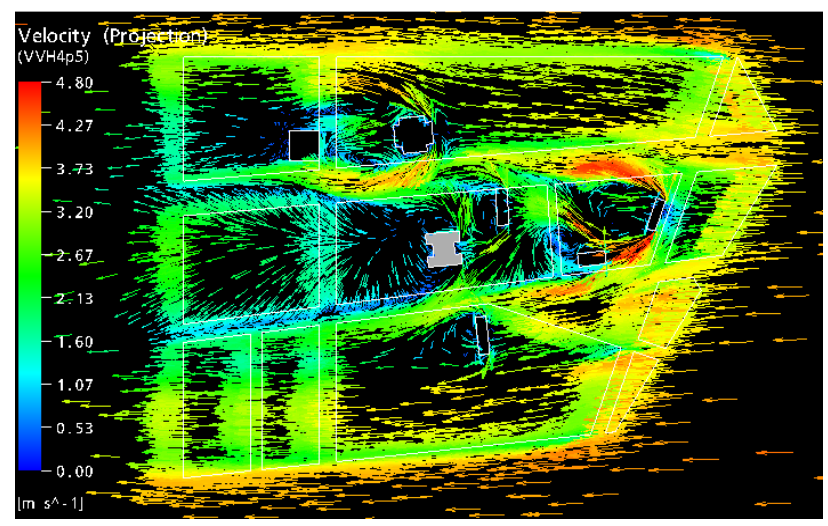

Figura 4.27 - Vetores de vel. do vento no plano horizontal a 4,5m (ortogonal)

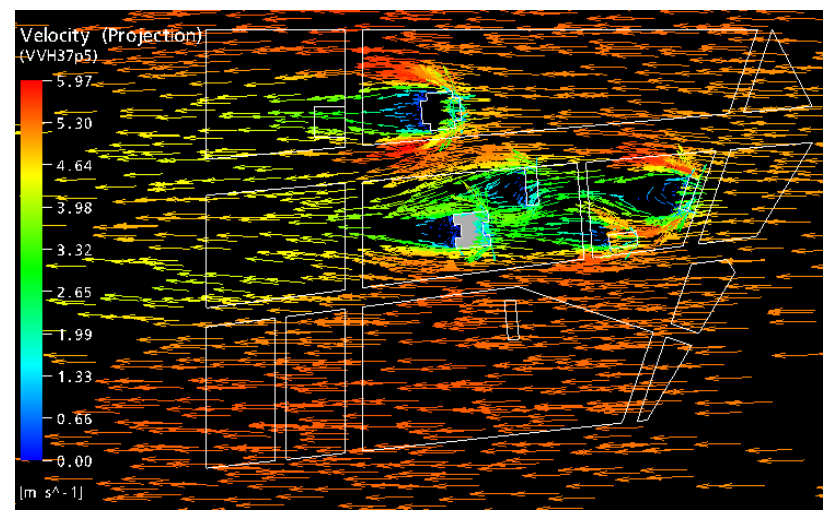

Figura 4.28 - Vetores de vel. do vento no planos horizontal a 37,5m (ortogonal) 
Notamos pelas figuras 4.26 a 4.28 que a direção do vento se modifica ao encontrar as barreiras, formando uma sombra de vento e turbulências a sotavento. Além disso, quanto maior a altura do plano, maior a velocidade e menos alterações no fluxo pela diminuição de barreiras físicas. Nas figuras de 4.29 a 4.31, podem-se ver os vetores de vento nos mesmos planos horizontais, agora em perspectiva.

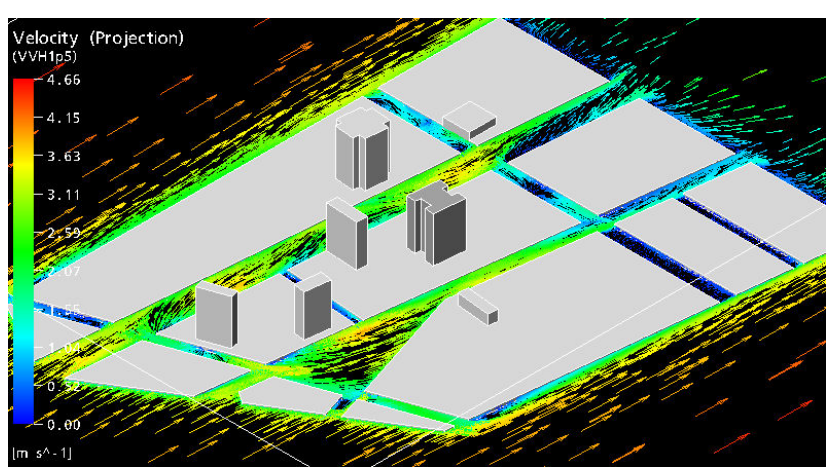

Figura 4.29 - Vetores de vel. do vento no plano horizontal a 1,5m (persp.)

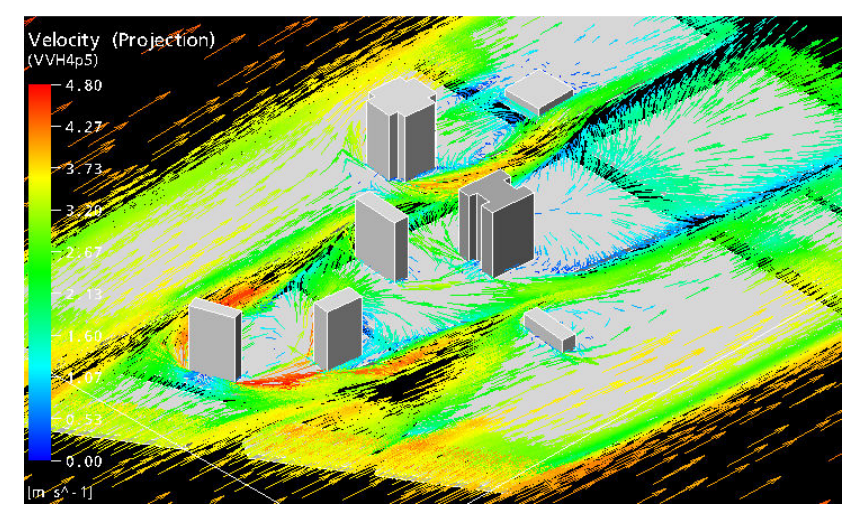

Figura 4.30 - Vetores da vel. do vento no plano horizontal a 4,5m (persp.)

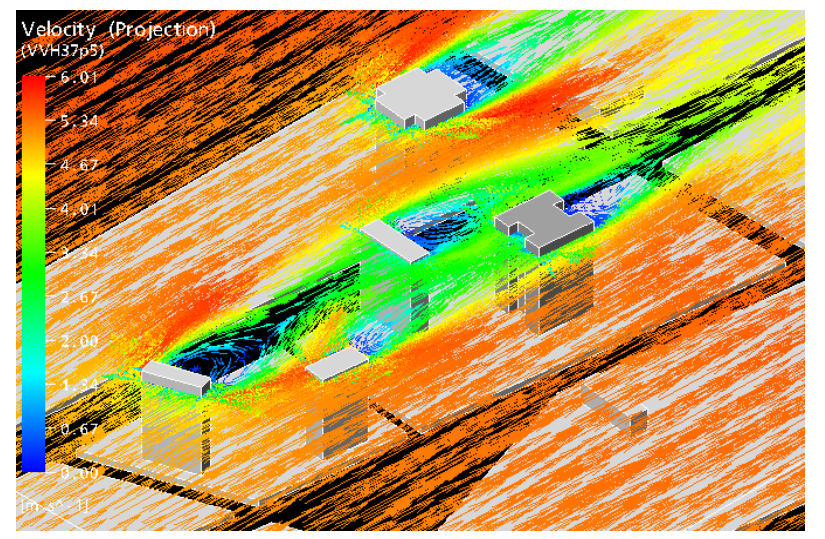

Figura 4.31 - Vetores da vel. do vento no plano horizontal a 37,5m (persp.) 


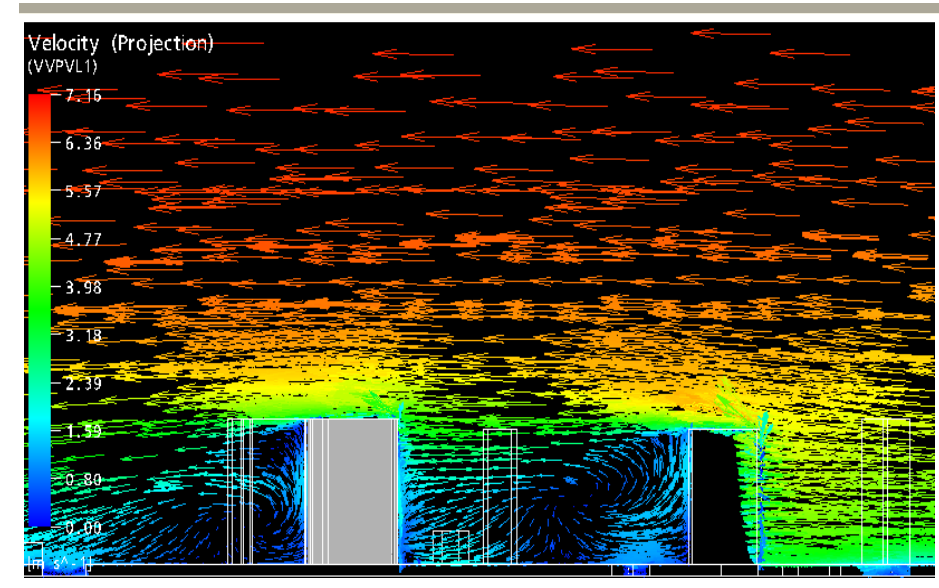

Figura 4.32 - Vetores de velocidade do vento no plano vertical longitudinal 01 (ortogonal)

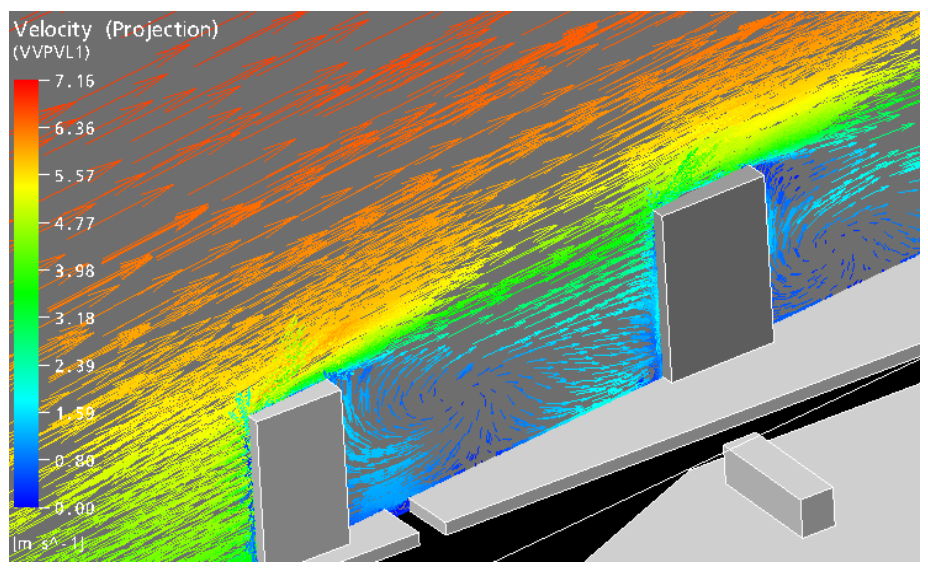

Figura 4.33 - Vetores de velocidade do vento no plano vertical longitudinal 01 (perspectiva)

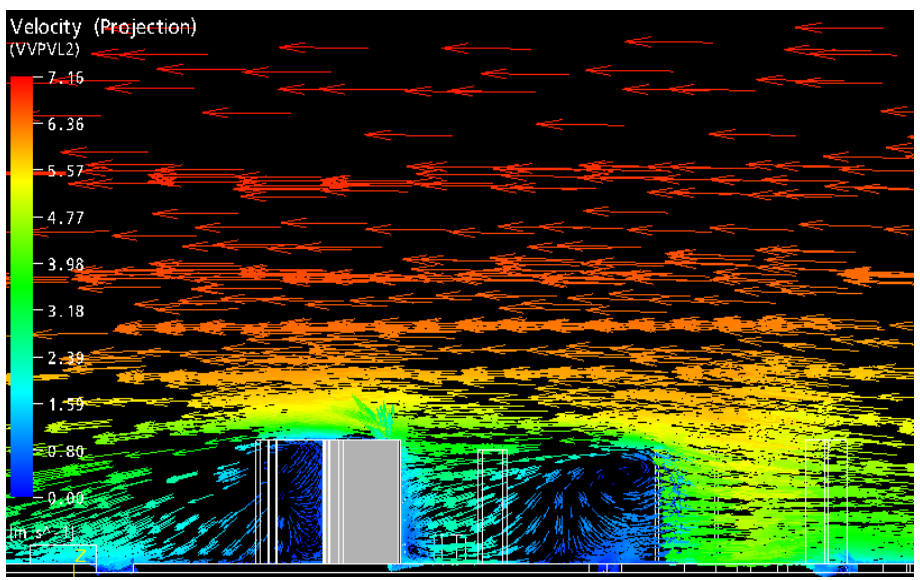

Figura 4.34 - Vetores de velocidade do vento no plano vertical longitudinal 02 (ortogonal)
Nas figuras $4.32 \mathrm{e}$

4.33 é possível ver os

vetores de velocidade $\mathrm{e}$ direção dos ventos respectivamente em corte e em perspectiva, no plano longitudinal que passa no centro da torre de final 02 do edifício Montparnasse.

$$
\text { Aqui se nota a }
$$

alteração da direção dos vetores causada pela presença de uma barreira e a conseqüência disto para a edificação vizinha.

È importante a análise dessas imagens na hora de definir, por exemplo, a localização das aberturas nas fachadas. As figuras $\quad 4.34$ e 4.35 mostram também um corte e uma perspectiva do plano 


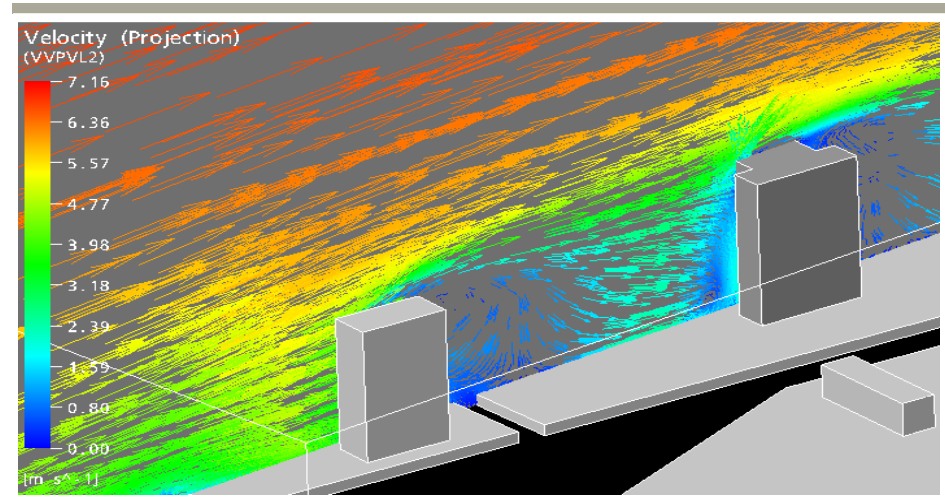

Figura 4.35 - Vetores de velocidade do vento no plano vertical longitudinal 02 (perspectiva) longitudinal que atravessa o centro do edifício. Nota-se novamente como a alteração na forma do edifício muda a configuração do vento, tanto em relação

à velocidade quanto à direção. Os dois planos longitudinais estão na mesma direção do vento, a 900, direção leste, cortando o eixo y do domínio.

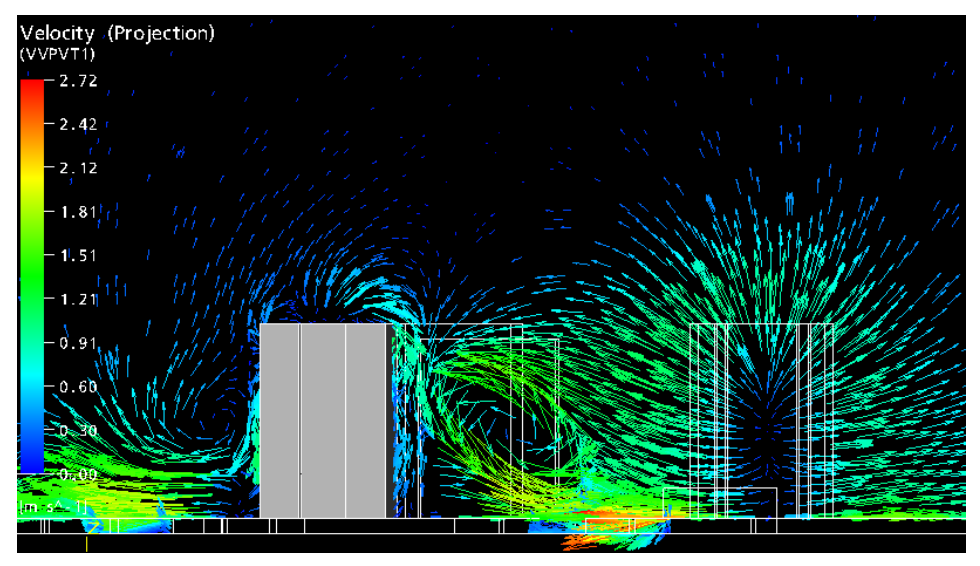

Figura 4.36 - Vetores de velocidade do vento no plano vertical transversal 01 (ortogonal)

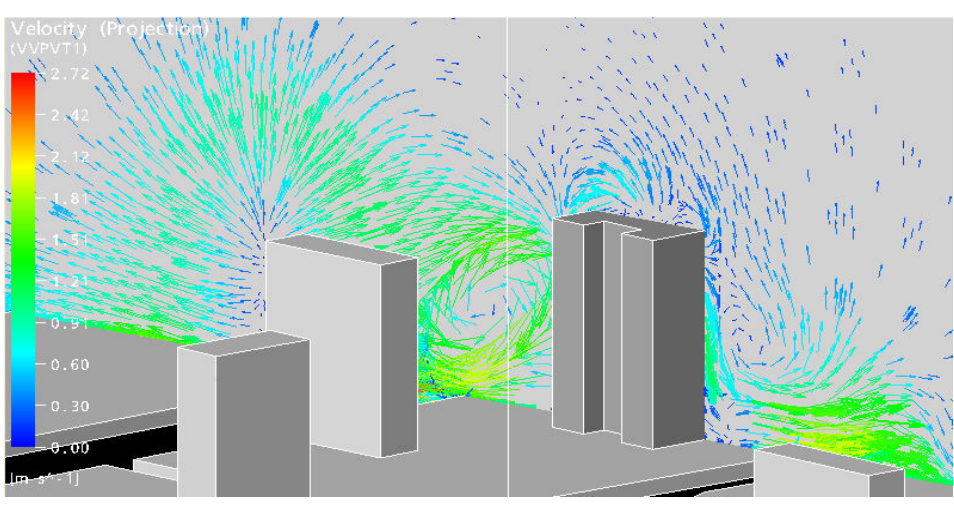

Figura 4.37 - Vetores de velocidade do vento no plano vertical transversal 01 (perspectiva)
As figuras $4.36 \mathrm{e}$

4.37 apresentam o plano transversal 01 que passa pelo centro do edifício, no sentindo perpendicular a direção do vento simulada neste caso, por isso notamos apenas a presença dos vetores representando o efeito causado na mudança de direção do fluxo de vento no entorno do edifício. 
São vetores na direção perpendicular a direção do vento predominante, cuja direção foi alterada exclusivamente pela presença de uma barreira física.

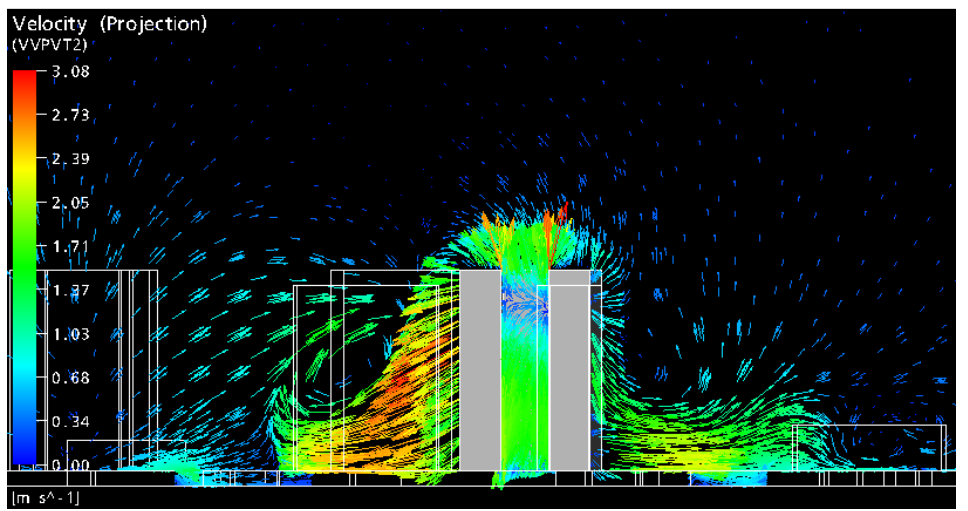

Figura 4.38 - Vetores de velocidade do vento no plano vertical transversal 02 (ortogonal)

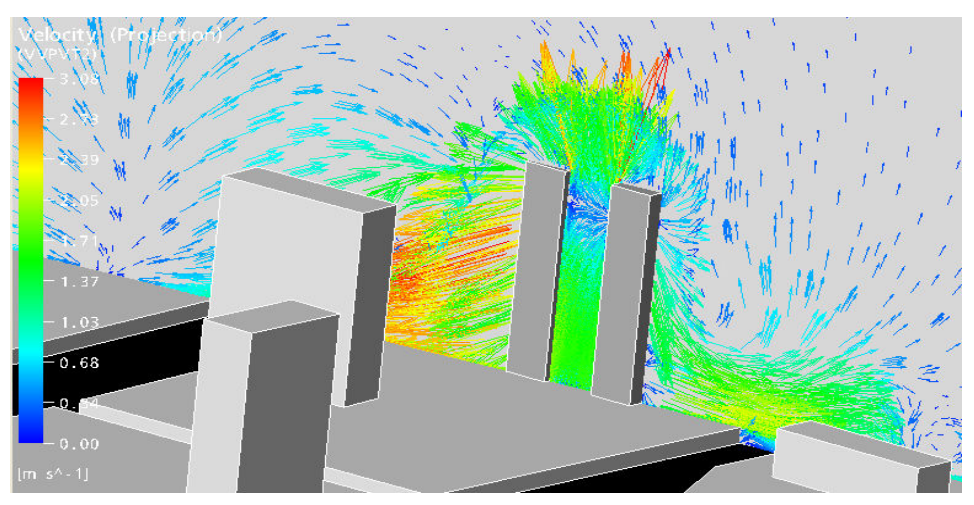

Figura 4.39 - Vetores de velocidade do vento no plano promove a vertical transversal 02 (perspectiva)

Nas figuras 4.38 e 4.39, o plano transversal passa próximo a extremidade do edifício e notamos que "a entrada" na forma da edificação proporciona um aumento da velocidade do vento na área central e também nas extremidades laterais, os chamados efeitos de canto ou de esquina, que aceleração da velocidade do vento nos ângulos das edificações.

\subsubsection{Contorno da pressão do vento na fachada}

Por fim, gerou-se uma imagem com o contorno da pressão do vento no Edifício Montparnasse na fachada leste e norte, localização do apartamento da torre 2, que será analisado em outra fase da pesquisa, na sequência da pesquisa experimental. 


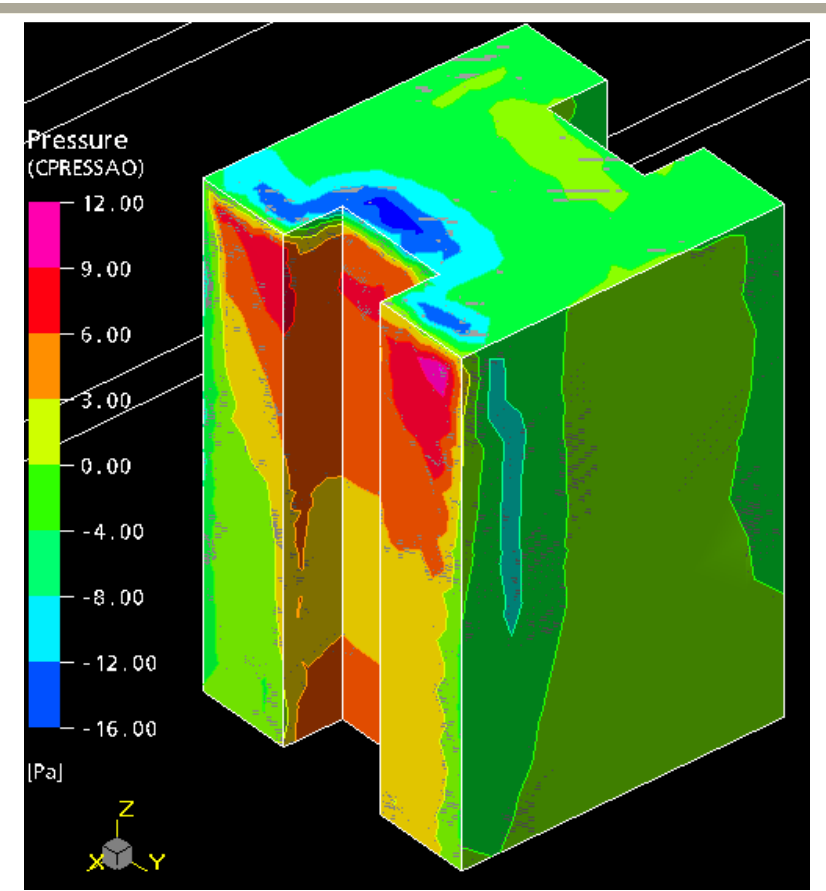

Figura 4.40 - Pressão do vento no edifício Montparnasse - fachadas leste e norte
Nota-se pela figura 4.40

que a maior parte das duas fachadas em destaque apresenta coeficiente de pressão positiva, com maior potencial na fachada leste, cuja orientação está coincidente com a direção dos ventos.

A princípio, o que se determina é a análise da pressão

dos ventos no volume fechado, tal qual a figura 4.40, para se determinar a melhor localização das aberturas de entrada e saída do ar. Como esta edificação já possui essa configuração definida e o uso da ferramenta computacional pode contribuir para esta análise e dependendo do resultado, estudar novas possibilidades para aumentar o potencial do vento no interior da edificação.

Após o término dessa simulação foi possível perceber como ocorre a configuração do vento local num dia típico de projeto. Ao se concluir anteriormente o levantamento de dados climáticos, chegou-se a um dia típico de projeto para a cidade de Aracaju, que apresentou uma média da velocidade do vento de $4,5 \mathrm{~m} / \mathrm{s}$, medida à $10 \mathrm{~m}$ de altura, e a direção predominante do vento a $90^{\circ}$, e foram esses os dados de entrada sobre o 
clima local nesta simulação ${ }^{9}$. Sabe-se que dependendo da época do ano e da hora do dia, essa velocidade pode aumentar consideravelmente e sem precisar repetir a simulação, podemos visualizar no CFX-Post esses mesmos resultados para velocidades menores ou maiores a utilizada e com isso verificar as possíveis alterações.

Viu-se por meio das figuras apresentadas que a área corresponde aos requisitos necessários para a realização da pesquisa, onde se tinha por objetivo escolher uma edificação que estivesse inserida numa área de bom potencial eólico, sem grande interferência por edificações vizinhas, para que as simulações no interior da edificação apresentassem respostas satisfatórias no final da pesquisa, sem precisar adotar um modelo fictício para isso.

Também se confirmou que o software escolhido para este trabalho atende aos requisitos desta pesquisa e sua forma de visualização dos resultados contribui na medida em que é de fácil interpretação, favorecendo não apenas as pesquisas científicas, mas provando ser uma grande ferramenta de auxílio na elaboração e análise do projeto arquitetônico e do espaço urbano.

${ }^{9} \mathrm{Na}$ definição dos parâmetros da simulação no CFX determina-se uma velocidade de entrada do vento e a altura correspondente a sua medição e então o programa faz os devidos cálculos de correção para todas as alturas e localizações do domínio. 


\section{DEFINIÇÃO DOS MODELOS PARA SIMULAÇÃO}

Dando continuidade a etapa de simulação desta pesquisa, após a elaboração e simulação do modelo experimental, neste capítulo será apresentada a delimitação da área de estudo e os modelos gerados a partir da análise obtida no capítulo anterior. Inicialmente foi definido o modelo base, para em seguida serem propostos os demais modelos, todos eles devidamente apresentados e descritos na sequência deste capítulo.

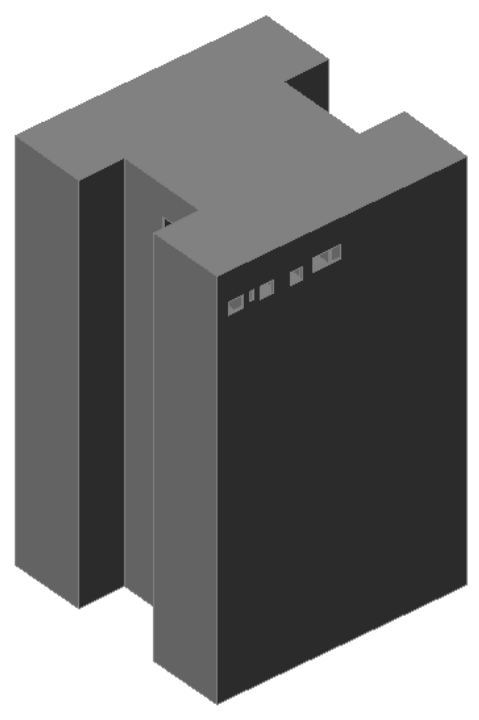

Figura 5.1 - Edifício com destaque para o espaço do apartamento 1102 definido.
Como visto, se utilizou para a simulação do modelo experimental o entorno pré-estabelecido com todas as edificações representadas por blocos maciços. A partir desta etapa, foi inserida, para a simulação no interior do apartamento, sua planta interna no bloco referente ao apartamento escolhido, representando todos os ambientes internos e todas as aberturas do apartamento por onde o vento entra e sai.

Em seguida, novos modelos foram confeccionados, com algumas alterações arquitetônicas propostas com o objetivo de analisar e comparar os resultados encontrados em relação à distribuição da ventilação natural no interior da edificação, que serão apresentados, juntamente com seus detalhes, análises e comparações na sequência. 
É evidente que na realidade, no edifício existem 48 apartamentos distribuídos nos 12 andares de apartamentos, mais os espaços referentes aos outros dois pavimentos térreos, porém a confecção de um modelo nesse nível de detalhamento seria incompatível com a capacidade computacional disponível para esta pesquisa. Por este motivo optou-se por simplificar o modelo, inserindo apenas o apartamento objeto de estudo e então apostar numa maior diversidade de propostas e resultados. Assim como também foi eliminado o subsolo, onde se localiza a área de garagem.

Além disso, é importante destacar que a inserção do apartamento no edifício foi a única alteração em relação ao modelo experimental, ou seja, o modelo continua com a mesma escala, mesmos obstáculos externos, mesma configuração urbana dos ventos locais, de forma a manter todas as respostas no interior da edificação o mais próxima possível da realidade.

A princípio tinha-se a idéia de que seria possível realizar as simulações internas separadamente, mas ao longo do estudo, percebeu-se que seria impossível determinar, por exemplo, a velocidade, pressão e direção dos ventos em cada uma das aberturas de forma precisa e realista se fosse separda a parte interna da externa da edificação. Assim, as características da ventilação no interior deste apartamento estão totalmente relacionadas com o seu entorno, assim como acontece em qualquer edificação existente. 
Antes da descrição detalhada de todos os modelos simulados, será apresentada a área de estudo e sua delimitação espacial.

\subsection{DELIMITAÇÃo DA ÁREA DE ESTUdo}

Como já citado, o universo de análise deste mestrado é a cidade de Aracaju-SE e buscou-se escolher um tipo de edificação que representasse um dos modelos padrão de construção que vem sendo explorado nesta cidade nos últimos anos, para um determinado perfil de habitantes, com a finalidade de aproximar os resultados alcançados da realidade atual.

Como não faz parte desta pesquisa uma análise sobre o comportamento imobiliário da cidade e nem o perfil sócio econômico da população, a escolha da edificação foi principalmente baseada nas características dos ventos locais e do entorno da edificação, ou seja, como a proposta é realizar um estudo da ventilação natural no interior da habitação, é importante que esta esteja inserida numa área ainda pouco verticalizada da cidade e com boa permeabilidade para os ventos locais para que as simulações nos ambientes internos apresentem respostas claras e com mais objetividade. Ou seja, se tomássemos como base um apartamento cujo potencial de vento em seu interior não fosse significativo, analisar a qualidade da ventilação natural em seu espaço seria certamente ineficiente e o objetivo da dissertação dificilmente alcançado. 


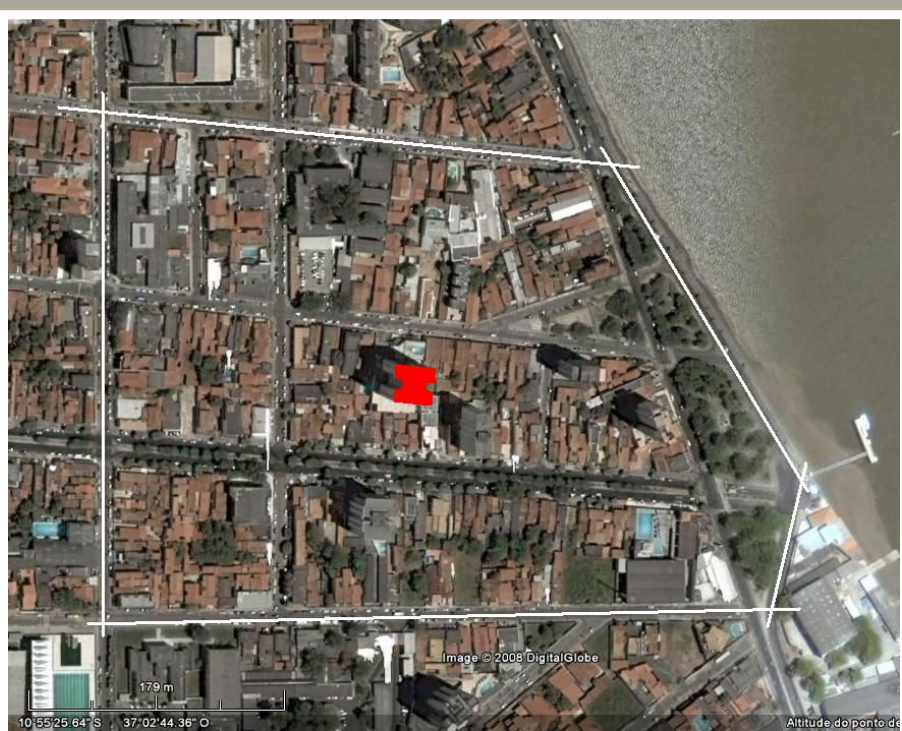

Figura 5.2- Delimitação da área de estudo

Fonte: Google Earth (acesso em 15 de outubro de 2008)

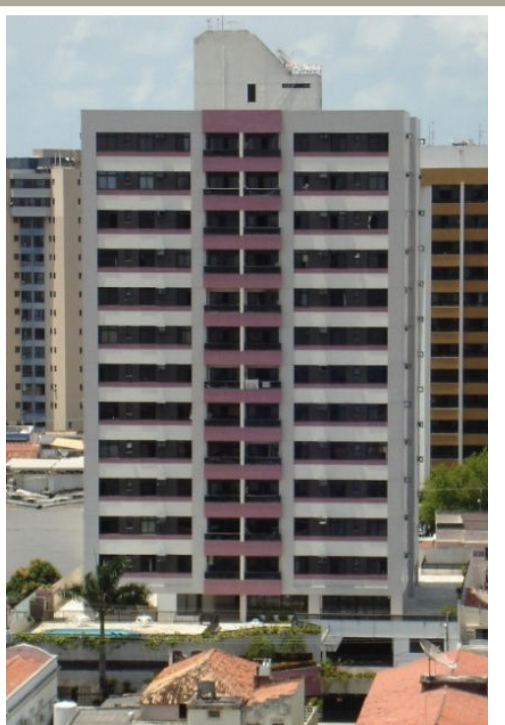

Figura 5.3 - Edifício Montparnasse

Fotografia - a autora

O modelo a ser simulado foi baseado no Edifício Montparnasse, figura 5.2, localizado na Rua Duque de Caxias, no 167, Bairro São José, e o seu entorno, delimitado por:

- Av. Ivo do Prado, a leste;

- R. Campos, ao norte;

- R. Dr. Leonardo Leite, a oeste;

- R. Campo do Brito, ao sul.

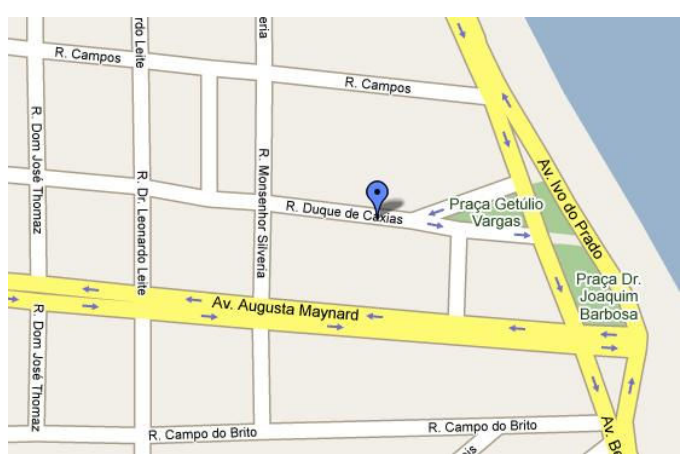

Figura 5.4 - Mapa da área de estudo Fonte: http://maps.google.com.br/

Acesso em 15 de outubro de 2008

Esse entorno foi definido para analisar a influência que as edificações mais próximas exercem no edifício escolhido para os estudos, de forma que a quadra onde o edifício Montparnasse está situado ficou bem no centro do modelo. 
Para a realização das simulações no interior da edificação, foi escolhido o apartamento 1102 , no $11^{\circ}$ andar. Vale ressaltar que cada pavimento possui quatro apartamentos com a mesma configuração de planta baixa, dispostas simetricamente. Na figura 5.5 se tem a distribuição dos ambientes no pavimento tipo com destaque para o apartamento que foi objeto de simulações computacionais com o software CFX.
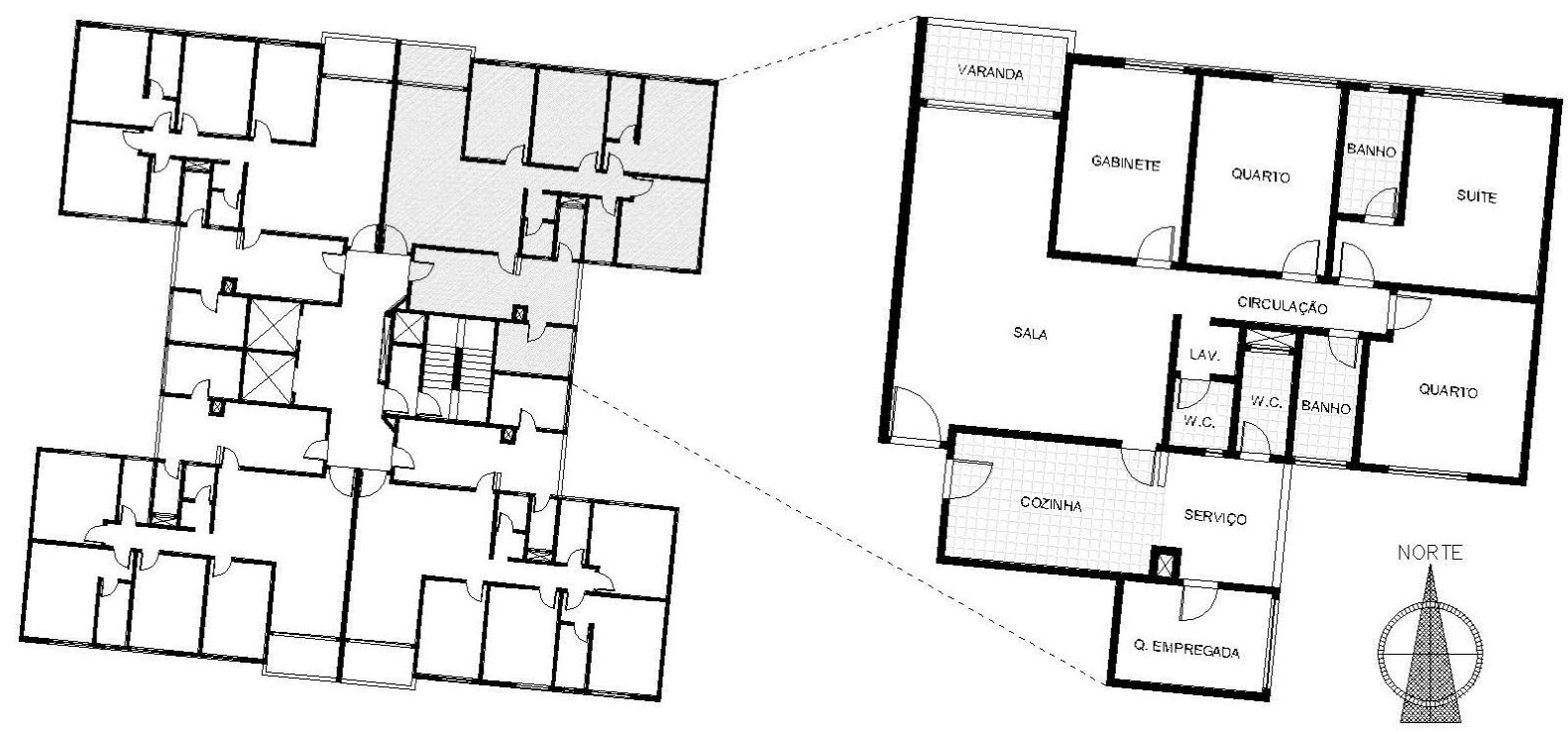

Figura 5.5 - Planta baixa do pavto tipo e dos aptos da torre de final 2 - sem escala. Fonte: Manual do proprietário do Edifício Montparnasse.

Assim, escolhidos a área, o edifício e o apartamento, deu-se início ao processo de confeç̧ão do modelo, experimento do software - no capítulo anterior - e finalmente a determinação e simulação dos modelos propostos com suas devidas alterações, dando início a fase experimental desta pesquisa. 


\subsection{MOdelo 01}

O modelo 01, definido como o "Modelo Base", consiste da planta original do apartamento com todas as suas aberturas sem a presença das esquadrias, ou seja, com 100\% das aberturas livres de obstáculos físicos.

Pode-se afirmar que este é um modelo muito importante, pois tem como principal função servir como base de comparação em relação aos demais modelos que apresentarão alterações nas principais aberturas.

Optou-se por excluir neste modelo inicial as esquadrias existentes em todas as aberturas, para posteriormente se analisar a influência que a obstrução parcial proporcionadas por estas mesmas esquadrias exerce sobre a qualidade da ventilação natural no interior do apartamento.

Quando se fala de aberturas, a pesquisa refere-se aos espaços destinados a janelas e portas existentes na edificação. É importante dizer que pela necessidade de simplificação na confecção do modelo, já citada anteriormente, nenhuma esquadria será desenhada nos modelos que serão utilizados nas simulações. Quando considerarmos a ausência de algumas ou todas, a representação se dará pelo vão referente livre de obstáculos e quando considerarmos a presença de alguma esquadria, o vão referente estará dimensionado de acordo com o vão livre proporcionado pela respectiva esquadria quando aberta, ou a inexistência de vãos quando as esquadrias forem consideradas totalmente fechadas.

Assim, pode-se representar o modelo 01 da seguinte forma: 


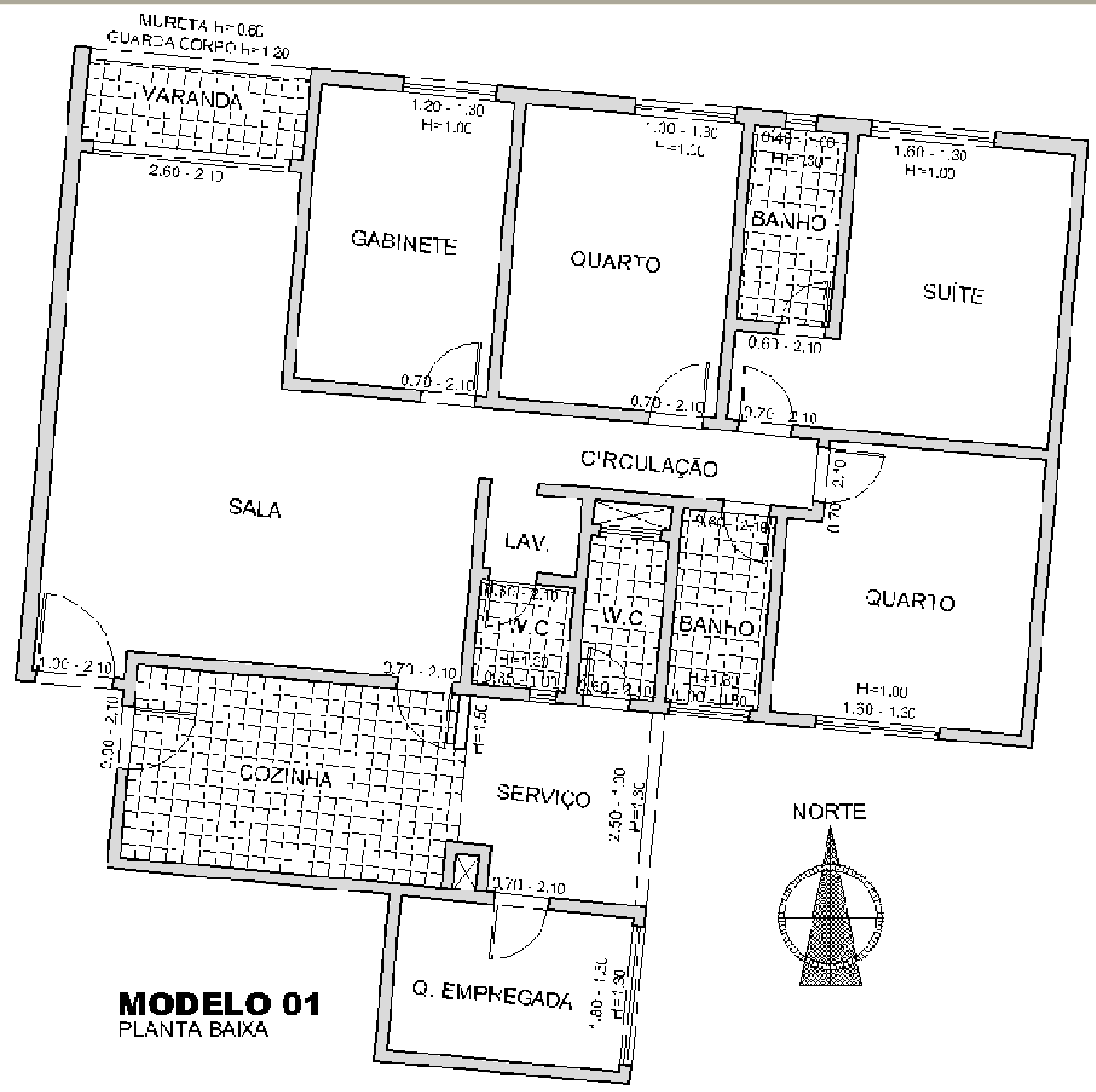

Figura 5.6 - Planta baixa do Modelo 01 com aberturas sem presença de esquadrias

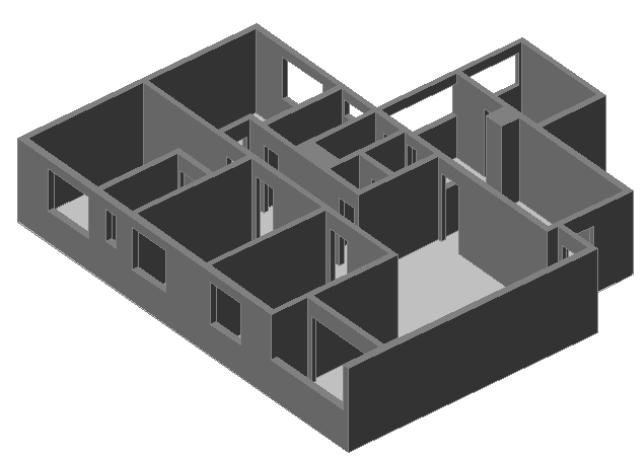

Figura 5.7 - Perspectiva Modelo 01

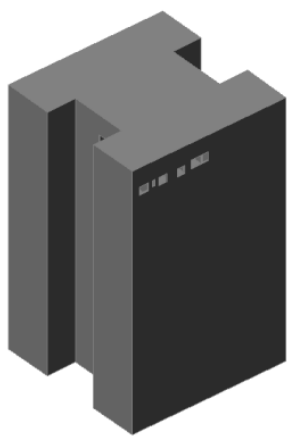

Figura 5.8 - Apartamento inserido no edifício - Modelo 01

Como o objetivo no capítulo 05 é apresentar as diferenças dos modelos na escala do apartamento, optou-se por representá-los neste 
capítulo separando o apartamento do restante do entorno, diferentemente do que ocorrerá no modelo utilizado nas simulações, como explicado anteriormente.

\subsection{MOdelo 02}

O modelo 02 se caracteriza pela alteração da localização das aberturas externas dos quartos conforme figura 5.9. O modelo continua sem considerar as esquadrias, mantendo os vãos totalmente livres.

Ao simular o modelo experimental, constatou-se que as fachadas leste do edifício apresentam pressão do vento positiva, enquanto que as demais, pressão negativa. Como já visto, um dos princípios básicos da ventilação natural na edificação é que as aberturas de entrada do ar devem estar localizadas na fachada de pressão positiva e as aberturas de saída, nas fachadas de pressão negativa para melhor desempenho por meio do princípio de ventilação cruzada dentro do espaço interno.

Além disso, uma vez que os ventos predominantes apresentam-se na direção $90^{\circ}$ na maior parte do dia e do ano, várias referências recomendam as aberturas de entrada do ar voltadas para a direção dos ventos, de forma a eliminar obstáculos e otimizar o fluxo de ar no interior do edifício.

Assim sendo, objetivo desta alteração é avaliar a diferença do padrão do fluxo de vento no interior da edificação no momento em que se 
dispõem estas aberturas em uma das fachadas com maior pressão positiva e na direção dos ventos predominantes.

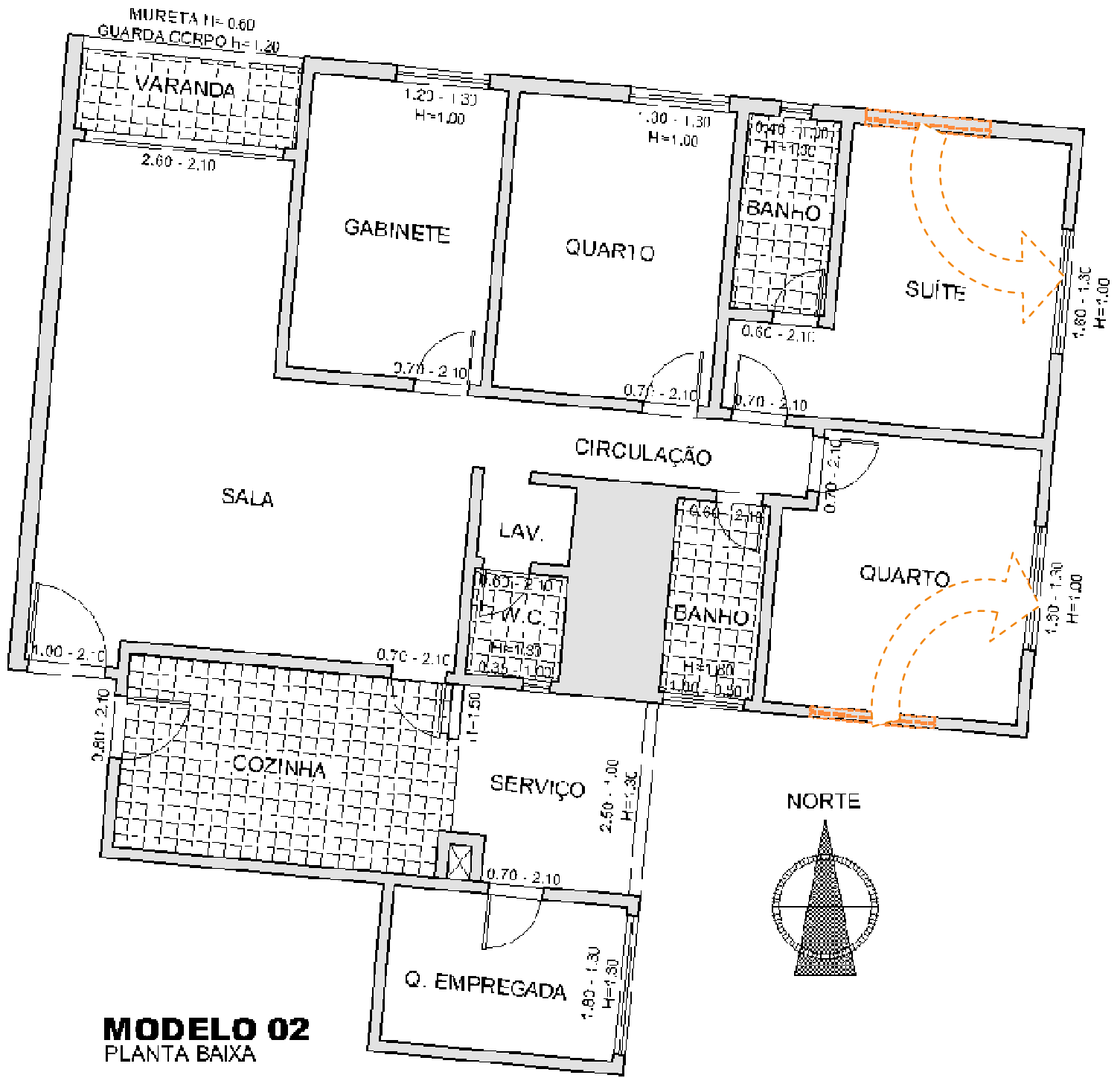

Figura 5.9 - Planta baixa do Modelo 02

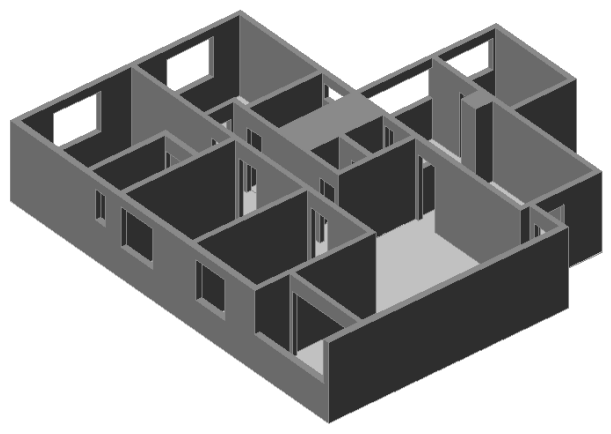

Figura 5.10 - Perspectiva Modelo 02

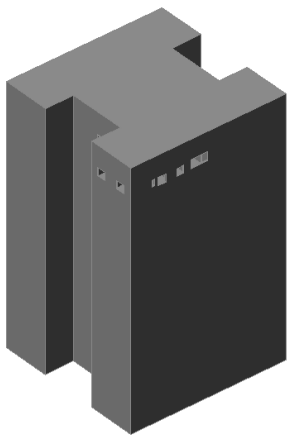

Figura 5.11 - Apartamento inserido no edifício - Modelo 02 
Outra alteração presente neste modelo e em todos os próximos foi a eliminação do espaço referente ao banheiro de empregada, localizado na área de serviço do apartamento, visto que o mesmo apresenta apenas uma porta como abertura para a passagem do ar, o que impede a ventilação cruzada neste ambiente. Além disso, este espaço praticamente não influencia na configuração do vento no restante do apartamento e sua eliminação fez com que a quantidade total de elementos neste modelo diminuísse, contribuindo para uma simulação mais ágil.

\subsection{Modelo 03}

No modelo 03 foram inseridas todas as esquadrias nas janelas do apartamento. As janelas dos quartos, gabinete e a porta da varanda são compostas por folhas de correr, portanto quando totalmente abertas ocupam $50 \%$ do vão. Assim, estipulou-se um lado de abertura de maneira a deixar o vão livre na parte mais central de cada ambiente. Porém, é importante ressaltar que cada usuário determinaria para que lado abrir tais janelas, o que provavelmente seria influenciado pelo layout de ocupação adotado em cada espaço, por exemplo.

As janelas dos banheiros são do tipo basculante e a proporção de abertura está representada na figura 5.12. As janelas da área de serviço e do quarto de empregada são do tipo pivotante de várias folhas e também na figura 5.12 pode-se perceber a proporção entre vãos livres e vãos fechados (representados pela linha de cor laranja) de cada uma delas. 


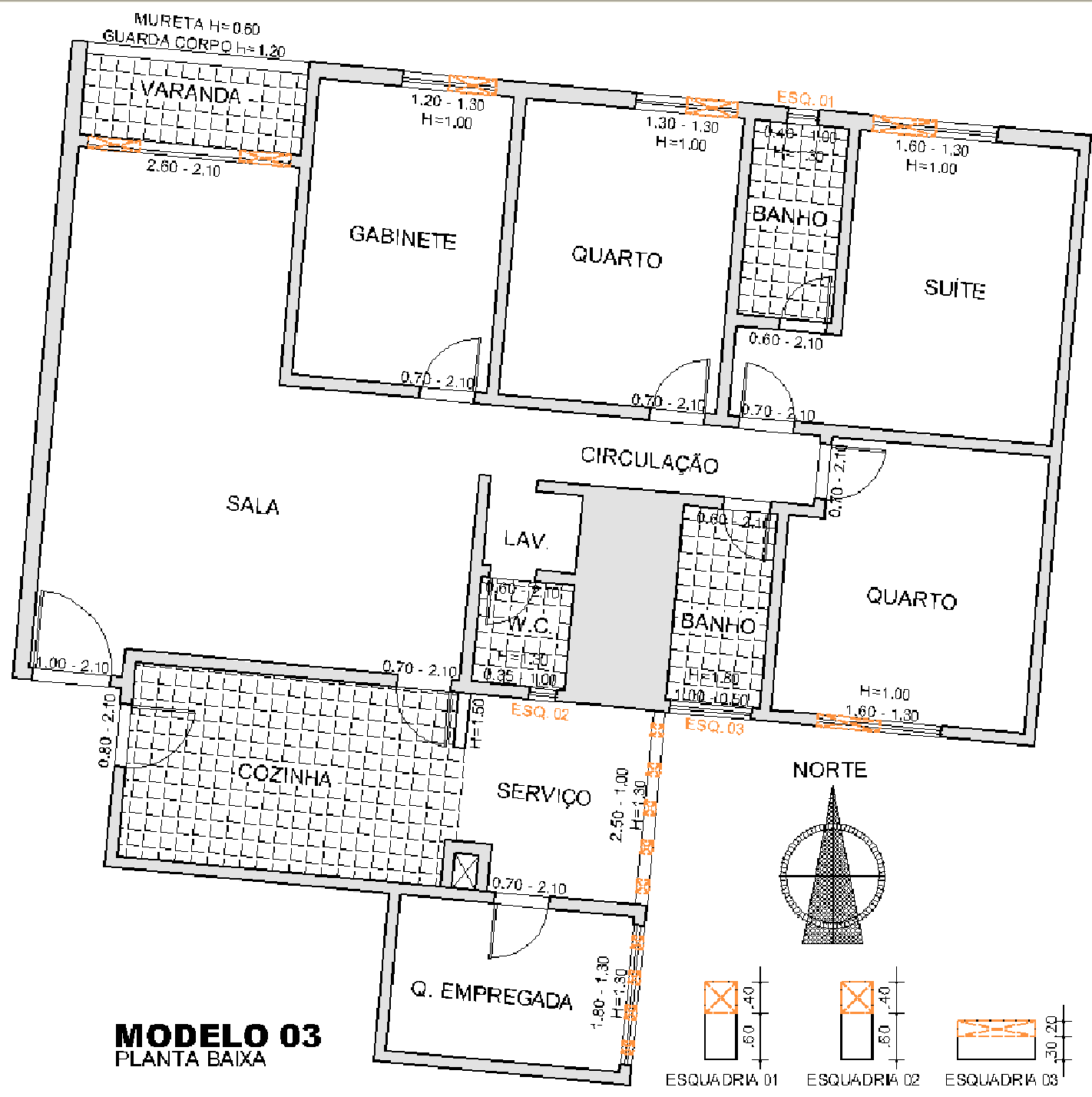

Figura 5.12 - Planta baixa do Modelo 03 com destaque das áreas obstruídas pelas esquadrias

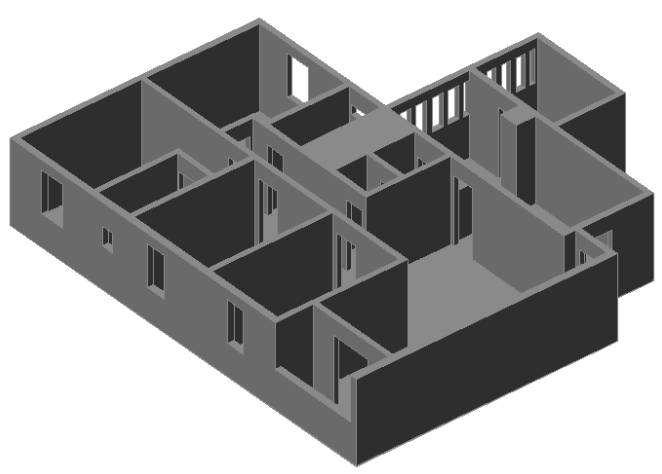

Figura 5.13 - Perspectiva do Modelo 03

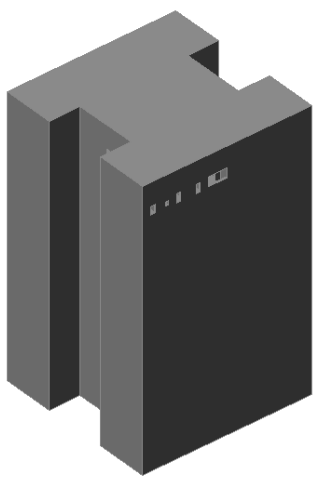

Figura 5.14 - Apartamento inserido no edifício - Modelo 03

Todas as portas internas foram consideradas abertas como observado na figura 5.13 . 


\subsection{MOdelo 04}

Quando se pretende adotar em qualquer projeto arquitetônico a estratégia da ventilação natural com o objetivo de obter conforto térmico dos usuários, dois princípios básicos devem ser esclarecidos para os ocupantes do espaço. Primeiro, que o vento é uma variável de difícil previsão e controle e que ao se adotar médias de velocidade e direção, não significa que esses dados ocorram todos os dias e horas do ano, podendo inclusive ocorrer horas de calmaria. Segundo, e mais importante para esclarecer as alterações deste modelo, para existir um fluxo de vento no interior de uma edificação, é importante garantir que haja uma abertura de entrada e outra de saída do ar. Ao abrir ou fechar qualquer uma desta abertura (parcialmente ou totalmente), o usuário pode controlar a intensidade e a direção do vento - dependendo do tipo de esquadria - como pode também bloquear totalmente este fluxo, seja consciente ou inconscientemente.

Para manter a privacidade, muitas vezes os habitantes de uma casa fecham as portas de seus quartos, por exemplo, e este ato pode influenciar não apenas a ventilação interna dos quartos, mas também de todo o apartamento. Pensando em analisar essas possíveis consequências, o modelo 04 se difere do modelo anterior apenas pelo fato de ter-se fechado as portas dos três quartos e do gabinete, mantendo todas as demais portas abertas, assim como também se manteve todas as 
características das janelas semelhantes ao modelo anterior, com suas esquadrias e aberturas totais, na proporção que cada modelo permite.

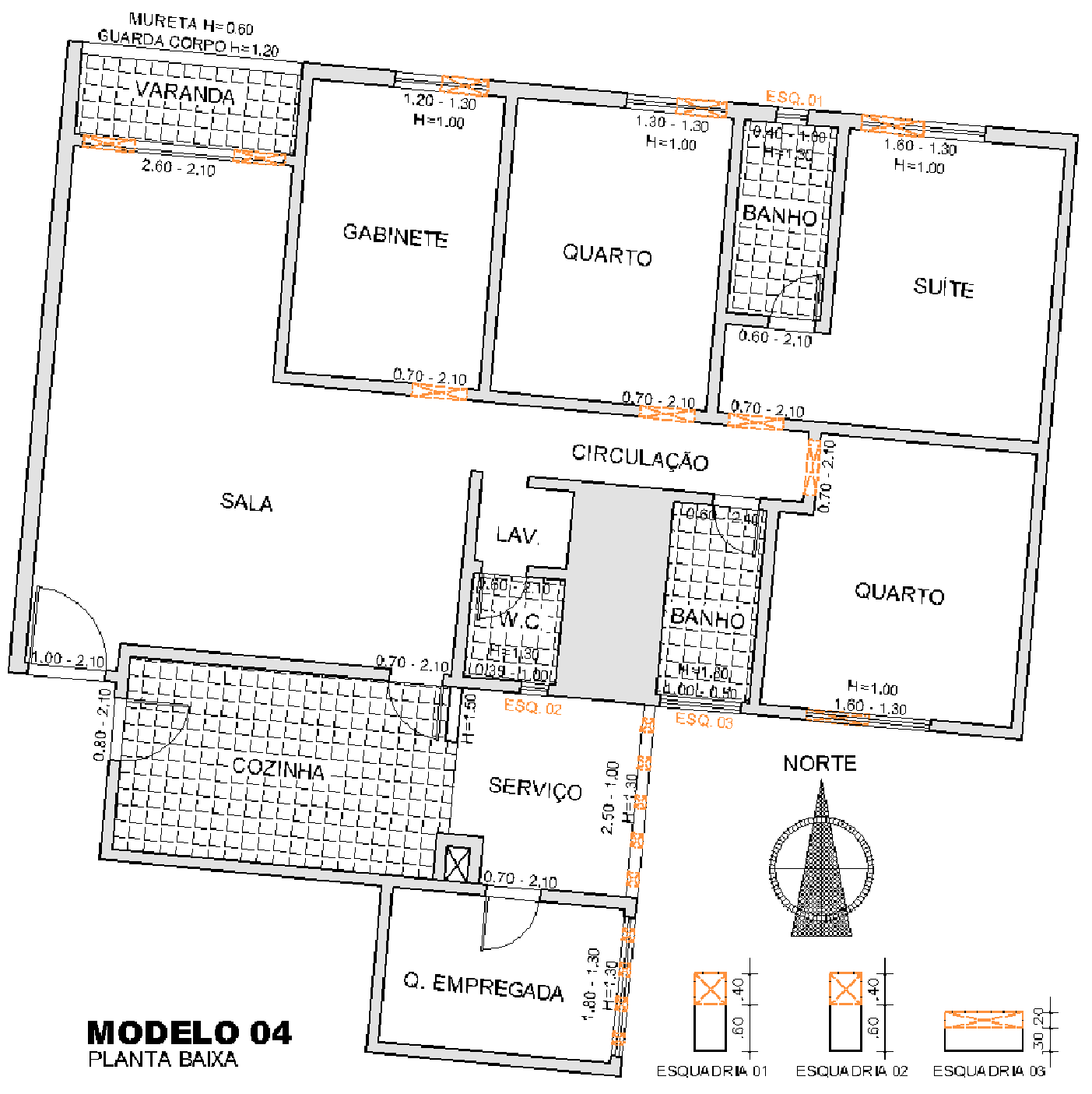

Figura 5.15 - Planta baixa do Modelo $04 \mathrm{com}$ destaque para as portas dos quartos fechadas

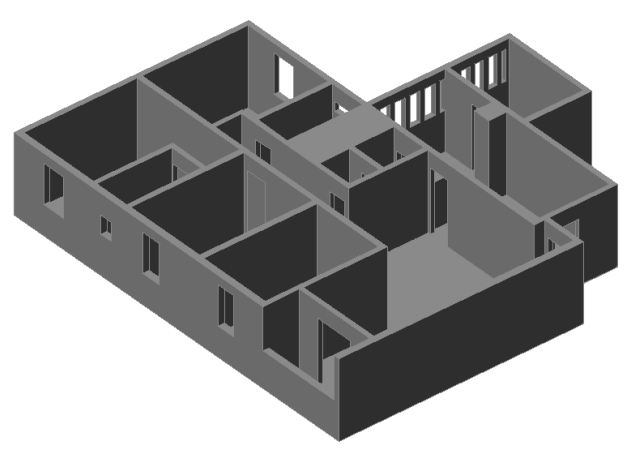

Figura 5.16 - Perspectiva do modelo 04

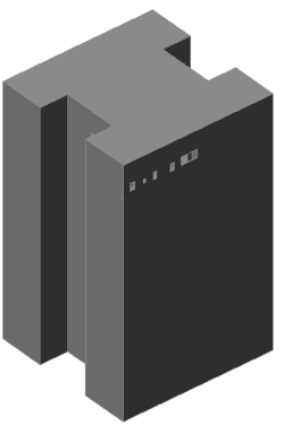

Figura 5.17 - Apartamento inserido no edifício - Modelo 04 
Dessa forma, pode-se dizer que a confecção do modelo 04 foi baseada num possível hábito de algum usuário e servirá para incentivar o projetista a prever esse tipo de atitude sempre que se adotar o partido da ventilação natural nas edificações.

\subsection{Modelo 05}

Ainda baseado na concepção do modelo anterior, o modelo 05 tem como objetivo propor uma possível solução aos danos causados no fluxo da ventilação interna pelo fechamento das portas dos quartos e verificar sua real eficácia. Assim, o modelo 05 se diferenciou do modelo 04 ao colocar bandeiras nas portas dos quartos, ou seja, criou-se um vão de $0,70 \mathrm{~m} \times 0,30 \mathrm{~m}$ acima das portas que continuaram fechadas, como se observa na perspectiva do modelo (figura 5.19).

Apenas como forma de enfatizar melhor as demais características do modelo 05, todas as janelas apresentam as esquadrias com suas aberturas correspondentes ao modelo e representadas na figura $5.18 \mathrm{com}$ uma linha na cor laranja; o banheiro de empregada não está inserido no modelo; e todas as outras portas não citadas apresentam $100 \%$ do vão livre para o escoamento do ar sem a presença de bandeiras.

O uso de bandeiras nas demais portas, além das portas dos quartos, poderia ser adotado em um modelo, porém, como o objetivo aqui é comparar os resultados de sua simulação do modelo 05 com a simulação do modelo 04, onde apenas as portas dos quartos estavam fechadas, 
optou-se por colocar bandeiras apenas nessas portas para evitar distorções na análise dos resultados alcançados.

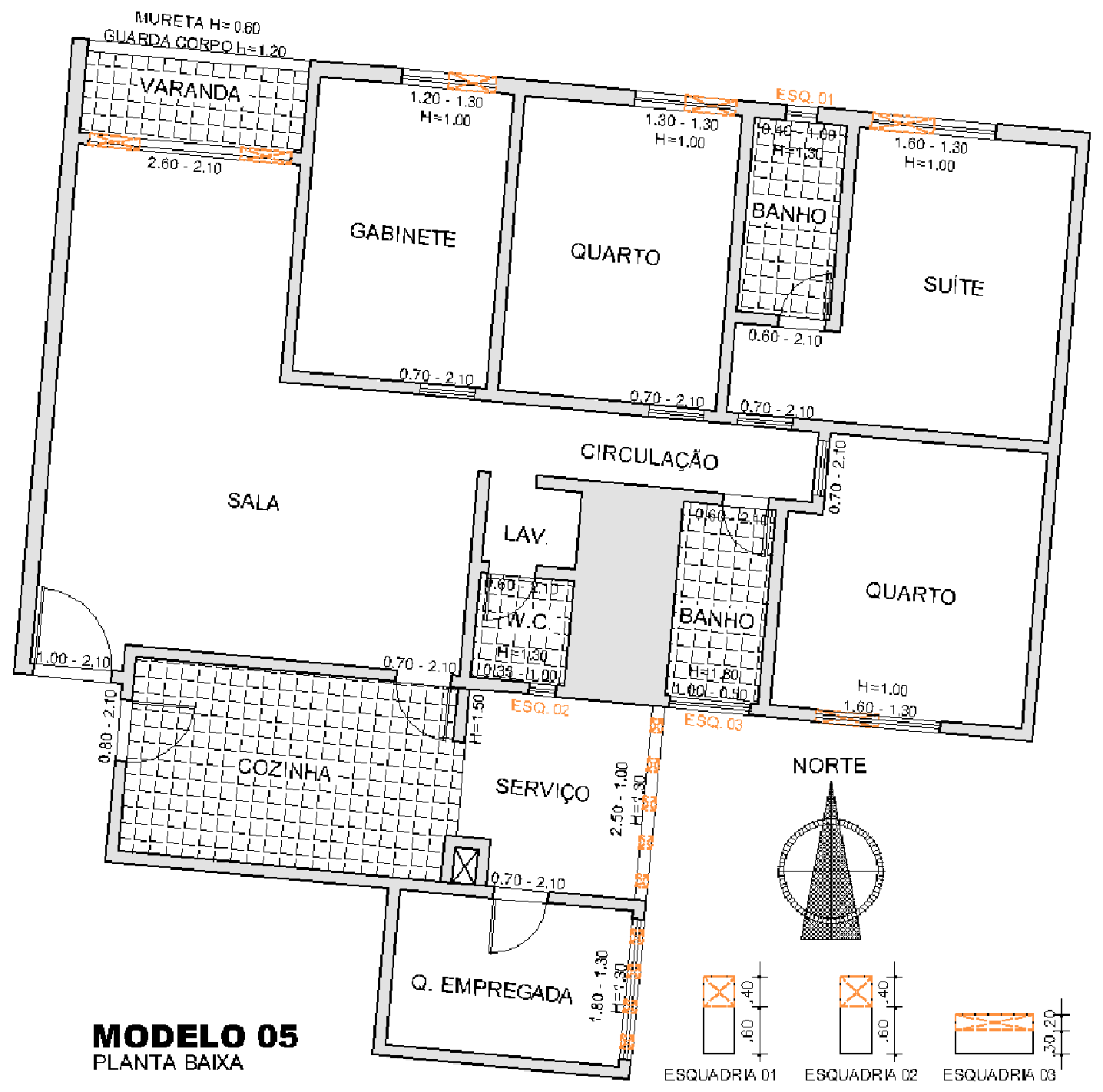

Figura 5.18 - Planta baixa do Modelo 05 com destaque para as portas dos quartos fechadas com bandeiras acima das mesmas com vãos livres de dimensão $.70 \mathrm{~m} \times .30 \mathrm{~m}$

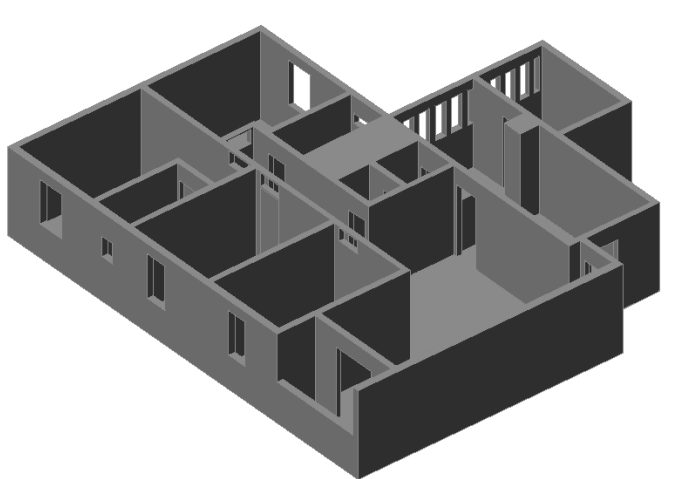

Figura 5.19 - Perspectiva do modelo 05

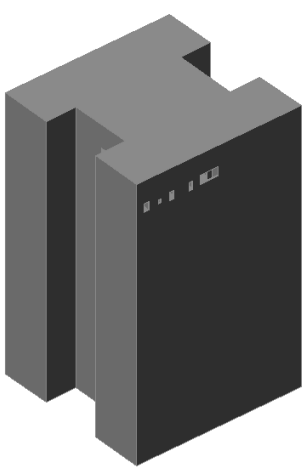

Figura 5.20 - Apartamento inserido no edifício - Modelo 05 


\subsection{MOdELO 06}

No modelo 06 houve uma alteração na planta arquitetônica, cuja alternativa foi oferecida aos proprietários quando o edifício ainda estava em construção. Essa modificação consiste na eliminação do gabinete e consequente aumento da sala de estar, transformação do lavabo em banheiro social e alteração da localização da porta do banheiro social de forma a transformar mais um quarto em suíte - todas representadas por linhas na cor laranja na figura 5.21.

Além deste aspecto, outras configurações continuam implantadas, como a permanência das esquadrias, todas as portas, inclusive as dos quartos, abertas e sem bandeiras e a eliminação do banheiro de empregada.

Neste modelo pretende-se analisar mais especificamente a relação entre a ventilação no interior de uma edificação e suas divisões internas. Até que ponto um ambiente mais amplo e com menos barreiras, caso da nova configuração da sala de estar no modelo 06 , pode interferir na qualidade do fluxo de ar, neste ambiente e nos ambientes adjacentes?

Outro questionamento existente: será que a alteração da localização da porta do banheiro social vai favorecer ou prejudicar o fluxo de ar no quarto ao lado e nos demais ambientes, uma vez que neste espaço a velocidade do ar é intensa quando comparada aos demais ambientes? 


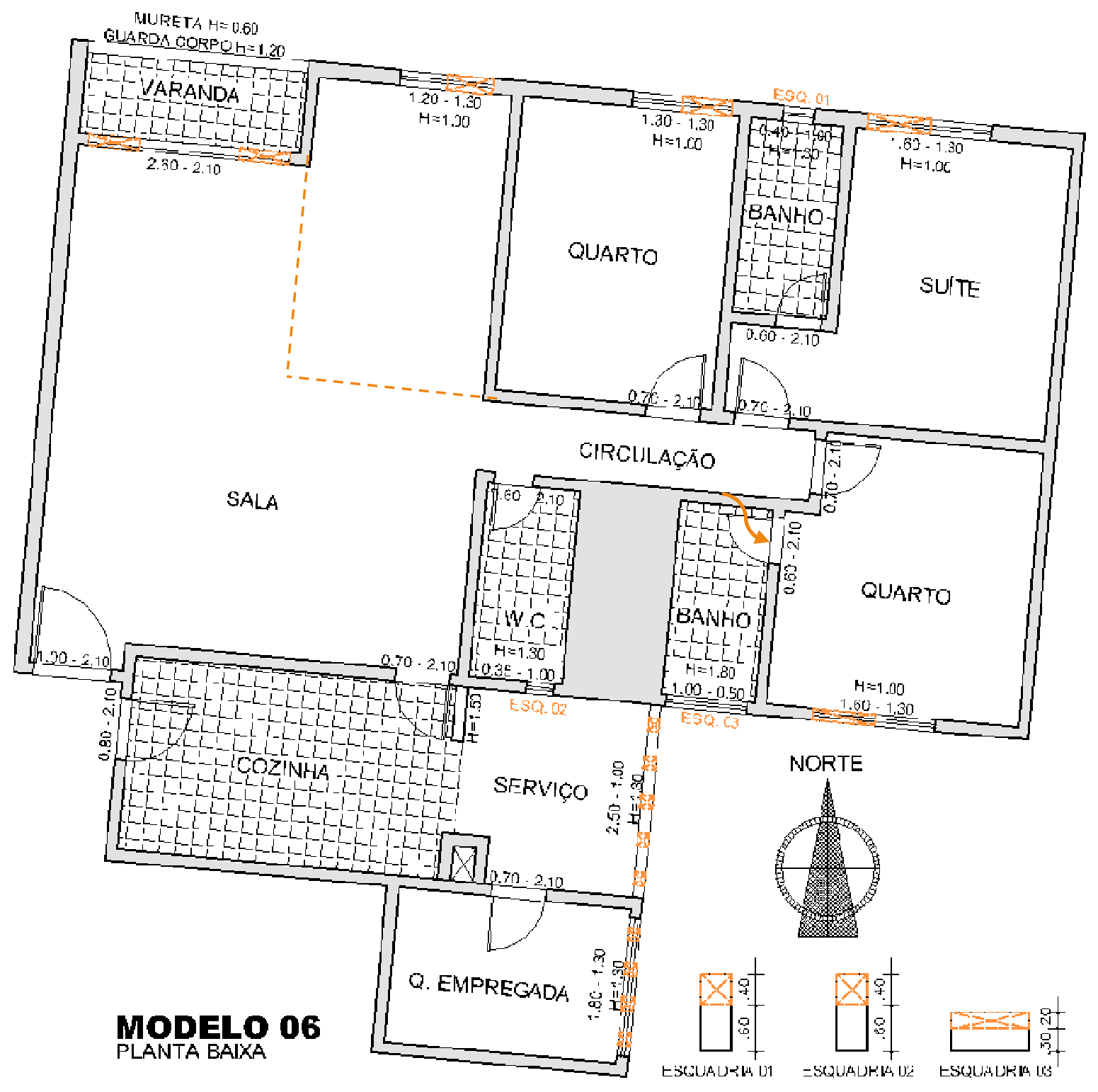

Figura 5.21 - Planta Baixa do modelo 06 com destaque para a alteração da planta original

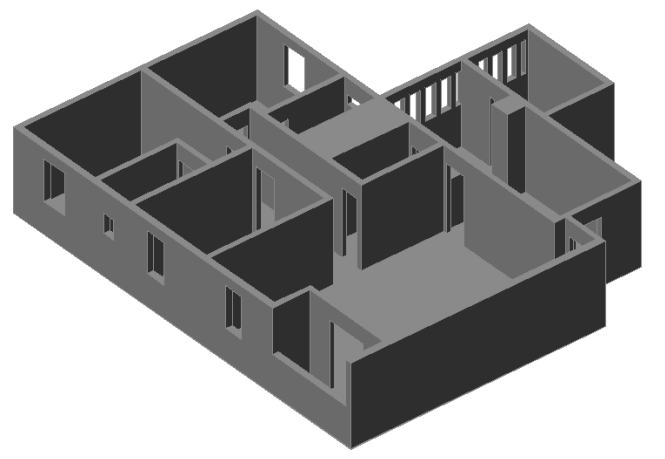

Figura 5.22 - Perspectiva do modelo 06

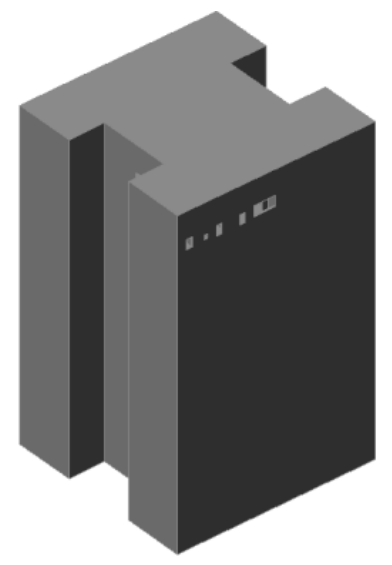

Figura 5.23 - Apartamento inserido no edifício - Modelo 06 
Assim, veremos que se tratando do estudo da ventilação natural, uma simples alteração da planta arquitetônica pode ser uma questão muito mais funcional quando se trata de conforto térmico do que uma questão de estética ou criatividade.

\subsection{MOdELO 07}

Comparando o modelo 07 ao modelo 01 (modelo base) a única alteração é a largura das janelas dos quatros quartos. Optou-se aqui por ocupar toda a largura da parede onde as aberturas foram previamente projetadas, mantendo as mesmas alturas do vão e do peitoril. Além disso, a eliminação do banheiro de empregada também se difere do modelo base.

Dessa forma, além de compararmos as aberturas das janelas em sua dimensão original, com e sem as esquadrias de correr, que ocupam $50 \%$ do vão livre, ainda poderemos encontrar respostas importantes ao compararmos esses resultados anteriores com as aberturas ocupando toda a largura das paredes e novamente sem as esquadrias.

Qual a importância da dimensão de uma janela para a ventilação natural de um ambiente? Será que um Plano Diretor acerta ao determinar uma proporção fixa da janela em relação ao tamanho do piso? Será que é uma solução relevante aumentar as dimensões da janela de qualquer ambiente, independente de sua localização, por exemplo? 


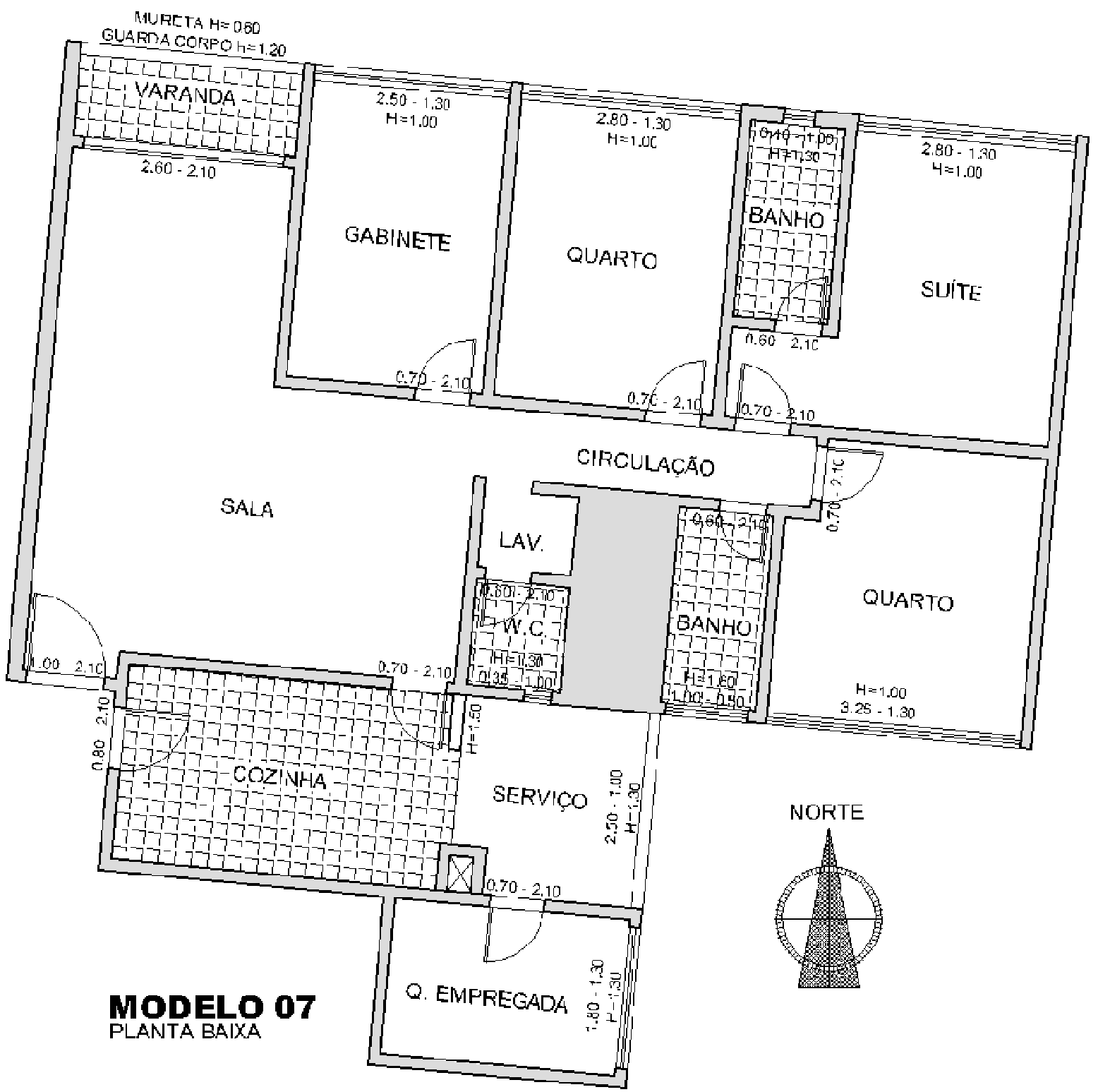

Figura 5.24 - Planta baixa do Modelo 07 com destaque para a dimensão das aberturas dos quartos

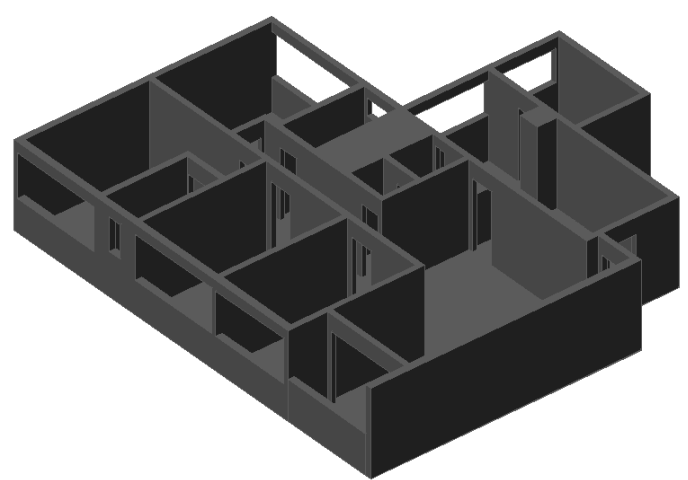

Figura 5.25 - Perspectiva do Modelo 07

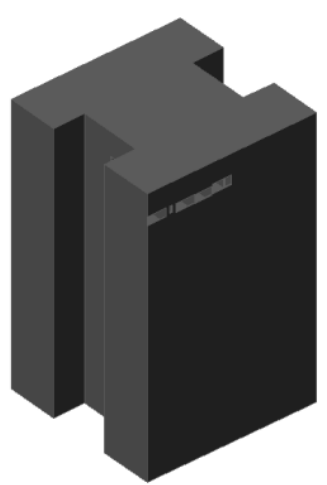

Figura 5.26 - Apartamento inserido no edifício - Modelo 07 


\subsection{MOdelo 08}

A definição do modelo 08 ocorreu após a realização das simulações de todos os modelos anteriores, quando se notou que o quarto do meio apresentava sempre a pior distribuição e velocidade do fluxo de ar em seu interior, com maiores áreas de ausência de vento em relação aos outros ambientes, independente do modelo proposto.

Assim sendo, este modelo propõe alterar a localização da porta de entrada do quarto de maneira a posicioná-la na diagonal em relação à abertura da janela localizada na parede oposta e estimular uma ventilação cruzada mais eficiente. Além disso, nessa nova localização, pretende-se verificar a possibilidade deste ambiente ser favorecido também pela corrente de vento que atravessa a porta da cozinha em direção a varanda da sala e do vento proveniente do lavabo também.

Dessa forma, 0 modelo 08 se difere do modelo base apenas pela localização da porta do quarto do meio, como sinalizado na figura 5.27 a seguir, e todas as aberturas também foram igualmente consideradas sem as esquadrias.

Por fim, o objetivo principal considerado para a elaboração destes modelos é tentar mostrar como a simulação computacional pode ser uma ferramenta extremamente útil tanto na fase de concepção do projeto, quanto na realização de uma reforma que tenha a pretensão de melhorar a circulação de ar no interior de uma edificação. 


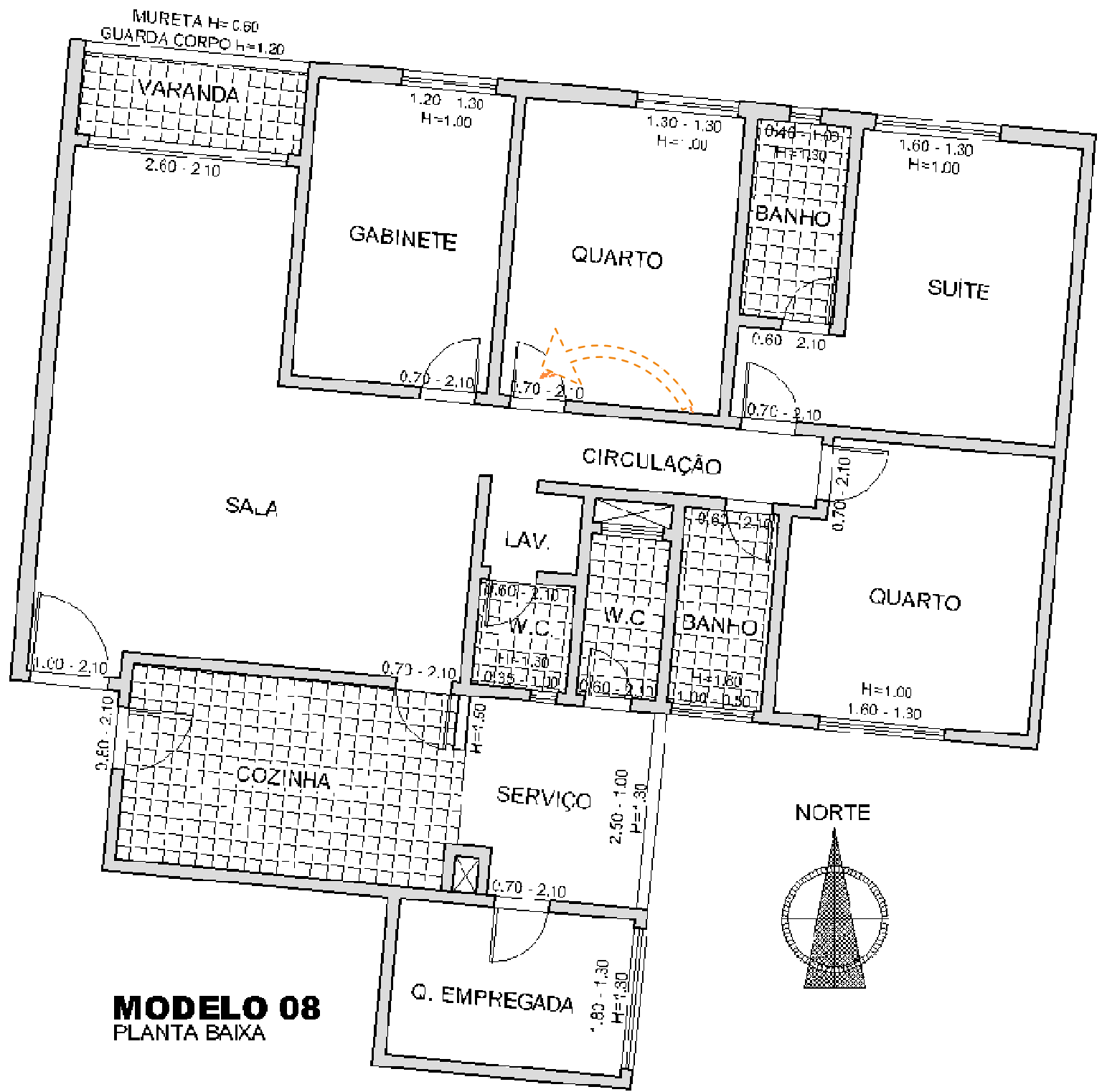

Figura 5.27 - Planta Baixa do modelo 08 com destaque na alteração da porta do quarto do meio

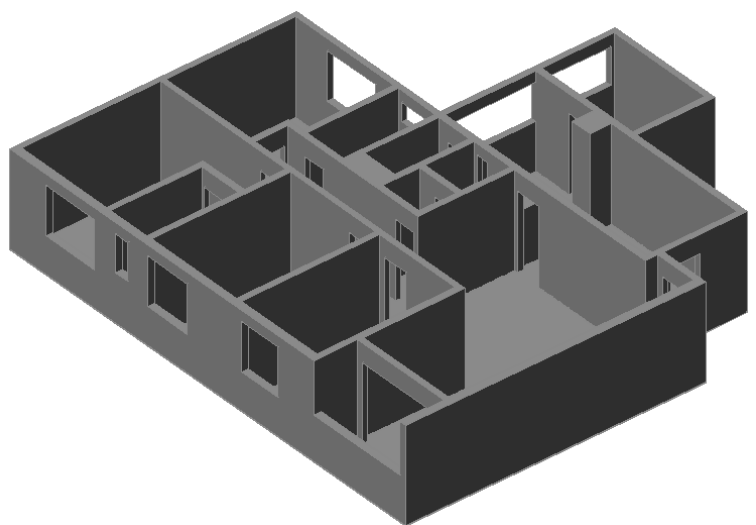

Figura 5.28 - Perspectiva do Modelo 08

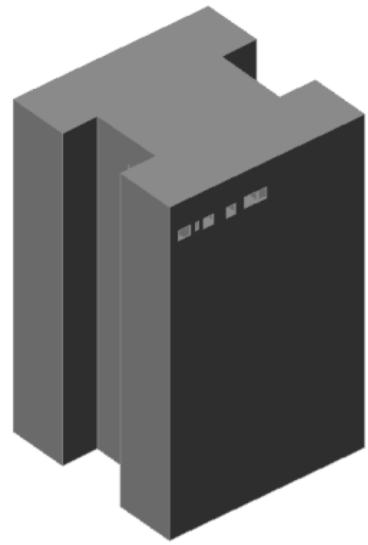

Figura 5.29 - Apartamento inserido no edifício - Modelo 08 
Nem sempre os resultados previstos serão confirmados ou nem sempre será fácil conseguir soluções simples pra resolver todos os problemas encontrados numa edificação pronta ou numa primeira simulação na fase de concepção de projeto. Porém, ao dispormos de uma ferramenta que nos possibilite analisar o maior número possível de propostas antes da idealização de um projeto, com certeza a chance de insatisfação será muito menor, apesar de que ao se trabalhar com uma variável como a ventilação natural, deve-se ter em mente que o comportamento do vento é sempre de difícil predição.

No próximo capítulo estarão expostos os resultados alcançados em todas as simulações realizadas com os oito modelos descritos até aqui, bem como as comparações realizadas entre eles com a análise qualitativa do vento no interior do apartamento em cada uma das situações. 


\section{DISCUSSÃO DOS RESULTADOS DAS SIMULAÇÕES}

Após a demonstração do processo de simulação no CFX no capítulo 4 e da apresentação de todos os modelos simulados nesta pesquisa no capítulo 5, aqui serão analisados qualitativamente os resultados obtidos, assim como serão discutidas as comparações necessárias entre os resultados dos modelos sugeridos.

Inicialmente serão demonstradas as imagens dos resultados referentes ao modelo experimental, cuja edificação principal não possuía aberturas em toda sua extensão, e o modelo base, cujo apartamento onde as análises serão feitas foi inserido no modelo, com o objetivo de comparar as possíveis diferenças e/ou semelhanças entre os dois resultados.

Em seguida será analisado o resultado da simulação do modelo 01 que, como já mencionado, é o modelo base para comparação dos demais resultados de forma mais clara e precisa. Depois, serão analisados os resultados de todos os modelos seguintes com suas devidas comparações.

Apenas as imagens mais significativas serão apresentadas neste capítulo para que todas as análises se tornem mais claras e objetivas. Desta forma optou-se por apresentar dois planos horizontais - uma imagem com contornos e outra com os vetores referentes à direção e velocidade do vento para cada uma das alturas - sendo um plano horizontal com altura de $37,40 \mathrm{~m}$ o que corresponde a uma altura de 
$1,20 \mathrm{~m}$ a partir do piso do apartamento localizado no $11^{\circ}$ andar, que se define aqui como altura do plano de trabalho, e outro com altura de $38,20 \mathrm{~m}$ referente a uma altura de $2,00 \mathrm{~m}$ a partir do piso do apartamento.

O primeiro plano corta as principais aberturas em seus pontos médios, ou seja, corta as principais aberturas passando por seus vãos livres, enquanto que o segundo plano horizontal corta também as aberturas mais altas, como as localizadas nos banheiros, área de serviço e quarto de empregada. É importante salientar que planos horizontais localizados em alturas diferentes podem apresentar resultados diferentes já que o fluxo do ar percorre todo o volume do espaço e de acordo com as características do espaço e as alturas das aberturas, o comportamento ao longo do eixo vertical e horizontal sofre alterações.

Nos anexos desta pesquisa estão inseridas imagens complementares de todas as simulações realizadas aqui, inclusive as imagens de quatro planos verticais que cortam longitudinalmente e transversalmente a área do apartamento.

Para todas as simulações foram utilizados dois computadores do LABAUT, em paralelo, para atender a necessidade imposta pelo número total de elementos de cada um dos modelos confeccionados. Como todos os modelos geraram mais de 2 milhões de elementos, cada um dos computadores utilizados dispunham de 2 Gb de memória RAM, sendo necessário, portanto, pelo menos duas máquinas para cada simulação, 
uma vez que cada $1 \mathrm{~Gb}$ de memória RAM tem capacidade para rodar no máximo 1 milhão de elementos.

Apesar da meta inicial em todas as simulações ser atingir convergências de $1 \times 10^{-4}$, todas as simulações desta pesquisa apresentaram convergências entre $5 \times 10^{-4}$ e $1 \times 10^{-4}$, que são consideradas pelo manual do programa CFX (2003) como regulares e aplicáveis na maioria das simulações. Uma convergência melhor não foi conseguida devido ao grande número de elementos da malha e pela grande diferença entre as dimenções de todas as faces que compõem o modelo, que vão desde a espessura das paredes $(0,15 \mathrm{~m})$ até os grandes vãos dos maiores edifícios, por exemplo.

O principal obstáculo encontrado ao longo de todo o processo que envolveu as simulações foi o tempo disponível. Até que se estabeleçam todos os detalhes como: modelagem, parâmetros para confecção da malha, qualidade da malha, definição das variáveis envolvidas, número total de elementos compatível com a capacidade computacional, convergência apropriada e criação das imagens dos resultados finais, além do surgimento de alguns imprevistos e do período necessário para se dominar a ferramenta; muito tempo foi utilizado na etapa de ajustes sem a geração de nenhum resultado. Quando se encontra algum erro ou se chega a alguma resposta inadequada, todo o processo é reiniciado a partir da primeira etapa até que se encontre o resultado adequado e todas as dúvidas sejam sanadas. 
Tabela 6.1 - Quadro resumo das simulações dos modelos 1 a 8

\begin{tabular}{|c|c|c|c|c|}
\hline \multicolumn{2}{|r|}{$\begin{array}{c}\text { IMAGEM DO } \\
\text { MODELO }\end{array}$} & $\begin{array}{c}\text { NO DE } \\
\text { ELEMENTOS }\end{array}$ & INTERAÇÕES & TEMPO \\
\hline 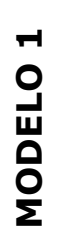 & & $\begin{array}{c}2.285 .180 \text { elementos, } \\
\text { sendo } 1.435 .935 \\
\text { tetraedros, } 846.228 \\
\text { prismas e } 3.017 \\
\text { pirâmides. }\end{array}$ & $\begin{array}{c}552 \text { interações e } \\
\text { convergência regular } \\
\text { com resultados } \\
\text { confiáveis }\end{array}$ & 19 horas \\
\hline 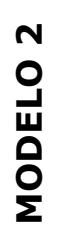 & & $\begin{array}{l}2.208 .305 \text { elementos } \\
\text { sendo, } 1.400 .725 \\
\text { tetraedros, } 805.095 \\
\text { prismas e } 2.485 \\
\text { pirâmides. }\end{array}$ & $\begin{array}{c}500 \text { interações e } \\
\text { convergência regular } \\
\text { com resultados } \\
\text { confiáveis }\end{array}$ & $\begin{array}{c}18 \text { horas e } \\
17 \\
\text { minutos }\end{array}$ \\
\hline 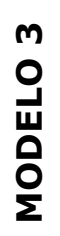 & & $\begin{array}{l}\text { 2.142.166 elementos, } \\
\text { sendo } 1.352 .165 \\
\text { tetraedros, } 787.269 \\
\text { prismas e } 2.732 \\
\text { pirâmides. }\end{array}$ & $\begin{array}{c}500 \text { interações e } \\
\text { convergência regular } \\
\text { com resultados } \\
\text { confiáveis }\end{array}$ & $\begin{array}{c}17 \text { horas e } \\
51 \\
\text { minutos }\end{array}$ \\
\hline 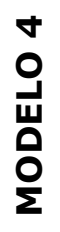 & & $\begin{array}{c}\text { 2.119.521 elementos, } \\
\text { sendo } 1.324 .293 \\
\text { tetraedros, } 789.861 \\
\text { prismas e } 5.367 \\
\text { pirâmides. }\end{array}$ & $\begin{array}{c}500 \text { interações e } \\
\text { convergência regular } \\
\text { com resultados } \\
\text { confiáveis }\end{array}$ & $\begin{array}{c}17 \text { horas e } \\
25 \\
\text { minutos }\end{array}$ \\
\hline 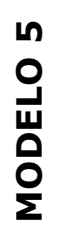 & & $\begin{array}{c}2.152 .970 \text { elementos } \\
\text { sendo } 1.343 .247 \\
\text { tetraedros, } 807.327 \\
\text { prismas e } 2.396 \\
\text { pirâmides. }\end{array}$ & $\begin{array}{c}300 \text { interações e } \\
\text { convergência regular } \\
\text { com resultados } \\
\text { confiáveis }\end{array}$ & $\begin{array}{c}10 \text { horas e } \\
40 \\
\text { minutos }\end{array}$ \\
\hline 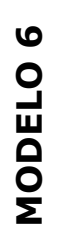 & & $\begin{array}{l}2.287 .728 \text { elementos } \\
\text { sendo } 1.477 .782 \\
\text { tetraedros, } 807.450 \\
\text { prismas e } 2.496 \\
\text { pirâmides. }\end{array}$ & $\begin{array}{c}300 \text { interações e } \\
\text { convergência regular } \\
\text { com resultados } \\
\text { confiáveis }\end{array}$ & $\begin{array}{c}11 \text { horas e } \\
22 \\
\text { minutos }\end{array}$ \\
\hline 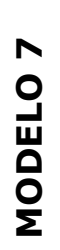 & & $\begin{array}{l}2.191 .210 \text { elementos, } \\
\text { sendo } 1.399 .693 \\
\text { tetraedros, } 788.976 \\
\text { prismas e } 2.541 \\
\text { pirâmides. }\end{array}$ & $\begin{array}{c}300 \text { interações e } \\
\text { convergência regular } \\
\text { com resultados } \\
\text { confiáveis }\end{array}$ & $\begin{array}{c}10 \text { horas e } \\
48 \\
\text { minutos }\end{array}$ \\
\hline 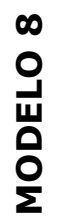 & & $\begin{array}{c}\text { 2.277.140 elementos, } \\
\text { sendo } 1.434 .578 \\
\text { tetraedros, } 839.487 \\
\text { prismas e } 3.075 \\
\text { pirâmides. }\end{array}$ & $\begin{array}{c}300 \text { interações e } \\
\text { convergência regular } \\
\text { com resultados } \\
\text { confiáveis }\end{array}$ & $\begin{array}{c}11 \text { horas e } \\
11 \\
\text { minutos }\end{array}$ \\
\hline
\end{tabular}


Vários meses desta pesquisa foram dedicados apenas ao processo de simulação como um todo, mas os arquivos finais só contabilizam o tempo dispendido na realização da etapa CFX-SOLVER, quando ocorre o processamento da simulação, como organizado na tabela 6.1 a seguir.

Porém, as etapas anteriores ao SOLVER são as mais trabalhosas e determinantes para o bom resultado da simulação, uma vez que depende do usuário para desenvolver cada passo, enquanto que no SOLVER apenas os computadores trabalham realizando a simulação e caso não se atinja a convergência adequada ou ocorra algum erro, todo o processo é reiniciado, como já dito anteriormente.

Após esta fase, cabe ao usuário novamente interferir e gerar todas as imagens necessárias para a análise final dos resultados, que serão expostas nos itens a seguir.

\subsection{ENTORNO DO APARTAMENTO - MODELO EXPERIMENTAL X MODELO BASE}

Nas figuras 6.1 e 6.2 , a parte preta representa o vazio interno do edifício por onde o fluxo não passa, com exceção da parte referente ao apartamento inserido no modelo base.

A comparação entre a figura 6.1 e 6.2 é para analisar quais as diferenças e semelhanças do perfil do vento no entorno da edificação entre o modelo totalmente fechado (experimental) e o que apresenta as aberturas para entrada e saída do vento (base). O ideal seria poder trabalhar com todas as aberturas dos quatro apartamentos existentes em 
cada andar da edificação, porém inúmeros testes iniciais realizados na elaboração dos modelos comprovaram que esta opção seria totalmente impossível pela incompatibilidade entre a geração de um número muito grande de elementos em cada modelo e a capacidade computacional disponível para a pesquisa. Dessa forma, após uma sucessão de modelos descartados, foi determinado o equilíbrio ideal entre a capacidade computacional disponível e o modelo que pudesse responder a todos as questões existentes nesta pesquisa de maneira mais realista possível.

Voltando a comparação entre o modelo experimental e o modelo base, notam-se algumas diferenças no contorno que representa a velocidade do vento no entorno do edifício, principalmente próximos as fachadas onde as aberturas foram inseridas, o que, evidentemente, já era esperado. Pois, uma vez que um obstáculo (como um edifício) apresenta aberturas permeáveis ao vento, o vento tende a apresentar uma velocidade maior próximo às aberturas quando comparada a uma fachada cega que tende a desviar a direção do vento e diminuir sua intensidade na proximidade do limite da barreira, como visto nas figuras 6.1 e 6.2.

Assim sendo, pode-se concluir a existência da compatibilidade esperada entre a ventilação externa e interna no modelo estudado, demonstrando que o mesmo corresponde à real correlação entre o exterior e o interior de um edifício quando o assunto abordado é a ventilação natural. 
211

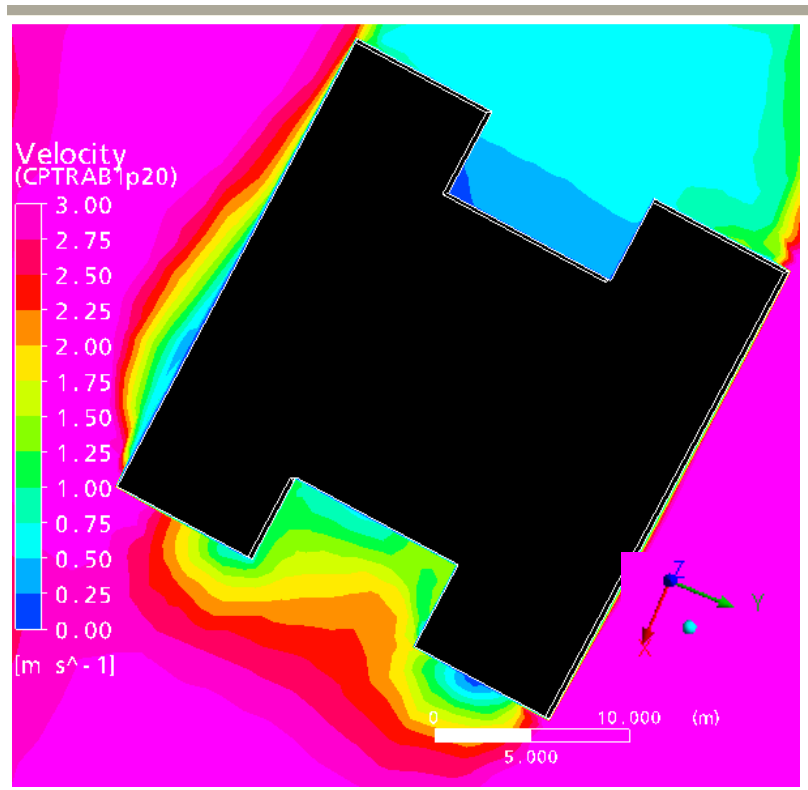

Figura 6.1 - Contorno da velocidade do vento no entorno do edifício no modelo experimental

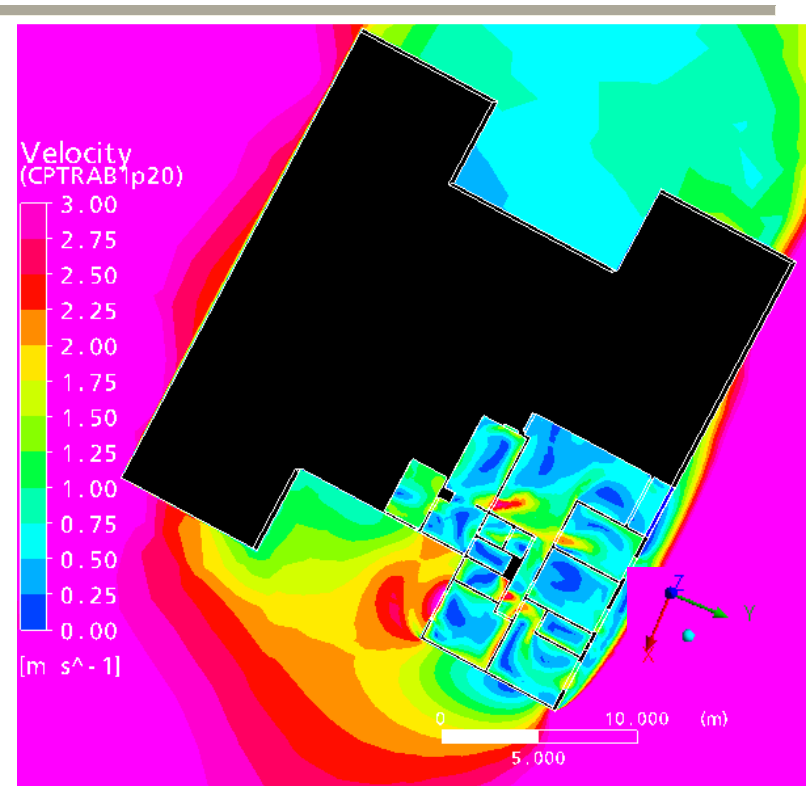

Figura 6.2 - Contorno da velocidade do vento no entorno do edifício no modelo base

Como já citado, é possível que se pudéssemos inserir todas as aberturas e espaços internos ao modelo, obtivéssemos resultados um pouco diferentes, mas pelas respostas representadas nas figuras $6.1 \mathrm{e}$ 6.2, podem-se considerar os resultados encontrados bastante satisfatórios e suficientes para realizar todas as análises desta pesquisa.

6.2 MOdelo 01

O modelo 01 corresponde à planta baixa original do apartamento, sem as esquadrias e todas as aberturas com vãos $100 \%$ livres. Considerado modelo base, pois servirá como referência na comparação da maior parte dos modelos.

Alcançado o resultado final da simulação deste modelo, comprovouse como pretendido desde o início, que a localização do apartamento escolhido apresentava um ótimo potencial de ventilação natural em seus espaços internos favorecendo desta maneira a visualização mais clara dos

CAPÍTULO 6 - DISCUSSÃO DOS RESULTADOS DAS SIMULAÇÕES 
resultados apresentados após todas as interferências arquitetônicas

propostas em seu interior. Isto pode ser visto a seguir nas figuras 6.3 a 6.6 que apresentam os contornos e os vetores da velocidade e direção dos ventos nos planos horizontais.

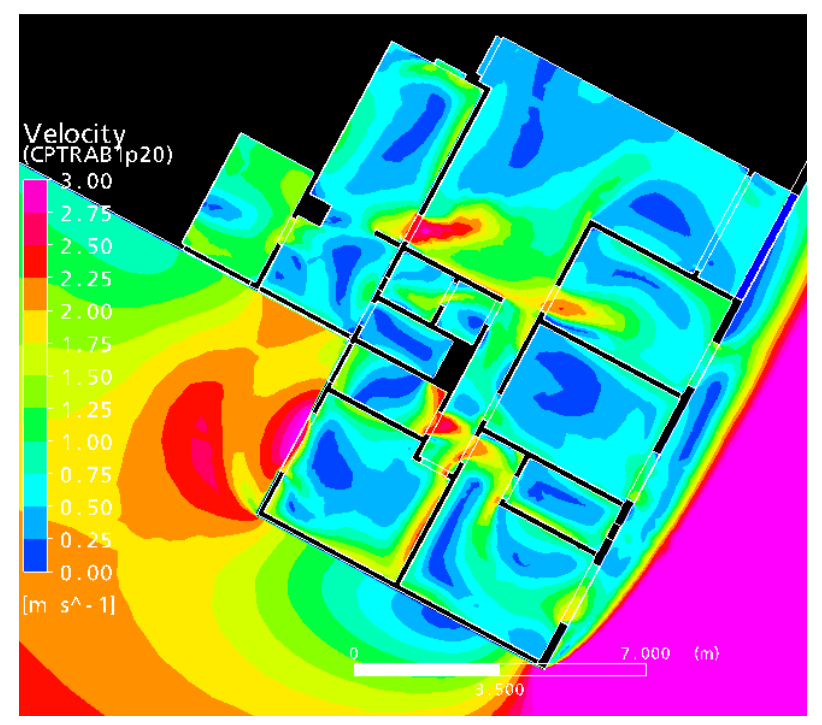

Figura 6.3 - Contorno da velocidade do vento no interior do apartamento no modelo 01 - Plano horizontal $h=1.20 \mathrm{~m}$

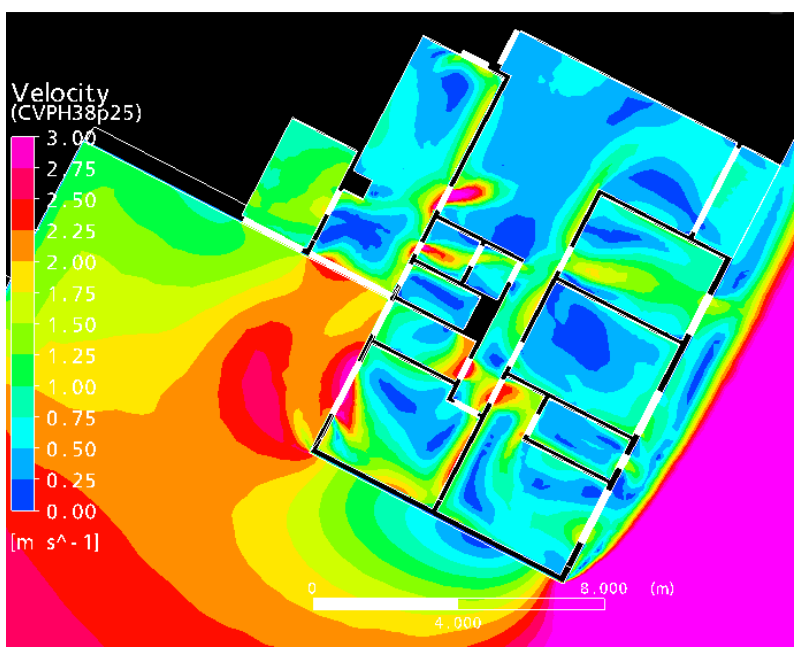

Figura 6.5 - Contorno da velocidade do vento no interior do apartamento no modelo 01 - Plano horizontal $h=2.00 m$

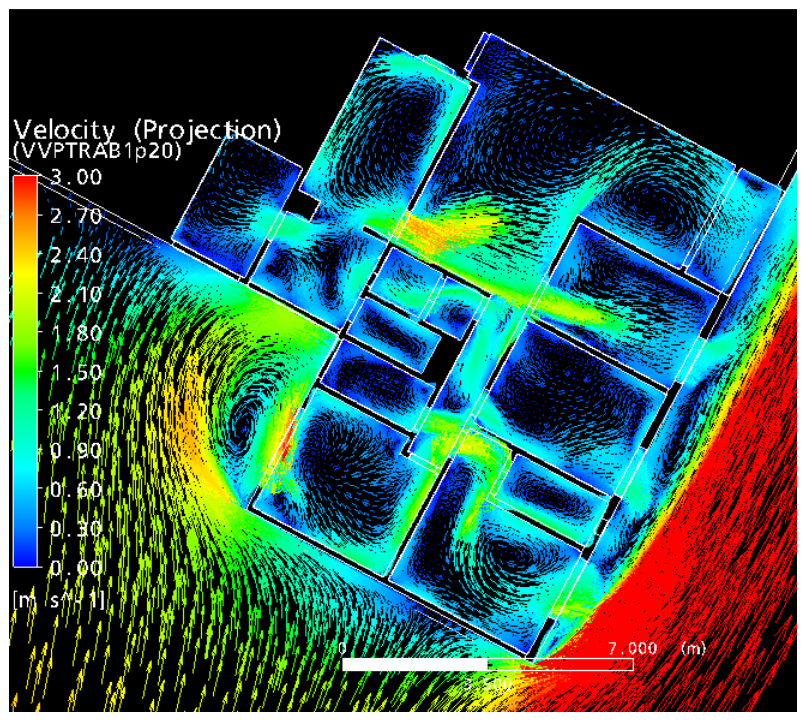

Figura 6.4 - Vetores de direção e velocidade do vento no interior do apartamento no modelo 01 - Plano horizontal $h=1.20 \mathrm{~m}$

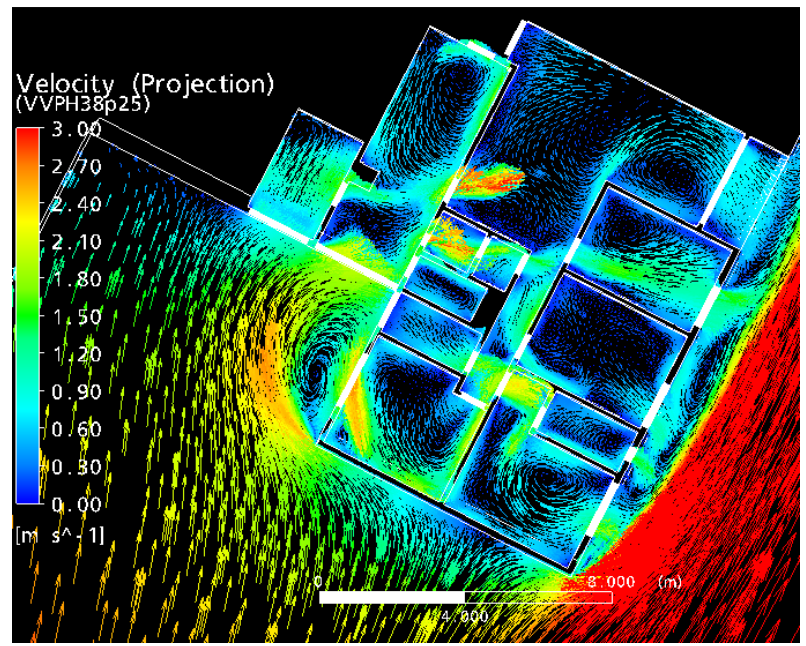

Figura 6.6 - Vetores de direção e velocidade do vento no interior do apartamento no modelo 01 - Plano horizontal $h=2.00 \mathrm{~m}$

Analisando no geral as figuras 6.3 a 6.6 , pode-se perceber que há uma distribuição regular do ar em todos os ambientes, com poucos 
espaços de estagnação de vento. Na maior parte do espaço a velocidade do vento varia entre 0,0 e $1,25 \mathrm{~m} / \mathrm{s}$, apesar da presença de áreas que apresentam correntes de ar mais forte, podendo chegar a 3,0m/s. Esta característica pode ser explicada, primeiro, por uma turbulência no final do corredor, possivelmente gerada pelo encontro de correntes de ar oriundas de aberturas diferentes e que se cruzam num espaço pequeno. Em segundo, na área entre a entrada da cozinha e a entrada do gabinete, o fluxo pode ter sofrido a influência não apenas da diferença de pressão entre as aberturas de entrada e saída do ar, mas também da ausência de um obstáculo que pudesse desviar e diminuir esta velocidade final.

É importante esclarecer que os resultados encontrados nestas simulações referem-se a um determinado perfil de vento definido a partir do levantamento dos dados climáticos da cidade que apresentou o dia típico de projeto como citado no capítulo 03. Desta forma em todas as simulações foi estabelecida a direção dos ventos a $90^{\circ}$ e sua velocidade de $4,5 \mathrm{~m} / \mathrm{s}$ para facilitar e organizar todas as análises.

\subsection{Modelo 01 x Modelo 02}

A alteração realizada no modelo 02 foi a mudança da localização das janelas dos dois quartos localizados na fachada leste do edifício.

Como já explicado no capítulo anterior, ao optar por esta alteração se buscou verificar como uma decisão tomada na fase de projeto e baseada no estudo de pressão nas fachadas pode representar uma melhor qualidade na distribuição do fluxo de ar no interior de uma edificação. Ao 
transferir as aberturas de entrada do ar dos dois quartos para a fachada que apresentou maior pressão do vento na simulação do modelo experimental, não apenas estes ambientes apresentaram uma melhora significativa da distribuição e velocidade do ar, como todos os outros quartos e a sala do apartamento também apresentaram melhores resultados, além da diminuição de áreas com ar estagnado neste plano analisado.

O resultado alcançado após a alteração proposta no modelo 02 demonstra claramente, por meio das figuras 6.7 a 6.12 , como uma simples decisão na fase de projeto, baseada numa simulação do modelo pode favorecer o conforto térmico natural em áreas com bom potencial eólico e evitar o uso desnecessário de condicionamento artificial do ar e consequente aumento no consumo de energia elétrica. 


\section{5}

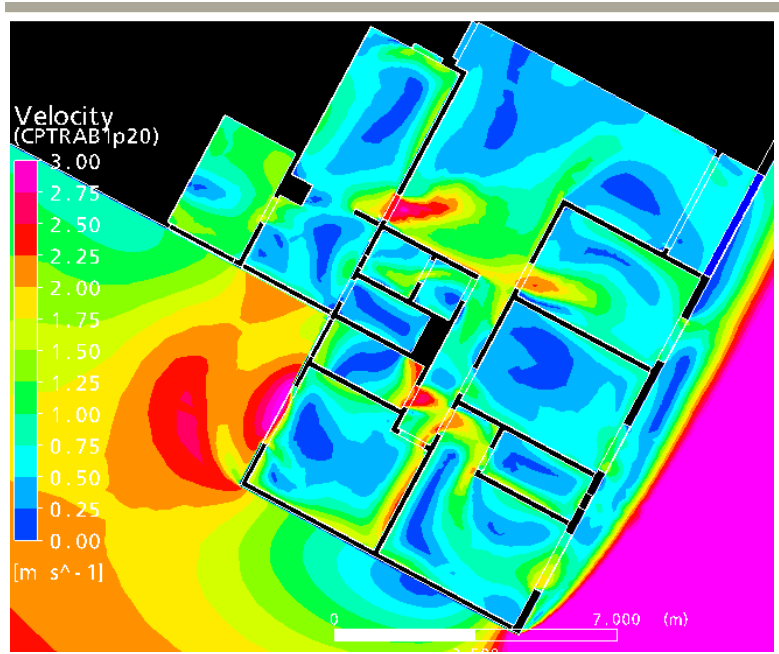

Figura 6.7 - Contorno da velocidade do vento no interior do apartamento no modelo $01-h=1.20 m$

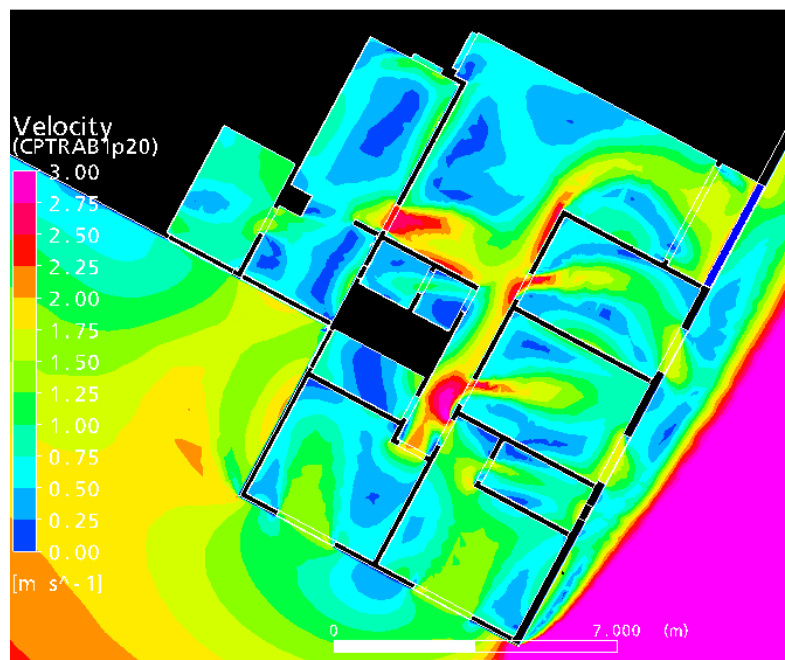

Figura 6.9 - Contorno da velocidade do vento no interior do apartamento no modelo $02-h=1.20 m$

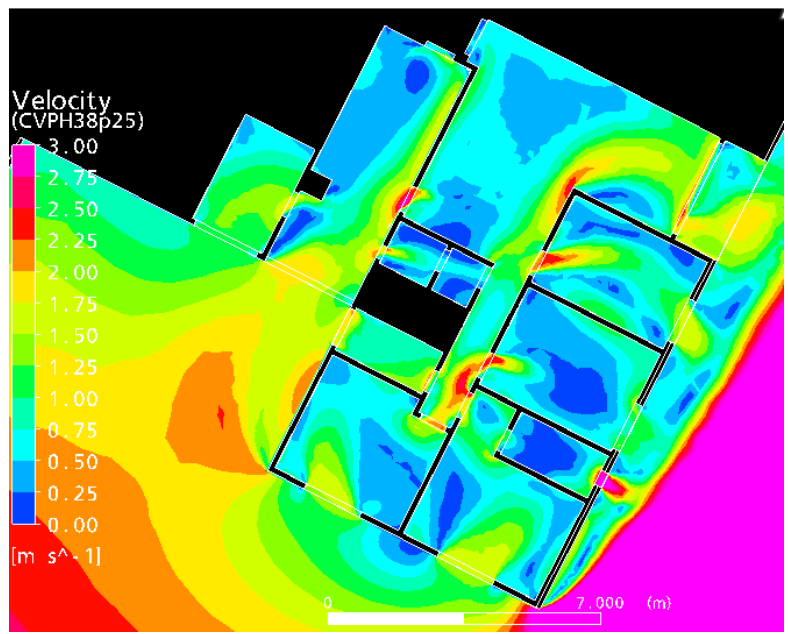

Figura 6.11 - Contorno da velocidade do vento no interior do apartamento no modelo $02-h=2.00 m$

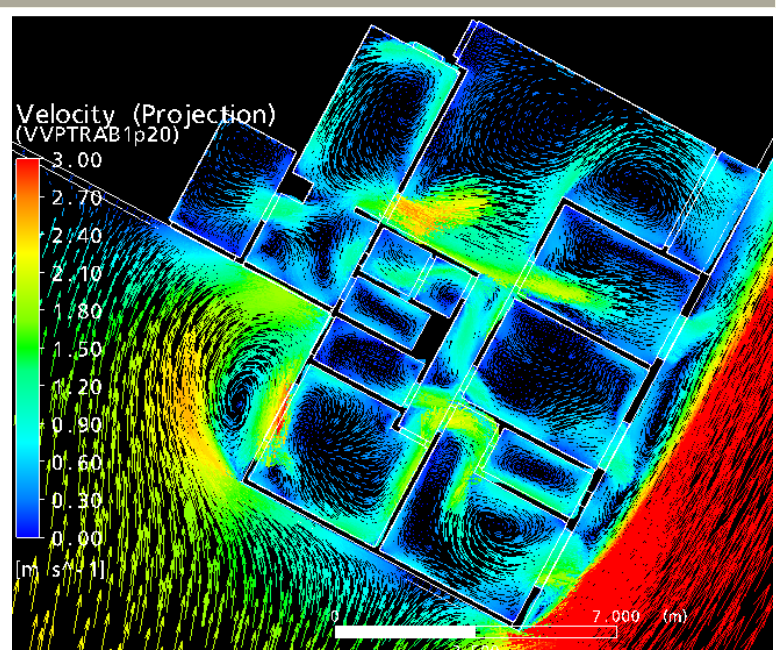

Figura 6.8 - Vetores da direção e velocidade do vento no interior do apartamento no modelo $01-h=1.20 \mathrm{~m}$

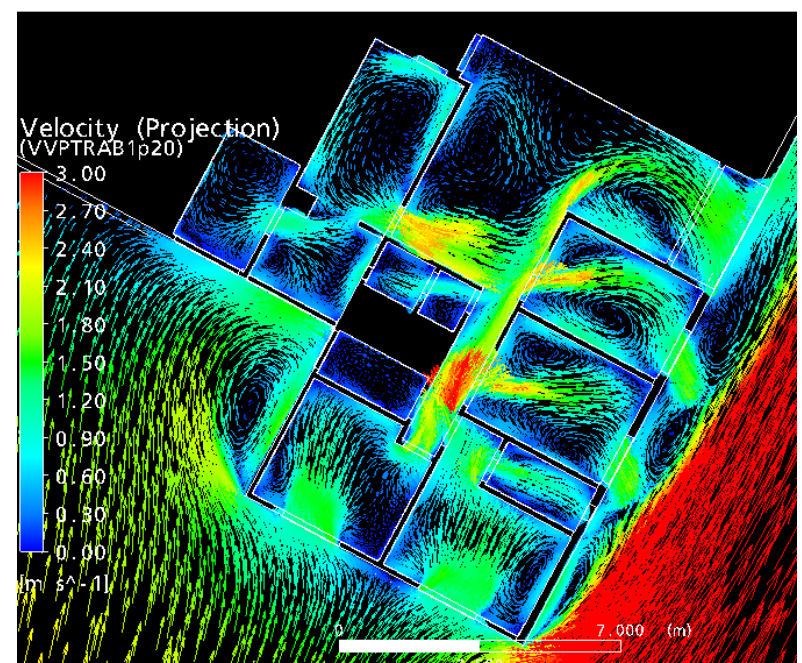

Figura 6.10 - Vetores da direção e velocidade do vento no interior do apartamento no modelo $02-h=1.20 m$

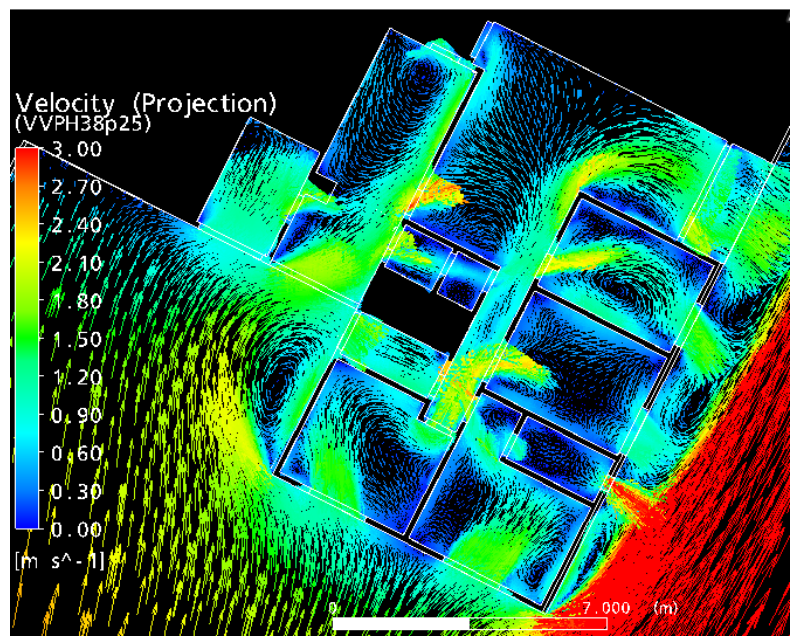

Figura 6.12 - Vetores da direção e velocidade do vento no interior do apartamento no modelo $02-h=1.20 m$ 


\subsection{MOdelo 01 X MOdelo 03}

No modelo 03 foram inseridas as esquadrias em todas as janelas, ou melhor, as aberturas foram dimensionadas para corresponderem aos vãos livres máximos proporcionais aos modelos de cada uma das esquadrias.

Ao comparar o resultado da simulação do modelo 01 ao modelo 03, verifica-se que apesar do aumento da velocidade do vento principalmente próximo as aberturas de entrada e saída do ar do modelo 03, devido ao aumento da pressão causado pela diminuição do espaço livre para a passagem do fluxo de vento, o resultado na qualidade da distribuição do ar no interior do apartamento não é prejudicada na mesma proporção.

É evidente que, em alguns ambientes, houve um aumento das áreas com ar estagnado. Além disso, a velocidade do vento próximo as paredes aumentou e no centro dos ambientes diminuiu, mas no geral apresentou valores que podem ser considerados satisfatórios.

Interessante notar a diferença da uniformidade na distribuição do ar entre o plano a $1,20 \mathrm{~m}$ e o plano a $2,00 \mathrm{~m}$ de altura no modelo 03 . No segundo plano pode-se perceber que ao inserir obstáculos uniformemente distribuídos no vão das aberturas da área de serviço e quarto de empregada, referentes às folhas da janela pivotante, ocorreu um aumento da pressão do ar nestas aberturas, a velocidade do vento ao penetrar o ambiente aumentou e consequentemente a qualidade do fluxo de ar em todos os ambientes do apartamento no plano a $2,00 \mathrm{~m}$ foi melhor, considerando a distribuição mais uniforme do ar. 


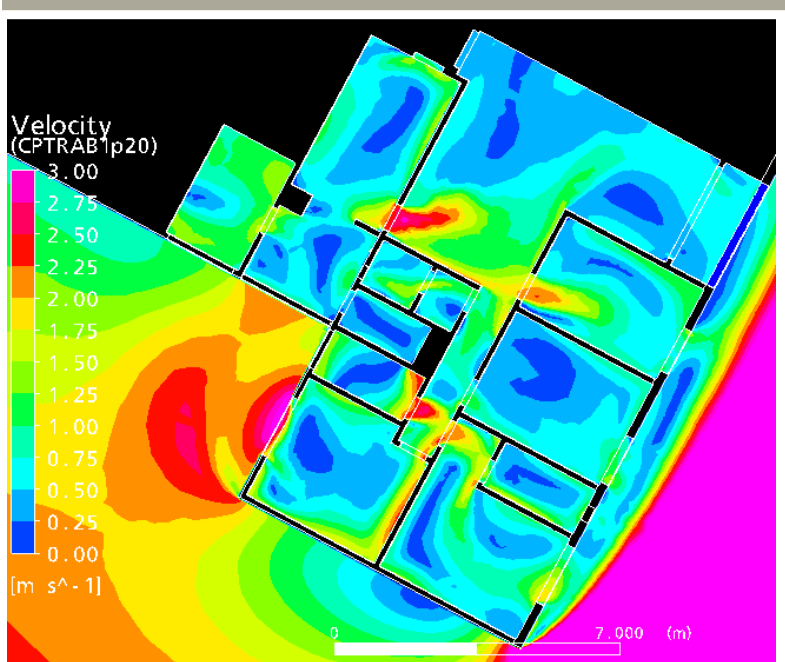

Figura 6.13 - Contorno da velocidade do vento no interior do apartamento no modelo $01-h=1.20 m$

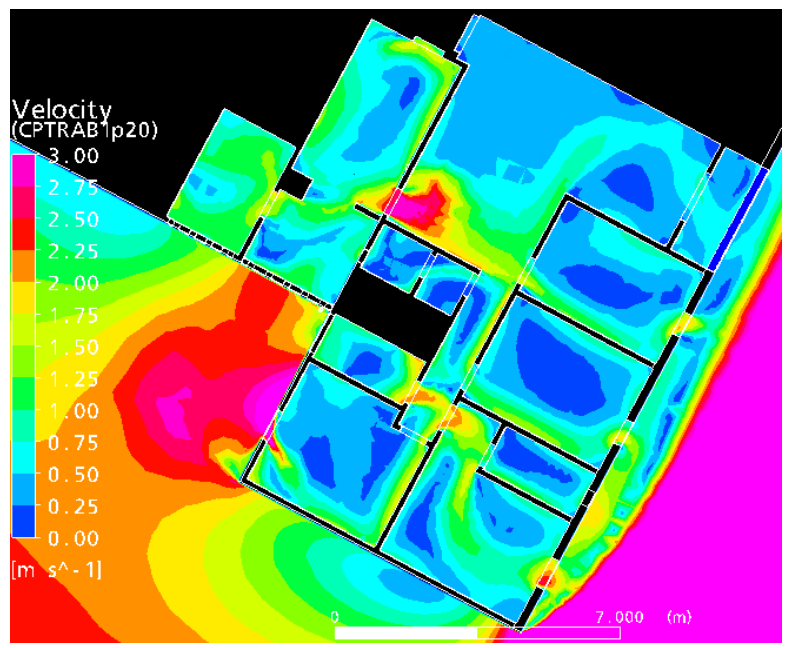

Figura 6.15 - Contorno da velocidade do vento no interior do apartamento no modelo $03-h=1.20 m$

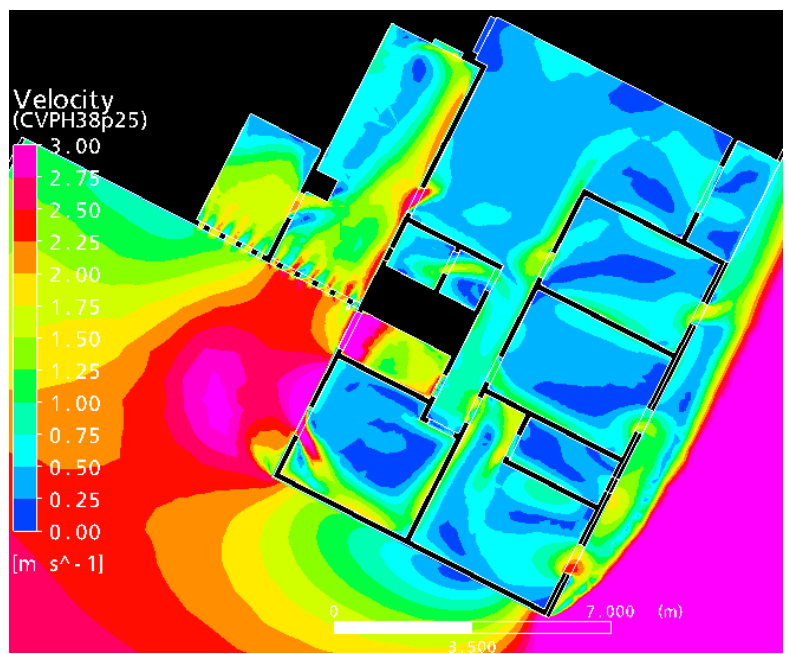

Figura 6.17 - Contorno da velocidade do vento no interior do apartamento no modelo $03-h=2.00 m$

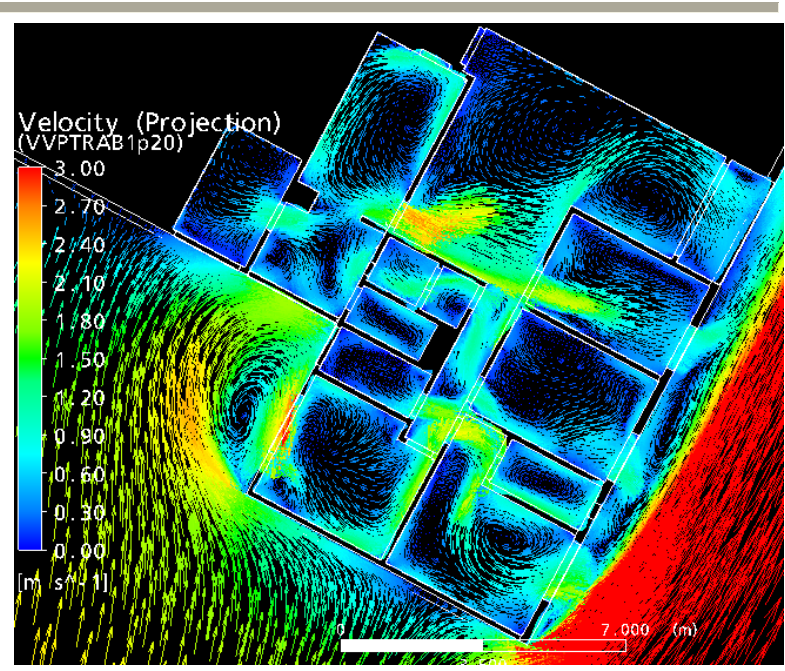

Figura 6.14 - Vetores da direção e velocidade do vento no interior do apartamento no modelo $01-h=1.20 \mathrm{~m}$

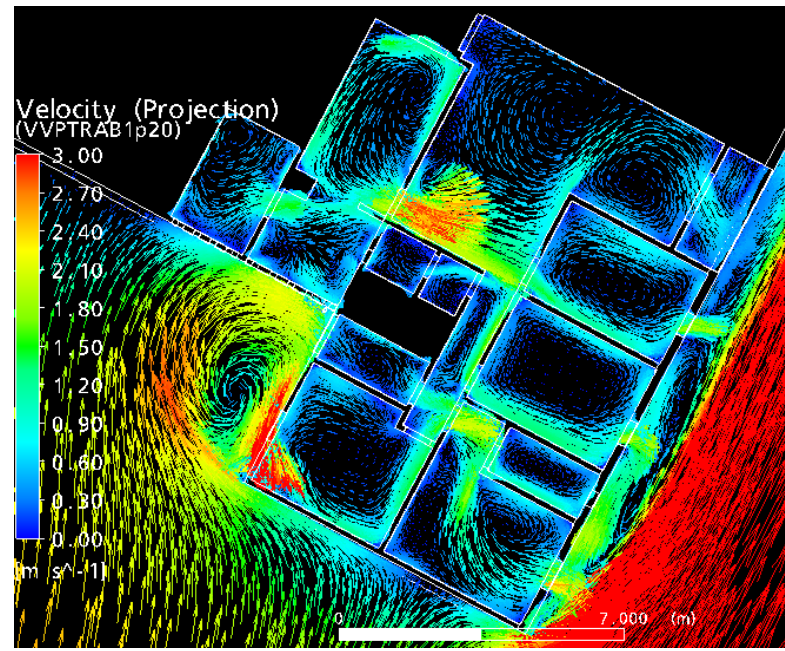

Figura 6.16 - Vetores da direção e velocidade do vento no interior do apartamento no modelo $03-h=1.20 m$

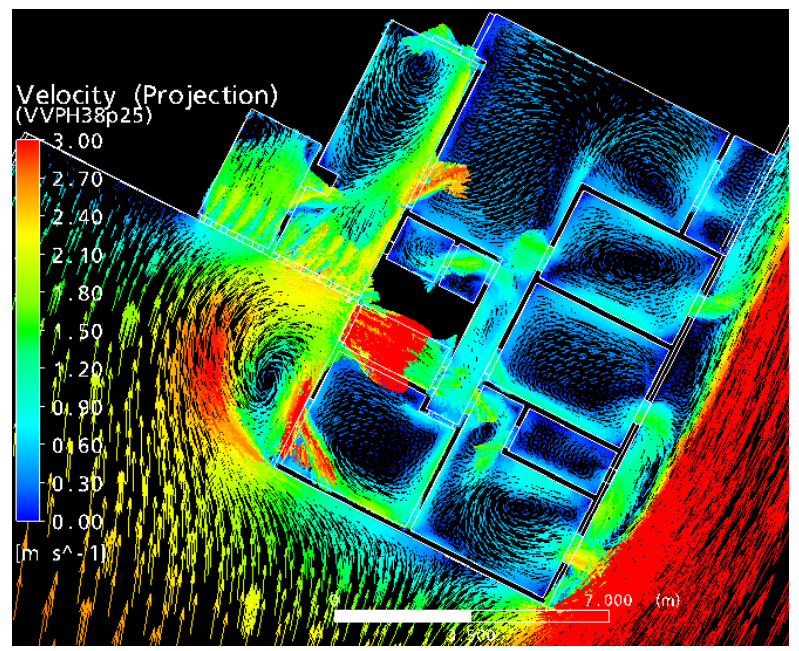

Figura 6.18 - Vetores da direção e velocidade do vento no interior do apartamento no modelo $03-\mathrm{h}=\mathbf{2 . 0 0 \mathrm { m }}$ 


\subsection{MOdELO 03 X MODELO 04}

O modelo 04 se caracteriza por simular a ventilação natural no interior do apartamento quando as portas dos quatro quartos estão fechadas, situação muito comum quando os usuários desejam maior privacidade em seus quartos.

Assim como esperado, ao comparar o resultado do modelo 04 com o modelo 03 - por apresentar todas as características físicas semelhantes, com exceção das portas fechadas - a resposta encontrada correspondeu às expectativas, uma vez que não existe uma ventilação eficiente dentro de uma ambiente onde só existe uma abertura. É preciso que haja duas aberturas, uma de entrada e outra de saída, com diferenças de pressão entre elas para que o ar circule dentro do espaço.

Apenas na suíte houve algum movimento de ar em seu interior porque a janela e porta do banheiro permaneceram abertas neste ensaio, mas ainda assim não privilegiou a ventilação no quarto, que ficou tão prejudicada como nos outros três, como comparado nas figuras 6.19 a 6.24 .

Com a impossibilidade de fazer o ar circular pelos quartos, o fluxo de ar vindo das aberturas da área de serviço e do quarto de empregada incrementou a velocidade do ar na parte da sala próxima à varanda e na própria varanda que acabou sendo a única abertura disponível para a saída de todo o fluxo de ar do apartamento. 


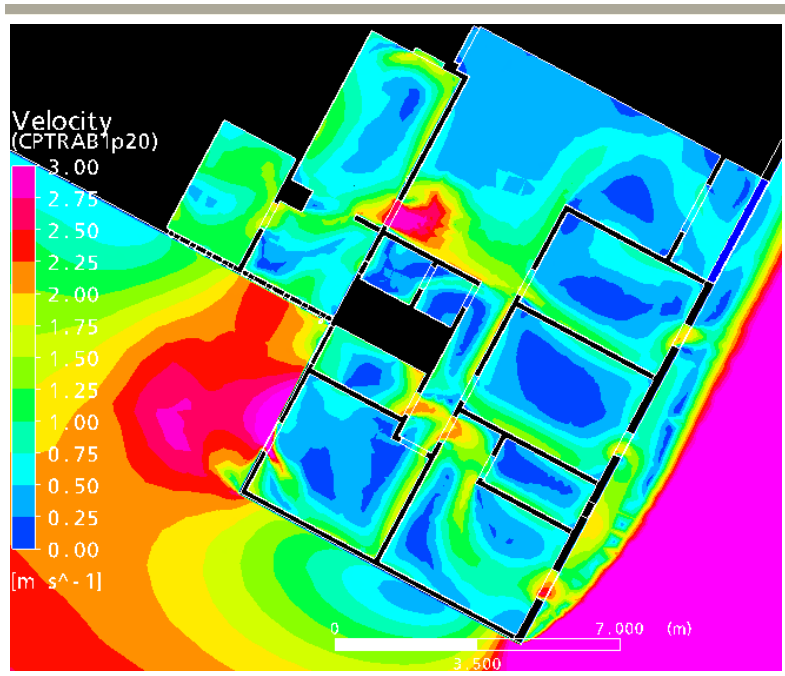

Figura 6.19 - Contorno da velocidade do vento no interior do apartamento no modelo $03-h=1.20 m$

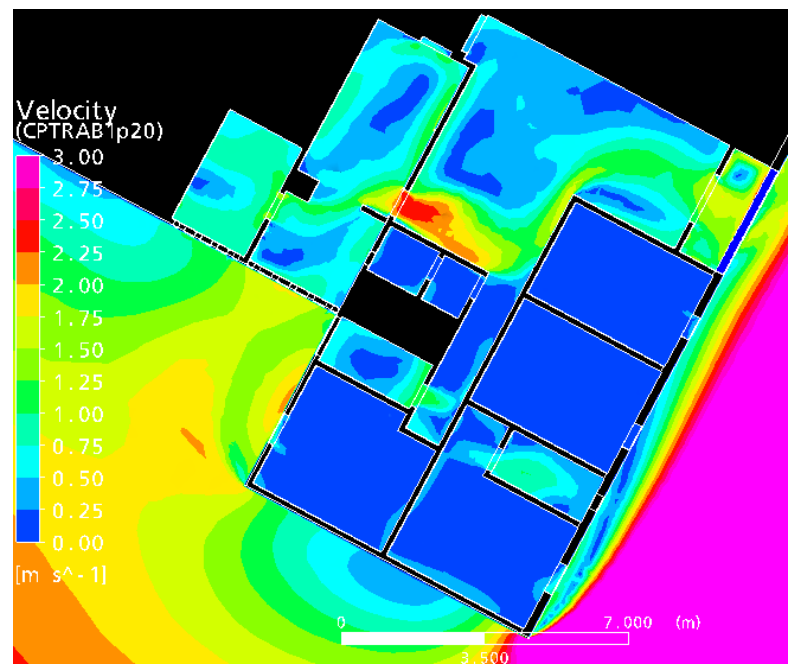

Figura 6.21 - Contorno da velocidade do vento no interior do apartamento no modelo $04-h=1.20 m$

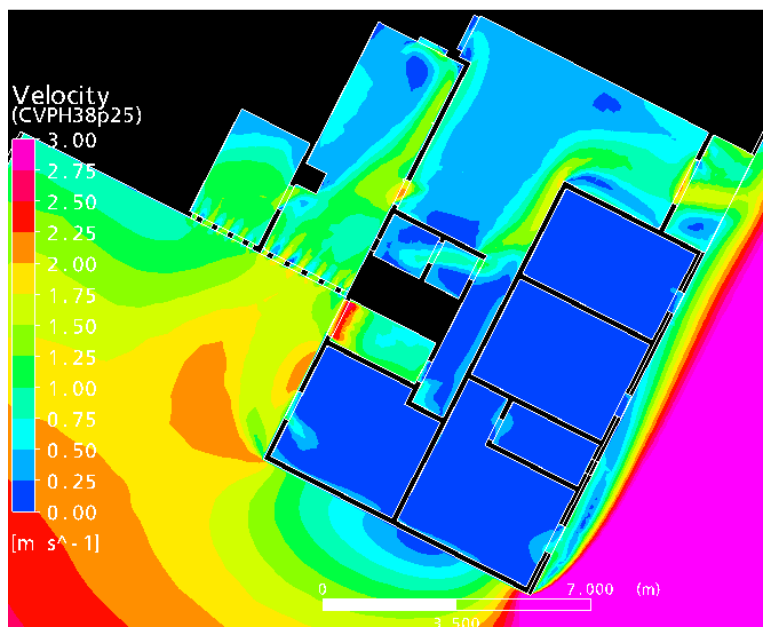

Figura 6.23 - Contorno da velocidade do vento no interior do apartamento no modelo $04-h=2.00 m$

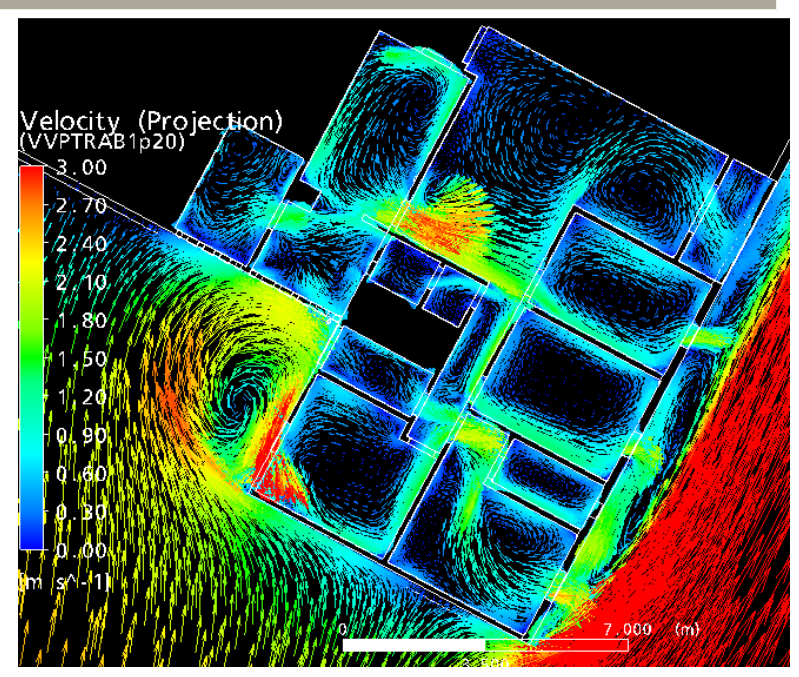

Figura 6.20 - Vetores da direção e velocidade do vento no interior do apartamento no modelo 03

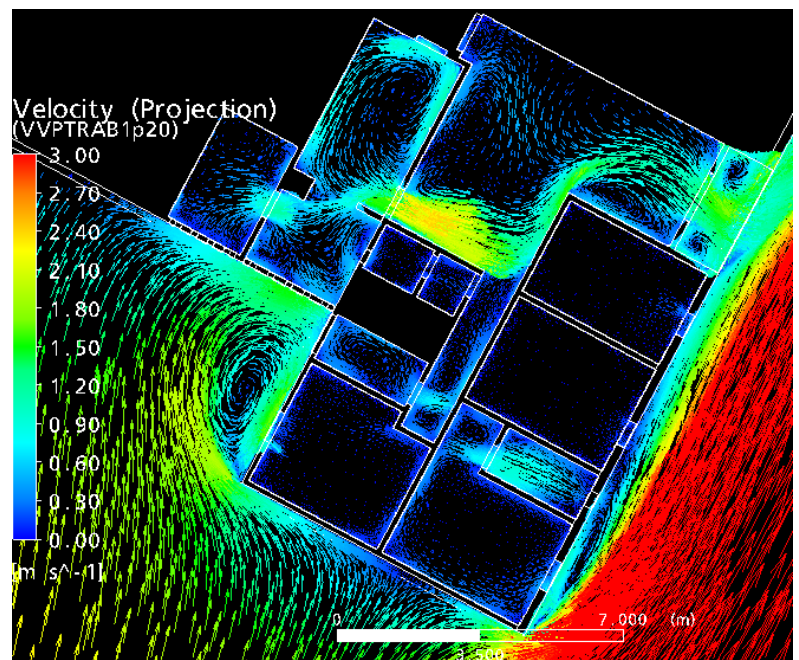

Figura 6.22 - Vetores da direção e velocidade do vento no interior do apartamento no modelo $04-\mathrm{h}=1.20 \mathrm{~m}$

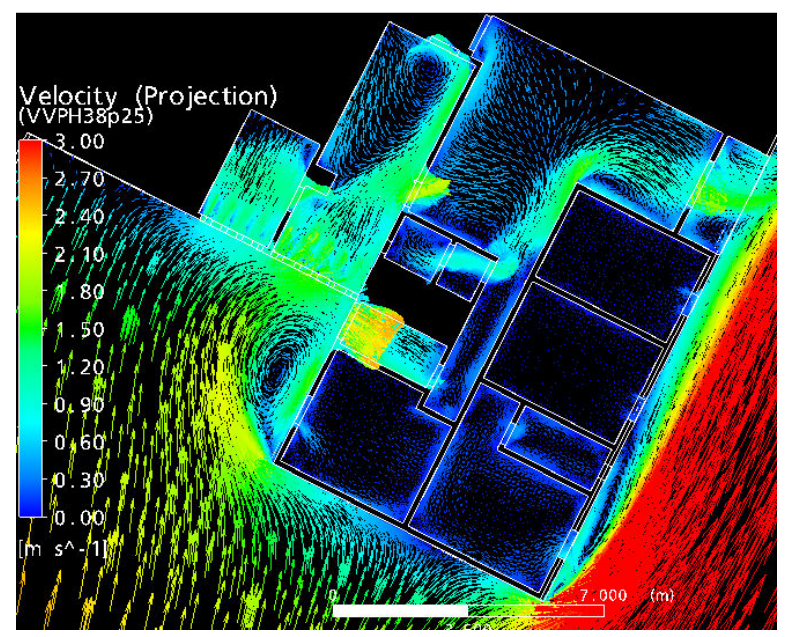

Figura 6.24 - Vetores da direção e velocidade do vento no interior do apartamento no modelo $04-\mathrm{h}=2.00 \mathrm{~m}$ 
Este resultado tem como vantagem poder alertar sobre a importância de se analisar os costumes dos usuários em seu dia-a-dia antes de propor uma solução final. Num projeto arquitetônico que pretenda maximizar a ventilação natural em seu interior é de suma importância a participação consciente do usuário para que suas atitudes não prejudiquem o resultado final. Além disso, é importante que todos possam controlar a intensidade e a direção dos ventos por meio do ajuste dos vãos de abertura das esquadrias, no caso de ventos muito fortes ou chuvas com vento.

\subsection{MOdelo 04 X MOdelo 05}

O modelo 05 difere do modelo 04 apenas por apresentar aberturas conhecidas como bandeiras - de 0,70 x 0,30m acima das portas dos quatro quartos que permaneceram fechadas como no modelo anterior.

Comparando as figuras a seguir, notamos que a inserção das bandeiras na parte superior das portas dos quartos no modelo 05 alterou a movimentação do ar no interior dos ambientes em relação ao modelo anterior. Analisando as imagens 6.25 a 6.30 geradas em dois planos horizontais, nota-se que a velocidade do ar varia de 0,00 a $1,00 \mathrm{~m} / \mathrm{s}$, com algumas áreas sem movimentação de ar, mas apresenta melhor resultado no plano a 2,00m de altura, pela maior proximidade dos vãos livres, evidentemente. 


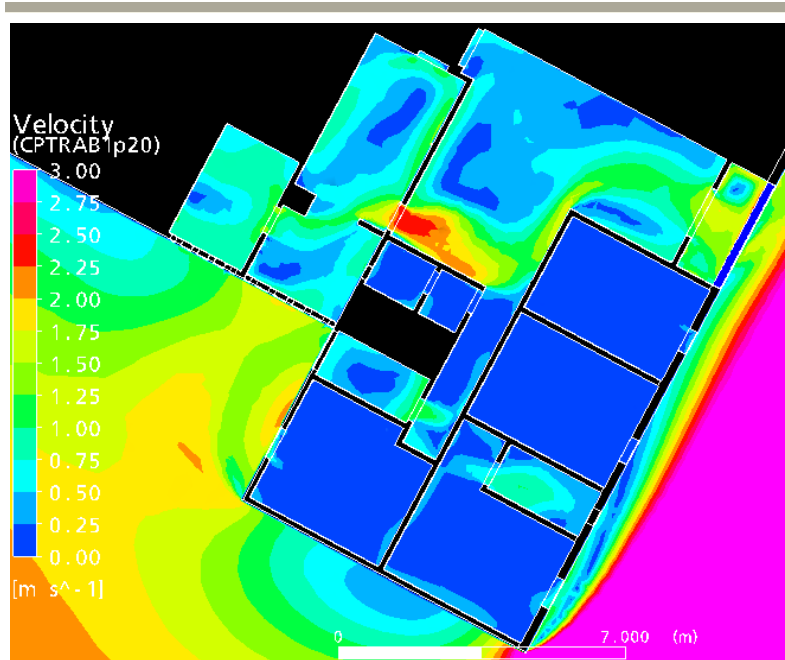

Figura 6.25 - Contorno da velocidade do vento no interior do apartamento no modelo $04-\mathrm{h}=1.20 \mathrm{~m}$

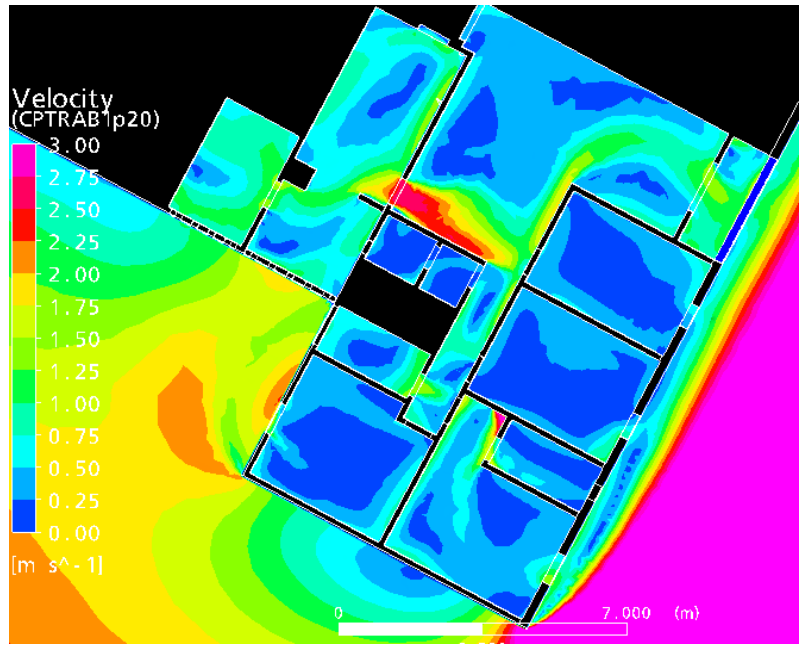

Figura 6.27 - Contorno da velocidade do vento no interior do apartamento no modelo $05-h=1.20 m$

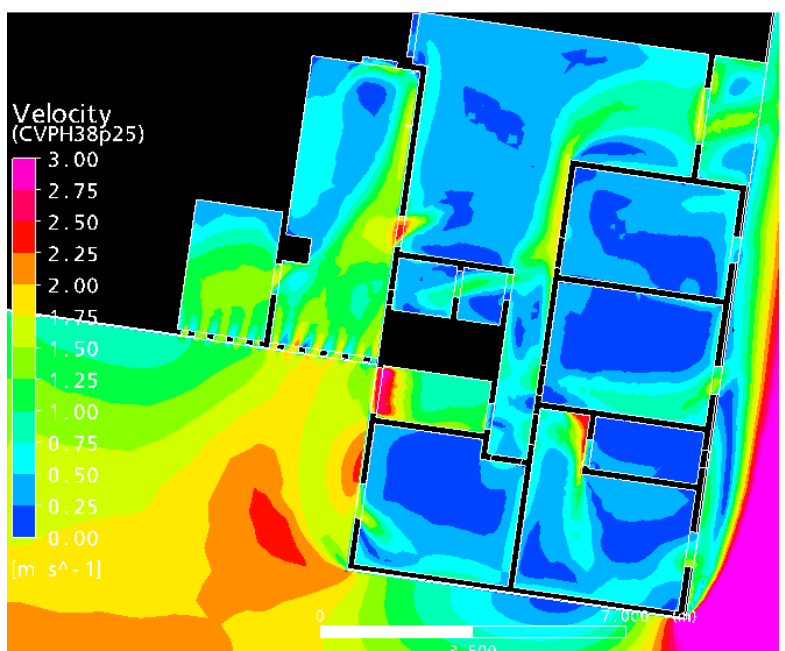

Figura 6.29 - Contorno da velocidade do vento no interior do apartamento no modelo $05-h=2.00 m$

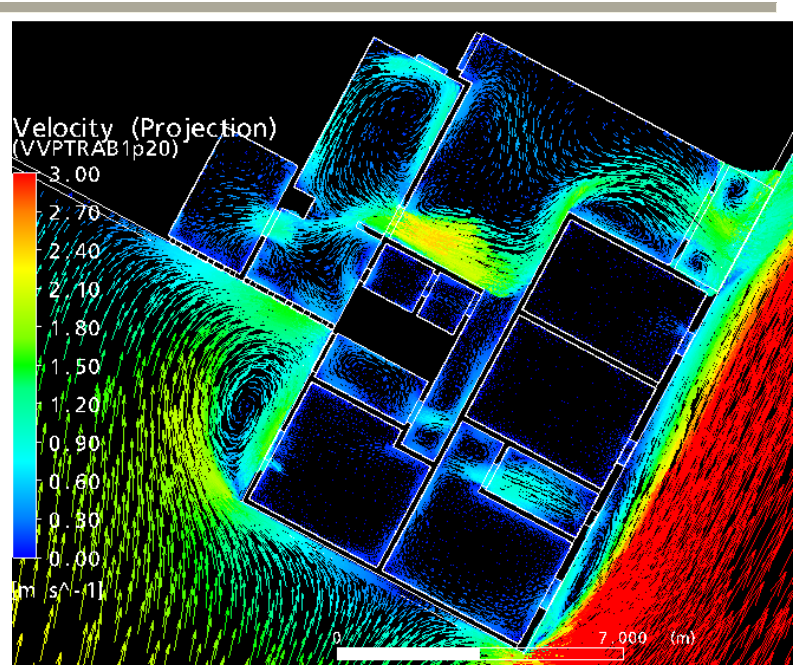

Figura 6.26 - Vetores da direção e velocidade do vento no interior do apartamento no modelo $04-\mathrm{h}=1.20 \mathrm{~m}$

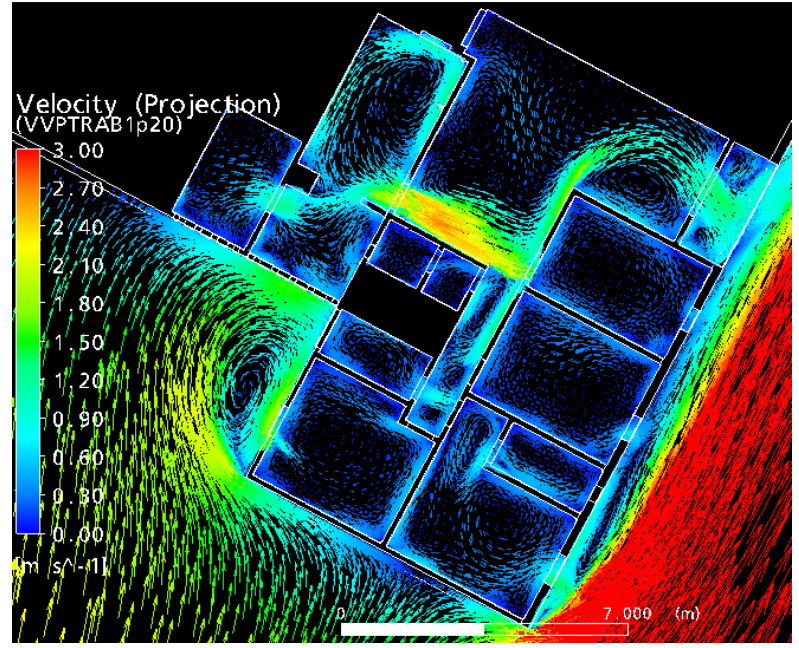

Figura 6.28 - Vetores da direção e velocidade do vento no interior do apartamento no modelo $05-h=1.20 m$

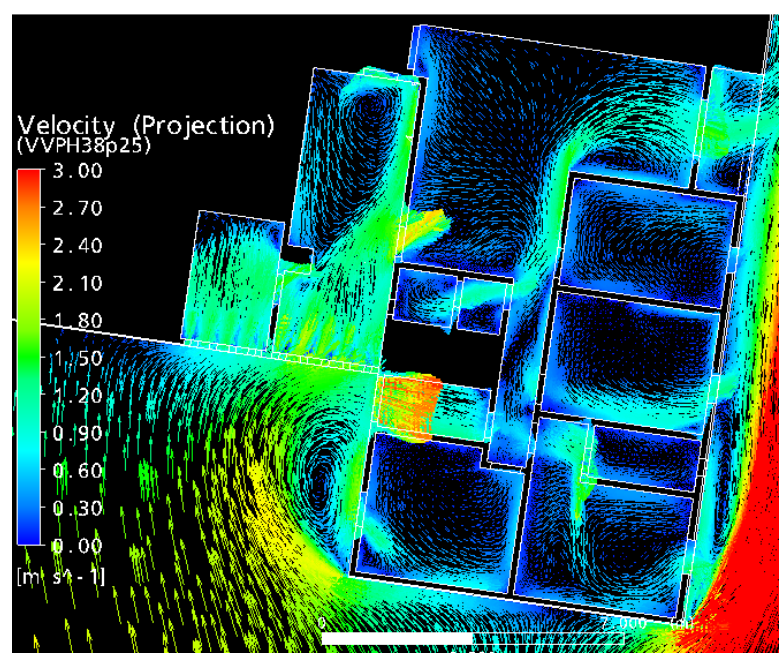

Figura 6.30 - Vetores da direção e velocidade do vento no interior do apartamento no modelo $05-\mathrm{h}=\mathbf{2 . 0 0 \mathrm { m }}$ 
Após uma análise com todas as imagens geradas desta simulação (Anexo 9) pela configuração da localização, direção e intensidade do fluxo de ar nos quartos, chegou-se a conclusão de que a ventilação natural no interior destes ambientes neste caso pode ser suficiente para remover a carga térmica gerada pelos usuários, e prover o conforto térmico, principalmente nos períodos de descanso uma vez que pode não ser confortável uma corrente de ar forte na altura das pessoas enquanto dormem em suas camas durante toda a noite.

Sendo assim, com menor intensidade da velocidade do vento no interior destes ambientes no período de descanso e uma distribuição do ar que consiga remover a carga térmica e o excesso de umidade do ambiente pode ser suficiente para o conforto térmico dos usuários e ainda assim permitir, neste caso, que as portas permaneçam fechadas desde que as mesmas possuam bandeiras por onde o ar poderá circular.

\subsection{MOdelo 03 X MOdelo 06}

O modelo 06 representa uma alteração na planta arquitetônica original do apartamento que foi proposta pela construtora aos compradores ainda na fase de execução do projeto e consiste na eliminação do gabinete e consequente aumento da sala, transformação do lavabo em banheiro social e a mudança da localização da porta do antigo banheiro social de forma a transformar mais um quarto em suíte. 


\section{3}

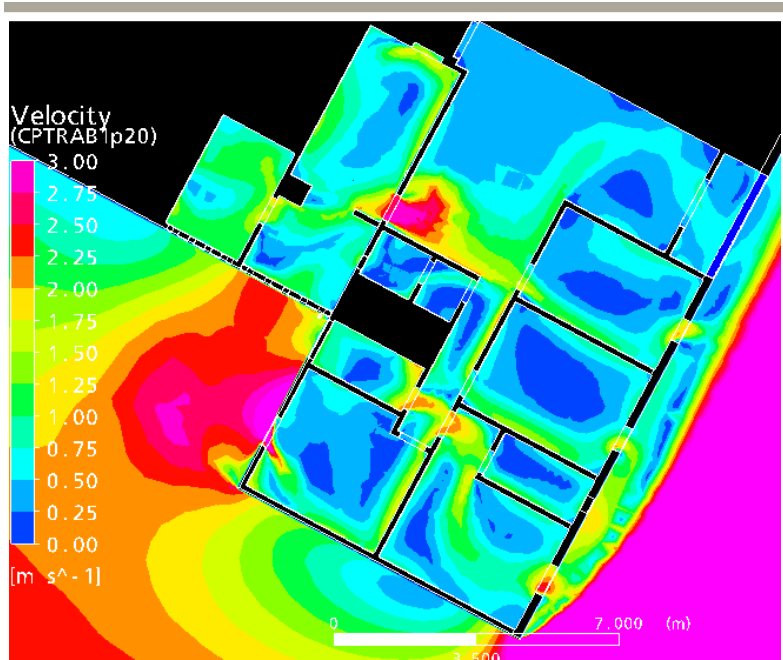

Figura 6.31 - Contorno da velocidade do vento no interior do apartamento no modelo $03-h=1.20 \mathrm{~m}$

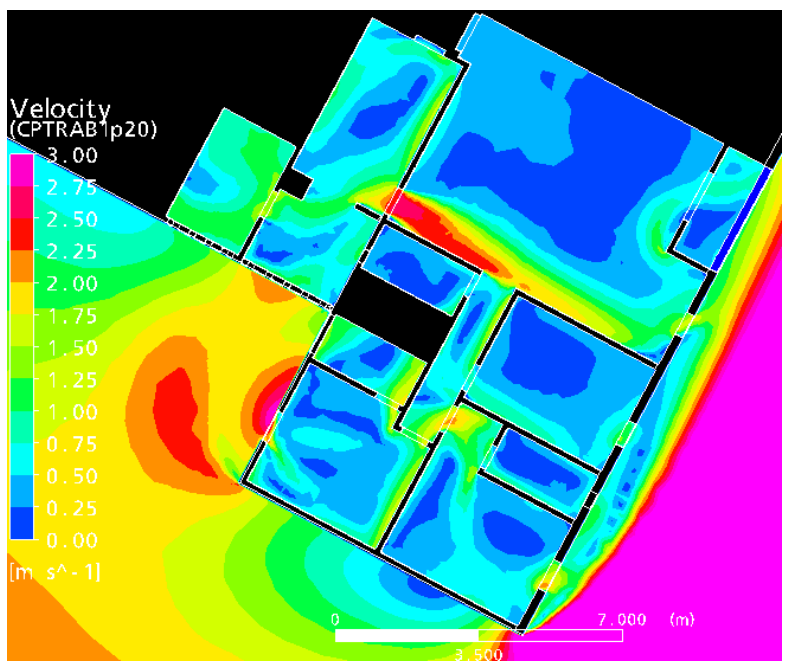

Figura 6.33 - Contorno da velocidade do vento no interior do apartamento no modelo $06-\mathrm{h}=1.20 \mathrm{~m}$

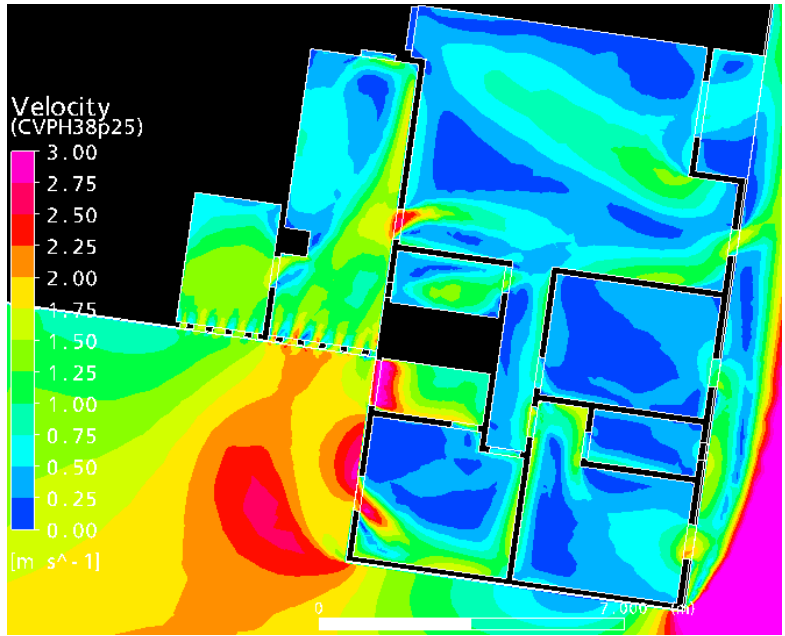

Figura 6.35 - Contorno da velocidade do vento no interior do apartamento no modelo $06-\mathrm{h}=2.00 \mathrm{~m}$

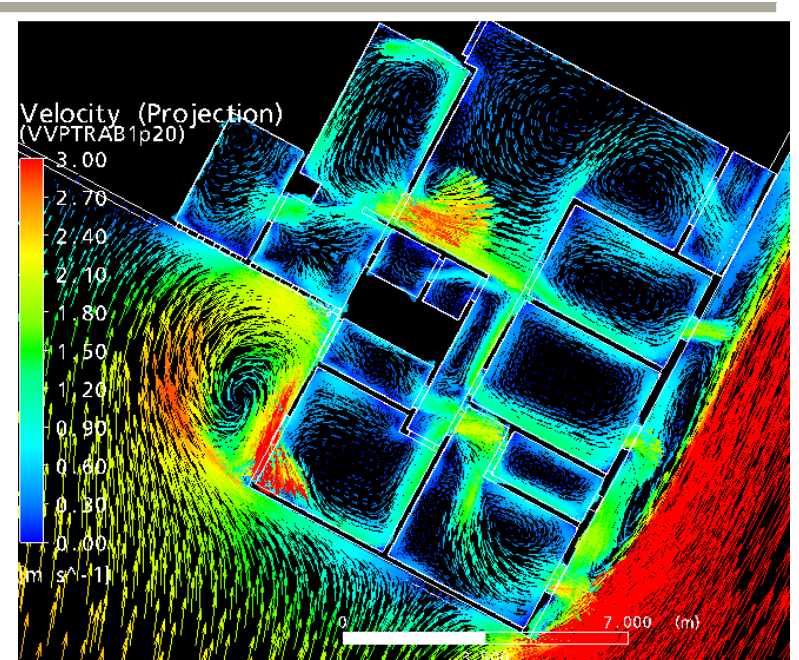

Figura 6.32 - Vetores da direção e velocidade do vento no interior do apartamento no modelo $03-\mathrm{h}=1.20 \mathrm{~m}$

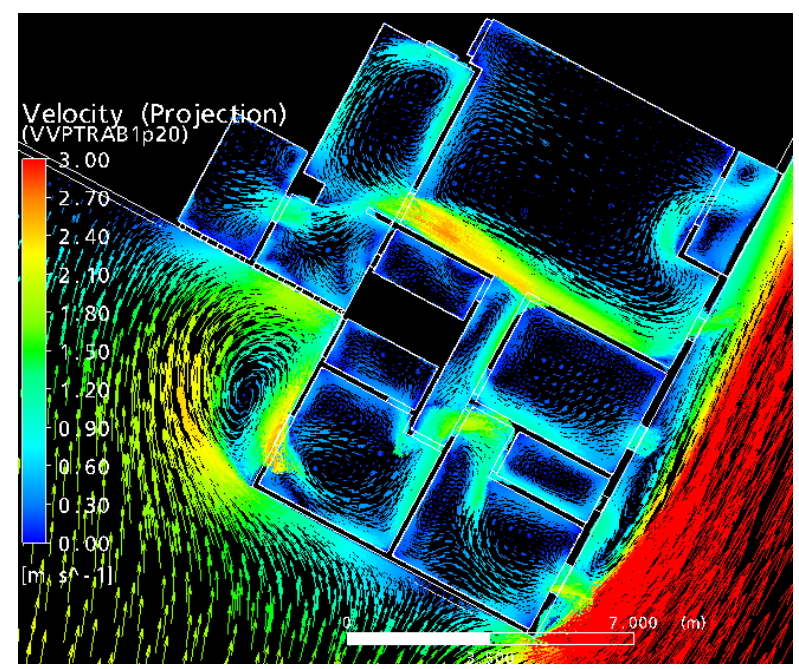

Figura 6.34 - Vetores da direção e velocidade do vento no interior do apartamento no modelo $06-\mathrm{h}=1.20 \mathrm{~m}$

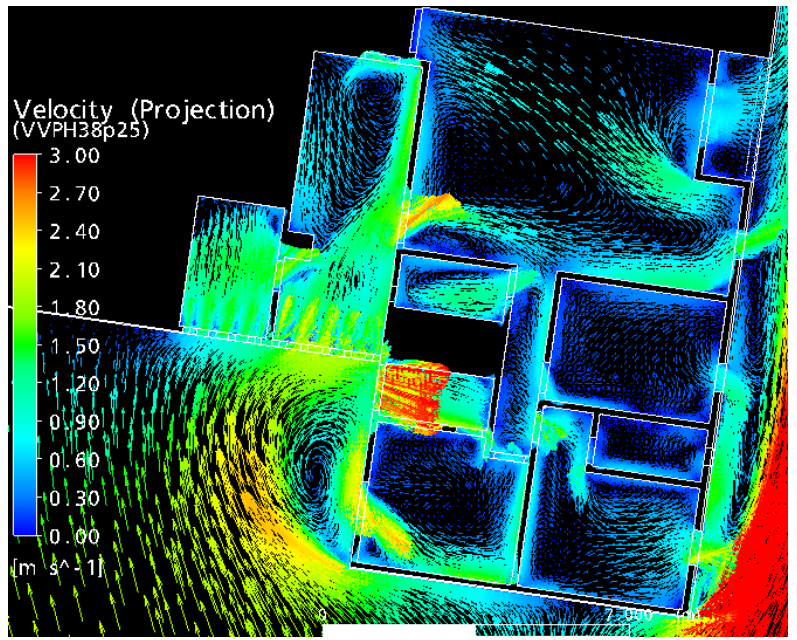

Figura 6.36 - Vetores da direção e velocidade do vento no interior do apartamento no modelo $06-\mathrm{h}=2.00 \mathrm{~m}$ 
Assim, o resultado da simulação do modelo 06 comparado ao resultado da simulação do modelo 03 - as esquadrias estão sendo consideradas - poderá mostrar, em relação à qualidade da ventilação natural no interior do apartamento, qual a melhor opção de planta oferecida.

Analisando as imagens dos resultados das duas simulações - figuras 6.31 a 6.36 - pode-se dizer que em termos da qualidade da ventilação natural na edificação a alteração do modelo 06 no geral não apresentou vantagem em relação ao modelo 03.

Nas áreas íntimas do apartamento não aconteceu uma mudança significativa na distribuição do fluxo de ar, mas houve uma diminuição na velocidade do ar nestes ambientes, porém não representa um fator negativo, uma vez que velocidade do vento acima de $1,50 \mathrm{~m} / \mathrm{s}$ em ambientes fechados - principalmente quando o ar está canalizado - pode causar desconforto dependendo da atividade realizada no local.

A diferença mais significativa entre os modelos aconteceu na área social do apartamento. Com a eliminação das paredes que formavam o espaço do gabinete, verificamos nas figuras 6.33 e 6.34, referentes ao plano a 1,20m de altura, que uma grande área com estagnação de ar apareceu no centro da sala e uma forte corrente de ar com velocidades que podem ultrapassar os $2 \mathrm{~m} / \mathrm{s}$ se formou paralelamente à parede lateral entre a porta da cozinha e a janela da sala. Apesar do mesmo fenômeno 
não ter se apresentado no plano superior, isto pode causar certo desconforto aos usuários.

Diferente do que geralmente é pregado em estudos sobre a ventilação natural na edificação, nem sempre um ambiente com menos divisões e com aberturas de entrada e saída do vento em paredes opostas representam a melhor opção. No modelo 03, com todas as divisões da planta original, apresentou melhor distribuição do fluxo de ar na sala e na varanda do que no modelo 06.

A área de serviço do modelo 06 não apresentou nenhuma mudança significativa na qualidade do fluxo de ar, principalmente no plano a $1,20 \mathrm{~m}$ de altura (figuras 6.33 e 6.34), mas se analisássemos o plano a $2 \mathrm{~m}$ de altura (figuras 6.35 e 6.36), quando o mesmo corta o meio das aberturas da área de serviço e quarto de empregada, perceberíamos que houve um aumento significativo na velocidade do vento na área de serviço, sem alteração significativa na cozinha, assim como a área de estagnação do ar na sala diminuiu e o fluxo de vento que forma uma corrente de ar no plano de trabalho, apresenta-se com menor intensidade.

\subsection{Modelo 01 X Modelo 07}

O modelo 07 voltou a excluir as esquadrias das janelas e aumentou a largura das janelas dos quartos para toda a extensão da parede onde as mesmas estão localizadas, ou seja, as larguras das janelas dos quartos praticamente dobraram de dimensão, mas mantiveram a mesma altura da abertura e do peitoril. 
Pode ser uma tendência acreditar que quanto maior as aberturas de um ambiente, melhor a qualidade - maior velocidade e uniformidade na distribuição do ar. Por este motivo o resultado da simulação do modelo 07 será comparado ao modelo 01 para a análise desta hipótese.

Retomando a questão da pressão do vento na fachada do edifício, sabe-se que apenas o quarto do lado esquerdo, no final do corredor, tem sua janela em uma fachada de pressão positiva e, portanto caracteriza-se como abertura de entrada do ar, enquanto que os outros três quartos tem suas janelas localizadas na fachada de pressão negativa e consequentemente são caracterizadas como aberturas de saída do fluxo de ar.

Deste modo, ao comparar os resultados apresentados nas figuras 6.37 a 6.42, pode-se claramente concluir que no caso da configuração da planta deste apartamento - que apresenta em seus quartos uma abertura para o exterior e a outra abertura para o interior - aumentando uma das aberturas de um ambiente e mantendo as demais com a mesma dimensão e localização, sua resposta será mais expressiva quando esta abertura se localizar na fachada de pressão positiva da edificação. Ou seja, o único quarto onde ocorreu uma aceleração na velocidade do ar considerada proporcional a diferença da largura da janela foi o quarto cuja abertura se localiza na fachada de pressão positiva, apesar da configuração do fluxo ter sido pouco afetada. 


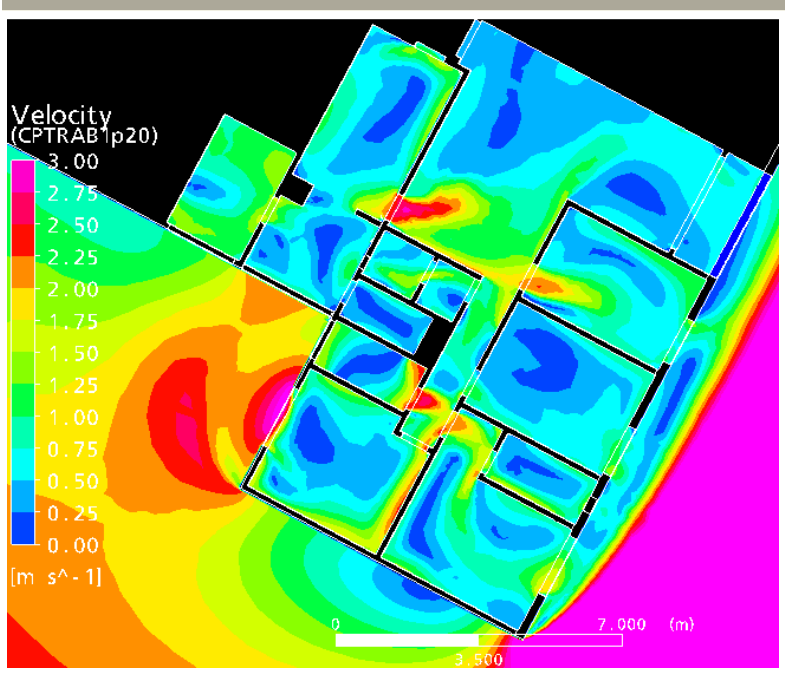

Figura 6.37 - Contorno da velocidade do vento no interior do apartamento no modelo $01-h=1.20 m$

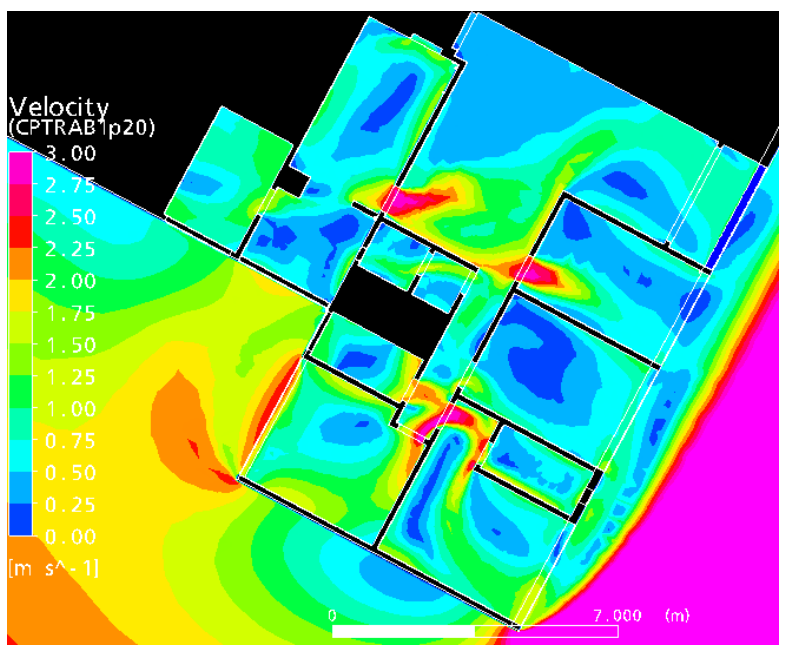

Figura 6.39 - Contorno da velocidade do vento no interior do apartamento no modelo $07-h=1.20 m$

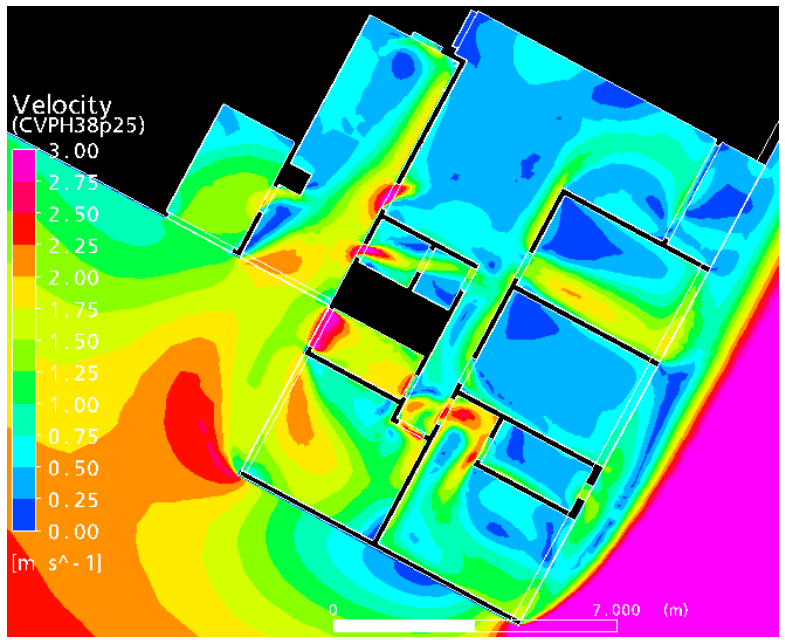

Figura 6.41 - Contorno da velocidade do vento no interior do apartamento no modelo $07-\mathrm{h}=\mathbf{2 . 0 0 m}$

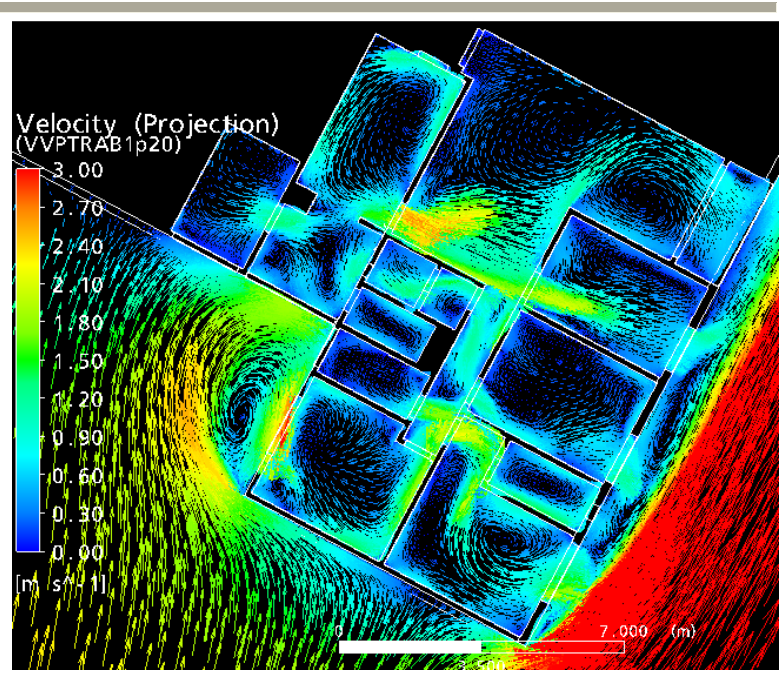

Figura 6.38 - Vetores da direção e velocidade do vento no interior do apartamento no modelo $01-\mathrm{h}=1.20 \mathrm{~m}$

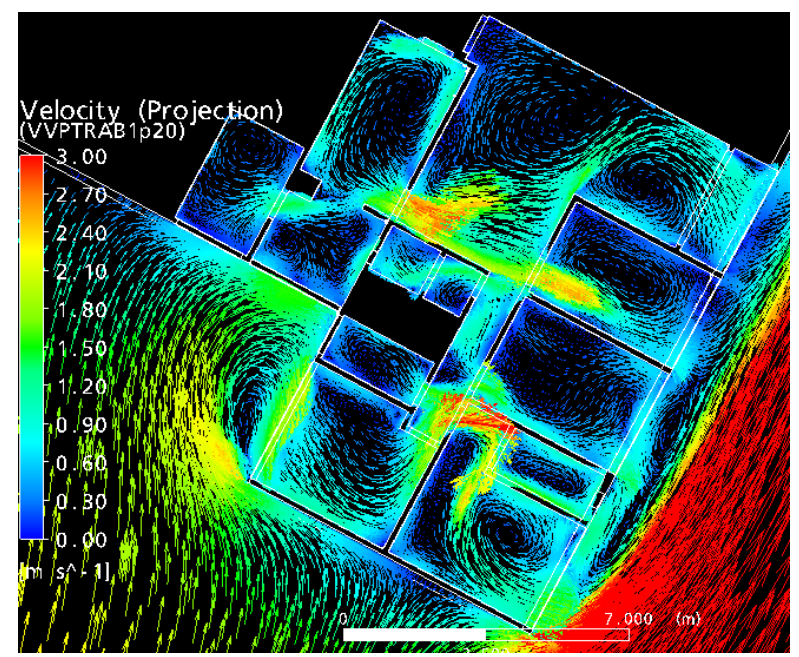

Figura 6.40 - Vetores da direção e velocidade do vento no interior do apartamento no modelo $07-\mathrm{h}=1.20 \mathrm{~m}$

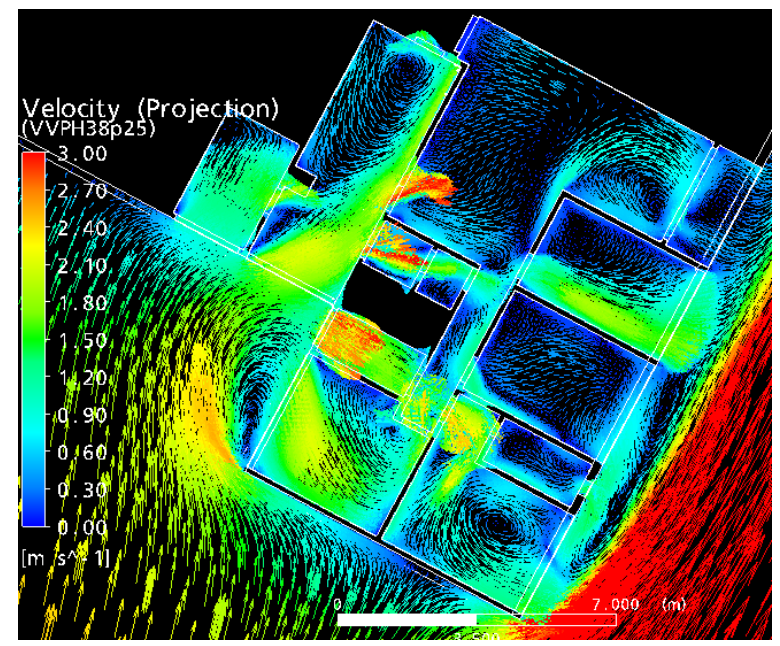

Figura 6.42 - Vetores da direção e velocidade do vento no interior do apartamento no modelo $07-\mathrm{h}=2.00 \mathrm{~m}$ 
Nos demais quartos, as mudanças verificadas no plano a $1,20 \mathrm{~m}$ de altura foram pouco significativas e se analisadas minuciosamente a qualidade da ventilação interna até piorou pelo fato de ter aumentado a área com menor velocidade de ar, principalmente no gabinete e no quarto ao lado. Já no plano a 2,00m de altura, percebe-se um incremento significativo na velocidade do ar que entra pelo quarto à esquerda da planta. Isso ocorre porque na altura deste plano há aberturas na fachada onde estão localizadas as janelas da área de serviço e quarto de empregada, e com menos obstáculos, o vento apresenta-se com maior velocidade e permite uma distribuição do ar mais uniforme neste plano em todos os ambientes do apartamento.

É interessante notar que no capítulo 2 foi citado um estudo de Givoni (1976) onde se concluiu uma resposta diferente quando analisada a taxa de ventilação média do ar em função da relação entre as aberturas de entrada e saída do ar no interior de um ambiente. Em seu estudo, ele conclui que se a entrada de ar for maior que a saída, o fluxo do ar é reduzido, porém melhor distribuído. Já quando a abertura de saída do vento é maior que a de entrada, a taxa de ventilação interna é maior.

Em seu estudo, este autor analisa o ambiente de forma hipotética e isolado. Ou seja, ele determinou um modelo com todas as paredes de mesma dimensão e duas aberturas localizadas em paredes opostas alterando as dimensões da largura dessas aberturas. Não considerou, por 
exemplo, as características do entorno, a pressão do vento nas fachadas, entre outras variáveis.

Sabe-se que a ventilação natural, seja no meio urbano, seja no interior de uma edificação, é de difícil predição e controle devido a uma série de fatores que influenciam direta e indiretamente seu perfil. Assim, a análise de apenas uma variável, apesar de poder esclarecer algumas dúvidas na teoria, dificilmente poderá responder precisamente a uma questão em relação ao vento.

Assim, por meio dos resultados apresentados nas simulações desta dissertação e outro trabalho de suma importância como o de Givoni (1976), referência no estudo da ventilação natural, percebe-se como uma ferramenta computacional atual e complexa pode aproximar cada vez mais a pesquisa, a prática e a realidade da arquitetura.

\subsection{MOdelo 01 X MOdELo 08}

Terminadas as simulações dos sete modelos anteriores, percebeu-se que o ambiente mais prejudicado em relação à qualidade da ventilação natural foi o quarto do meio. Com exceção do modelo 02, à medida que novas alterações eram propostas, este ambiente em geral mostrava-se menos favorecido em relação aos demais. Assim sendo, o modelo 08 propôs uma simples alteração na localização da porta de entrada deste ambiente para verificar se ao posicionar as aberturas em diagonal seria possível obter uma qualidade melhor da distribuição do ar e aumento da velocidade do vento. 


\section{0}

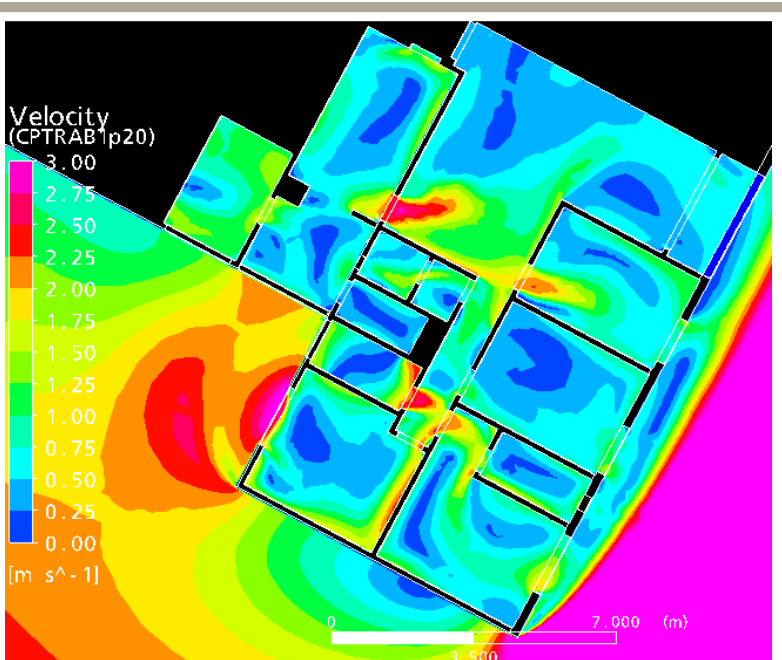

Figura 6.43 - Contorno da velocidade do vento no interior do apartamento no modelo $01-h=1.20 m$

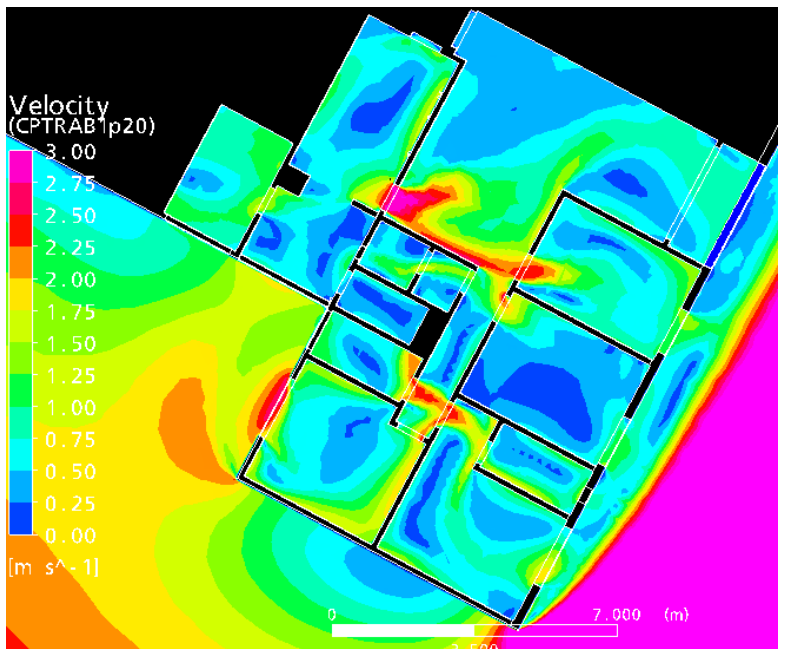

Figura 6.45 - Contorno da velocidade do vento no interior do apartamento no modelo $08-h=1.20 m$

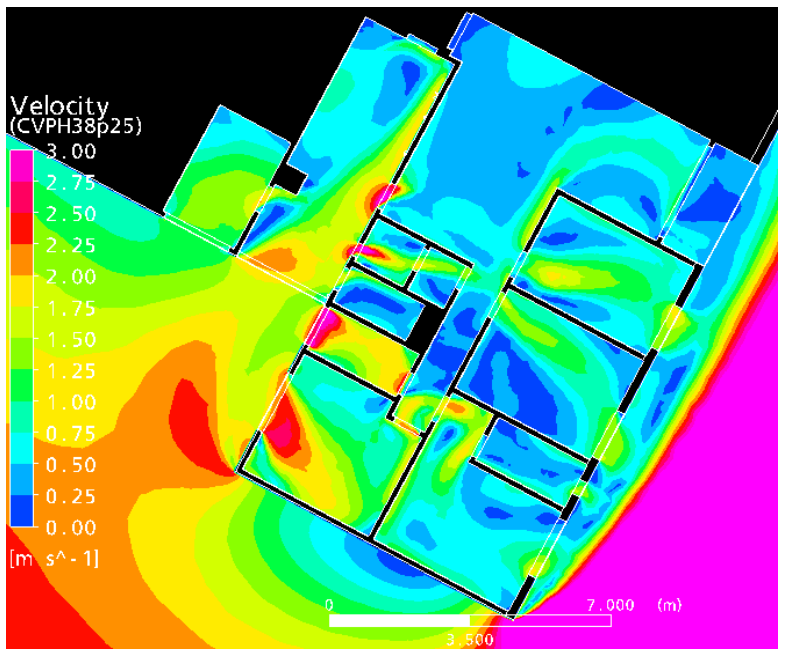

Figura 6.47 - Contorno da velocidade do vento no interior do apartamento no modelo $08-h=2.00 m$

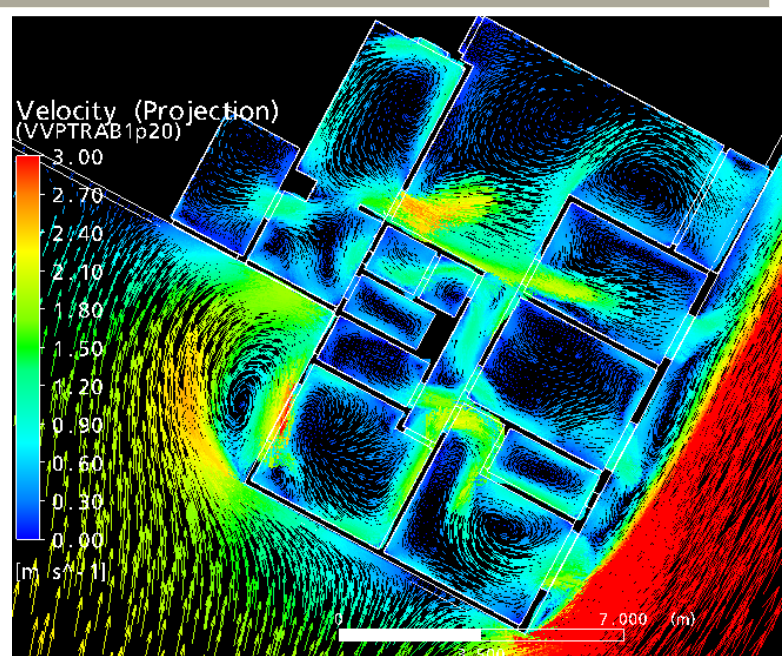

Figura 6.44 - Vetores da direção e velocidade do vento no interior do apartamento no modelo $01-h=1.20 \mathrm{~m}$

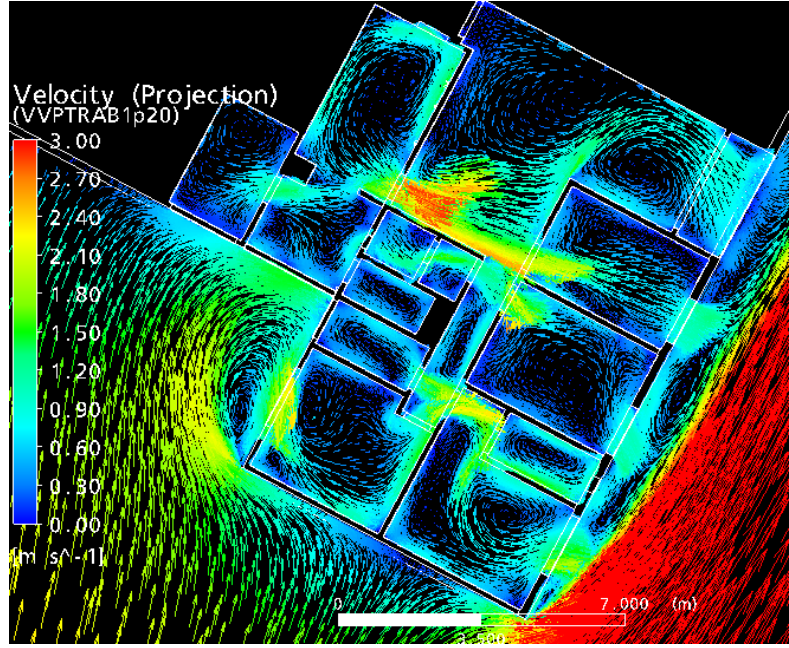

Figura 6.46 - Vetores da direção e velocidade do vento no interior do apartamento no modelo $08-h=1.20 m$

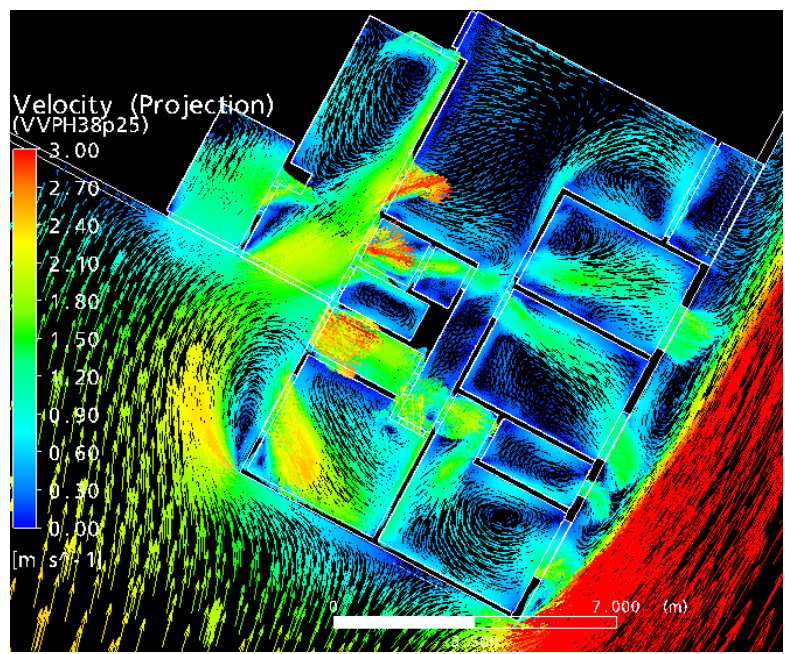

Figura 6.48 - Vetores da direção e velocidade do vento no interior do apartamento no modelo $08-\mathrm{h}=\mathbf{2 . 0 0 m}$ 
Comparando as figuras 6.43 a 6.48 referentes às simulações dos modelos 01 e 08 , nota-se que no plano a 1,20 m de altura a alteração do quarto do meio influenciou positivamente na qualidade da ventilação da sala, do corredor e do quarto do final do corredor - lado esquerdo da imagem - porém o resultado encontrado no próprio quarto onde houve a alteração pode ser considerado pior que o anterior obtido no modelo 01 , uma vez que a área com menor velocidade do vento aumentou no modelo 08. Porém, praticamente nenhuma diferença significativa foi notada no plano a 2,00m de altura.

Várias suposições podem ser citadas para explicar o resultado obtido nesta última simulação, assim como todas as anteriores. Viu-se que alguns resultados estavam dentro do esperado enquanto que outros apresentaram resultados até surpreendentes, de certa forma. Assim, ao término deste capítulo a resposta mais clara obtida foi a de que, para se conseguir o melhor resultado possível da ventilação natural dentro de uma edificação, é aconselhável, além do conhecimento teórico sobre o assunto, recorrer ao auxílio da simulação computacional, por meio de um software que reúna o máximo de variáveis possíveis, para se entender e tentar prever o comportamento do vento na edificação e então poder propor as devidas estratégias de projetos compatíveis com o objetivo de maximizar o conforto térmico do usuário. 


\section{CONCLUSÃO}

A proposta desta dissertação foi unir a pesquisa científica à prática profissional da arquitetura que defende o conforto ambiental, mais precisamente o conforto térmico do usuário, utilizando como principal estratégia de projeto o uso da ventilação natural nas edificações localizadas em cidades de clima quente e úmido.

A divisão dos capítulos procurou seguir uma sequência lógica de etapas a serem seguidas no exercício de projetar uma edificação adequada ao clima local.

Inicialmente, foi apresentada a fundamentação teórica que fez um apanhado geral sobre a relação entre a ventilação natural e a arquitetura, dando ênfase a ventilação natural na edificação. Apesar de ser um tema muito complexo e muito pouco estudado diante da importância que apresenta, todo profissional que se compromete a estabelecer essa relação em seu trabalho deve ter conhecimento teórico mínimo para iniciar qualquer projeto bem sucedido, portanto é fundamental analisar o que já foi pesquisado e discutido na área.

Passando pela fase teórica, a etapa seguinte foi a apresentação da cidade universo de análise da pesquisa e o estudo minucioso do clima local e suas principais variáveis. O levantamento dos dados climáticos dos anos de 2003 a 2006 possibilitou inicialmente a criação de um ano climático de referência que reuniu todos os dados climáticos dos quatro 
anos disponibilizados e apresentou o perfil climático de Aracaju ao longo de um ano, com dados sobre a temperatura do ar, velocidade e direção dos ventos, além da umidade relativa do ar. Diante deste perfil, foi estipulado um dia típico de projeto de verão que serviu como dado importante na etapa de simulação computacional e análise dos resultados por representar a situação climática mais crítica da cidade. Todo esse processo foi realizado porque poucos estudos enfatizam de forma detalhada o clima de Aracaju e a autora achou importante realizar esse levantamento para poder comparar com as referências existentes. Assim, o capítulo correspondente a esta etapa poderá colaborar para pesquisas e trabalhos futuros, uma vez que estará disponibilizando a sistematização dos principais dados climáticos utilizados na prática da arquitetura, eliminando esta etapa que demanda de bastante tempo e muita atenção para tratamento de uma quantidade enorme de dados necessários. Além disso, a realização desta etapa logo no início mostrou o potencial climático da cidade e a viabilidade do clima para o estudo da ventilação natural e permitiu a continuação da pesquisa mantendo-se na mesma linha.

Seguindo o roteiro estipulado pela sequência dos capítulos, após uma pesquisa sobre qual a ferramenta computacional mais adequada para atingir aos objetivos estipulados no inicio deste trabalho, foi escolhido o software CFX. Partiu-se então à etapa de investigação sobre o funcionamento desta ferramenta e de como vencer todos os obstáculos impostos na confecção do modelo, na geração da malha, na configuração 
dos parâmetros para simulação e até mesmo da disponibilidade da capacidade computacional disponível para rodar todas as simulações pretendidas. Foi uma fase de grande concentração, importantes escolhas e definições além de muito demorada, mas que no fim apresentou resultados satisfatórios e reveladores.

À medida que se atingiu o equilíbrio entre todas as restrições existentes (poucas referências científicas de outras simulações no interior da edificação, definição de modelo, pouca capacidade computacional disponível, demanda alta de tempo, busca de convergência, entre outros), e o processo de simulação realmente se iniciou de forma proveitosa, a definição de cada alteração proposta ao modelo base foi surgindo em função da necessidade de se atingir novas respostas e buscar novos desafios dentro de questões que são constantes e comuns no cotidiano da vida profissional de um arquiteto.

O modelo escolhido para as simulações já apresentava um bom desempenho de ventilação natural em seu interior desde a primeira simulação, devido a sua configuração, sua localização e ausência de obstáculos significativos. Mas isso não significa que este mesmo modelo sob outras condições externas respondesse da mesma forma. Por isso, procurou-se deixar claro que sua escolha foi baseada na proposição de que ele apresentasse grande potencial de ventilação natural em seu interior justamente para que pudéssemos realmente verificar o resultado das alterações arquitetônicas propostas. Nunca foi objetivo escolher uma 
edificação com ausência de fluxo de ar interno e provar que mudando alguma característica da arquitetura seria possível apresentar um resultado brilhante na qualidade da ventilação natural, mesmo porque é sabido que existem diversos fatores envolvidos neste processo.

É evidente que nem sempre será possível se conseguir o resultado desejado numa determinada edificação, por diversos motivos que vai muito além da tipologia do edifício, mas até nestes casos a contribuição da simulação computacional no processo de definição de projeto será de suma importância, pois ao perceber que o uso da estratégia da ventilação natural não será eficiente para remover a carga térmica e a umidade de um ambiente e assim prover conforto térmico aos usuários, o partido arquitetônico adotado poderá ser descartado ou adaptado e então outro partido surgirá em função da estratégia mais eficiente para atingir o objetivo pretendido de forma a evitar o gasto desnecessário de energia elétrica para fornecer um espaço adequado às atividades do local.

É claro que o conforto ambiental não se resume à térmica, ou a ventilação natural. Várias técnicas e softwares ultimamente são utilizados por especialistas na área para analisar e aliar o conforto térmico, acústico e luminoso num mesmo projeto. Todas as estratégias adotadas, sejam passivas e/ou ativas, devem buscar um equilíbrio entre todas as faces do conforto ambiental, levando em consideração o uso final da edificação para se estabelecer prioridades no caso de ser necessário prejudicar um quesito em função de outro considerado mais importante. 
No caso desta pesquisa, o foco dado foi apenas na ventilação natural na edificação localizada em regiões de clima quente e úmido. Mas não diminui a importância de todas as áreas do conforto ambiental e nem se prega aqui que as soluções devem ser sempre passivas, caso contrário não será eficiente. O que se pretende incentivar é a análise do clima local, a definição de estratégias de projeto compatíveis ao clima e à tipologia da edificação, e o uso de ferramentas de simulação confiáveis que preveja o resultado final de forma a verificar a eficiência do partido adotado e, se for o caso, propor alterações necessárias ainda em fase de projeto para se evitar surpresas desagradáveis no final da construção, o que provavelmente acarretaria em maior gasto com energia elétrica, maior gasto na manutenção ou o desconforto dos usuários. Mas, é claro que a simulação computacional também pode ser utilizada em caso de reformas que buscam atingir melhores condições ambientais através das escolhas mais adequadas a cada situação.

Finalizando esta pesquisa as conclusões que merecem destaque são:

- Por ser um software de dinâmica dos fluidos, quando se estuda a ventilação natural o CFX atende perfeitamente aos requisitos impostos pela arquitetura, fornecendo resultados quanto à velocidade e direção dos ventos, além da pressão que o vento exerce sobre a edificação;

- É necessário analisar e conhecer as condições da ventilação natural no meio urbano impostas pelas características de seu entorno e condição 
climática local, para se obter uma resposta mais realista da ventilação natural no interior da edificação;

- A construção da geometria do modelo deve ser a mais próxima da realidade possível, porém é preciso encontrar um equilíbrio entre o nível de detalhamento deste modelo e a capacidade computacional necessária, uma vez que quanto mais detalhada a geometria, maior número de elementos a malha apresentará e consequentemente maior capacidade computacional será necessária para realizar o processo de simulação;

- Apesar das simulações apresentarem os valores referentes à velocidade do ar nos planos determinados, a análise feita nesta pesquisa considerou qualitativamente o nível de uniformidade da distribuição dos ventos, uma vez que, ao realizar as simulações, um valor fixo da velocidade do vento na entrada do domínio foi determinado, porém é sabido que na realidade esse valor varia ao longo do dia e da época do ano e assim, neste tipo de clima a melhor alternativa é sempre procurar trabalhar com valores referentes ao dia típico de projeto de verão (que apresenta condições térmicas mais críticas) e prever uma forma de controlar o fluxo de ar nas aberturas da edificação quando necessário. Dessa forma será possível garantir o mínimo de fluxo de ar necessário para o conforto térmico na maior parte do ano dentro dos ambientes analisados;

- O estudo prévio da pressão do vento nas fachadas da edificação é importante no momento de definir a localização das aberturas de 
entrada e saída do ar. Ao posicionar as aberturas de entrada do ar na fachada de maior pressão positiva do vento, melhor será a qualidade do fluxo do ar no interior edifício, principalmente quando se tem aberturas de saída do ar na face oposta à de entrada. E, consequentemente, posicionando aberturas ao longo das fachadas de pressão negativa, serão definidas as aberturas de saída do ar. Além disso, ao simular é possível prever mais precisamente a direção e velocidade do fluxo do ar, assim como determinar a pressão do vento em qualquer ponto nas fachadas do edifício;

- A tipologia de janelas adotadas influencia a configuração do fluxo de ar dentro dos ambientes. No caso das janelas de correr, cujo vão livre máximo representa $50 \%$ do total da abertura, a diferença no resultado final quando comparadas ao fluxo do ar cujas aberturas representam $100 \%$ de vão livre não piora a qualidade da ventilação natural interna na mesma proporção, mas provocam uma maior pressão do vento na fachada onde se localizam, aumentando a velocidade do ar nas aberturas e provocando a formação de correntes de ar mais fortes nas proximidades das paredes e consequentemente pior distribuição deste ar nos ambientes internos;

- O princípio básico, para que se tenha circulação de ar no interior de um espaço, é que é necessário que haja uma abertura de entrada e outra de saída para que ocorra a conhecida ventilação cruzada. Nas simulações se constatou - ao se fechar algumas portas internas - a veracidade desta teoria quando analisada na prática. Também se viu 
como uma simples alteração no tipo de esquadria pode solucionar este fato, como adotar portas internas com bandeiras, por exemplo, fazendo o ar circular por todos os ambientes mesmo mantendo a privacidade nos ambientes proporcionada pela porta fechada;

- A existência de divisórias dentro do edifício - por exemplo, as paredes limítrofes dos ambientes de um apartamento - pode ser uma aliada na distribuição do fluxo de ar, uma vez que muda a direção do ar atingindo maior parte do ambiente antes de sair do espaço. Por outro lado, ambientes maiores e sem divisão, proporcionam maior velocidade do ar circulante, mas este ar pode se apresentar canalizado próximo aos limites do ambiente e tende a aumentar as áreas de estagnação de ar;

- Existem alguns autores referência quase unânime no estudo da ventilação natural, porém nem sempre os resultados apresentados por eles podem ser aplicados a toda e qualquer edificação, uma vez que um estudo hipotético e de um espaço isolado dificilmente representará a realidade. Assim sendo, nos dias atuais é possível e extremamente importante aliar os conhecimentos científicos e empíricos aos tecnológicos para se obter uma melhor compreensão de todo o fenômeno que representa a ventilação natural.

Assim, as simulações exibidas nesta pesquisa são o resultado de uma ferramenta auxiliar e eficiente que pode ser inserida numa nova etapa de uma metodologia de projeto arquitetônico. Uma vez que esta 
prática se tornar mais difundida, algumas diferenças, entre várias outras, poderão ocorrer no futuro:

- Existirá uma arquitetura muito mais energeticamente eficiente, mais confortável termicamente, mais apropriada ao clima local e muito mais criativa, uma vez que ainda em fase de projeto o arquiteto tentará buscar as melhores soluções para cada caso isoladamente, pois entenderá que quando se trata de ventilação natural, cada caso é único;

- Um maior número de escritórios e profissionais especializados na área surgirá prestando consultoria na área de conforto com o auxílio de ferramentas de simulação computacional ou mesmo empregando esta técnica em seus próprios projetos;

- As prefeituras poderão utilizar esses recursos tecnológicos no planejamento urbano de seus municípios, auxiliando melhor nas futuras revisões ou elaborações de planos diretores;

- Será possível estudar não apenas o edifício e a cidade em suas condições atuais, como também prever como futuras ocupações poderão influenciar em um determinado ambiente, edifício ou no meio urbano e assim será possível traçar novas diretrizes de ocupação do solo mais eficientes, por exemplo.

Algumas das conclusões apresentadas acima podem não representar grandes novidades em termos teóricos na pesquisa da ventilação natural na edificação, mas com certeza poderá esclarecer muitas dúvidas ao 
propor a análise climática juntamente com a prática da simulação computacional concomitante ao processo de elaboração de qualquer projeto, de forma a possibilitar a visualização clara do fenômeno antes que o mesmo ocorra na realidade. Além disso, mostra que intuitivamente é impossível prever a velocidade e direção dos ventos, sejam urbanos ou no interior de uma edificação, uma vez que uma infinidade de variáveis e fatores externos influencia diretamente no resultado final.

Concluindo, pode-se afirmar que esta pesquisa procura resgatar os princípios básicos de uma arquitetura adequada ao clima local sem, portanto, propor que sejam esquecidas as inovações tecnológicas presentes cada vez mais na vida das pessoas. Ou seja, procura-se neste trabalho reunir o conhecimento empregado na arquitetura vernacular ao conhecimento científico e tecnológico disponíveis atualmente, para incentivar que os mesmos sejam empregados pelos projetistas desde os primeiros esboços do projeto, na criação de edifícios adaptados ao clima local, com consciência do meio ambiente, proporcionando um aumento na qualidade de vida dos usuários no interior de um espaço construído e no seu entorno e criando espaços esteticamente agradáveis, funcionais e ecologicamente corretos. 


\section{REFERÊNCIAS}

ABNT: Associação Brasileira de Normas Técnicas. Projeto de Norma 02-

135: Desempenho Térmico de Edificações. Rio de Janeiro, 2003.

ABNT, ASSOCIAÇÃO BRASILEIRA DE NORMAS TÉCNICAS. Norma 02136: Desempenho de edifícios habitacionais de até cinco pavimentos. Rio de Janeiro. 2004.

AKUTSU, Maria, et. al. Análise da ventilação natural em ambientes não condicionados. NUTAU. São Paulo, 1998.

ALUCCI, Márcia Peinado. Software CLIMATICUS_4.1.xIs, criado em 2003, com acesso em julho de 2007, disponível no site: http://www.usp.br/fau/ensino/graduacao/disciplinas/paginas/conforto .html.

ASHRAE. Handbook of Fundamentals. New York: American Society of Heating Refrigerating and Air Conditioning Engineers, 1993.

BENEDETTO, Gisele Saveriano de. Análise de dados climáticos: São Paulo e Rio de Janeiro. Trabalho Programado (Programa de PósGraduação). FAUUSP. São Paulo, maio de 2006

BITTENCOURT, L. S. LÔBO, D.G.F. A influência da localização das aberturas na ventilação natural de edificações escolares. Artigo Técnico, $2^{\circ}$ Encontro Latino Americano de Conforto no Ambiente Construído, $5^{\circ}$ Encontro Nacional de Conforto no Ambiente Construído, Fortaleza, 1999.

BITTENCOURT, L. S. LÔBO, D.G.F. A influência dos captadores de ventos na ventilação natural de habitações populares localizadas em climas quentes e úmidas. Ambiente Construído 3 (Junho 2003): 57-67. 
BITTENCOURT, L.S. PEIXOTO, L.K. de O. Estudo da ventilação natural na UFAL através de simulação computacional. Curitiba: Encontro Nacional de Conforto no Ambiente Construído, 2003.

BITTENCOURT, Leonardo S. Princípios de ventilação natural para climas quentes e úmidos. Apostila da disciplina Ventilação Natural nas Edificações, do curso de especialização em Estudos do Habitat construído com ênfase na questão ambiental, Natal/RN, 13 a 23 de outubro de 1998.

BITTENCOURT, Leonardo, e CÂNDIDO, Christhina. Introdução à ventilação natural. Maceió: EDUFAL, 2005.

BITTENCOURT, Leonardo Salazar. Comparando os programas BREEZE e EASYFLOW como instrumentos de simulação da ventilação natural. Encontro Nacional de Modelos de Simulação de Ambientes, Universidade de São Paulo, Faculdade de Arquitetura e Urbanismo, São Paulo, 1995.

BRANDÃO, Rafael Silva. Interações Espaciais Urbanas: Bases para a incorporação de análises térmicas, acústicas, luminosas e energéticas no planejamento urbano. Boneco de Tese de Doutorado apresentado como Relatório Científico de bolsista FAPESP, São Paulo, 2008.

BRANDÃO, Rafael Silva. As interações espaciais urbanas e o clima; incorporação de analises térmicas e energéticas no planejamento urbano. Tese de Doutorado. Faculdade de Arquitetura e Urbanismo, Universidade de São Paulo, São Paulo, 2009. 350p.

BROWN, G.Z., e DEKAY, M. Sol, vento \& luz. Estratégias para o projeto de arquitetura. 2.ed. Tradução: Alexandre F. da Silva Salvaterra. Porto Alegre: Bookman, 2004. 
CFX. CFX 5 Solver Models. Diddcot Oxfordshire: CFX: 2003

CORBELLA, Oscar, e YANNAS, Simos. Em busca de uma arquitetura sustentável para os trópicos - conforto ambiental. Rio de Janeiro: Revan, 2003.

CÓSTOLA, Daniel. Ventilação por ação do vento no edifício: procedimento para quantificação. Dissertação de Mestrado. São Paulo: FAUUSP, 2006.

EVANS, Benjamin $\mathrm{H}$. Natural air flow around buildings. Texas: College Station - Texas Engineering Experiment Station, 1957.

FANGER, P. O. Thermal comfort, analisys and application in environmental engineering. Nova York, McGraw-Hill, 1972

FIGUEIREDO, Cíntia Mara de. Ventilação Natural em edifícios de escritórios na cidade de São Paulo: limites de possibilidades do ponto de vista do conforto térmico. Dissertação de Mestrado. São Paulo: FAUUSP, 2007.

FRANÇA, Vera Lúcia Alves. Cruz, Maria Tereza Souza. Atlas escolar Sergipe: espaço geo-histórico e cultural. João Pessoa: Ed. Grafset, 2007.

FROTA, Anésia Barros. Ventilação Natural. Apostila da disciplina Ventilação natural nas edificações, do curso de Especialização em Conforto Ambiental e Conservação de Energia, São Paulo/SP, 2004.

FROTA, Anésia Barros, e SCHIFFER, Sueli Ramos. Manual de conforto térmico. 6. ed. São Paulo: Studio Nobel, 2003.

GASPAR, Carolina Gaspar. Alterações da ventilação urbana frente ao processo de verticalização de avenidas litorâneas: o caso da Avenida Litorânea de São Luís/MA. Dissertação de Mestrado, São Paulo: FAUUSP, 2008. 
GIVONI, B. Man, climate and architecture. London: Applied Science Publishers, 1976.

GOULART, S.V.G., BARBOSA, M.J., PIETROBON,C.E., BOGO, A., PITTA,T. Bioclimatologia aplicada ao projeto de edifícios visando 0 conforto térmico. Relatório Interno n.02/94. Florianópolis, SC: Núcleo de Pesquisa em Construção, UFSC, 1994.

HERTZ, John B. Ecotécnicas em arquitetura: como projetar nos trópicos úmidos do Brasil. São Paulo: Pioneira, 1998.

LABORATÓRIO DE CONFORTO AMBIENTAL E EFICIÊNCIA ENERGÉTICA LABAUT (2004). CENPES-II, Arquitetura e Eco-eficiência: Clima, Insolação e Índices de Conforto (Relatório técnico de acesso restrito). FAUUSP. São Paulo.

LAMBERTS, R., DUTRA, L., PEREIRA, F. O. R. Eficiência energética na arquitetura. 2.ed, revisada. São Paulo: ProLivros, 2004.

MARCONDES, Mônica Pereira. UMAKOSHI, Erica Mitie. Ferramentas computacionais para avaliação ambiental de áreas urbanas: estudo de caso em São Paulo. IX Encontro Nacional e $\mathrm{V}$ Latino Americando de Conforto no Ambiente Construído, Ouro Preto, 2007.

MONTEIRO, Jorge Isaac Perén. Ventilação e iluminação naturais na obra de João Filgueiras Lima, Lelé: Estudo dos hospitais da Rede Sarah Kubitschek Fortaleza e Rio de Janeiro. São Carlos: Universidade de Sâo Paulo, Escola de Engenharia de São Carlos, 2006.

NEVES, Letícia de Oliveira. Arquitetura Bioclimática e a obra de Severiano Porto: estratégias de ventilação natural. São Carlos: Universidade de Engenharia de São Carlos da Universidade de São Paulo, 2006. 
OLGYAY, Victor. Arquitectura y Clima - manual de diseño bioclimático para arquitectos y urbanistas. Ed. Gustavo Gioli, Barcelona, 1998. 203p.

PRATA, Alessandra Rodrigues. Impacto da altura dos edifícios nas condições de ventilação natural em meio urbano. Tese de Doutorado. São Paulo: FAUUSP, 2005.

ROAF, Sue, Manuel FUENTES, e Stephanie THOMAS. Ecohouse: a casa ambientalmente sustentável. 2.ed. Tradução: Alexandre Ferreira da Silva Salvaterra. Porto Alegre: Bookman, 2006.

SILVA, Francisco de Assis Gonçalves da. O vento como ferramenta no desenho do ambiente construído: uma aplicação ao nordeste do Brasil. Tese de Doutorado, Faculdade de Arquitetura e Urbanismo, Universidade de São Paulo, São Paulo, 1999. 234p.

TOLEDO, Alexandre Márcio. Inadequação entre geometria e desempenho nos índices para dimensionamento de vãos e aberturas para ventilação natural a partir da área de piso. $2^{\circ}$ Encontro Latino Americano de Conforto no Ambiente Construído, $5^{\circ}$ Encontro Nacional de Conforto no Ambiente Construído, Fortaleza, 1999, Artigo Técnico.

TOLEDO, Alexandre Márcio. Ventilação natural e conforto térmico em dormitórios: aspectos bioclimáticos para uma revisão do código de obras de Maceió. Dissertação de Mestrado. Universidade Federal do Rio Grande do Sul, Porto Alegra, 2001.

TOLEDO, Eustáquio. Ventilação Natural das Habitações. Coordenação da publicação brasileira por Alexandre Toledo, EDUFAL, Universidade Federal das Alagoas, 1999. 170p.

VIANNA, Nelson Solano. O estado da arte em ensino e pesquisa na área de conforto ambiental no Brasil. Dissertação de Mestrado. 
Faculdade de Arquitetura e Urbanismo, Universidade de São Paulo, São Paulo, 2001.

www.ansys.com/products/cfx.asp . (acesso em 13 de outubro de 2008).

http://www.flickr.com/photos/gilneyfontes/412659361/ (acesso em 26 de novembro de 2007)

http://www.inmet.gov.br/html/rede obs.php (acesso em 23 de novembro de 2007).

http://www.max.org.br/imgs/mapas/ (acesso em 26 de novembro de 2007) 


\section{ANEXOS}

a. ANEXO 1 - GRÁfICOS DA MÉdIA DA TEMPERATURA DO AR MÊS A MÊS ENTRE

2003 E 2006 COM BASE NO TRATAMENTO DOS DADOS FORNECIDOS PELO INMET.

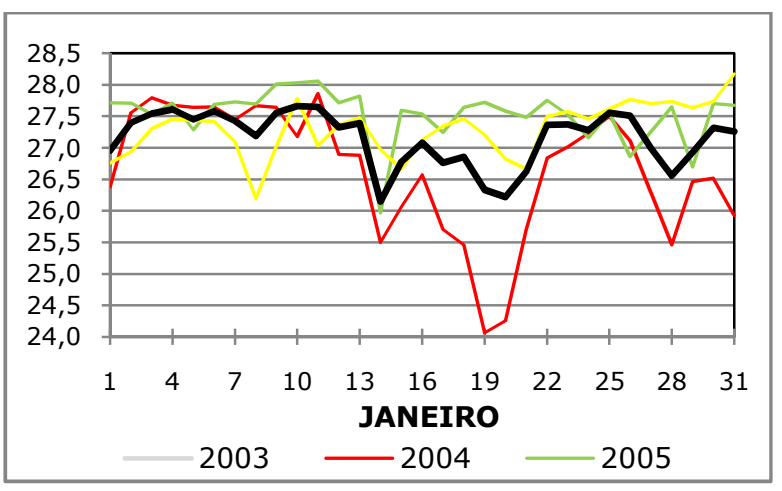

Gráfico A.1 - Média diária da temperatura do ar $\left({ }^{\circ} \mathrm{C}\right)$ - mês de Janeiro

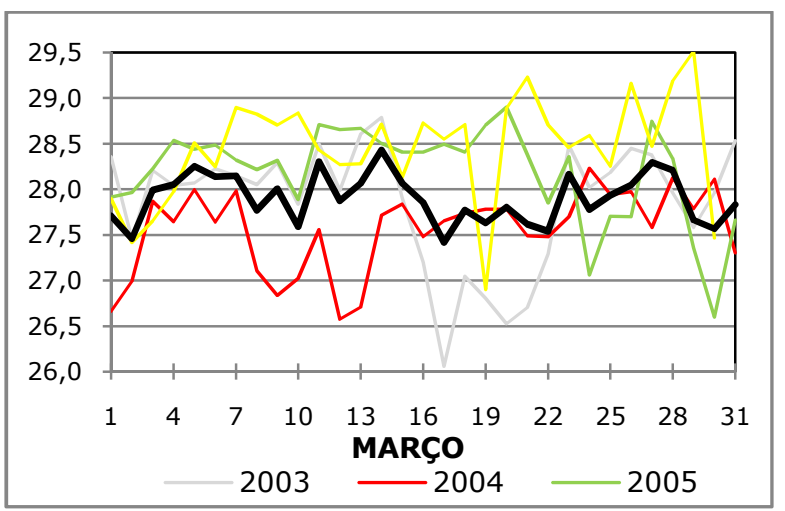

Gráfico A.3 - Média diária da temperatura do ar ( $\left.{ }^{\circ} \mathrm{C}\right)$ - mês de Março

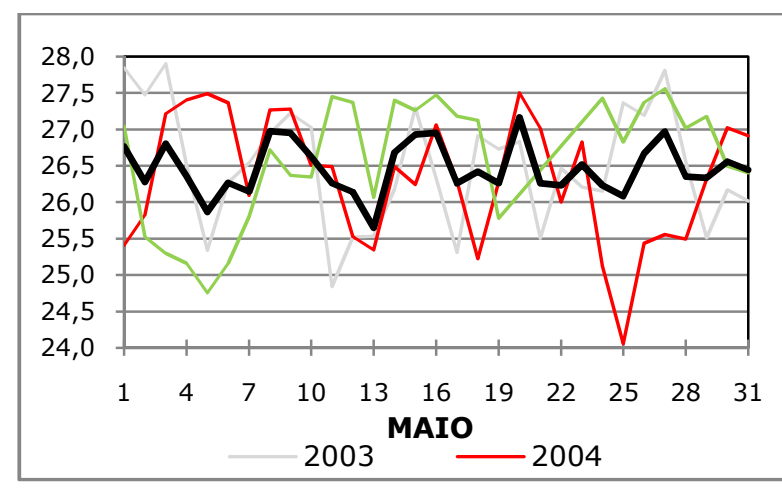

Gráfico A.5 - Média diária da temperatura do ar $\left({ }^{\circ} \mathrm{C}\right)$ - mês de Maio

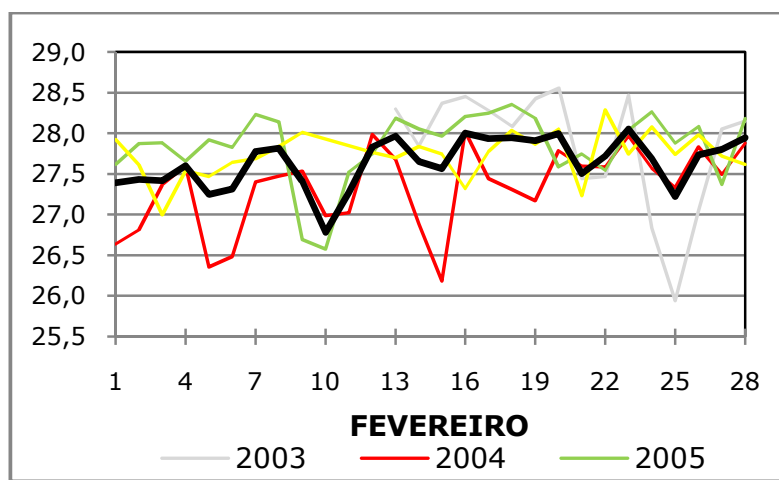

Gráfico A.2 - Média diária da temperatura do ar $\left({ }^{\circ} \mathrm{C}\right)$ - mês de Fevereiro

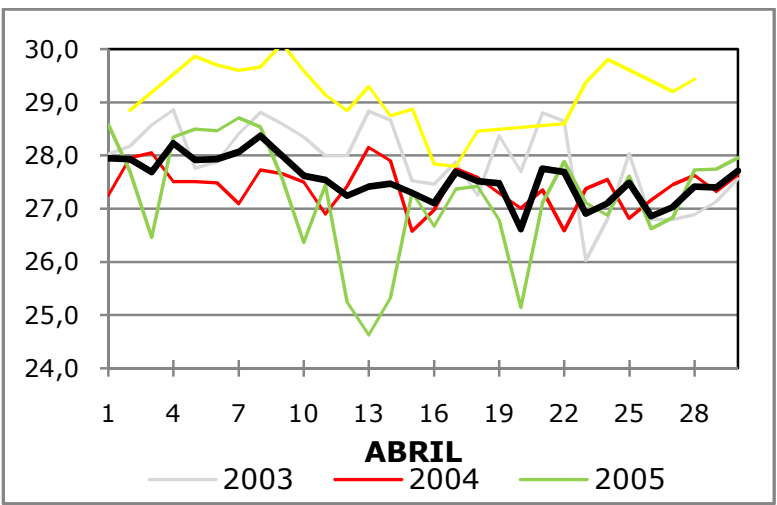

Gráfico A.4 - Média diária da temperatura do ar $\left({ }^{\circ} \mathrm{C}\right)$ - mês de Abril

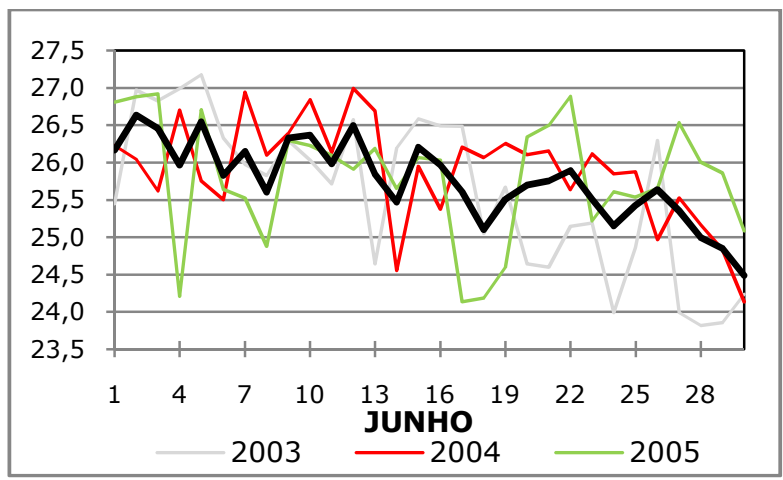

Gráfico A.6 - Média diária da temperatura do ar $\left({ }^{\circ} \mathrm{C}\right)$ - mês de Junho 


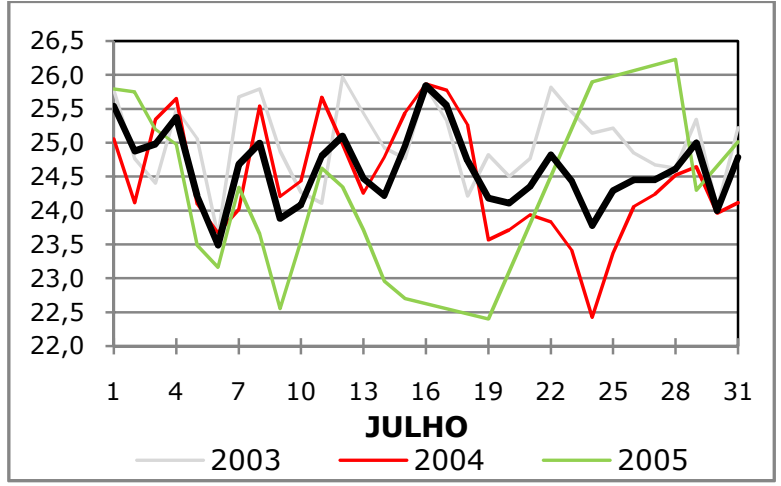

Gráfico A.7 - Média diária da temperatura do ar $\left({ }^{\circ} \mathrm{C}\right)$ - mês de Julho

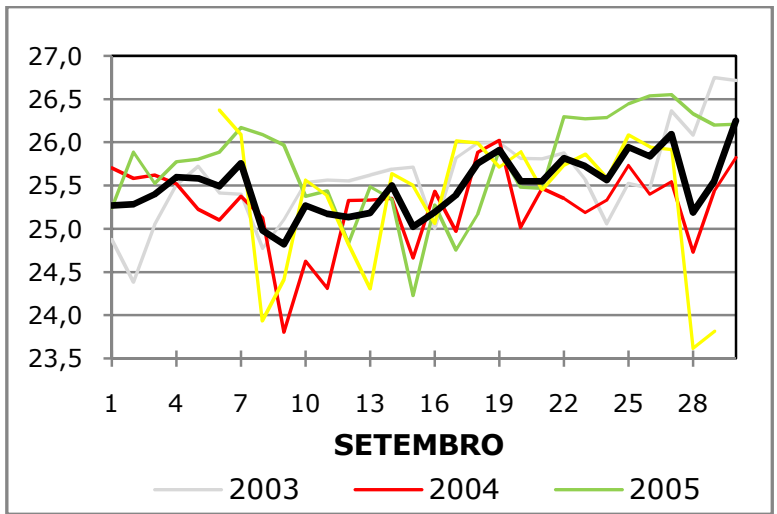

Gráfico A.9 - Média diária da temperatura do ar $\left({ }^{\circ} \mathrm{C}\right)$ - mês de Setembro

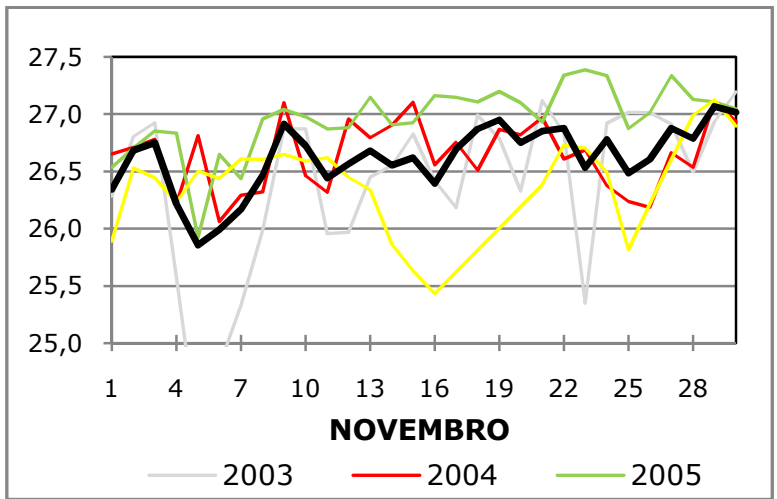

Gráfico A.11 - Média diária da temperatura do ar $\left({ }^{\circ} \mathrm{C}\right)$ - mês de Novembro

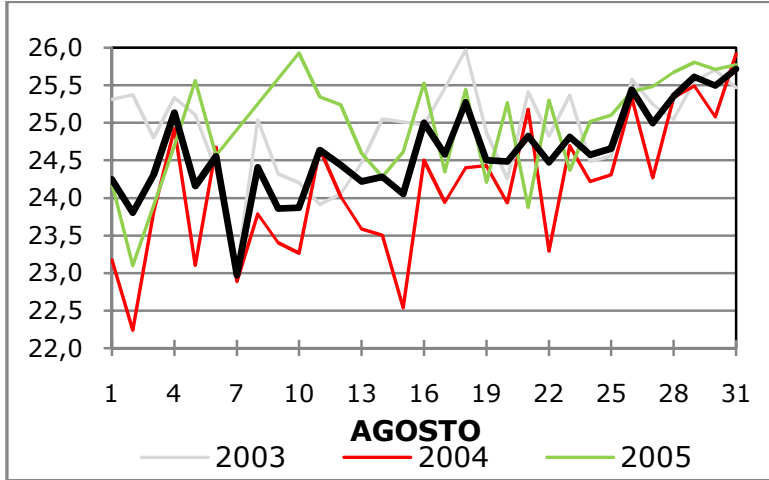

Gráfico A.8 - Média diária da temperatura do $\operatorname{ar}\left({ }^{\circ} \mathrm{C}\right)$ - mês de Agosto

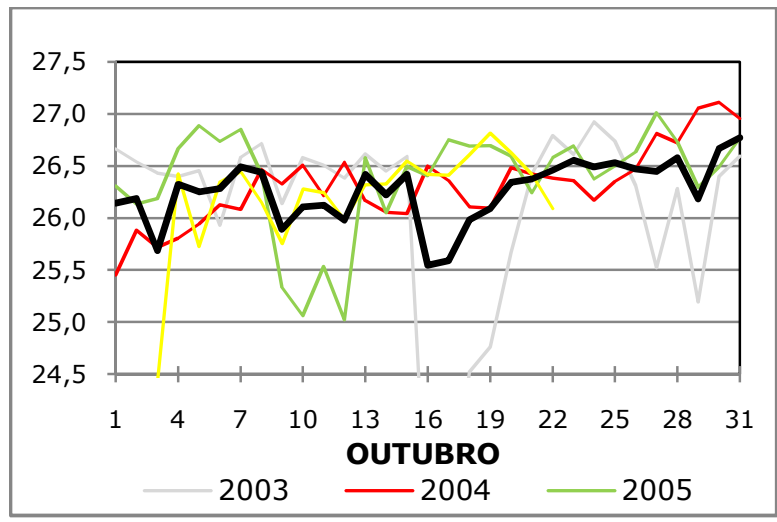

Gráfico A.10 - Média diária da temperatura do ar $\left({ }^{\circ} \mathrm{C}\right)$ - mês de Outubro

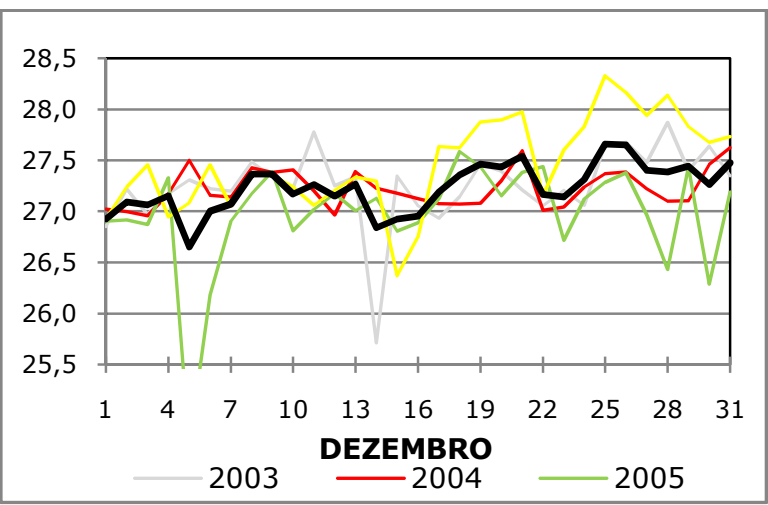

Gráfico A.12 - Média diária da temperatura do ar $\left({ }^{\circ} \mathrm{C}\right)$ - mês de Dezembro 
b. ANEXO 2 - GRÁfICOS DA MÉDIA DA UMIDADE RELATIVA do AR MÊS A MÊS ENTRE 2003 E 2006 COM BASE NO TRATAMENTO DOS DADOS FORNECIDOS PELO INMET.

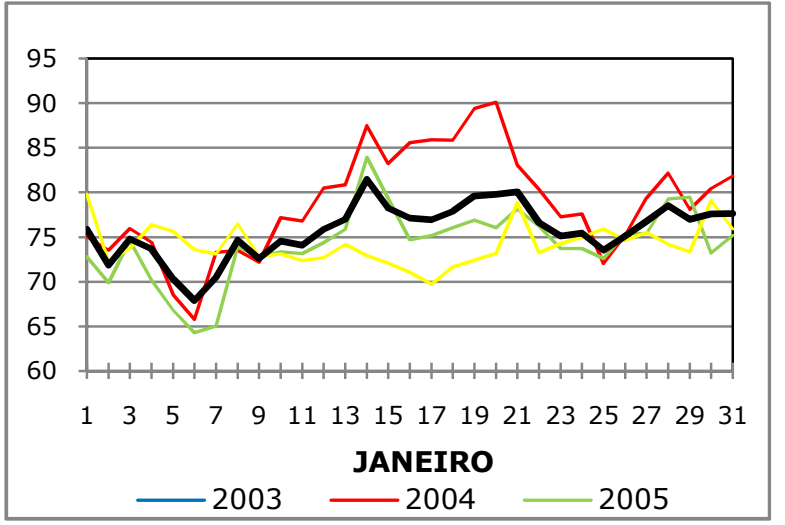

Gráfico A.13 - Média diária da umidade relativa do ar (\%) - Janeiro

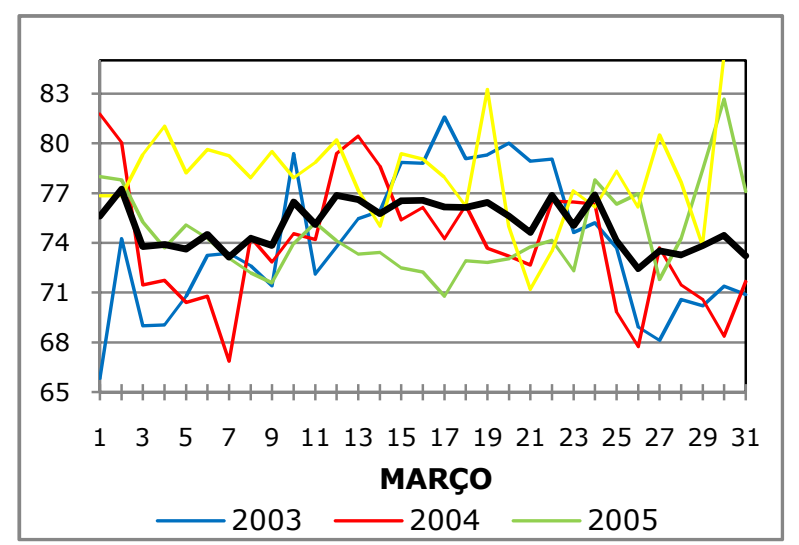

Gráfico A.15 - Média diária da umidade relativa do ar (\%) - Março

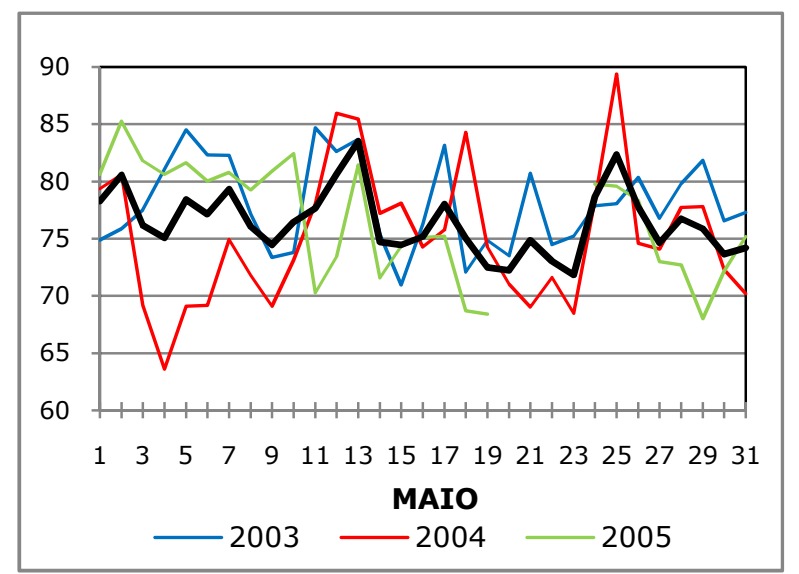

Gráfico A.17 - Média diária da umidade relativa do ar (\%) - Maio

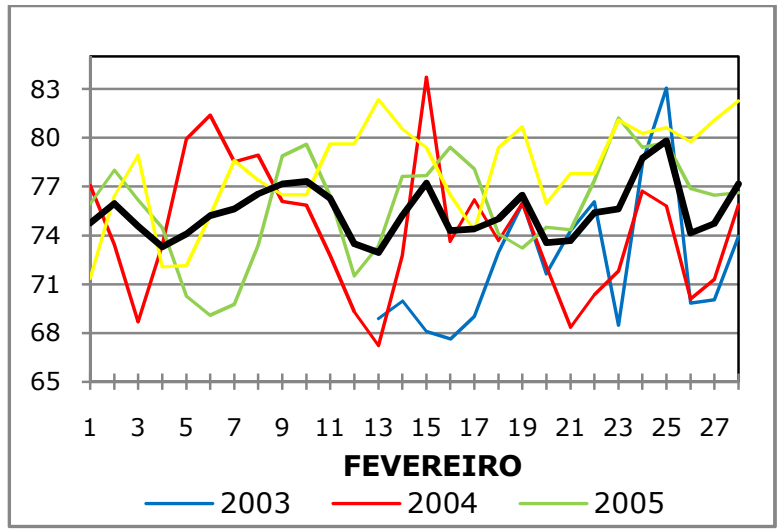

Gráfico A.14 - Média diária da umidade relativa do ar (\%) - Fevereiro

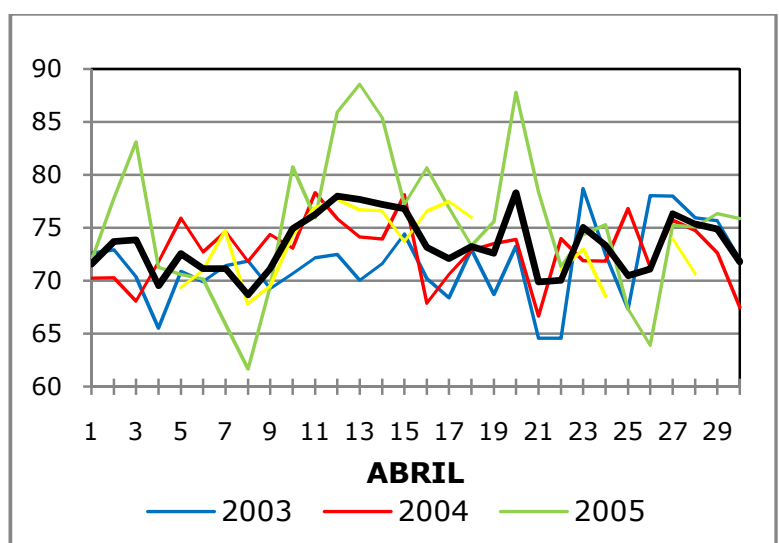

Gráfico A.16 - Média diária da umidade relativa do ar (\%) - Abril

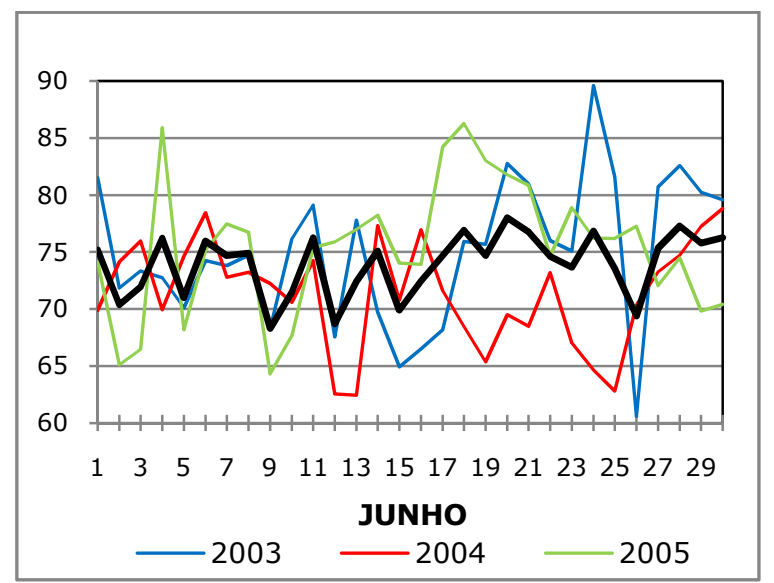

Gráfico A.18 - Média diária da umidade relativa do ar (\%) - Junho 


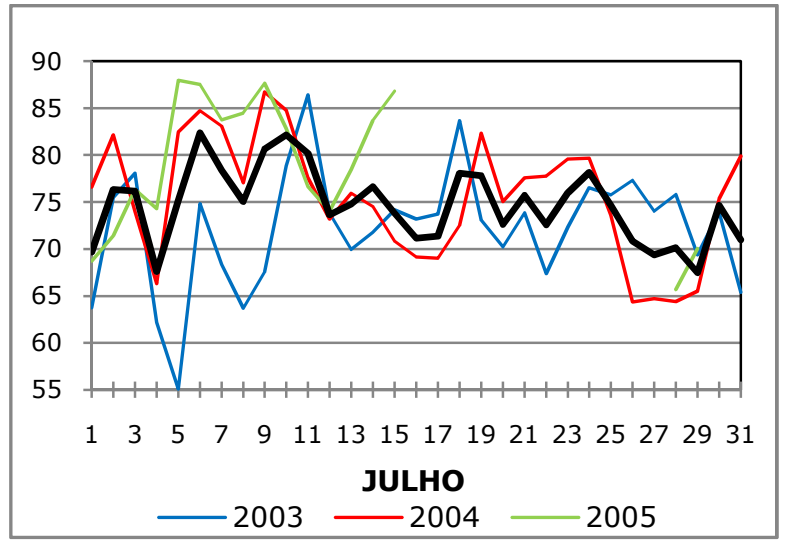

Gráfico A.19 - Média diária da umidade relativa do ar (\%) - Julho

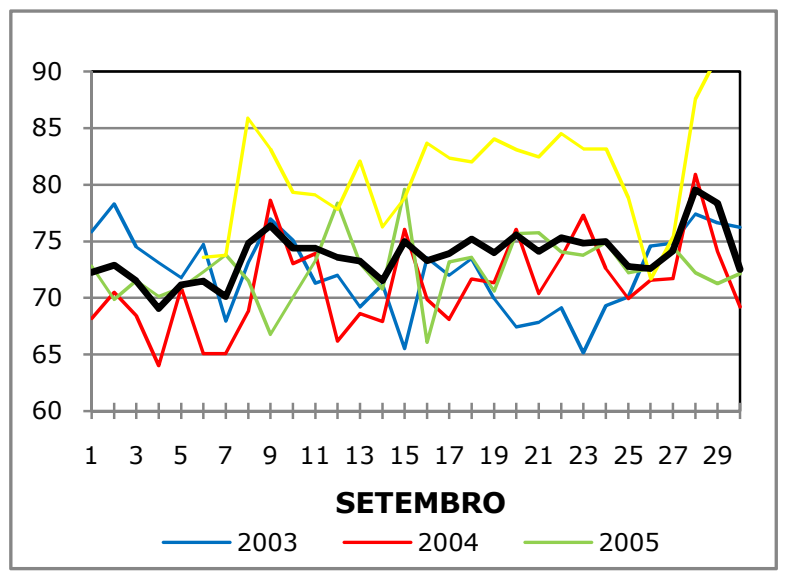

Gráfico A.21 - Média diária da umidade relativa do ar (\%) - Setembro

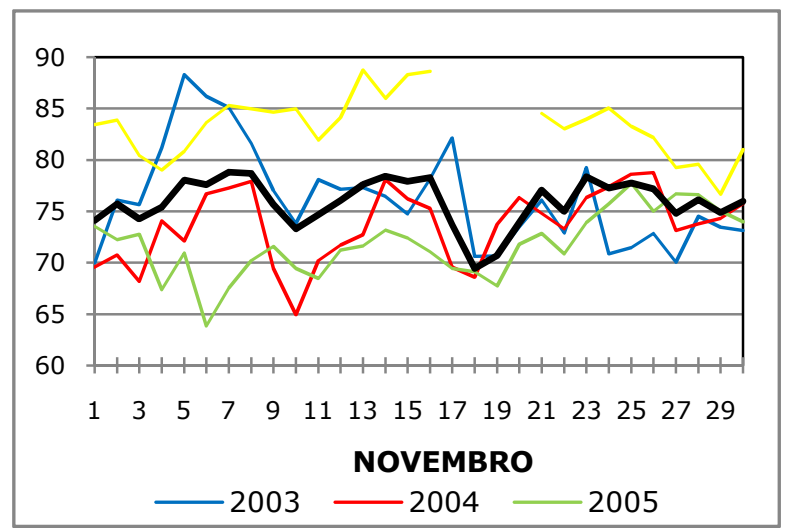

Gráfico A.23 - Média diária da umidade relativa do ar (\%) - Novembro

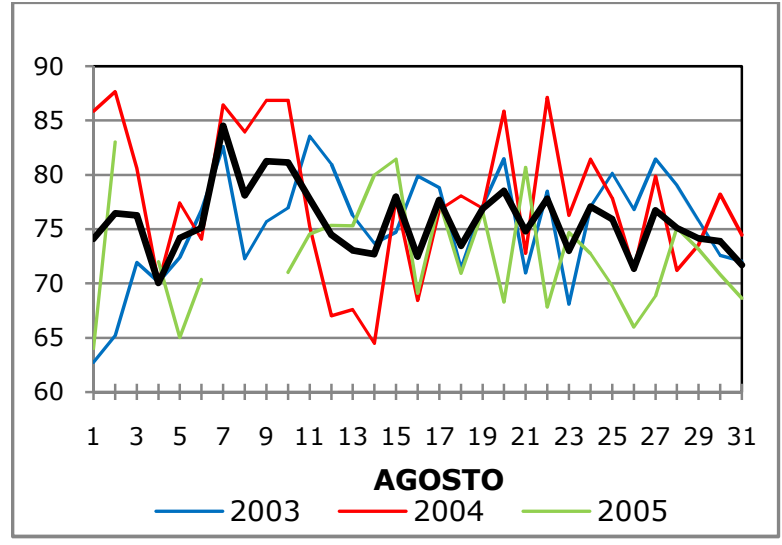

Gráfico A.20 - Média diária da umidade relativa do ar (\%) - Agosto

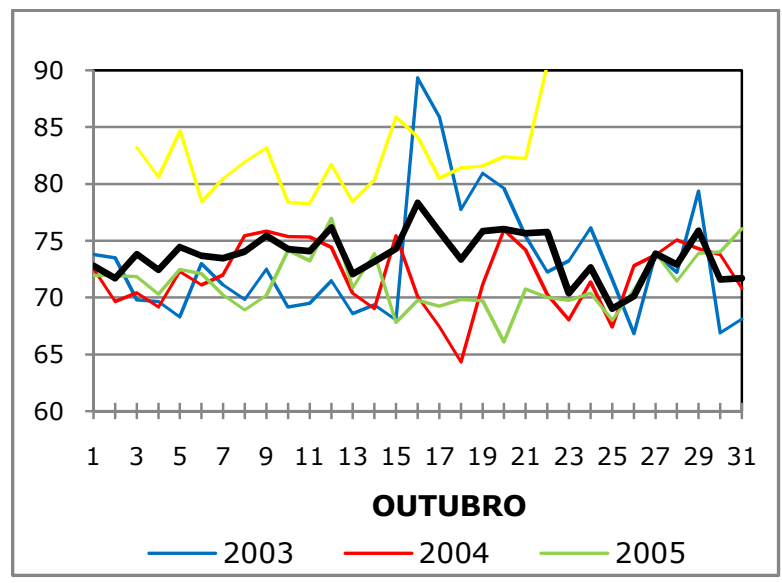

Gráfico A.22 - Média diária da umidade relativa do ar (\%) - Outubro

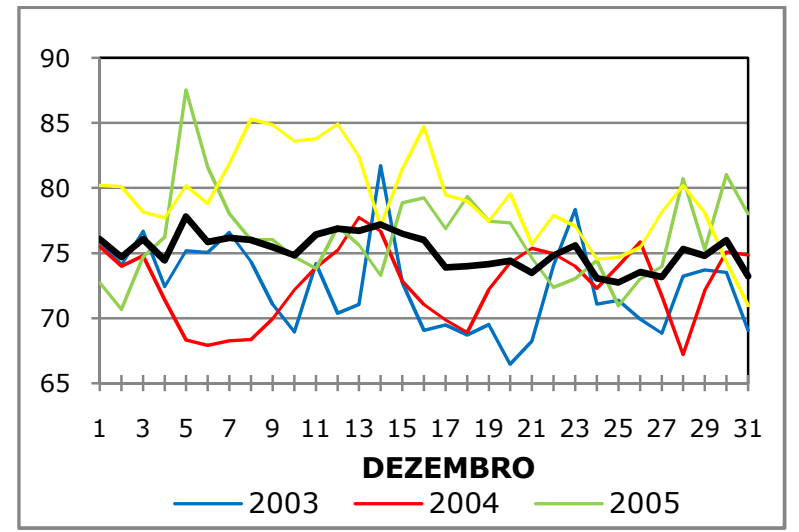

Gráfico A.24 - Média diária da umidade relativa do ar (\%) - Dezembro 
c. ANEXO 3 - Gráficos da diREçÃo PREdominante doS VENTOS MÊS A MÊS ENTRE 2003 E 2006 COM BASE NO TRATAMENTO DOS DADOS FORNECIDOS PELO INMET.

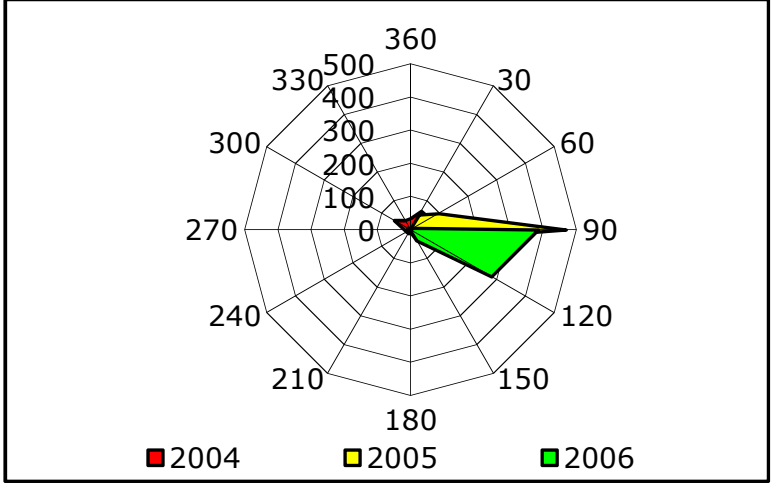

Gráfico A.25 - Direção predominante dos ventos - Janeiro

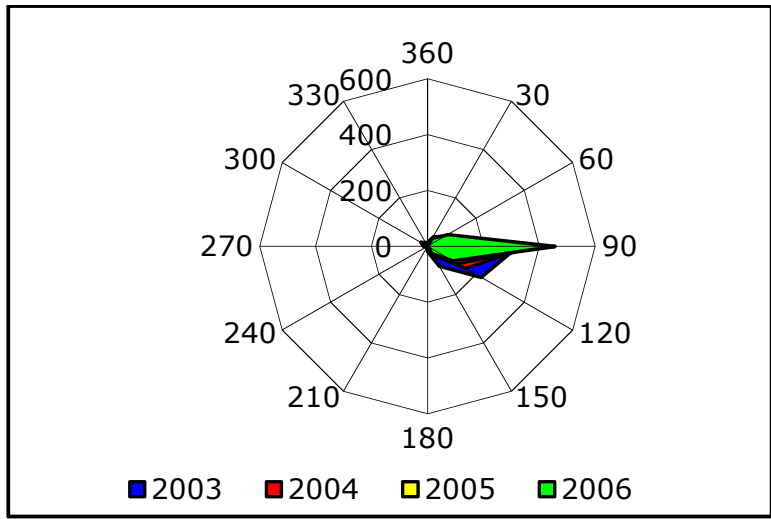

Gráfico A.27 - Direção predominante dos ventos - Março

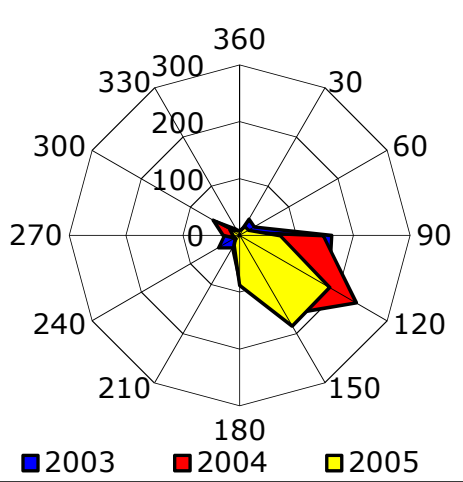

Gráfico A.29 - Direção predominante dos ventos - Maio

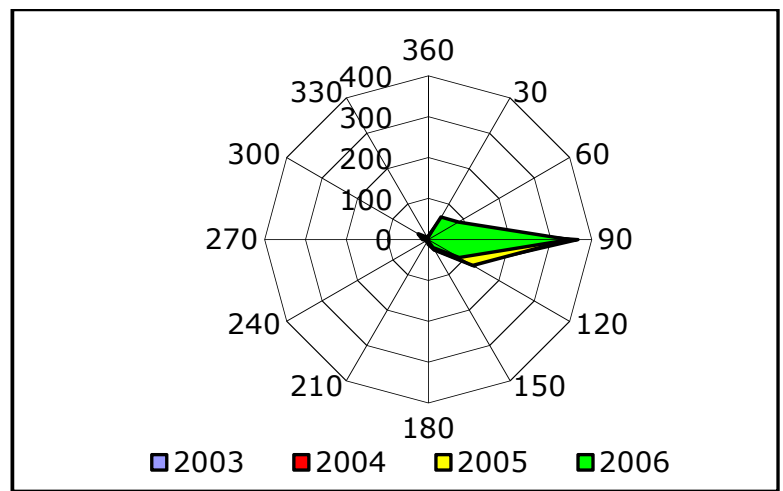

Gráfico A.26 - Direção predominante dos ventos - Fevereiro

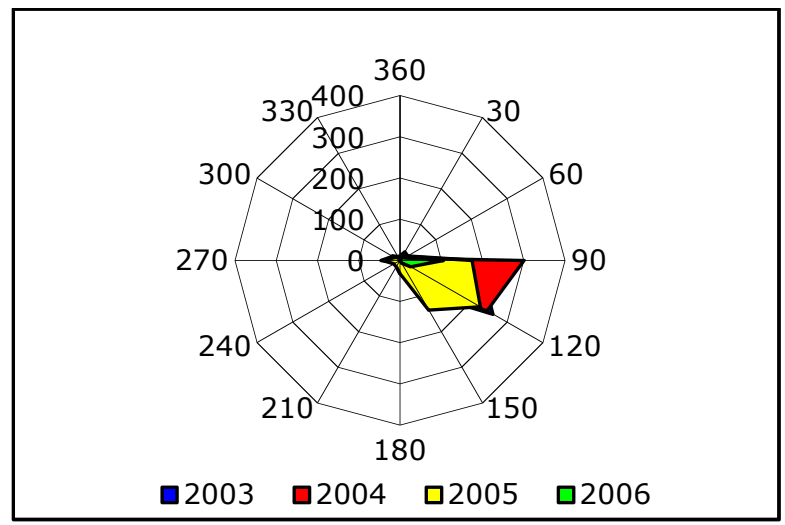

Gráfico A.28 - Direção predominante dos ventos - Abril

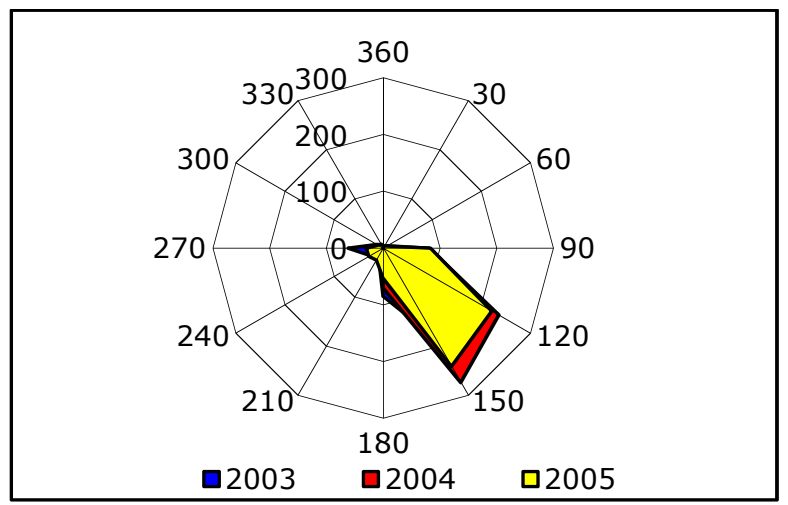

Gráfico A.30 - Direção predominante dos ventos - Junho 


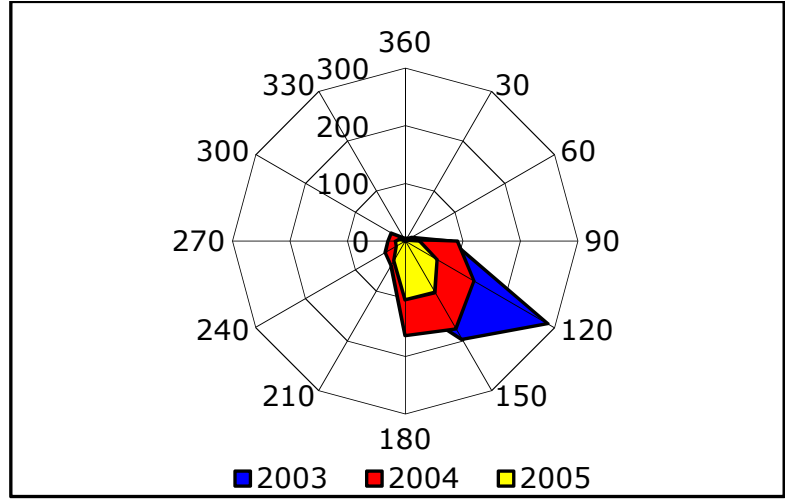

Gráfico A.31 - Direção predominante dos ventos - Julho

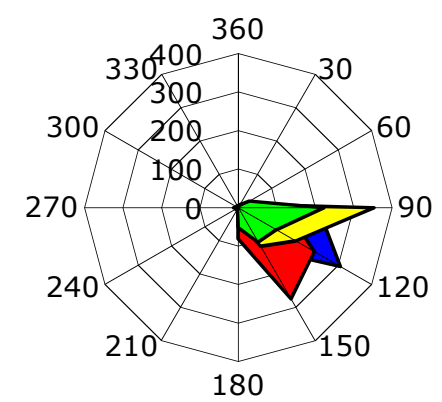

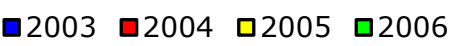

Gráfico A.33 - Direção predominante dos ventos - Setembro

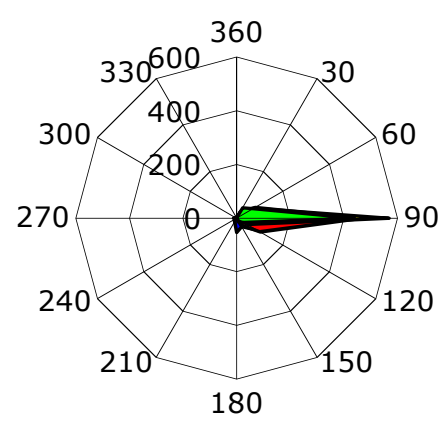

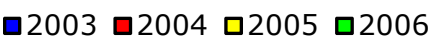

Gráfico A.35 - Direção predominante dos ventos - Novembro

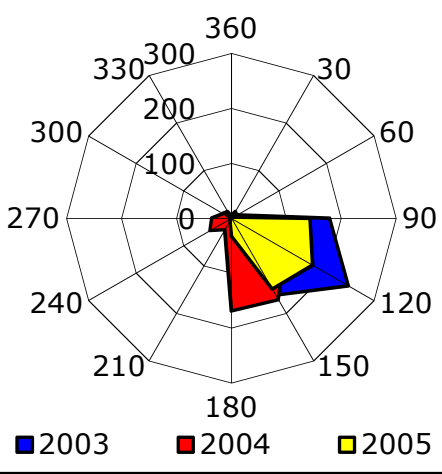

Gráfico A.32 - Direção predominante dos ventos - Agosto

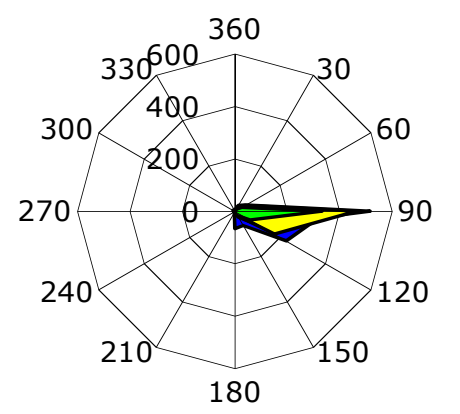

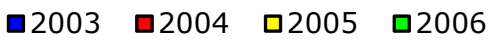

Gráfico A.34 - Direção predominante dos ventos - Outubro

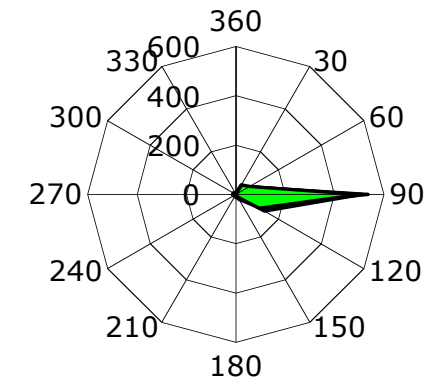

ロ2003 2004 2005 2006

Gráfico A.36 - Direção predominante dos ventos - Dezembro 
d. ANEXO 4 - GRÁFICOS DA VELOCIDADE MÉDIA dOS VENTOS MÊS A MÊS ENTRE

\section{E 2006 COM BASE NO TRATAMENTO DOS DADOS FORNECIDOS PELO INMET.}

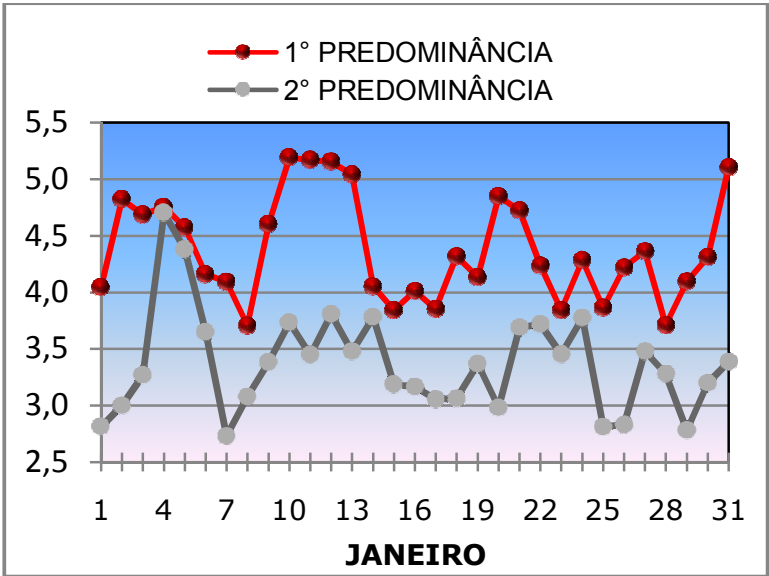

Gráfico A.37 - Velocidade média do vento $(\mathrm{m} / \mathrm{s})$ - Janeiro

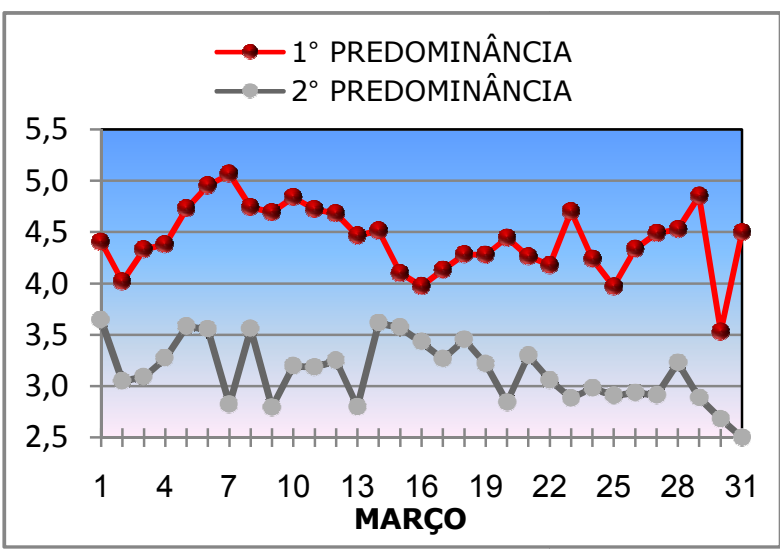

Gráfico A.39 - Velocidade média do vento $(\mathrm{m} / \mathrm{s})$ - Março

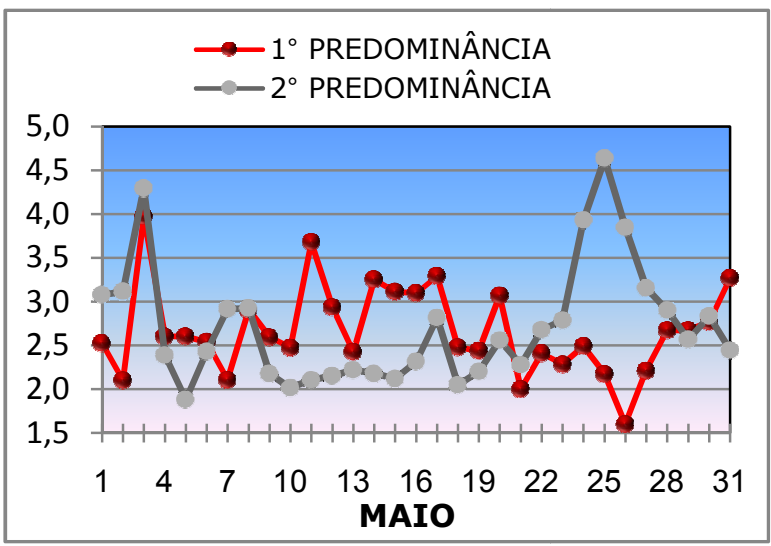

Gráfico A.41 - Velocidade média do vento $(\mathrm{m} / \mathrm{s})$ - Maio

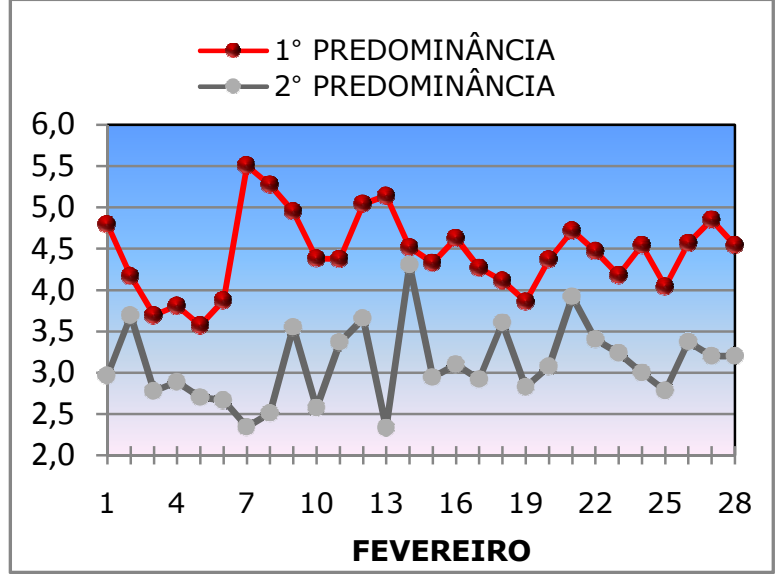

Gráfico A.38 - Velocidade média do vento $(\mathrm{m} / \mathrm{s})$ - Fevereiro

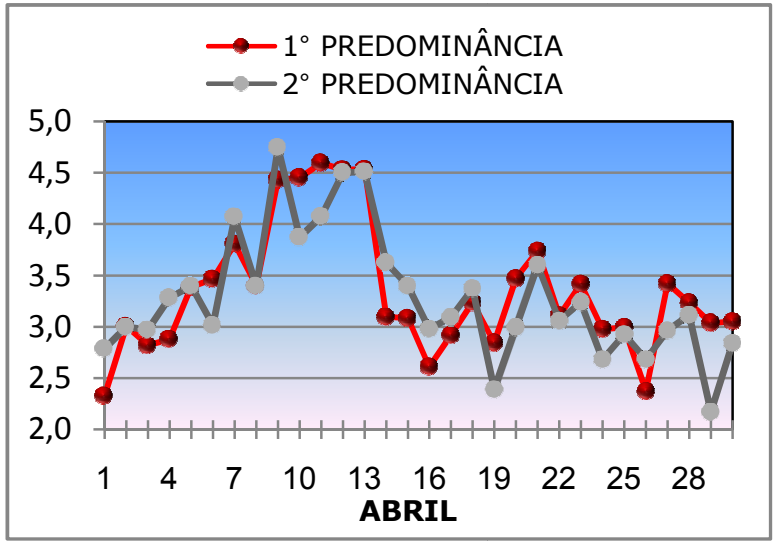

Gráfico A.40 - Velocidade média do vento (m/s) - Abril

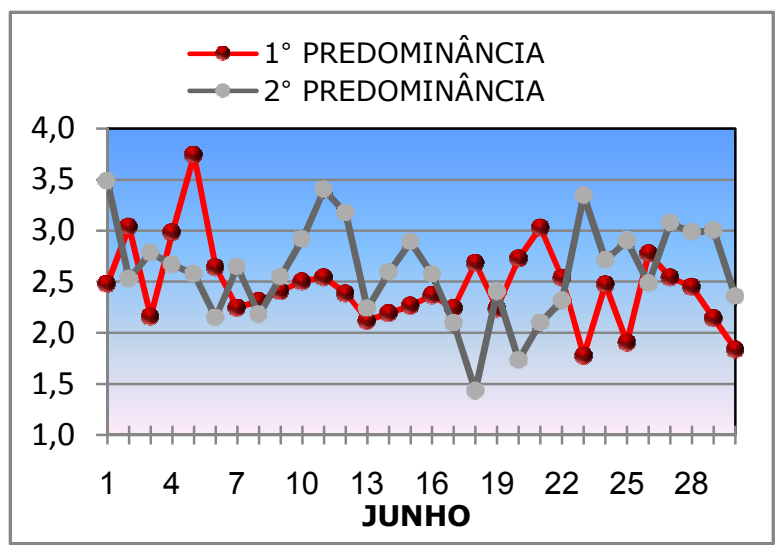

Gráfico A.42 - Velocidade média do vento (m/s) - Junho 


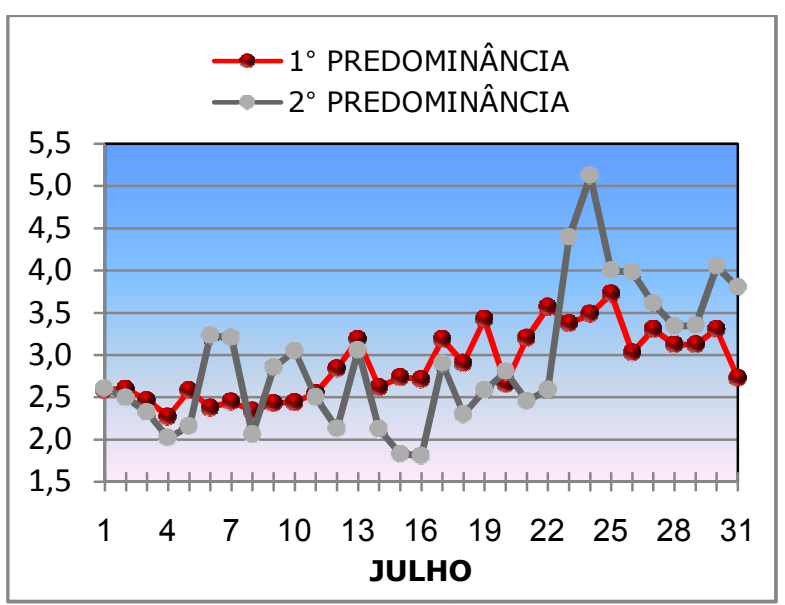

Gráfico A.43 - Velocidade média do vento (m/s) - Julho

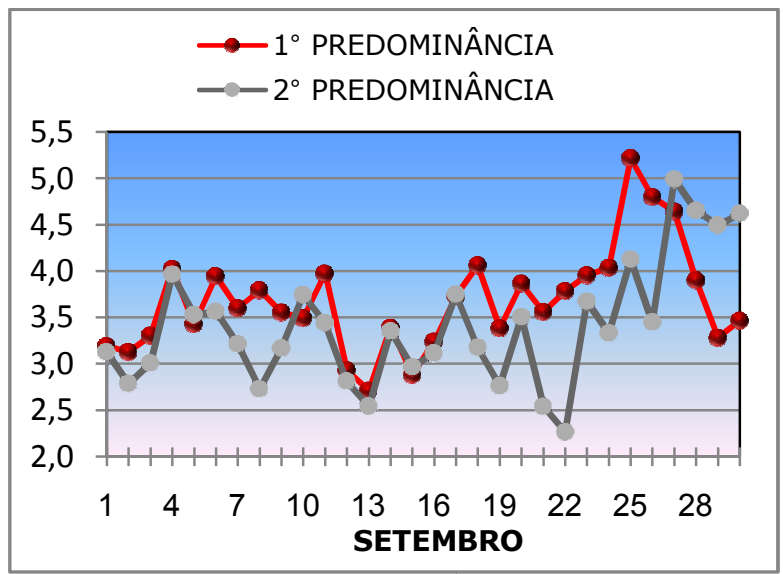

Gráfico A.45 - Velocidade média do vento $(\mathrm{m} / \mathrm{s})$ - Setembro

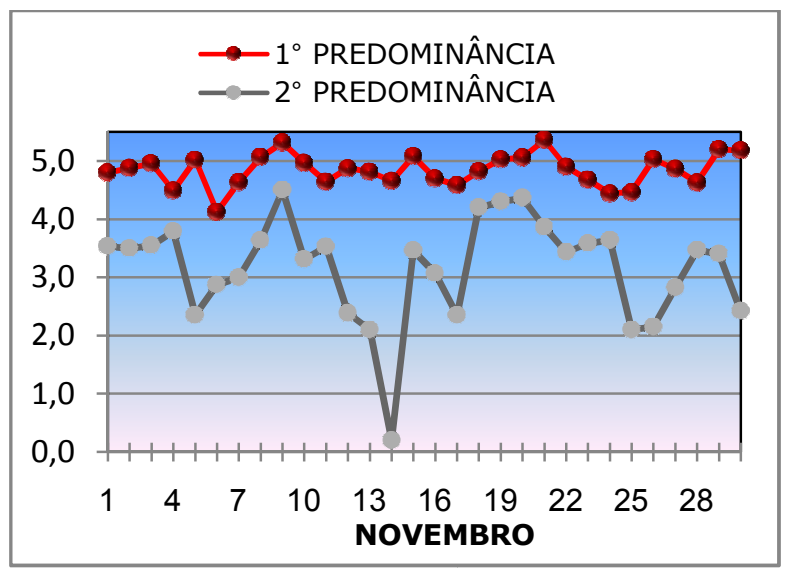

Gráfico A.47 - Velocidade média do vento $(\mathrm{m} / \mathrm{s})$ - Novembro

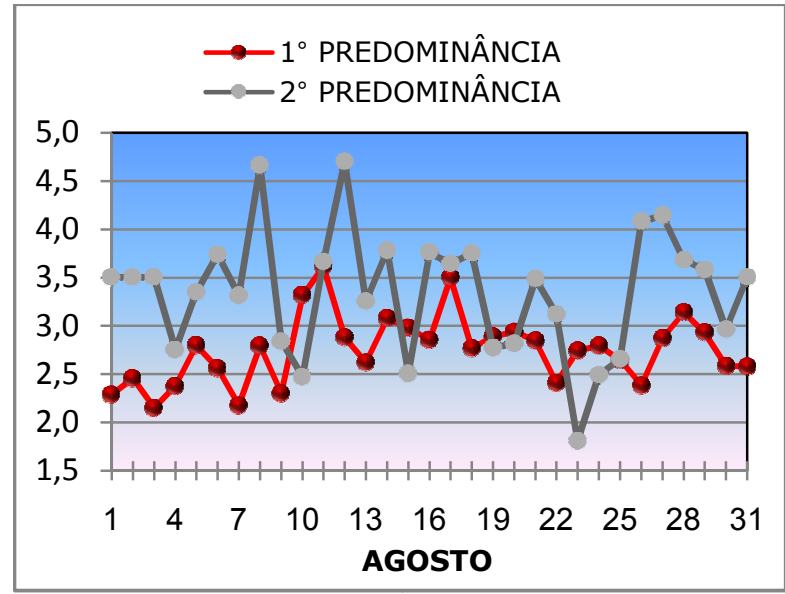

Gráfico A.44 - Velocidade média do vento (m/s) - Agosto

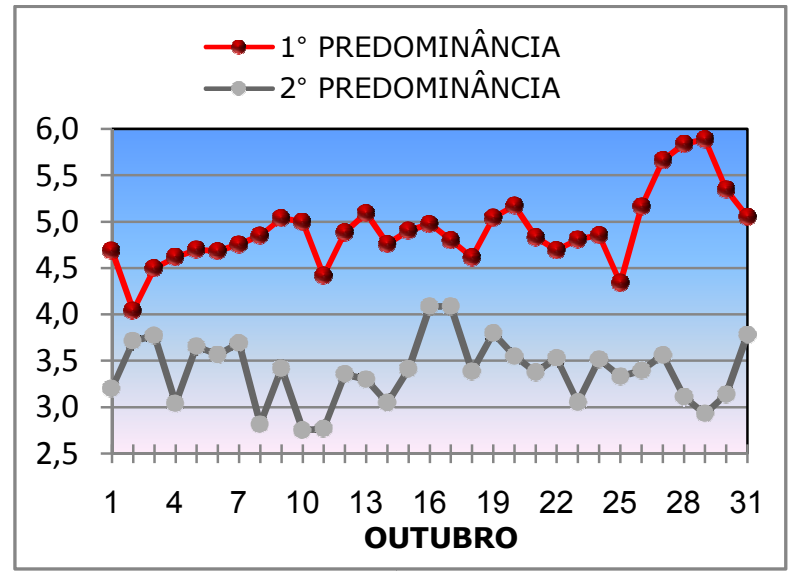

Gráfico A.46 - Velocidade média do vento $(\mathrm{m} / \mathrm{s})$ - Outubro

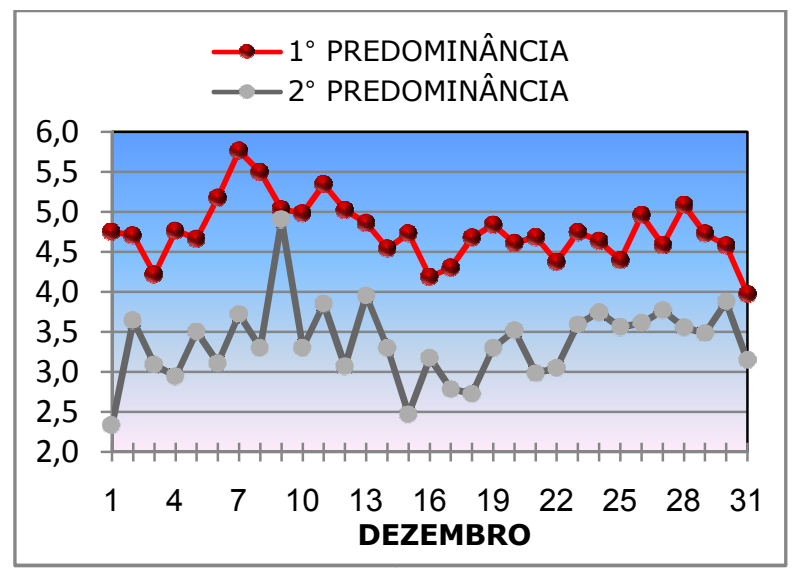

Gráfico A.48 - Velocidade média do vento $(\mathrm{m} / \mathrm{s})$ - Dezembro 


\section{e. ANEXO 5 - IMAGENS COMPLEMENTARES DA SIMULAÇÃO DO MODELO 01}

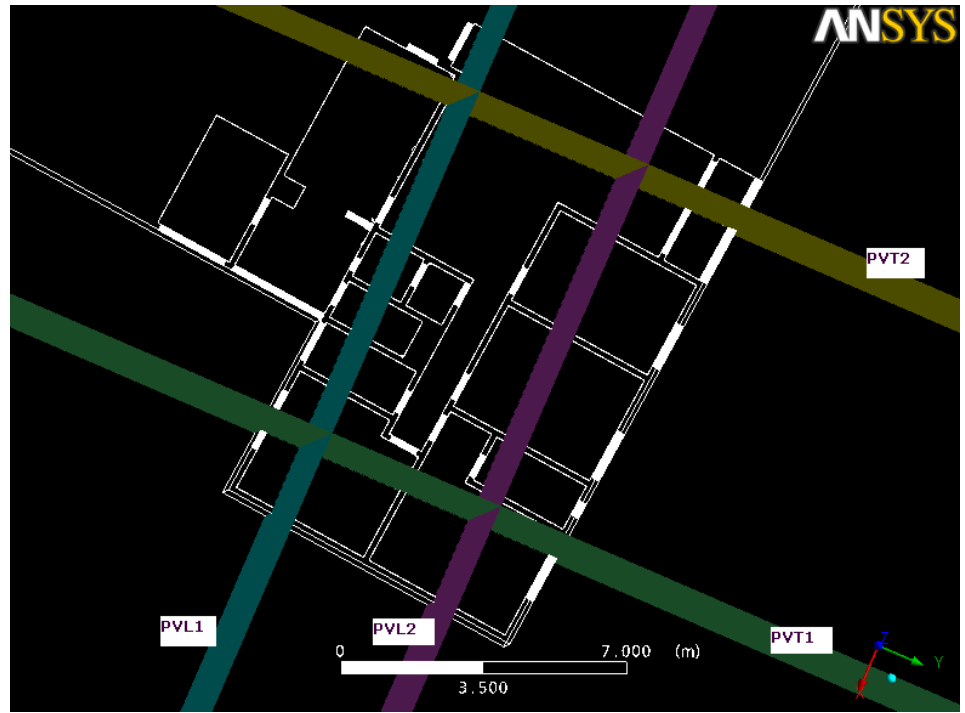

Figura A.1 - Localização dos planos verticais longitudinais e transversais

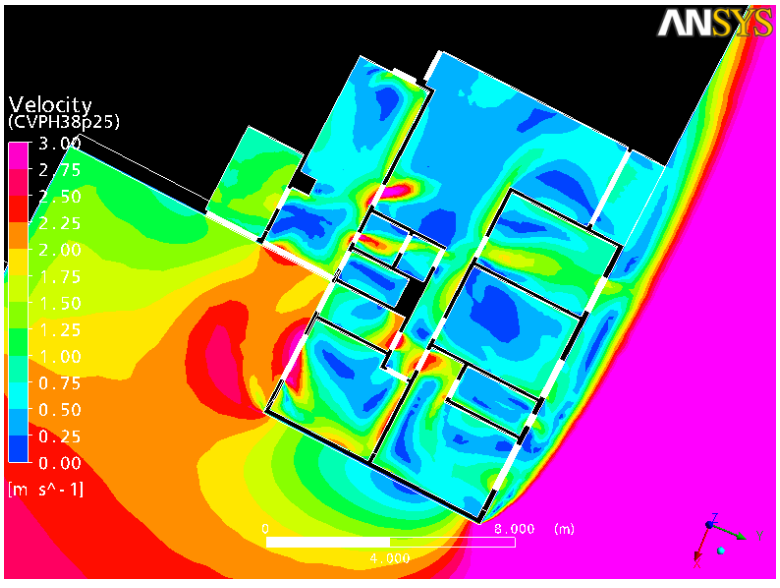

Figura A.2 - Modelo 01 - Contorno da velocidade do vento no plano horizontal $h=2.00 \mathrm{~m}$

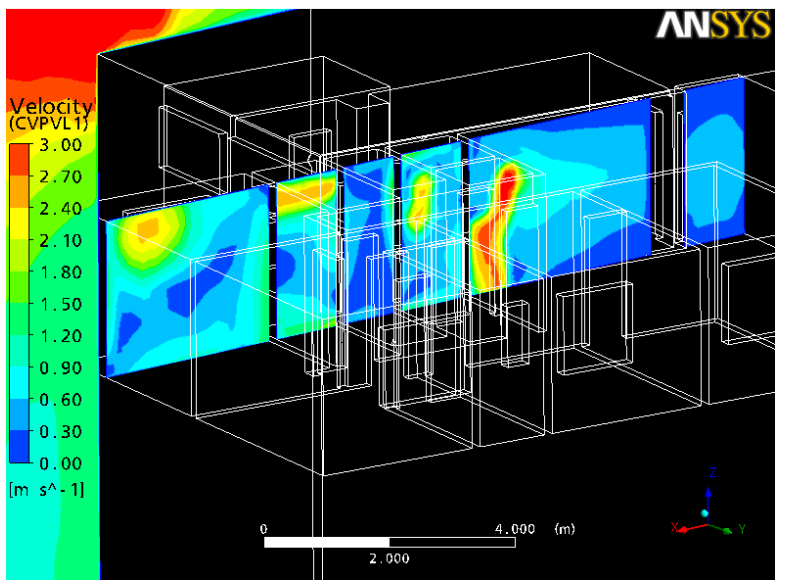

Figura A.4 - Modelo 01 - Contorno da velocidade do vento no plano vertical longitudinal 1 (PVL1)

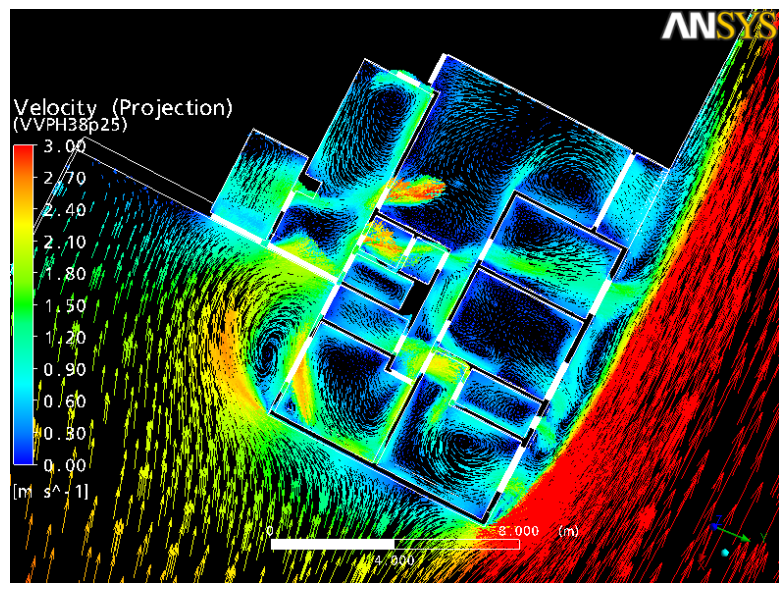

Figura A.3 - Modelo 01 - Vetores da velocidade e direção do vento no plano horizontal $\mathbf{h}=\mathbf{2 . 0 0 m}$

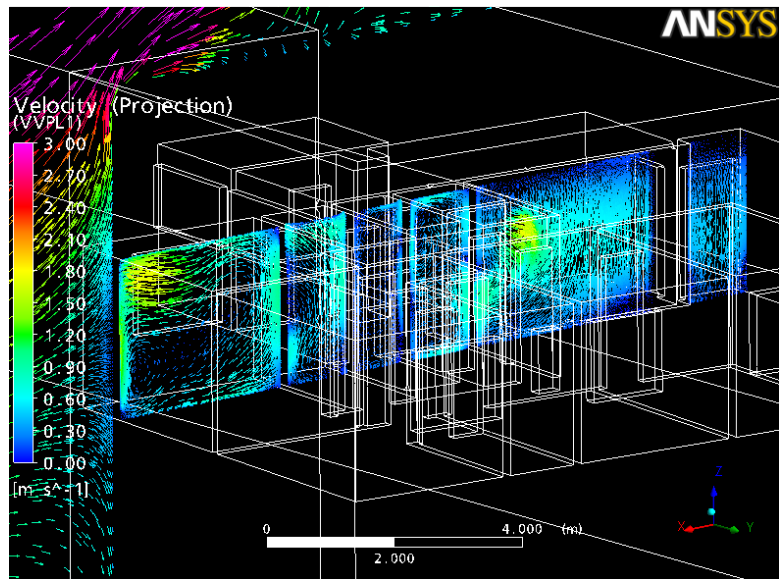

Figura A.5 - Modelo 01 - Vetores da velocidade e direção do vento no plano vertical longitudinal 1 (PVL1) 


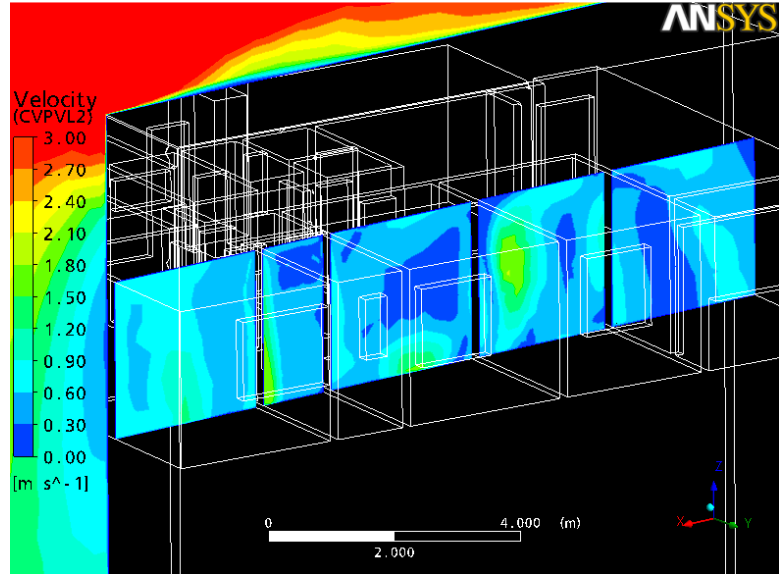

Figura A.6 - Modelo 01 - Contorno da velocidade do vento no plano vertical longitudinal 2 (PVL2)

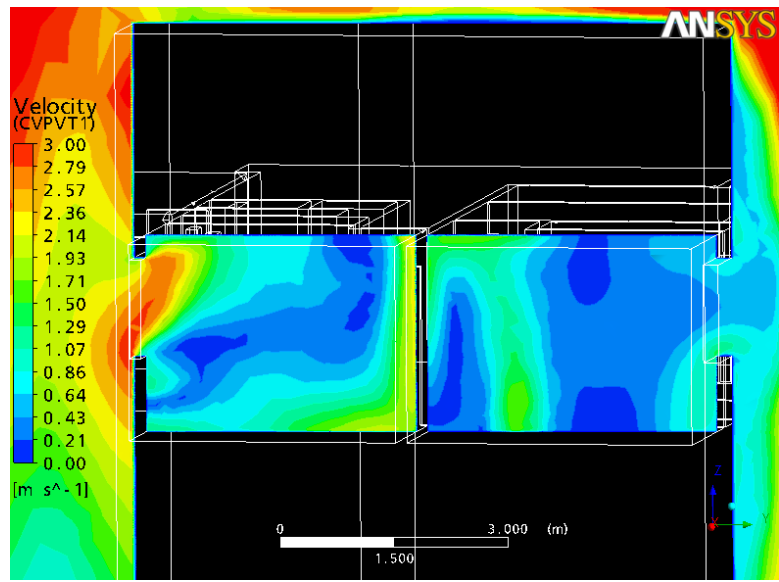

Figura A.8 - Modelo 01 - Contorno da velocidade do vento no plano vertical transversal 1 (PVT1)

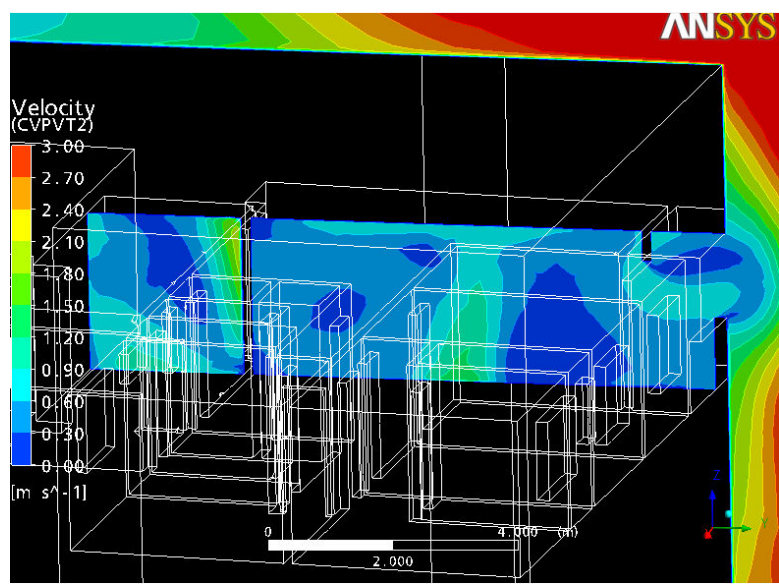

Figura A.10 - Modelo 01 - Contorno da velocidade do vento no plano vertical transversal 2 (PVT2)

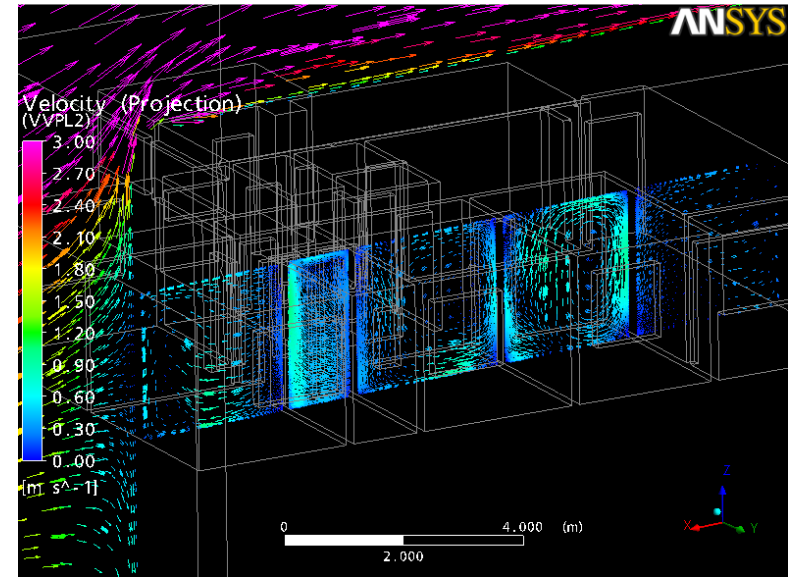

Figura A.7 - Modelo 01 - Vetores da velocidade e direção do vento no plano vertical longitudinal 2 (PVL2)

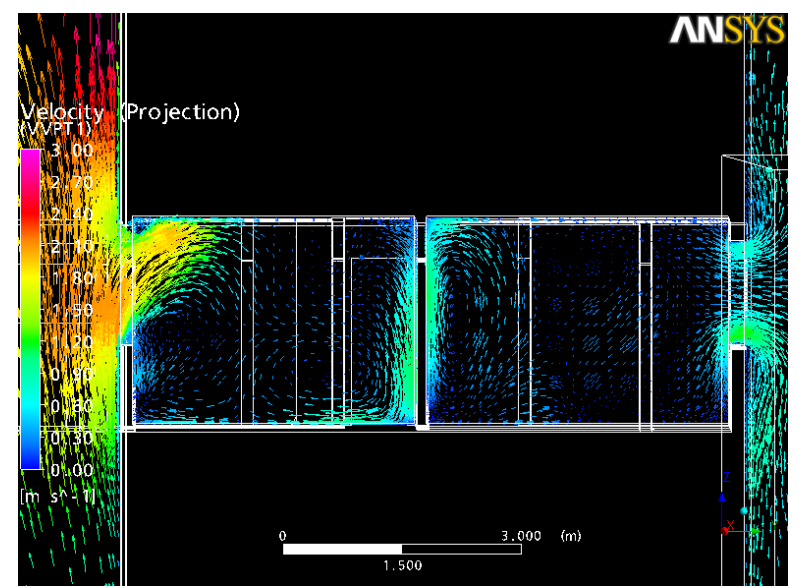

Figura A.9 - Modelo 01 - Vetores da velocidade e direção do vento no plano vertical transversal 1 (PVT1)

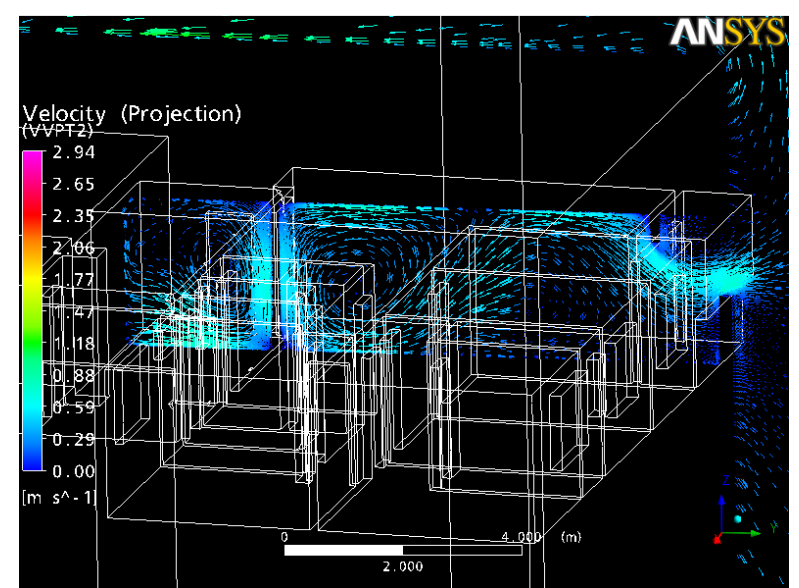

Figura A.11 - Modelo 01 - Vetores da velocidade e direção do vento no plano vertical transversal 2 (PVT2) 


\section{f. ANEXO 6 - IMAGENS COMPLEMENTARES DA SIMULAÇÃO DO MODELO 02}

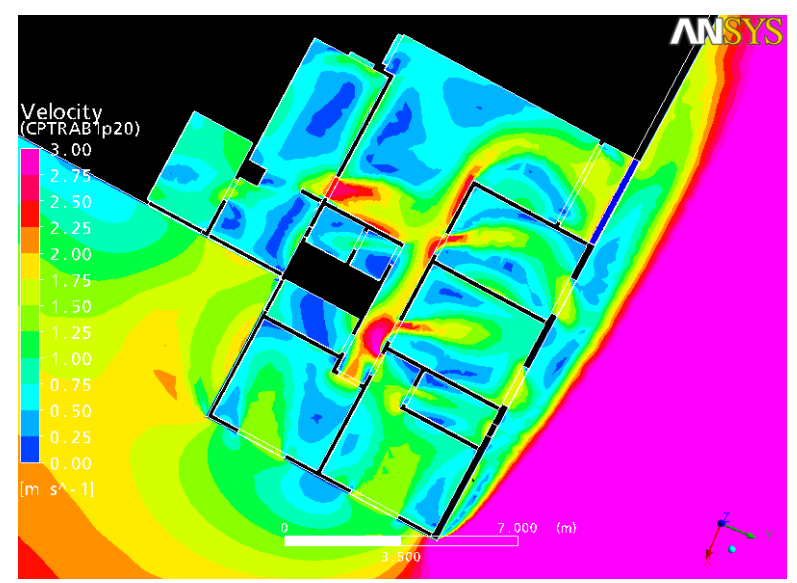

Figura A.12 - Modelo 02 - Contorno da velocidade do vento no plano horizontal $\mathrm{h}=1.20 \mathrm{~m}$

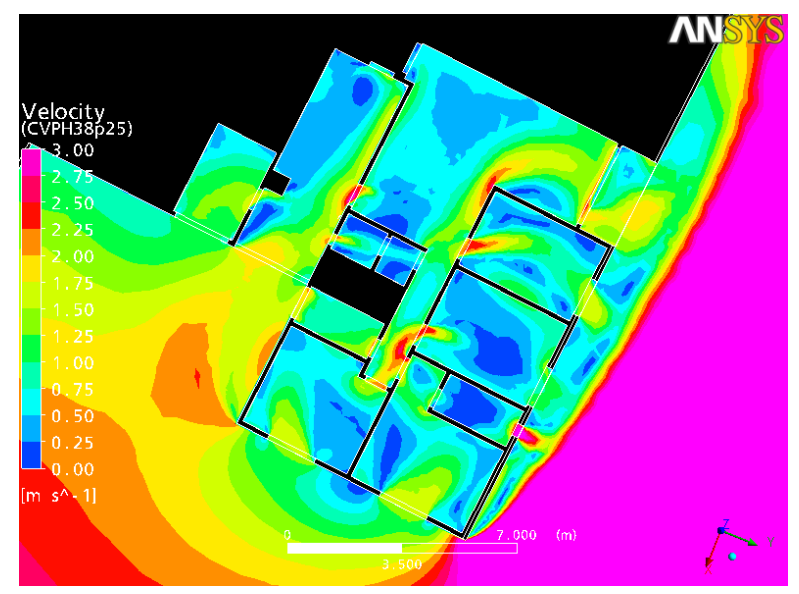

Figura A.14 - Modelo 02 - Contorno da velocidade do vento no plano horizontal $\mathrm{h}=\mathbf{2 . 0 0 \mathrm { m }}$

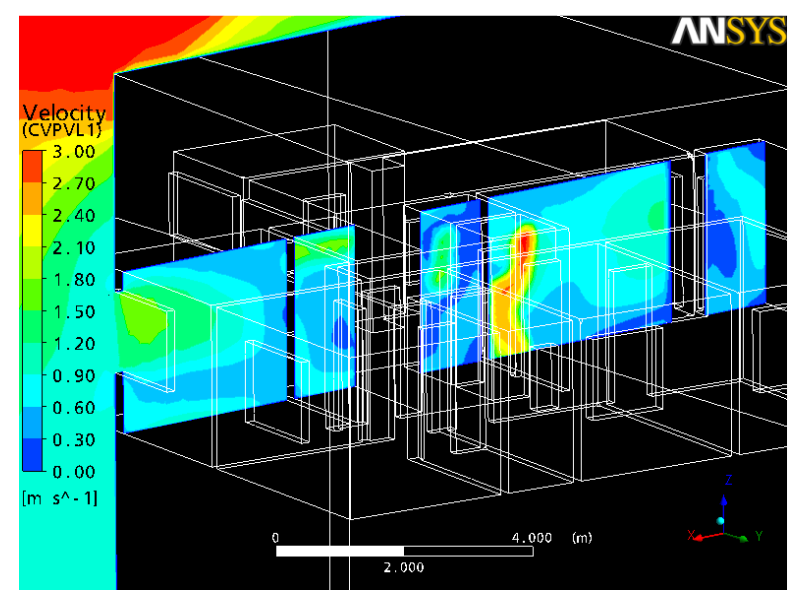

Figura A.16 - Modelo 02 - Contorno da velocidade do vento no PVL1

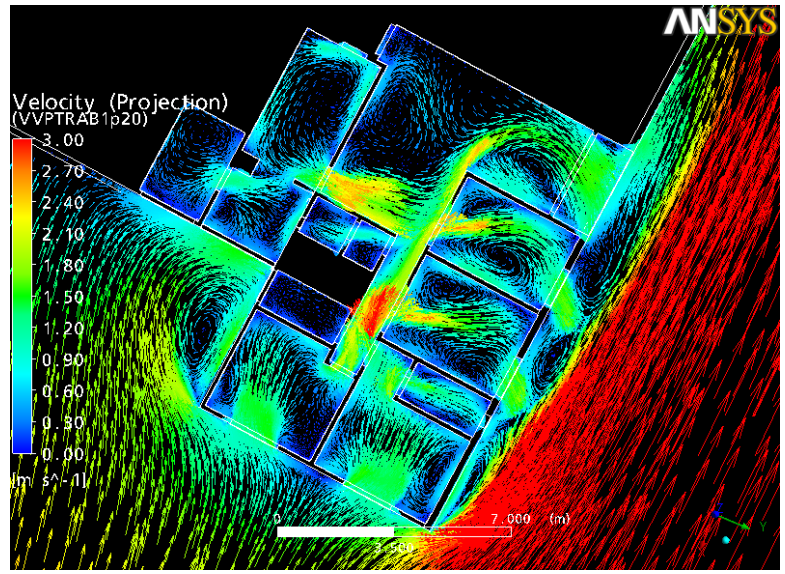

Figura A.13 - Modelo 02 - Vetores da velocidade e direção do vento no plano horizontal $h=1.20 \mathrm{~m}$

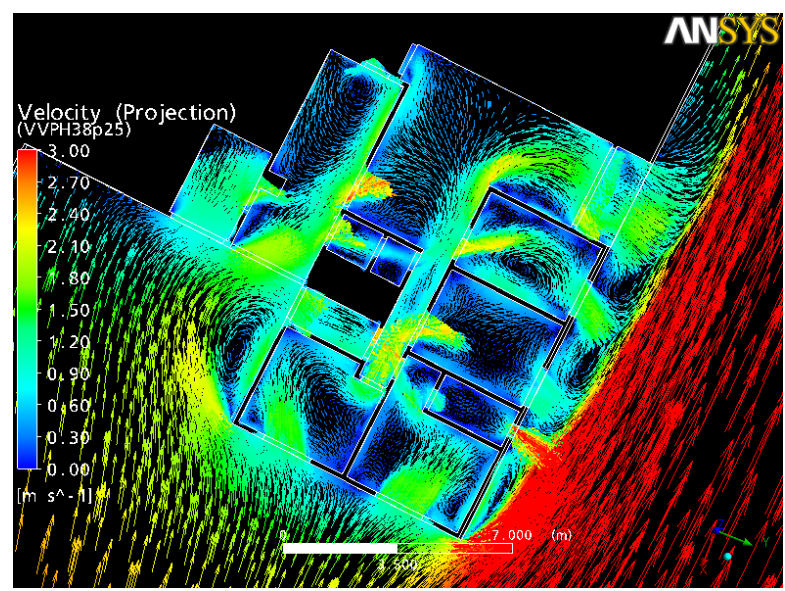

Figura A.15 - Modelo 02 - Vetores da velocidade e direção do vento no plano horizontal $\mathbf{h}=\mathbf{2 . 0 0 m}$

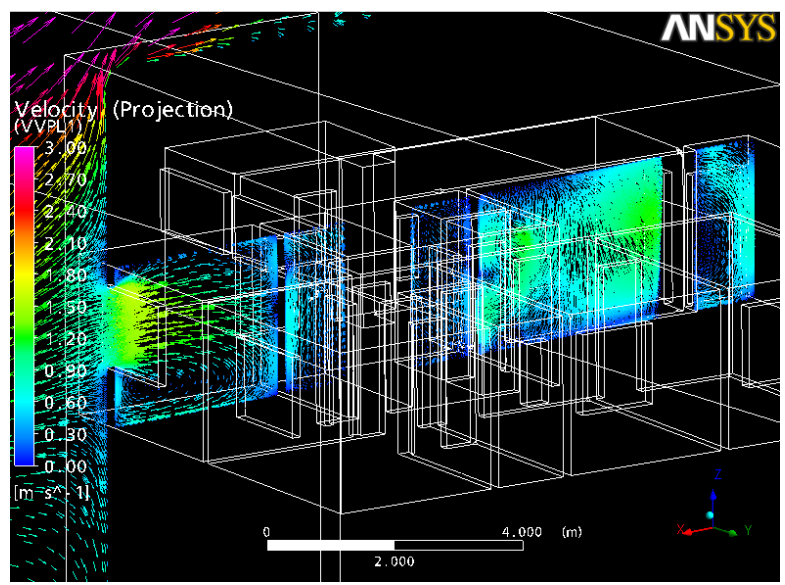

Figura A.17 - Modelo 02 - Vetores da velocidade e direção do vento no PVL1 


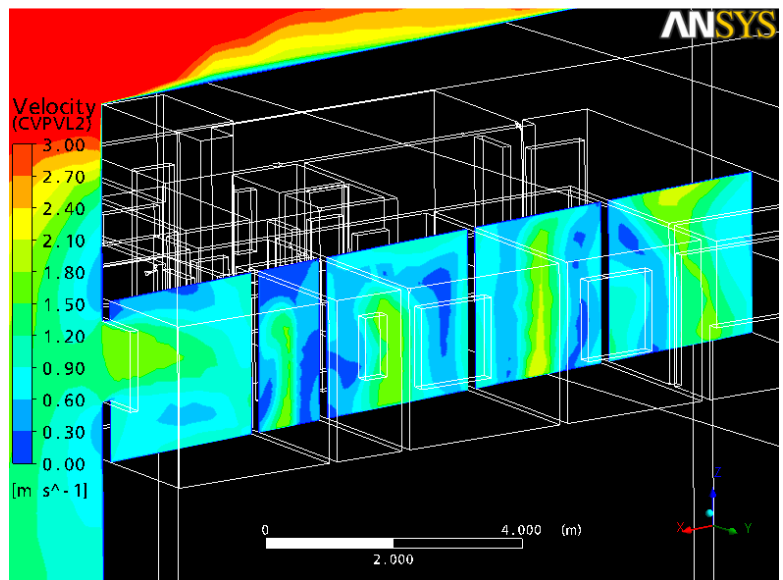

Figura A.18 - Modelo 02 - Contorno da velocidade do vento no PVL2

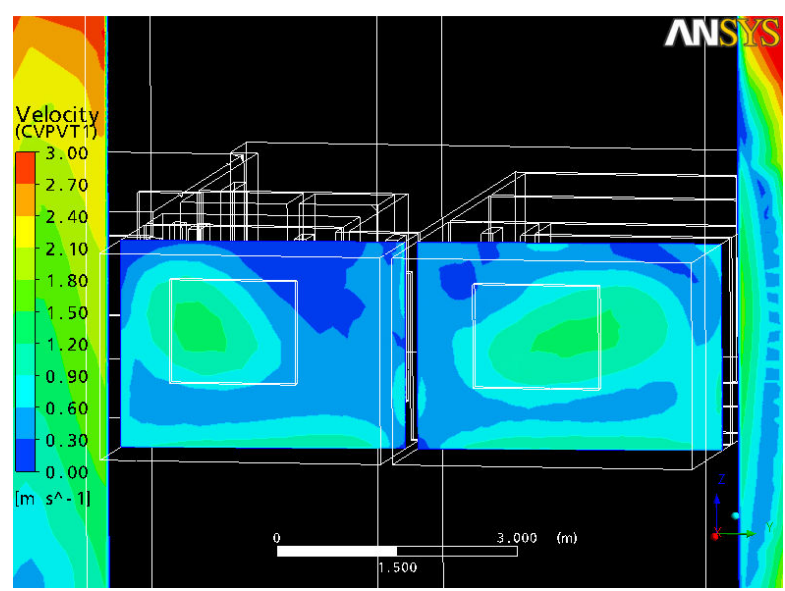

Figura A.20 - Modelo 02 - Contorno da velocidade do vento no PVT1

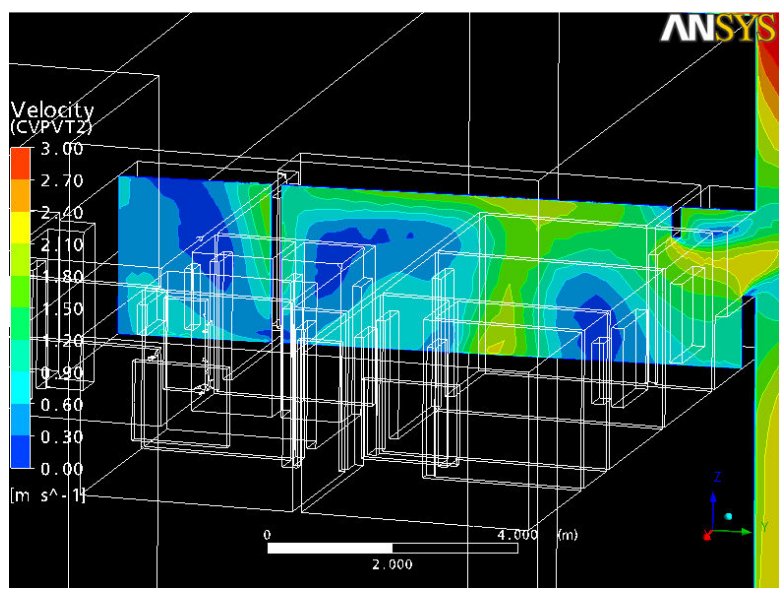

Figura A.22 - Modelo 02 - Contorno da velocidade do vento no PVT2

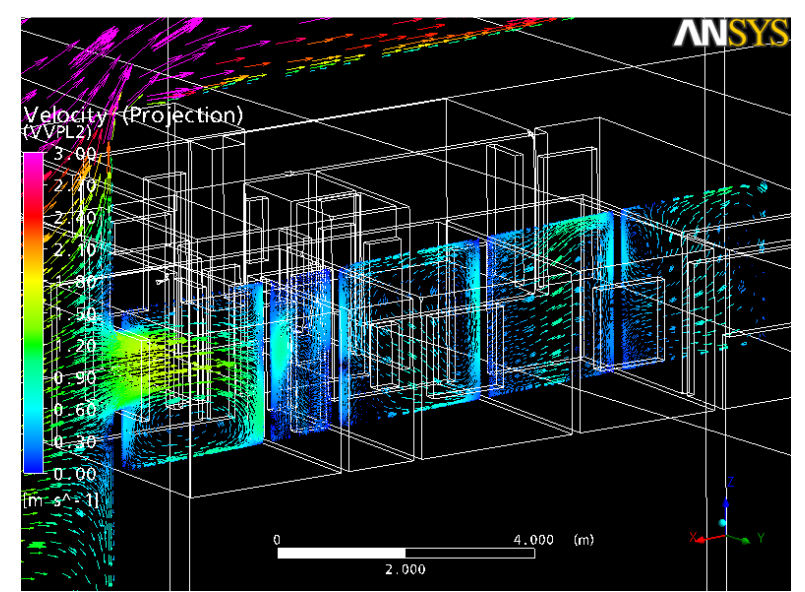

Figura A.19 - Modelo 02 - Vetores da velocidade e direção do vento no PVL2

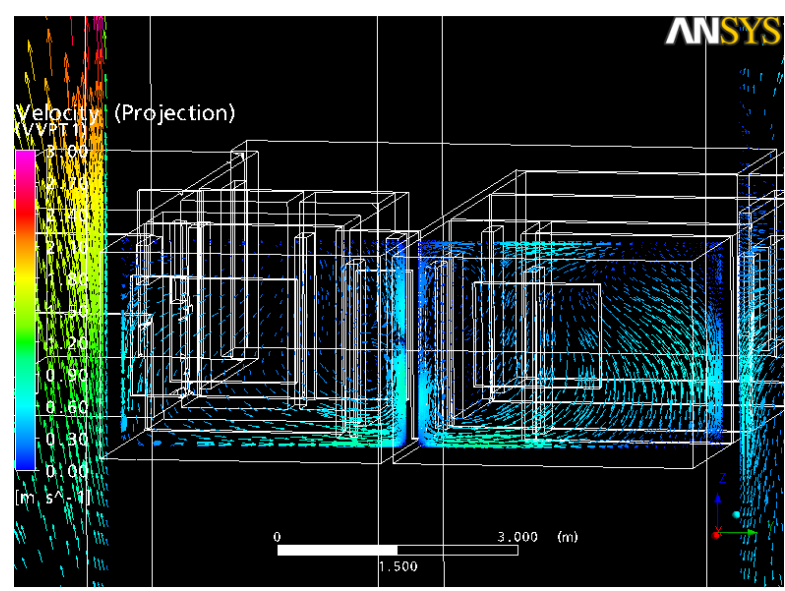

Figura A.21 - Modelo 02 - Vetores da velocidade e direção do vento no PVT1

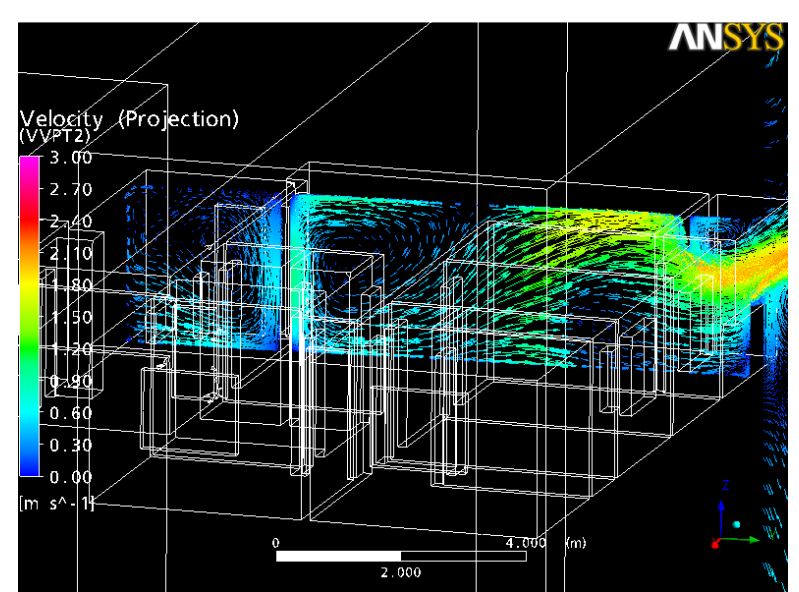

Figura A.23 - Modelo 02 - Vetores da velocidade e direção do vento no PVT2 


\section{g. ANEXO 7 - IMAGENS COMPLEMENTARES DA SIMULAÇÃO DO MODELO 03}

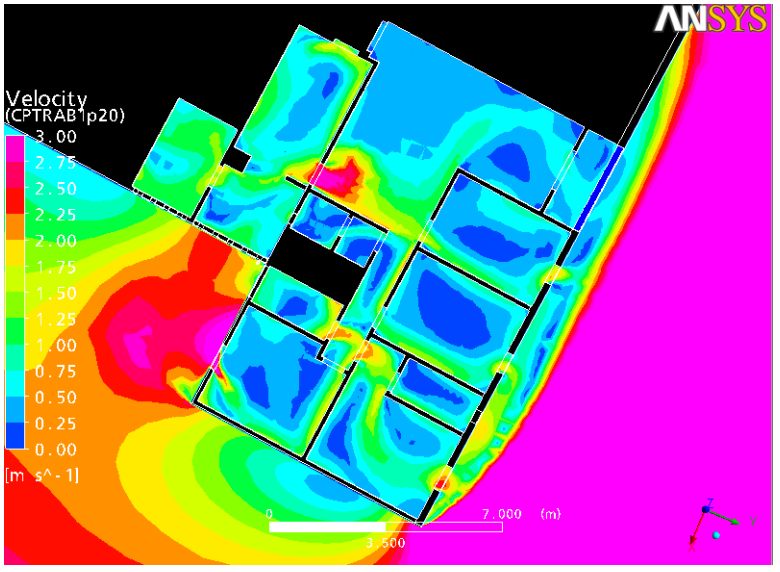

Figura A.24 - Modelo 03 - Contorno da velocidade do vento no plano horizontal $\mathrm{h}=\mathbf{1 . 2 0 \mathrm { m }}$

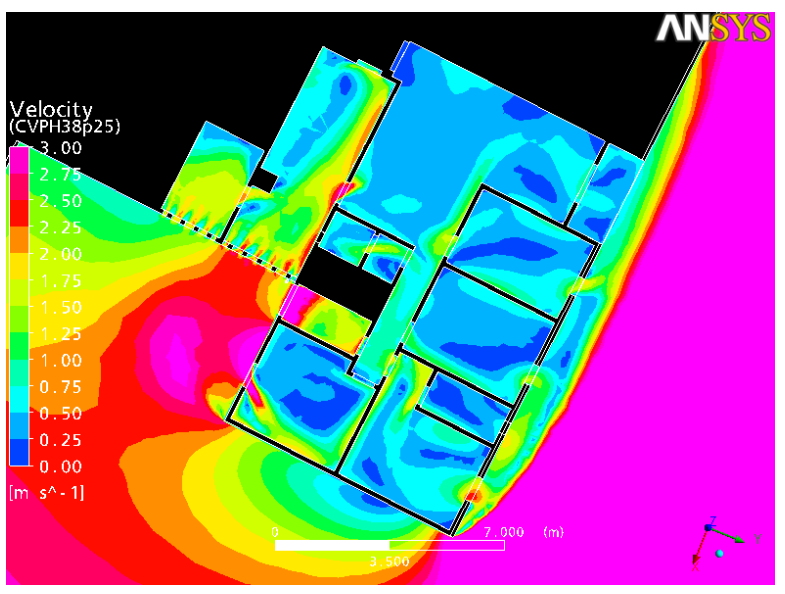

Figura A.26 - Modelo 03 - Contorno da velocidade do vento no plano horizontal $\mathrm{h}=\mathbf{2 . 0 0 \mathrm { m }}$

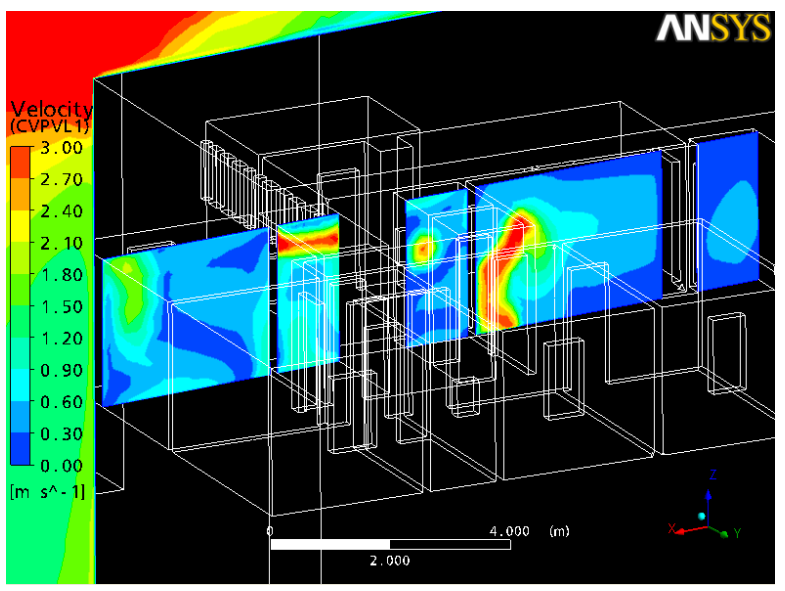

Figura A.28 - Modelo 03 - Contorno da velocidade do vento no PVL1

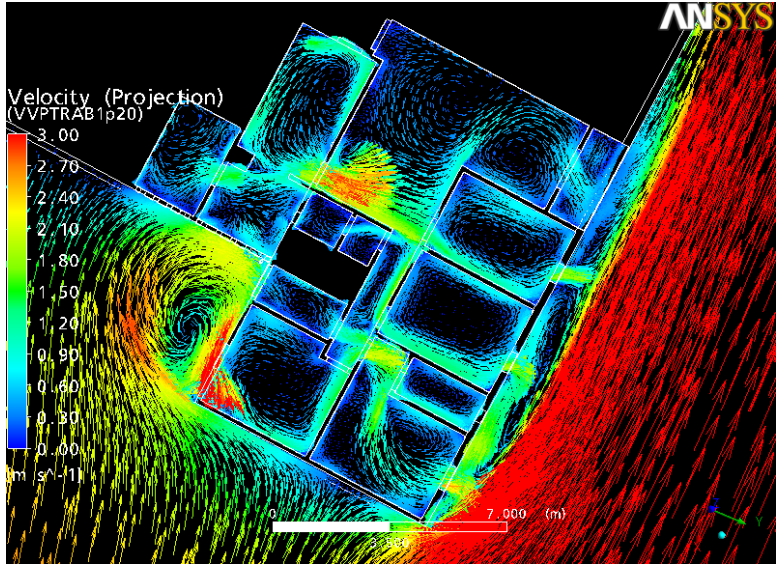

Figura A.25 - Modelo 03 - Vetores da velocidade e direção do vento no plano horizontal $h=1.20 \mathrm{~m}$

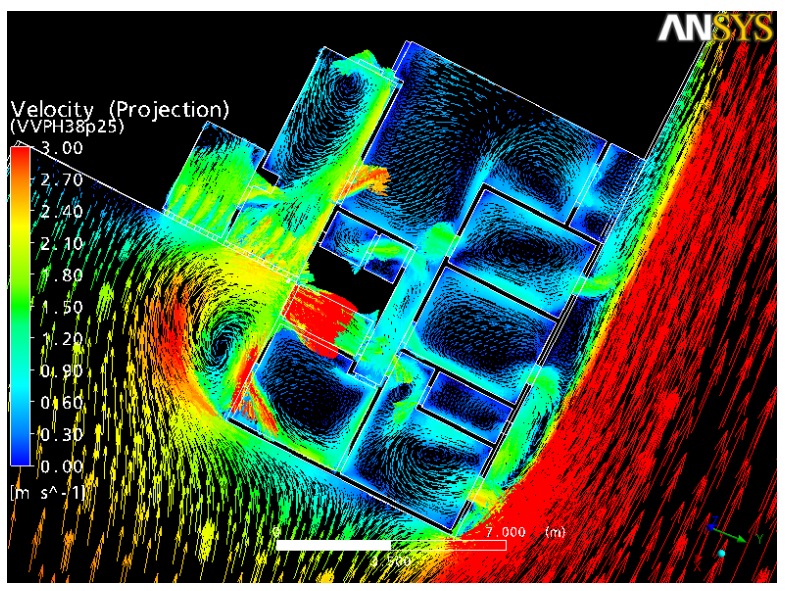

Figura A.27 - Modelo 03 - Vetores da velocidade e direção do vento no plano horizontal $\mathbf{h}=\mathbf{2 . 0 0 m}$

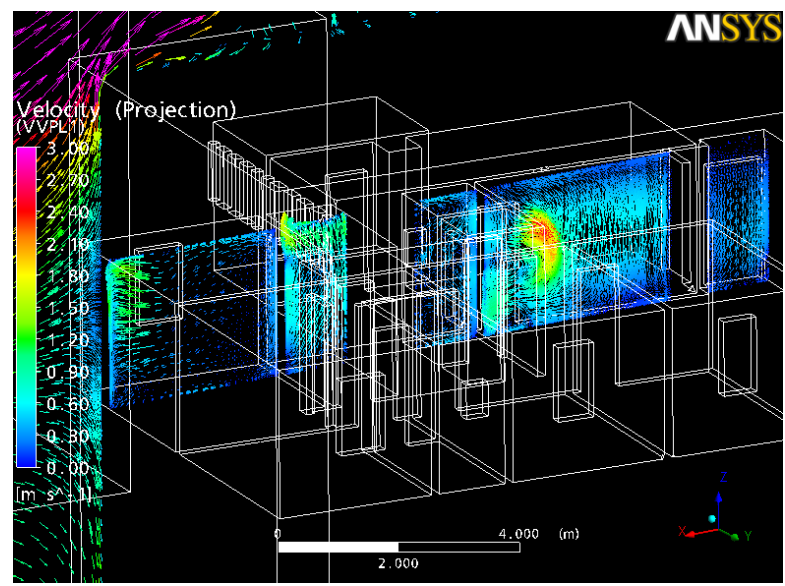

Figura A.29 - Modelo 03 - Vetores da velocidade e direção do vento no PVL1 


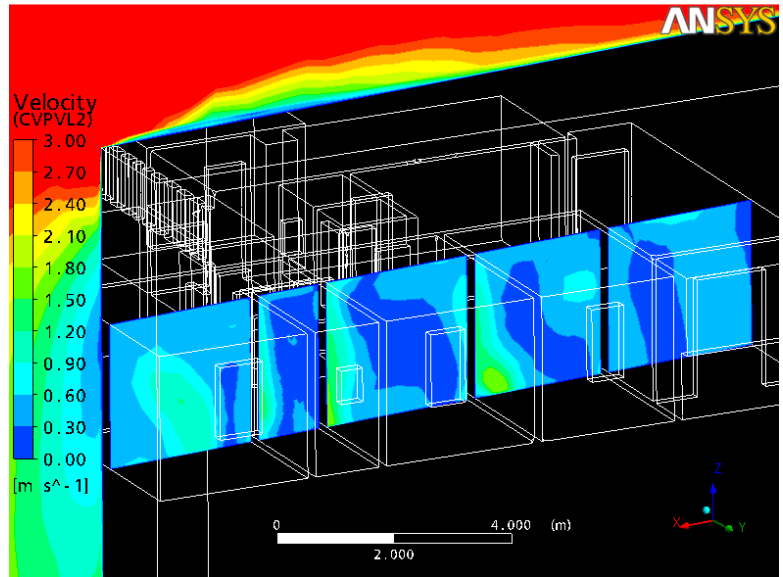

Figura A.30 - Modelo 03 - Contorno da velocidade do vento no PVL2

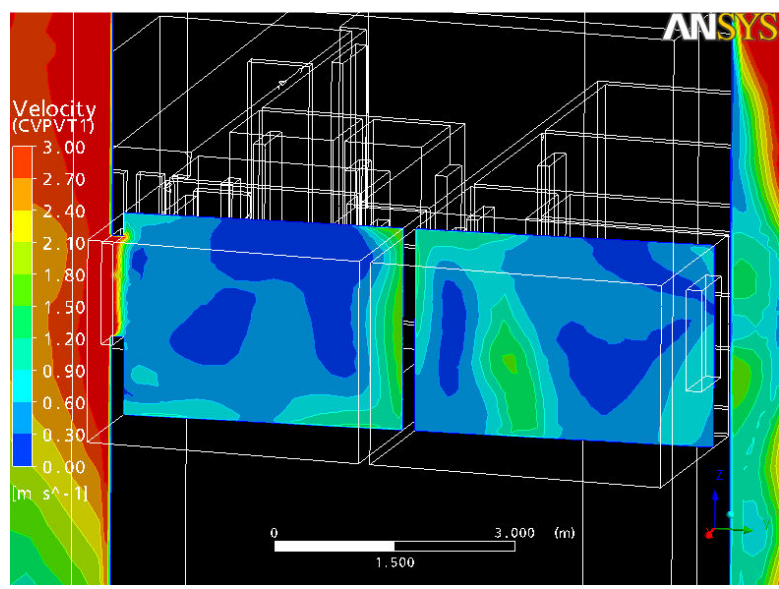

Figura A.32 - Modelo 03 - Contorno da velocidade do vento no PVT1

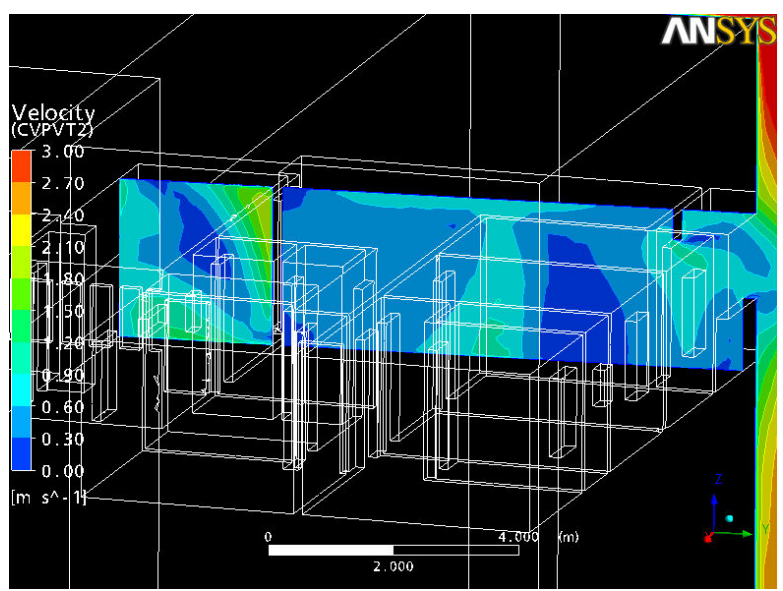

Figura A.34 - Modelo 03 - Contorno da velocidade do vento no PVT2

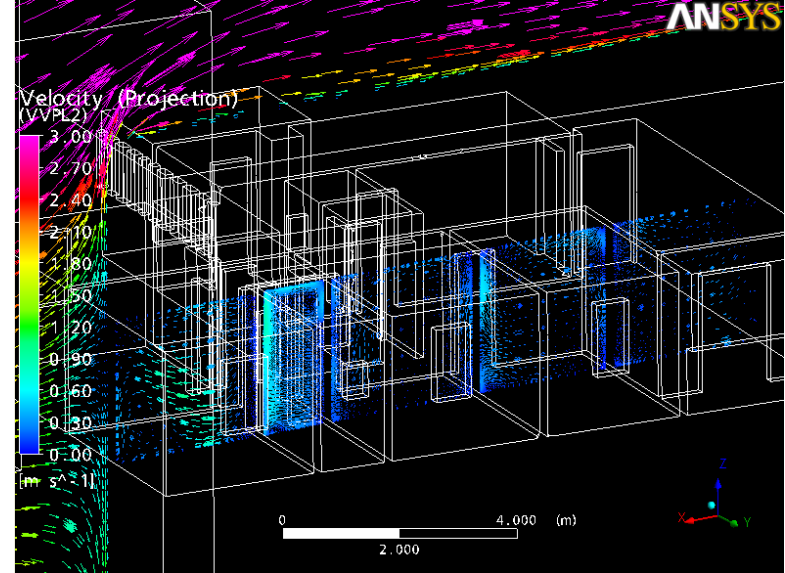

Figura A.31 - Modelo 03 - Vetores da velocidade e direção do vento no PVL2

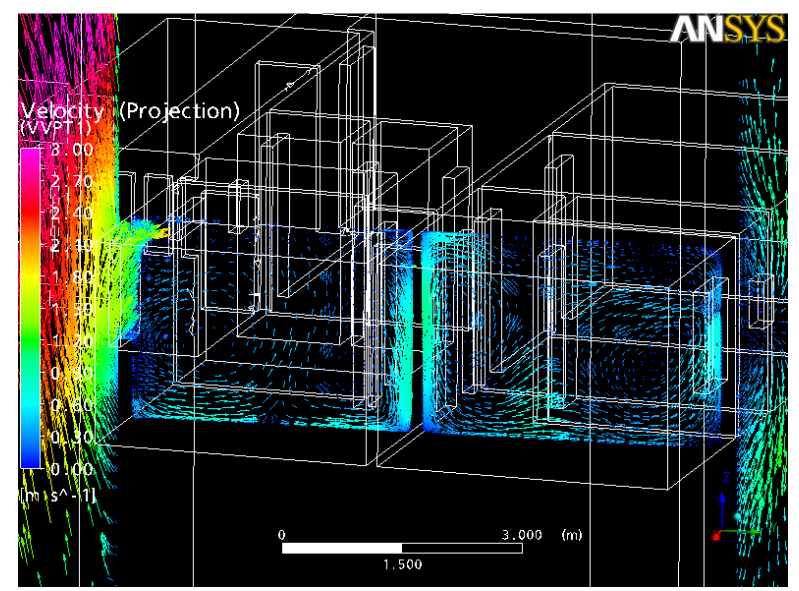

Figura A.33 - Modelo 03 - Vetores da velocidade e direção do vento no PVT1

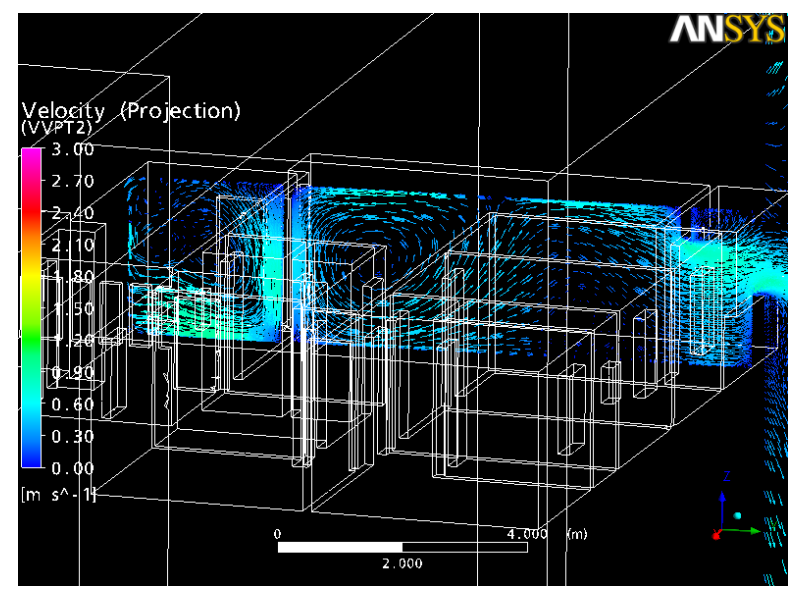

Figura A.35 - Modelo 03 - Vetores da velocidade e direção do vento no PVT2 


\section{h. ANEXO 8 - IMAGENS COMPLEMENTARES DA SIMULAÇÃO DO MODELO 04}

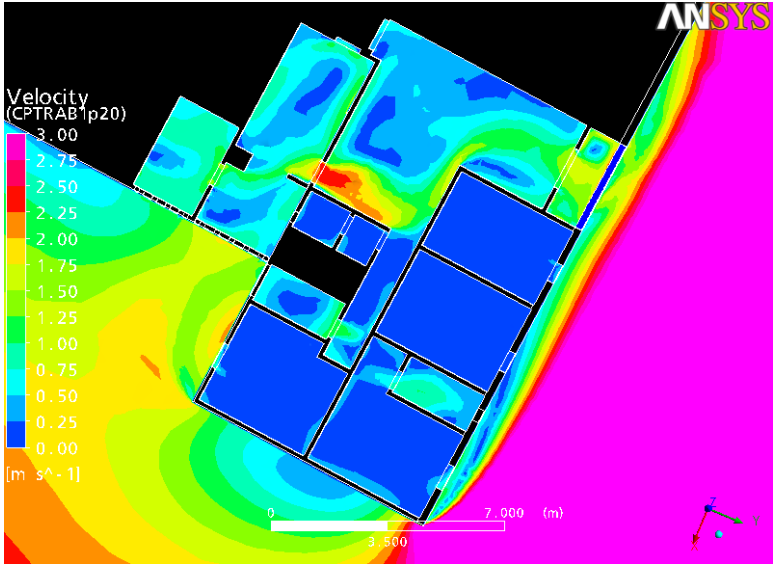

Figura A.36 - Modelo 04 - Contorno da velocidade do vento no plano horizontal $\mathrm{h}=\mathbf{1 . 2 0 \mathrm { m }}$

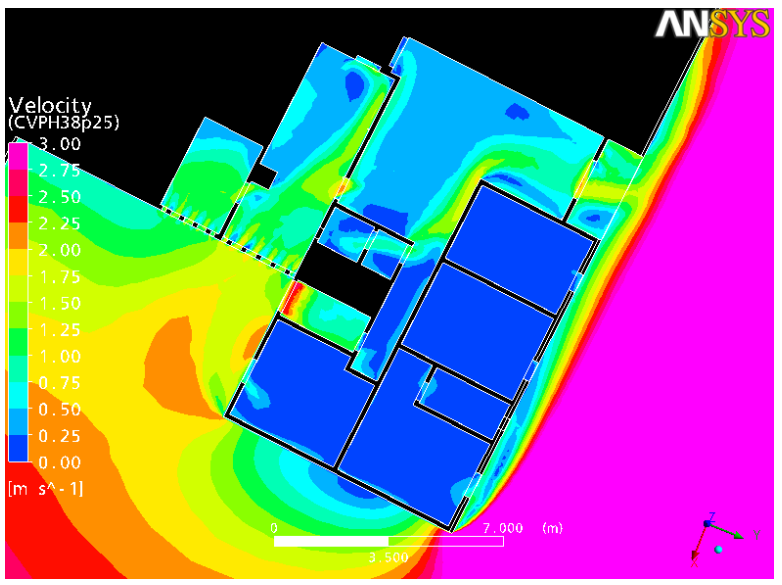

Figura A.38 - Modelo 04 - Contorno da velocidade do vento no plano horizontal $h=2.00 \mathrm{~m}$

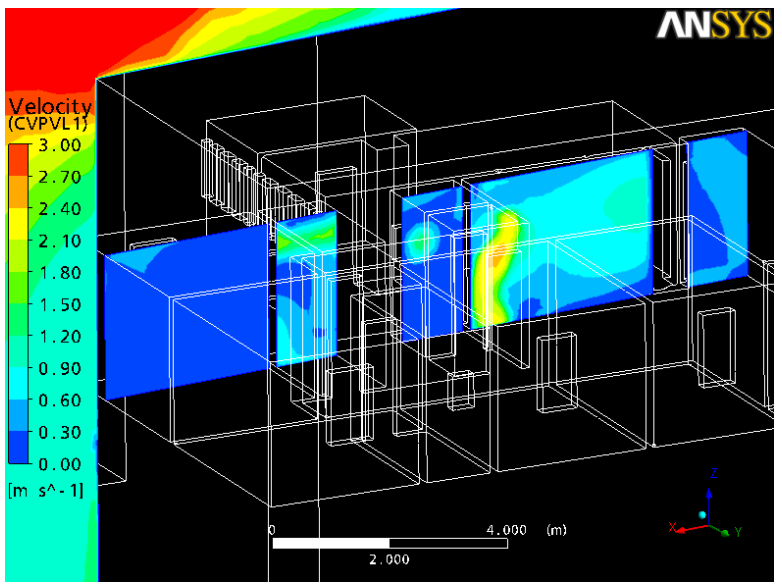

Figura A.40 - Modelo 04 - Contorno da velocidade do vento no PVL1

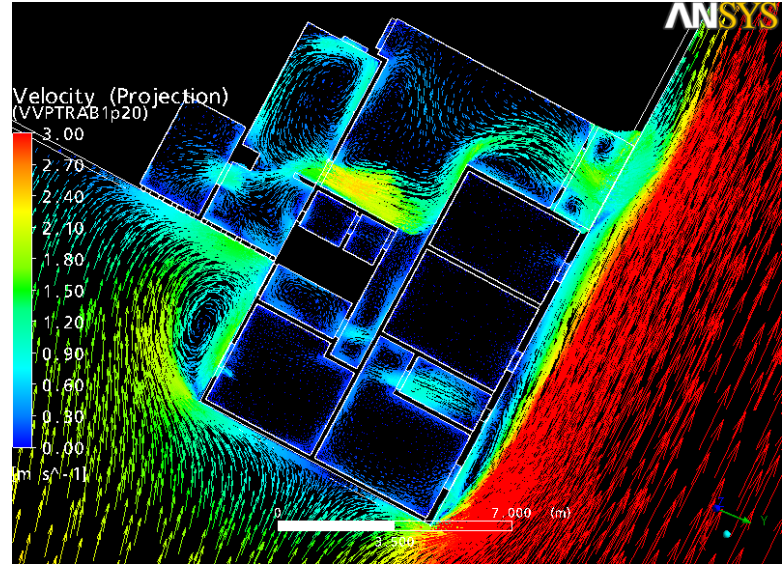

Figura A.37 - Modelo 04 - Vetores da velocidade e direção do vento no plano horizontal $h=1.20 \mathrm{~m}$

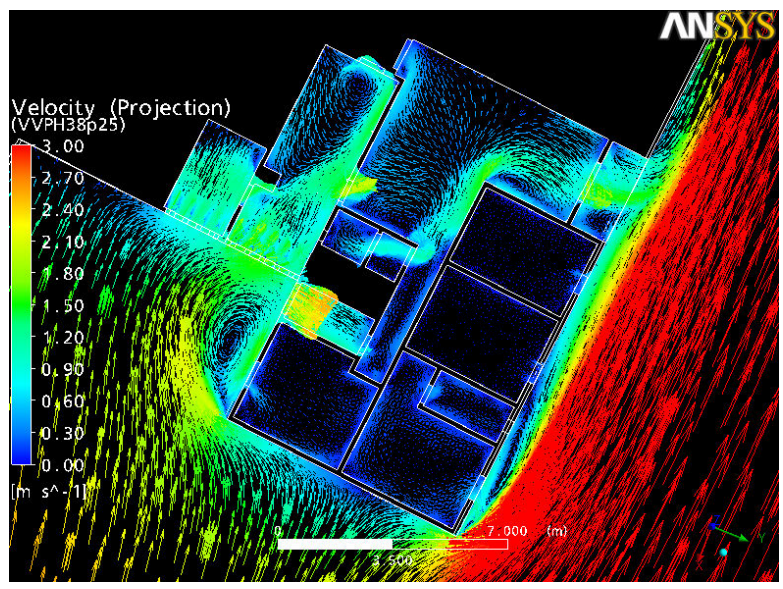

Figura A.39 - Modelo 04 - Vetores da velocidade e direção do vento no plano horizontal $\mathbf{h}=\mathbf{2 . 0 0 m}$

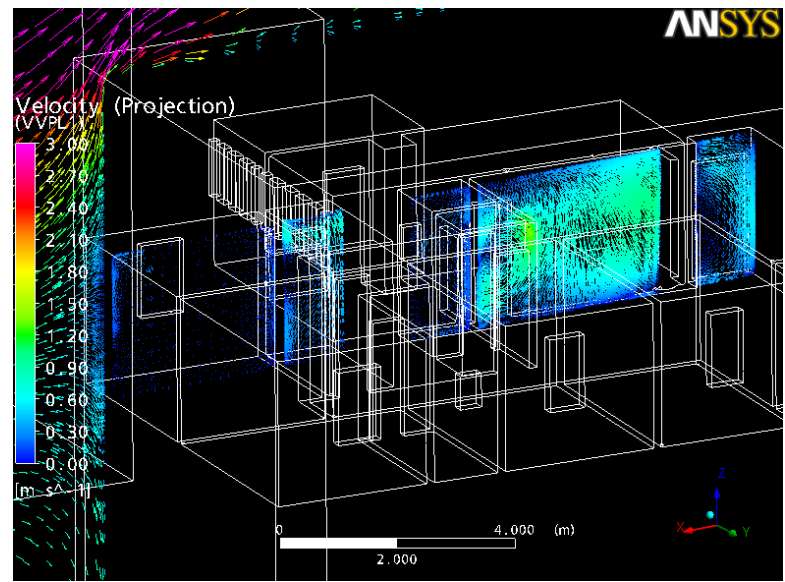

Figura A.41 - Modelo 04 - Vetores da velocidade e direção do vento no PVL1 


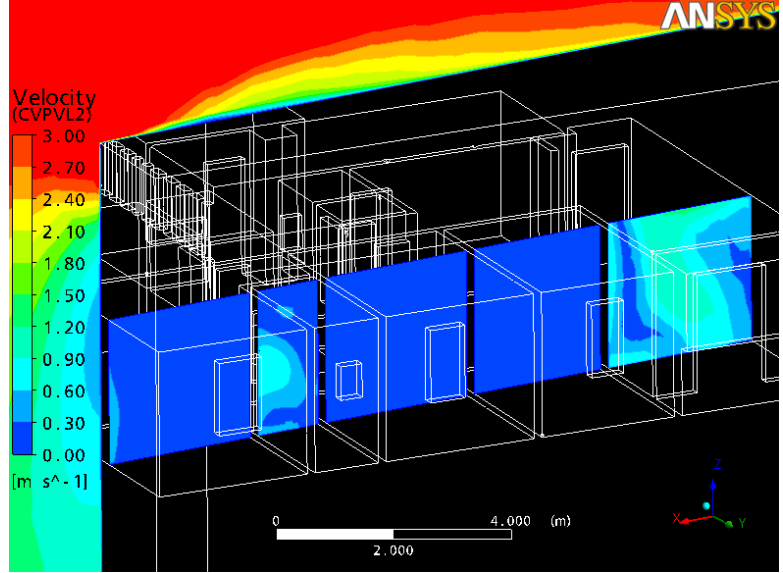

Figura A.42 - Modelo 04 - Contorno da velocidade do vento no PVL2

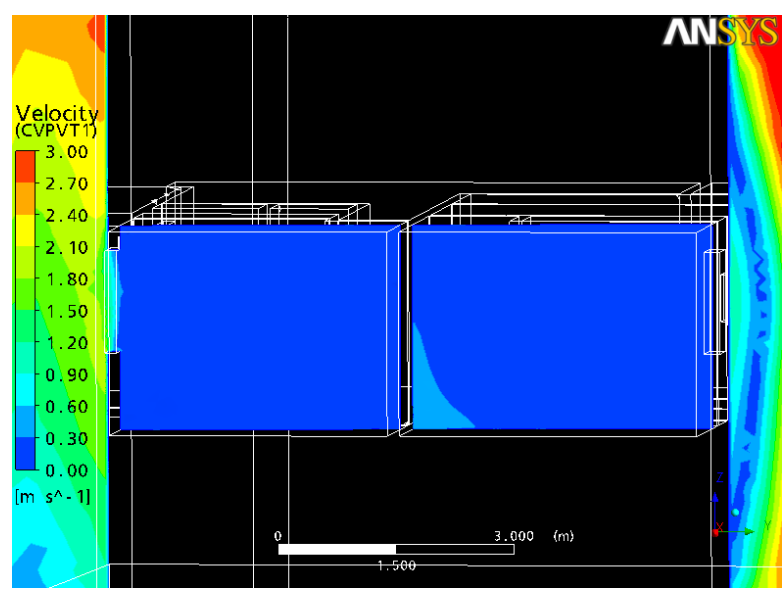

Figura A.44 - Modelo 04 - Contorno da velocidade do vento no PVT1

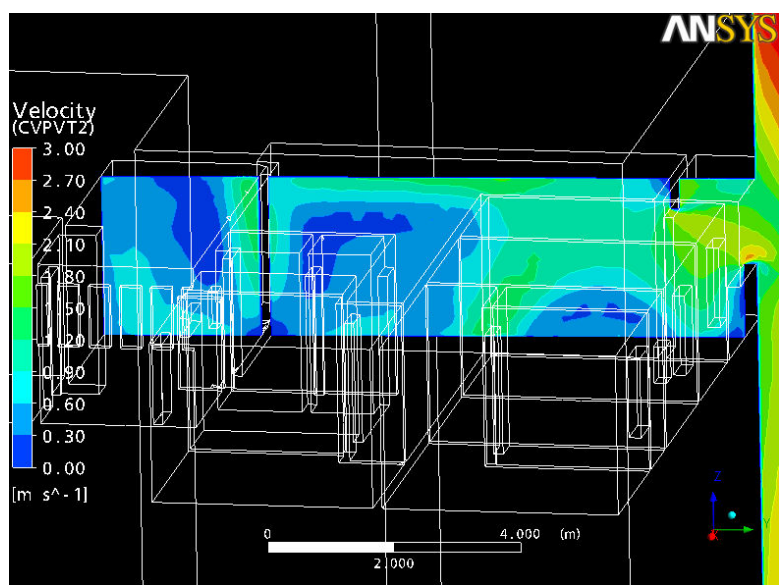

Figura A.46 - Modelo 04 - Contorno da velocidade do vento no PVT2

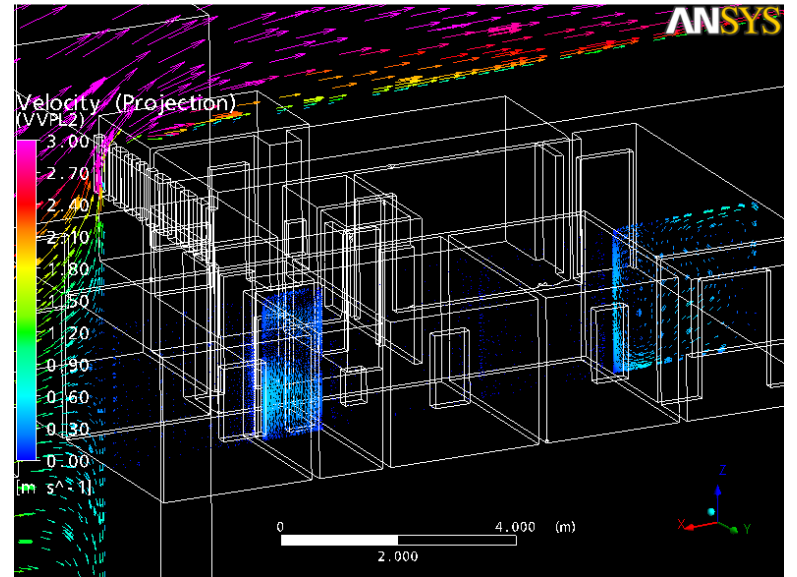

Figura A.43 - Modelo 04 - Vetores da velocidade e direção do vento no PVL2

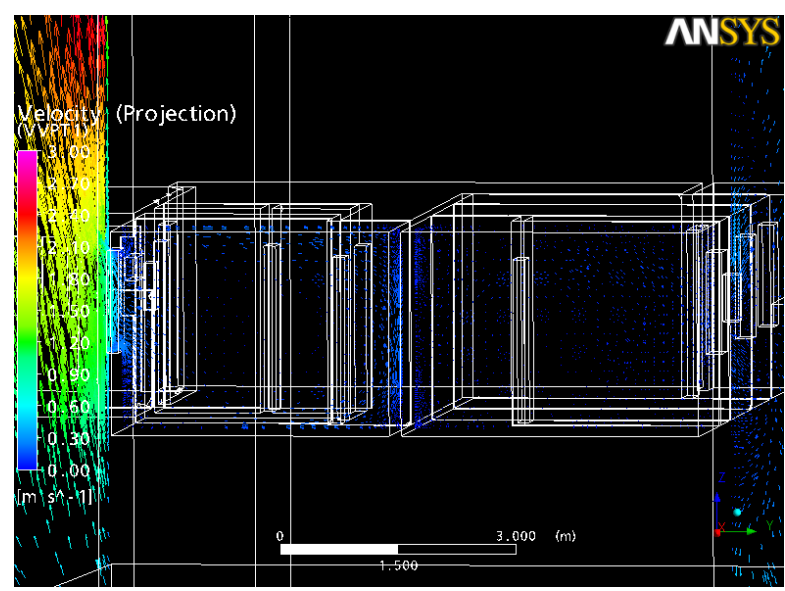

Figura A.45 - Modelo 04 - Vetores da velocidade e direção do vento no PVT1

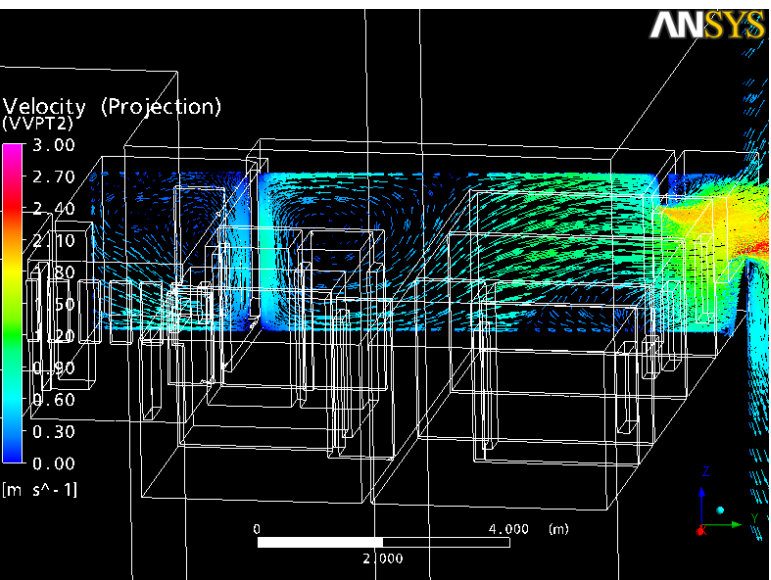

Figura A.47 - Modelo 04 - Vetores da velocidade e direção do vento no PVT2 


\section{i. ANEXO 9 - IMAGENS COMPLEMENTARES DA SIMULAÇÃO DO MODELO 05}

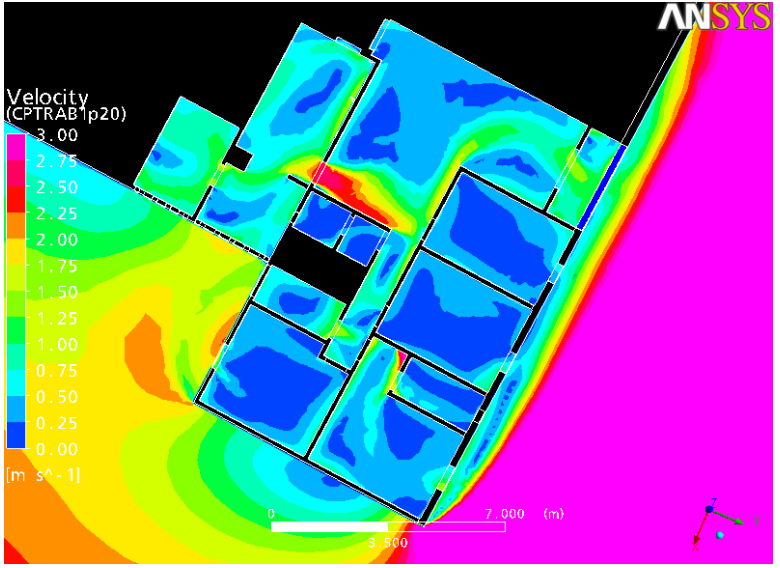

Figura A.48 - Modelo 05 - Contorno da velocidade do vento no plano horizontal $\mathrm{h}=\mathbf{1 . 2 0 \mathrm { m }}$

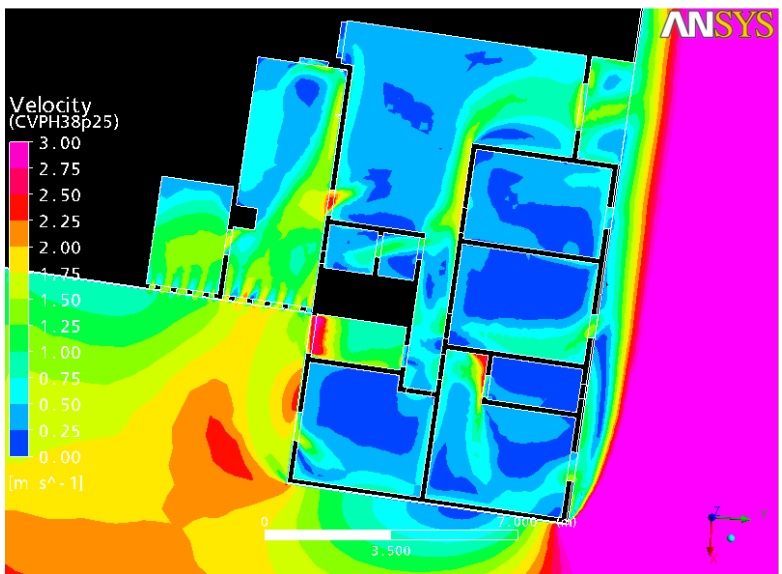

Figura A.50 - Modelo 05 - Contorno da velocidade do vento no plano horizontal $h=\mathbf{2 m}$

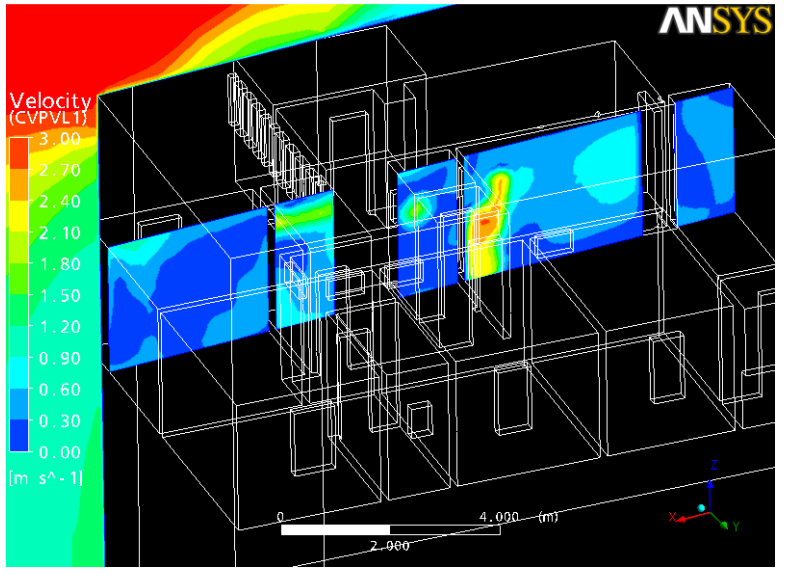

Figura A.52 - Modelo 05 - Contorno da velocidade do vento no PVL1

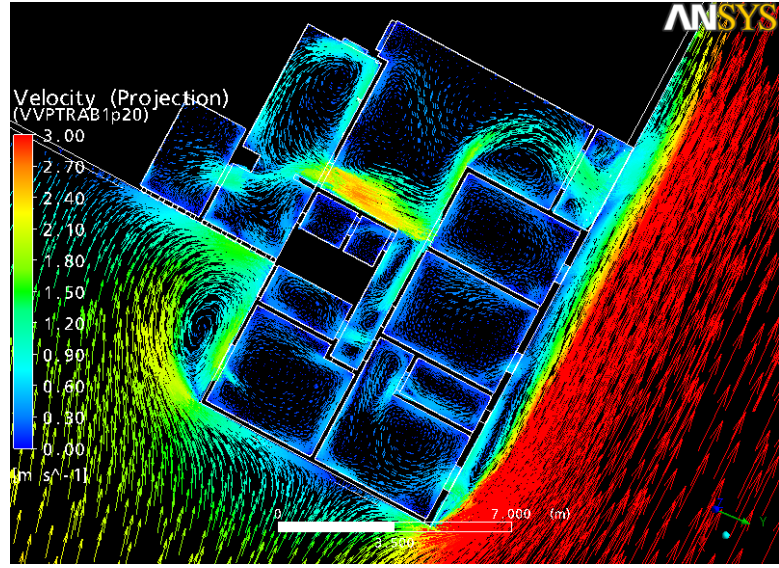

Figura A.49 - Modelo 05 - Vetores da velocidade e direção do vento no plano horizontal $h=1.20 \mathrm{~m}$

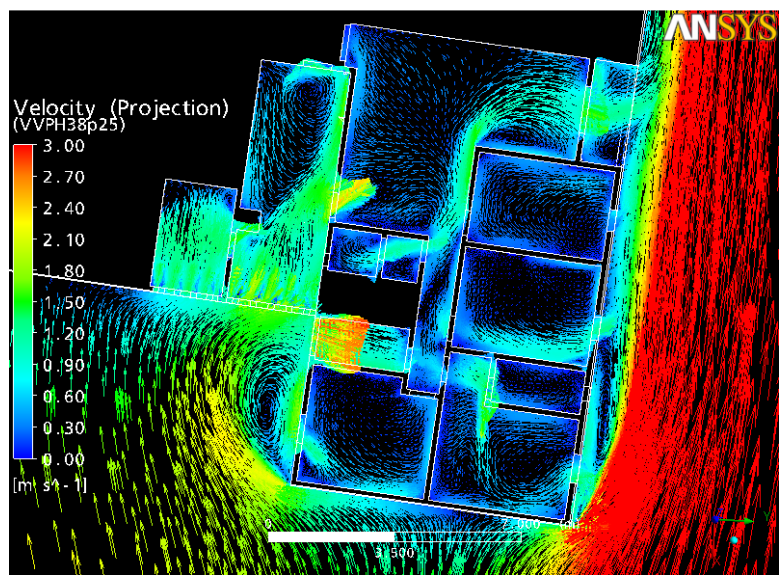

Figura A.51 - Modelo 05 - Vetores da velocidade e direção do vento no plano horizontal $\mathbf{h}=\mathbf{2 m}$

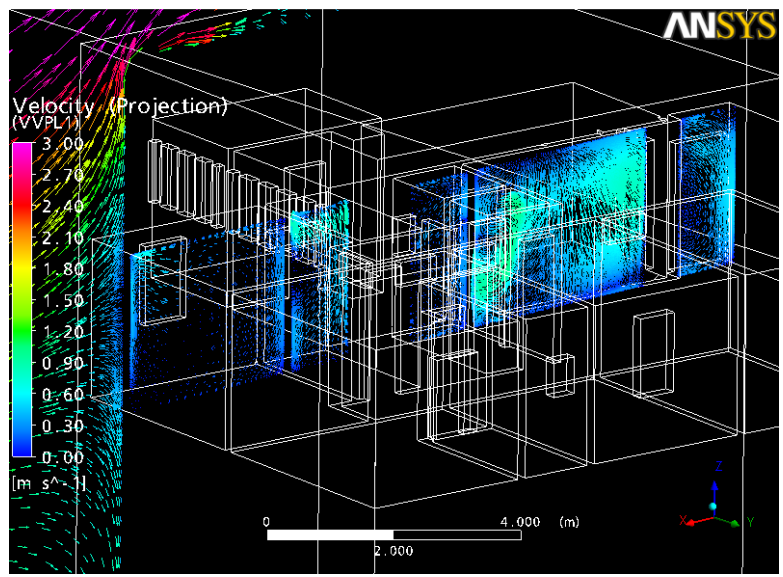

Figura A.53 - Modelo 05 - Vetores da velocidade e direção do vento no PVL1 


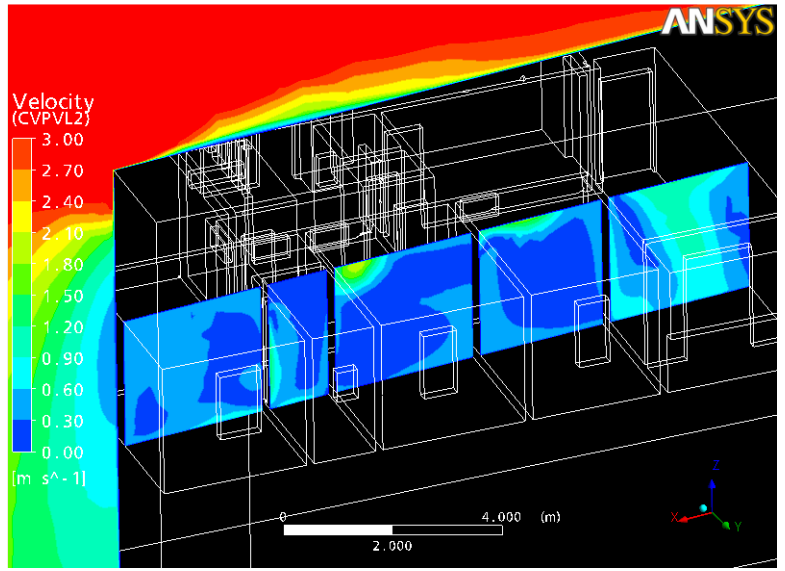

Figura A.54 - Modelo 05 - Contorno da velocidade do vento no PVL2

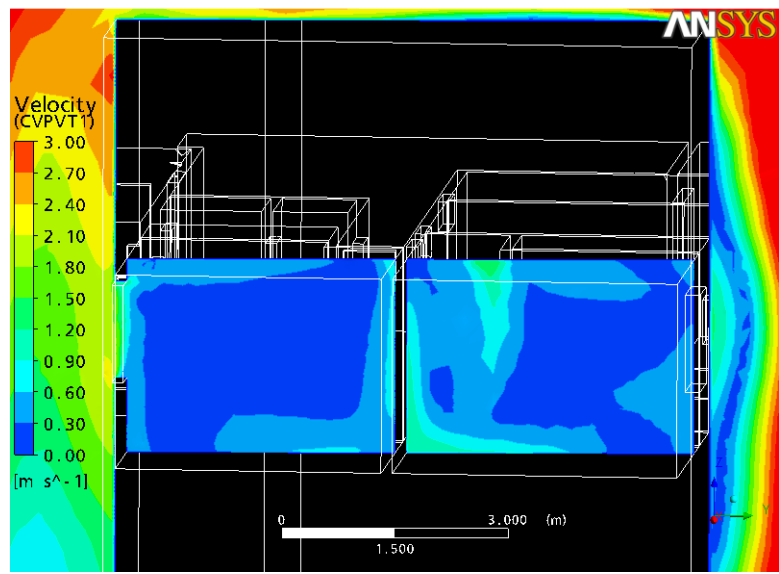

Figura A.56 - Modelo 05 - Contorno da velocidade do vento no PVT1

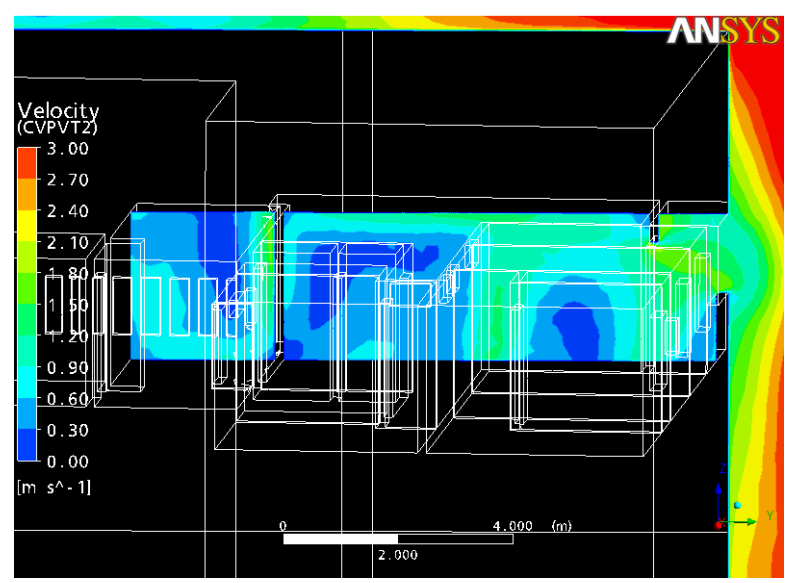

Figura A.58 - Modelo 05 - Contorno da velocidade do vento no PVT2

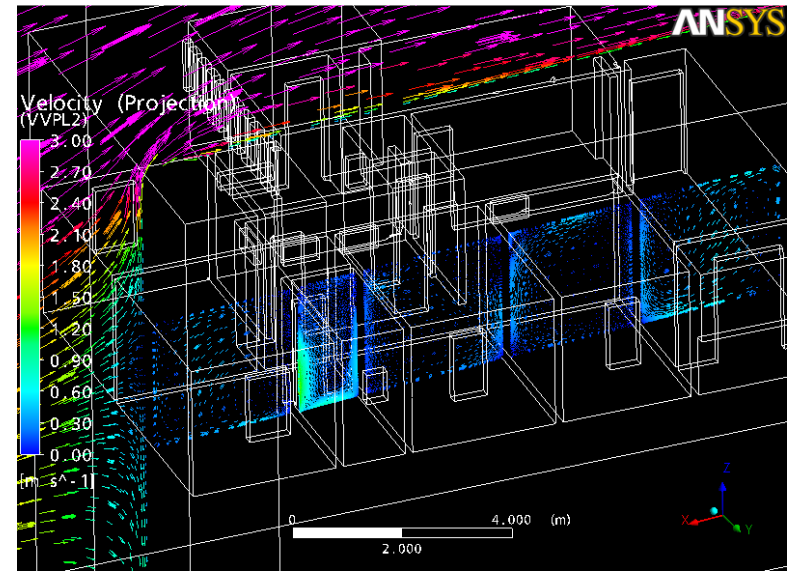

Figura A.55 - Modelo 05 - Vetores da velocidade e direção do vento no PVL2

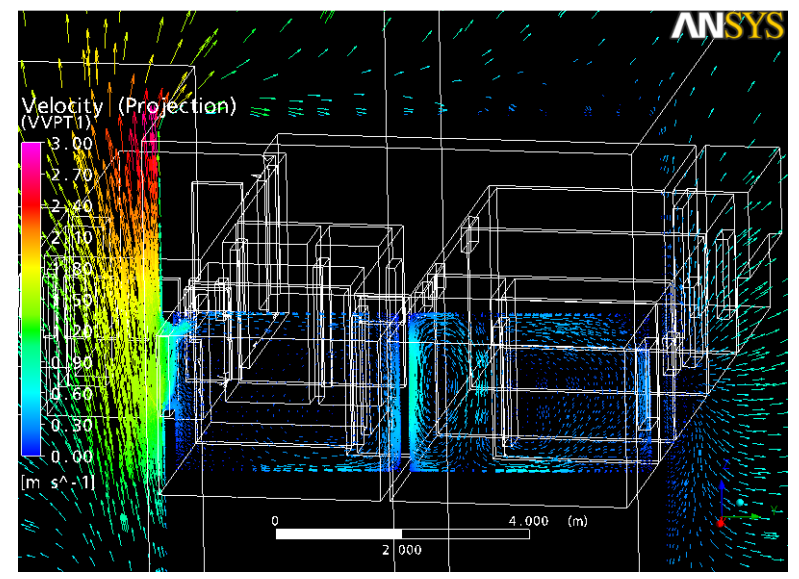

Figura A.57 - Modelo 05 - Vetores da velocidade e direção do vento no PVT1

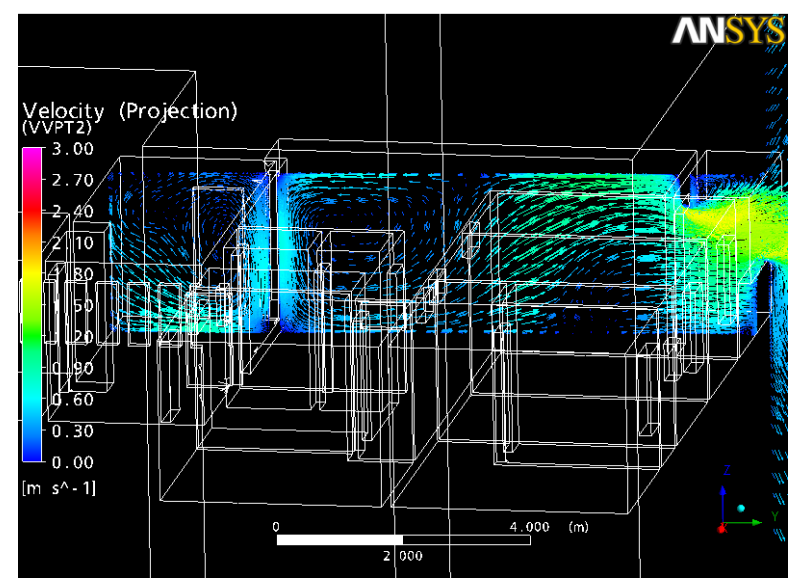

Figura A.59 - Modelo 05 - Vetores da velocidade e direção do vento no PVT2 


\section{j. ANEXO 10 - IMAGENS COMPLEMENTARES DA SIMULAÇÃO DO MODELO 06}

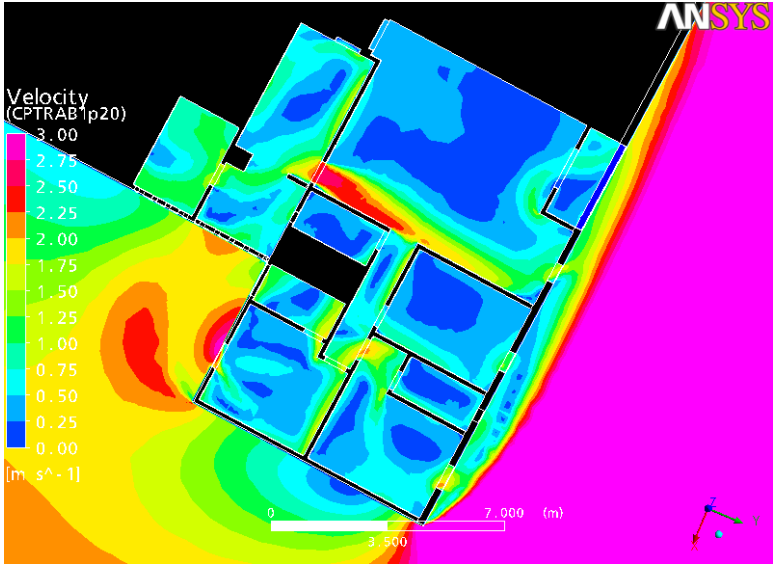

Figura A.60 - Modelo 06 - Contorno da velocidade do vento no plano horizontal $h=1.20 \mathrm{~m}$

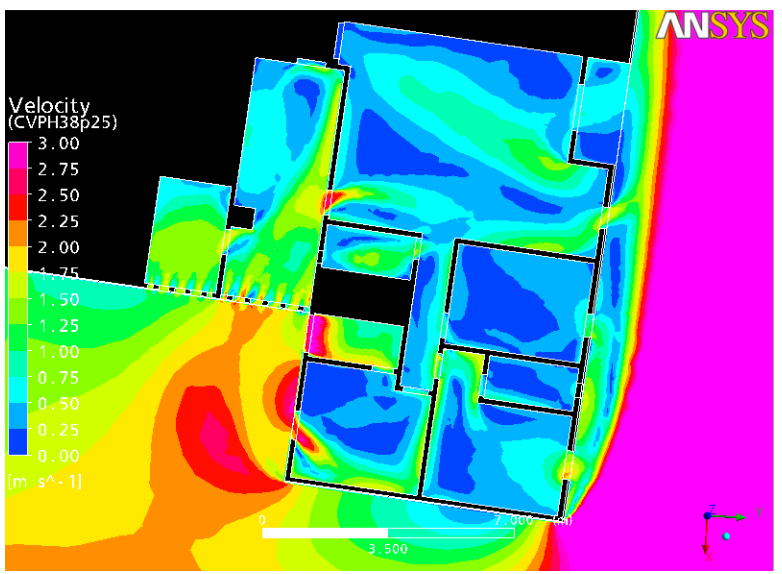

Figura A.62 - Modelo 06 - Contorno da velocidade do vento no plano horizontal $\mathrm{h}=2.00 \mathrm{~m}$

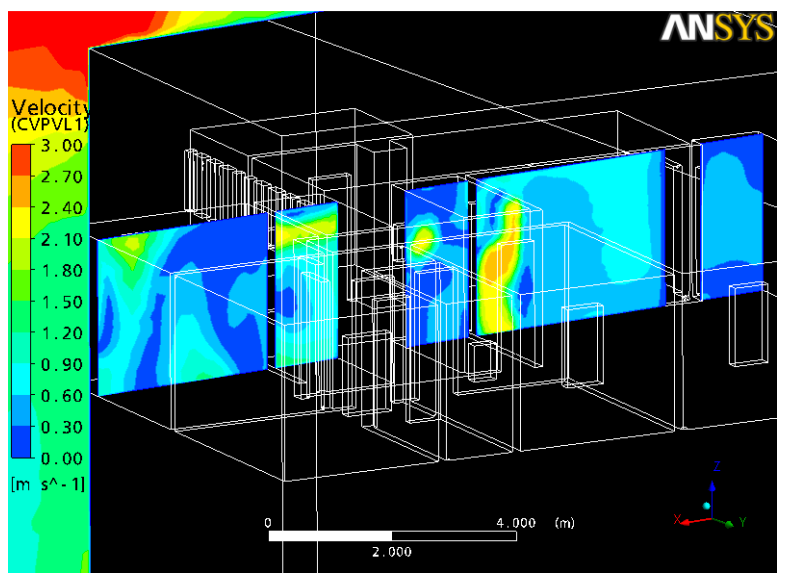

Figura A.64 - Modelo 06 - Contorno da velocidade do vento no PVL1

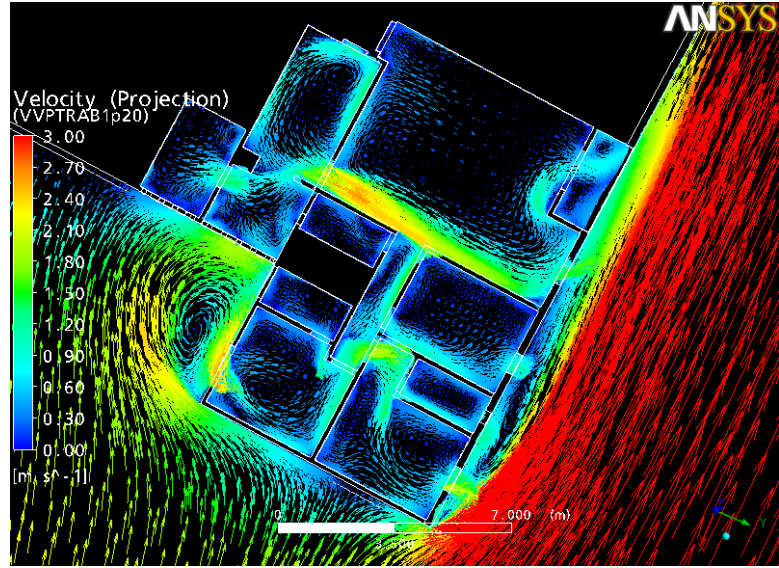

Figura A.61 - Modelo 06 - Vetores da velocidade e direção do vento no plano horizontal $h=1.20 \mathrm{~m}$

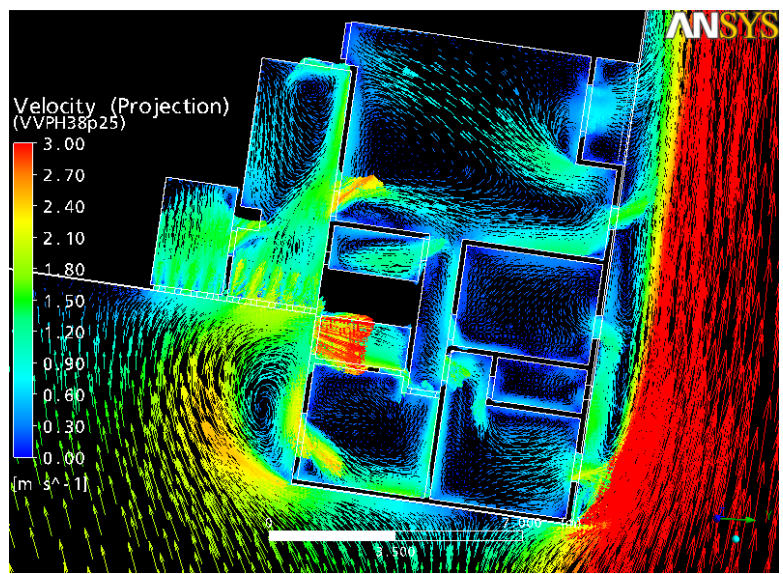

Figura A.63 - Modelo 06 - Vetores da velocidade e direção do vento no plano horizontal $\mathbf{h}=\mathbf{2 . 0 0 m}$

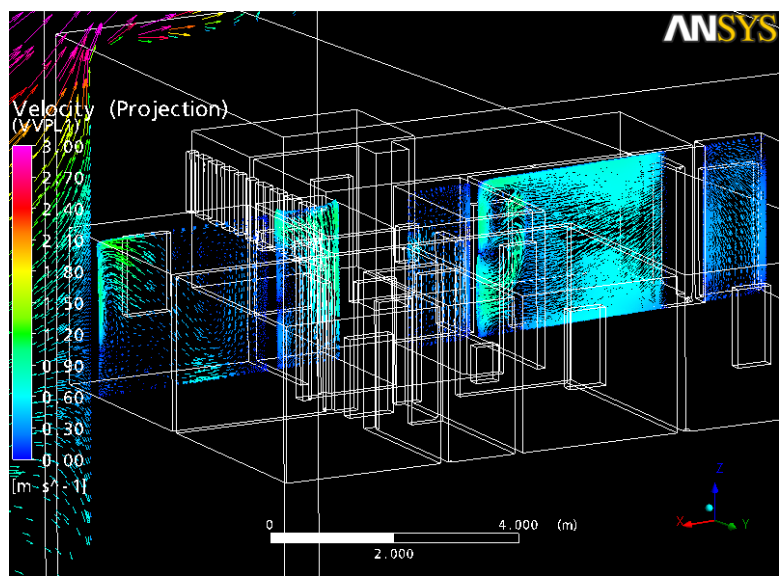

Figura A.65 - Modelo 06 - Vetores da velocidade e direção do vento no PVL1 


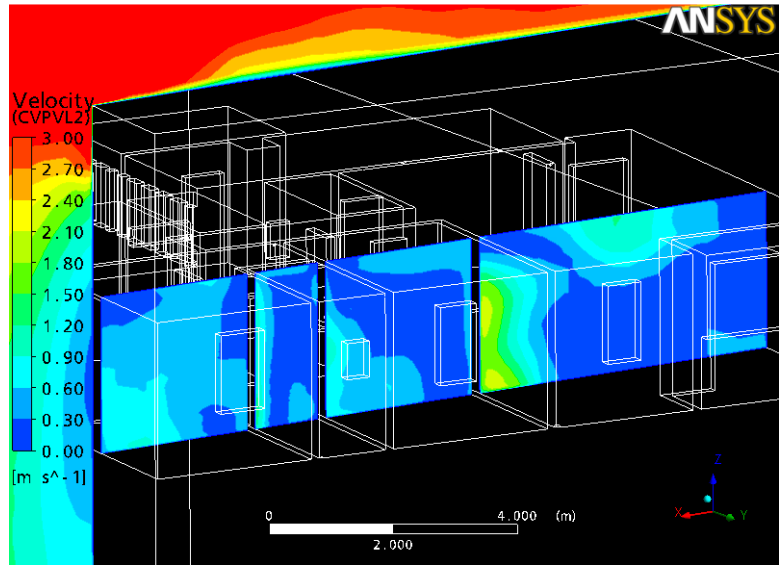

Figura A.66 - Modelo 06 - Contorno da velocidade do vento no PVL2

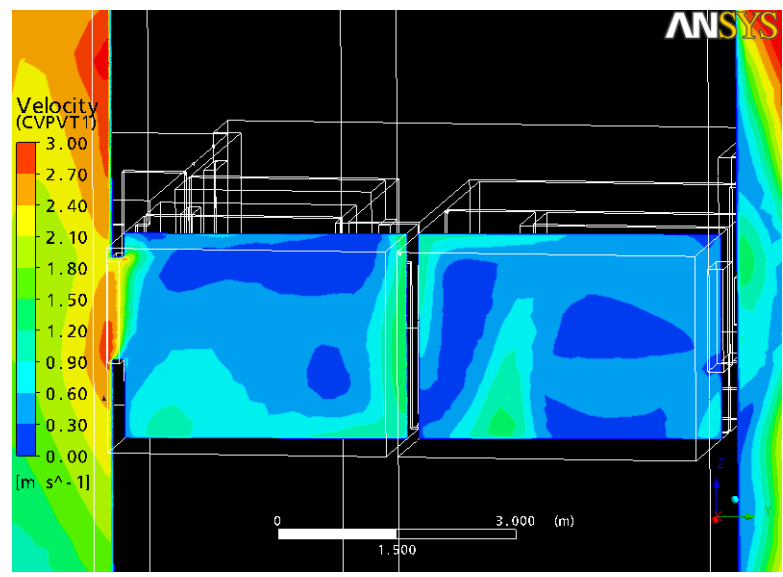

Figura A.68 - Modelo 06 - Contorno da velocidade do vento no PVT1

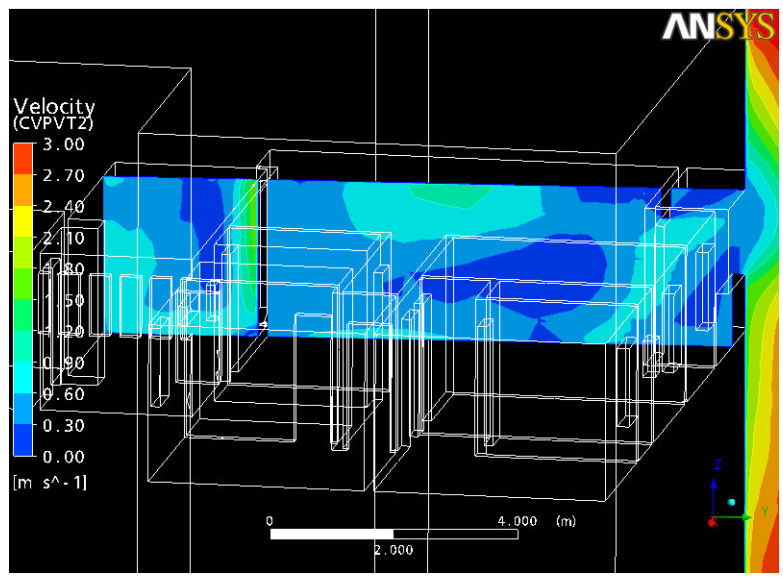

Figura A.70 - Modelo 06 - Contorno da velocidade do vento no PVT2

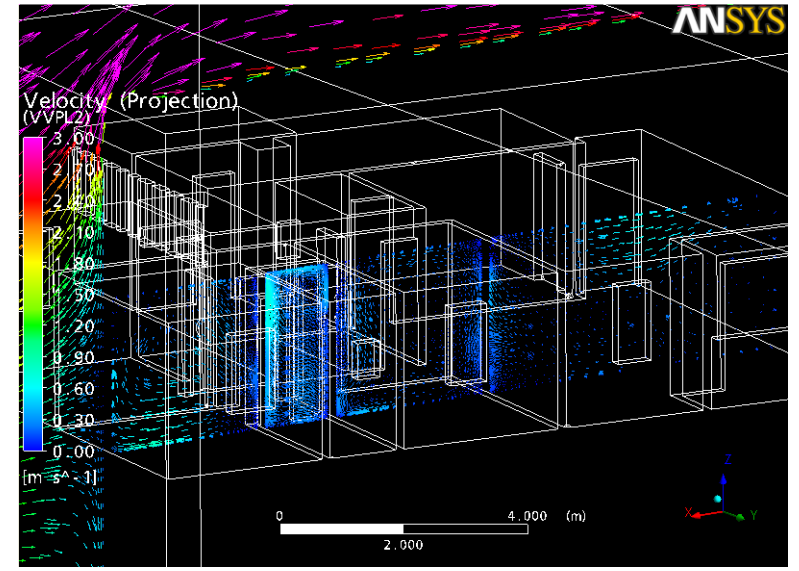

Figura A.67 - Modelo 06 - Vetores da velocidade e direção do vento no PVL2

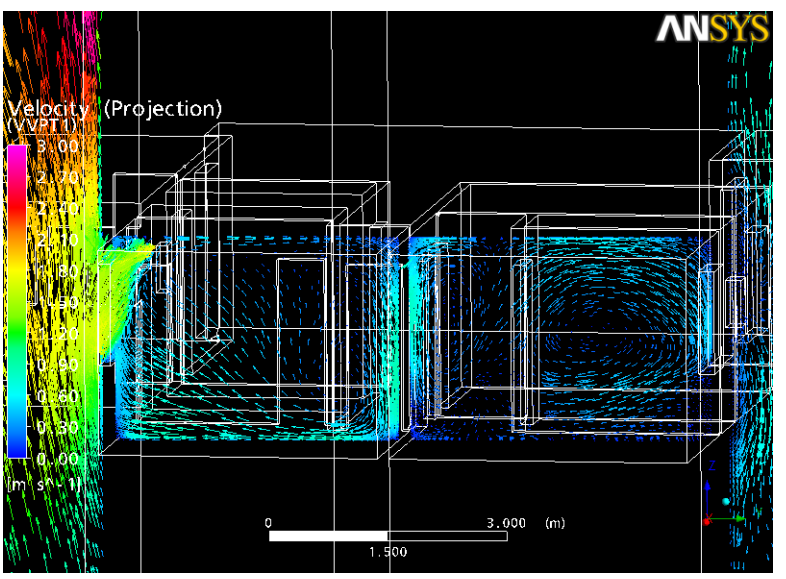

Figura A.69 - Modelo 06 - Vetores da velocidade e direção do vento no PVT1

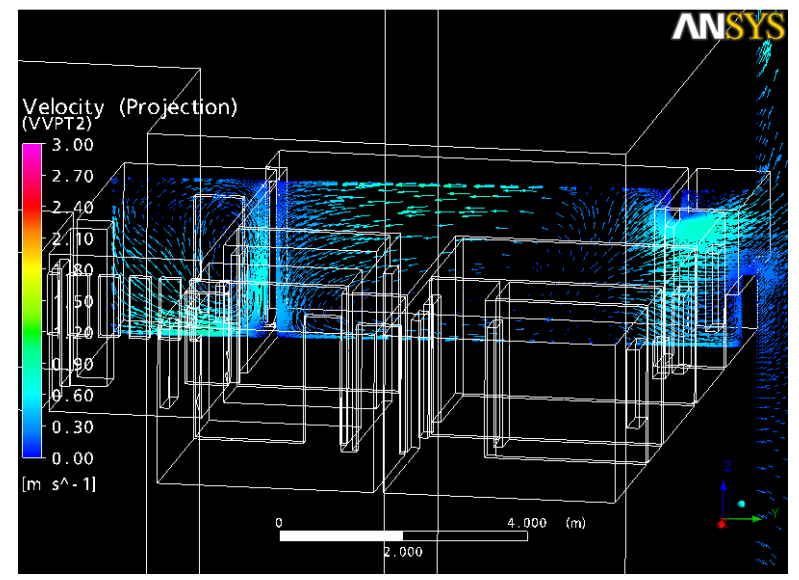

Figura A.71 - Modelo 06 - Vetores da velocidade e direção do vento no PVT2 


\section{k. ANEXO 11 - IMAGENS COMPLEMENTARES DA SIMULAÇÃO DO MODELO 07}

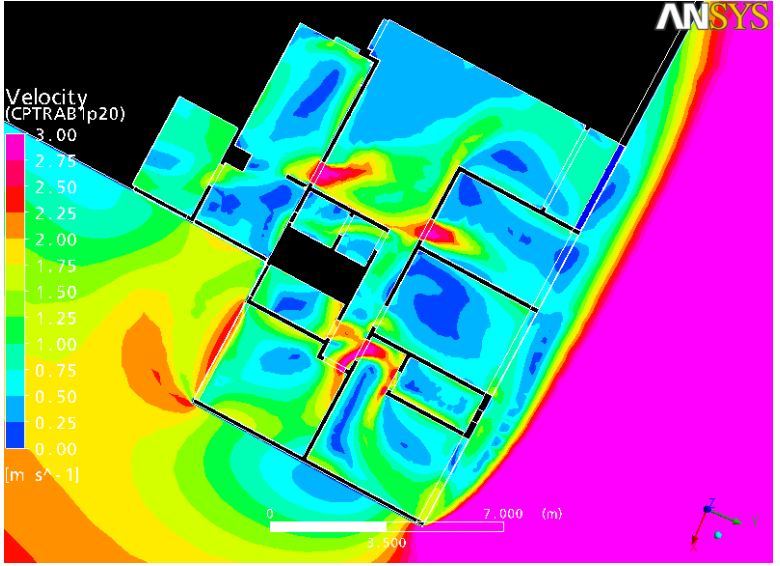

Figura A.72 - Modelo 07 - Contorno da velocidade do vento no plano horizontal $\mathrm{h}=\mathbf{1 . 2 0 \mathrm { m }}$

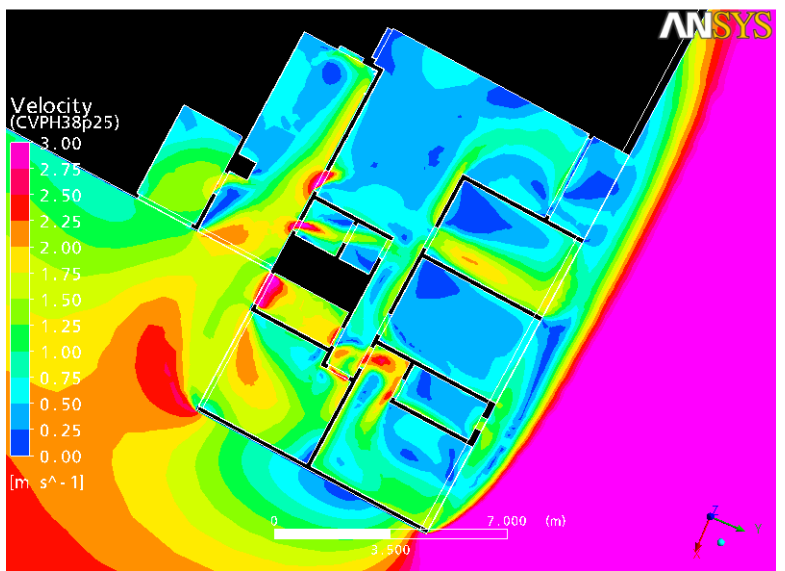

Figura A.74 - Modelo 07 - Contorno da velocidade do vento no plano horizontal $\mathrm{h}=\mathbf{2 . 0 0 \mathrm { m }}$

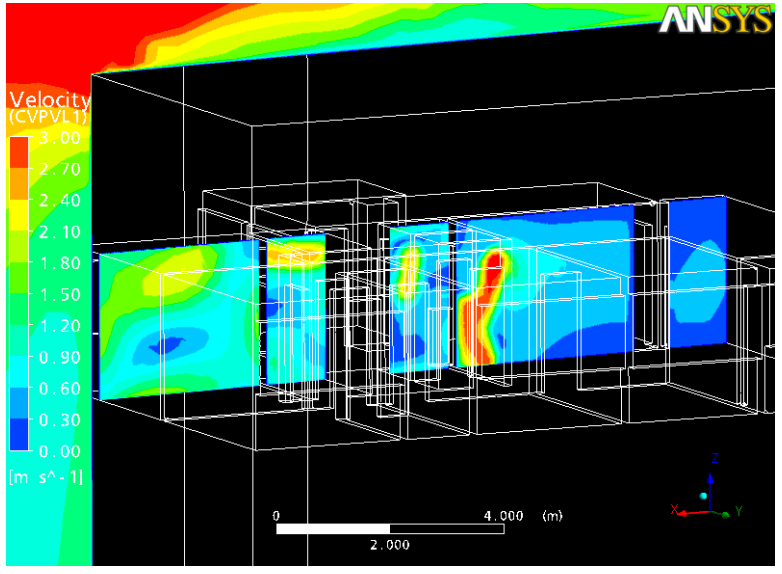

Figura A.76 - Modelo 07 - Contorno da velocidade do vento no PVL1

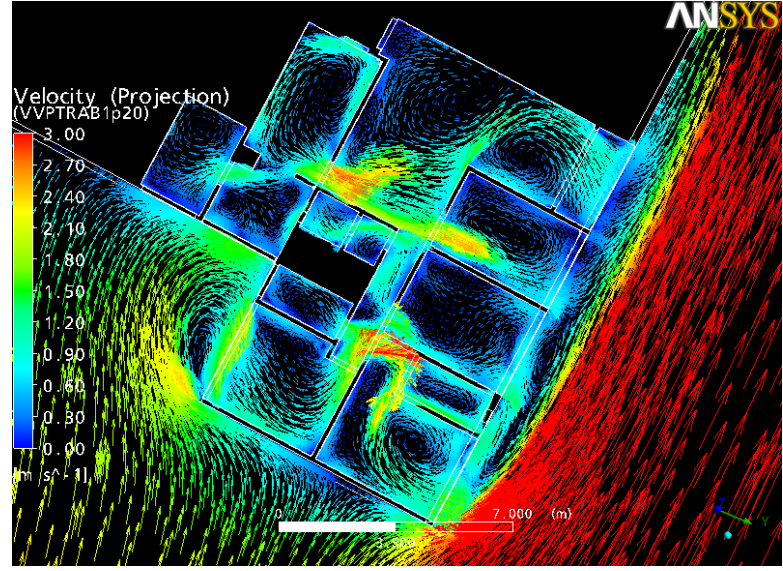

Figura A.73 - Modelo 07 - Vetores da velocidade e direção do vento no plano horizontal $\mathbf{h}=1.20 \mathrm{~m}$

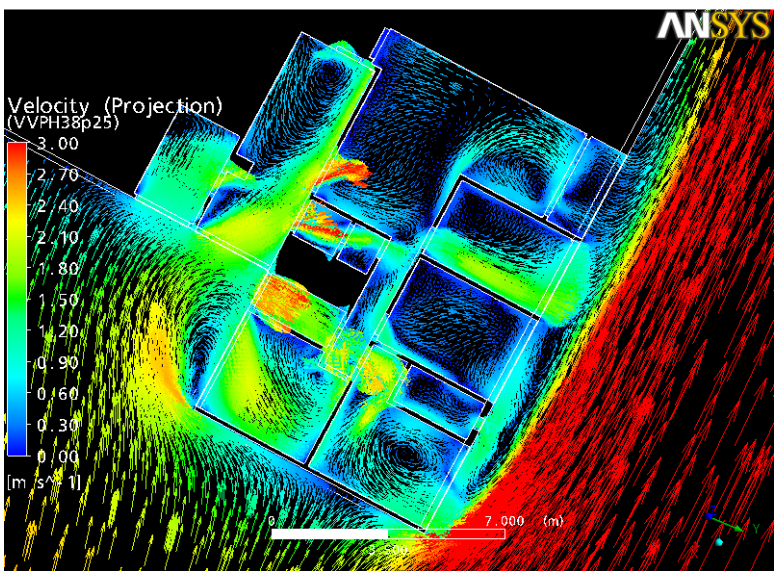

Figura A.75 - Modelo 07 - Vetores da velocidade e direção do vento no plano horizontal $\mathbf{h}=\mathbf{2 . 0 0 \mathrm { m }}$

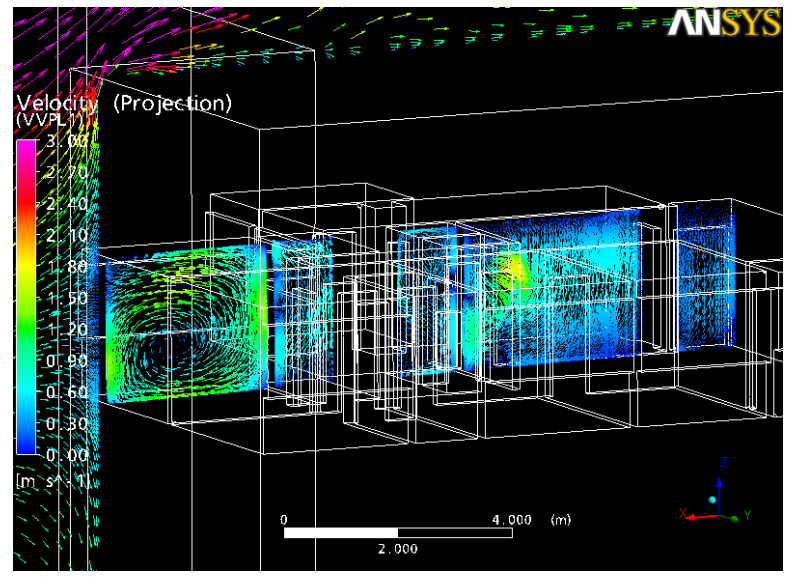

Figura A.77 - Modelo 07 - Vetores da velocidade e direção do vento no PVL1 


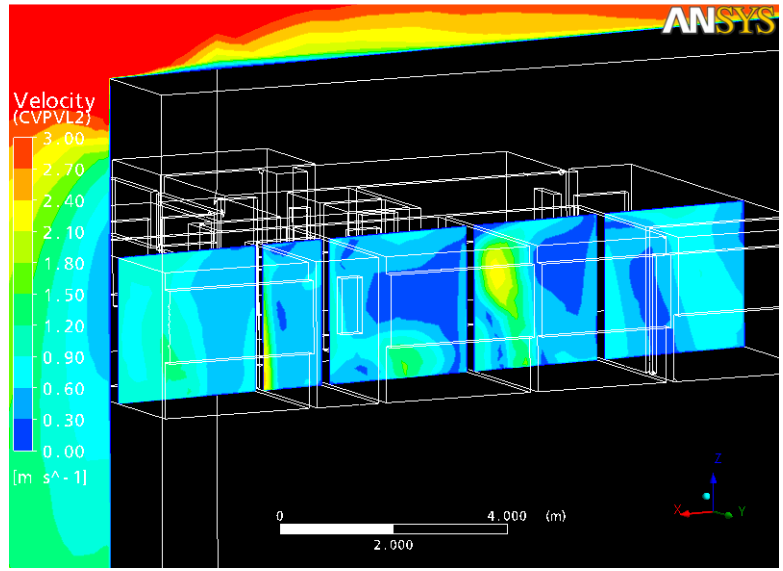

Figura A.78 - Modelo 07 - Contorno da velocidade do vento no PVL2

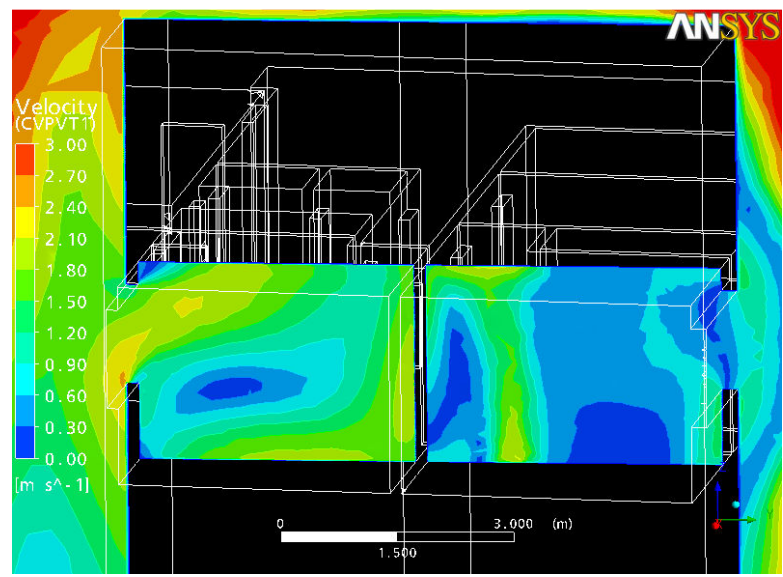

Figura A.80 - Modelo 07 - Contorno da velocidade do vento no PVT1

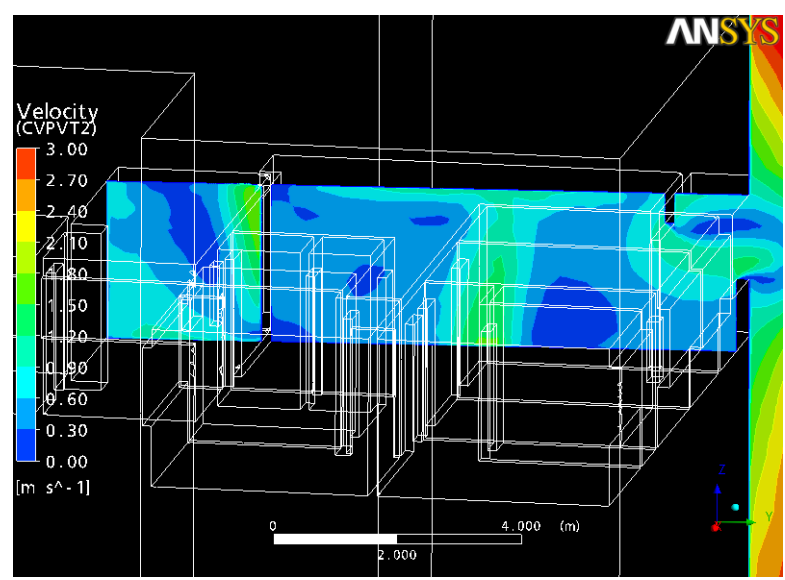

Figura A.82 - Modelo 07 - Contorno da velocidade do vento no PVT2

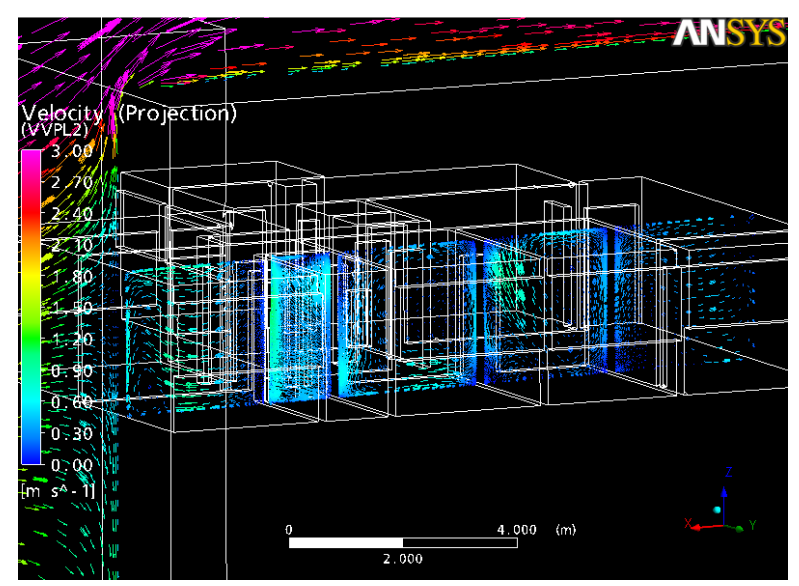

Figura A.79 - Modelo 07 - Vetores da velocidade e direção do vento no PVL2

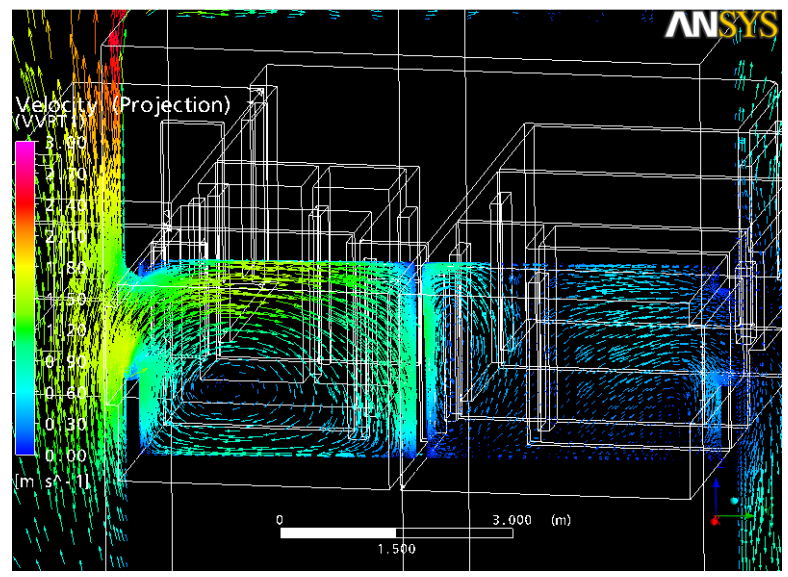

Figura A.81 - Modelo 07 - Vetores da velocidade e direção do vento no PVT1

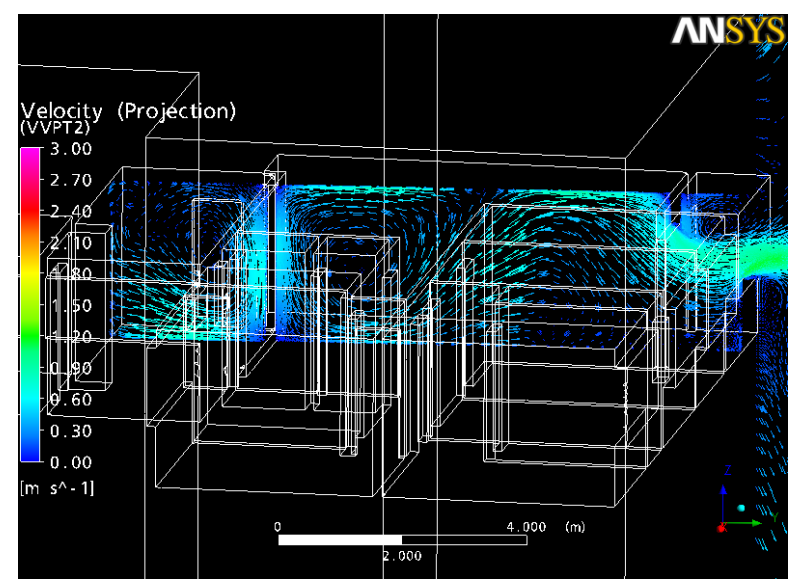

Figura A.83 - Modelo 07 - Vetores da velocidade e direção do vento no PVT2 


\section{ANEXO 12 - IMAGENS COMPLEMENTARES DA SIMULAÇÃO DO MODELO 08}

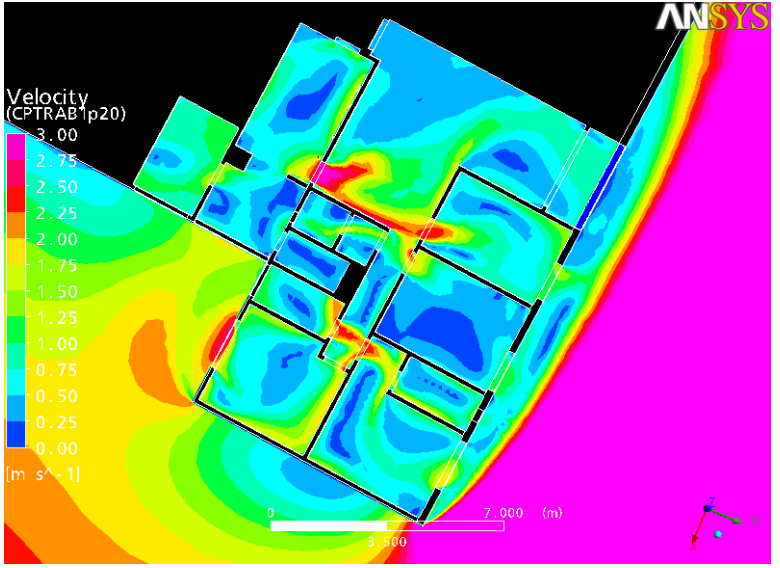

Figura A.84 - Modelo 08 - Contorno da velocidade do vento no plano horizontal $\mathrm{h}=\mathbf{1 . 2 0 \mathrm { m }}$

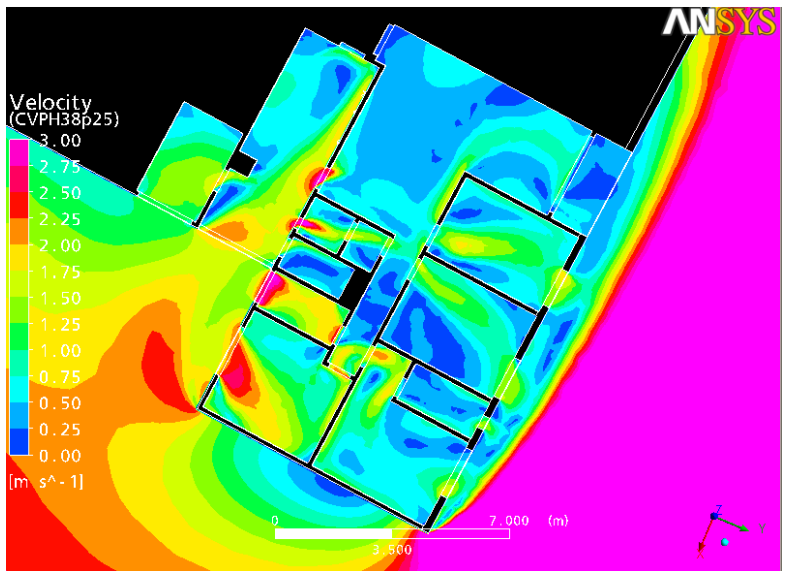

Figura A.86 - Modelo 08 - Contorno da velocidade do vento no plano horizontal $\mathrm{h}=\mathbf{2 . 0 0 \mathrm { m }}$

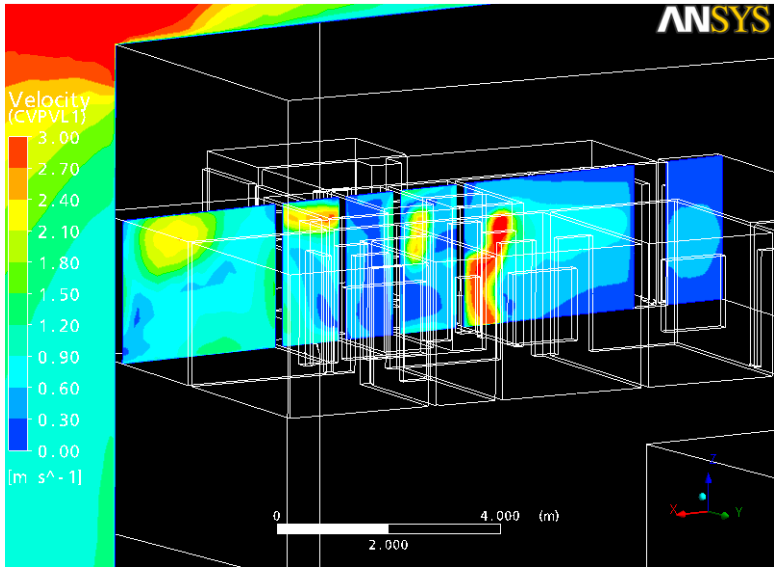

Figura A.88 - Modelo 08 - Contorno da velocidade do vento no PVL1

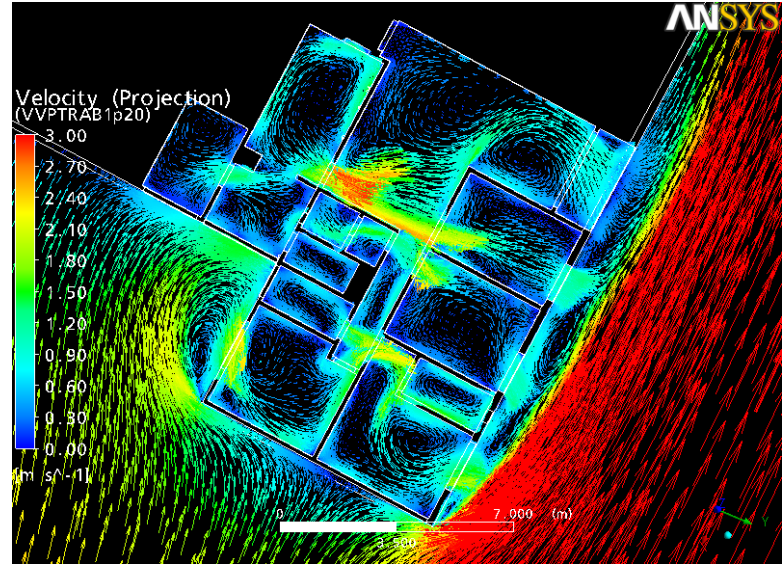

Figura A.85 - Modelo 08 - Vetores da velocidade e direção do vento no plano horizontal $h=1.20 \mathrm{~m}$

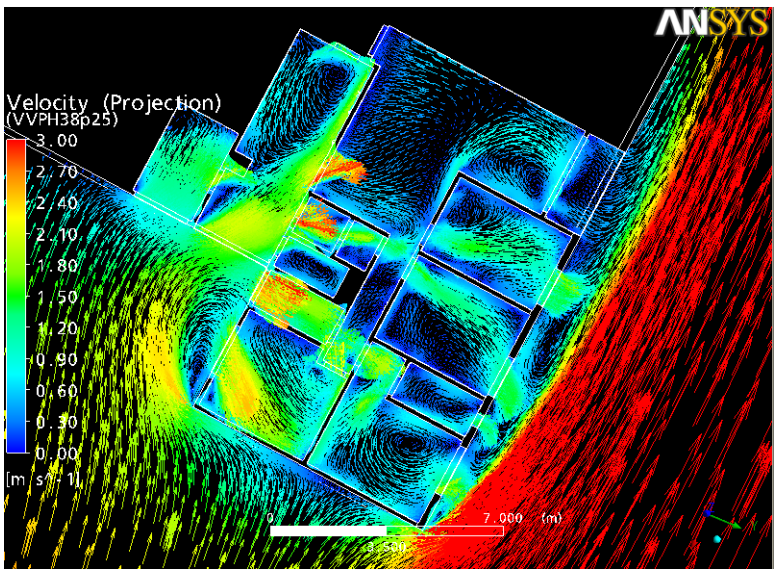

Figura A.87 - Modelo 08 - Vetores da velocidade e direção do vento no plano horizontal $\mathbf{h}=\mathbf{2 . 0 0 m}$

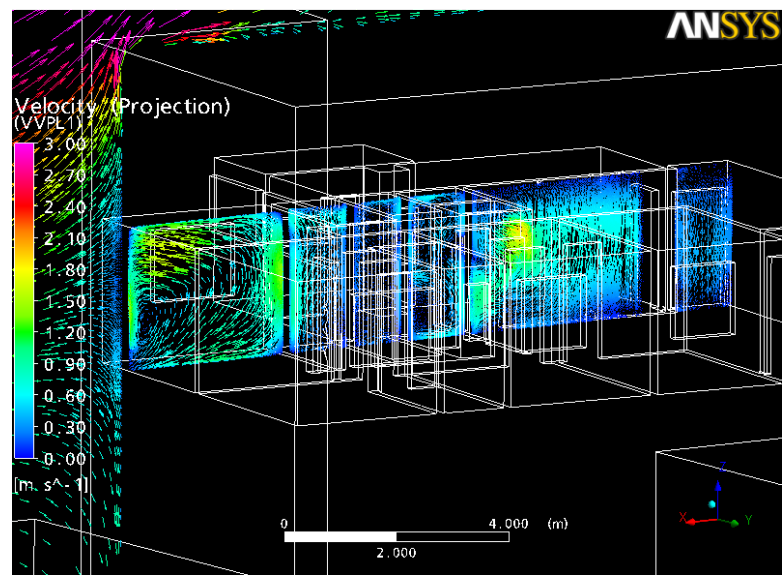

Figura A.89 - Modelo 08 - Vetores da velocidade e direção do vento no PVL1 


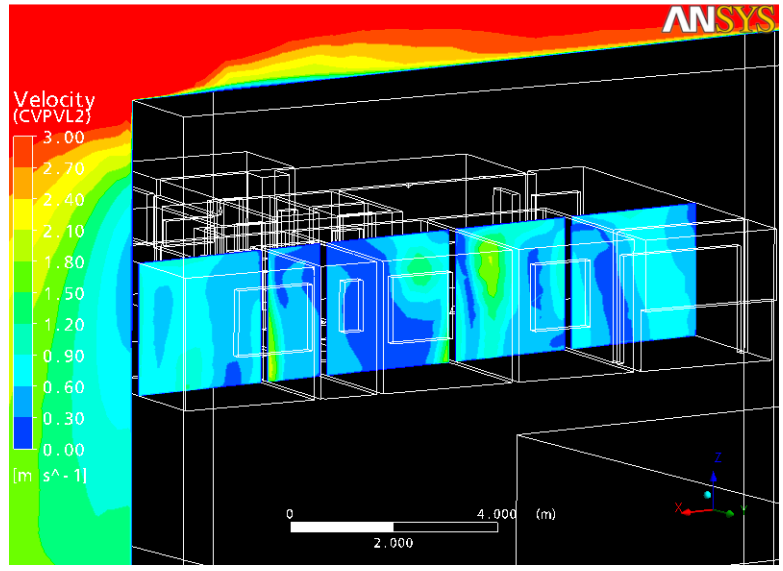

Figura A.90 - Modelo 08 - Contorno da velocidade do vento no PVL2

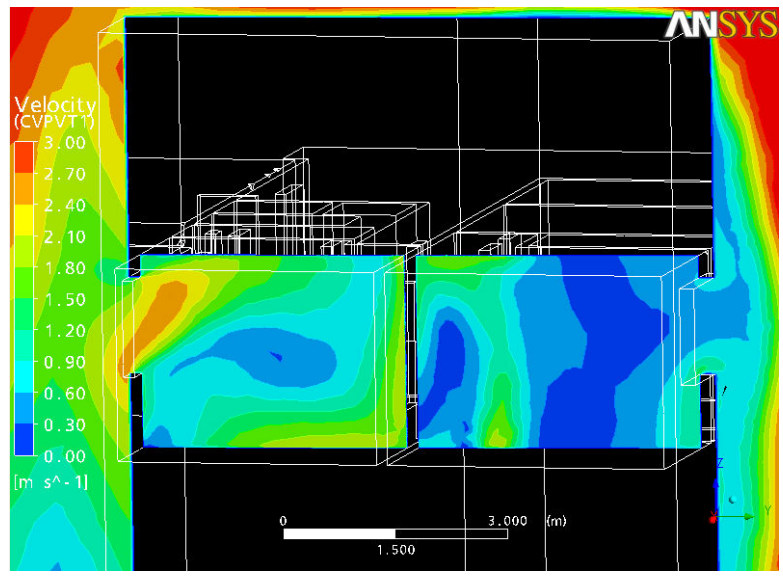

Figura A.92 - Modelo 08 - Contorno da velocidade do vento no PVT1

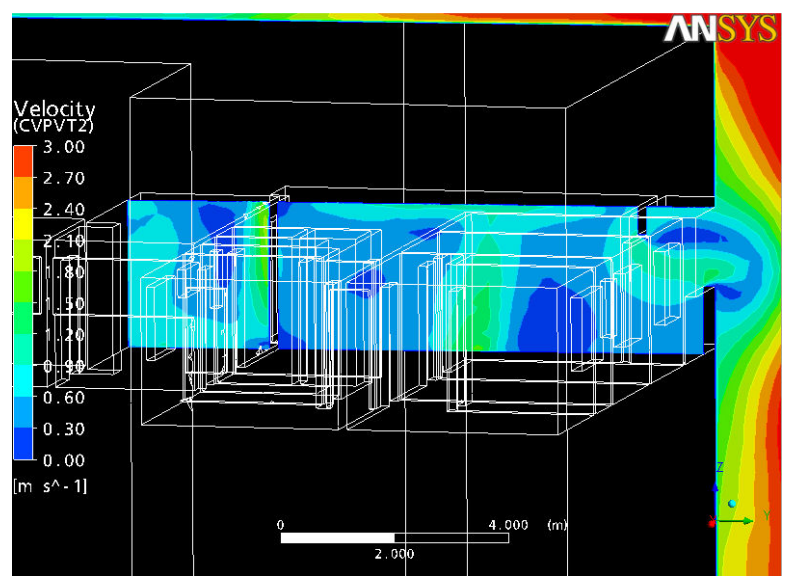

Figura A.94 - Modelo 08 - Contorno da velocidade do vento no PVT2

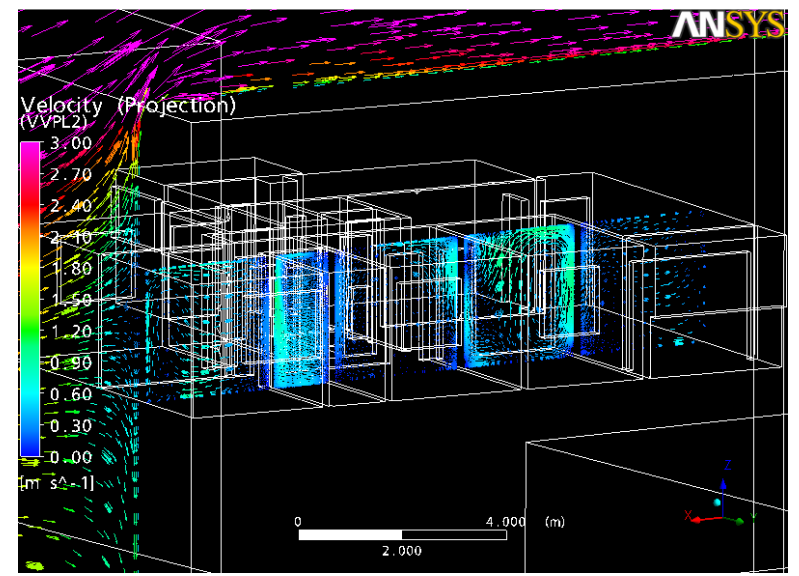

Figura A.91 - Modelo 08 - Vetores da velocidade e direção do vento no PVL2

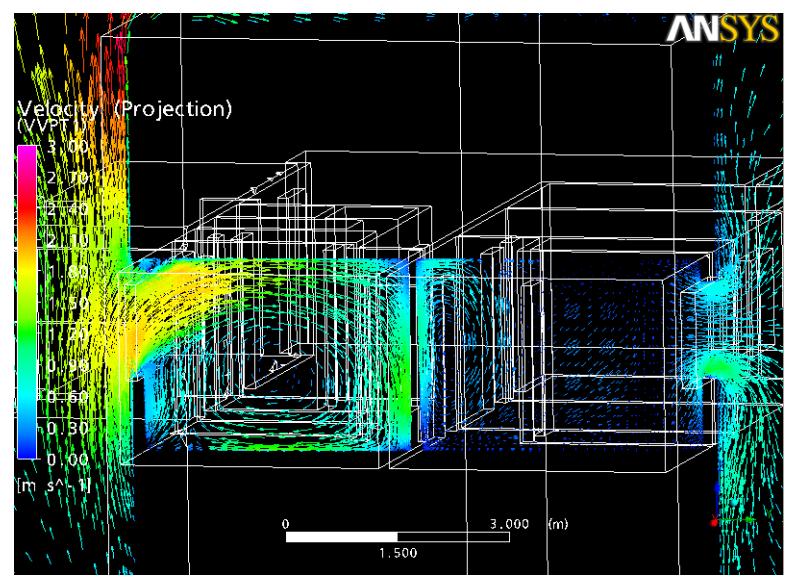

Figura A.93 - Modelo 08 - Vetores da velocidade e direção do vento no PVT1

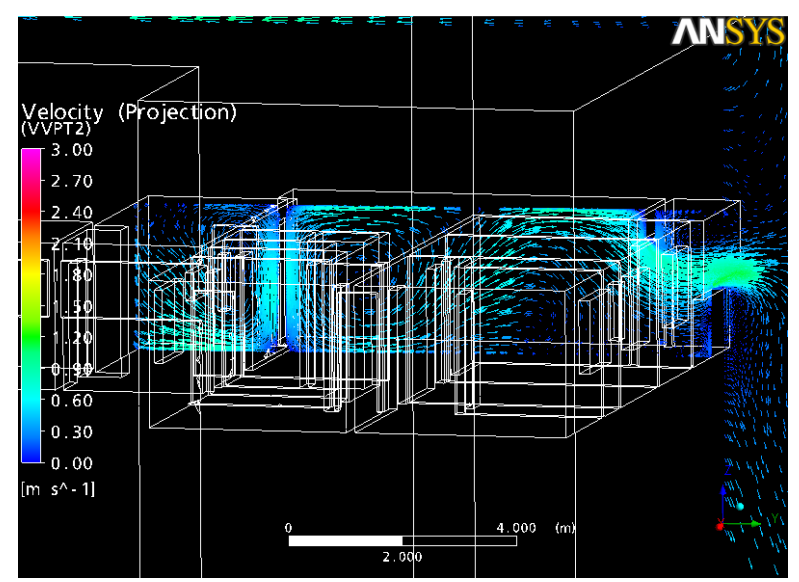

Figura A.95 - Modelo 08 - Contorno da velocidade do vento no PVT2 